\title{
Late Holocene archaeology in Namaqualand, South Africa: hunter-gatherers and herders in a semi-arid environment.
}

\author{
Jayson D. J. Orton \\ St Hugh's College \\ Thesis submitted for the degree of \\ Doctor of Philosophy \\ at the \\ University of Oxford
}

Trinity Term 2012 


\title{
Late Holocene archaeology in Namaqualand, South Africa: hunter-gatherers and herders in a semi-arid environment.
}

\author{
Jayson Orton, St Hugh's College \\ D.Phil, Trinity 2012
}

\begin{abstract}
This study examines mid- to late Holocene Later Stone Age archaeological residues specifically flaked stone artefacts, ostrich eggshell beads and pottery - from Namaqualand, north-western South Africa. Through its implication in all models so far proposed, Namaqualand is crucial to understanding the introduction of herding to the southern African subcontinent. Despite numerous publications on early herding, many key debates remain unresolved.
\end{abstract}

The study focuses on the northern and central Namaqualand coastline, but sites from other parts of Namaqualand are also described. The stone assemblages are grouped according to variation in materials and retouch and then, along with data from ostrich eggshell beads and pottery, analysed graphically for temporal and other patterning. A cultural sequence is then presented.

Using this sequence, key debates on early herding are explored and a hypothesis on its origins is constructed. Indigenous hunter-gatherers occupied the region throughout the Holocene and made Group 1 lithic assemblages from quartz and cryptocrystalline silica with frequent retouched tools primarily in cryptocrystalline silica. A new population likely Proto-Khoekhoe-speaking hunter-gatherers with limited numbers of livestock entered the landscape approximately 2000 years ago. They made Group 3 assemblages from clear quartz focusing on backed bladelets. Diffusion of stock and pottery among the local population occurred during this period. Later, c. AD 500, a new wave of migrants appeared. These last were the ancestors of the historically observed Khoekhoe pastoralists; they made Group 2 lithic assemblages on milky quartz without retouched tools. Bead diameter generally increases with time and contributes nothing to the debate. The pottery sequence is still too patchy for meaningful interpretation but differs from that elsewhere. Overall, the differing cultural signatures in western South Africa suggest that, although many questions will likely remain unanswered, a better understanding of southern African early herding will only be possible with a study addressing all regions simultaneously. 
"Assumption is built upon assumption and a consensus is reached, but ultimately statements about the past are about the unobservable and they are unverifiable."

"The leaps of faith that have to be made in interpreting archaeological data are great because so little is known and yet so much is said."

--- $\quad$ lan Hodder $(1984: 27,28) \quad---$ 


\section{Acknowledgements}

A doctoral thesis is a big thing that one person cannot do alone. I am thus indebted to many. First and foremost my beautiful wife, Carol, has inspired and encouraged me to get this done. Peter Mitchell supervised the research and proved a constant source of knowledge and support for which I am most grateful. Dave Halkett, Tim Hart and Lita Webley, my colleagues at ACO Associates cc in South Africa, provided access to material and support, primarily in the form of time off work. In Oxford, lan Hinde and Lesley Sergent offered excellent hospitality.

Many contributed time and energy to the excavations, sorting and analysis, both during CRM work and specifically for this thesis. In this regard I am grateful to Mzunzima Mjikeliso, Mzwandile Sasa, Ntandazo Mzikeliso and Mpakamo Sasa for their efforts in the field and laboratory, while Dave Halkett, Tim Hart, Lita Webley, Alex Mackay, Steve Schwortz, Genevieve Dewar, Richard Klein and Teresa Steele provided assistance through fieldwork, analysis and valuable discussion. The latter three in particular conducted the faunal analyses presented here. Others who contributed in various ways include Judy Sealy, Louisa Hutton, Foreman Bandama and others at the University of Cape Town Archaeology Department, John Compton, Antonieta Jerardino and Benjamin Smith. Email discussions over several years with Anne Thackeray and Peter Mitchell helped develop and refine the LSA typology presented here. William Parry in the USA kindly posted me reprints of publications not otherwise available to me.

Throughout my fieldwork I found both locals and landowners in Namaqualand to be friendly and helpful and I am most grateful for their assistance. These include in particular the Van der Vyvers (Kat-ma-koep Guesthouse), the Vissers (Varsche Rivier), the Visagies (Goerap) and the Wieses (Quaggaskop).

Heritage Western Cape (HWC) and the South African Heritage Resources Agency (SAHRA) approved permits for excavation and export (for dating) as follows:

- Excavation Permit No. 2009-04-001 (HWC);

- Excavation Permit No. 2010-04-002 (HWC);

- Excavation Permit No. 2010-10-005 (HWC);

- Export Permit No. 80/09/04/001/52 (SAHRA);

- Export Permit No. 80/09/10/001-020/52 (SAHRA); 
- Export Permit No. 80/10/02/007/52 (SAHRA);

- Export Permit No. 80/10/09/004/52 (SAHRA); and

- Export Permit No. 80/11/04/004/52 (SAHRA).

Any project this size requires funding, for all of which I am most grateful. Before I started, De Beers Consolidated Mines NM supported CRM excavations that produced much of the material analysed. A Clarendon Fund Scholarship covered tuition fees and a School of Archaeology Studentship my living expenses. Research grants towards fieldwork were awarded by the School of Archaeology (Meyerstein Award) and St Hugh's College (Barbinder Watson Fund). A grant from the United States National Science Foundation Program for High-Risk Research in Anthropology (NSF\#0930363 awarded to Dr Teresa Steele) provided the impetus to begin excavations in the Knersvlakte.

Most radiocarbon dates were conducted through the Natural Environment Research Council (NERC) funded National Radiocarbon Facility (NRCF) with the analyses conducted at the Oxford Radiocarbon Accelerator Unit (ORAU). Here Tom Higham assisted with the application process and was most helpful in discussing and interpreting the dates. Other new dates were processed at the University of Georgia's Centre for Applied Isotope Studies where Alexander Cherkinsky provided efficient service. 


\section{Table of Contents}

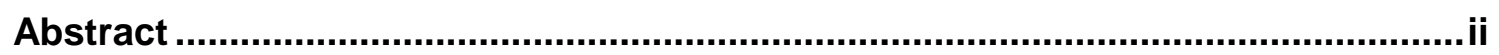

Acknowledgements ........................................................................................

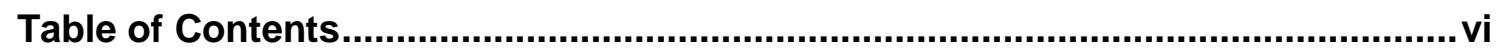

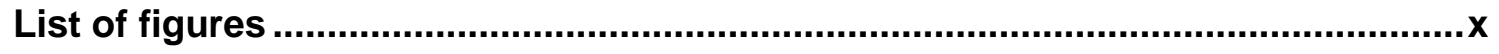

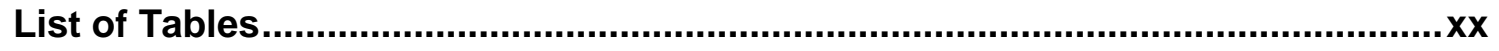

Definitions and conventions ..................................................................................

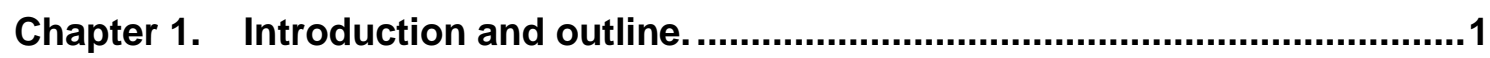

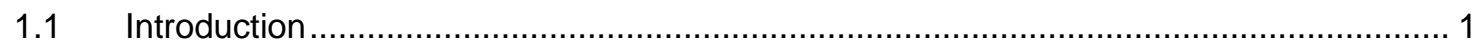

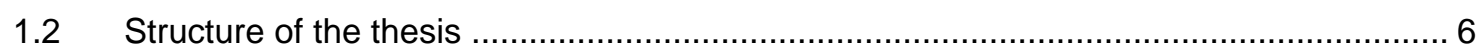

Chapter 2. Pastoralist and hunter-gatherer studies in South Africa ....................7

2.1 The archaeological identity of hunter-gatherers and herders ..................................... 12

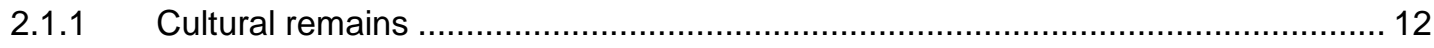

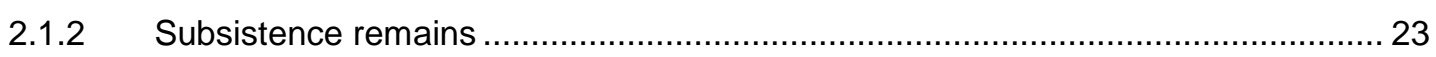

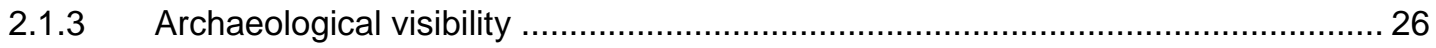

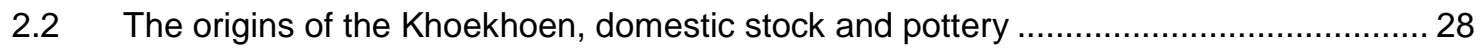

2.3 The possible routes and timing of entry of the Khoekhoen, domestic stock and pottery

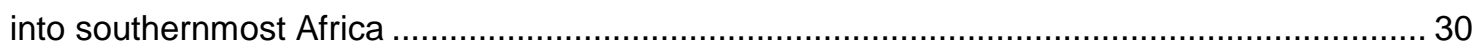

2.4 The nature of introduction of domesticates and pottery to southernmost Africa............. 39

2.5 Sheep, goats, dogs and cattle: a pastoralist package? .......................................... 56

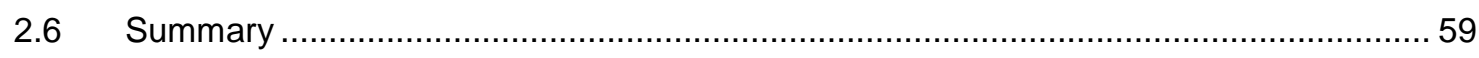

Chapter 3. The research area in context..........................................................61

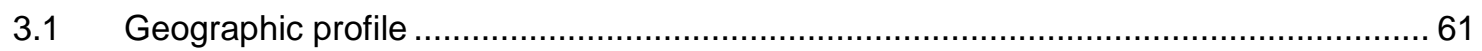

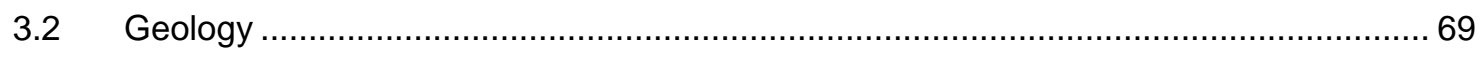

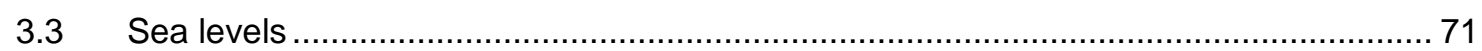

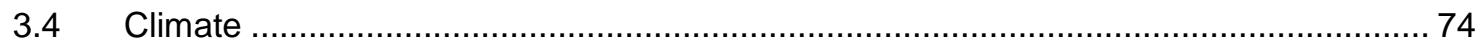

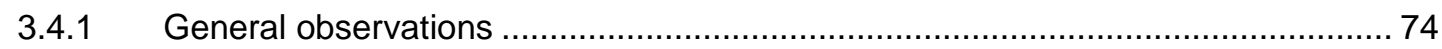

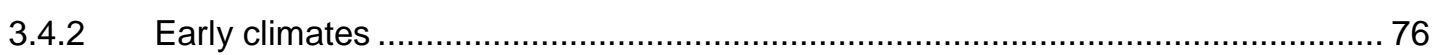

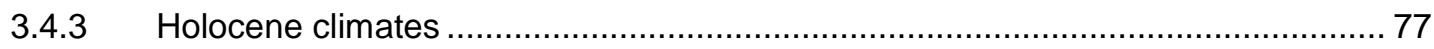

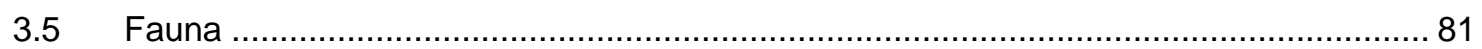

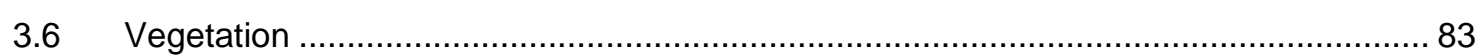

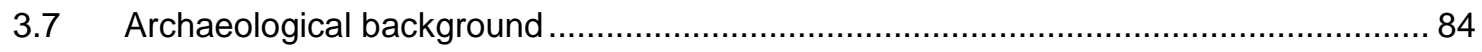

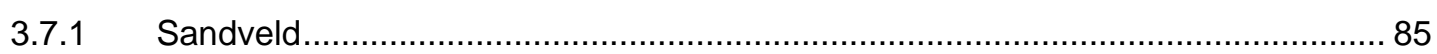

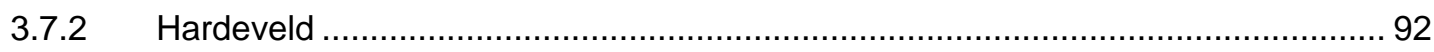




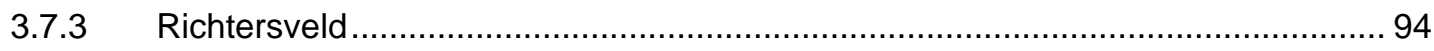

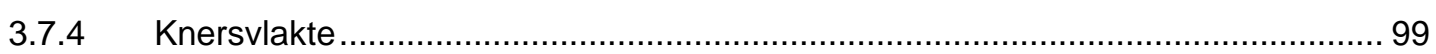

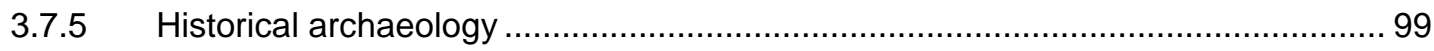

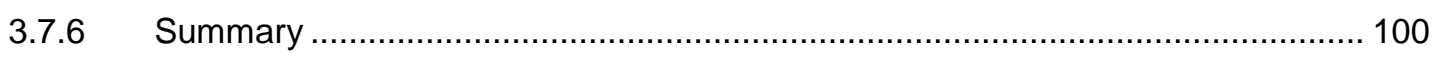

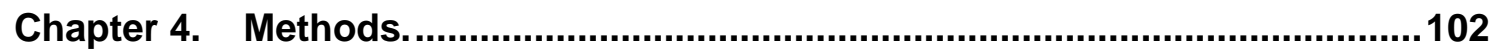

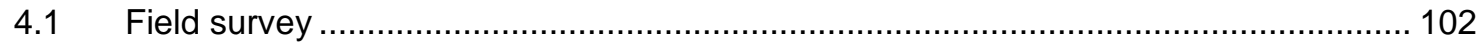

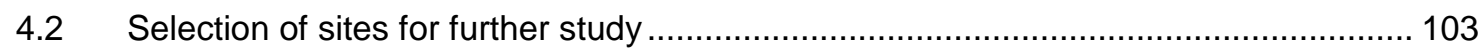

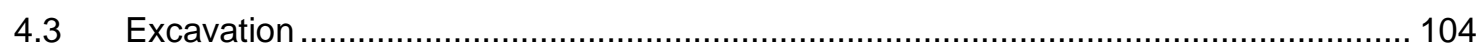

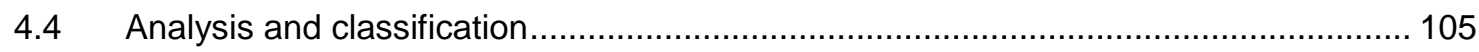

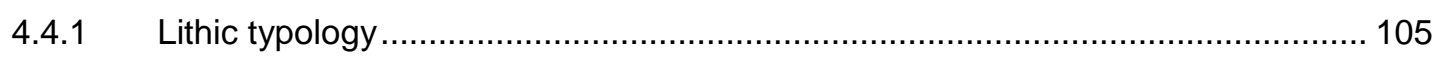

Stone materials......................................................................................... 110

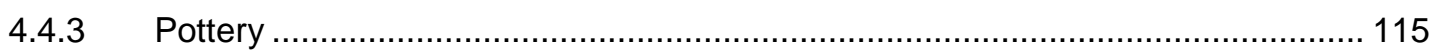

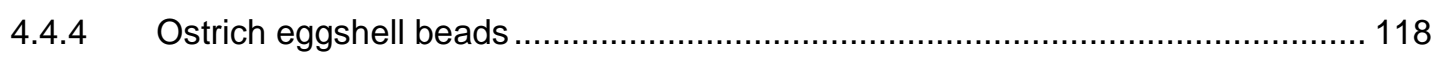

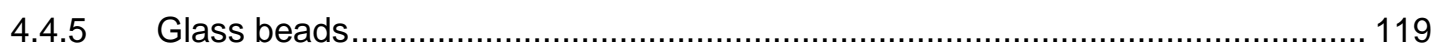

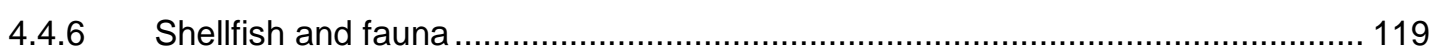

Chapter 5. Namaqualand assemblages ......................................................120

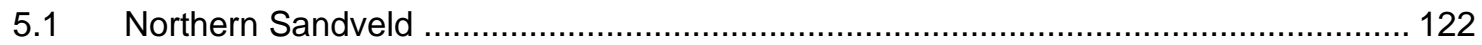

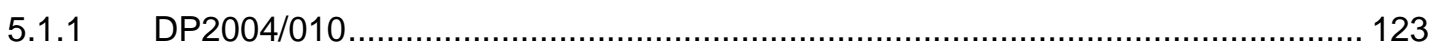

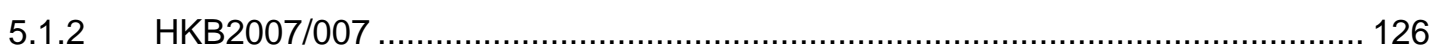

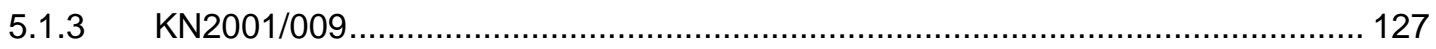

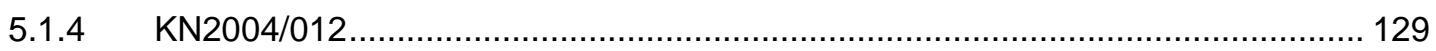

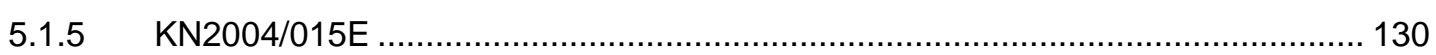

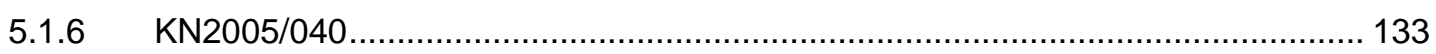

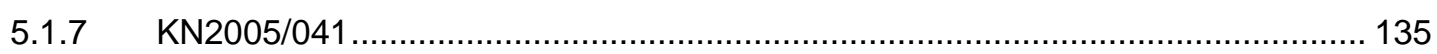

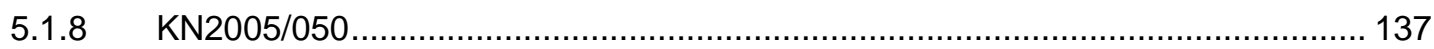

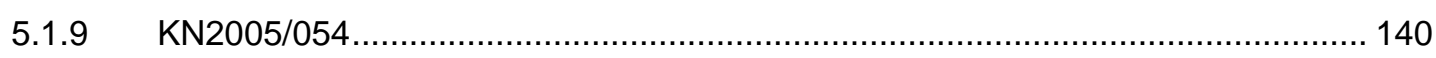

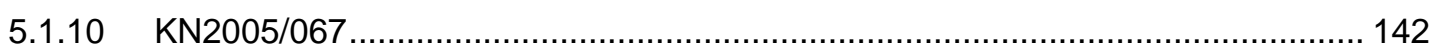

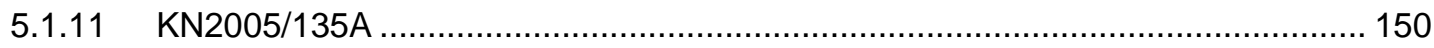

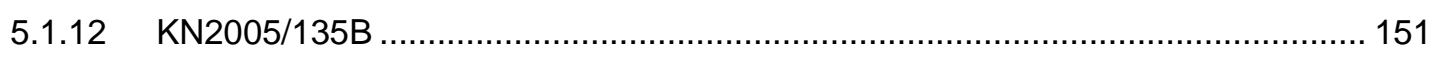

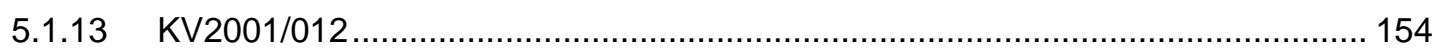

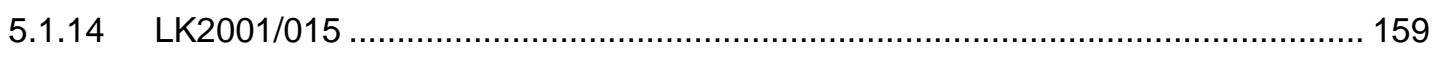

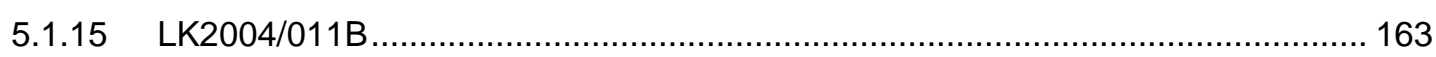

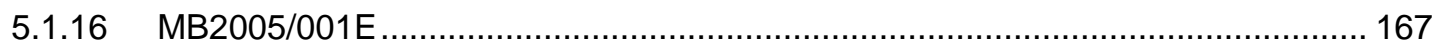

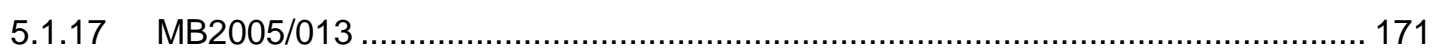

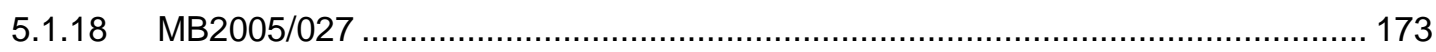

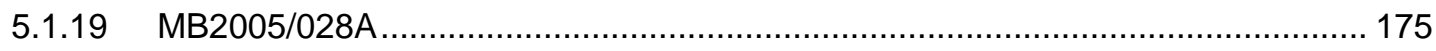

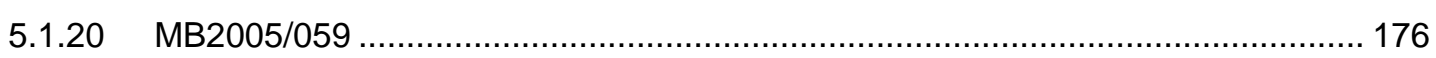

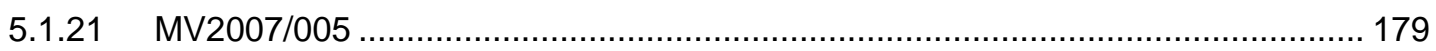

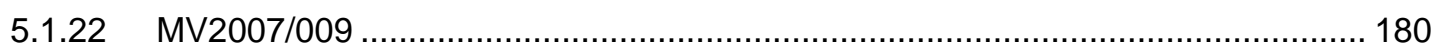




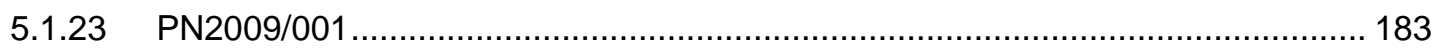

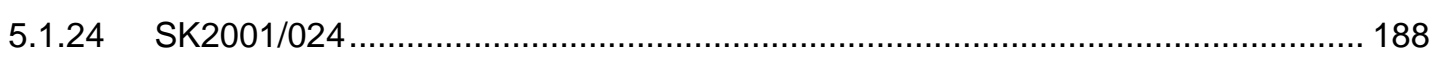

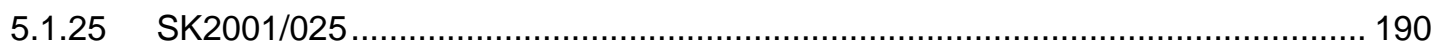

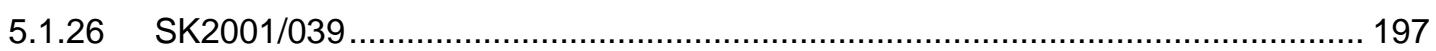

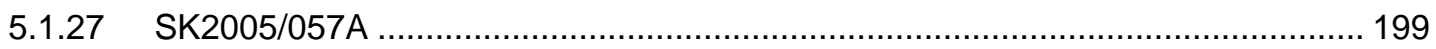

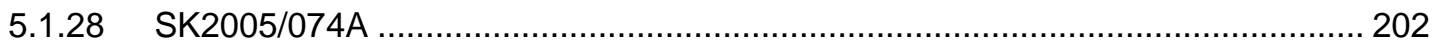

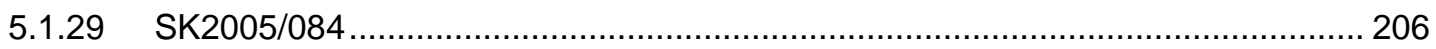

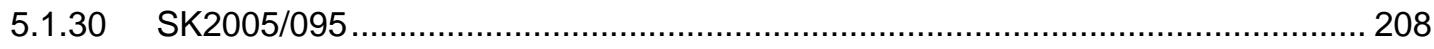

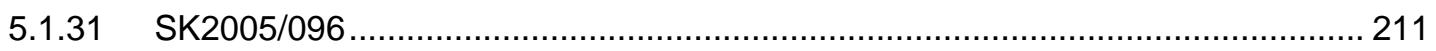

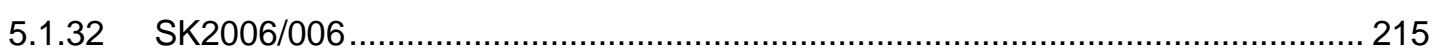

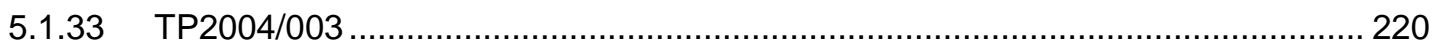

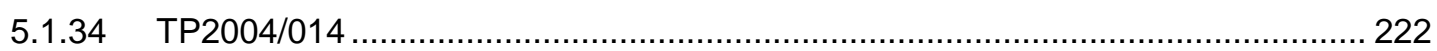

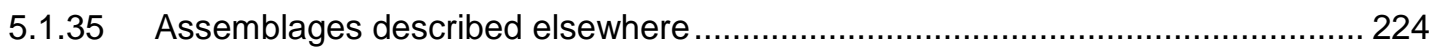

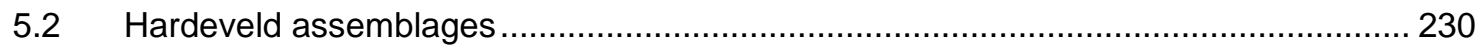

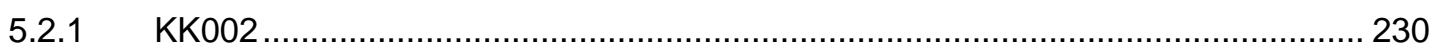

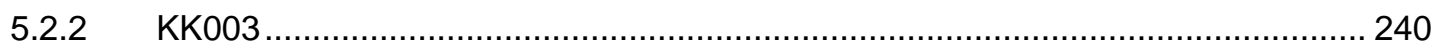

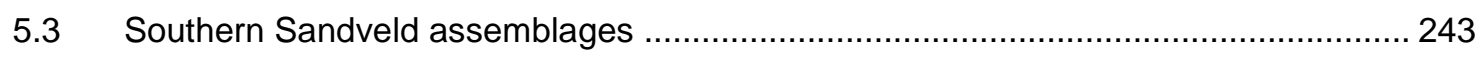

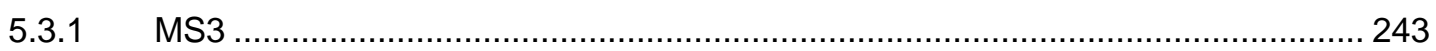

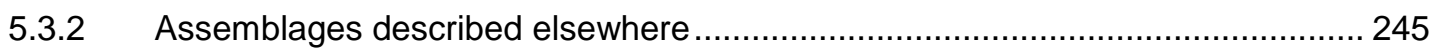

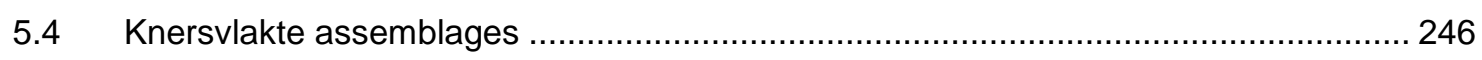

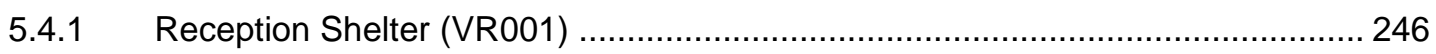

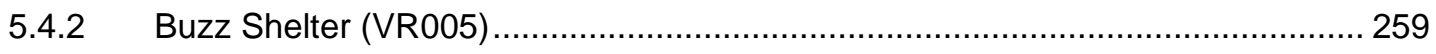

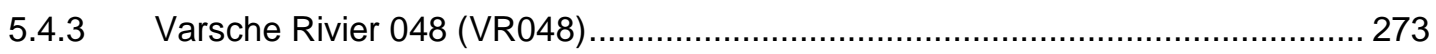

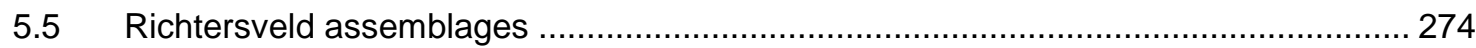

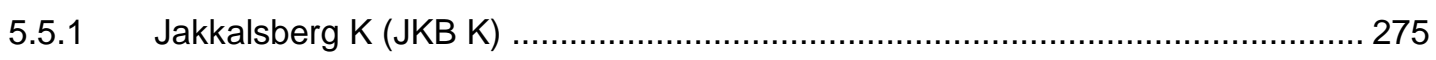

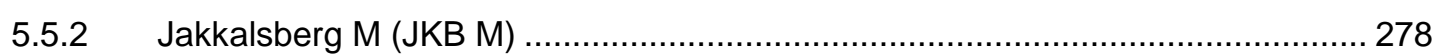

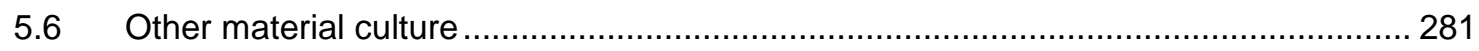

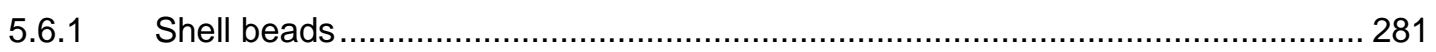

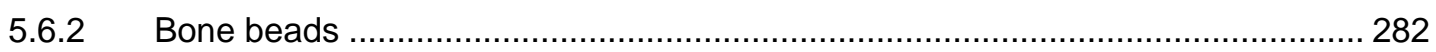

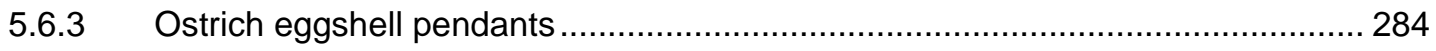

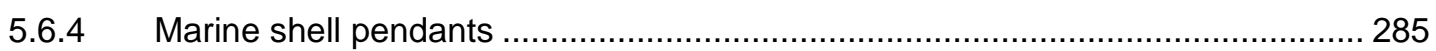

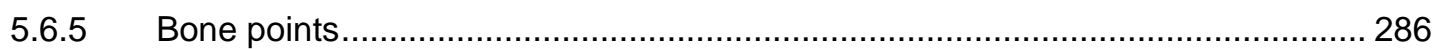

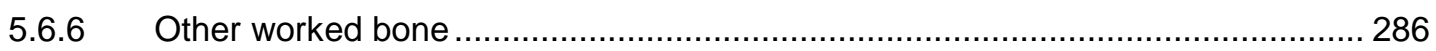

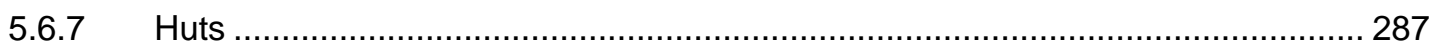

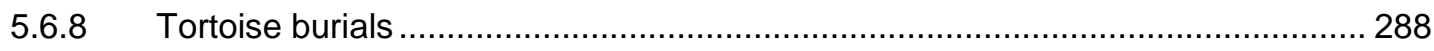

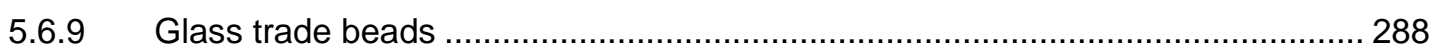

Chapter 6. Archaeological signatures in Namaqualand ....................................289

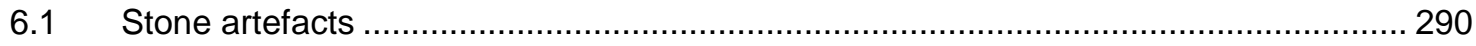

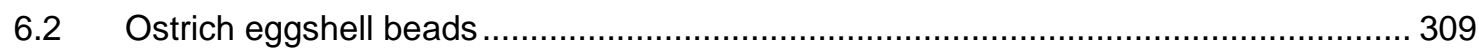

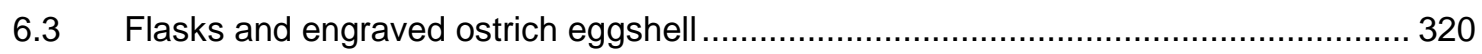




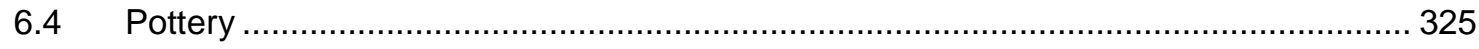

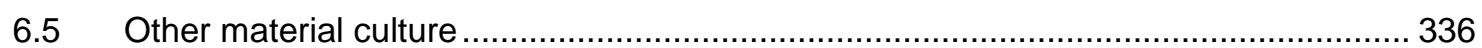

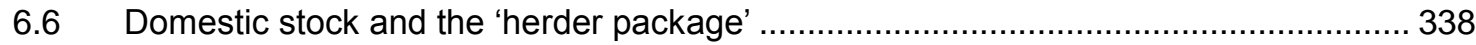

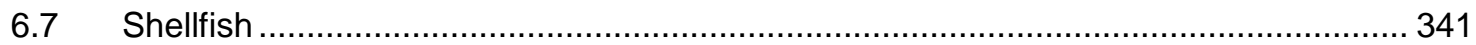

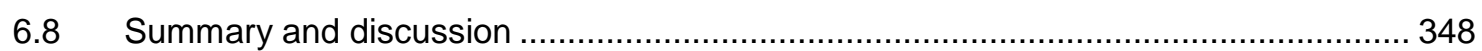

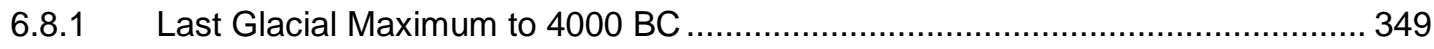

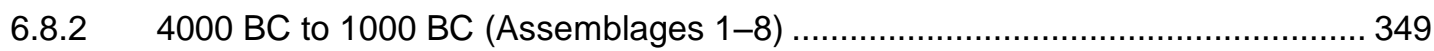

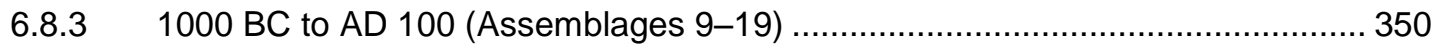

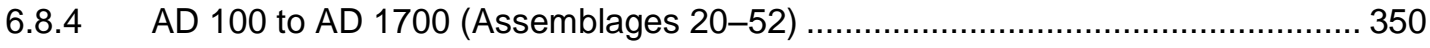

Chapter 7. Pottery-period hunter-gatherers and herders..................................354

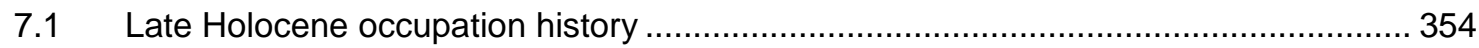

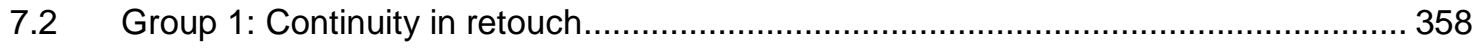

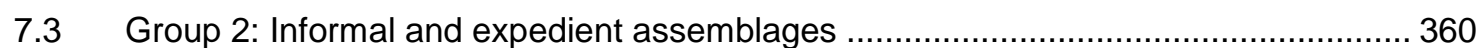

7.4 Group 3: Quartz-rich assemblages dominated by backed artefacts ............................. 364

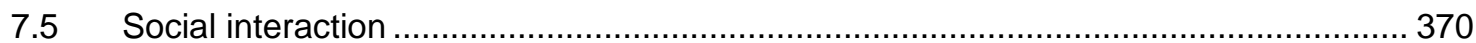

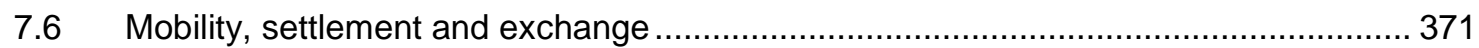

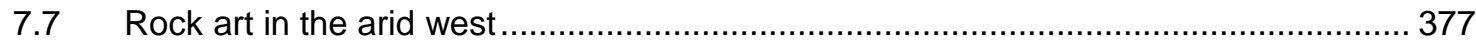

7.8 The southward spread of pastoralism: what, where, when and how? .......................... 385

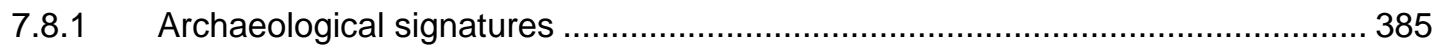

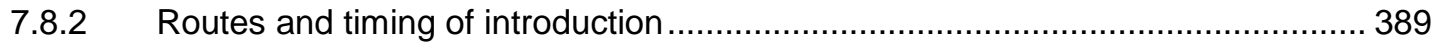

7.8.3 The nature of introduction: migration or diffusion? ............................................ 391

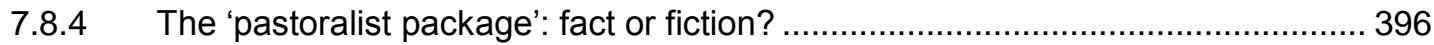

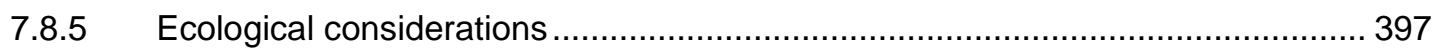

7.9 The introduction of herding: a summary from Namaqualand ...................................... 399

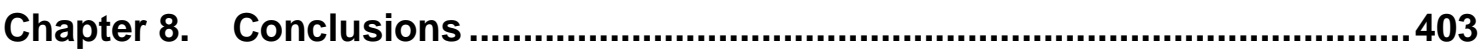

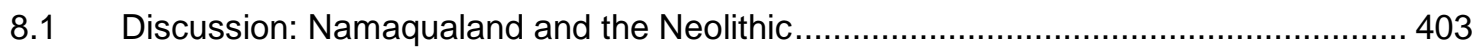

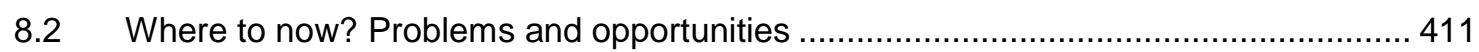

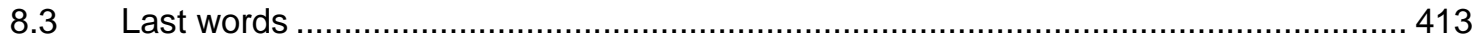

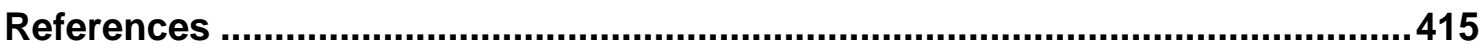

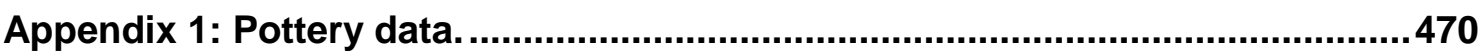

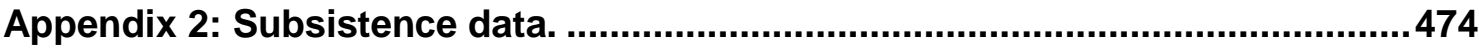

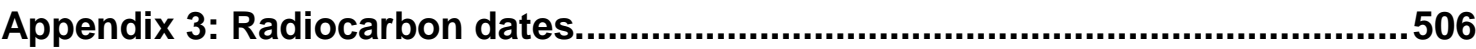




\section{List of figures}

Figure 1.1: Map of western South Africa showing places mentioned in Chapter 1. The dotted line indicates the approximate eastern boundary of Namaqualand between the Orange and Olifants Rivers

Fig. 2.1: Map showing the locations of sites significant to the discussion of early pastoralism in South Africa. The grey shading indicates the current study area (see Table 2.1 for references). .8

Figure 2.2: Ehret's (1982) suggested routes of entry of the Khoekhoe into southern Africa (modified from Ehret 1982: map 13). My research area is indicated by the shaded grey area. 30

Figure 2.3: Elphick's (1985) suggested routes of entry of the Khoekhoe into southern Africa (modified from Elphick 1985: map 1). My research area is indicated by the shaded grey area. 32

Figure 2.4: Barnard's (1992) suggested routes of entry of the Khoekhoe into southern Africa (modified from Barnard 1992: fig. 2.6). My research area is indicated by the shaded grey area

Figure 2.5: Bousman's (1998) suggested routes of entry of domestic stock into southern Africa based on radiocarbon dates (modified from Bousman 1998: fig. 4). My research area is indicated by the shaded grey area.

Figure 2.6: A. Smith's (1992, 2008a) suggested routes of entry of domestic stock into southern Africa (modified from A. Smith 1992: fig. 10.1; 2008a: fig. 12.4). My research area is indicated by the shaded grey area.

Figure 3.1: Map showing the subdivisions of the study area (after Cowling \& Pierce 1999).

Figure 3.2: Coastal dune fields in the northern Sandveld. 63

Figure 3.3: Gently undulating red sands in the southern interior 63

Figure 3.4: A small rocky valley in the south-western Hardeveld. Sites KK002 (white arrow) and KK003 (black arrow) are indicated. 65

Figure 3.5: A typical winter scene in the central Hardeveld. 65

Figure 3.6: View across the open quartz gravel plains. 66

Figure 3.7: View towards the south across the Sout River showing the distinctive erosional landscape characterising the area.

Figure 3.8: View across the Varsche River showing the limestone cliffs and riparian Acacia karoo trees.

Figure 3.9: S. granularis and C. granatina limpets on the rocks at Kleinzee. 68 
Figure 3.10: View southwards along the rocky shore at Koingnaas. .68

Figure 3.11: Map showing places and archaeological sites mentioned in Chapter 3. ..72

Figure 3.12: Schematic and simplified summary of temperature and precipitation data for Namaqualand from available records. .80

Figure 3.13: An unusually well-made rim fragment from site GR05 in the southern Sandveld 92

Figure 4.1: Terminology used in the classification of pottery. A: rim orientations, B: lip forms and C: external features (redrawn from Sadr \& Sampson 1999: fig. 3; Sampson \& Sadr 1999: fig 2 \& fig. 3; Rudner 1968, table 1 \& fig. V). While A and B are comprehensive, $\mathrm{C}$ includes only features relevant to the present samples. 117

Figure 5.1: Map showing the locations of the sites discussed in Chapter 5. 121

Figure 5.2: Lateral and plan views of the sandstone milled-edge pebble from Patch $A$ at DP2004/010. Scale in $10 \mathrm{~mm}$ intervals. 124

Figure 5.3: Scatter plot of ostrich eggshell bead dimensions from DP2004/010. 125

Figure 5.4: The refitting flask mouth fragments from KN2001/009. Scale in $5 \mathrm{~mm}$ intervals. 128

Figure 5.5: The two decorated pot sherds from KN2004/012. Scale in $5 \mathrm{~mm}$ intervals.130 Figure 5.6: The well worn bone tube from KN2004/012. Scale in $5 \mathrm{~mm}$ intervals. .....130 Figure 5.7: Stone artefacts from KN2004/015E. A: scraper fragment; B: miscellaneous retouched piece; C: adze. All in CCS. Scale in $5 \mathrm{~mm}$ intervals. 132

Figure 5.8: Stone artefacts from KN2005/040. A, B: sidescrapers; C: miscellaneous scraper; D, E: miscellaneous backed scrapers; F: segment. All in CCS. E has heatinduced crazing and a pot-lid fracture on its ventral surface. Scale in $5 \mathrm{~mm}$ intervals.

Figure 5.9: CCS artefacts from KN2005/040 showing the variety in colour from beige through yellow, mustard, brown and red. The lower right artefact has surface crazing due to heat-treatment. Scale in $5 \mathrm{~mm}$ intervals. 135

Figure 5.10: The silcrete large miscellaneous scraper from KN2005/041. Scale in $5 \mathrm{~mm}$ intervals.

Figure 5.11: The two S. argenvillei rims from KN2005/041. The left one is water-worn and the right sand-blasted. Scale in $10 \mathrm{~mm}$ intervals. 137

Figure 5.12: View towards the east showing the in situ midden between the figures and the deflated area in front of the toolbox. 138

Figure 5.13: Stone artefacts from KN2005/050. A: backed scraper; B: scraper fragment; C: miscellaneous backed scraper; D, E: segments; F: backed point. All in CCS. Scale bar in $5 \mathrm{~mm}$ intervals. 139

Figure 5.14: Surface appearance of the KN2005/054 shell midden..........................140 
Figure 5.15: The comb-incised pot sherds from KN2005/054. Scale in $5 \mathrm{~mm}$ intervals. 141 Figure 5.16: Layout of the main excavation area at KN2005/067. The separation of

Patches $1 \mathrm{~A}$ and $1 \mathrm{~B}$ is arbitrary. 143

Figure 5.17: Section through the in situ midden deposits of Patch 1A. Scale in $10 \mathrm{~mm}$ intervals. 143

Figure 5.18: Two refitted flask mouths from Patch $1 \mathrm{~A}$ (left) and opposite sides of the engraved and refitting bead debris from Patch 1B. Scale in $5 \mathrm{~mm}$ intervals. .... 147 Figure 5.20: Water-worn S. argenvillei shells from KN2005/067 (A-C: Patch 1C; D-F:

Patch 1B). Only $\mathrm{F}$ has non-abraded breaks. Scale in $5 \mathrm{~mm}$ intervals. 148

Figure 5.19: Refitting pottery from Patch 1B. The two sherds at upper right appear to have broken post-excavation. Scale in $5 \mathrm{~mm}$ intervals. 148

Figure 5.21: Bone artefacts from KN2005/067. Top: melon knife from Patch 1A, bottom: worked bone from Patch $1 \mathrm{C}$. Scale bars in $5 \mathrm{~mm}$ intervals. 149

Figure 5.22: The two lower grindstones from KN2005/135A. Scale in 10 and $50 \mathrm{~mm}$ intervals. 151

Figure 5.23: A heavily ground upper grindstone/hammer stone from KN2005/135B. Scale in $10 \mathrm{~mm}$ intervals 153

Figure 5.24: Scatter plot of ostrich eggshell bead dimensions from KN2005/135B....153 Figure 5.25: Ostrich eggshell beads from KN2005/135B. Scale in 1 and $5 \mathrm{~mm}$ intervals.

Figure 5.26: Schematic diagram of the excavation at KV2001/012. The division between Areas $A$ and $B$ is arbitrary. The mine trench lay to the east. 154

Figure 5.27: Stone artefacts from KV2001/012 Area A (A-D), Area B (E-G) and Area C

$(\mathrm{H}-\mathrm{I})$. A-C: notched pieces; D, E: miscellaneous retouched pieces; F: sideendscraper; G: thumbnail scraper; $\mathrm{H}$ : miscellaneous backed piece; I: sidescraper. All in CCS except E: silcrete; F: quartz. Scale in $5 \mathrm{~mm}$ intervals. 157

Figure 5.28: Scatter plot of ostrich eggshell bead dimensions from Area B of KV2001/012. 158

Figure 5.29: Ostrich eggshell flask mouth fragments from KV2001/012, Area A. Scale in $5 \mathrm{~mm}$ intervals. 158

Figure 5.30: Schematic map of the excavation at LK2001/015. The dashed circles indicate approximate limits of visible surface shell scatter at each patch. 160

Figure 5.31: The decorated seal scapula from LK2001/015, Patch Ci. Scale in $5 \mathrm{~mm}$ intervals. 163

Figure 5.32: View westwards showing the position of the in situ shell midden (at the base of the spade) in the side of a mine trench. 164 
Figure 5.33: A segment (upper left) and eight backed bladelets from LK2004/011B. All have their backed edges towards the top of the page. Scale in 1 and $5 \mathrm{~mm}$ intervals. 166

Figure 5.34: Plot of length to breadth for whole backed flakes and bladelets from LK2004/011B. 166

Figure 5.35: Scatter plot of ostrich eggshell bead dimensions from LK2004/011B. ... 167

Figure 5.36: Plan of the excavation at MB2005/001E. 168

Figure 5.37: The three collected shells from MB2005/013, two Marginella sp. on the left and a cowrie fragment on the right. Scale in $5 \mathrm{~mm}$ intervals. 173

Figure 5.38: The MB2005/027 shell midden as revealed from above and in section. 174

Figure 5.39: The grooved lower grindstone found at MB2005/028A. The left view was facing down. Scale in $50 \mathrm{~mm}$ intervals. .................................................. 176

Figure 5.40: The refitted pottery from MB2005/059. Scale in $10 \mathrm{~mm}$ intervals........... 178

Figure 5.41: View towards the northwest across the deflated area containing MV2007/005. 179

Figure 5.42: The impressed rim sherd from MV2007/005. Scale in $5 \mathrm{~mm}$ intervals. .. 180 Figure 5.43: Pottery from MV2007/009, Area 1(A). A: lug; B: base of a large vessel.

Scale in $5 \mathrm{~mm}$ intervals. 183

Figure 5.44: Layout of the excavated areas at PN2009/001. The X marks the origin of the date sample. 183

Figure 5.45: Stone artefacts from PN2009/001. A-P: sidescrapers; Q-DD: backed scrapers. All in silcrete except A: CCS \& K: quartz. O has a notch opposite the scraper retouch, $P$ has a truncation with the platform removed. Scale in $5 \mathrm{~mm}$ intervals.

Figure 5.46: Stone artefacts from PN2009/001. EE: thumbnail scraper; FF: endscraper; GG-II: miscellaneous backed scrapers; JJ-KK: miscellaneous scraper; LL: large segment; MM: curve-backed bladelet; NN: miscellaneous backed piece; OO-PP: backed piece fragments; QQ-RR: denticulates; SS-VV: notched pieces; WW-YY: miscellaneous retouched pieces. All in silcrete except PP: quartz \& EE, JJ, KK, MM, QQ, RR, SS, UU, VV: CCS. Scale in $5 \mathrm{~mm}$ intervals. 187

Figure 5.47: Engraved ostrich eggshell fragments from PN2009/001. Scale in $5 \mathrm{~mm}$ intervals. 188

Figure 5.48: Schematic map of the patches at SK2001/024 ............................... 189

Figure 5.49: Pottery rims from SK2001/024, Patch M. Scale in 10 mm intervals. ...... 190

Figure 5.50: Layout of the excavated areas at SK2001/025 .................................191

Figure 5.51: Scatter plot of ostrich eggshell bead dimensions from SK2001/025...... 196 
Figure 5.52: The striated body sherd and decorated rims from SK2001/039. Scale in 5 $\mathrm{mm}$ intervals. 198

Figure 5.53: The quartzite large chopper from SK2005/057A. Stippling denotes cortex.

Scale in $5 \mathrm{~mm}$ intervals. 200

Figure 5.54: The decorated rim sherd from SK2005/057A. Scale in $5 \mathrm{~mm}$ intervals. .202 Figure 5.55: Stone artefacts from SK2005/074. All from M1/L1 except D: Surface. A, B: sidescrapers; C: thumbnail scraper; D: notched piece; E: large thumbnail scraper; F: segment; G: backed blade; H: curve-backed bladelet. All in CCS except D \& E: quartz. Scale in $5 \mathrm{~mm}$ intervals. 205

Figure 5.56: Surface appearance of the deflated shell scatter at SK2005/084...........206

Figure 5.57: Stone artefacts from SK2005/084. A, B: miscellaneous backed scrapers; C: miscellaneous scraper; D: segment. All in CCS except D: quartz. Scale in $5 \mathrm{~mm}$ intervals. 207

Figure 5.58: The engraved ostrich eggshell fragment from SK2005/084. Scale in $5 \mathrm{~mm}$ intervals. 208

Figure 5.59: Layout of SK2005/095. The dotted lines indicate visible surface shell scatter and the small black oval in Patch $A$ is a tortoise burial 209

Figure 5.60: Stone artefacts from SK2005/095. A: calcrete large thumbnail scraper

(Patch A); B: CCS adze (Patch B). Scale in $5 \mathrm{~mm}$ intervals. 210

Figure 5.61: Stone artefacts from SK2005/096A. A-D: sidescrapers; E-F: thumbnail scrapers; G: notched piece. All in CCS. Scale in $5 \mathrm{~mm}$ intervals. 213

Figure 5.62: The unusually deeply grooved lower grindstone from SK2006/096A. Scale in $50 \mathrm{~mm}$ intervals

Figure 5.63: Two perforated Bullia shells from SK2005/096A. Scale in 5 mm intervals. 215

Figure 5.64: Stone artefacts from SK2006/006 Patch 2 Upper (A-C) and Lower (D-G). A: sidescraper; B, D: thumbnail scrapers; C: miscellaneous backed scraper; E: double endscraper; F: borer; G: notched piece. All in CCS. Scale in $5 \mathrm{~mm}$ intervals. ..218

Figure 5.65: Stone artefacts from SK2006/006 Patch 3. A: sidescraper; B: scraper fragment; C: miscellaneous retouched piece with scraper, denticulate and backing retouch all present as indicated. All in CCS. Scale in $5 \mathrm{~mm}$ intervals. 219

Figure 5.66: The pot lug from SK2006/006, Patch 2, Upper. Scale in $5 \mathrm{~mm}$ intervals.220 Figure 5.67: The two engraved ostrich eggshell fragments from TP2004/003. Scale in 5 $\mathrm{mm}$ intervals. 222

Figure 5.68: Stone artefacts from TP2004/014. A: sidescraper; B: backed scraper; C: segment; D: curve-backed bladelet; E: notched piece; F: truncated bladelet. All in CCS. Scale in $5 \mathrm{~mm}$ intervals 223 
Figure 5.69: Floor plan of KK002.

Figure 5.70: Section through the KK002 deposits facing east. 232

Figure 5.71: Northwest view towards KK002 (dome-shaped shelter in mid-picture). .232 Figure 5.72: Stone artefacts from KK002, Upper. A, B: sidescrapers; C, G, H: backed bladelet; D: curve-backed bladelet; E: backed point; F: segment; I: borer; J-L: triangles; M: segment with red mastic stain (stippled); N: backed piece fragment; O, R: miscellaneous retouched piece; P: scraper fragment; Q: miscellaneous scraper; S: notched piece. A, D, M, N, Q, R: quartz; B, C, E, J-L, P, S: clear quartz; G, I, O: CCS. F, H: silcrete. Scale in $5 \mathrm{~mm}$ intervals. 234

Figure 5.73: Stone artefacts from KK002, Lower. A: segment; B: backed bladelet with yellow-green mastic stain (stippled); C: miscellaneous retouched piece; D: adze. AC: quartz; D: silcrete. Scale in $5 \mathrm{~mm}$ intervals. 236

Figure 5.74: Scatter plot of ostrich eggshell bead dimensions from KK002. Upper are in black (whole beads) and white (broken beads with $>50 \%$ preserved), Lower are in red. 237

Figure 5.75: A wooden artefact from the bedding layer in Upper at KK002. Scale in $5 \mathrm{~mm}$ intervals. 238

Figure 5.76: The iron rod from the bedding layer in Upper at KK002. Scale in $10 \mathrm{~mm}$ intervals. 239

Figure 5.77: The brass pendant from Upper in KK002. Scale in $5 \mathrm{~mm}$ intervals. 239

Figure 5.78: View of KK003 showing the location of the primary painted panel (arrow) and the knee-high cavity beneath the boulder. 240

Figure 5.79: Oblique aerial view of KK003 showing the approximate extent of the artefact-bearing talus (between the dashed lines).

Figure 5.80: Circular motifs in the upper left and upper right parts of the main panel. The dotted line at top left represents the position of a seam in the boulder from which precipitate has flowed. Black denotes red paint and the stippled areas are white.

Scales in $10 \mathrm{~mm}$ intervals. 241

Figure 5.81: The lower group of images on the main panel. The right hand motifs in Figure 5.80 lie just above the right hand side of this image. Black denotes red paint and the stippled areas are white. Scale in $10 \mathrm{~mm}$ intervals. 242

Figure 5.84: View of Reception Shelter and its talus facing east. Its tiny entrance is arrowed

Figure 5.83: Floor plan of the interior of Reception Shelter. 248

Figure 5.84: Section through the Reception Shelter deposits along the 40/41 line. ...249 Figure 5.85: Scatter plot of ostrich eggshell bead dimensions from Reception Shelter.

Red symbols represent layer means as labelled. .256 
Figure 5.86: Painted (A-E) and worked (F-G) ostrich eggshell fragments from Reception Shelter Layer 6 . Scale in $5 \mathrm{~mm}$ intervals.

Figure 5.87: Decorated potsherds from the Reception Shelter talus. Scale in $5 \mathrm{~mm}$ intervals. 259

Figure 5.88: Floor plan of the interior of Buzz Shelter. The dashed outlines denote other test excavations. 260

Figure 5.89: View into Buzz Shelter looking towards the northwest. The excavation described here is the rear trench.

Figure 5.90: Section through the deposits inside Buzz Shelter along the 10/11 line. Aside from the disturbed area which does not intersect this section (see Orton et al. 2011, fig. 6 for a section further east), there are several thinner bedding layers which are not indicated. 263

Figure 5.91: Grooved and notched stone from Layer 4 in Buzz Shelter. 269

Figure 5.92: Scatter plot of ostrich eggshell bead dimensions from Buzz Shelter. Red symbols represent layer means as labelled. 271

Figure 5.93: Ostrich eggshell and seed beads strung with sinew from Layer $3(A)$ and an ochred bead tied on a loop of string from Layer 4 (B) of Buzz Shelter. Scale in 1 $\mathrm{mm}$ intervals. 272

Figure 5.94: Ostrich eggshell artefacts from Buzz Shelter. Engraved fragments from Layers $3(A \& B)$ and 6A (C-E), painted fragments from Layer $3(F)$ and Layer 4 $(\mathrm{G})$, pendant blanks from Layers $4(\mathrm{H})$ and $5(\mathrm{I})$ and 'retouched' fragments from Layer 3 ( $\mathrm{J} \& \mathrm{~K})$. Scale in $5 \mathrm{~mm}$ intervals. 272

Figure 5.95: View to the east showing a dense patch of artefact scatter on VR048...274 Figure 5.96: Scatter plot of ostrich eggshell bead dimensions from JKB K. 277

Figure 5.97: Pottery from JKB K. Scale in $5 \mathrm{~mm}$ intervals. 278

Figure 5.98: Upper and lower surfaces of one of the 'ochre cakes' from JKB M. Scale in $10 \mathrm{~mm}$ intervals. 280

Figure 5.99: Pottery from JKB M. Scale in $5 \mathrm{~mm}$ intervals. .281

Figure 5.100: Outer (left) and inner (right) surfaces of shell beads from AK2001/002 showing. Scale in $1 \mathrm{~mm}$ intervals. 282

Figure 5.101: External and aperture diameters of the shell beads from AK2001/002.282

Figure 5.102: Graph showing the ratio of external to aperture diameters of bone beads from Namaqualand and bone rings from Nelson Bay Cave. Source data as in Table 5.133 above and NBC from Inskeep (1987: appendix 35) 284

Figure 5.103: Front (left) and back (right) of the ostrich eggshell pendant fragment from site AK2005/001. The rear is ochred. Scale in $5 \mathrm{~mm}$ intervals. 285 
Figure 5.104: The wind-blasted ostrich eggshell pendant fragments from the background scatter at KN2004/012. The right hand one has part of a hole visible (arrowed).

Scale in $5 \mathrm{~mm}$ intervals. 285

Figure 105: Bone pendant (top; scale in $5 \mathrm{~mm}$ intervals) and melon knife (bottom; scale in $10 \mathrm{~mm}$ intervals) from AK2006/006. 286

Figure 5.106: Glass bead from LK2001/010A. Scale in $1 \mathrm{~mm}$ intervals. 288

Figure 6.1: Stone material composition of the assemblages by assigned Group. Quartz is excluded and comprises the remaining amount in each assemblage.

Figure 6.2: Stone material frequencies among all retouched tools by assigned group. The number of retouched tools per assemblage is indicated above each column. ..292

Figure 6.3: Stone material composition of the assemblages in temporal order. Quartz is excluded and comprises the remaining amount in each assemblage. 297

Figure 6.4: Stone material frequencies among all retouched tools in temporal order. The number of retouched tools per assemblage is indicated above each column. ..298

Figure 6.5: Primary core type frequencies among all quartz cores by assigned group.

Minor types are omitted and the number of quartz cores per assemblage is indicated above each column 299

Figure 6.6: Retouch frequency in temporal order. 300

Figure 6.7: Scatter plot of formal tool index against pottery index. Assemblage numbers are indicated. For the sake of clarity, all sites older than 2000 years and with no pottery are excluded, since all would fall on the y-axis. The dashed line indicates the separation between Group 2 and Group 2/3 assemblages and the rest. ....301

Figure 6.8: Retouch types in temporal order. 302

Figure 6.9: Number of retouched tool classes by assigned assemblage group. Brown bars are assemblages with pottery and stars indicate pottery but no retouch...305 Figure 6.10: Number of retouched tool classes in temporal order. Brown bars are assemblages with pottery and stars indicate pottery but no retouch..................305

Figure 6.11: Ostrich eggshell bead size by assigned group. 311

Figure 6.12: Ostrich eggshell bead size in temporal order showing the relative contributions of the various size categories to each assemblage.

Figure 6.13: Ostrich eggshell bead size in temporal order for each size category based on the data in Figure 6.12 (from which assemblage numbers, groups and bead counts can be obtained) 313

Figure 6.14 Histograms showing the change in ostrich eggshell bead size classes through time. Intervening periods that are not represented have no data available.

Figure 6.15: Ostrich eggshell bead mean external diameter in temporal order..........315 
Figure 6.16: Ostrich eggshell bead mean aperture diameter in temporal order. 316

Figure 6.17: Scatter plot of all ostrich eggshell bead external and aperture diameters showing the relationship between them as a linear regression. 317

Figure 6.18: Mean ostrich eggshell bead size according to assigned lithic group. .....318

Figure 6.19: Mean ostrich eggshell bead size change through time at Spoeg River Cave (base don Webley 2002: table 12). 319

Figure 6.20: Frequency of engraved fragments and flask mouth fragments among all ostrich eggshell fragments excluding bead manufacturing debris. 321

Figure 6.21: Engraved ostrich eggshell from the Richtersveld. A-G: Jakkalsberg N, fourth-third millennia BC (Orton \& Halkett 2010, fig. 2); H-K: Jakkalsberg L, second millennium BC (Orton \& Halkett 2010, fig. 7); L-M: Jakkalsberg A, first millennium AD (Webley 1997a: fig. 10); N-Q: /hei-/khomas, first \& second millennia AD (Webley 2001: fig. 12). D, K \& P are flask mouths. 322

Figure 6.22: Engraved ostrich eggshell from the Knersvlakte. A: Buzz Shelter, c. fourth millennium BC; B-H: Buzz Shelter, first millennium AD; I-J: Reception Shelter talus excavation, second millennium AD. 322

Figure 6.23: Pottery Index in temporal order. 329

Figure 6.24: Pottery wall thickness in temporal order. Collections with eight or more sherds are shown in brown and assumed to be more reliable. Numbers along the top indicate number of sherds and the white arrow shows AD 1200. 334

Figure 6.25: Unpublished decorated pottery from the Bloeddrift area of the Richtersveld (D. Halkett, pers. comm. 2012). No date is available. Bold line above right hand sherd is the rim. 335

Figure 6.26: C. granatina and S. granularis frequencies in temporal order. 344

Figure 6.27: $S$. argenvillei and $S$. barbara frequencies in temporal order. 345

Figure 6.28: C. meridionalis and Burnupena sp. (whelk) frequencies in temporal order. 345

Figure 6.29: Group 1 shellfish species frequencies. .......................................... 346

Figure 6.30: Group 2 shellfish species frequencies. ......................................... 347

Figure 6.31: Group 3 shellfish species frequencies. ............................................ 347

Figure 6.32: Combination groups shellfish species frequencies. ..............................348

Figure 6.33: Summary chart showing the cultural change evident in Namaqualand. The black bars represent clear patterns, while the grey bars indicate periods of uncertainty, due either to limited observations, lack of clarity of the observations or lack of dating precision 353

Figure 7.1: Temporal distribution of radiocarbon dates from Namaqualand in 200 year intervals. 356 
Figure 7.2: Temporal distribution of occupation date ranges from the northern and central Sandveld (rounded off to the nearest 50 years and excluding Spoeg River Cave).

Figure 7.3: Extract from a 1907 British map of northern Namaqualand showing 'Native huts at intervals' inland of the Buffels River Mouth (Source: Pietermaritzburg Archives) 358

Figure 7.4: Map showing all sites in Namaqualand at which domesticates have been found. Note that most, if not all, sheep are likely to be caprines but I have retained the identifications published. 362

Figure 7.5: RMRI for primary stone materials by assigned group. 375

Figure 7.6: Relationship of stone material abundance and quality and its effect on northern and central Sandveld assemblages (modified from Andrefsky 1994: fig. 2).

Figure 7.7: Map showing the distribution of known rock art sites in Namaqualand. Typical hunter-gatherer art, 'herder art' and other finger-painted geometrics are distinguished. Sites known to the author in the sandstone mountains fringing Namaqualand to the southeast are also indicated.

Figure 7.8: Dark red geometric motifs from Wolfkraal. The left three are shown in true association. Scale bar in $10 \mathrm{~mm}$ intervals. Note that the rock surface is exfoliating and the original images may have differed slightly. .383

Figure 7.11: Finger-painted rock art at ON001. Colour saturation and contrast adjusted to emphasize the art. Scale in $10 \mathrm{~mm}$ intervals. .384

Figure 7.9: Finger-painted rock art at ON001. Colour saturation and contrast adjusted to emphasize the art. Scale in $10 \mathrm{~mm}$ intervals. 384

Figure 7.10: Finger-painted rock art at ON001. Colour saturation and contrast adjusted to emphasize the art. Scale in $10 \mathrm{~mm}$ intervals.

Figure 8.1: Ages of domestic animal bones from the Sandveld. Black bars indicate directly dated bones and grey bars are those dates associated with domestic bones. The '?' indicates an estimate from an undated layer. 406 


\section{List of Tables}

Table 2.1: Dates discussed in this chapter that are specifically relevant to the introduction of sheep, cattle and pottery to the western and southern parts of South Africa. This list is necessarily selective and does not include all dates from each site. The dates are listed alphabetically by site and those in bold highlight directly dated stock bones and pot sherds. Calibrations were conducted on OxCal (Bronk-Ramsey 1995, 2009)

Table 2.2: Selected Western Cape pottery period hunter-gatherer and herder sites identifiable by A. Smith et al.'s (1991) criteria.

Table 2.3: Thin-walled pottery in south-western Africa. Compiled from Sadr (2008a),

Sadr \& Sampson (2006) and Sadr \& Smith (1991). This sequence was first described from Kasteelberg by Sadr \& Smith (1991) and subsequently clarified by Sadr \& Sampson (1999) .15

Table 2.4: Comments relevant to the introduction of sheep and pottery to southern African sites.

Table 2.5: Ratios of livestock over time. 2002 data calculated from Samuels et al. (2008: table 1), 1865 data calculated from Hoffman \& Rohde (2007), 1661 data calculated from Penn (1995).

Table 3.1: List of mammal species historically documented in Namaqualand. Only those whose presence could be reliably ascertained by Skead (1980) are listed.........81

Table 4.1: Stone artefact typology .................................................................. 106

Table 4.2: Terminology used in the classification of Cape coastal pottery types from oldest to youngest as proposed by Sadr and Smith (1991) and refined by Sadr and Sampson (1999). 116

Table 4.3: Grain sizes of pottery temper. 117

Table 4.4: Classification stages of unfinished ostrich eggshell beads as described by Orton (2008d: table 1). 118

Table 5.1: Stone artefacts from Patch A at DP2004/010 (Group 2). 124

Table 5.2: Summary statistics for finished ostrich eggshell beads from DP2004/010.125

Table 5.3: Stone artefacts from HKB2007/007 (Group 1/3). 127

Table 5.4: Stone artefacts from KN2001/009 (Group 3). 128

Table 5.5: Stone artefacts from KN2004/012 (Group 2). 129

Table 5.6: Summary statistics for finished ostrich eggshell beads from KN2004/012.130 Table 5.7: Stone artefacts from KN2004/015E (Group 1/3). 132 Table 5.8: Summary statistics for finished ostrich eggshell beads from KN2004/015E.133 
Table 5.9: Stone artefacts from KN2005/040 (Group 1).

Table 5.10: Summary statistics for finished ostrich eggshell beads from KN2005/040.135

Table 5.11: Stone artefacts from KN2005/041 (Group 2/3). 136

Table 5.12: Summary statistics for finished ostrich eggshell beads from KN2005/041.137

Table 5.13: Stone artefacts from KN2005/050 (Group 1). 138

Table 5.14: Summary statistics for finished ostrich eggshell beads from KN2005/050.139

Table 5.15: Stone artefacts from KN2005/054 (Group 3).

Table 5.16: Summary statistics for finished ostrich eggshell beads from KN2005/054.141

Table 5.17: Stone artefacts from KN2005/067, Patch 1A (Group 2). 144

Table 5.18: Stone artefacts from KN2005/067, Patch 1B (Group 3)......................... 144

Table 5.19: Stone artefacts from KN2005/067, Patch 1C (Group 2)......................... 145

Table 5.20: Stone artefacts from KN2005/067, Patch 2 (Group 2)............................ 145

Table 5.21: Stone artefacts from KN2005/067, Patch 3 (Group 2)............................ 145

Table 5.22: Stone artefacts from KN2005/067, Patch 5 (Group 2)............................. 146

Table 5.23: Summary statistics for finished ostrich eggshell beads from KN2001/067.146

Table 5.24: Pathway 1 ostrich eggshell bead manufacturing debris from KN2005/067,

Patch $1 \mathrm{~A}$. 147

Table 5.25: Stone artefacts from KN2005/135A (Group 1). 150

Table 5.26: Summary statistics for finished ostrich eggshell beads from KN2005/135A.

Table 5.27: Stone artefacts from KN2005/135B (Group 1). 152

Table 5.28: Summary statistics for finished ostrich eggshell beads from KN2005/135B.

Table 5.29: Stone artefacts from KV2001/012, Area A (Group 1) ............................. 155

Table 5.30: Stone artefacts from KV2001/012, Area B (Group 1) .............................. 155

Table 5.31: Stone artefacts from KV2001/012, Area C (Group 1)............................. 156

Table 5.32: Summary statistics for finished ostrich eggshell beads from KV2001/012.158

Table 5.33: Stone artefacts from LK2001/015, Patch Cii Group 2). .......................... 161

Table 5.34: Stone artefacts from LK2001/015, Patch D (Group 1)........................... 161

Table 5.35: Stone artefacts from LK2001/015, Patch I (Group 3)........................... 161

Table 5.36: Measurements of the two finished ostrich eggshell beads from LK2001/015,

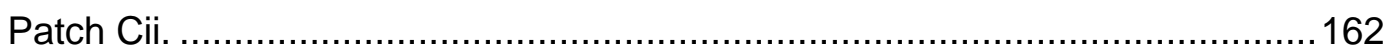

Table 5.37: Summary statistics for finished ostrich eggshell beads from LK2001/015,

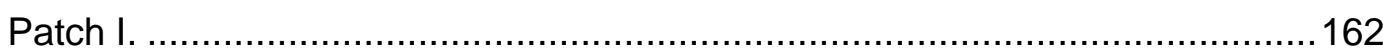

Table 5.38: Unfinished ostrich eggshell beads from LK2001/015 ........................... 162

Table 5.39: Stone artefacts from LK2004/011B (Group 3).....................................165 
This is the largest Group 3 assemblage from Namaqualand so it is useful to present size data for the common backed elements (Table 40). Figure 5.34 shows that backed flakes and bladelets do separate into two groups but that backed flakes tend to be quite elongate, probably suggesting that they were all one type as far as their makers were concerned. The hammer stone/upper grindstone is well worn with two adjoining facets. 165

Table 5.40: Size data of unbroken backed artefacts from LK2004/011B. ................. 166

Table 5.41: Summary statistics for finished ostrich eggshell beads from LK2004/011B. 167

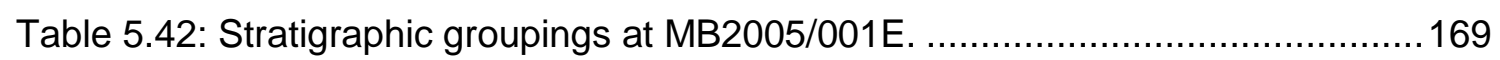

Table 5.43: Stone artefacts from MB2005/001E, Layer 1 (Group 3)......................... 169

Table 5.44: Stone artefacts from MB2005/001E, Layer 2 (Group 1)......................... 170

Table 5.45: Stone artefacts from MB2005/001E, Layer 3 (Group 1)......................... 170

Table 5.46: Stone artefacts from MB2005/001E, Layer 4 (Group 1)........................ 170

Table 5.47: Measurement of the three finished ostrich eggshell beads from

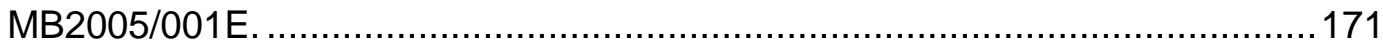

Table 5.48: Stone artefacts from MB2005/013 (Group 1)....................................172

Table 5.49: Summary statistics for finished ostrich eggshell beads from MB2005/013.173

Table 5.50: Stone artefacts from MB2005/027 (Group 3)........................................ 174

Table 5.51: Stone artefacts from MB2005/028A (Group 3) .................................... 175

Table 5.52: Stone artefacts from MB2005/059, Patch A (Group 1/3) ........................ 177

Table 5.53: Stone artefacts from MB2005/059, Patch B (Group 1/3) ....................... 177

Table 5.54: Stone artefacts from MV2007/009, Area 1 (Group 2).............................. 180

Table 5.55: Stone artefacts from MV2007/009, Area 2 (Group 2)............................. 181

Table 5.56: Stone artefacts from MV2007/009, Area 3 (Group 2)............................. 181

Table 5.57: Stone artefacts from MV2007/009, Area 4 (Group 2)............................ 181

Table 5.58: Summary statistics for finished ostrich eggshell beads from MV2007/009.182

Table 5.59: Stone artefacts from PN2009/001 (Group 1). ...................................... 184

Table 5.60: Ratio of sidescrapers to backed scrapers at PN2009/001 ...................... 185

Table 5.61: Summary statistics for finished ostrich eggshell beads from PN2009/001.187

Table 5.62: Stone artefacts from SK2001/024, Patch A (Group 2). .......................... 189

Table 5.63: Stone artefacts from SK2001/024, Patch B (Group 2). .......................... 189

Table 5.64: Stone artefacts from SK2001/024, Patch M (Group 2)........................... 190

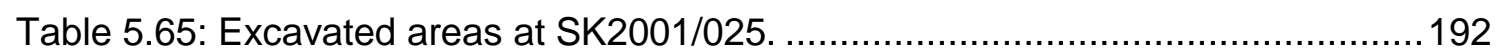

Table 5.66: Stone artefacts from SK2001/025 Area A (Group 1).............................. 192

Table 5.67: Stone artefacts from SK2001/025 Area B (Group 1).............................. 193

Table 5.68: Stone artefacts from SK2001/025 Area C (Group 1).............................193 
Table 5.69: Stone artefacts from SK2001/025 Area D (Group 1).............................. 194

Table 5.70: Stone artefacts from SK2001/025 Area E (Group 1)............................. 194

Table 5.71: Stone artefacts from SK2001/025 Area F (Group 1)............................. 195

Table 5.72: Summary statistics for finished ostrich eggshell beads from SK2001/025.196

Table 5.73: Stone artefacts from SK2001/039 (Group 1/3)....................................197

Table 5.74: Stone artefacts from SK2005/057A (Group 2). .....................................200

Table 5.75: Ostrich eggshell bead manufacturing debris from SK2005/057A...........201

Table 5.76: Summary statistics for finished ostrich eggshell beads from SK2005/057A.

201

Table 5.77: Excavated areas and artefact densities at SK2005/074A. Surface, L1 and L2 are shell scatter, while $\mathrm{M} 1$ and $\mathrm{M} 2$ are midden levels. .................................203

Table 5.78: Stone artefacts from SK2005/074A, Layer 1 (Group 1)...........................203

Table 5.79: Stone artefacts from SK2005/074A, Layer 2 (Group 1)...........................204

Table 5.80: Stone artefacts from SK2005/074A, Layer 3 (Group 1)...........................204

Table 5.81: Summary statistics for finished ostrich eggshell beads from SK2005/074A.

205

Table 5.82: Stone artefacts from SK2005/084 (Group 1).....................................207

Table 5.83: Summary statistics for finished ostrich eggshell beads from SK2005/084.207

Table 5.84: Stone artefacts from SK2005/095, Patch A (Group 3)............................209

Table 5.85: Stone artefacts from SK2005/095, Patch B. ....................................210

Table 5.86: Summary statistics for finished ostrich eggshell beads from SK2005/095.211

Table 5.87: Ostrich eggshell bead manufacturing debris from SK2005/095. ............211

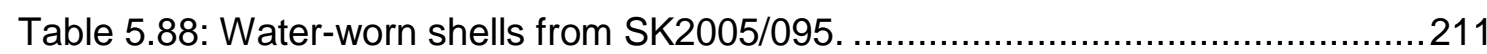

Table 5.89: Stone artefacts from SK2005/096A (Group 1/3). .................................212

Table 5.90: Stone artefacts from SK2005/096B (Group 1)...................................213

Table 5.91: Evidence for the origin of the CCS retouched tools in SK2006/096 .......214

Table 5.92: Summary statistics for finished ostrich eggshell beads from SK2005/096A.

Table 5.93: Stone artefacts from SK2006/006, Patch 1 (Group 1)............................217

Table 5.94: Stone artefacts from SK2006/006, Patch 2 Upper (Group 1/3). ..............217

Table 5.95: Stone artefacts from SK2006/006, Patch 2 Lower (Group 1/3). ..............217

Table 5.96: Stone artefacts from SK2006/006, Patch 3 (Group 1) ...........................218

Table 5.97: Summary statistics for finished ostrich eggshell beads from SK2006/006.219

Table 5.98: Stone artefacts from TP2004/003 (Group 3)........................................221

Table 5.99: Stone artefacts from TP2004/014 (Group 1)..........................................223

Table 5.100: Stone artefacts from DP2004/014 (Group 2/3)..................................224

Table 5.101: Stone artefacts from KN2001/008C, Upper (Group 1)........................226 
Table 5.102: Stone artefacts from KN2001/008C, Lower (Group 1). 227

Table 5.103: Stone artefacts from KK002, Upper (Group 3, with residual Group 1)...233

Table 5.104: Stone artefacts from KK002, Lower (Group 3).................................235

Table 5.105: Summary statistics for finished ostrich eggshell beads from KK002. ....237

Table 5.106: K002 glass bead attributes. ...........................................................239

Table 5.107: Stone artefacts from KK003 (Group 1 \& possibly others).......................242

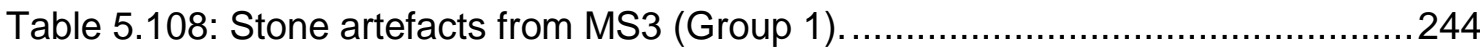

Table 5.109: Stone artefacts from MS1 (Group 1; source: Hart \& Halkett 1994)........245

Table 5.110: Stratigraphic grouping of levels at Reception Shelter. Layer numbers follow Orton et al. (2011) but Layers 4 and 9 are newly divided.

Table 5.111: Stone artefacts from Reception Shelter, Layers 1-4A. Clear quartz artefacts are summed in parentheses in the quartz column. 251

Table 5.112: Stone artefacts from Reception Shelter, Layers 4B-5. Clear quartz retouched artefacts are indicated in parentheses in the quartz column. 251

Table 5.113: Stone artefacts from Reception Shelter, Layer 6. Clear quartz retouched artefacts are indicated in parentheses in the quartz column. 252

Table 5.114: Stone artefacts from Reception Shelter, Layer 7. Clear quartz retouched artefacts are indicated in parentheses in the quartz column. 253

Table 5.115: Stone artefacts from Reception Shelter, Layers 8-9A. 253

Table 5.116: Stone artefacts from Reception Shelter, Layer 9B. Clear quartz artefacts are summed in parentheses in the quartz column. 254

Table 5.117: Summary statistics for finished ostrich eggshell beads from Reception Shelter. .255

Table 5.118: Stratigraphic grouping of levels at Buzz Shelter. Layer numbers follow Orton et al. (2011). 261

Table 5.119: Stone artefacts from Buzz Shelter, Layer 1 (Group 2). 265

Table 5.120: Stone artefacts from Buzz Shelter, Layer 2. Clear quartz retouched artefacts are indicated in parentheses in the quartz column. 265

Table 5.121: Stone artefacts from Buzz Shelter, Layer 3. Clear quartz retouched artefacts are indicated in parentheses in the quartz column. 266

Table 5.122: Stone artefacts from Buzz Shelter, Layer 4. Clear quartz retouched artefacts are indicated in parentheses in the quartz column. 266

Table 5.123: Stone artefacts from Buzz Shelter, Layer 5. 267

Table 5.124: Stone artefacts from Buzz Shelter, Layer 6. 268

Table 5.125: Stone artefacts from Buzz Shelter, Layer 7. 269

Table 5.126: Summary statistics for finished ostrich eggshell beads from Buzz Shelter. 
Table 5.127: Ostrich eggshell bead manufacturing debris from Buzz Shelter. 271

Table 5.128: Stone artefacts from JKB K (Group 2). .............................................276

Table 5.129: Summary statistics for finished ostrich eggshell beads from JKB K. ....276

Table 5.130: Stone artefacts from JKB M................................................... 279

Table 5.131: Summary statistics for finished ostrich eggshell beads from JKB M.....280

Table 5.132: Ostrich eggshell bead manufacturing debris from JKB M. ...................280

Table 5.133: Dimensions of flat bone beads from Namaqualand. Source data from

Dewar (2008:82), Dewar \& Stewart (2012) and Orton and Halkett (2010:15) ...283

Table 6.1: Relationships between technology and mobility and implications for

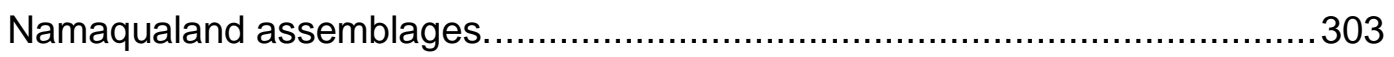

Table 6.2: Retouch types at Spoeg River Cave (ages calibrated and data calculated from

Webley 2002: tables $2 \& 4$ ). .307

Table 6.3: Engraved ostrich eggshell patterns as they appear in the coastal

Namaqualand archaeological record.

Table 6.4: Pottery decoration styles as they appear in the coastal Namaqualand

archaeological record. Rim sherds are indicated. Not to scale.

Table 6.5: Occurrence of water-worn shells and melon knives from Sandveld

assemblages. Numbers in parentheses indicate additional fragments.

Table 6.6: Formal tool index (FTI), pottery index (PI) and mean external ostrich eggshell bead diameter for Namaqualand assemblages associated with domestic stock (sheep, goats or cattle). For deep sites appropriate surrounding layers without stock are included for comparison. (SRC = Spoeg River Cave; JKB = Jakkalsberg; VR001 = Reception Shelter; VR005 = Buzz Shelter; NISP $=$ number of identified specimens). 339

Table 6.7: Minimum and maximum shellfish frequencies by assigned lithic group with the scarcity of mussels and whelks in Group 2 highlighted. 342

Table 7.1: Hunter-gatherer assemblage criteria (A. Smith et al. 1991) and their applicability to post-AD1 Namaqualand assemblages. A '?' indicates lack of clarity. 359

Table 7.2: Relative frequencies of seal, domesticate and small bovid bones from postAD1 coastal Namaqualand assemblages. Assemblages listed are: all Group 2 assemblages with meaningful faunal collections, all assemblages with domesticates, and all other assemblages with more than 5 seal bones. 361

Table 7.3: Comparison between the characteristics of typical 'herder' and huntergatherer rock art. Sources: Eastwood 2003; Eastwood \& Smith 2005; S. Hall \& Smith 2000; B. Smith \& Ouzman 2004). 378 
Table A2.1: Ostrich eggshell frequencies and weights. Note that some of these data predate this research and are variable and/or incomplete. Since OES is not germane to the research, the analyses were not repeated. Missing/non-calculable data are indicated by ' - '. Density is provided for single occupation open sites only.

Table A2.2: Marine shellfish. Frequencies of occasional unidentifiable limpets and minor species probably introduced incidentally are not provided, but their numbers are included in the overall MNI. Figures are percent of overall MNI of the counted samples. Rare shells assumed to be deliberately collected for decorative purposes are excluded. All own data except PN2009/001: Webley \& Orton (2010).........480

Table A2.3: Rock lobster. Mean lengths in $\mathrm{mm}$. 484

Table A2.4.1: Fauna (part 1). NISP/MNI listed where available, otherwise presence is marked by an ' $x$ '. Please see A2.4.3 for references and notes. 488

Table A2.4.2: Fauna (part 2). NISP/MNI listed where available, otherwise presence is marked by an ' $x$ '. Please see A2.4.3 for references and notes. 494

Table A2.4.3: Fauna (part 3). NISP/MNI listed where available, otherwise presence is marked by an ' $x$ '. Where tortoise has an ' $h$ ' this refers to the number of distal humeri present. References denote formal analyses done by specialists 500

Table A3.1: Complete archaeological radiocarbon database for Namaqualand (sorted alpha-numerically by site name within each area, except the central Sandveld which is further split into farms, north to south). Not all $13 \mathrm{C}$ values were published and in such cases they were obtained directly from the authors or original radiocarbon laboratory reports where possible. Note that dates in Dewar et al. 2012 were only published after completion of the body of this thesis. .506

Table A3.2: Complete burial radiocarbon database for Namaqualand (sorted alphanumerically). Some $\delta^{13} \mathrm{C}$ readings are unknown and because calibration follows the method of Dewar and Pheiffer (2010), only those with $\delta^{13} \mathrm{C}$ values are calibrated. Two burials are dated twice. The calibrated dates were calculated on Calib 6.0 (Stuiver et al. 2012) by Genevieve Dewar pers. comm. 2012). Note that many other burials have been found, but only those below are dated. 512 


\section{Definitions and conventions}

\section{$\underline{\text { Namaqualand }}$}

Although the Orange River separates Great Namaqualand (in Namibia) from Little Namaqualand (in South Africa), I have, for convenience, referred to Little Namaqualand simply as 'Namaqualand'. References to Great Namaqualand are specified as Namibia.

\section{$\underline{\text { Political and geographical regions }}$}

This thesis is set in the Western Cape and Northern Cape Provinces of South Africa. However, in referring to geographical areas south of Namaqualand it is sometimes more convenient to describe the area within about a $250 \mathrm{~km}$ radius of Cape Town as the 'south-western Cape' and the area to the east of this as the 'southern Cape'.

\section{$\underline{\text { People }}$}

The various terms used by different researchers to refer to the indigenous peoples of southern Africa are discussed by Wilson (1986) and Barnard (1992). Most are objected to by someone. In the hope of remaining fairly neutral, and following Wilson who recommended the use of (socio-)economic terms by archaeologists, I use the following:

$>$ 'Hunter-gatherers' refers to the aboriginal inhabitants of southern Africa present before 2000 years ago. These people continued to live in the area after this and some may have adopted herding to a greater or lesser degree.

> 'Pastoralists' and 'herders' refer to those people who tended domestic livestock in southern Africa from at least 2000 years ago. That they subsisted primarily by hunting and gathering is in no way denied through the application of these terms and Rosen's (1998) "herder-gatherers" may be a more appropriate term. While many authors use the two terms interchangeably, A. Smith (2000) makes the 
distinction that pastoralists incorporate their stock into ritual activity (but see Homewood (2008:1) for a broader look at the scope of pastoralism). Herders merely keep stock as a cash resource. Although I prefer 'herder' and 'herding' due to the limited evidence for pastoralism so defined in southern Africa, I use 'pastoralist' and 'pastoralism' in the more general sense when appropriate.

The term 'Khoesan' (or 'Khoisan') is frequently used to refer generically to both ethnic groups and is avoided here. 'Khoekhoen' refers to the people (noun), while 'Khoekhoe' is the adjective (Smith \& Webley 2000). For southern Africa's indigenous hunter-gatherers, 'Bushmen' is favoured over 'San', although both are acknowledged to be problematic and no suitable alternative exists (Wilson 1986).

\section{Dating}

Traditionally Stone Age archaeologists in South Africa have made little use of calibration, preferring uncalibrated radiocarbon years BP. This has recently begun changing and, in keeping with this trend, all Holocene radiocarbon dates presented below are calibrated and referred to in calendar years $\mathrm{BC}$ or $\mathrm{AD}$ at $95.4 \%$ probability. Where uncalibrated ages are preferred (i.e. for much older ages where calibration is unreliable) these are indicated by 'BP'. For consistency I have employed the Oxford Calibration Program throughout (OxCal; Bronk-Ramsey 1995, 2009). Terrestrial calibrations use the SHCAL04 curve (McCormac et al. 2004), while marine shell calibrations use MARINE09 (Reimer et al. 2009) and the newly calculated $\Delta \mathrm{R}$ of $138 \pm 98$ (Dewar et al. 2012). Ostrich eggshell dates are corrected $(-180 \pm 120)$ prior to calibration following Vogel et al. (2001).

Many Namaqualand dates were conducted in other contexts, but those obtained for this research were run through the AMS facility at Oxford and the Centre for Applied Isotope 
Studies at the University of Georgia, USA. All dates are calculated using the 5568 year half-life.

The phrases 'pre-pottery period' and 'pottery period' are used to denote the periods falling before and after approximately $A D 1$ respectively. Similarly, 'pre-colonial' or 'prehistoric' and 'colonial' or 'historic(al)' refer to periods before and after the commencement of European occupation of South Africa respectively. This change is not tied to any particular date since it began in Cape Town in 1652 and spread progressively northwards and eastwards, although historical observation ultimately began in 1488 . 


\section{Chapter 1. Introduction and outline.}

\subsection{Introduction}

Compared to other parts of South Africa, archaeological research in Namaqualand, north-western South Africa (Figure 1.1), is relatively youthful. Two doctoral theses (Dewar 2007, 2008; Webley 1992b) and a handful of published journal papers (Dewar et al. 2006; Dewar \& Jerardino 2007; Jerardino et al. 1992; Orton 2007d, 2008a, 2008d; Orton et al. 2005; Webley 1992a, 2002, 2007) have been produced from the central region since the early 1990s, although commercial archaeologists began work in the coastal diamond mines around the same time. Publications have also resulted from research in the Richtersveld in the extreme north (Figure 1.1; Miller \& Webley 1994; Orton 2007b; Orton \& Halkett 2010.; A. Smith et al. 2001; Webley 1997a; Brink \& Webley 1996; Webley et al. 1993), while new research projects there (Dewar \& Stewart 2012) and in the far south (Mackay et al. 2010; Orton et al. 2011; Steele et al. 2012) are also underway. Underlining the tremendous archaeological potential of coastal Namaqualand, Parkington (1993:3), in one of the earliest commercial reports, noted the poor state of research there "with only a few cubic metres of archaeological excavation along some $400 \mathrm{~km}$ of coastline that almost certainly houses hundreds of thousands of cubic metres of fossiliferous deposits". Three decades of commercial work in Namaqualand have proved Parkington correct, but we still have a very long way to go in terms of properly understanding the region's prehistory.

Namaqualand is critical to understanding the spread of pastoralism through western South Africa and its introduction to the country in general, both much debated topics yet to find satisfactory resolution (Fauvelle-Aymar \& Sadr 2008). A key aspect is the identification of pastoralist sites in the archaeological record - this despite the fact that 
we are looking at the most recent and well preserved period with the greatest number of sites. All the proposed routes of pastoralist dispersal include Namaqualand (Deacon et al. 1978:fig. 1) and the region offers the opportunity to examine a potentially simpler set of cultural residues, since, unlike the eastern parts of the subcontinent, only two groups of people, the Bushmen and Khoekhoen, were present during prehistory and overprinting and disturbance are greatly reduced. No attempt at distinguishing these two groups has yet been made on open coastal sites in Namaqualand and neither has the Holocene cultural sequence of the region been studied in any detail.

The search for the archaeological identity of hunter-gatherers and herders in South Africa is not new. The subject has been examined repeatedly through the years and has been underpinned by two central tenets:

- The belief that a 'herder population' migrated into South Africa some 2000 years ago bringing with it sheep and pottery; and

- Based on the excavated assemblages from the south-western Cape site of Kasteelberg (Figure 1.1; Klein \& Cruz-Uribe 1989; A. Smith 1987, 2006a), the belief that 'herder sites' should contain both sheep and pottery.

It is only since the 1990s that new opinions have emerged, challenging the wellestablished and generally accepted theories. Championed primarily by Karim Sadr, the new ideas reject both the above beliefs. Briefly, the incursion is now suggested to have occurred through a process of diffusion ${ }^{1}$ around AD 900-1200 with sheep and pottery having spread prior to this (Sadr 2003). Kasteelberg is seen as being a special purpose site and not the norm for herder occupations (Sadr 2004).

\footnotetext{
${ }^{1}$ Diffusion is taken to refer to all mechanisms by which stock and pottery might have spread other than through migration of the Khoekhoe people themselves.
} 
So, with an apparently well worn topic, what is there still to do? Based partly on the ideas put forward by Sadr and partly on my experience in the near-coastal Sandveld ${ }^{2}$, I believe that the search for herder sites has been incorrectly carried out. Seeking sites with sheep and pottery is futile, since many herder sites are likely to contain neither, at least not in any quantity, while Bushman sites sometimes contain limited quantities of either or both. I, therefore, follow a different course. Based on the overall visual impression created by the stone artefacts in each assemblage, the assemblages are placed into three groups with strongly contrasting but regionally consistent features. Then, through study of the cultural sequence and comparison of the groups, the latter are explored in an attempt to ascribe cultural affinities to each. It is hoped that rather than studying sites in isolation, this fresh approach over a very wide area will yield results that can contribute to future studies of prehistoric stock-keeping.

By focusing on material culture and exploring new areas in southern Namaqualand I hope to compliment the work of Webley (1992b), who examined social change through the last 2000 years, and of Dewar (2008), who focused on subsistence and settlement strategies; both worked in central and northern Namaqualand. The Namaqualand cultural record consists primarily of stone artefacts, ostrich eggshell (OES) beads and pottery, which together form the heart of my study. The use of many single occupation sites should help refine the dating of particular cultural periods that are less easily separated at deep sequence sites (Villa \& Courtin 1983 and references therein).

My research draws heavily on commercial excavations conducted by the Archaeology Contracts Office (ACO) of the University of Cape Town since $2001^{3}$, the vast majority of which remain unpublished. These excavations focused on the coastal and near coastal

\footnotetext{
${ }^{2}$ Defined in Section 3.1.

${ }^{3}$ Now privatised as ACO Associates cc.
} 
diamond mining areas of central Namaqualand adjacent to the towns of Kleinzee, Koingnaas and Hondeklipbaai (Figure 1.1; Halkett 2002, 2003; Halkett \& Dewar 2007; Orton 2005a, 2005b, 2009a; Orton \& Halkett 2005, 2006, 2007a) with far less between some 5 and $10 \mathrm{~km}$ inland (Orton 2007c; Orton \& Halkett 2007a). The southern parts of Namaqualand, northwest of Vredendal (Figure 1.1), have had few excavations with all again being coastal or near coastal (Hart and Halkett 1994; Halkett et al. 1993; Hart \& Lanham 1997), while in the Richtersveld one commercial excavation has occurred inland (Halkett 2001b) and one on the coast (Webley \& Orton 2010).

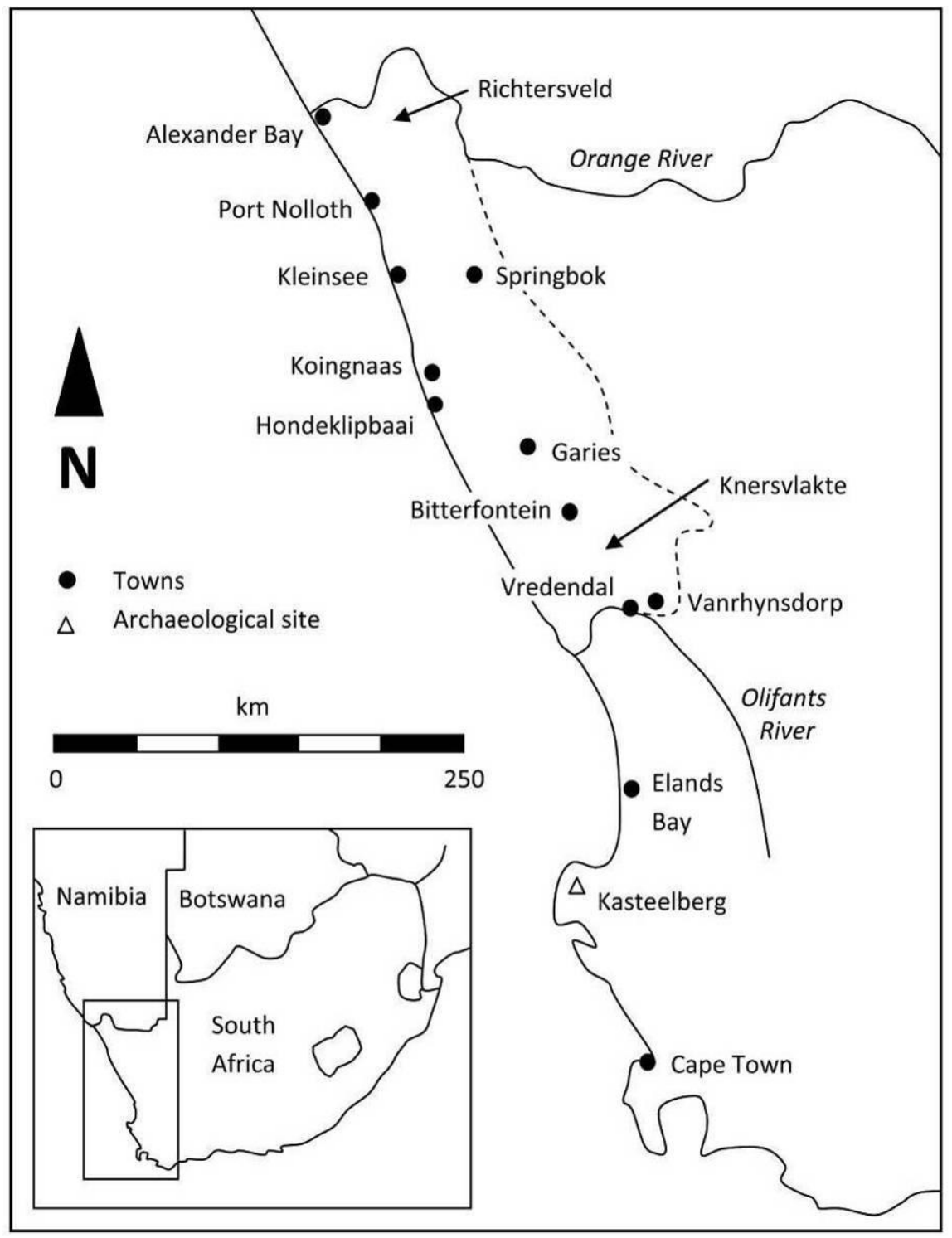

Figure 1.1: Map of western South Africa showing places mentioned in Chapter 1. The dotted line indicates the approximate eastern boundary of Namaqualand between the Orange and Olifants Rivers. 
Although this work has documented material dating to the Early (ESA), Middle (MSA) and Later (LSA) Stone Ages, the last few thousand years of the latter period are by far the best represented. A climate unsuited to farming left Namaqualand sparsely settled by European colonists such that historical sites are only thinly spread over the landscape and few contact period sites have been documented (Orton 2009a; Webley 1984, 1986; Orton et al. 2011). This thesis incorporates LSA material from the coastal areas and Richtersveld as well as newly excavated sites from the Knersvlakte. Although material dating throughout the latter half of the Holocene is discussed, the last 2000 years are emphasised, with the specific goal of reassessing the distinction between the cultural remains of hunter-gatherer and herder groups.

Until late in the twentieth century archaeologists concerned themselves primarily with the description of material before switching to a deeper concern with social organisation and cultural processes (Kusimba 2003). This new approach has in recent years led to many new ideas and a potent theoretical debate over the origins of pastoralist society in southern Africa. However, we seem no closer to resolving many of the topical issues. Bearing in mind Arthur's (2008) suggestion that we need to change the way we look for herder sites, I have elected to revert to the descriptive approach, focusing on typology, but from a different angle, and will combine my results with ideas emerging from the more theoretical debates in formulating an interpretation of the Namaqualand archaeological record.

Ultimately this thesis has five primary aims:

- To present and analyse the material cultural signatures of the prehistoric occupants of the far western and north-western parts of South Africa throughout the second half of the Holocene;

- To attempt to differentiate hunter-gatherer and herder archaeological signatures; 
- To examine the interactions between hunter-gatherers and herders as revealed by their cultural artefacts;

- To examine a poorly understood late Holocene industry emphasising clear quartz and backed artefacts and occurring in the central Sandveld; and finally

- To summarise the late Holocene archaeological sequence in Namaqualand.

\subsection{Structure of the thesis}

Chapter 2 examines some of the contentious and problematic issues that have beset pastoralist and hunter-gatherer studies through the last few decades and that are explored further in this thesis. In so doing, it presents the theory behind our current understanding of early herding in South Africa. Chapter 3 describes the study area and establishes the environmental, palaeoclimatic and past research context in which the thesis is set. I consider both published and unpublished archaeological reports (grey literature) in order to assess what is currently known for each physiographic region of Namaqualand.

In Chapter 4 the research methodology is described. This includes the rationale behind selection of sites for further study and describes the excavation methods and typological classification systems employed. Chapter 5 presents the sites and data studied in this project, region by region. Relevant data and statistics pertaining to the cultural material are given, along with some brief interpretation. Based on this evidence, Chapter 6 analyses the patterns present in the cultural assemblages and builds a basic chronology through establishing the Sandveld sequence then comparing it with wider Namaqualand. Chapter 7 then explores the last 2000 years in Namaqualand via various topics that arose during the study, after which the final chapter sums up and concludes the thesis. 


\section{Chapter 2. Pastoralist and hunter-gatherer studies in South}

\section{Africa}

Pastoralism was widespread in the western and south-western parts of South Africa at the time Europeans arrived in the subcontinent. The first European explorer reached the area in 1488, while a colony was established by the Dutch East India Company (VOC) at Cape Town in 1652. Many remarked on the presence of Khoekhoe herders with very large herds of cattle and flocks of sheep (Raven-Hart 1967; Van Riebeeck 1952, 1954). Archaeological evidence, however, has not been forthcoming and one of the most deepseated questions in southern African archaeology remains: 'Where are the residues of these herders with their massive herds?'

Pastoralism has long been recognised as "an exotic cultural pattern to South Africa that can only have been introduced from the north" (A. Smith 1983: 79). Several authors have reviewed the evidence for its origin in the LSA of southern Africa at great length (Deacon et al. 1978; Klein 1986; Mitchell 2002b; Sealy \& Yates 1994; A. Smith 2005a, 2006a; Webley 1992b), with Webley (2007) attempting an updated and Namaqualand-specific assessment. Despite limited evidence, a surprisingly large volume of literature on the topic has arisen. Here I review and discuss the primary contentious issues to have emerged. I first examine the key issue of the identification of hunter-gatherer and herder remains on the ground, following this with a look at the origins of pastoralism in South Africa (this discussion is limited to the LSA Khoe speakers, since a later (Early Iron Age) introduction of domestic stock and agriculture occurred via Bantu speakers in the eastern half of the subcontinent). LSA pastoralism is thus restricted primarily to the semi-arid west that was too dry for Iron Age agropastoralism, although B. Smith \& Ouzman (2004) do also find evidence for a Khoekhoen presence in north-eastern South Africa. Table 2.1 lists dates relevant to the introduction of sheep and pottery to South Africa, many of 
which are discussed below, and Figure 2.1 identifies the locations of key sites. Sadr and Sampson (2006) provide a more comprehensive listing relevant only to pottery and covering a wider geographical area.

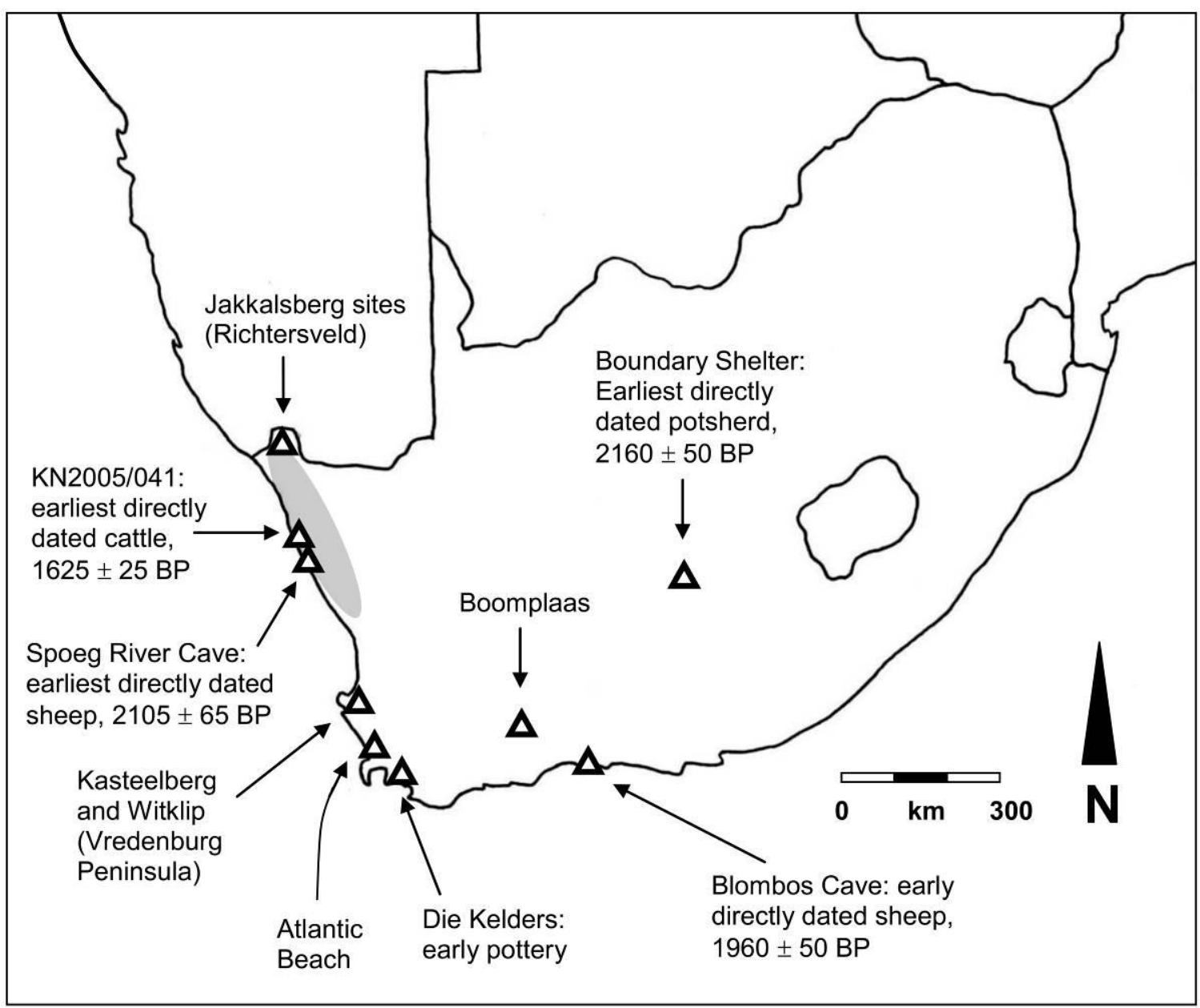

Fig. 2.1: Map showing the locations of sites significant to the discussion of early pastoralism in South Africa. The grey shading indicates the current study area (see Table 2.1 for references). 
Table 2.1: Dates discussed in this chapter that are specifically relevant to the introduction of sheep, cattle and pottery to the western and southern parts of South Africa. This list is necessarily selective and does not include all dates from each site. The dates are listed alphabetically by site and those in bold highlight directly dated stock bones and pot sherds. Calibrations were conducted on OxCal (Bronk-Ramsey 1995, 2009).

\begin{tabular}{|c|c|c|c|c|c|c|}
\hline Site & Lab No. & ${ }^{14} \mathrm{C}$ age (BP) & Material & $\begin{array}{l}\text { Calibrated date } \\
\text { at } 2 \sigma(95.4 \%)\end{array}$ & Relevance / Context & References \\
\hline /Ai tomas & Pta-5530 & $1980 \pm 80$ & $\begin{array}{l}\text { Charred } \\
\text { bone }\end{array}$ & 159 BC-AD 317 & $\begin{array}{l}\text { Early sheep and pottery, } \\
\text { Richtersveld }\end{array}$ & Webley 1992b \\
\hline $\begin{array}{l}\text { Boundary } \\
\text { Shelter }\end{array}$ & Gr-A13564 & $2160 \pm 50$ & $\begin{array}{l}\text { Fibre } \\
\text { temper }\end{array}$ & 355 BC-AD 18 & $\begin{array}{l}\text { Early pottery (directly dated, } \\
\text { fibre temper), Upper Karoo }\end{array}$ & Sadr \& Sampson 2006 \\
\hline Blombos & OxA-4543 & $1960 \pm 50$ & Bone & 34 BC-AD 237 & $\begin{array}{l}\text { Directly dated sheep bone, } \\
\text { earliest sheep, south coast }\end{array}$ & Henshilwood 1996 \\
\hline Blombos & OxA-4544 & $1880 \pm 55$ & Bone & AD 62-344 & $\begin{array}{l}\text { Directly dated sheep bone, early } \\
\text { sheep, south coast }\end{array}$ & Henshilwood 1996 \\
\hline Boomplaas & UW-338 & $1700 \pm 55$ & Charcoal & AD 255-543 & $\begin{array}{l}\text { Base of dung deposit indicating } \\
\text { kraal }\end{array}$ & H. Deacon et al. 1978. \\
\hline Boomplaas & UW-337 & $1630 \pm 50$ & Charcoal & AD 384-604 & $\begin{array}{l}\text { Top of dung deposit indicating } \\
\text { kraal }\end{array}$ & H. Deacon et al. 1978. \\
\hline Byneskranskop & Beta- 232590 & $1740 \pm 40$ & Bone & $A D 241-526^{\dagger}$ & $\begin{array}{l}\text { Directly dated possible cattle } \\
\text { bone, south coast }\end{array}$ & Horsburgh 2008 \\
\hline Byneskranskop & Beta-232588 & $1840 \pm 40$ & Bone & AD $128-380^{\dagger}$ & As above & Horsburgh 2008 \\
\hline Byneskranskop & Beta-232591 & $1880 \pm 40$ & Bone & AD $79-324^{\dagger}$ & As above & Horsburgh 2008 \\
\hline Byneskranskop & Beta-232589 & $2100 \pm 40$ & Bone & $174 \mathrm{BC}-\mathrm{AD} 54^{\dagger}$ & As above & Horsburgh 2008 \\
\hline
\end{tabular}




\begin{tabular}{|c|c|c|c|c|c|c|}
\hline Site & Lab No. & ${ }^{14} \mathrm{C}$ age (BP) & Material & $\begin{array}{l}\text { Calibrated date } \\
\text { at } 2 \sigma(95.4 \%)\end{array}$ & Relevance / Context & References \\
\hline $\begin{array}{l}\text { Cape St } \\
\text { Francis, SFB1/1 }\end{array}$ & Pta-9311 & $1770 \pm 50$ & Charcoal & AD $140-431$ & $\begin{array}{l}\text { Earliest pottery on Eastern Cape } \\
\text { coast }\end{array}$ & Binneman 1995, 2001 \\
\hline $\begin{array}{l}\text { Cape St } \\
\text { Francis, } \\
\text { Unspecified }\end{array}$ & Pta-5982 & $1560 \pm 40$ & Bone $^{t t}$ & AD 433-642 & $\begin{array}{l}\text { Earliest sheep \& cattle on Eastern } \\
\text { Cape coast }\end{array}$ & Binneman 2001 \\
\hline Die Kelders & Gak-3878 & $2620 \pm 100$ & Charcoal & 896-409 BC & $\begin{array}{l}\text { Early pottery, south coast (but } \\
\text { considered unreliable by } \\
\text { excavator) }\end{array}$ & Schweitzer 1979 \\
\hline Die Kelders & Gak-3877 & $1650 \pm 90$ & Charcoal & AD 255-637 & Early pottery, south coast & Schweitzer 1979 \\
\hline Die Kelders & GX-1688 & $1960 \pm 85$ & Charcoal & 109 BC-AD 336 & As above & $\begin{array}{l}\text { Schweitzer 1979; Wilson } \\
1996\end{array}$ \\
\hline Die Kelders & Gak-3955 & $1600 \pm 120$ & Charcoal & AD 223-763 & As above & Schweitzer 1979 \\
\hline Die Kelders & GX-1685 & $1465 \pm 100$ & Charcoal & AD 420-862 & $\begin{array}{l}\text { Layer } 2 \text { containing large numbers } \\
\text { of sheep }\end{array}$ & Schweitzer 1979 \\
\hline $\begin{array}{l}\text { Dunefield } \\
\text { Midden } 11\end{array}$ & Pta-8912 & $2220 \pm 20$ & $\begin{array}{l}\text { Marine } \\
\text { shell }\end{array}$ & $A D$ 92-521 * & Earliest pottery in Elands Bay area & Orton 2004, 2006 \\
\hline Equus Cave & Pta-2452 & $2390 \pm 60$ & Charcoal & 749-204 BC & $\begin{array}{l}\text { Sheep/goat in hyaena lair, } \\
\text { Northern Cape }\end{array}$ & $\begin{array}{l}\text { Beaumont \& Vogel 1984; } \\
\text { Vogel et al. } 1986\end{array}$ \\
\hline Hawston & Pta-834 & $1860 \pm 60$ & Charcoal & $A D$ 68-317 & Early sheep, south coast & G. Avery 1975 \\
\hline Hawston & Pta-835 & $1900 \pm 40$ & Charcoal & AD 77-382 & Early sheep, south coast & G. Avery 1975 \\
\hline Kasteelberg A & Pta-3711 & $1860 \pm 60$ & Charcoal $^{\dagger \dagger}$ & AD 77-382 & $\begin{array}{l}\text { Early sheep and pottery on } \\
\text { Vredenburg Peninsula }\end{array}$ & $\begin{array}{l}\text { A. Smith 1987, 2006a; Klein } \\
\text { \& Cruz-Uribe } 1989\end{array}$ \\
\hline
\end{tabular}




\begin{tabular}{|c|c|c|c|c|c|c|}
\hline Site & Lab No. & ${ }^{14} \mathrm{C}$ age (BP) & Material & $\begin{array}{l}\text { Calibrated date } \\
\text { at } 2 \sigma(95.4 \%)\end{array}$ & Relevance / Context & References \\
\hline Kasteelberg A & OxA-3864 & $1630 \pm 60$ & Bone & AD 343-613 & $\begin{array}{l}\text { Directly dated sheep bone at } \\
\text { same level as Pta-3711 }\end{array}$ & Sealy \& Yates 1994 \\
\hline KN2005/041 & OxA-22933 & $1625 \pm 25$ & Bone & AD 421-559 & $\begin{array}{l}\text { Directly dated cattle bone, } \\
\text { earliest cattle in central } \\
\text { Namaqualand }\end{array}$ & Orton et al. in press \\
\hline $\begin{array}{l}\text { Nelson Bay } \\
\text { Cave }\end{array}$ & GrN-5703 & $1930 \pm 60$ & Charcoal & AD 34 BC-237 & Immediately below first pottery & $\begin{array}{l}\text { Inskeep \& Vogel 1985; } \\
\text { Vogel } 1970\end{array}$ \\
\hline $\begin{array}{l}\text { Nelson Bay } \\
\text { Cave }\end{array}$ & OxA-873 & $1100 \pm 80$ & Bone & AD 780-1158 & $\begin{array}{l}\text { Directly dated sheep bone from } \\
\text { same layer as above NBC date }\end{array}$ & Gowlett et al. 1987 \\
\hline Noetzie & UGAMS-3063 & $2240 \pm 30$ & $\begin{array}{l}\text { Marine } \\
\text { shell }\end{array}$ & AD 230-457 ** & $\begin{array}{l}\text { Early pottery and sheep, south } \\
\text { coast }\end{array}$ & $\begin{array}{l}\text { Halkett \& Orton 2009; Orton } \\
\text { \& Halkett 2007b }\end{array}$ \\
\hline $\begin{array}{l}\text { Spoeg River } \\
\text { Cave }\end{array}$ & OxA-3862 & $2105 \pm 65$ & Bone & 350 BC-AD 115 & $\begin{array}{l}\text { Directly dated sheep bone, } \\
\text { earliest sheep, west coast and } \\
\text { South Africa }\end{array}$ & Sealy \& Yates 1994 \\
\hline Tortoise Cave & Pta-3312 & $1680 \pm 50$ & Charcoal & AD 260-559 & Earliest sheep in Elands Bay area & Robey 1987 \\
\hline
\end{tabular}

* Marine shell date with $\Delta \mathrm{R} 146 \pm 85$ (following Dewar et al. 2012)

** Marine shell date with $\Delta \mathrm{R} 205 \pm 30$ (following Southon et al. 2002)

$\dagger$ These early dates for cattle are possibly unreliable as the species identifications are now regarded as requiring confirmation through further study (A. Horsburgh, pers. comm. 2012)

${ }^{+\dagger}$ Materials unpublished but supplied by S. Woodborne (pers. comm. 2012) 


\subsection{The archaeological identity of hunter-gatherers and herders}

\subsubsection{Cultural remains}

Whether hunter-gatherers and pastoralists/herders can be distinguished on the basis of material culture has been widely debated in South Africa, especially since the publication of a seminal paper by A. Smith et al. in 1991. After reviewing their model, I examine in more detail stone artefacts, pottery, campsites and kraals as the main identifiers of possible pastoralist occupation. Not enough work has been done on ostrich eggshell beads to enable further discussion on them, although it is generally accepted that smaller beads predate larger ones, with the latter being linked to herders - this seems to be based purely on their presence in sites dating after the introduction of domesticates and pottery (Jacobson 1987; A. Smith et al. 1991; Yates et al. 1994).

Using excavated evidence from a suite of sites on the Vredenburg Peninsula and its hinterland, A. Smith et al. (1991) proposed a typical cultural signature expected on hunter-gatherer sites with Witklip as their prime example. This they contrasted with residues suggested to be from herder sites, of which Kasteelberg B was considered typical.

Hunter-gatherer sites were said to have the following characteristics among their cultural artefacts:

$>$ relatively high frequencies of retouch in their stone artefact assemblages;

$>$ relatively high frequencies of fine-grained stone materials, especially among the retouched component;

$>$ low densities of potsherds; 
$>$ presence of shell scrapers made on the sand mussel, Donax serra; and

$>$ ostrich eggshell beads with mean external diameters less than about $5.5 \mathrm{~mm}$ and mean aperture diameters less than $2.0 \mathrm{~mm}$ (although A. Smith (2005a:48) later set the upper margin for external diameter at $5 \mathrm{~mm}$ ).

These cultural residues were expected to accompany relatively small quantities of seal and sheep bones and larger numbers of wild fauna. By implication, the residues of herders would reflect the opposite. These contrasting signatures were identified in coeval, nearby sites and interpreted as reflecting the continued independent existence of aboriginal Cape hunting societies, both in the face of a growing population of pastoralists, and until after the onset of colonial occupation (A. Smith et al. 1991). Despite its dating though, the consistent presence at Witklip of certain stone artefacts characteristic of mid- to late mid-Holocene occupations (particularly segments and backed scrapers) calls into question the reliability of the site as a typical late Holocene accumulation. Instead, it may have mixed assemblages and a comparison between it and Kasteelberg A and B may thus be invalid.

Nonetheless, A. Smith et al. (1991) readily assigned their assemblages to their hunter or herder groups, although in a subsequent paper Yates and Smith (1993) suggested that the material composition of hunter sites was far more distinctive than that of herder sites. Apparently contradictory evidence (namely large ostrich eggshell beads in hunter sites), particularly in the most recent period, was said to be the result of "an acceptance [by hunter-gatherers] of cultural material or norms of manufacture from the herder communities" (A. Smith et al. 1991:89). This cultural exchange was said to be unidirectional, since large beads were found in Smith et al.'s (1991) hunter-gatherer sites but very few small beads entered the herder deposits. Their most obvious example was Voëlvlei with its impressive assemblage of retouched tools, pottery and large beads $(8.2 \pm 1.2 \mathrm{~mm})$. Some other Western Cape sites also fit the model quite well (Table 2.2). 
Table 2.2: Selected Western Cape pottery period hunter-gatherer and herder sites identifiable by A. Smith et al.'s (1991) criteria.

\begin{tabular}{lll}
\hline & Site & References \\
\hline \multirow{3}{*}{$\begin{array}{l}\text { Hunter- } \\
\text { gatherer }\end{array}$} & Grootrif G & Jerardino (2007b) \\
& Klein Kliphuis & Orton (2009b) \\
& & Van Rijssen (1992); Orton \& Mackay \\
& Heuningklip & (2008) \\
\hline \multirow{3}{*}{ Herder } & Boomplaas upper pottery & Hadr \& Smith (1991) \\
& levels & Voacon et al. (1978); Klein (1978); \\
& Atlantic Beach & Sealy et al. (2002) \\
& Smitswinkelbaai Cave & Poggenpoel \& Robertshaw (1981)
\end{tabular}

A. Smith et al. (2001) felt able to separate hunter-gatherer and herder residues at Bloeddrift 23 in the Richtersveld, while in the central Northern Cape Beaumont et al. (1995) suggested a similar distinction, going as far as identifying distinct industries - the Swartkop and Doornfontein respectively - belonging to the two groups. These industries were poorly described but Parsons (2007) has collated the available information. She notes the Swartkop to be blade-rich and made mostly on hornfels with backed blades being common retouched elements. Pottery occurs and increases with time. The Doornfontein is an informal industry based primarily on quartz and associated with much pottery.

Despite these apparent consistencies, A. Smith et al.'s (1991) model has begun to crumble in recent years. Specifically, Sadr et al. (2003) have shown, using some of the same Vredenburg Peninsula sites along with others, all from Kasteelberg (Figure 2.1), that the cultural remains, specifically pottery (Table 2.3) and ostrich eggshell beads that have clear stylistic characteristics, show far more overlap than A. Smith et al. (1991) described. They found no evidence for two signatures representing two population groups. This conclusion was already reached by Schrire (1992) who added that it would have been very difficult for two distinct ethnic groups to have successfully avoided each 
other (and their camp sites) within the confines of the approximately $450 \mathrm{~km}^{2}$ Vredenburg Peninsula over a period of nearly 2000 years. Although stone artefacts showed more disparity, Sadr et al. (2003) proposed that the variation might reflect functional differences in subsistence strategies with more mobile groups focusing their foraging inland and more sedentary groups concentrating on coastal resources.

Table 2.3: Thin-walled pottery in south-western Africa. Compiled from Sadr (2008a), Sadr \& Sampson (2006) and Sadr \& Smith (1991). This sequence was first described from Kasteelberg by Sadr \& Smith (1991) and subsequently clarified by Sadr \& Sampson (1999).

\begin{tabular}{|c|c|c|c|}
\hline Pot features & Decoration & $\begin{array}{l}\text { Temporal } \\
\text { occurrence }\end{array}$ & Comment \\
\hline & Plain & $\begin{array}{l}\text { Late first millennium } \\
B C \text { to early first } \\
\text { millennium } A D\end{array}$ & $\begin{array}{l}\text { Inland examples are fibre } \\
\text { tempered. }\end{array}$ \\
\hline $\begin{array}{l}\text { Small, short-necked } \\
\text { vessels with spouts }\end{array}$ & $\begin{array}{l}\text { Decorated necks } \\
\text { and sometimes } \\
\text { extends to body: } \\
\text { incised lines, } \\
\text { punctuates, jab-and- } \\
\text { drag, scoring on lip }\end{array}$ & $\begin{array}{l}\text { Early to mid-first } \\
\text { millennium AD } \\
\text { (to AD } 650 \text { in south- } \\
\text { western Cape) }\end{array}$ & $\begin{array}{l}\text { Inland examples fibre } \\
\text { tempered; incision and } \\
\text { comb-stamping sometimes } \\
\text { co-occur. Comb-stamping } \\
\text { with Donax serra shell } \\
\text { (Wilson \& Halkett 1981). }\end{array}$ \\
\hline $\begin{array}{l}\text { Small, short-necked } \\
\text { vessels with spouts, } \\
\text { sometimes with a boss } \\
\text { opposite shoulder }\end{array}$ & $\begin{array}{l}\text { Decorated necks } \\
\text { and spouts only: } \\
\text { impressed }\end{array}$ & $\begin{array}{l}\text { mid- to late first } \\
\text { millennium } A D \\
\text { (AD 650-850 in } \\
\text { south-western } \\
\text { Cape) }\end{array}$ & \\
\hline $\begin{array}{l}\text { Larger necked jar with } \\
\text { lugs and pointed base }\end{array}$ & Undecorated & $\begin{array}{l}\text { Late first to early } \\
\text { second millennium } \\
\text { (AD 850-1250 in } \\
\text { south-western } \\
\text { Cape) }\end{array}$ & \\
\hline $\begin{array}{l}\text { Larger necked jar with } \\
\text { lugs and pointed base }\end{array}$ & $\begin{array}{l}\text { Parallel incised lines } \\
\text { and impressed dots }\end{array}$ & $\begin{array}{l}\text { Mid- to late second } \\
\text { millennium AD } \\
\text { (Post-AD } 1250 \text { in } \\
\text { south-western } \\
\text { Cape) }\end{array}$ & $\begin{array}{l}\text { Widespread, most recent } \\
\text { pottery tradition }\end{array}$ \\
\hline
\end{tabular}


Of course, this type of debate is not new and recalls that of Bordes and Binford (ethnicity versus functionality) in the European Mousterian. In reviewing that debate, Mellars (1996) suggested that simple chronological change might be responsible. Parsons' (2007) research into the Swartkop and Doornfontein industries also suggested a lack of clarity; the variability displayed by most artefact classes resulted in significant overlap between the two assemblage types. Wilson (1996) also found A. Smith et al.'s (1991) criteria to be unsatisfactory, since, using them, he could not say whether hunters or herders had occupied the coastal site of Die Kelders in the south-western Cape, a conclusion already alluded to by Schweitzer (1979). Possibly invalidating the whole debate, Barnard (1992:159) suggested that the "equation of ethnicity with the hunter/herder boundary is, arguably, an invention of European commentators" and saw the Khoe-speakers who arrived in South Africa to have included both hunter-gatherer and herder populations as reviewed by Mitchell (2010:75).

While some sites do fit the A. Smith et al. (1991) model as noted above, many others do not. Pottery sites at Jakkalsberg (JKB A, B, K and M; Figure 3.1) conform in some respects but not in others (Orton 2007b; Webley 1997a). All have informal, quartzdominated lithic assemblages, but ostrich eggshell bead sizes and frequencies of domesticates and pottery vary considerably, suggesting the Smith et al. (1991) model to be inappropriate there. JKB M, in particular, contained highly contrasting remains that included much pottery, relatively small beads (mean $4.9 \pm 0.9 \mathrm{~mm}$ ), and a predominantly wild fauna with a few sheep bones (R. Klein \& T. Steele, pers. comm. 2006; Orton 2007b). Of these four sites, only JKB K (AD 1212-1459, GX-32761; Orton \& Halkett 2010) was perhaps recent enough to have experienced the exchange of material culture claimed by Smith et al. (1991:89) to have occurred within the last 500 years. The other three all date to the first millennium AD (Orton 2008d; Webley 1997a). In southern Namibia, Skorpion Cave, dating within the last 1500 years, also provides contrasting evidence. Large beads accompany numerous potsherds but there are no domesticates 
and the stone artefacts include some formal tools (J. Kinahan \& J.H.A. Kinahan 2003). In northern Namibia, J. Kinahan (2001) found sites containing retouched tools and pottery but no positively identifiable sheep. Unfortunately, bead sizes were not provided.

On the Cape south coast, the early first millennium AD levels at Die Kelders (GaK-3877, GX-1685, GX-1688; Figure 3.1; Schweitzer 1979) and Noetzie (UGAMS-3063; Halkett \& Orton 2009; R. Klein \& T. Steele, pers. comm. 2008; Orton \& Halkett 2007b) have numerous potsherds and minimal sheep remains. The mean diameter on 14 ostrich eggshell beads from Noetzie's pottery-period layers is $5.25 \pm 0.61 \mathrm{~mm}$ with only two falling between $6 \mathrm{~mm}$ and $7 \mathrm{~mm}$ (own data); following A. Smith et al. (1991) this is clearly not a herder signature, although a single broken large bead ( 12 $\mathrm{mm}$ in diameter) found on the surface may indicate contact. The lower 'herder' layers at Boomplaas contain an apparently typical hunter-gatherer lithic assemblage, but with pottery, dung and a few sheep; again, no bead sizes are given (Deacon et al. 1978; Klein 1978). It seems unlikely that all these assemblages with mixed signatures are the result of overprinting or of hunter-gatherer/herder interactions.

H. Deacon et al. (1978:58) suggest that the Boomplaas evidence is "more in keeping with acculturation models than with the displacement of local hunter-gatherers by immigrant herders." In contrast, Barth (1969) sees cultural diversity as a product of interaction rather than isolation. Webley (1992b) agrees, suggesting that the greater the degree of contact between two cultural groups, the more likely they would want to express their separate identities; if hunter-gatherers desired pastoralist material culture, such as pottery (the markings of which can be very strongly tied to group or family identity (Gatto 2002; Hodder 1982; Pikirayi 2007)) or large ostrich eggshell beads (claimed by A. Smith et al. (1991) to be strong indicators of the Khoekhoen), how would they maintain their identity? Stow's (1905:252-256) description of the great hostilities between the Bushmen and the Namaqua during the late eighteenth and early nineteenth centuries offers further support for a desire to maintain their respective social and cultural 
identities, at least in more recent times. The archaeological examples above do not support this though, with many sites showing apparently mixed signatures.

At Oudepost 1 on the Churchhaven Peninsula, south of Vredenburg, historical sources show Khoekhoe people and Dutch colonists interacting. Schrire and Deacon (1989) found that the Stone Age artefacts associated with the historical occupation debris were similar to the majority of late pre-colonial (and usually hunter-gatherer) assemblages in the south-western Cape. Assuming these artefacts to represent the documented indigenes, they argued that the assemblage, and by implication similar ones from elsewhere, could thus not be readily assigned to either hunter-gatherers or pastoralists. Schrire (1980) had previously criticised Parkington and Poggenpoel's (1971) ascription of the De Hangen assemblage to hunter-gatherers, when both they and herders were known to have been active in that area historically and the assemblage could support occupation by either group. Schrire and Deacon (1989:112) asserted, perhaps somewhat contentiously (see below), that "it is the context of the artefacts rather than their form or typology that will inform on who made them."

The implication here is enormous, since many of the small rock shelters (like De Hangen) thought by others to have been occupied by hunter-gatherers could be interpreted to represent "herders doing whatever they did in the foothills and mountains of the south-western Cape" (Schrire \& Deacon 1989:112). While this suggestion is important and should be borne in mind, three problems are pertinent: the Oudepost deposits were heavily churned by dune moles (Bathyergus suillus; Schrire et al. 1990); no evidence of a pre-colonial midden was found (Schrire \& Deacon 1989); and the variable composition of the small assemblage suggests some mixture of deposits of varying origin (Wilson et al. 1990). This last point is supported by the bimodal distribution of Oudepost bead diameters (Yates \& Smith 1993), while I regard the presence of a backed scraper in the Oudepost 1 collection (Schrire \& Deacon 1989: figure 2) as 
particularly strong evidence for the inclusion of material in excess of 2000 years old. On the Vredenburg Peninsula backed scrapers are always $>2000$ and usually $>3000$ years old (Sadr 2009; Sadr \& Gribble 2010). The same is true in Namaqualand (Dewar 2008) and, with one exception, at Elands Bay (Orton 2006; Robey 1987).

While the lithic assemblages of some sites could be interpreted either way, as suggested by Schrire and Deacon (1989), some west coast assemblages are clearly different to other late assemblages containing retouched artefacts. Examples are Atlantic Beach 1 and 3 (Figure 2.1; Sealy et al. 2002) where the flaked artefacts are highly informal, strongly dominated by quartz and found in association with pottery, large beads and reasonable numbers of sheep bones (they were the most commonly identified species at Atlantic Beach 1). Similarly informal artefacts have been documented in Namaqualand deflation hollows overlooking the Buffels River, sometimes associated with pottery (Orton 2007c), as well as in coastal shell middens (e.g. Dewar 2008; Dewar et al. 2006; Orton 2007d; Orton \& Halkett 2005, 2006).

Shott (1986) argues that the more mobile a community, the less diverse its technology will be; as mobility increases the toolkit must be reorganised into fewer classes with each being more flexible in terms of its application. Veth (2005:106) puts it another way: sites with fewer artefacts exhibiting a lower degree of modification signify lower intensity occupation and more expedient use of local materials. It could be that sites with small, informal assemblages simply represent very brief occupations by highly mobile groups with far simpler tool kits, although, following Wadley (1987), these could also represent dispersal sites. Conversely, Wadley sees aggregation sites as having more standardised tools and curated artefacts, like beads, and more debris related to the manufacture of presumed gift exchange items such as ostrich eggshell beads. 
A particular type of stone artefact in use by contemporary pastoralists for working hides was documented by Webley $(1990,2005)$. It is a rough sandstone pebble known as a //khom stone (Nienaber \& Raper 1977) which is used to scrape (with a rubbing motion) the fatty tissue off the inside of a skin (Webley 1990). These artefacts are identified by the fatty residues adhering to them and Webley (2005) sees the //khom stone from Spoeg River Cave (Figure 2.1) as further evidence for the presence of pastoralists at the site c. AD 770. She suggests that these stones replaced conventional retouched scrapers and might be the reason for the lack of retouched scrapers in pottery-period deposits. Unfortunately organic residues do not preserve well on the open sites of Namaqualand and, with just one exception from Buzz Shelter in the far south (Orton et al. 2011), no other examples of //khom stones are known from that region (Lita Webley, pers. comm. 2011), although another was reported from Renosterkop 1, near Kakamas (Morris \& Beaumont 1991), and they do seem to have been used by hunter-gatherers in Lesotho as late as the nineteenth century (Mitchell 2006/2007).

Turning now to pottery, two main types of thin-walled LSA pottery are recognised in western South Africa: 'Cape coastal ware' and 'fibre-tempered ware'. The latter are primarily flat-bottomed bowls from the central interior of South Africa and ascribed to Bushman hunter-gatherers (Bollong et al. 1993, 1997; Rudner 1979), but J. Deacon (1972) reports small fragments from Wilton Large Rock Shelter in the southern Cape and one fibre-tempered sherd was found in southern Namaqualand at VR003 (unpublished data). Of relevance here is the Cape coastal ware, which was first fully described at Kasteelberg (Sadr \& Smith 1991). This pottery is ascribed to the Khoekhoen and occurs throughout south-western South Africa. Its presence, however, does not confirm the identity of a site's occupants, since exchange undoubtedly occurred and the vast majority of sites in the region seem to have stronger hunter-gatherer affinities despite the presence of pottery. It is perhaps only in sites with abundant pottery (a rare phenomenon in western South Africa) that it can be informative: in the Seacow Valley, Hart (1989) and 
Sampson (2010) used the relative frequency of Cape coastal sherds to fibre-tempered sherds to determine the ethnicity of site occupants but this obviously cannot be used on the west coast where fibre-tempered sherds are all but absent. Sadr et al.'s (2003) ceramic index ${ }^{4}$ can be applied, however. It calculates the proportion of potsherds represented in the sum of all ceramic and stone artefacts in an assemblage ${ }^{5}$. Using this index Sadr et al. demonstrated that hunter-gatherer and herder sites had indices of $<20 \%$ and $>60 \%$ respectively.

At the site level, Webley (1986:60) noted that the campsites of recent herders in Namaqualand are recognisable through the presence of "stones for anchoring the huts, baked mud and dung hut floors, the raised and baked hearths of the kookskerms [cooking screens] and dung floors of kraals [stock enclosures]" (parentheses mine). This pattern has yet to be identified archaeologically, although Webley $(1984,1986)$ did find two posts, an ash heap and some calcined dung at Bethelsklip, a site known to have been used by herders during historic times. Webley (1984) described how ropes thrown over the tops of the huts were anchored with rocks to keep the huts together and also saw stones used as hut anchors among recent herders in the Kamiesberg Mountains (Webley 1982). In the Little Karoo, a set of very ephemeral sites includes a few rocks under some old acacia trees that may well indicate archaeological evidence for hut anchors (Orton 2008c). Other remains were minimal - just a few flakes and manuports and it is unlikely that these Little Karoo sites could be proved to have been used by either herder or hunter-gatherer groups. Although dung layers are known from rock shelter deposits (H. Deacon et al. 1978; Sandelowsky et al. 1979), Shahack-Gross et al. (2003) have demonstrated that sediments from open livestock enclosures are visually indistinguishable from regional sediments within thirty years of abandonment of the site.

\footnotetext{
4 'Ceramic index' is referred to as 'pottery index' in this thesis.

${ }^{5}$ Note that Yates \& Smith (1993:97) originally calculated the pottery index as "the total number of sherds divided by the total number of pieces of flaked stone". I use Sadr et al.'s (2003) method.
} 
Through her work in the central Hardeveld area of Namaqualand, Webley (1986) suggested that summer camps will be more readily reoccupied and hence should contain higher densities of finds, particularly the bones of domestic stock that are more likely to have been slaughtered during the lean summer months. Being clustered around water sources, these camps would have been occupied by larger groups and witnessed more frequent ceremonial activities. By contrast, sites occupied during winter and spring, as she suggests was the case at Bethelsklip, would contain very few bones of domestic animals and would be smaller, more ephemeral and more widely dispersed.

An element of material culture seldom considered in the far western parts of South Africa is stone-walled settlements or livestock enclosures (kraals). These have been much recorded in central South Africa (Hart 1989; Hart 2005; Sampson 1985) and Namibia (J. Kinahan 2001; Noli \& Avery 1987 and references therein), but have only recently been discovered in western South Africa (Jerardino \& Maggs 2007; Orton \& Hart 2005). There is generally no rock with which to build in Namaqualand, but in some areas the layout and form of bushes would make kraal manufacture very simple through the relocation of a few bushes into gaps around clearings (personal observation). Such kraals obviously would not be found today.

In terms of the Smith et al. (1991) model, no obvious herder sites have been located in coastal Namaqualand, although sites with many formal tools (mostly made on finegrained materials) and generally no pottery have been distinguished from those with highly informal lithic assemblages often including pottery (e.g. Dewar 2008). Orton et al. (2005) noted that the limited Namaqualand data of the time were provisionally weighted towards the A. Smith et al. (1991) model, but that this was by no means certain.

A relatively new avenue of research in the Central Limpopo Basin (CLB) in the far north of South Africa has suggested a new aspect of material culture that might reflect the 
Khoekhoen. There, geometric rock art that appeared as a new and distinctive tradition with no precursor in South Africa was described and linked with Khoekhoe herders (Eastwood 2003; Eastwood \& Smith 2005; B. Smith \& Ouzman 2004).

\subsubsection{Subsistence remains}

Sheep are the most frequently identified domesticate in the region and their presence at a site indicates various possibilities. One view is that hunter-gatherers deposited the bones. Occasional sheep or parts of sheep may have been obtained from herders, perhaps via exchange or theft, or hunter-gatherers might have owned stock in small numbers themselves resulting in what Sadr (2003:196) terms "hunters-with-sheep". In the latter case Yellen (1984:59) imagines "the integration of goats and sheep as a single element into what remained an essentially hunting and gathering society". It is equally possible, however, that the site represents the residues of a herder occupation where sheep were slaughtered and eaten. Archaeological faunas demonstrate that herders still relied quite strongly on hunted fauna rather than limiting themselves to their domestic stock (e.g. Klein 1978; Klein \& Cruz-Uribe 1989; Sadr et al. 2003; Sealy et al. 2002; Smith 2006a) and, as such, even herder residues likely contain very few sheep bones. In support, pastoralists only slaughter stock out of necessity (Paine 1971; Poppov 1966) or for special purposes, such as sacrifice, feeding the sick or communal celebrations (Galaty 1979), while Sealy et al. (2002) suggest that coastal and near-coastal sites may under-represent the importance of sheep in the herding economy due to the close proximity of plentiful marine foods. Historical accounts from the Cape are conflicting. Ten Rhyne (1686 in Schapera \& Farrington 1933) and Kolbe (1741 in Fauvelle-Aymar 2004) recorded the special purpose slaughtering of stock among seventeenth and eighteenth century Khoekhoen and noted that in general they did not eat much meat. In contrast, Grevenbroek (1695 in Schapera \& Farrington 1933:179) noted that "They live for the most part on beef, mutton, all sorts of game, and other flesh that suits their taste..." 
It has been proposed that when sheep are found in reasonable numbers at a site then the occupants could be discerned from the age profile of the slaughtered sheep. A high frequency of young animals and a number of older, post-prime individuals should indicate the kind of flock management strategy likely to be employed by herders aiming to achieve a mix of meat and milk yield (Klein \& Cruz-Uribe 1989), but Webley (1992b) saw this strategy as being aimed more at maximising only the milk yield of the flock. Brink and Webley (2007) noted that modern Khoekhoen in Namaqualand consider a wide variety of factors when choosing an animal to slaughter and suggested that high frequencies of juveniles in archaeological sites could well relate to natural mortality. In the contrasting signature, hunter-gatherer sites should contain a mixture of ages depending on what they were able to obtain, by fair means or foul. The former signature seems present to some degree at Kasteelberg A and B on the Vredenburg Peninsula (Klein \& Cruz-Uribe 1989), presumably suggesting occupation by full-scale herders. However, we might still question the degree to which hunter-gatherers may have applied the same sort of strategy with a small flock of animals. Clearly though, the very small number of sheep bones in most sites means that we can seldom employ this line of evidence to discern whether the occupants were hunter-gatherers or herders.

At a larger scale, and because he does not believe that hunter-gatherers could rear stock, A. Smith (2005b, 2006a) suggested that, no matter who deposited them, any number of sheep bones in a site must imply the presence in the surrounding landscape of herders with large flocks. Based on Dahl and Hjört's (1976) review of East African and Middle Eastern data he assumes that in South African conditions of c. 2000 years ago at least 100 sheep would have been required to sustain the flock assuming an off-take for meat and milk; he later (A. Smith 2008b, 2009) reduced this figure to 60 animals. I discuss this issue further in Section 2.3. 
It seems from Kasteelberg that herders (or at least people with sheep) also had a great interest in seals (A. Smith 2006b). These animals contain much fat and the practice of smearing their bodies with fat and ochre is well documented among the historic Khoekhoen and other pastoralist groups (e.g. Andersson 1857; Dapper 1668 in Schapera \& Farrington 1933; Raven-Hart 1967), although butter fat may have been preferred (A. Smith \& Pheiffer 1993). At Kasteelberg seal bones are more numerous than any other animal, with sheep second in importance (Klein \& Cruz-Uribe 1989; A. Smith 2006a, 2006b). Two residue analyses confirm the use of pots in processing marine mammal fat at Kasteelberg (Copley et al. 2004; Patrick et al. 1985), with the more recent assuming their sherds to be from spouted vessels. These conclusions may well support the use of seal fat as mentioned above. However, it is probably only possible to assign a large seal bone collection to herders when in the company of reasonable numbers of sheep bones, since we know from sites on the Namaqualand coastline that seals were also extensively collected in the absence of sheep (Dewar 2008; Dewar \& Orton, in prep.; Orton 2007c; Orton et al. 2005).

Given the general rarity of domestic stock bones in Namaqualand sites, it is impossible to comment further on the identification there of hunter-gatherer and herder sites through subsistence remains. Furthermore, given the extreme importance of cattle within historical Khoekhoe society as documented by Kolbe (1741 in Fauvelle-Aymar 2004) and the scarcity of their bones in archaeological sites, it might well be that true pastoralists (of the sort that, following Fauvelle-Aymar (2004), we understand the historic Khoekhoen to have been) were generally infrequent in western South Africa until relatively recently. Sadr (1998: footnote 5) even speculates as to whether specialised pastoralism may only have developed in response to the European demand for beef and mutton.

On the south-eastern coast of South Africa Binneman (2001) found that sites with pottery and domesticates usually contained shellfish yielding a high meat mass, generally the 
bivalves, while those with pottery but no domesticates emphasized Perna perna (brown mussels) and Oxystele sp. from the upper Balanoid zone. Such distinctions have yet to be explored elsewhere.

\subsubsection{Archaeological visibility}

Many have remarked on the likelihood of seeing and identifying the remains of nomadic herder camps on the landscape (see Cribb 1991: 65-68). Recognising this issue in southern Africa, Robertshaw (1978a) studied a recently abandoned pastoralist camp in the Richtersveld. He noted that structures left little trace after ten to twenty years and that what was there would soon disappear. He also supposed that if one were to substitute prehistoric materials for the modern items, and assuming that bone would not last more than one or two decades on the surface, then "one would be left after a few years with only a surface scatter of stone artefacts and potsherds" (Robertshaw 1978a:29). Of course, to this we should add ostrich eggshell which is ubiquitous on sites of various age throughout the Northern Cape. On the strength of this study and further work on southwestern Cape archaeological sites he went on to comment that "the identification of pastoralists in the archaeological record remains a problem both in the Cape and in other regions" (Robertshaw 1979:251). Yellen (1984) suggested that, in the absence of kraals, hunter-gatherer and pastoralist camps would not differ much from one another in terms of their residues with both having low archaeological visibility, while M. Hall (1987) suggested that pottery was often the only thing that could distinguish a hunter-gatherer from a herder camp (this, as shown above, is not necessarily true). The implication of these statements was that herders made use of existing indigenous technology. While the above generally refers to the identification of pastoralist residues, Kusimba (2005) questions whether we can really even identify hunter-gatherer lifeways archaeologically particularly those we think we know so well from ethnographic studies. 
Supporting Robertshaw's study on preservation, A. Smith (2005a) found that most items of material culture owned by African pastoralists were of non-preserving organic materials such as skin, fibre and wood. He also noted that in the earlier years of their presence in South Africa the low visibility of pastoralists may be attributable to their sparseness on the landscape and that later, after AD 1100 when Kasteelberg occupation ceases, the different needs of cattle, which he suggests might have increased in number about that time, would have forced pastoralists to become even more highly mobile. The more mobile they are, the less likely we are to find traces of their camps. However, Fauvelle-Aymar et al. (2006) see no reason why the residues of mobile pastoralists should be any less visible than those of mobile hunter-gatherers whose open-air sites have been widely documented. They see the presence of vitrified dung to be key in the identification of past kraal locations and hence pastoralist sites. From an analysis of historical sources they concluded that Khoekhoe kraals would likely have been several kilometres inland rather than on the coast and that these sources would help locate kraals on the ground. They concluded that without historical sources and knowledge of where kraals are likely to be found it would remain difficult to identify contact period kraals. Arthur (2008) agreed, seeing the dominant research bias of rock shelters and shell middens to be misleading - Khoekhoe sites, as observed historically, will be large, open-air camps along rivers. This, of course, certainly applies to the ecologically rich and more productive southern Cape where Arthur was working, but the semi-arid west may be different: Carstens (1969) believed that Khoekhoe settlements in Namaqualand were very small. A. Smith (2008a) suggested that ephemeral inland camps were probably destroyed by modern ploughing and that known herder sites tended to be along the coast where marine shell increases their visibility and the greater pottery frequencies might indicate their more intensive use. Being clustered around water sources, the more strongly recognisable pastoralist summer camps described by Webley (1986) are far more likely to have been destroyed by recent settlement, further impacting on our ability to recognise clear herder camps. 
Arthur's (2008) observations on archaeological visibility that are key to my research. He considers some of the main reasons for the apparent low visibility of herders to be the very rigid definitions of hunter and herder sites that have typically been applied and the lack of consideration given to possible diversity within each group. What others explained as the result of cultural exchange or contact (e.g. A. Smith et al. 1991), he proposes, may simply be variability. Arthur (2008:217) suggested that new ways of looking for herders should be developed and concluded that "it may yet turn out to be that pastoralists were not invisible after all; it was just that we did not know how to see them."

\subsection{The origins of the Khoekhoen, domestic stock and pottery}

The Khoekhoen and their languages are widely accepted to have originated outside southernmost Africa, which was seemingly occupied only by the Bushmen before about 2000 years ago. Most researchers agree that the region of northern Botswana, southern Zambia and the Namibian Caprivi Strip was either a primary point of Khoekhoe origin or that dispersal southwards occurred via that area. Pottery and domestic stock are seen to have come from or via the same area, originating either from Iron Age people or perhaps an earlier pastoral society (A. Smith 1998a). Directly dated sheep (83 BC-AD 131; Beta186669) and cattle (162 BC-AD 75; Beta-190488) bones from Toteng 1, in northern Botswana, show that both species were present there some 2000 years ago (Robbins et al. 2005). Genetic research supports the spread of people through Tanzania to southerncentral Africa (Henn et al. 2008) but, due to a lack of samples, so far offers no resolution

further south. However, a demic diffusion of Khoekhoen into southern Africa some 2000 years ago is postulated.

Turning to linguistics, Westphal (1963) hypothesised that the Khoekhoe language had its roots in north-eastern Botswana. He based this on linkages between the Tshu-Kwe and 
'proto-Cape Hottentot' languages and the likelihood that the Tshu-Kwe had not moved. Following on from this, Elphick (1985) argued that the Khoekhoen in that area obtained stock from Bantu speakers to the north, then, under the pressure of their own population, began expanding southwards into South Africa. More recently, Güldemann (2008) has agreed with northern Botswana as a place of origin but cautions against equating the historically known Khoekhoen with the people responsible for the introduction of pastoralism to the Cape.

Archaeological support for an origin in Botswana and subsequent expansion southwards might be found in the distribution of Bambata pottery. In southern Africa this controversial and poorly understood pottery style may have originated amongst farming communities in Angola but was later used by LSA hunter-gatherers rather than Iron Age farmers in the eastern and central parts of southern Africa (Huffman 2005; Reid et al. 1998; Sadr 2008a). It seems to have again been used by mixed farming communities in southern Africa after about AD 350 (Huffman 2005). Its distribution is confined to Botswana, southern Zimbabwe and northern South Africa (Huffman 2005: fig. 3) and it is associated with very early sheep remains there (Reid et al. 1998; Walker 1983), of which those from Toteng 1 are now directly dated (Robbins et al. 2005). The only directly dated Bambata potsherd is from Toteng 3 at AD 259-534 (Robbins et al. 2008). That this earliest pottery is not found elsewhere may support an origin for pastoralism in Botswana as Elphick (1985) thought.

Barnard (1992:30) considered it "likely that pastoral Khoekhoe society began with the acquisition of ... livestock and material culture, by southern African Bushmen, from a people of northern origin" and suggested that more than enough evidence existed to support a subsequent Khoekhoe migration through southern Africa. When and by what routes this might have happened are highly contentious and, focusing on the South African evidence, I now review and discuss the main arguments. 


\subsection{The possible routes and timing of entry of the Khoekhoen, domestic stock and pottery into southernmost Africa}

Within southernmost Africa two main routes, through the west and central regions, have been suggested in various combinations for both the southward migration of the Khoekhoen and, by implication, the introduction of domestic stock and pottery (Figures 2.2 to 2.4). However, it is important to remember that these hypotheses sought primarily to identify the movements of the people rather than their stock and pottery $(\mathrm{H}$. Deacon et al. 1978). By contrast, Bousman (1998) and A. Smith (1992, 2008a) have mapped possible routes of entry of stock (Figures 2.5 to 2.6 ).

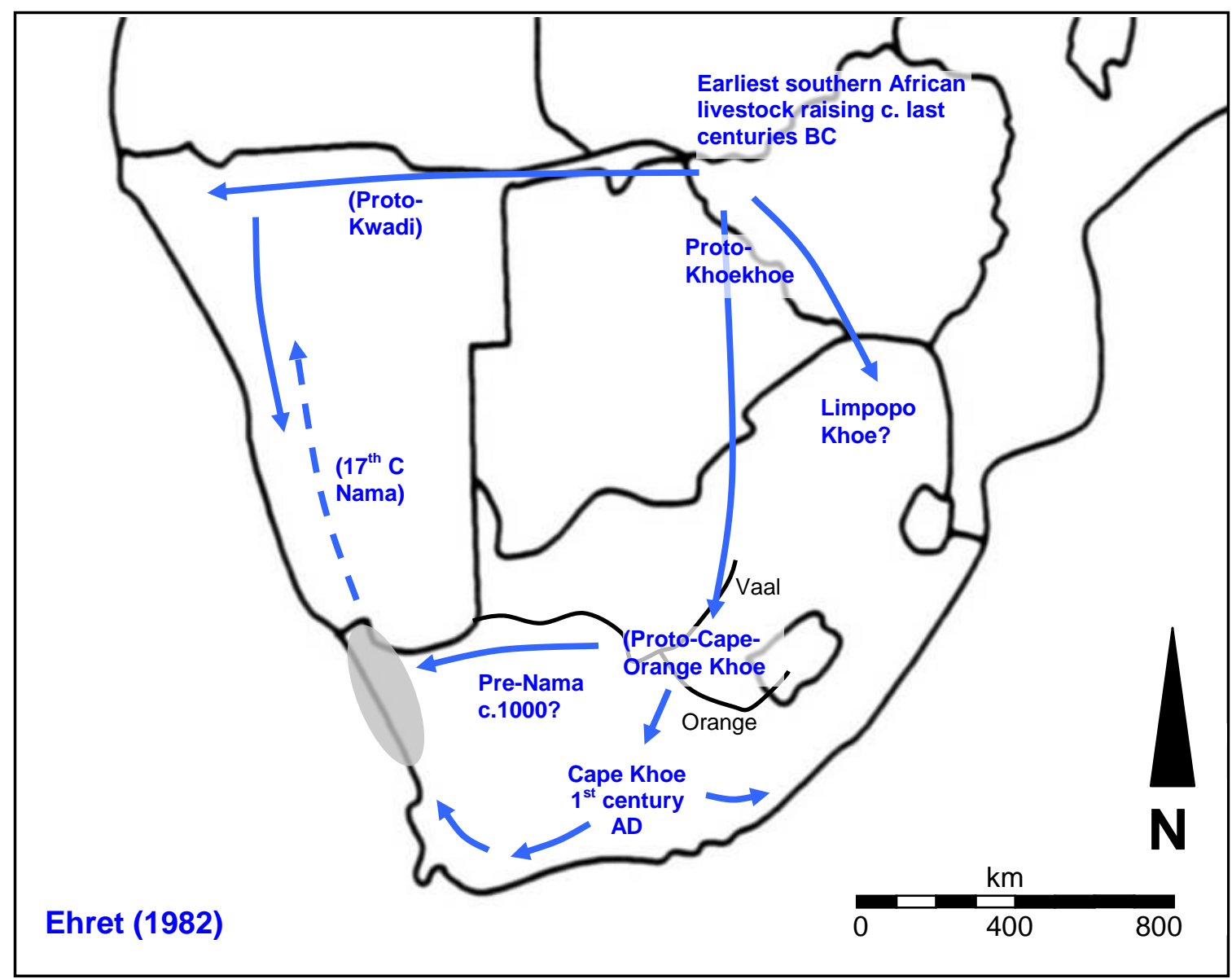

Figure 2.2: Ehret's (1982) suggested routes of entry of the Khoekhoe into southern Africa (modified from Ehret 1982: map 13). My research area is indicated by the shaded grey area. 
Initially, by examining oral traditions, Stow (1905) suggested that pastoralists moved from East Africa, through the northern part of southern Africa into Namibia and then southwards into the Western Cape (he placed this C. AD 1400). Cooke (1965) later supported this route using rock art evidence, although he saw the traverse westwards occurring further south. Elphick (1985) proposed movement from northern Botswana southwards towards the confluence of the Orange and Vaal Rivers and then westwards along the Orange into Namibia and the Northern Cape, as well as southwards through the eastern Karoo into the southern and south-western parts of the Western Cape (Figure 2.3). Interestingly, and in support, he thought that the historically observed differences between the Nama and Cape Khoekhoen may have been from the resulting long period of separation between west and south coast Khoe groups. Bousman's (1998) suggested western route for sheep begins in the region of Zambia and traces a line into northern Namibia and then southwards along the west coast to the Cape. He saw this as a 'Khoisan' route with a slightly later Iron Age equivalent occurring through south-eastern Africa. In reviewing these routes and their possible timing I focus first on the western route, then move onto evidence potentially supporting both routes and finally examine evidence from the central interior.

Limited archaeological support for the west coast routes exists. At Warmquelle, in northern Namibia, J. Kinahan (1981; Vogel \& Visser 1981) reported pottery associated with a date of 350 BC-AD 49 (Pta-2552), while Pleurdeau et al. (2012) directly dated two caprine teeth to 358-45 BC (Beta-270163) and 388-180 BC (Beta-270164). Several sheep bones were found in layers dated close to 2000 years ago in Spoeg River Cave (Webley 1992a; Vogel et al. 1997), and a first phalange directly dated to 350 BC-AD 115 (OxA-3862; Sealy \& Yates 1994) remains the oldest direct evidence for sheep in South Africa. Other sheep bones came from layers dating up to 518-366 BC (Pta-7200; Webley 1992a; Vogel et al. 1997), but without direct dates their true ages cannot be guaranteed. Nearby KN2005/041 has recently produced an age of AD 421-559 (OxA- 
22933) on cattle bone - this is the oldest dated cattle bone in South Africa (Orton et al. in press).

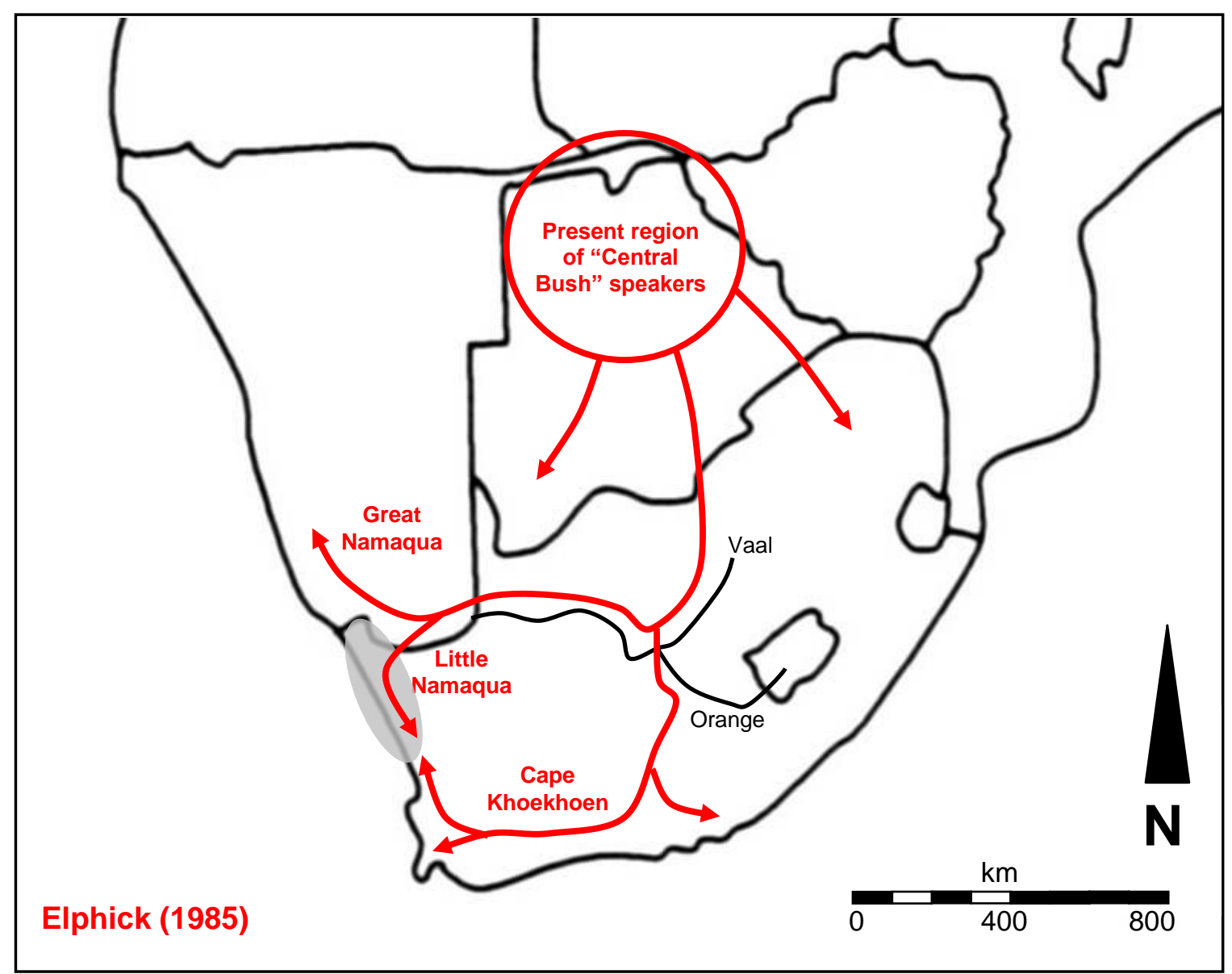

Figure 2.3: Elphick's (1985) suggested routes of entry of the Khoekhoe into southern Africa (modified from Elphick 1985: map 1). My research area is indicated by the shaded grey area.

Aside from KN2005/041, sheep and cattle have yet to be identified at open coastal sites with most of the best faunal collections already analysed (Dewar 2008). Although probable cow bones were found at a few sites (R. Klein, pers. comm. 2006), two were unsuccessfully tested for DNA content by Ann Horsburgh (pers. comm. 2008). Interior sites in central Namaqualand also contain very minimal remains of possible domesticates. It is only when one looks northwards to the Richtersveld that domestic fauna are present in reasonable numbers. /Ai tomas has a good sample, including two sheep/goat bones in a layer dated to 159 BC-AD 317 (Pta-5530; Webley 1992b). However, given the vastly different ages of deposits at similar depths in different parts of 
the site, the presence of several pits and the lack of clear stratigraphy, it may be prudent not to emphasise this early date without directly dating the relevant bones (c.f. Sealy \& Yates 1994, 1996). Other Richtersveld sites with sheep are a few hundred years younger (Brink \& Webley 1996). Spoeg River Cave thus remains the only site with reliable early sheep remains in Namaqualand.

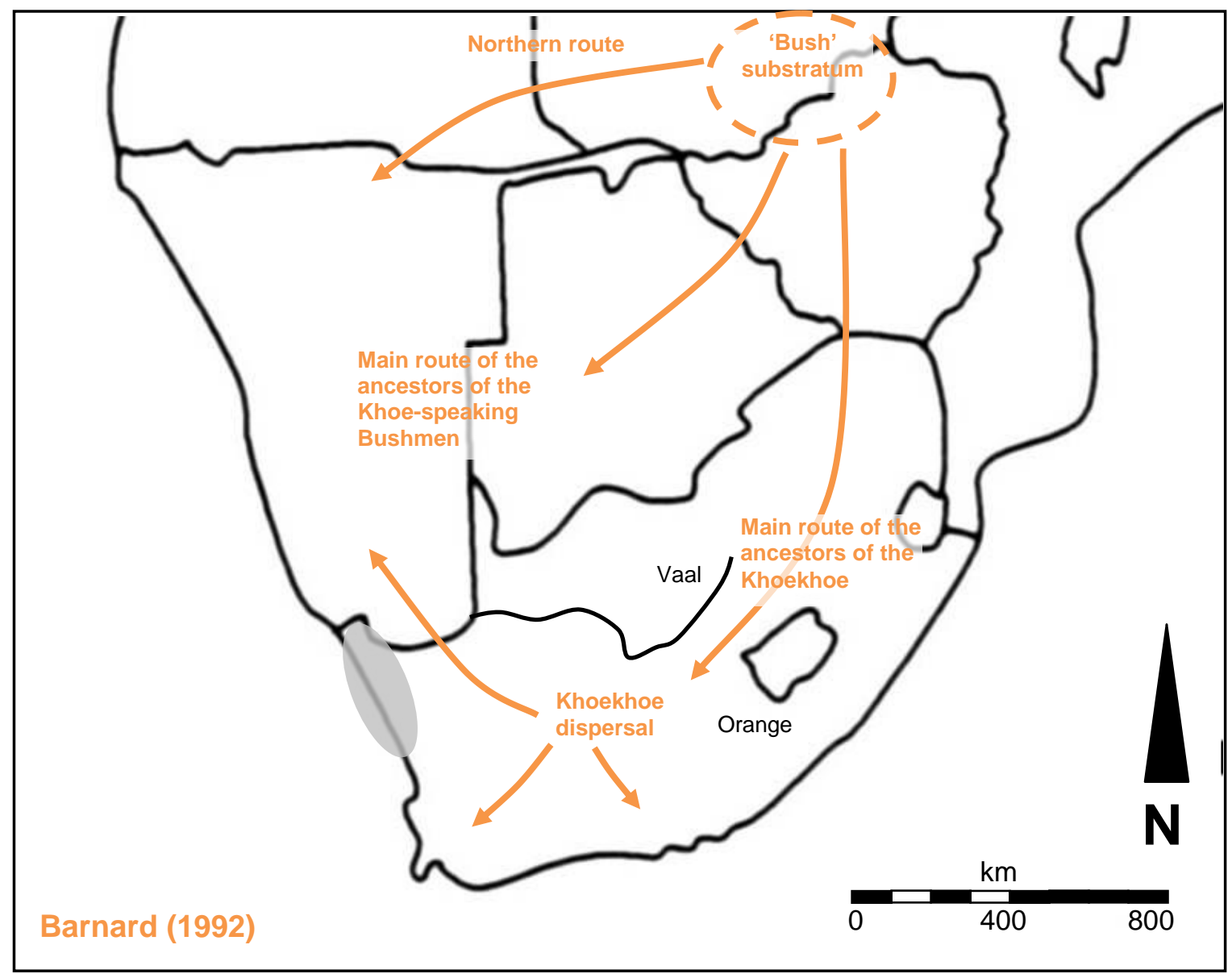

Figure 2.4: Barnard's (1992) suggested routes of entry of the Khoekhoe into southern Africa (modified from Barnard 1992: fig. 2.6). My research area is indicated by the shaded grey area.

Environmental support for the west coast route also exists. A study of micromammal species composition at Spoeg River Cave suggested that the Namaqualand climate of 2000 years ago was amenable enough to support sheep, with a subsequent deterioration (D. Avery 1992). Their salt and water needs (Dahl \& Hjört 1976) could easily have been met by the small springs and seeps at the interface of bedrock and aeolian overburden along the coast (Orton et al. in press). North of the Orange River, Andersson (1857:248) 
found "a kraal of Hottentots ... living in a locality altogether destitute of water". He noted that they got all their liquid from the milk of their livestock and the animals in turn lived off a succulent plant common in the region. Further north, just inland of Walvis Bay, he also reported good water and grazing that he thought would make adequate cattle fodder.

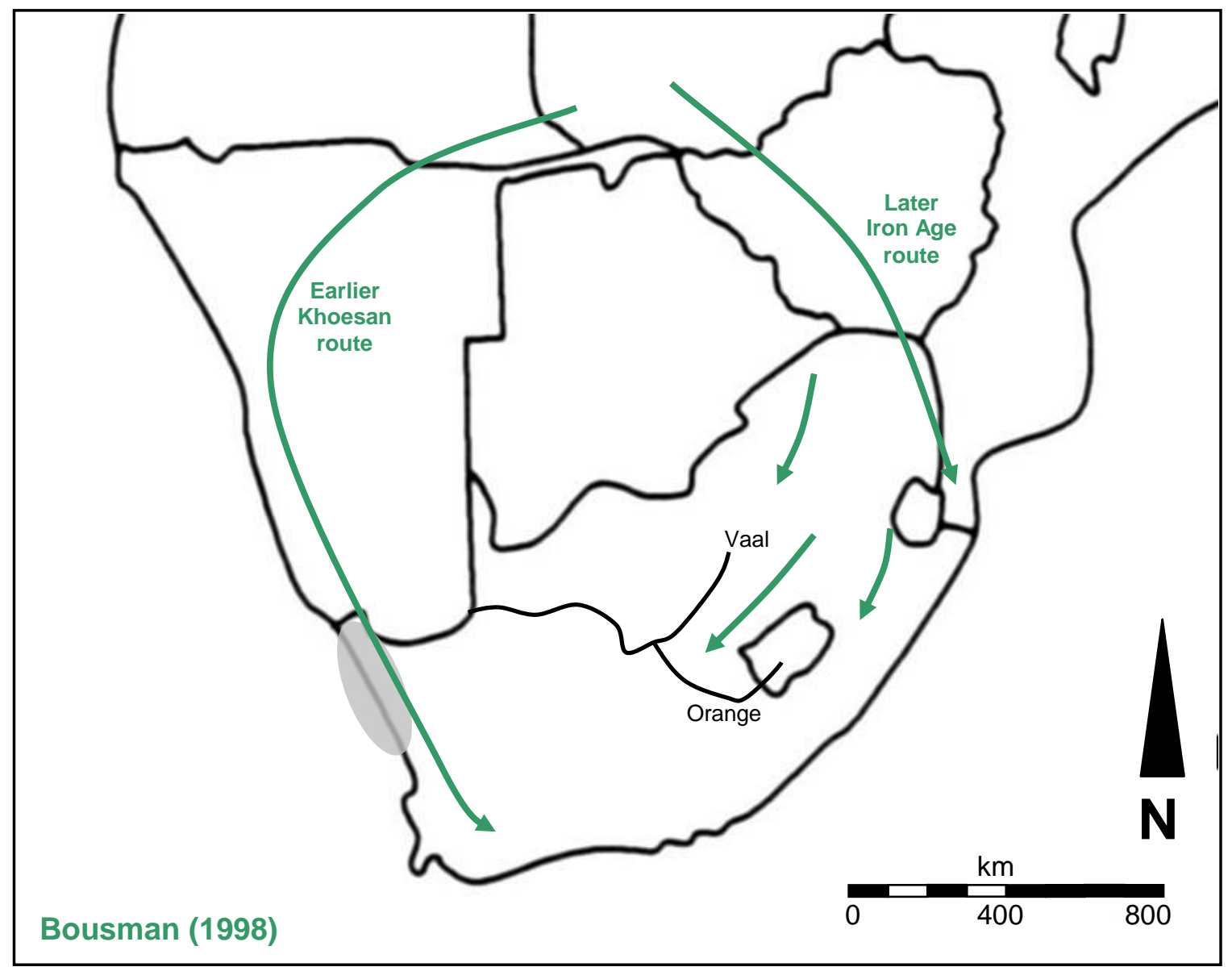

Figure 2.5: Bousman's (1998) suggested routes of entry of domestic stock into southern Africa based on radiocarbon dates (modified from Bousman 1998: fig. 4). My research area is indicated by the shaded grey area.

While the preceding discussion serves the western arm of Elphick's (1985) route, excavated evidence that could support either route comes from both cave and open sites in the southern Cape. At Blombos (Figure 2.1) two directly dated sheep bones yielded dates of 34 BC-AD 237 (OxA-4543) and AD 62-342 (OxA-4544; Henshilwood 1996), while sheep and pottery come from a layer dated to 20 BC-323 AD at Nelson Bay Cave (Inskeep \& Vogel 1985). A sheep bone from this latter layer has, however, been directly dated to AD 780-1158 (OxA-873; Gowlett et al. 1987). Slightly inland, the relatively low 
frequency of wild animals (Klein 1978) and the presence of dung deposits at Boomplaas Cave provide evidence of stock-keeping, as opposed to just stock-eating, just after AD 255-543 (H. Deacon et al. 1978). Further west, both sheep and pottery were found at AD 68-382 at Hawston (Pta-834, Pta-835; G. Avery 1975). Although Horsburgh (2008) reported a directly dated and genetically identified cattle bone at 174 BC-AD 54 (Beta232589) from nearby Byneskranskop (Figure 2.1), she now doubts the identification of this and three other early first millennium $A D$ bones as replications of the experiments have produced inconsistent results. She is now applying new next generation DNA sequencing technology in an attempt to resolve the issue (A. Horsburgh, pers. comm. 2012).

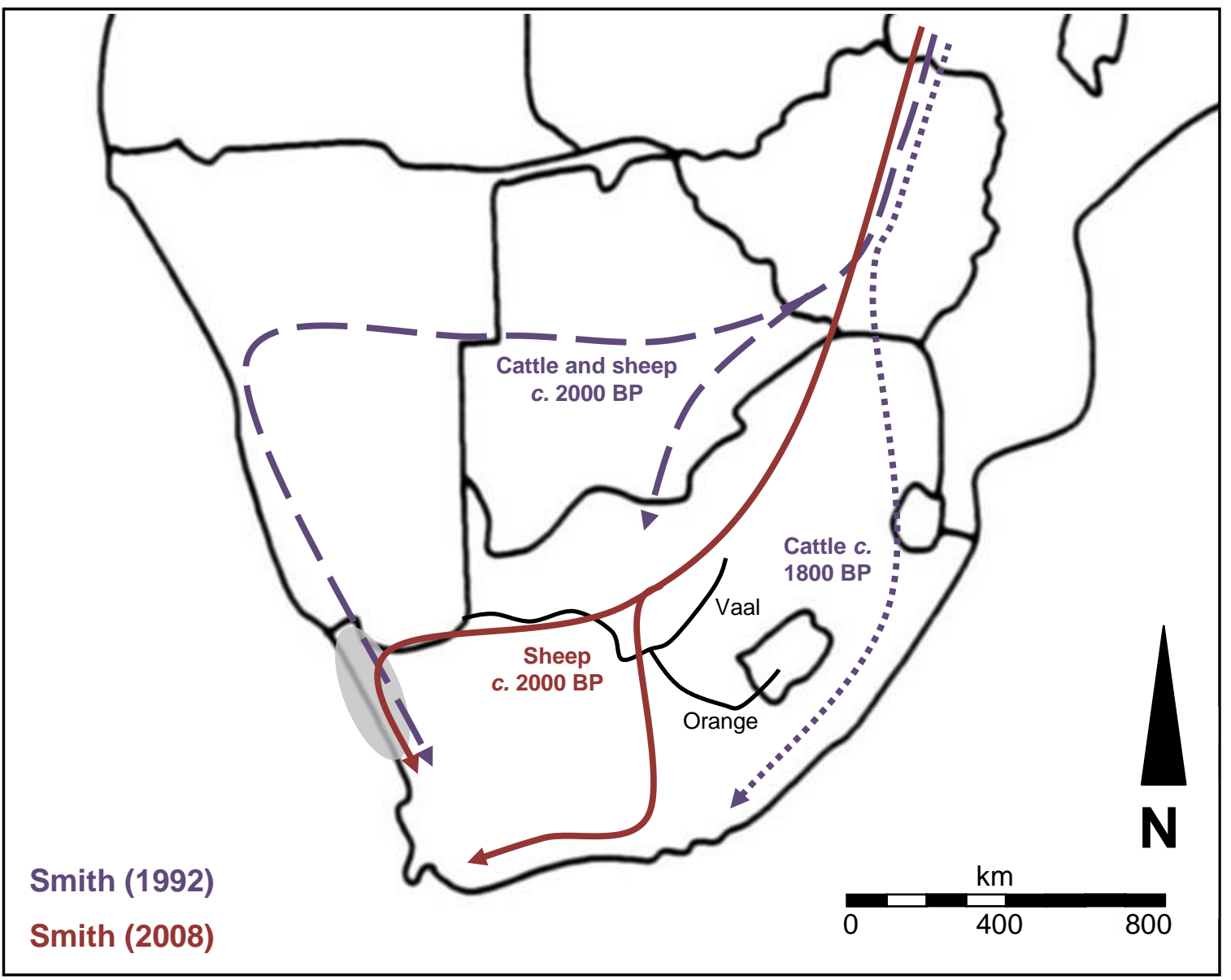

Figure 2.6: A. Smith's (1992, 2008a) suggested routes of entry of domestic stock into southern Africa (modified from A. Smith 1992: fig. 10.1; 2008a: fig. 12.4). My research area is indicated by the shaded grey area. 
During construction of his two-pronged model, Elphick (1985) noted two key features of Khoekhoe culture: (1) significant cultural differences occurred between the historic Cape Khoekhoen and the Nama to their north, possibly signifying separate directions of entry to their respective areas, and (2) the south-western Cape Khoekhoen acknowledged their eastern neighbours as being of more senior kinship, suggesting an east to west flow. Archaeological support for Elphick's model may be seen in the relatively late appearance of both sheep (AD 260-559 at Tortoise Cave; Pta-3312; Robey 1987) and pottery (AD 92-521 at Dunefield Midden 11; Pta-8912; Orton 2006) in the extremely well researched Elands Bay area, since it might have been one of the last areas to experience the introductions (Figure 2.3). Slightly to the south, on the Vredenburg Peninsula, sheep and pottery are associated with a date of AD 77-382 at Kasteelberg $A$ (Pta-3711; A. Smith 2006a), but both are earlier at Spoeg River cave in Namaqualand (Vogel et al. 1997; Webley 2002) suggesting either entry from the north, or perhaps both directions. Note that the very few sheep bones found in pre-pottery levels at Steenbokfontein (Jerardino \& Yates 1996, table 2) and Kasteelberg G (Sadr 2004, table 1) are likely to be intrusive. This is suggested by the out-of-sequence dating at Kasteelberg G (Sadr 2004, table 2), perhaps a sign of bioturbation, and the surface truncation of the strata at Steenbokfontein (Jerardino \& Yates 1996: fig. 4). Direct dating of these bones would undoubtedly provide further valuable insights. Using the admittedly small set of available direct radiocarbon dates for early sheep, Russell (2004) conducted statistical analyses that lent more support to an Elphick-type (1985) model than to a west coast route ${ }^{6}$.

Turning now to the central interior, Sadr and Sampson (2006) reported four directly dated potsherds from the Seacow Valley with the oldest at 355 BC-AD 18 (GrA-13564) but, being fibre-tempered, these sherds are ascribed to Bushman hunter-gatherers, not

\footnotetext{
${ }^{6}$ Note that Elphick explored the spread of the Khoekhoen and not specifically that of sheep.
} 
Khoekhoe pastoralists (Bollong et al. 1993, 1997; Thorp 1996). Evidence relating to sheep remains poor. From the far eastern Northern Cape, Beaumont and Vogel (1984) reported caprine teeth associated with a date of 749-204 BC (Pta-2390) from a hyaena lair known as Equus Cave. They claim the teeth were distributed throughout a $45 \mathrm{~cm}$ layer with the date being from its 23 to $30 \mathrm{~cm}$ level. This could thus be the earliest evidence of sheep in the central interior, supporting Elphick's (1985) route, but given the small size of teeth and the ease with which subterranean movement of small items takes place, especially in dry, sandy substrates (Gifford-Gonzalez et al. 1985; Richardson 1992; Villa \& Courtin 1983), these data are not fully reliable without direct dating. The extremely well surveyed Seacow Valley would be the most probable line of movement between the Orange River and the south coast and was described by Barrow (1801:255) as having long stretches of open water up to "five or six miles in length, and deep enough to have floated a line-of-battle ship". He noted on the surrounding plains "springboks in countless troops, hartebeests, and bonteboks ... quachas from fifty to a hundred in a troop were hourly seen" (Barrow 1801: 263). That the Seacow River could support so much wild game certainly suggests that it could have been a conduit of sheep and pastoralism to the south coast. Known herder occupation of this valley is, however, quite late, with the three earliest dates associated with sheep, pottery and dung all postdating AD 600 (Pta-6302; SMU-1850; SMU-1925; Bollong \& Sampson 1996; Bousman 1991, 1998; Hart 1989; Plug et al. 1994; Sampson \& Vogel 1995). Many interior sites contain no sheep at all (Klein 1979) and directly dated sheep bones from some have turned out to be far younger than expected (Sealy \& Yates 1996). We thus still lack direct early evidence for sheep in the Karoo and this potentially precludes this area as an early route of sheep movement. Although possibly due to a lower intensity of research (the Seacow Valley excluded) and the presence of fewer caves, the lack of early dates in the interior favours the west coast route of entry for sheep with a rapid spread to the south coast. Barnard (1992: fig. 2.6) also supports this route steering east of the harsh central Kalahari region but, again, other archaeological evidence is lacking (Mitchell 2004a). 
Brief mention must be made of the antiquity of sheep relative to pottery. Although Robertshaw (1978b:120) thought that the appearance of pottery and domestic stock was almost simultaneous and that their spread through the Cape was linked, it now seems that pottery is more frequently associated with early dates than are sheep (see Sealy \& Yates 1994). Views as to which appeared first in southern Africa have shifted with time and with the resolution of radiocarbon dating we may never know the answer.

The original timing of the Khoekhoe arrival has recently been questioned by Sadr. Excavated evidence in the form of changing pottery styles suggests that the Khoekhoen may have only reached the south-western Cape by the late first millennium AD with indigenous herders occupying the area before then (Sadr 1998, 2003, 2004, 2005a). Güldemann (2008:126), on linguistic grounds, hints at a similar timing.

In the CLB area Eastwood and Smith (2005; B. Smith 2006) used various lines of evidence, including the borrowing of Khoekhoe herding vocabulary by Bantu speakers (Ehret 1998) and the super-positioning of the different types of art to propose an early first millennium $A D$ influx of the Khoekhoen to that area. While their conclusion is probably best regarded as tentative, and perhaps based on somewhat controversial linguistics (see Argyle 1994/95; Blench 2006; Güldemann 2008), they do make for interesting thought.

Whatever the origin of the Khoekhoen, it is pertinent to note that the Namaqua origin myth related by Smith \& Pheiffer (1992) and the story about the origin of hunters and herders recorded by Bleek (1864) suggest some degree of common ancestry between pastoral (Khoekhoe) and hunter-gatherer people. One of them (Smith \& Pheiffer 1992) even describes the progenitors of the two groups as having been brothers. The implications of this are quite significant given the suggestion that the two groups should be archaeologically distinguishable on the basis of their respective cultural materials (see 
Section 3.1 above). A mid-nineteenth century interview with an elderly Korana man revealed a Korana legend that "in ancient times the whole nation of Hottentots lived close together along the banks of the Vaal and Orange River(s)" (Wuras 1929:290). After a quarrel they apparently split three ways, one group moving down the Orange River, another moving southwards and the third remaining behind; Barnard (1992) sees some support for this story in linguistic evidence. Stow (1905) recounted a further Korana tale (alluded to above) that he supposed was played out in about $C$. AD 1400. In it the people came from the northeast where there was plenty of water (Stow interprets this to mean the Great Lakes area). Then, as a result of Bantu incursions, they fled westwards until halted by the coast which they subsequently followed south. With the arrival of the Dutch they were said to have returned north to the vicinity of the Orange River and then inland. Whether these tales can be used as hard evidence is debatable, but they certainly seemed to Elphick (1985) to offer partial support for some of his dispersal routes as described above.

\subsection{The nature of introduction of domesticates and pottery to southernmost Africa}

Pottery and sheep are generally accepted to have first appeared in the south-western Cape by the early first millennium AD (Sadr 1998), although the manner of their introduction remains debated (Sadr 2003). On current evidence, both appeared in widely disparate parts of southern Africa at similar times, suggesting a rapid spread (J. Deacon 1984a). New research allows us to include cattle in the discussion as well (Orton et al. in press). It was long considered that the Khoekhoen migrated into southern Africa some 2000 years ago bringing sheep and pottery with them but, despite dogged support from Andrew Smith (2006a, 2008b), this view has begun changing in recent years. Although a migration probably did occur, whether it occurred c. 2000 years ago or close to a millennium later as discussed above is open to debate. Also, Sadr et al. (2003) found the 
cultural residues from six first millennium AD putative hunter and herder sites (three of each) at Kasteelberg to be similar enough to not support any distinction at that time.

There are two schools of thought with regard to the nature of sheep, pottery and Khoekhoen arrival at the Cape. The classic view, supported by many writers until the mid-1990s, saw them arriving together through a population migration into the southern and south-western Cape some 2000 years ago (e.g. Barnard 1992; Boonzaier et al. 1996; Ehret 1982; Elphick 1985; Parkington 1984; Parkington et al. 1986; A. Smith 1983, 1992; Walker 1983). Sadr (1998, 2004; Reid et al. 1998) is the main proponent of the alternative diffusion hypothesis in which the acquisition of knowledge, pottery and domestic stock through sharing and exchange is said to have occurred prior to the arrival of the Khoekhoen themselves, although J. Kinahan (1994/1995) had earlier postulated a similar process in the Namib. More than a decade earlier Klein (1984:287) had already suggested diffusion as a likely means of spread of pastoralism, saying that "the earliest herders were probably very similar physically to the hunter/gatherers they encountered and probably shared a great deal of culture with them, including the manufacture of stone artefacts and a considerable reliance on hunted and gathered foods". These common features, he suggested, would have facilitated diffusion. Similarly, Webley (1984:193) suggested that "the introduction of livestock and pottery was a complex process involving both the movement of herders as well as the diffusion of herder elements." Although direct evidence of diffusion is limited, several ideas support a late migration and, by implication, an earlier diffusion of pastoral products.

Along with a partial shift towards a more terrestrially-oriented diet c. 2000 years ago, Sealy's (2010) analysis of skeletons has documented a shift from $C_{3^{-}}$to $C_{4}$-based foods in the early second millennium AD which, she argues, is likely due to the increased dietary importance of domestic stock, specifically cattle. She also documents evidence for a new burial style and sees the two features as early evidence of the historically- 
known Khoekhoen. In support, Güldemann (2008) finds the linguistic homogeneity of Khoekhoe to be difficult to reconcile with a 2000 year antiquity in South Africa.

Hausman (1982) found no skeletal evidence for population change among coastal populations c. $2000 \mathrm{BP}$, while a recent study of skeletal characteristics in the Eastern Cape concluded that no new genetic stock was added c. 2000 BP (because body shape remained unchanged) and that change in body size was linked to external factors (Ginther 2008). Specifically, reducing body size post-3500 BP was seen to reflect increasing nutritional stress on the population, while, as also suggested by A. Smith and Pheiffer (1993), a post-2000 BP increase was probably due to the increased nourishment provided by milk. These studies support a local adoption of domestic stock with the Khoekhoen arriving sometime later. Only in the last 500 years when variability in body shape and size is greatest is a genetic influx from immigrant Bantu agropastoralists possibly supported (Ginther 2008). Stynder (2009) saw craniometric data supporting neither a large-scale immigration of a genetically distinct people nor a long-term coexistence of genetically distinct populations: either local hunter-gatherers adopted stock or there was a small-scale immigration of herders whose genetic signature would have been quickly absorbed into the local gene pool. These studies were conducted in southernmost South Africa and it seems more likely that genetic absorption or dilution would have occurred in the north where the populations initially mixed. Unfortunately, too few dated skeletons come from northern South Africa to allow similar research there.

If the Khoekhoen did only arrive in south-western South Africa c. AD 900-1200 (Sadr 2003), then the implication is that pottery and sheep were a firmly established part of the indigenous economy prior to their arrival and that the earliest herders were not Khoekhoen. The possibility of pottery being obtained from Iron Age people was dispelled by Sadr and Sampson (2006) who showed that Later Stone Age pottery preceded its Iron Age counterpart in southern Africa by 200 to 400 years. Similarly, M. Hall (1987) 
postulated that stock must have been in the hands of herders half a millennium before the advent of the Iron Age in eastern Botswana/western Zimbabwe, a notion supported by the c. 2000 year old sheep and cattle in a LSA context at Toteng in northern Botswana (Robbins et al. 2005) and the slightly older caprines from Leopard Cave in central Namibia (Pleurdeau et al. 2012).

Andrew Smith uses two primary arguments to support a migration around 2000 years ago. Firstly, he considers the Vredenburg Peninsula archaeological signatures to be different enough to represent two culturally and economically distinct groups - hunters and herders - and that these can be distinguished throughout the last 2000 years (A. Smith 1998b, 2006a; A. Smith et al. 1991). Problems with this interpretation have already been covered, both at Kasteelberg and further afield (see Section 2.1). Furthermore, however, the high frequencies of pottery (Sadr \& Smith 1991; A. Smith 1998b) and sheep (Klein \& Cruz-Uribe 1989) led Sadr (2004, 2005a) to consider Kasteelberg a special purpose feasting locality rather than a typical herder site. A feature at Kasteelberg B in particular is the presence of numerous grinding grooves in the bedrock (Boonzaier et al. 1996: fig. 16; A. Smith 1998b, 2005a: fig. 6.11) that A. Smith (1998b:211) concedes might be "an indication of selective social activity, perhaps even of a ceremonial nature". He later added that "Kasteelberg may have been a ritual aggregation site for pastoral ceremonial purposes" (A. Smith 2005a: 173; see also A. Smith \& Webley 2000:89). The significance of the bedrock grooves is two-fold: (1) because of their depth and great number at Kasteelberg, A. Smith (1998) notes that much energy had to have been expended in their creation and that they must therefor have been very important, and (2) on the basis of portable upper and lower grindstones being ochre-stained, he assumes the bedrock grooves to have also been used to grind ochre that might have been ritually used. Similar grooves are recorded at Heuningklip, southeast of Kasteelberg (A. Smith 2006a) and at occasional sites in the Kamiesberg, but they are abundant in western Bushmanland (Orton \& Webley 2012b; Webley 1992b). 
Besides Heuningklip, the Kasteelberg Hill is also geologically distinctive in the Western Cape environment. Whether occupied by herders or Sadr's (2003) 'hunters-with-sheep', that Kasteelberg is unique in both appearance and content seems undeniable and it should not be considered a typical herder occupation. Artefactual evidence opposing Smith's ideas is reviewed below.

Smith's second line of evidence is theoretical. Shared by Parkington et al. (1986), it revolves around the idea that hunter-gatherers with an immediate-returns economy, as defined by Woodburn (1980:99), would have been unable to nurture, maintain and protect a herd of domestic stock and that an ingrained sharing ethic would have prevented the accumulation of wealth in the form of stock (A. Smith 1990, 1992, 1998b, 2006a). Oddly, and in contrast, A. Smith (1998b:209) actually supposes that huntergatherers might in fact have herded domestic stock for the Khoekhoen. Smith argues that hunter-gatherers would see any herbivore as food and that should sheep be acquired by them, they would immediately be killed, shared and eaten, or exchanged rather than herded. In this way hunter-gatherers would not be able to build up a viable flock, let alone one of 100 individuals (A. Smith 2006a). In rejecting diffusion, A. Smith (2005a, 2006a) also suggests that a long term relationship with food-producers, and perhaps some incorporation into their society, was needed before the skills of animal husbandry could be acquired; he guesses that several generations might be necessary. These theories raise several concerns.

Woodburn (1980:98) listed several groups of hunter-gatherers who were familiar with and practised a delayed-returns economy and Kusimba (2005) found such strategies to be widespread among African hunter-gatherers. Proponents and critics alike quote recent ethnography in support of their respective arguments on the ability of huntergatherers to keep stock, but modern analogues may not be appropriate given the contrasting evidence that exists. Parkington et al. (1986:317) discussed ethnographic 
examples of hunter-gatherers struggling to maintain stock due to their sharing obligations, while Kent (1992:49-50) and Hitchcock and Ebert (1984: table 1) showed that twentieth century Kalahari Bushmen subsisted in diverse ways with the spectrum including hunting, gathering, herding, farming and all manner of combinations thereof. Stepping back in time, Humphreys (1988) noted that early nineteenth century Bushmen living in 'villages' along the Vaal River were said by historic travellers (e.g. Burchell 1822, 1824) to own sheep, goats and cattle and to have been far better off than their compatriots to the west. He stresses that the historic distinction between the Khoekhoen (then termed Hottentots) and Bushmen was reliable, although in earlier accounts this was not the case (Wilson 1969). It seems, though, that at least some of this stock was "part of plunder obtained from the Caffres" (Burchell 1822:436) or even from white farmers - "that they were stolen, I had no doubt ... the greater part of the oxen ... belonged to a boor ${ }^{7}$ named Cobus Pretorius" (Burchell 1824:197). That they "guarded and corralled them, rather than butchering and eating them on the spot" seems, to Schrire (1980:23), significant. A. Smith (2000) counters that hunters with small herds are not pastoralists unless they incorporate their stock into ritual activity. Either way, goatraising is prominent among the Kalahari Bushmen today, although perhaps largely due to promotion by the Botswanan government in the 1980s (Ikeya 1993). The sum of the evidence presented suggests it best not to read too much into recent analogues and it seems unwise to project too much onto the indigenous populations of two thousand years ago. Indeed, as Woodburn (1980:95) puts it: "projection backwards seems to me as a social anthropologist to be an enormously difficult task and likely to yield no more than, at best, plausible hypotheses". He also emphasises that hunter-gatherers live the way they do through conscious choice and not because of their environment or because they lack the means to live another way. As we know today, people will change their social choices and behave anti-socially if they perceive it necessary to fulfil their needs.

\footnotetext{
${ }^{7}$ Farmer
} 
Archaeological evidence to surmount Woodburn's difficulty is scant. Although few indigenous southern African groups likely practised delayed-returns economies, the enormous mussel-dominated 'megamiddens' deposited between about 1100 BC and AD 300 on the western Cape coast may provide one archaeological exception: Henshilwood et al. (1994; Parkington 2012) suggested that mussel meat might have been dried in large quantities for transport inland. While this may have occurred, Jerardino and Yates (1997) argued that sufficient other debris relating to animal butchery and artefact production is present at Mike Taylor's Midden near Elands Bay to argue for its use as a domestic camp site. The only obvious instance of pre-colonial storage is of plant foods in underground pits at Boomplaas (H. Deacon 1976, 1979; H. Deacon et al. 1978). The south-western Cape coastal fish traps that allow mass-harvesting were initially considered prehistoric (G. Avery 1975; Goodwin 1946), but are more likely colonial (Hine 2008; Hine et al. 2010) and can be excluded from this discussion. Whether the historically recorded trapping of fish in inland rivers by the Bushmen (Lichtenstein 1812; Mossop 1935; Stow 1905; Willcox 1965) could have produced sufficient fish for storage is unknown.

Mitchell et al. (2008; Mitchell 2009) argue against the notion of immediate slaughter by citing Likoaeng, a late first millennium AD site in highland Lesotho located 100 to $150 \mathrm{~km}$ from the nearest contemporary farming settlement and on the other side of a $3000 \mathrm{~m}$ escarpment. The domestic stock from this site could not possibly have been moved there quickly enough to still count as having been 'immediately' killed and eaten. Hobart (2004:9) found many domestic bones at Pitsaneng and argued similarly that perhaps hunter-gatherers should be credited "with the pro-active adoption and introduction of stock ... not so much as farmers or even pastoralists, but as opportunists who saw benefits for themselves in owning stock". The sheep bones at nearby Sehonghong (Plug \& Mitchell 2008) would support similar arguments. While hunter-gatherers in southern Africa are very unlikely to have ever stored enough food to bring about a sedentary 
lifestyle (see Testart 1982), delayed-return systems are more likely to develop in areas where food storage is easy and desirable (Woodburn 1980) and it is entirely possible that the ease and desirability of 'storing' live - and easily transportable - meat was recognised by local hunter-gatherers, as must have occurred among Smith's "hunters who lived in northern Botswana" (Boonzaier et al. 1996:25) when sheep were initially acquired. Ingold (1980) suggested that hunters would not see live animals as a form of property - only dead ones. He proposed "the distinction between hunting and pastoralism to be an ideological one: briefly, pastoralists recognise rights over live animals, hunters over dead ones" (Ingold 1975: 619). Thus, if hunter-gatherers acquired and adopted flocks, they could well have recognised them as a communal reserve food supply and continued to subsist almost wholly on hunted prey.

Smith's statement on flock size requires unpacking. Firstly, Dahl and Hjört (1976: 218) Smiths original source - made it clear that "the large variations in the way flocks of small stock are utilized and in the yields from different breeds makes it impossible to generalize about a minimum viable flock." Also, they stated that their estimates of flock sizes were based on a family of six taking all their milk and meat from their stock, while we know from the faunal lists from Atlantic Beach, Kasteelberg and Boomplaas, for example, that hunting and scavenging occurred in conjunction with the eating of sheep (Klein 1978; Klein \& Cruz-Uribe 1989; Sadr et al. 2003; Sealy et al. 2002; A. Smith 2006a), probably even comprising the bulk of the diet at these sites. Similarly diverse frequencies of wild and domestic stock were reported from East African sites (Marshall 1994). That all indigenous groups in western South Africa subsisted primarily on wild fauna could have allowed for smaller sustainable flocks than those expected of groups much more wholly dependent on the meat, blood and dairy products of their livestock.

Other factors regarding the size of herds and flocks argue both ways. Although small stock are more gregarious and easier to herd than large stock, smaller herds lack 
internal coherence such that individual animals are more likely to stray (Ingold 1980). Nomadic sheep herders in Pakistan pool their sheep to maintain a combined flock of approximately 250-500 animals, those being their upper and lower limits for a successful flock (Swidler 1972), while in Kenya Brown (1971) found the minimum and ideal mixed species herds to maintain a pastoralist family of eight to be 15-17 and 20-24 standard stock units ${ }^{8}$ respectively. It is important to recognise that in southern Africa, however, we do not have - and did not in the seventeenth century, the time of our first detailed written accounts, have - true pastoralists. Due to the variety of wild food sources utilised, people in the Kalahari rarely own more than forty goats. These herds are also usually combined and tended together (Kent 1993). Whether such practices may have existed in the early pottery-period we will never know, but Sadr (2008b) considers it likely. Due to the difficulty in herding them, pastoralists in the Richtersveld leave their small herds of cattle (ranging from just a few individuals to more than thirty) to fend for themselves while they tend their goats. The cattle are quite content and make their own way between water holes in the south and the Orange River in the north following their fodder and water as required (O. Cloete, pers. comm. to S. Le Roux 2009). Today, of course, they have no predators. Modern goat herds in the area are very much larger, but the possibility is nevertheless raised that small herds of cattle are feasibly maintainable; Redlinghuis (1981 in Webley 1984) found average herds in Namaqualand to number just four. Also in the Richtersveld, Hendricks et al. (2005) concluded that, while small herds carried a higher risk, all herds would be eliminated during severe drought conditions.

Bearing in mind the inherent dangers of ethnographic analogy already discussed, a few more cases are pertinent. In the Kalahari hare-sized or smaller animals are not always subject to the same sharing rules as larger ones (e.g. Kent 1993; Marshall 1986). Sadr

\footnotetext{
${ }^{8}$ Brown (1971) describes a standard stock unit as $453.6 \mathrm{~kg}$ (1000 lb) of meat or 2 adult cattle or 10 sheep or goats.
} 
and Plug (2001) found that sheep appeared to have replaced small animals in the faunal remains from two Botswanan rock shelters and suggested that if sheep were included among small animals this may have allowed hunter-gatherers to incorporate stock in their economy without having to share their produce. Social sharing obligations could still have been fulfilled through the sharing of larger game. Modern goat herding foragers continue their strictly egalitarian way of life, drawing milk from their herds but slaughtering them only in times of need. They procure some $95 \%$ of their meat through hunting with their small goat herds serving only as a backup meat source should hunting be unsuccessful (Kent 1992, 1993). This compliments the archaeological observations on diet quoted above. Yellen (1984) sees the adoption of herding as a logical means of broadening the subsistence base of hunter-gatherer groups with the impetus for its adoption being greatest in areas with a high degree of environmental uncertainty. However, he expected that social constraints and, among other things, the need to maintain a high degree of mobility, would have limited the reliance on domestic stock. In this way social structure and a basic hunting and gathering life style could have been maintained. Marshall and Hildebrand (2002) suggested that increasing reliance on wild ungulates helped overcome the reduced predictability of plant resources in low rainfall environments. Since ungulates process a larger variety of plant foods, this also helps, by proxy, to diversify the species available to people. In arid conditions it would have been difficult to locate wild herds and domestication would have offered a way of increasing their predictability. Extending this logic, it would only be a small step for southern African hunter-gatherers to adopt sheep and/or cattle in order to increase the predictability of their food supply, whether through milk or meat. Adoption of small flocks by huntergatherers as reserve supplies could account for the very low numbers of sheep found in sites across the western part of South Africa and the lack of sites similar to Kasteelberg.

Despite the opposing evidence, A. Smith (2006a:71, 2008b) still expounds the view that "the ancestors of the historical Khoekhoen arrived at the southern tip of Africa with their 
sheep, some 2000 years ago, having immigrated and travelled fast over the intervening area between the Limpopo Province and the Cape". He considers the speed of movement to have been due to the need to find and colonise riverine systems, possibly after environmental deterioration in northern Botswana (A. Smith 2006a), or perhaps due to the unfriendly relations with local hunter-gatherers from whom they had to hurriedly move away (A. Smith 1990). However, if Khoekhoe immigration was due to the expansion of their population as suggested by Ehret (1982) and Elphick (1985), then why move so far so fast?

Elphick (1985:14) noted that "it is not likely that the Khoikhoi set out on a rapid, longdistance trek ... their movement was probably stimulated mainly by the need to find and exploit new pastures, and is best described by the term 'migratory drift"' as used by Stenning $(1964)^{9}$. Also, such rapid expansion would have left the Khoekhoen extremely thinly spread on the southern African landscape - probably far more so than they would have liked. Marshall and Hildebrand (2002:121) noted this in East Africa where they suggested herders moving into the area would have had "limited access to other herders, breeding stock, and social safety networks". Boonzaier et al. (1996:27) state somewhat simplistically that the herders "probably travelled southwards to the winter rainfall area of the western Cape" as if they knew where they were going and were not interested in any of the other areas known to have been later occupied by herders! This was clearly not the case and some fairly inhospitable terrain would have to have been traversed before arrival at the better-watered south-western Cape. In order to survive them, new environments would have needed learning during colonisation (Meltzer 2003; Rockman 2003). This includes, for example, locating lithic resources and understanding the flow regimes of local rivers. In environments with an existing resident population the rate of

9 Stenning's (1964:22) term 'migratory drift' describes "the continuous adjustment of transhumance patterns to subtle changes of an ecological nature." 
learning is increased through friendly interaction with the residents. A. Smith (1990) thinks that herders would have avoided the local people; surely this would thus have slowed the migration process? Elphick (1985) noted that Namaqualand could not have been crossed in the dry season, since the fodder would have been too poor to support stock. Of course, this view may only be relevant to today's climate, since D. Avery (1992) found the $c .2000$ BP climate to have been more favourable. Rapid movement through inhospitable areas as discussed above (A. Smith 2006a) would be very bold given no guarantee of finding water and fodder 'on the other side'. Rapid diffusion amongst a knowledgeable pre-existing population may have been more feasible and, discussing the spread of food production in Europe, Mitchell (2004b: table 1) noted that the complex interaction networks of hunter-gatherers were "capable of transmitting knowledge of new technologies and resources swiftly and over long distances". While Ehret (1982) thought that diffusion would be slow due to the successive periods of accommodation that would be required, Sadr (1998) noted that the available date ranges at $95.4 \%$ probability allowed up to 200 years for the spread from south-western Zimbabwe to the Cape; only $10 \mathrm{~km}$ need be covered per year.

I turn now to pottery, which perhaps reflects a marginally clearer situation. Although technologically similar, early pottery styles in Namibia, Botswana and the south-western Cape are very different, suggesting production by culturally distinct groups (Reid et al. 1998; Sadr 1998). This argues against a single cultural group migrating across the subcontinent. Sadr and Sampson (2006) later thought this regional diversity could be an indication of indigenous southern African invention, since early, thin-walled pottery does not appear to be present north of the Zambezi River. In contrast, Gifford-Gonzalez (2000) noted that learning the skills of pottery-making would have been difficult and required intentional social interaction between groups in possession of the knowledge and technology and those without. She suspects that relationships between early pastoralists and indigenous foragers may have been friendlier than those recently 
observed, with exchange relationships being enhanced by the creation of familial ties. Such a situation might well have aided the early diffusion of pottery-making technology from northern Botswana southwards, whether it was independently invented there or not. While archaeological evidence to support either contention is sparse, more can be said of the later spread of pottery into South Africa.

Pottery evidence argues for a late Khoekhoen migration into South Africa and, by implication, an initial introduction of sheep and pottery through diffusion some 1000 years earlier. Two observations are significant. Firstly, Reid at al. (1998, fig. 4.8; Sadr 1998, fig. 3) noted the coincidence of pierced lugs and the proposed routes of movement of the Khoekhoen through southern Africa. None of these lugs are reliably dated to more than 1200 to 1100 years ago (Sadr 1998). Secondly, Sadr (2003) documented a significant change in pottery style at Kasteelberg around AD 900-1200, involving replacement of narrow-necked, spouted and decorated pots by larger, undecorated lugged vessels. Lugged pots are often associated with the Khoekhoen (Bollong et al. 1997; Reid et al. 1998; Rudner 1979; Sadr 1998, 2003) and are seen by Sadr (2003) as indicating their arrival in the Western Cape c. AD 900-1200. Interestingly, Jacobson (1987) had long since postulated the replacement in Namibia of thin-walled pottery by a thicker variant as being a possible signifier of the arrival of the historically documented Khoekhoen. It may well be that early, non-lugged pottery in southern Africa was used by relatively less mobile societies who returned frequently to their home bases. In contrast, lugged ware, which was easily suspended from cattle, might have been developed by herders in response to the need for greater mobility. Sadr (1998: 116) also details distinct changes in almost every other class of remains at Kasteelberg $B$ between about $A D 900$ and $A D$ 1200 as further support. At about the same time J. Kinahan (1994/1995) notes a similar change in pottery style from small globular vessels to large bag-shaped ones on !Kuiseb Delta sites in the Namib Desert. 
On the other side of the subcontinent, Mazel (1992) suggests LSA pottery to have been present from the first century $\mathrm{BC}$, but some of the dates and contexts he presents do not inspire confidence. His data do, however, make it clear that LSA pottery was present there by at least AD 100, well before the Iron Age incursion. That this early pottery is not Iron Age is well demonstrated by its far thinner walls. Significantly, Mazel (1992) reports no sheep remains, raising the possibility that pottery reached the area independently via diffusion. Similarly, from Cape St Francis in the Eastern Cape, Binneman (1995, 2001) reports the earliest recorded pottery to be about AD 350 (Pta-9311), with domesticates only occurring some two centuries later.

Limited sheep and pottery in the prehistoric landscape prior to AD 900 are likely to have had a far smaller impact on the economies of traditional hunter-gatherers than the presence of a new group of people practising a vastly different mode of existence. In the south-western Cape, though, Parkington et al. (1986, 1988) recorded a changing settlement pattern from the early centuries of the first millennium AD which they ascribed to an influx of pastoralists (i.e. a population replacement): deflation hollows and the large coastal 'megamiddens' were abandoned in favour of inland rock shelters. Whether this shift can still be proved is uncertain, with many new coastal sites being found to date within the last 2000, and particularly 1000, years (Jerardino et al. 2009a: table 2). It seems possible that hunter-gatherers showed renewed interest in coastal areas, but used them only for very short stays. With the relatively limited research undertaken to date in Namaqualand, and particularly its interior Sandveld, it has not yet been possible to consider settlement changes there. One can note, however, that at least some sites dating throughout the last 5500 years are present along the coastline (Dewar 2008).

In terms of lithics, Parkington's (1984) population replacement and A. Smith's migration (2006a) find little support; perhaps most convincing is the observation that late assemblages from the Western Cape mountains resemble pre-pottery assemblages, but 
with increased adze frequencies (e.g. Mazel 1978; Orton \& Mackay 2008; Parkington 1980). However, a wide variety of sites across western southern Africa seem to indicate cultural continuity in their stone artefact assemblages both around 2000 years ago and at whatever point in their sequences sheep and pottery appeared (Table 2.4). Interestingly, the same situation pertains in East Africa (Bower 1991:74 and references therein). It should be noted that Smith and Jacobson (1995:11) explained the continuity at Geduld, in Namibia, as being due to occupation of the site not by pastoralists but by "huntergatherers on the periphery of a pastoralist society". Whether all sites could be viewed this way seems doubtful. One site where the researchers were confident of the appearance of herding is Spoeg River Cave. There, a lack of retouched scrapers during the pottery-period was taken to signify one of two things: either herders moved into the cave, or hunter-gatherers successfully made the transition to herding (Vogel et al. 1997). A third possibility, surely, would have people simply using the cave in different ways? Interestingly, in northern Namibia, Vogelsang et al. (2002) have identified contrasting and co-existing lithic industries, both associated with pottery ${ }^{10}$. One they describe as "a continuation of the LSA tradition with ... a few small microliths" and the other as "an indifferent unstandardised stone artefact industry with nearly no retouched tools" (Vogelsang et al. 2002:120). The latter, they speculate, may represent the 'donor pastoral society'.

Table 2.4: Comments relevant to the introduction of sheep and pottery to southern African sites.

\begin{tabular}{lll}
\hline Area (Site) & Comments & References \\
\hline \multirow{2}{*}{ Namibia (many) } & $\begin{array}{l}\text { Less change co-incident with first sheep and pottery } \\
\text { than } 1000 \text { years ago. }\end{array}$ & J. Kinahan 1984, \\
& "A continuation of the cultural tradition across the & Smith \& Jacobson \\
Namibia (Geduld) & ceramic threshold". & $1995: 11$
\end{tabular}

\footnotetext{
${ }^{10}$ Although Vogelsang et al.'s (2002) preliminary assessment claimed that domesticates were present, Joris Peters (pers. comm. 2012) has confirmed that he has made no positive identifications in his subsequent detailed study.
} 


\begin{tabular}{|c|c|c|}
\hline Area (Site) & Comments & References \\
\hline $\begin{array}{l}\text { Namibia: Hungorob } \\
\text { Ravine (many) }\end{array}$ & $\begin{array}{l}\text { "A single, evolving technological tradition, rather than } \\
\text { the replacement of one tradition by another". }\end{array}$ & $\begin{array}{l}\text { J. Kinahan } \\
2001: 34\end{array}$ \\
\hline $\begin{array}{l}\text { Namibia (Big } \\
\text { Elephant Shelter) }\end{array}$ & $\begin{array}{l}\text { "Lithic and non-lithic artefacts ... (suggest occupation) } \\
\text {... by a stable population group and that the } \\
\text { introduction of pottery and possibly domestic animals } \\
\text {... neither caused the displacement of the population } \\
\text { nor radically affected their conservative implement- } \\
\text { making traditions". Minor differences reflect "a shift } \\
\text { rather than a change in the norms of artefact } \\
\text { manufacture". }\end{array}$ & Wadley 1979:52 \\
\hline Namibia: Kaokoland & $\begin{array}{l}\text { "A continuance of cultural traditions with the advent of } \\
\text { domestic animals and pottery" }\end{array}$ & $\begin{array}{l}\text { Vogelsang et al. } \\
2002: 121\end{array}$ \\
\hline $\begin{array}{l}\text { Northern Cape } \\
\text { interior (many) }\end{array}$ & No lithic change with the introduction of pottery. & $\begin{array}{l}\text { Humphreys and } \\
\text { Thackeray } 1983\end{array}$ \\
\hline $\begin{array}{l}\text { Northern Cape } \\
\text { coast: Namaqualand } \\
\text { (many) }\end{array}$ & $\begin{array}{l}\text { "A continuous evolution of the Holocene microlithic } \\
\text { cultural sequence ... with no indication of abrupt } \\
\text { changes". }\end{array}$ & Dewar 2008:160 \\
\hline Elands Bay (many), & $\begin{array}{l}\text { Less change co-incident with first sheep and pottery } \\
\text { than } 1000 \text { years ago. }\end{array}$ & Orton 2006 \\
\hline $\begin{array}{l}\text { Elands Bay } \\
\text { (Tortoise Cave) }\end{array}$ & $\begin{array}{l}\text { Artefacts display gradual de-formalisation, more likely } \\
\text { exacerbated by introduction of herding than caused } \\
\text { by it. }\end{array}$ & Robey 1987 \\
\hline $\begin{array}{l}\text { Vredenburg } \\
\text { Peninsula (many) }\end{array}$ & $\begin{array}{l}\text { Less change co-incident with first sheep and pottery } \\
\text { than } 1000 \text { years ago. }\end{array}$ & Sadr et al. 2003 \\
\hline $\begin{array}{l}\text { Vredenburg } \\
\text { Peninsula (many) }\end{array}$ & $\begin{array}{l}\text { *Non 'Kasteelberg-type' sites indicate "cultural } \\
\text { continuity before and after the introduction of } \\
\text { domestic stock and pottery". }\end{array}$ & $\begin{array}{l}\text { A. Smith } \\
\text { 1998a:154 }\end{array}$ \\
\hline $\begin{array}{l}\text { Southern Cape } \\
\text { (Boomplaas) }\end{array}$ & $\begin{array}{l}\text { "No apparent change in the nature of the stone tool } \\
\text { industry in ... (the herder) ... units as compared with } \\
\text { the immediately pre-herder levels and this suggests a } \\
\text { measure of continuity in the stone artefact tradition". }\end{array}$ & $\begin{array}{l}\text { H. Deacon et al. } \\
\text { 1978:57 }\end{array}$ \\
\hline $\begin{array}{l}\text { Southern Cape } \\
\text { (Noetzie Midden) }\end{array}$ & $\begin{array}{l}\text { Continuity in stone material and artefacts through last } \\
3000 \text { years. }\end{array}$ & $\begin{array}{l}\text { Halkett \& Orton } \\
2009\end{array}$ \\
\hline $\begin{array}{l}\text { Eastern Cape } \\
\text { (many) }\end{array}$ & $\begin{array}{l}\text { Striking change in coastal middens from c. second } \\
\text { century AD but reflects changes elsewhere more than } \\
1000 \text { years earlier. }\end{array}$ & $\begin{array}{l}\text { Binneman 1995; } \\
\text { H. Deacon 1976; } \\
\text { Robertshaw } 1984\end{array}$ \\
\hline
\end{tabular}


In summarising the then available southern African evidence, J. Deacon (1984a:269) suggested that "the overall impression is that pottery and domestic stock were added to the pre-existing Stone Age tradition and that there is continuity in the stone tools made in each region". It seems, then, that the South African lithic evidence clearly does not point to an abrupt early first millennium $A D$ cultural change as would be associated with a population replacement. Rather, it points to gradual change which may have been accelerated by the introduction of sheep and pottery but not directly caused by it.

Turning now to ostrich eggshell beads, few bead size sequences from the western part of the subcontinent have been published and the lack of deep deposits compounds this problem. However, a few observations are available. At both Spoeg River Cave (Webley 2002: table 12) and Geduld (Yates 1995) there seems to be a relatively gradual increase in bead size with time, something that does not support a population replacement, while in Dewar's (2008) open sites larger beads (>6 mm external diameter) only appear in conjunction with small beads around AD 1300 after an apparent occupational hiatus in the area. Yates et al. (1994) summarise the south-western Cape sequence: from c. 4800 $\mathrm{BC}$ to $c . \mathrm{AD} 50$ there was relative stability in bead size with mean bead diameters being 4.5-4.7 mm. From c. AD 300-500 small beads continued to dominate the assemblages but larger beads were being added. About AD 650-1000 still larger beads were added. The effect was more pronounced at the coast with inland assemblages then averaging around $5 \mathrm{~mm}$ and coastal ones up to $7 \mathrm{~mm}$. Significant numbers of larger beads only appeared inland after 1100 AD. There are clearly too few observations to enable further interpretation.

A completely different take on the nature of pastoralism has been offered by Yellen (1984) and Elphick (1985). They described a cyclical model in which one cultural group of people could present as hunter-gatherers or herders depending on where they were in the cycle. During times of plenty when they had stock they would be herders. However, if 
they lost their stock, perhaps through drought, theft or disease, they would simply revert to hunting and gathering until such time as they were able to acquire new stock and become herders again. Elphick (1985) also notes that the herder economy would still have been based on hunting and gathering (as described above). This model suggests a fluid relationship between the two economies and, while based on historical observations, there seems little reason why it could not have operated during prehistory as well. It offers no contribution to the debate on the nature of the introductions though.

As is evident from this brief review, there is still plenty of room for debate with the need for more dates, particularly directly dated domesticates, perhaps being the most debilitating factor in the refinement of these issues.

\subsection{Sheep, goats, dogs and cattle: a pastoralist package?}

Sheep and cattle have been discussed above but goats and dogs were also documented historically as being owned by the Khoekhoen. Recent direct dates on domestic bones (Henshilwood 1996; Orton et al. in press; Sealy \& Yates 1996) suggest that cattle and sheep (assuming the identification to be correct) had both arrived by the mid-first millennium $A D$ but no very early dates are yet associated with either goats or dogs.

Goats are little mentioned in studies of herders in the South African LSA. This is no doubt due to the great difficulty in distinguishing them from sheep, the only reliable means being through their horncores (Klein 1984), certain teeth (Zeder \& Pilaar 2010) or by DNA analysis (Badenhorst 2006). Badenhorst (2006) considers that the emphasis placed on sheep and cattle may have obscured the role goats might have played in prehistoric herding societies. He suggests that since goats are more intelligent than sheep (Dahl \& Hjört 1976), small numbers of them may have been used by the 
Khoekhoen to assist in herding of sheep but that keeping goat numbers deliberately low will have resulted in their reduced archaeological visibility. Based on the lack of secure identifications though, Klein (1986) considers goats to have been rare or absent in prehistoric contexts in the south and south-western parts of South Africa but postulates that they might have been more common in the northwest. Modern subsistence pastoralists in central Namaqualand focus on goats but the ratios of stock types have changed considerably over time (Table 2.5 , see also Webley 1982: table 1). Interestingly, this increase in small stock is perhaps implicit in Stow's (1905) observation that during the course of the eighteenth century the Namaqua had dwindled in number and lost their great herds of cattle. Badenhorst's $(2002,2006)$ reviews suggest that archaeological evidence for goats in the southern African LSA is scant but that they were present in Iron Age communities from about the fourth century AD. Mitchell (2004b) sees these communities as a source for goats in the LSA. Historical accounts are conflicting. Kimble (1937 in Seddon \& Vinnicombe 1967) suggests that sheep, cattle and goats were present in the south-western and southern Cape before AD 1508, while others disagree. Schweitzer (1974) uses the lack of mention of goats in the late fifteenth century historical literature - where large, hairy, fat-tailed sheep were noted - to support their absence among his Die Kelders fauna, and Schapera and Farrington ${ }^{11}$ (1933) note that the goat brought to Van Riebeeck by the Namaqua in 1661 was the first he had seen at the Cape, implying that they were not owned by the local Cape Khoekhoen at that time.

Table 2.5: Ratios of livestock over time. 2002 data calculated from Samuels et al. (2008: table 1), 1865 data calculated from Hoffman \& Rohde (2007), 1661 data calculated from Penn (1995).

\begin{tabular}{lccc}
\hline & 2002 & 1865 & 1661 \\
\hline cattle & 1 & 1 & 1 \\
sheep & 20.27 & 5.35 & 0.75 \\
goats & 49.87 & 3.53 & $?$ \\
\hline
\end{tabular}

\footnotetext{
${ }^{11}$ Described in the notes to Schapera's translation of Dapper.
} 
The bones and chew marks of dogs, virtually identical to those of jackals, are also not reliably distinguished. Furthermore, it is unlikely that dead dogs would have found their way into archaeological deposits (Maggs and Sealy 2008; Plug 1996). However, Klein and Cruz-Uribe (1989) consider the high incidence of chewing at Kasteelberg A and B and corresponding very low incidence at other local sites to support their presence at Kasteelberg. From chew marks, several sites are thought to include dogs (Cruz-Uribe \& Klein 1994; Klein \& Cruz-Uribe 1989; Voigt 1983). Mitchell (2008) notes that all these occurrences are at least possibly related to herders but notes just one site, in Lesotho, where dogs are considered present in a clear hunter-gatherer context (Hobart 2003; Plug 2003). Historical accounts report their presence among the Khoekhoen (e.g. Dapper 1668 in Schapera \& Farrington 1933), while Boonzaier et al. (1996) consider the dogowning locals met by Vasco da Gama at St Helena Bay to have been Bushmen rather than Khoekhoen. On the available evidence there seems little reason for this.

Cattle bones have occasionally been physically identified in sites dating within the last 2000 years. They too, however, are not easily separated from their wild counterpart, the Cape buffalo (Klein 1984, 1986) and most relevant bones are usually listed as 'bovine'. Horn-cores (Klein 1984) and skulls are the only reliably distinguished elements, with teeth slightly less secure (R. Klein, pers. comm. 2012). Boonzaier et al. (1996) and A. Smith (1998a) suggest that, while sheep must have moved south with the Khoekhoen, cattle might have been obtained later, perhaps around 1000 years ago, from Iron Age Bantu farmers in the Eastern Cape. Mitchell (2004b) also suggested a farmer source. This view is no longer tenable in the light of early direct dates obtained by Robbins et al. (2005) and Orton et al. (in press), the latter identification having been confirmed by aDNA studies. The variety in root words for cattle among Central Khoesan languages may support an arrival independent of sheep (Vossen 1996 in Blench 2006). Blench (2006) takes this to mean that the Khoekhoen had sheep but not cattle at the time of their first expansion, although evidence from Toteng might argue otherwise. There, 
Robbins et al. (2005) suggest that similarly dated sheep and cattle remains about 2000 years ago indicate that both were present at initial expansion, but the slightly earlier sheep at Spoeg River Cave (Sealy \& Yates 1996) and caprines from Leopard Cave (Pleurdeau et al. 2012) might undermine their claim, since the expansion must then have started earlier. In any event, these dates are far older than the earliest Iron Age settlement in eastern South Africa (M. Hall 1987; Sadr \& Sampson 2006; Sadr 2008a: figs 2-4) precluding Bantu speakers as a direct source of domestic stock in that region.

While goats are controversial and have yet to receive detailed study, it seems that sheep and cattle at least were present in the south-western Cape some 2000 years ago. Dogs may have been a very much later addition. Sheep, cattle and pottery (which was also present very early) thus probably arrived within about a century or so of one another but, given the resolution of dating, and still very small sample of early dates, we are unlikely to be able to prove their contemporaneity beyond doubt.

\subsection{Summary}

This chapter has reviewed the current state of knowledge on the archaeology of huntergatherers and herders in the western half of southern Africa. The difficulty in distinguishing the archaeological remains of each group is demonstrated, with the only extant model, established by A. Smith et al. (1991), shown to be problematic. Specifically, some sites fit the model while others do not. They proposed that huntergatherer sites would be identified by the presence of retouched stone tools and Donax scrapers, small ostrich eggshell beads, wild fauna and minimal pottery. Herder assemblages should reflect the opposite pattern. Problems with the archaeological visibility of herder sites are highlighted, as is the possibility that researchers are not looking for herders in the right places or in the right ways (Arthur 2008). 
It seems reasonably well established that the Khoekhoen, who are traditionally associated with pottery and livestock, had their origin in the vicinity of northern Botswana and then expanded in a southerly and south-westerly direction into South Africa. The routes by which this expansion took place, however, are still debateable. Two plausible options exist involving the west coast and central interior with early directly dated stock bones perhaps favouring the western route, at least for the stock. Although A. Smith (2006a, 2008b) and others consider the expansion to have occurred as a rapid migration 2000 years ago, Sadr (2003) sees the majority of evidence pointing towards a later migration perhaps around AD 900-1200. Linguistics may suggest something similar, but as part of a more complex overall sequence of events (Güldemann 2008). Sadr (2005b:216) also proposes a state of economic flux: "intensive pastoralists became hunters-with-sheep, hunters-with-sheep went back to full time hunting and gathering, and full time hunter-gatherers elsewhere decided to give intensive animal husbandry a go, at least for a while". If Sadr is correct, then the Khoekhoen can no longer be considered together with the livestock and pottery traditionally associated with them, since sheep, cattle and pottery were clearly present in southernmost Africa some 2000 years ago. This would imply their influx via cultural rather than demic diffusion. That dogs and goats were present historically is known, but their antiquity remains unresolved.

A common thread in the migration/diffusion debate is that most of the 'evidence' relates to disproving the opposing ideas. This surely points towards the great difficulty archaeologists have had in researching these issues, perhaps largely due to the scarcity of early evidence for domesticates, pottery and, particularly, the Khoekhoen themselves. It is hoped that what follows will make a small contribution in this regard. 


\section{Chapter 3. The research area in context.}

\subsection{Geographic profile}

The geographic boundaries and ecological subdivisions of Namaqualand are variously drawn by different authors (e.g. Cowling \& Pierce 1999; Desmet 2007; Le Roux \& Schelpe 1988). Although the northern and southern limits are well accepted as being the Orange and Olifants Rivers respectively, Cowling and Pierce (1999) note that most of the boundaries are somewhat arbitrary, since patches of Namaqualand-type flora occur on granite hills in Bushmanland to the east and in dry areas of the Cape region to the south. Following these authors, Namaqualand can be divided into five zones based on landscape features and climate: the Richtersveld, Sandveld, Hardeveld, Kamiesberg and Knersvlakte (Figure 3.1). They all fall within the Succulent Karoo Biome, "a semidesert region with a strong maritime influence characterized by an even, mild climate" (Mucina et al. 2006b:223). For easier reference, I further subdivide the Sandveld into the northern, central and southern zones in which archaeological work has been carried out. These are conveniently separated by the $30^{\circ} \mathrm{S}$ and $31^{\circ} \mathrm{S}$ parallels (Figure 3.1).

I now describe the five geographic zones in turn, based primarily on Cowling and Pierce (1999), but supplemented by many of my own observations. Specific landscape features described are not necessarily ubiquitous but are present within areas I have visited.

The westernmost strip, within $20-30 \mathrm{~km}$ of the coast, is the Sandveld, a region with much variability. In the northern and central parts one finds extensive coastal dune fields (Figure 3.2), some still fully active and receiving their sand supply from the variably sized pocket beaches dotting the rocky coastline. Just north of the Buffels River, the palaeomarine terrace is particularly prominent $3-8 \mathrm{~km}$ inland with several large pans on the 
plain to its west. In places, dune fields also occur further inland. These are generally less mobile and better vegetated than those at the coast but occasional deflation hollows are found.

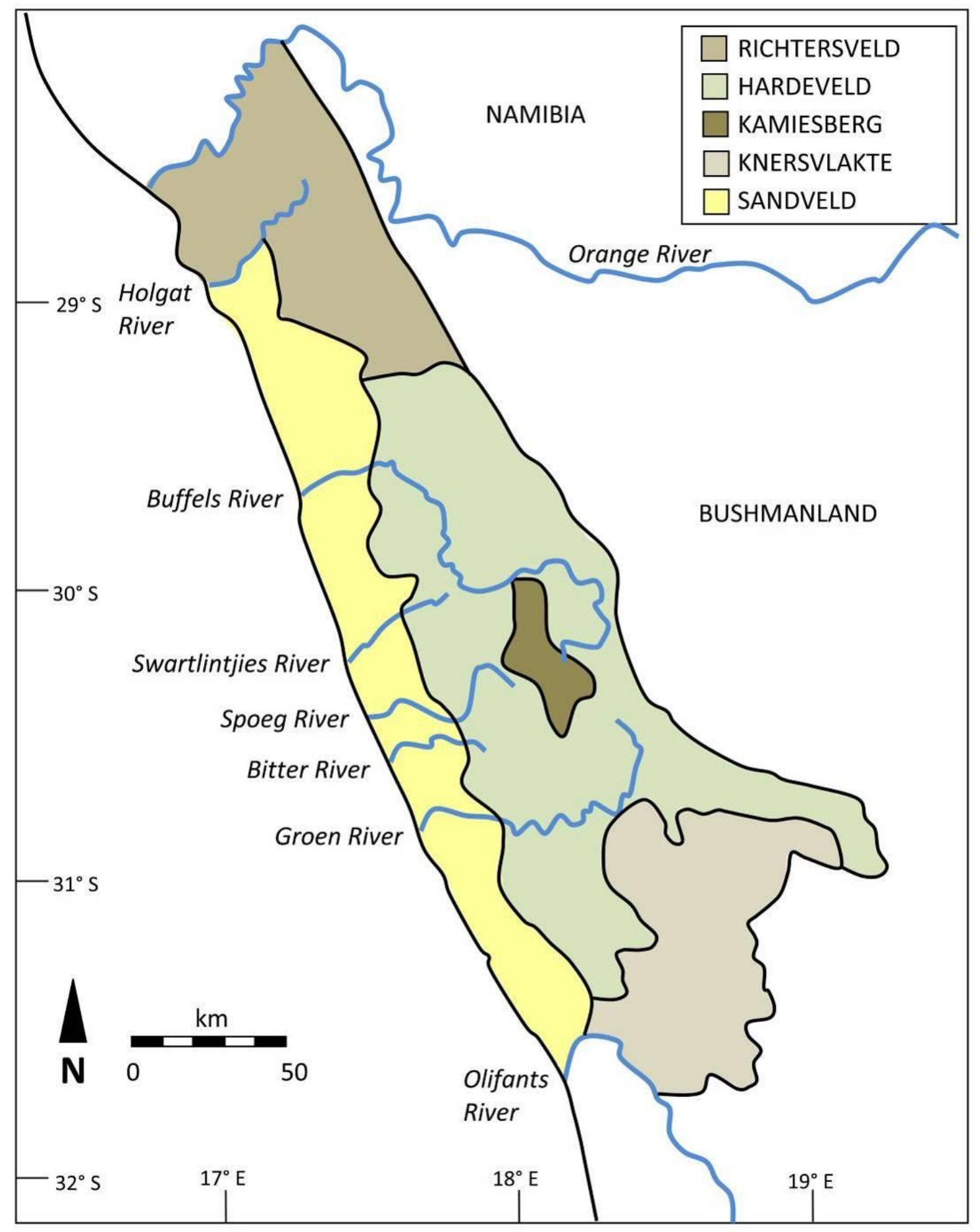

Figure 3.1: Map showing the subdivisions of the study area (after Cowling \& Pierce 1999). 


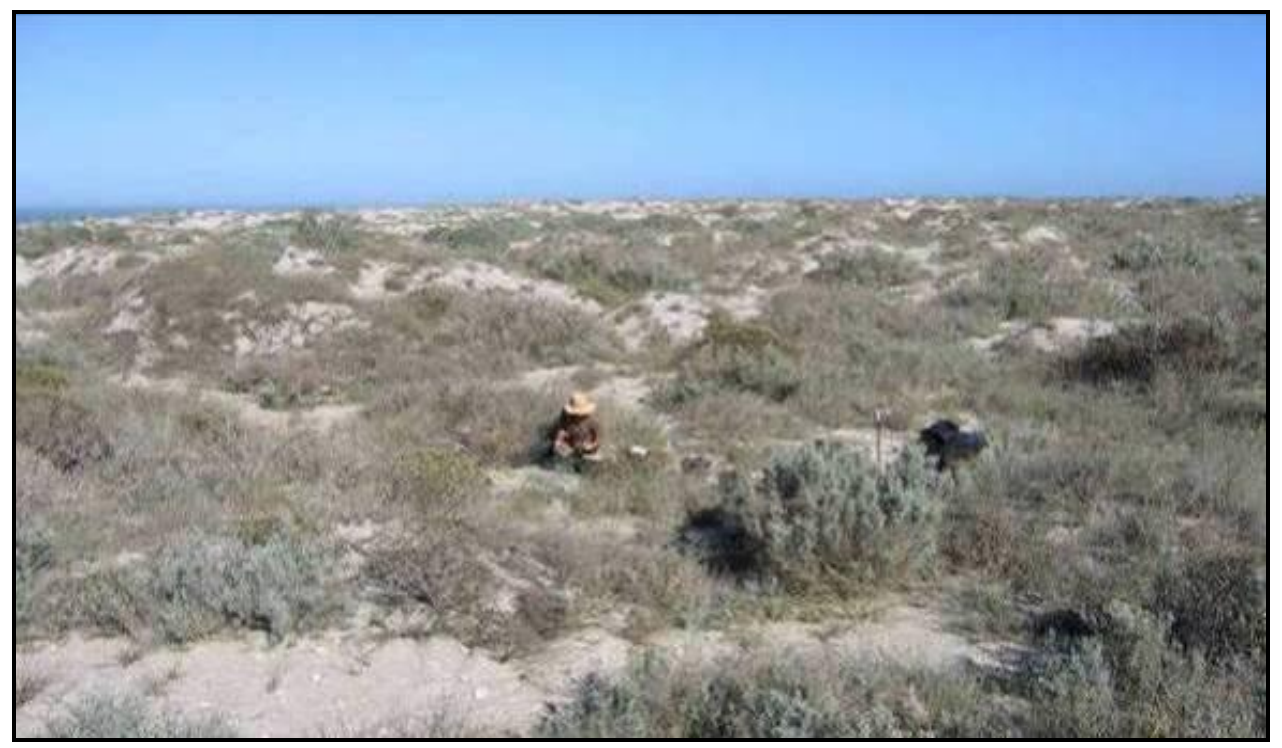

Figure 3.2: Coastal dune fields in the northern Sandveld.

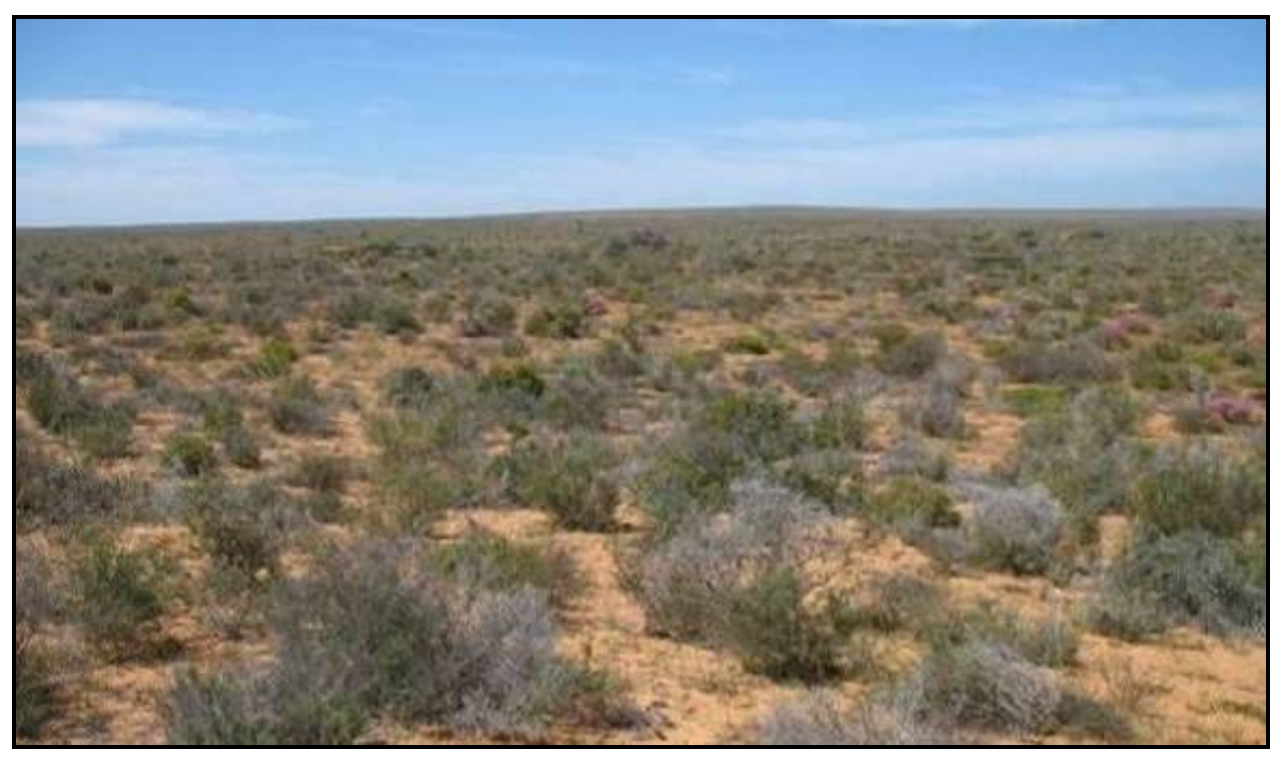

Figure 3.3: Gently undulating red sands in the southern interior.

In southern Namaqualand the coastline is far steeper with rocky cliffs in places. A high coastal ridge separates the sea from the gently undulating plains to the east (Figure 3.3).Vegetation is denser than it is to the north, but occasional deflation hollows occur on dune tops and a few pans have eroded down to the surface of the hardpan layer that underlies the area. These pans currently hold water during the winter rainy season. All the Sandveld dune fields are likely to have been less vegetated and far more mobile during the warmer and drier mid-Holocene than they are today (Chase 2005). 
Annual rainfall in the Sandveld varies from about $150 \mathrm{~mm}$ in the south to $<100 \mathrm{~mm}$ in the north, but the frequent coastal fogs provide much moisture to the vegetation. In the Richtersveld, coastal rainfall is $<50 \mathrm{~mm}$ (Cowling \& Pierce 1999). Fog is a more reliable water source than rainfall (Desmet \& Cowling 1999) but heavy dewfalls, especially in spring and autumn, provide additional moisture. Several rivers cross the Sandveld and, although some have permanent water in their estuaries, they usually only flow in response to heavy inland rains. The rivers, from north to south, are the Holgat, Buffels, Swartlijntjies, Spoeg, Bitter, Groen and Olifants - the first and last being the northern and southern boundaries of the Sandveld respectively. The Olifants, which has its catchment in the mountains to the south, is perennial and has a large open estuary. Two vegetation types occur in this zone: Strandveld on sands of marine origin and Sandveld Fynbos on sands of fluvial origin (Cowling \& Pierce 1999). Along the coast the Strandveld is dominated by low grasses and bushes, stunted by the prevailing southerly winds that blow for much of the year. In the north, occasional clumps of higher vegetation do occur in places, mainly in the sheltered hollows among hummock dunes, while in the south, owing to increased moisture, the high coastal ridge has markedly higher and denser vegetation cover than further inland. Vegetation in the interior Sandveld is variable, depending primarily on the depth of the soil which frequently overlies hardpan layers, either silcrete, ferricrete or calcrete. Where fynbos extends into the Sandveld it is strongly dominated by restioids (reeds). It is in the coastal and near-coastal Sandveld that archaeological sites are most dense and where most excavation has occurred.

Inland of the Sandveld lies the Hardeveld, a zone of granite and gneiss hills and valleys from which the rivers of Namaqualand arise (Figures $3.4 \& 3.5$ ). It is in the definition of this zone that the main difference between the divisions of Cowling and Pierce (1999) and Desmet (2007) lies. The former include much of the mountainous terrain around the highest parts of the Kamiesberg, while Desmet includes only the lower hills to the south and west of the mountain massif. This very rugged mountainous landscape forms the 
western part of southern Africa's Great Escarpment and experiences rainfall of 100$300 \mathrm{~mm}$ per year. The vegetation along the base of the hills, and extending into the Sandveld in places, is known as Vygieveld and predominantly comprises very low succulents. The mountains are covered by Namaqualand Broken Veld which, due to the diverse topography, displays much variation in composition. Scattered trees are present throughout. In general, the bushes get steadily larger with altitude and in places, especially among large boulders, one finds dense thickets of trees. Surrounded by the Hardeveld and east of my study area is a small, very high-lying region, the Kamiesberg. This high mountain zone reaches more than $1700 \mathrm{~m}$ above sea level, attracts $\geq 400 \mathrm{~mm}$ of rain annually and gives rise to the rivers of the central Sandveld. Namaqualand Renosterveld and Kamiesberg Fynbos occur in this region.

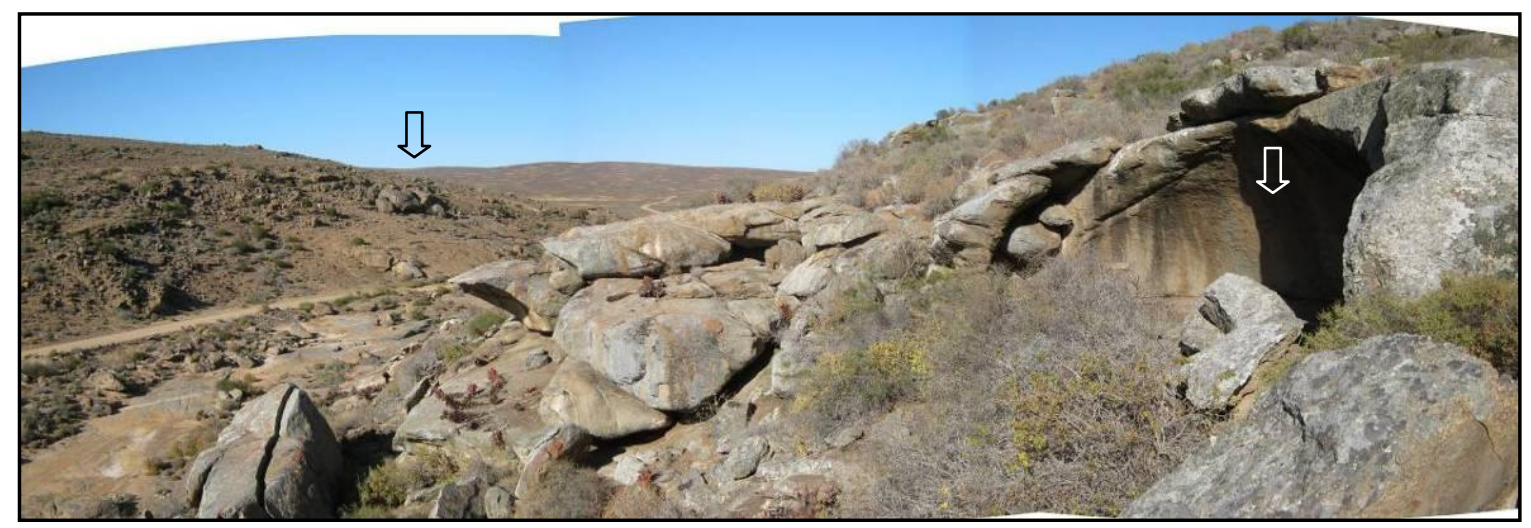

Figure 3.4: A small rocky valley in the south-western Hardeveld. Sites KK002 (white arrow) and KK003 (black arrow) are indicated.

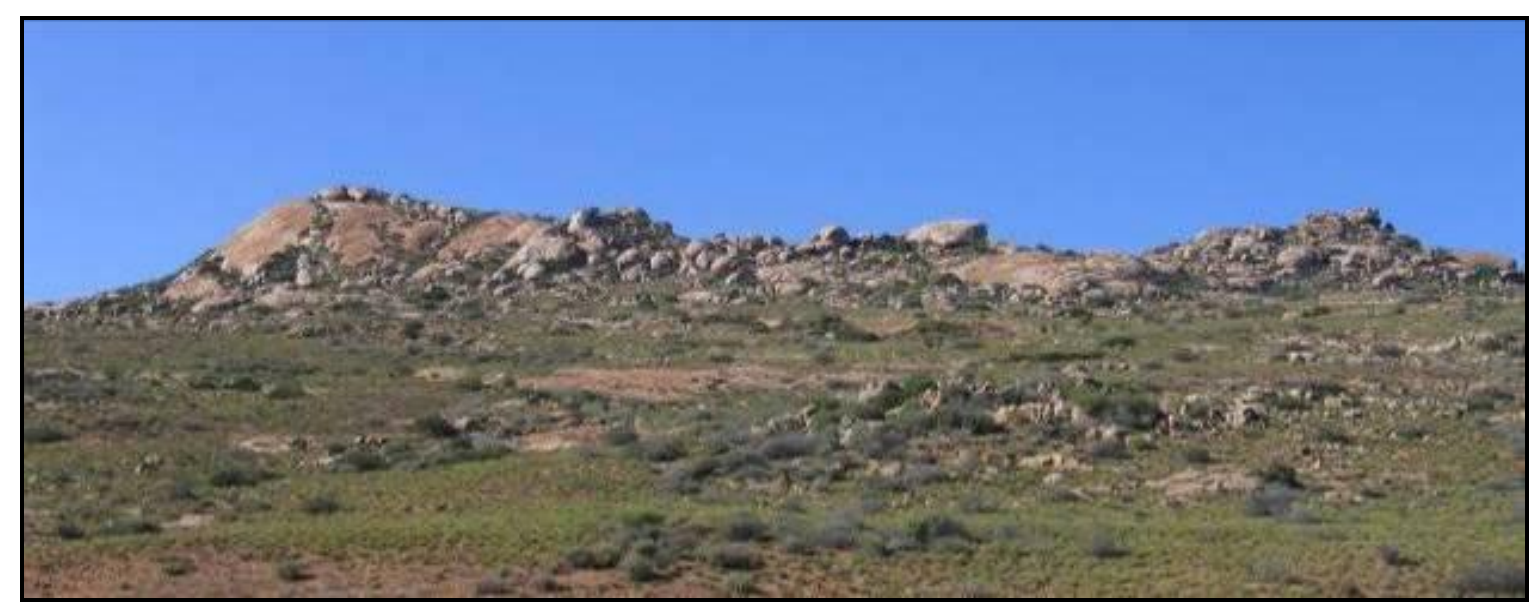

Figure 3.5: A typical winter scene in the central Hardeveld. 
To the north and south of these regions lie two vastly different but similarly desert-like areas. The Richtersveld is a rocky mountain desert and sandy coastal plain between the Orange and Holgat Rivers; the former is the only perennial river in the northern part of the study area. Rainfall is variable, with the low-lying valleys and western parts receiving only c. $50 \mathrm{~mm}$ of rain annually and the high mountains in the east $300 \mathrm{~mm}$ or more. The inland mountains are vegetated by Namaqualand Broken Veld, but the majority of the Richtersveld is Vygieveld. A strip of relatively lush riparian woodland occurs along the banks of the Orange River, however, providing the only continuous shade in the region.

The Knersvlakte contains extensive quartz gravel plains studded with a unique succulent flora - part of the Vygieveld - with sandy spinescent grasslands in places (Figure 3.6). The region receives $\leq 150 \mathrm{~mm}$ of rain annually and is cut from east to west by the Sout and Varsche Rivers, which flow only in response to heavy rains (Figure 3.7). Pools of salty water do, however, stand throughout the year at a point where a spring feeds into the Sout River. Starting quite flat in the south, the area becomes progressively hillier towards the north, eventually giving way to the hills of the Hardeveld. In the central parts an area of limestone cliffs has been carved in two by the Varsche River and rock shelters have formed (Figure 3.8). This large plain was created by the proto-Orange River and forms "a very distinct physical boundary between the sandstone and shale sedimentary rocks of the Cape Fold Mountains (Cape Floristic Region) to the south, and the predominately igneous landscape of Namaqualand to the north" (Desmet 2007:573).

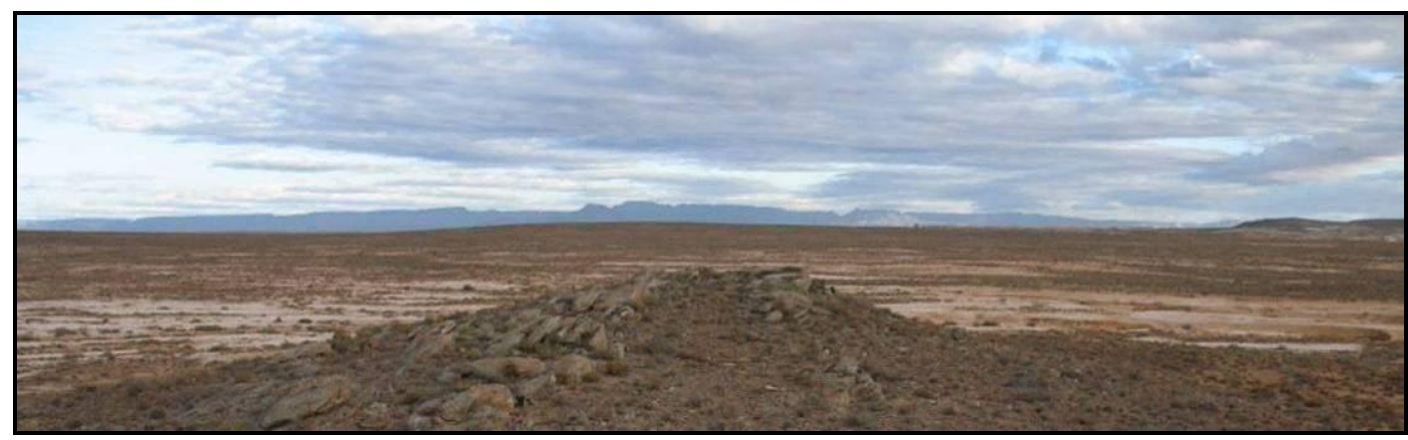

Figure 3.6: View across the open quartz gravel plains. 


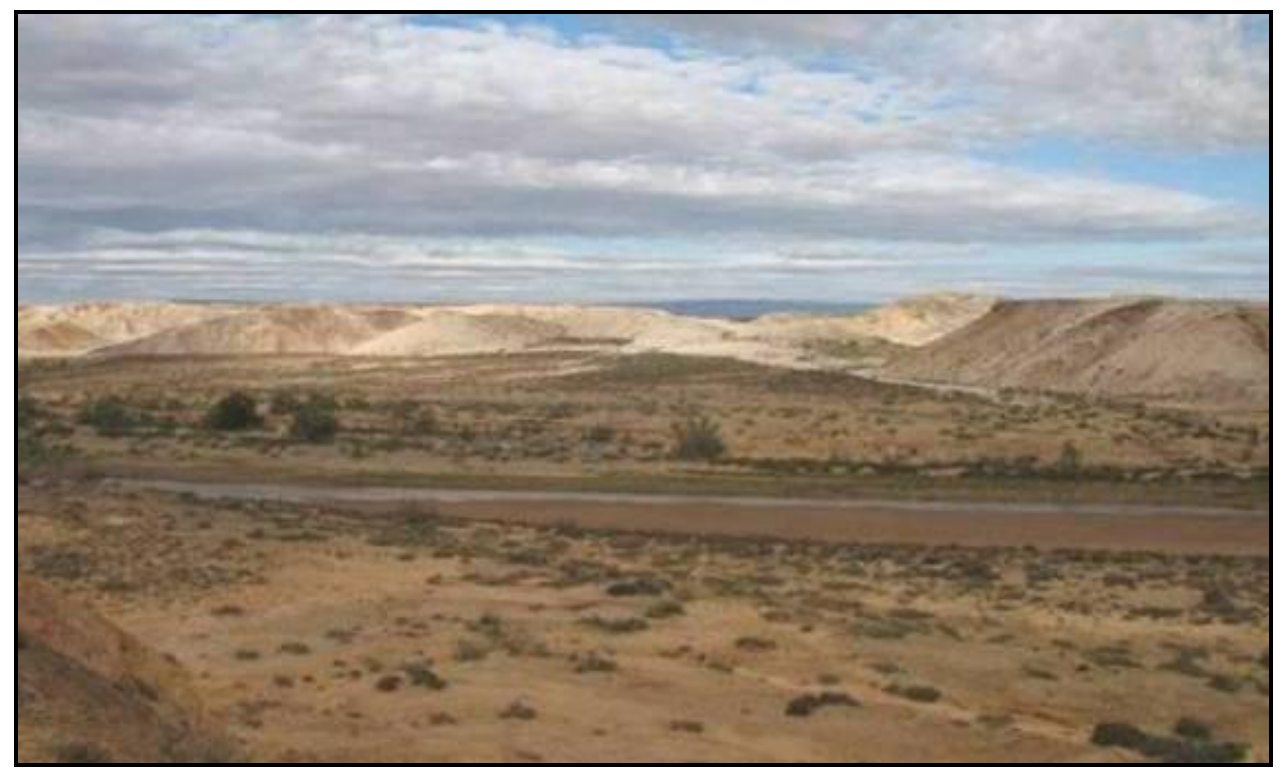

Figure 3.7: View towards the south across the Sout River showing the distinctive erosional landscape characterising the area.

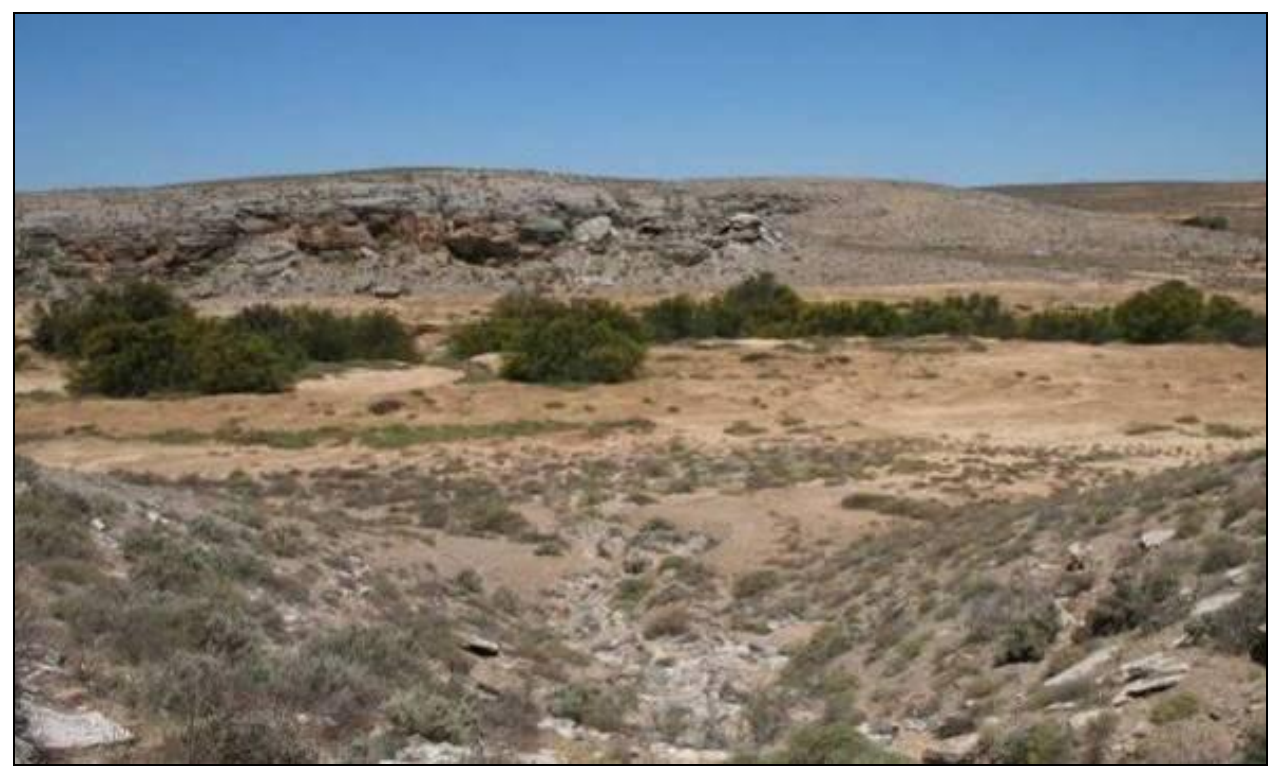

Figure 3.8: View across the Varsche River showing the limestone cliffs and riparian Acacia karoo trees.

The density of coastal archaeological sites in the immediate coastal zone of Namaqualand relates directly to the exploitation of marine resources. The Benguela Current off southern Africa's west coast feeds one of the most productive marine areas in the world (Brown et al. 1991) and "supports an important global reservoir of biodiversity and biomass of zooplankton, fish, seabirds, and marine mammals" (O'Toole et al. $2001: 230$ ). The rocks are generally clothed in a multitude of shellfish which proved a 
ready food supply to the prehistoric population (Figure 3.9). This richness is a direct result of the cold water upwelling that occurs along the coast. The vast majority of the Namaqualand coastline is rocky (Figure 3.10), with sandy beaches generally limited to relatively small embayments formed either by current river mouths or the intersection of palaeoriver channels with the coast. It is these sandy beaches that act as the initiation points for the Holocene dune fields extending northwards into the coastal plain in several areas.

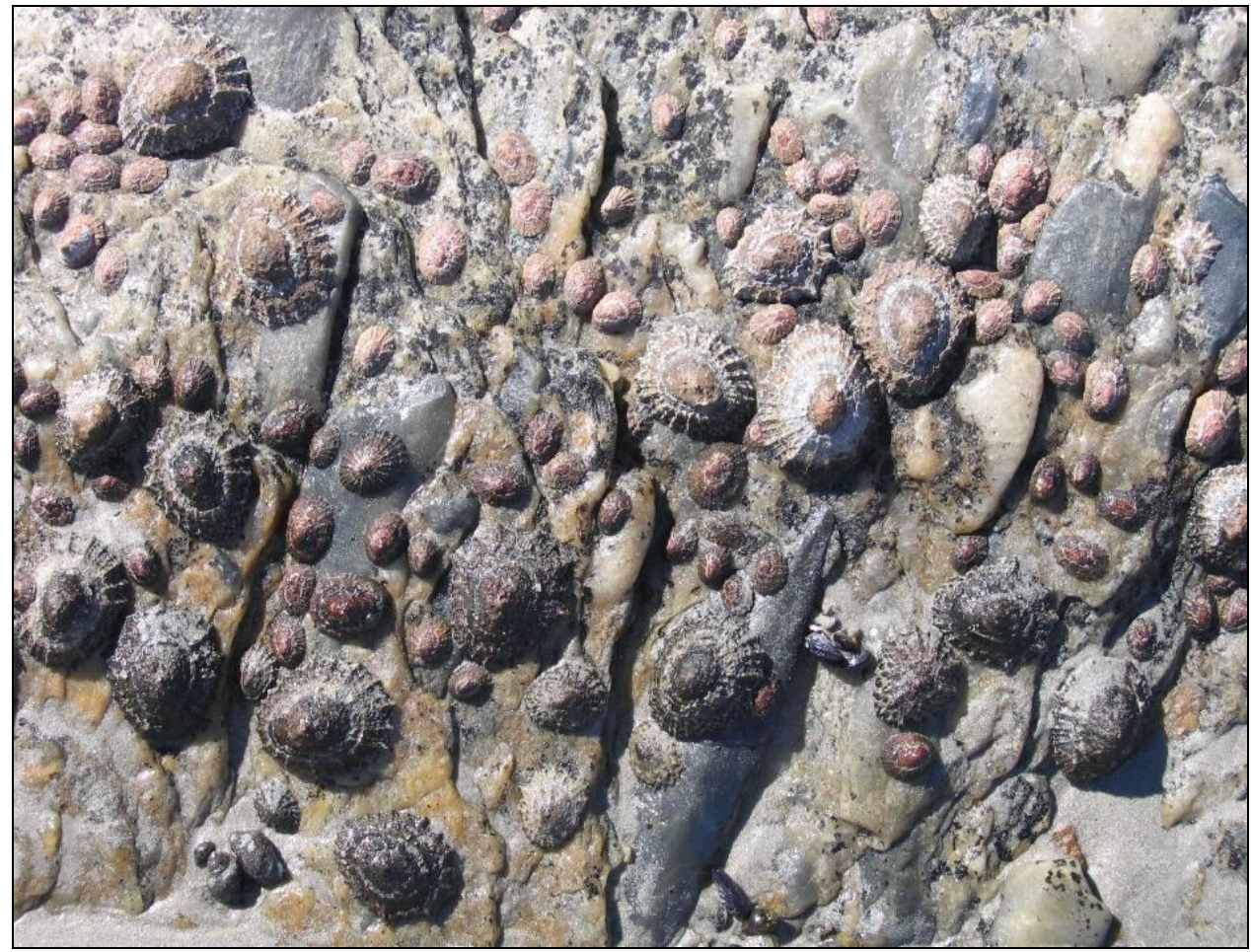

Figure 3.9: $S$. granularis and $C$. granatina limpets on the rocks at Kleinzee.

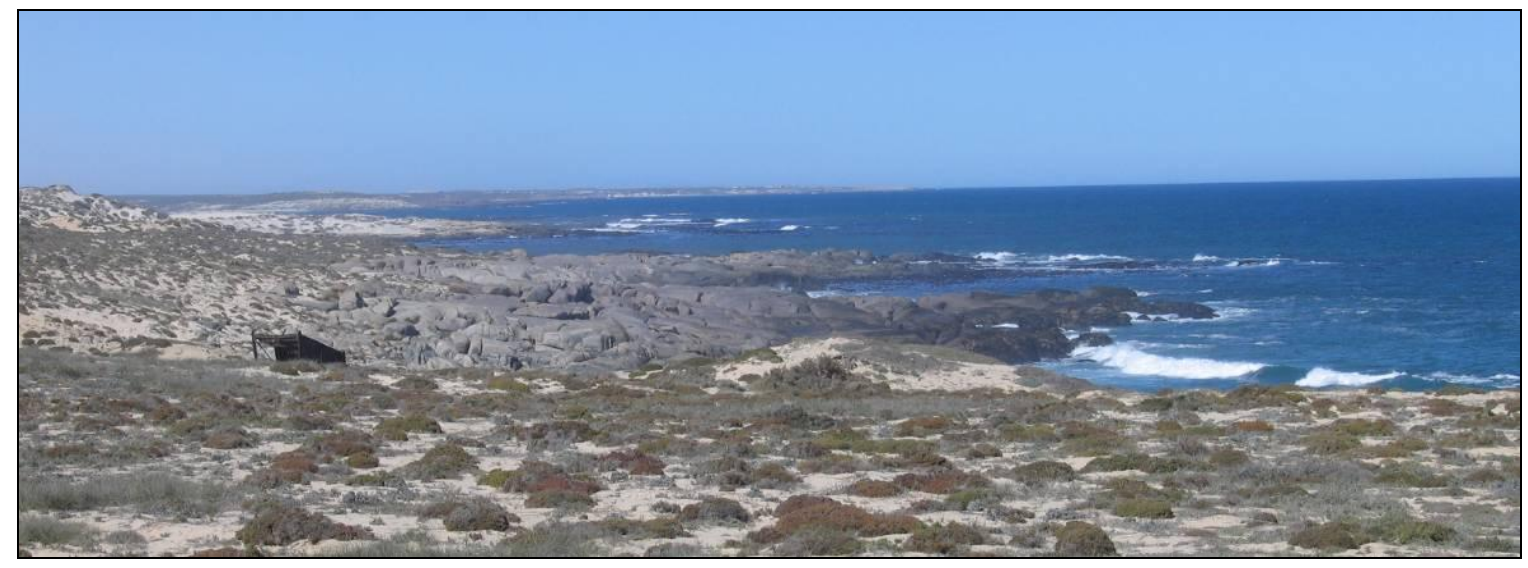

Figure 3.10: View southwards along the rocky shore at Koingnaas. 


\subsection{Geology}

A good technical overview of the local geology is given by Cornell et al. (2006) and Roberts et al. (2006) and here I only summarise the relevant features.

The rocks of Namaqualand are part of the Namaqua-Natal Province of igneous and metamorphic rocks (Cornell et al. 2006). They form the belt of hills and mountains along the Great Escarpment some 30 to $90 \mathrm{~km}$ from the coast. Within this belt the high granite mountains of the Kamiesberg are formed by a massive igneous intrusion surrounded by variously metamorphosed and weathered granite gneisses, the latter visible at the surface today. These result in many exfoliating dome-shaped hills, large valleys and abundant spheroidal boulders (Norman \& Whitfield 2006). Quartzites are also present in places (Martin 1965; Truswell 1970). The usually flat-bottomed valleys are filled with shallow, base-rich to calcareous soils with hardpans not far below the surface (Mucina et al. 2006b). The mountains of the Richtersveld region are mostly of metamorphic rocks but include quartzite, granite, gneiss, schist, dolomite, tillite, limestone and others (Martin 1965; Truswell 1970). Along the Orange River are several large palaeo-terraces composed of cobbles and pebbles of a wide variety of rock types brought from the interior. Quartz seams occur throughout the region.

Seaward of the mountains, where most of my research lies, much of the coastal plain is mantled by sandy and sometimes calcareous soils (Mucina et al. 2006b). These aeolian sediments include the middle to late Pleistocene aeolianite cliffs of southern Namaqualand, just north of the Olifants River mouth (Roberts 1999, cited in Roberts et al. 2006), as well as reddish mobile aeolian sand that probably derives from older dunes. Nearer the sea, white to grey unconsolidated dune plumes extend northwards from the many sandy bays that dot the coast (Roberts et al. 2006). The majority of the Sandveld is stable with less than $10 \%$ of the surface being mobile under the current wind regime, and 
that often due to modern disturbance (Harmse 1988). The sands of the Sandveld and Hardeveld are underlain by silica- and calcium-rich hardpans - silcrete and calcrete. The younger, whiter sand (less than 100,000 years old) tends to overlie only calcrete, while beneath the older red sand (c. 2 million years old) lies silcrete, which in turn overlies calcrete (Desmet 2007). The sand can be up to several metres thick, although in some areas the hardpans are exposed by the wind. In the coastal region calcrete is frequently visible in mine trenches one to two metres below the surface and is even exposed at the surface in places, while further inland Chase (2005) recorded hardpans at variable depths of up to several metres. Inland, coppice dunes up to $70 \mathrm{~m}$ long, $40 \mathrm{~m}$ wide and 8 $\mathrm{m}$ high occur but longitudinal dunes up to $2 \mathrm{~km}$ long, $50 \mathrm{~m}$ wide and $15 \mathrm{~m}$ high are also present. Near the coast are smaller parabolic and transverse dunes (Harmse 1988). Gneiss extends beneath the coastal plain to be exposed along the coastline and in the central Sandveld river valleys (Truswell 1970).

Just north of Kleinzee, the wide, wave-cut marine terrace is capped by silcrete (Roberts et al. 2006). This terrace forms one of the few major landscape features in the central and northern coastal region along with several shallow river valleys and low hills.

Similar to valleys further north, the Knersvlakte in the south is also mantled by base-rich to calcareous soils overlying hardpans (Mucina et al. 2006b). Unique to the Knersvlakte, though, are limestone beds that have been largely recrystallised to marble (Martin 1965; Norman \& Whitfield 2006), one being that through which the Varsche River flows. Although largely covered by sand, the palaeo-terraces of the Varsche and Sout Rivers include cobbles of various rocks and both channels display occasional gravel patches, remnants of the palaeo-Orange River which once flowed through the area (De Wit 1999). 


\subsection{Sea levels}

While much research has been conducted on sea levels globally, I focus here on the local southern African evidence, much of it from Elands Bay some $100 \mathrm{~km}$ south of southern Namaqualand (Figure 3.11). Last Glacial Maximum sea levels are widely accepted to have been some 120-130 m lower than the present level. Miller (1990) postulates a fairly rapid rise in sea level until the early Holocene, although it was probably slightly slower during the last few millennia of the Pleistocene. Baxter and Meadows (1999) suggest that a transgression may have occurred c. 8000 BP followed by a 3-4 $\mathrm{m}$ drop and a recovery about $6000 \mathrm{BP}$. Changing sea levels during the Holocene are widely documented but little parity exists between researchers. While most agree that the post-LGM rising sea level stabilised by about 6000 years ago, the magnitude and timing of smaller variations after this time are more contentious.

It is likely that sea levels were elevated by up to 2 to $3 \mathrm{~m}$ during the mid-Holocene (Baxter \& Meadows 1999; Miller 1990; Miller et al. 1993), although the timing of the peaks differs among authors. Studies at Saldanha Bay support a first transgression of modern sea level about 7000 years ago (Compton 2001; Flemming 1977; Tankard 1976) and, in agreement, Compton (2006) found that sea levels in southern Namibia were some $3 \mathrm{~m}$ higher between 7300 and 6500 years ago but then dropped and remained low until about 4900 years ago. In contrast, at Dunefield Midden 1 near Elands Bay, Orton and Compton (2006) found evidence for human occupation c. $4800 \mathrm{BC}$ in an area that was shown to have been a beach environment (if not consistently, then at least sporadically) during the last 3000 years (Miller et al. 1993; Orton \& Compton 2006), while Baxter (1997) saw a rapid rise to just below modern levels about 8000 years ago followed by a regression of some 3 to $4 \mathrm{~m}$ before again rising to the well-documented mid-Holocene high. Meadows and Baxter (2001), on the other hand, proposed two 
periods of raised sea levels between about $5070 \mathrm{BC}$ and $1750 \mathrm{BC}$ from sediment cores along Verlorenvlei.

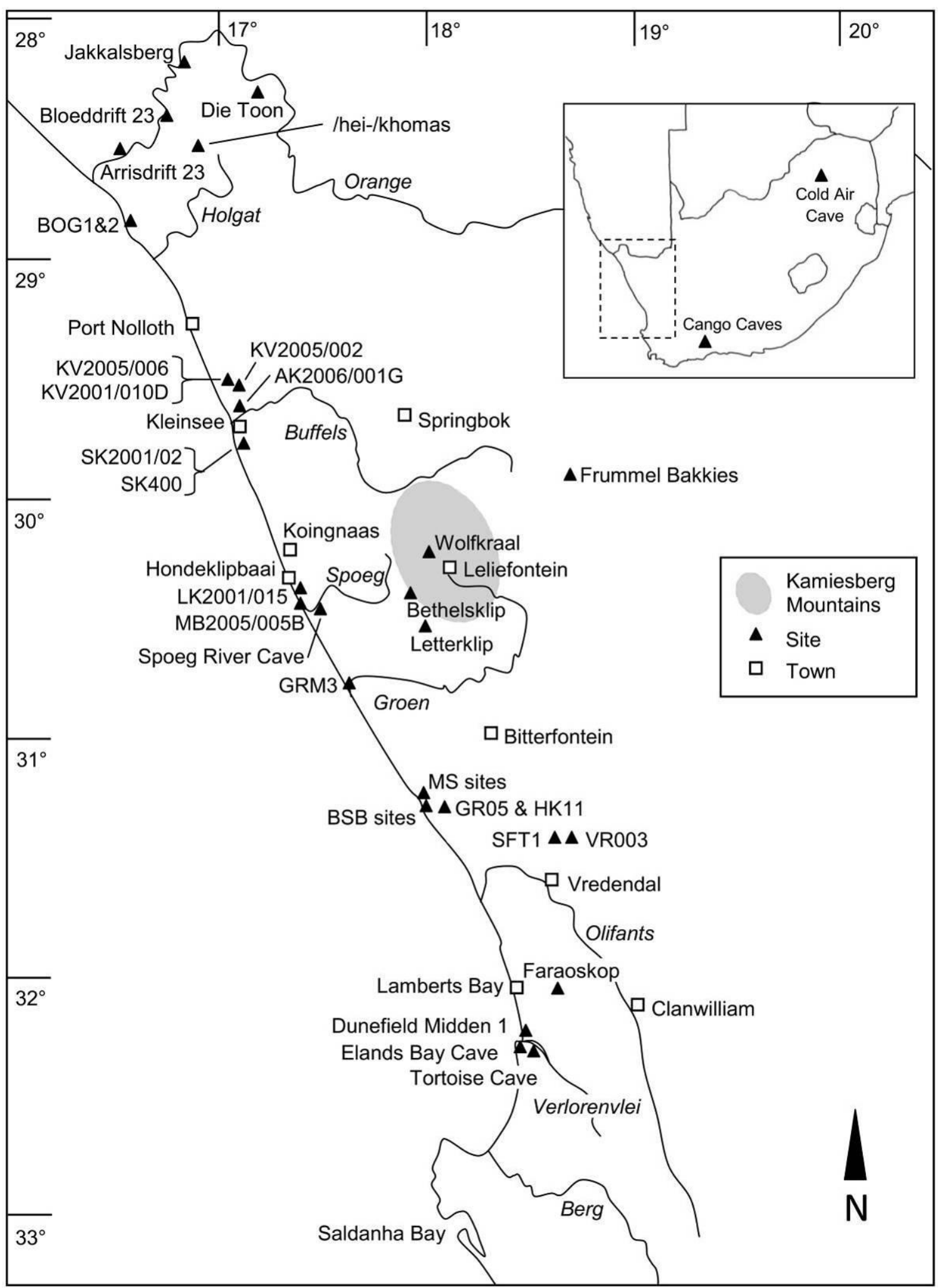

Figure 3.11: Map showing places and archaeological sites mentioned in Chapter 3. 
Further evidence for a mid-Holocene high stand comes from sediment cores from the upper reaches of the Verlorenvlei; an estuarine environment is suggested there between about 3700 and 2900 BC (Meadows et al. 1996). This situation may also have prevailed in Namaqualand estuaries such as the Spoeg River, although an early date of around 3650 BC (Dewar 2008) from MB2005/005B on its barrier dune cordon suggests a more complicated/ambiguous picture. This observation compliments Compton's (2006) finding that sea levels were lowered at that time and then probably never more than about $1 \mathrm{~m}$ above modern levels within the last 4200 years. At Elands Bay, Tortoise Cave contains estuarine shellfish at c. 2900 BC (Jerardino 1993) indicating raised sea levels, and $c$. 2500 BC sea levels were probably about $2 \mathrm{~m}$ higher than present (Baxter 1997; Jerardino 1993, 1996; Yates et al. 1986). After this time the Western Cape is thought to have experienced several minor sea level adjustments but with none greater than about $1 \mathrm{~m}$ above or below the present mean (Compton 2001; Compton \& Franceschini 2005; Jerardino 1996). Tortoise Cave shows minimal estuarine shell availability c. AD 250 but none after that (Jerardino 1993).

Unlike shores south of the Olifants River, the Namaqualand coastline is mostly rocky and quite steep. As such, changing Holocene sea levels are unlikely to have had much effect on the archaeology behind the rocky shores during this period, with higher seas probably just pushing back the line of coastal dunes and prompting settlement slightly further inland. Higher sea levels might have resulted in some of the river estuaries becoming open to the sea which would have changed the fish species available (see Poggenpoel 1987), but with no studies of archaeological fish assemblages yet conducted in Namaqualand this remains unknown. 


\subsection{Climate}

\subsubsection{General observations}

Following the Köppen-Geiger climate classification that considers temperature and rainfall, Namaqualand is a cold desert (Peel et al. 2007) with mean maximum summer temperatures of less than $30^{\circ} \mathrm{C}$ (Desmet 2007). Ironically, the warmest days at the coast $\left(>35^{\circ} \mathrm{C}\right)$ are recorded in winter during berg wind conditions when hot, dry air moves coastward from the interior plateau (Desmet 2007). These winds are most frequent in winter and early spring (Desmet \& Cowling 1999). The Succulent Karoo biome as a whole has a mean annual temperature of $16.8^{\circ} \mathrm{C}$ (Mucina et al. 2006b). The berg winds temper the cold winters, while the cold ocean and fog help reduce summer temperatures, especially near the coast. The fog banks form out at sea and generally do not move very far inland where they thin and evaporate due to the heating of the arid land. Despite this, they occasionally penetrate as far as the escarpment (Desmet \& Cowling 1999), but their frequency declines rapidly towards the east (Olivier 1995). Conditions for fog formation are best in summer, but, due to the elevated summer wind speeds, fog is most commonly experienced in autumn and spring (Desmet \& Cowling 1999).

The rainfall patterns described in Section 3.1 above are largely determined by two rainfall gradients. These operate perpendicularly to one another with the first being an aridity gradient that results in decreasing rainfall as one moves northwards. The second is a longitudinal seasonality gradient with the coastal region experiencing $100 \%$ winter rainfall and the furthest interior 100\% summer rainfall (Desmet \& Cowling 1999). Based on the fact that at least $66 \%$ of its rainfall arrives between the months of April and September, the whole area presently under study can be considered winter rainfall as mapped by Chase (2005: fig. 2.5). The rainfall regime is relatively predictable (Hoffman \& Cowling 1987), with the westerly fronts typically bringing widespread gentle orographic rain that 
falls more on the mountains than on the coastal plain. The tropical summer thunderstorms on the inland plateau bring short-lived, heavy rainstorms which fail to reach the coastal plain due to the stabilising influence exerted on the local climate by the cold Atlantic Ocean (Desmet 2007). Snow occasionally falls on the highest peaks and hailstorms and frost are very rare, but frost occurs occasionally on the Namaqualand escarpment (Mucina et al. 2006b). Part of the regularity in the rainfall regime is the regularity of droughts identified through an examination of nineteenth century documentary sources (Kelso \& Vogel 2007). Droughts typically lasted three to five years. The study also showed that in some years when 'normal' annual rainfall was received, crop $^{12}$ failures occurred because the rain fell in the wrong season. Newspaper reports quoted by Kelso and Vogel (2007: 371-372) show that some droughts had devastating consequences on local domestic stock and similar consequences may well have been felt in prehistoric times, perhaps on a different scale and possibly leading to the abandonment of Spoeg River Cave (D. Avery 1995; see below). Prolonged droughts, however, are very rare (Desmet \& Cowling 1999).

Southerly winds dominate, and this constant onshore cool air flow results in frequent fog banks and, particularly in winter, heavy dewfalls (Desmet 2007). The latter are formed by the interaction of high coastal humidity and cool nocturnal temperatures and can fall all year round (Cowling et al. 1999; Desmet \& Cowling 1999). These provide a valuable source of moisture in an environment where rainfall is otherwise low (cf. Matimati et al. 2010; Schulze \& McGee 1978). Under thick fog the summer coastal temperatures can remain quite cold until the early afternoon when the fog typically retreats out to sea.

\footnotetext{
${ }^{12}$ Wheat was introduced to the high-lying areas where sufficient rain falls in 1816 (Shaw 1840) and is still grown there today, although oats are now the most common crop (Samuels et al. 2008).
} 
Aside from the fog and dew, water is scarce but the few rivers present generally contain standing water in their estuaries. Buried palaeoriver channels still carry water and Alexander (1838) reported that at Rooiwalbaai one could obtain water by digging on the beach $^{13}$. The small coastal springs and seeps at the intersection of dunes and bedrock are currently (and probably always were) valuable water sources as testified by the many animal tracks one sees leading to them.

In general, Namaqualand is a transitional zone between the Mediterranean climate of the far south-western Cape and the true desert climate of the Namib to the north. With its steep north-south climate gradients, conditions range from quite moderate in the south to more extreme in the north. Even today, though, the unique climate of Namaqualand's winter rainfall zone allows modern crop farming and pastoral activities that would be impossible in a similar rainfall regime elsewhere (Desmet 2007). Although this is largely in the higher-lying inland areas, it does bode well for pre-colonial pastoralism in the greater Namaqualand area.

\subsubsection{Early climates}

Although palaeoclimatic records for the western parts of southern Africa are patchy, Chase and Meadows (2007) provide a review of currently available data. What follows is a summary of some of the more salient observations based on the most recent work.

The modern Namaqualand climate developed around five million years ago with the last 1.5 million years characterised by alternating cold glacials and warm interglacials (Cowling \& Pierce 1999). The Last Glacial Maximum (LGM) probably ended about

\footnotetext{
${ }^{13}$ This prominent bay lies at the confluence of two palaeoriver channels, $1.5 \mathrm{~km}$ north of the Spoeg River mouth.
} 
17,500 years ago as climates ameliorated with the onset of the current interglacial period. Although drier to the north (Shi et al. 1998), Namaqualand would have experienced a strengthening of the winter rainfall regime and been wetter during the LGM (Midgley et al. 2005). The rapid warming during the late Pleistocene was interrupted only by the Older Dryas, two short cool, wet periods (Coetzee 1967), and the Younger Dryas, a short-lived cooling event at or just after 11,000 BP (Abell \& Plug 2000; Coetzee 1967; Cohen et al. 1992; Tyson 1999; Tyson \& Partridge 2000; Tyson \& Preston-Whyte 2000, but see M. Kaplan et al. 2010). Supporting evidence occurs to the south where tree species at Elands Bay Cave (Cartwright \& Parkington 1997; Parkington et al. 2000) and the presence of hedgehogs (Erinaceus frontalis) both there (Klein \& Cruz-Uribe 1987) and at Faraoskop (Manhire 1993) argue for cooler, wetter late Pleistocene climates. We are currently nearing the end of an interglacial period and it is this period, the Holocene, with which this thesis is concerned.

\subsubsection{Holocene climates}

As noted by Dewar (2008), few palaeoenvironmental studies have been conducted in Namaqualand. Those that do exist, however, provide a body of evidence that allows some characterisation of Holocene climates when examined alongside other west coast studies. Only limited data are available for the early Holocene, but the last 2000 years are better understood (Figure 3.12). I focus on evidence from southernmost Africa since opinions seem to vary with latitude.

Although temperature and aridity generally increased after the LGM, a particularly warm spell known as the Holocene Altithermal occurred during the early to mid-Holocene (Heaton et al. 1986; Meadows \& Baxter 2001; Partridge et al. 1999; Shi et al. 1998; Tyson \& Partridge 2000; Tyson \& Preston-Whyte 2000; Vogel 1989). Although authors disagree on the precise timing and duration of this event, a review of the available 
southern African data brackets it between about 8000 and 4000 years ago (Chase 2005; Chase \& Meadows 2007). Although the northern parts of the subcontinent may have received higher rainfall (Gingele 1996; Partridge 1997), evidence from further south and east of Namaqualand points towards a south-western Africa that was somewhat drier and a few degrees warmer than present day values (Cockcroft et al. 1987; H. Deacon et al. 1984; Heaton et al. 1986; Meadows \& Baxter 1999, 2001). This increased aridity likely reduced vegetation cover and resulted in more aeolian activity in the west coast region, seemingly focused on the remobilisation of existing sand bodies rather than emplacement of new ones (Chase 2005; Chase \& Thomas 2006).

Following the Holocene Altithermal, from about 4000 years ago, climates became cooler and wetter again (Baxter 1989; Jerardino 1995; Meadows \& Baxter 1999, 2001), although Scott (1993) suggests that wetness would have begun earlier in the northerly parts of the subcontinent (north of $28^{\circ} \mathrm{S}$ ), perhaps c. $7500-6500 \mathrm{BP}$. The Cango (Talma \& Vogel 1992; Tyson 1999) and Cold Air Cave (Holmgren et al. 2003) stalagmites indicate cooler temperatures than today from the mid-Holocene until 2500 years ago, with the former showing warming again around 2000 years ago. Oxygen isotope studies of midden shells from the Elands Bay area support cooling between about 4000 and 2000 years ago (Cohen et al. 1992).

Based on the first excavations at Spoeg River Cave (Webley 1992b), D. Avery (1992) used the incidence of micromammal remains within the deposits to infer climatic conditions in this part of Namaqualand during the time of deposition of the analysed layers: c. AD 1-650. In general, she saw deterioration in climatic conditions through time with the initial two centuries of this period having higher rainfall. Tyson \& Preston-Whyte (2000) see this as a warm, wet spell, while others consider it cool (Tyson \& Lindesay 1992; Scott 1996). 


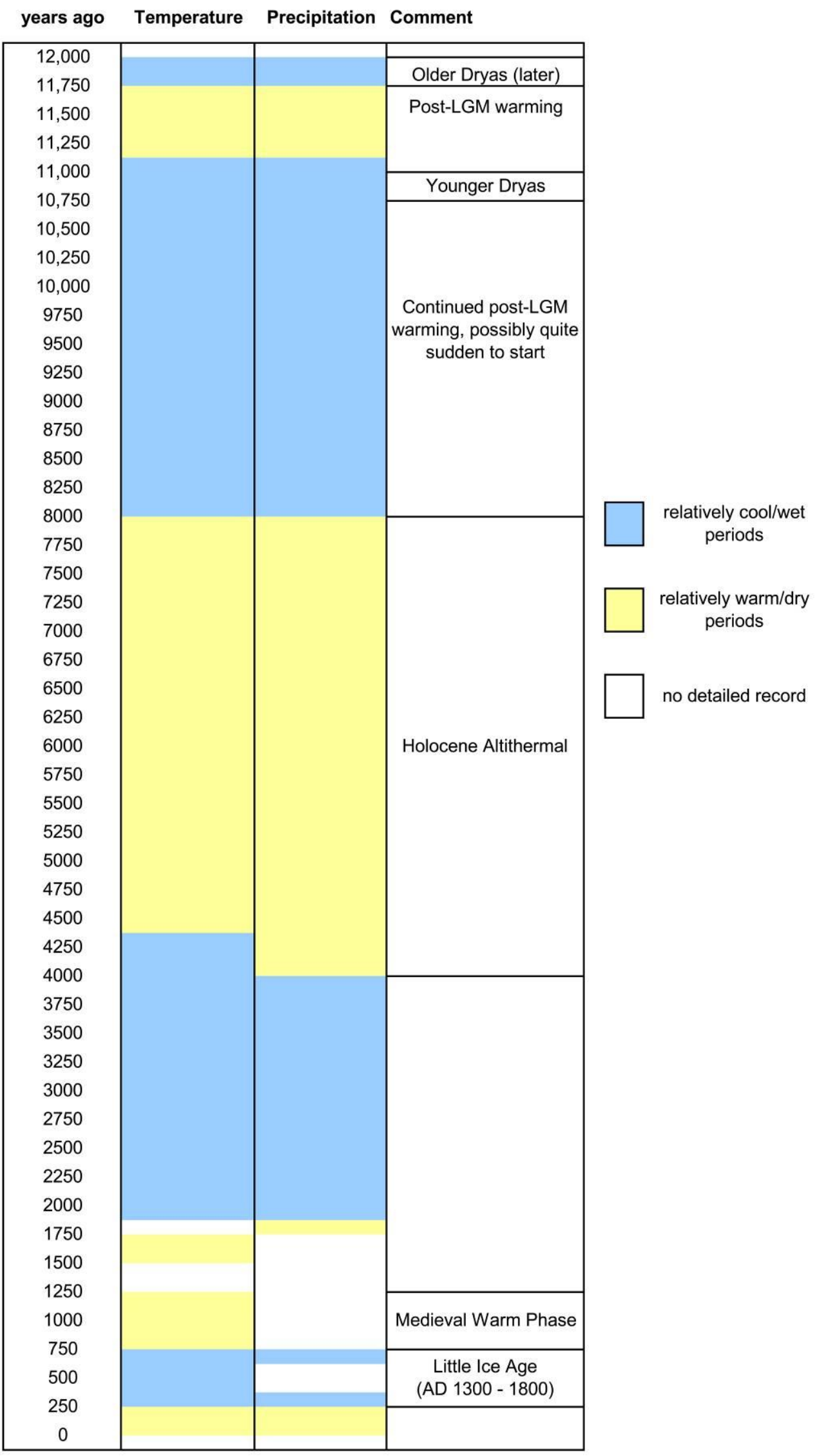


Figure 3.12: Schematic and simplified summary of temperature and precipitation data for Namaqualand from available records.

The micromammals present in layers dating to AD 450-650, indicate reduced and less predictable rainfall with fewer grasses and more scrub vegetation, while the intermediate layers show transitional conditions (D. Avery 1992). Temperatures were warmer between about AD 250 and AD 600 (Tyson \& Lindesay 1992), although the warming may have begun around AD 100 (Tyson 1999). An important aspect of this climatic reconstruction is that conditions some 2000 years ago were superior to those of today with a wider variety of grasses and other species that could quite likely have supported sheep (D. Avery 1992). Unfortunately, no supporting charcoal studies have been done in the region. Webley (2002) sees an abandonment of Spoeg River Cave post-AD 700 that she links partly to the deteriorating climate and increased aridity as the Medieval warm phase set in. Partial support, at least for the later part of the Medieval Warm Phase, is found in Namibia where a cool, wetter spell ended some 900 years ago (Vogel 1989). Of course what we do not know at Spoeg River Cave is whether later deposits were removed or eroded from its floor prior to Webley's (1992b) excavation. Given the plethora of later dates from the region and how poorly the cave is known to have been treated during the late twentieth century, this is likely.

The Medieval warm phase lasted for a few centuries either side of AD 1000 (Holmgren et al. 2001, 2003; Scott 1996; but see Vogel 1989) and, although warmer and wetter, it was highly variable (Tyson \& Preston-Whyte 2000) with the warmest years seemingly around AD 1250 (Tyson et al. 2000). The final period of prehistory was dominated by a cold spell known as the "Little Ice Age" from about AD 1300 to 1800 (Cohen et al. 1992; Holmgren et al. 2001, 2003; Tyson 1999). Interestingly, in the mid-nineteenth century Andersson $(1857: 251)$ noted that "the Namaquas, as well as the Damaras, are loud in their complaints that less rain falls now than half a century back"; this corresponds well with the end of the Little Ice Age. Namibian Little Ice Age evidence is contrasting, with some 
supporting it (Vogel 2003) and others indicating a warm, dry spell around 700-600 years ago (Scott 1996; Vogel 1989). During the last few centuries Vogel (1989) documented increased run-off in Namibian rivers that might have made the area slightly more habitable. During September of 1685, during his journey northwards, Simon van der Stel noted several swamps and streams between the Olifants and Groen Rivers (Waterhouse 1932), but this could have been the result of unusually heavy winter rains.

\subsection{Fauna}

Skead (1980) provides a valuable record of the local fauna constructed from historical travel diaries. The south-western Cape in general was richly blessed with wild game, while Stow (1905:252) describes the country of the Namaquas as having "formerly abounded with elands, hartebeests, gemsboks, quaggas and zebras, together with the giraffe, rhinoceros and great numbers of beasts of prey". Since subsistence is not central to my research, I provide only a list of those species inhabiting the study area to indicate their availability to indigenous people (Table 3.1). Many were recorded only from the well watered Orange River valley - possibly due to its greater number of visitors. Skead (1980) found no micromammal records, but an indication of the species likely to be found can be gleaned from D. Avery's (1992) list of 21 species present at Spoeg River Cave.

Table 3.1: List of mammal species historically documented in Namaqualand. Only those whose presence could be reliably ascertained by Skead (1980) are listed.

\begin{tabular}{lll}
\hline Common name & Latin name & Comments \\
\hline Chacma Baboon & Papio ursinus & Probably restricted to mountains. \\
\hline Vervet monkey & $\begin{array}{l}\text { Cercopithecus } \\
\text { pygerythrus }\end{array}$ & Orange River only. \\
\hline Cape fox & Vulpes chama & Probably most common on coastal plain. \\
\hline Bat-eared fox & Otocyon megalotis & Probably present. \\
\hline Black-backed jackal & Canis mesomelas & Reported from Orange River. \\
\hline Wild dog & Lycaon pictus & $\begin{array}{l}\text { Assumed widespread by Skead, species not } \\
\text { differentiated historically and no Namaqualand } \\
\text { records. }\end{array}$ \\
\hline Honey badger & Metonyx striatus & Mellivora capensis
\end{tabular}




\begin{tabular}{|c|c|c|}
\hline Common name & Latin name & Comments \\
\hline Small-spotted genet & Genetta genetta & $\begin{array}{l}\text { Assumed widespread by Skead, species not } \\
\text { differentiated historically and no Namaqualand } \\
\text { records. }\end{array}$ \\
\hline Water mongoose & Atilax paludinosus & \\
\hline Yellow mongoose & Cynictis penicillata & Assumed country-wide range by Skead. \\
\hline Suricate & Suricata suricatta & No Namaqualand records but common today. \\
\hline Brown hyena & Hyaena brunnea & \\
\hline Spotted hyena & Crocuta crocuta & \\
\hline Aardwolf & Proteles cristatus & \\
\hline Wild cat & Felis lybica & Assumed present but not identified historically. \\
\hline Caracal & Felis caracal & \\
\hline Leopard & Panthera pardus & Probably restricted to mountains. \\
\hline Lion & Panthera leo & Probably restricted to mountains. \\
\hline Cheetah & Acinonyx jubatus & Richtersveld only. \\
\hline Aardvark & Orycteropus afer & \\
\hline Elephant & Loxodonta africana & More common along Orange River. \\
\hline Rock hyrax & Procavia capensis & $\begin{array}{l}\text { Recorded in far south \& inland rocky areas but } \\
\text { currently also present in central coastal region. }\end{array}$ \\
\hline Black rhinoceros & Diceros bicornis & Reported from Orange River. \\
\hline Mountain zebra & Equus zebra & \\
\hline $\begin{array}{l}\text { Plains zebra } \\
\text { (subspecies } \\
\text { Quagga) }\end{array}$ & Equus quagga & $\begin{array}{l}\text { Only hearsay, no direct observations. Now } \\
\text { extinct. }\end{array}$ \\
\hline Warthog & $\begin{array}{l}\text { Phacochoerus } \\
\text { aethiopicus }\end{array}$ & Possibly present. \\
\hline Hippopotamus & $\begin{array}{l}\text { Hippopotamus } \\
\text { amphibius }\end{array}$ & Reported from Orange River. \\
\hline Giraffe & Giraffa camelopardalis & \\
\hline Grey duiker & Sylvicapra grimmia & \\
\hline Steenbok & Raphicerus campestris & \\
\hline Grysbok & Raphicerus melanotis & $\begin{array}{l}\text { Possibly in mountains in extreme southwest of } \\
\text { study area. }\end{array}$ \\
\hline Klipspringer & Oreotragus oreotragus & Recorded in the Kamiesberg and Richtersveld. \\
\hline Grey rhebuck & Pelea capreolus & Possibly in mountains only. \\
\hline Springbok & Antidorcas marsupialis & \\
\hline Gemsbok & Oryx gazella & \\
\hline Red hartebeest & Alcelaphus buselaphus & \\
\hline Kudu & $\begin{array}{l}\text { Tragelaphus } \\
\text { strepsiceros }\end{array}$ & Reported from the mountains. \\
\hline Eland & Taurotragus oryx & $\begin{array}{l}\text { Reported from far south and Orange River but } \\
\text { was probably present in Kamiesberg. }\end{array}$ \\
\hline Buffalo & Syncerus caffer & $\begin{array}{l}\text { Reported only from Orange River but Buffels } \\
\text { River apparently named after buffalo. }\end{array}$ \\
\hline $\begin{array}{l}\text { Cape hare \& Spring } \\
\text { hare }\end{array}$ & $\begin{array}{l}\text { Lepus capensis } \\
\text { Pedetes capensis }\end{array}$ & $\begin{array}{l}\text { Hares reported from Orange River and } \\
\text { Kamiesberg but no species differentiation. }\end{array}$ \\
\hline $\begin{array}{l}\text { Namaqua dune } \\
\text { molerat }\end{array}$ & Bathyergus janetta & \\
\hline Porcupine & Hystrix africaeaustralis & \\
\hline Cape fur seal & Arctocephalus pusillus & \\
\hline Whales and dolphins & Order: Cetacea & $\begin{array}{l}\text { Various species present but not identified } \\
\text { historically. }\end{array}$ \\
\hline
\end{tabular}


Aside from these mammals, other creatures inhabiting this region include the angulate tortoise (Chersina angulata), the speckled padloper (Homopus signatus), the tented tortoise (Psammobates tentorius), several snakes, the African penguin (Spheniscus demersus) and various other sea birds. In the ocean and estuaries fish were caught (the fish bone assemblages have yet to be analysed), while on the rocky shore crayfish (Jasus lalandii), black mussels (Choromytilus meridionalis) and the four most common limpets (Cymbula granatina, Scutellastra granularis, Scutellastra argenvillei, Scutellastra barbara) are all archaeologically important (Dewar 2008; Orton \& Halkett 2005, 2006).

\subsection{Vegetation}

The entire study area is encompassed by the Succulent Karoo Biome, which includes a vast multitude of species with many endemics. Most are succulents and small shrubs, although small trees, geophytes, herbs and lichens also occur (Mucina et al. 2006b). Namaqualand's biological uniqueness is due largely to its distinctive and somewhat moderate climate with surprisingly regular winter rainfall (Cowling \& Pierce 1999).

Near-coastal parts of the study area are within the Namaqualand Coastal Duneveld, a dwarf shrubland including both succulent and non-succulent shrubs. Spiny grasses (Cladoraphis sp.) are abundant on the semi-stable aeolian coastal dunes in which most archaeological sites are found, while taller shrubs (1-2 m high) occur in the sheltered areas between dunes (Mucina et al. 2006b). The Namaqualand Strandveld generally occurs inland of the Coastal Duneveld but does stretch to near shore areas within the central river valleys (Buffels, Swartlintjies, Spoeg, Bitter and Groen) cutting the coastal plain. This vegetation type is strongly dominated by erect and creeping succulent shrubs (Mucina et al. 2006b). Pockets of Namaqualand Sand Fynbos occur in places and are dominated by restios (reeds) with scattered shrubs including species of Protea (Rebelo 
et al. 2006). Much of the Knersvlakte is covered by Knersvlakte Quartz Vygieveld which consists of dwarf succulent shrubs growing on extensive quartz-dominated gravel plains. In the south, a large tract of Namaqualand Spinescent Grassland includes succulent and non-succulent shrubs but is dominated by the spiny grass Cladoraphis spinosa (Mucina et al. 2006b). Along the immediate coastline just above the high water mark one finds Namaqualand Seashore Vegetation consisting of small, low density succulents, while the lower reaches of the rivers have Arid Estuarine Salt Marshes comprising dwarf succulents, creeping grasses and scattered reed beds (Mucina et al. 2006a).

An archaeologically important feature of Namaqualand is that it is too arid to allow wild fires. This results in much dead brush occurring that would have formed valuable fuel for camp fires. Near the coast, where long-lived trees are absent, this means that evidence of burning in sites must be anthropogenic; charcoal is thus good for dating. This may not be the case further inland where potentially long-lived Acacia trees grow along rivers.

\subsection{Archaeological background}

As described in Chapter 1, little academic research has been conducted in the study area, with much of what we know being a result of the extensive CRM surveys and mitigation programs conducted in central Namaqualand's coastal zone. Two doctoral theses (Dewar 2007; Webley 1992b) have contributed knowledge on the latter half of the Holocene from central and northern Namaqualand, but the south is far less known. This review addresses each zone in turn, focusing on Stone Age material and concludes with a brief historical overview of the region as a whole. The review is fairly extensive, since no comprehensive review of the Stone Age in Namaqualand has previously been produced. While Webley (2007) and Dewar (2008) do cover certain aspects, I have attempted to highlight all the important observations from the region. Namaqualand is 
unique in that most data emanate from CRM work conducted on the diamond mines; this review is thus important in disseminating information from the vast store of grey literature. Note that all radiocarbon dates are detailed in Appendix 2.

\subsubsection{Sandveld}

Archaeological work in the Sandveld has been focused in the northern and central parts around Kleinzee, Koingnaas and Hondeklipbaai. Fewer observations have been made in the southern and extreme northern parts.

\section{Early and Middle Stone Age}

Early (ESA) and Middle Stone Age (MSA) material has been documented in the coastal zone of the Sandveld but in situ occurrences are extremely rare. Silcrete and quartzite/sandstone were the usual materials used, but silcrete predominates in Namaqualand. ESA artefact scatters are uncommon but one significant scatter, found just east of Kleinzee, had Acheulian handaxes and cleavers associated with quarried silcrete outcrops (Halkett 2002). On the high ground near Kleinzee a very significant site mixing ESA and MSA artefacts includes mineralised bone (Orton \& Webley 2012c), while other scatters likely combine MSA and LSA artefacts (Orton \& Halkett 2007a). ESA artefacts occur in gravel exposures in places (Orton \& Webley 2012c) and isolated handaxes, often on the surface of aeolian sand (Orton \& Halkett 2005, 2007a), were likely transported by later people. In the southern Sandveld ESA and MSA artefacts occur in various areas with exposed hardpan (Hart 1999, 2003, 2007) and around silcrete outcrops (Hart \& Halkett 1994; Hart \& Orton 2005). One such outcrop (MS4) was extensively quarried and excavations revealed a dense, $0.75 \mathrm{~m}$ thick layer of artefacts with occasional bifaces and Levallois cores (Hart \& Halkett 1994). Parkington (1993) 
found both ESA and MSA artefacts associated with fossilised faunal remains on southern coastal sites.

A significant but mixed ESA and MSA assemblage occurred at KV2005/002. It was a quarry and artefact manufacturing locality extending several hundred metres along the silcrete outcrops capping the 90 m marine terrace just north of Kleinzee (Orton \& Halkett 2006). Most flakes were likely struck directly from the outcrops or loose blocks, but Levallois and other cores occurred. Handaxes and other uni- or bifacial artefacts were rare but ubiquitous. Flakes with lightly retouched edges, occasionally tending towards denticulation, may be MSA. Quartz and quartzite are also present and, although some of the quartz originated as clasts from within the silcrete, the quartzite indicates that other materials were carried to the site. The marked variation in patination, and perhaps also in artefact form, suggests that the site was used for a very long period. Similar finds have been reported from the Namibian coastline (Rudner \& Grattan-Bellew 1964).

Halkett and Hart (1997) reported a site with MSA backed artefacts but no shell along the coast north of Kleinzee but offered no further description. Another site exposed in a Holocene dune field deflation $17 \mathrm{~km}$ north of Koingnaas contained bifacial points associated with marine shell (Halkett \& Orton 2005), although the relationship may be spurious. MSA occurrences were also documented near the mouth of the Groen River in central Namaqualand (Jerardino et al. 1992); further investigation of one revealed artefacts and bone deflated on to the surface of a more resistant orange sand layer below the white Holocene dunes (Halkett 2001a). MSA artefacts also occur above the coastal cliffs in southern Namaqualand where they can be associated with mineralised bone (personal observation) and marine shell (Halkett 2000).

Two more Sandveld sites are worth mentioning. KV2005/006 is an extensive scatter of mostly quartz stone artefacts, highly fragmented bone (including much tortoise), ostrich eggshell and occasional marine shells in a deflation bay (Orton \& Halkett 2006). All the 
organic material is mineralised suggesting great antiquity, although preliminary examination of the stone yielded no diagnostic MSA pieces. Many cobbles showed evidence of use as hammer stones, grindstones or anvils, artefacts seldom found on MSA sites and the intriguing possibility remains that this site could represent a terminal Pleistocene or early Holocene LSA occurrence. The second site, KV2001/010D, is also of indeterminate age and, although not fully nexcavated, two test pits have established its stratigraphy (Halkett 2003). A $10 \mathrm{~cm}$ thick lower layer was comprised almost entirely of mineralised tortoise bone, but other species and occasional stone artefacts supported an anthropogenic origin for the accumulation. Above a layer of sterile sand there is a shell midden that seems to be at least partly mineralised but is probably LSA. A nearby deflated portion revealed ostrich eggshell beads and LSA stone artefacts among marine shells and extensive quantities of highly fragmented and mineralised bone fragments. The stone artefacts and beads indicate an LSA component, presumably the shell midden, but the mineralised bone could relate to an MSA or earlier LSA occupation.

\section{Later Stone Age}

Although the ESA and MSA are little studied, the CRM work and subsequent research by Dewar (2008) allow a good understanding of the coastal LSA, at least in the northern Sandveld. Prior to the 1990s, west coast archaeology was relatively unknown with just a few isolated reports having been made (Colson 1905; Heydorn \& Grindley 1981; Laidler 1929b, 1935; Rudner 1968). Since a number of northern and central Sandveld sites are already thoroughly described (Dewar 2008; Dewar et al. 2006; Orton et al. 2005; Orton 2008a), I provide only a brief summary of that area with more detail being furnished for other sites as necessary.

LSA sites are extremely common within a few kilometres of the coast (Dewar 2008; Halkett \& Hart 1997; Parkington 1993), undoubtedly due to the presence of secure 
marine food resources along an almost exclusively rocky coastline. Certain areas may have been more heavily used - Port Nolloth, for example, was repeatedly noted for its impressive shell mounds (Laidler 1935; Rudner 1968), many of which are being destroyed through unchecked property development. Stratified deposits are rare and most sites reflect single occupations. In the northern and central Sandveld, sites are well distributed along the coast and are not obviously clustered in particularly resource-rich areas or near rivers (Dewar 2008). Dewar concludes that Namaqualand's Holocene inhabitants were well adapted to life in an arid environment, although most occupation seems to have taken place during wetter phases when water would have been more easily available. Sites become very much smaller and more sparsely distributed beyond the immediate coastal strip (Orton \& Webley 2012a, 2012c).

Coastal sites vary in size, with very large shell middens presumably reflecting longer occupations or possibly aggregation sites. Most middens are about 8-15 m in diameter but some sites, like LK2001/015 and SK2001/024, manifest as loosely arranged clusters of smaller middens (Halkett 2003), that may reflect the camps of larger groups of people.

The earliest unequivocal LSA site yet found in Namaqualand is AK2006/001G, just north of Kleinzee, where a late Pleistocene microlithic assemblage was recovered from a secondary, erosional context (Orton 2008a). Material of this age occurs between $c$. 19,000 and 12,000 BP and possibly as late as 9500 BP in southern Africa (J. Deacon 1984a, 1984b; Mitchell 1995, 2000, 2002b; Wadley 1993) and, without any locally dated assemblages, it is not possible to constrain the age of this one any further. Only stone artefacts were found, but the high frequency of bladelets and bladelet cores clearly supports the age assignation. The assemblage is almost entirely of silcrete.

The most significant LSA site in the Sandveld area is Spoeg River Cave, a large rock shelter located in an igneous outcrop $2 \mathrm{~km}$ east of the Spoeg River mouth (Webley 
1992b, 2002). Its basal layers yielded an undated assemblage with large scrapers made on quartz which led Webley (2002; Vogel et al. 1997) to suggest an early Holocene age. This observation is supported by the stone artefacts from Elands Bay Cave in the Western Cape where large quartz scrapers dominate the retouched tools between about 8100 and 6800 BC (Orton 2004, 2006). Although similarly aged material is as yet unknown from the Sandveld, it likely exists given the late Pleistocene and early Holocene dates obtained from open sites in the Namib (Shackley 1985). The oldest radiocarbon date from Spoeg River Cave is $3580 \pm 60$ (Pta-6987; Webley 2002), although slightly older dates have been obtained from open sites. Importantly, Spoeg River Cave has yielded the oldest directly dated sheep bone from South Africa (2105 \pm 65 BP; OxA3862; Sealy \& Yates 1994) as discussed in Chapter 2.

Many open sites yielding good observations have been excavated along the central and northern Namaqualand coast. Shell middens dating throughout the last 5600 years have been recorded (Dewar 2008), with the most varied retouched artefact assemblages generally being from the older sites. Backed artefacts were more common until about 3000 years ago, while scrapers dominated during the next 1000 years. The last two millennia, after the introduction of pottery, saw assemblages becoming increasingly informal with cryptocrystalline silicates dropping out and quartz being used almost exclusively (Dewar 2008). The exceptions to the deformalisation are those sites containing backed microliths made on clear quartz (Orton et al. 2005). The earlier middens yield very small ostrich eggshell beads, sometimes as small as $3 \mathrm{~mm}$ maximum diameter, but the majority appear to be between 4 and $6 \mathrm{~mm}$. Recent sites, such as SK400, show larger beads up to $10.5 \mathrm{~mm}$ in diameter but include much variety (Dewar 2008). Pottery occurs on sites dating within the last 2000 years, with most complete or near complete pots being small and conical in shape (Colson 1905; Dewar 2008; Rudner 1968). Colson (1905:67) reports a pot "half full of magnetic iron sand" from a midden near Port Nolloth, showing that they were not only used for food but also for storing other 
materials. Worked bone is rare, but examples from coastal middens have been reported from the northern and central parts of Namaqualand (Colson 1905; Dewar 2008; Orton et al. 2005). Ostrich eggshell flasks have been found, but are usually only represented by mouth fragments. They are known to have been used for storing water (Schapera 1930). Rare whole flasks exist, including two decorated flasks from Port Nolloth (Jacobson \& Noli 2008). Caches of flasks are well documented, particularly in the Northern Cape (Henderson 2002; Jerardino et al. 2009; D. Morris 1994; D. Morris \& Von Bezing 1996). The shell middens are strongly dominated by limpets, and the bones of various marine and terrestrial animals are present. Angulate tortoises (Chersina angulata), steenbok (Raphicerus campestris) and seals (Arctocephalus pusillus) are the primary species found (Dewar 2008).

LSA observations in the southern Sandveld are more limited. Coastal surveys have found many sites, including open artefact scatters and shell middens (Halkett 2000; Hart 2003, 1999; Parkington \& Poggenpoel 1990). Stone artefacts in a variety of raw materials were reported and the presence of retouched artefacts, potsherds and ostrich eggshell beads on some sites indicates occupation during the last few thousand years. Six open sites have been excavated in the coastal zone around Brand-se-Baai, while another five were sampled about $3 \mathrm{~km}$ inland.

The Brand-se-Baai (BSB) sites offer the only window into the coastal occupation of this area. Notably, some are stratified middens. BSB2 in particular spans several thousand years, but others are more limited (Halkett et al. 1993). In all, BSB2 revealed six layers with the fifth dated to 2866-2281 BC (Pta- 6053) and the second to AD 1411-1854 (Pta6050). While the lower layers contained both backed tools and scrapers, the upper layers revealed only informal quartz artefacts. In general the BSB sites preserved the same species of shell as elsewhere in Namaqualand, while the stone artefact assemblages were quartz-dominated with relatively few retouched artefacts. The fauna include 
primarily tortoise, but small and small-medium bovids, birds and other small mammals are also present (Halkett et al. 1993).

Further inland, MS1 contained a quartz and silcrete dominated assemblage including backed artefacts but not scrapers; segments dominate. The retouched pieces were mostly in quartz (Hart \& Halkett 1994). The site dates to 2017-1419 BC (GX-32063; ACO, unpublished). Site MS2 had far fewer artefacts and was quartz-dominated. The assemblage included scrapers, one of which was a backed scraper in quartz. An age of greater than 3000 years was anticipated (Hart \& Halkett 1994; Hart \& Lanham 1997). Site MS3 is also strongly quartz dominated and backed tools are more numerous than scrapers (Hart \& Halkett 1994). It dates to 1184-524 BC (GX-32062; ACO unpublished). All three sites contained very small quantities of shell and minimal bone (due to poor preservation) with no other organics. One other site here, MS5, has a small informal lithic assemblage and no pottery and likely post-dates AD 1 (Hart \& Lanham 1997).

Sites in the immediate hinterland are varied (Hart \& Orton 2005; Hart 2007; Parkington \& Poggenpoel 1990). Small scatters of artefacts occur along rivers and on dune tops near seasonal pans, while shell and artefact scatters of varying size also neighbour pans. The former may relate to very short-term camps, but the latter seem less transient. Quarried silcrete outcrops occur and some artefact scatters in the hilly areas have pottery on them indicating relatively recent occupation. One site in particular (GR05; Hart \& Orton 2005) had a few sherds of extraordinarily well-made pottery with a clean, beautifully made overturned and flattened lip (Figure 3.13). Also in this area Hart and Orton (2005) located a rock shelter (HK11) with what appeared to be a good deposit and a very extensive talus on a granite outcrop some $12.8 \mathrm{~km}$ inland.

Bored stones (presumed to be digging stick weights) are rare in the Sandveld; perhaps the sandy soil precluded their necessity? Hausman (1980 in A. Morris 1992) reports a 
'perforated stone' associated with an approximately 1000 year old (Pta-4405) seated burial from the coast near Lutzville in the southern Sandveld. Whether this is a bored stone is unclear, but it seems likely. Half a bored stone was located at AK2006/006 (pottery-period) in the northern Sandveld. This site also contained a seated burial (Orton 2007c) that might, through burial style, be ascribable to the Khoekhoen (Dapper 1668 in Schapera \& Farrington 1933; Sealy 2010).

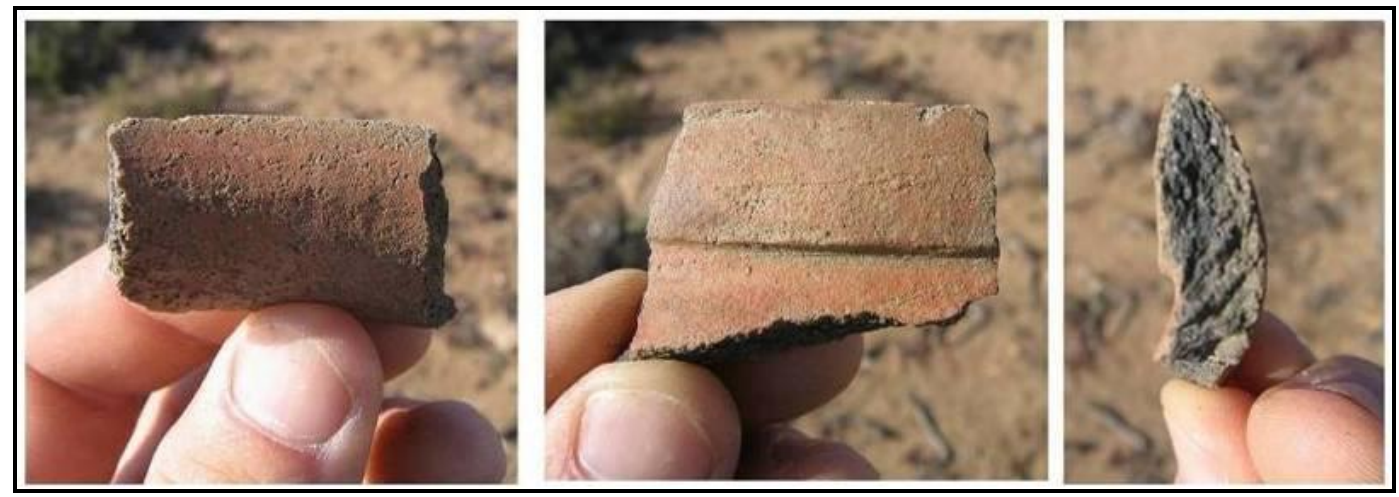

Figure 3.13: An unusually well-made rim fragment from site GR05 in the southern Sandveld.

\subsubsection{Hardeveld}

Webley's $(1984,1986,1992 b, 2007)$ archaeological research in the Hardeveld has focused on the LSA, but isolated ESA and MSA occurrences are known (D. Morris \& Webley 2004; Webley 1984). Most work has been done in the central parts with a few sites near Kamieskroon providing most of the observations (Webley 1984, 1986, 1992b). The south remains relatively unexplored. The vast majority of sites are small with minimal deposit depth (D. Morris \& Webley 2004; Webley 1992b).

Keurbos revealed a mixed MSA, LSA and historical surface layer, but beneath this a small hollow contained a seemingly late Holocene assemblage with formal tools and adiagnostic pottery. These units overlay only MSA deposits (Webley 1992b). Bethelsklip, near the western fringe of the Hardeveld, was suggested to have been sporadically 
occupied by herders throughout the last 1000 years. An age of AD 1182-1381 (Pta3512) was obtained two-thirds of the way down the $1 \mathrm{~m}$ deep deposit (Webley 1984), while a date of AD 1464-1643 (Pta-4741) was acquired higher up (Webley 1992b). The large flaked artefact collection included numerous retouched pieces; backed items, notably including segments, were common. Webley (1984) was unable to date the lower layers due to insufficient charcoal and I would suggest, based on typology and materials, that the finds indicate mixing of significant quantities of older material, perhaps from the mid-Holocene, with the pottery period deposits. The assemblage recalls aspects of those from Jakkalsberg $N$ and L (Orton \& Halkett 2010). Many ostrich eggshell beads were found, but no measurements are provided. Pottery features include oval and vertical impressions, horizontal incised lines, a spout, a horizontally-pierced lug and a slightly nippled base. One mouth diameter was estimated at $\sim 100 \mathrm{~mm}$ and sherd thickness varies between 3.4 and $9.0 \mathrm{~mm}$ (means on two separate samples were 5.6 and $5.9 \mathrm{~mm}$ ). The pottery had variable but generally fine-grained mineral temper (Webley 1984). As well as informal, stone-lined hearths and a large ash concentration, two post-holes and numerous pits and/or burrows were found. Webley $(1984,1986)$ surmises that stock may have been penned there, but found little good pre-colonial evidence for this. The fauna includes primarily rock hyrax (Procavia capensis) and tortoise (Chersina angulata), but also present were sheep/goat and possible cow. Mandibles and floral remains suggested the most likely season of occupation to be late winter to early summer (Webley 1984). Despite the large archaeological sample obtained from Bethelsklip, the extensive disturbances and seemingly mixed stone artefact assemblage suggest that we cannot rely on the archaeological signatures present.

Further inland, Wolfkraal appears to include mixed Holocene deposits of varying age overlying an MSA occupation. The upper deposits contain many fine-tempered, thinwalled and undecorated potsherds as well as some retouched tools. The site seems unlikely to have been occupied by herders for any period of time and probably functioned 
as a stopping point between summer and winter camps. Preservation was poor with the few faunal remains again dominated by tortoise and rock hyrax (Webley 1984, 1992b).

Frummelbakkies is actually in western Bushmanland but worth discussing here given its proximity to the Kamiesberg. It has bedrock basins that fill with water after rain and was thought by Webley (1992b) to be a summer camp for Nama herders. Although it only has one very recent date post-dating the mid-seventeenth century (Pta-4763), its associated stone tools, pottery (including some grass temper), ostrich eggshell beads and bedrock grinding grooves (Webley 1992b) likely suggest more extensive use.

An unusual record from the Kamiesberg area is that of stone cairn burials. Laidler (1929a) noted the presence of groups of graves containing 'Hottentots', some of whom were interpreted to have been murdered and buried by Bushmen. He considered the majority of graves to predate 1750 . To my knowledge, these records have not been corroborated. Similar burials are extensively documented further east near Augrabies Falls (Dreyer \& Meiring 1937; A. Morris 1995) and they also occur in Namibia throughout the last two millennia (Sandelowsky 1983).

Rock art is rare in Namaqualand, but paintings occur in the Hardeveld and engravings along the Orange River. The paintings have variable content but are not described further here, since they are reviewed in detail in Section 7.6 below.

\subsubsection{Richtersveld}

Our limited knowledge of this region's prehistory comes from a small number of academic research and CRM projects. In the coastal part of the Richtersveld two rock shelters are located in the rocky hill Boegoeberg. BOG1 was a brown hyena den dating around 35,000 BP, while BOG2 contained a stratified MSA shell midden (Klein et al. 
1999). A ${ }^{14} \mathrm{C}$ date places BOG2 at about $44,200 \pm 1200$ BP (Pta-6956), but the fauna imply a far greater antiquity (Klein et al. 1999). Further inland, recent work at Spitzkloof has revealed in situ LSA and MSA deposits, the latter extending back to pre-Still Bay times (>70 $000 \mathrm{BP}$ ), but this research is still in its infancy (Dewar \& Stewart 2012).

Similar sorts of sites occur on both the Namibian and South African sides of the Orange River (Hart \& Halkett 1999), but the latter is better documented. Many sites of various types occur along the silty floodplain of the southern bank, but ESA and MSA artefacts are generally rare (Halkett 1999a). One ESA/MSA scatter was found on a mountain slope above the river (Halkett 1999b), while such artefacts were found to be common in riverside gravel terraces (Hart and Halkett 1999; Orton \& Webley 2009). On the floodplain most sites are artefact scatters (Halkett 1999a) but burials, including both LSA and more formal historical graves, have been noted. A number of dolomite slabs and outcrops on the river banks contain engravings that include colonial period subject matter, animals and many geometric images (Hart \& Halkett 1999; D. Morris 1988). Some geometric images are heavily patinated, presumably indicating a greater antiquity (Hart \& Halkett 1999).

The first Richtersveld excavation was conducted by Webley in 1990 at /hei-/khomas (a.k.a. /Ai tomas or Vaalhoek) in the central Richtersveld (Webley 1992b, 2001). The site lies at the foot of some large boulders and a permanent spring occurs nearby. Two occupations are dated - the first just after 2000 years ago and the second during the mid-second millennium AD (Webley 2001). Like Bethelsklip, the many and varied formal tools recovered seem indicative of mixing, perhaps supported by the date of AD 1952 (Pta-5444) obtained for an archaeological layer $7 \mathrm{~cm}$ below surface, the inverted dates in Areas 1 and 2, and the many pits occurring in the deposit. Webley (2001) describes abundant pottery with decoration usually including oval or round impressions but occasionally horizontal lines below the lip. A hole of the type described by Laidler 
(1929b) and Rudner (1968) for mending pots was noted on one sherd and lugs were present. Ostrich eggshell beads are common, and manufacturing took place on site. Sizes vary, but generally seem to increase with time as expected (cf. Jacobson 1987; A. Smith et al. 1991). Sheep/goat bones are present in small numbers throughout and rare cattle bones were restricted to near the surface. Deliberate burial of animal bones occurred in small pits, one of which contained the complete skeletons of an adult and juvenile klipspringer (Oreotragus oreotragus) buried together (Webley 2001).

Excavations at Die Toon, some $15 \mathrm{~km}$ from the Orange River in the eastern Richtersveld, revealed a shallow deposit with dates of 2457-2034 BC (Pta-5960) and 1451-1121 BC (Pta-5963; Webley et al. 1993). Two potsherds on the surface indicated at least sporadic visits during the pottery period but most of the deposit is more than 3000 years old. As expected in assemblages of that age, the retouched artefacts are dominated by backed items and the ostrich eggshell beads average between 3.8 and $4.2 \mathrm{~mm}$ in diameter.

All other recorded and excavated sites in the Richtersveld lie on the Orange River floodplain. Bloeddrift 23 is an open site some $300 \mathrm{~m}$ from the Orange in the northwestern Richtersveld (A. Smith et al. 2001) and is one of many recorded in that area by Halkett (1999). Some were rich in retouched artefacts and mineralised bones, while others had many potsherds and small-medium bovids (A. Smith et al. 2001). The sites are preserved within silts deposited during flood events and Smith et al. (2001) suggest that modern dam construction upstream has retarded the silt supply such that archaeological sites are now becoming exposed and degraded through erosion. This was evidenced by the good preservation of ashy hearths at Bloeddrift 23 , despite their exposure; one was dated to AD 1501-1636 (Pta-7942; A. Smith et al. 2001). The lithics are informal, although one quartz backed bladelet was noted. Decorated pottery had a single row of round or oblong incisions just beneath the lip. The 153 ostrich eggshell beads were variable in diameter with a range of $3.4-11.8 \mathrm{~mm}$. The mean was $7.6 \mathrm{~mm}$ 
and only five were smaller than $5 \mathrm{~mm}$. A single copper tool with a shaft and flat blade was also found. The authors assume these finds to indicate occupation by herders.

Most work in the Richtersveld has been carried out in the vicinity of Jakkalsberg where six sites have been excavated (Halkett 2001b; Orton 2007b; Orton \& Halkett 2001, 2010; Webley 1997a) and many more recorded (Halkett 1999a). The first two, Jakkalsberg (JKB) A and B, were excavated by Webley (1997a; see also Gray 2009) and found to date between AD 610 and 970 (Pta-5958, Pta-6100, Pta-6101, Pta-6122, Pta-8494) with JKB B possibly the older of the two. In general, the lithics are very informal, but the presence of segments and other backed tools at JKB A indicates an older background scatter in the area. The large pottery assemblage included sherds with horizontal lines, impressions or combinations thereof on the neck, and also some sherds with crosshatching on the lip. Ostrich eggshell beads were common with the large collection from JKB A having a mean diameter of $6.0 \mathrm{~mm}$ and a wide distribution of sizes. The JKB B beads average $5.7 \mathrm{~mm}$. A range of worked bone artefacts was found, including points, awls and link shafts (Webley 1997a). Significantly, these sites contained many sheep bones (Brink \& Webley 1996). On the basis of pottery and link shaft decorations (lines and zigzags at JKB A and circular motifs at JKB B) and the presence of bead manufacturing debris and ochre (suggesting women's rituals), A. Smith and Webley (2000) have interpreted the remains from JKB B to indicate specialised women's activities. They also found an iron bead at JKB B of the kind known to have been worn by nineteenth century Nama women.

The other four sites lie to the southwest across a small tributary stream and were excavated commercially (Halkett 2001b). JKB M dates to the first millennium AD (GX32760; Orton 2008d) and contains many stone artefacts, beads and pot sherds. Retouched artefacts are absent, beads average $4.9 \mathrm{~mm}$ in diameter and the pottery includes lugs, bosses and rims decorated with horizontal lines. The fauna includes sheep 
(Orton 2007b). JKB K dates to AD 1212-1459 (Orton \& Halkett 2010). Retouch is again absent, the ostrich eggshell beads average $6.15 \mathrm{~mm}$ in diameter and the pottery is plain, but includes a drilled hole (Orton 2007b). Both sites are studied further below.

The last two excavated sites at Jakkalsberg are older. JKB N represents the oldest dated LSA site thus far excavated in the Richtersveld. It is a large, deflated and water-washed scatter composed primarily of stone artefacts and ostrich eggshell beads but including some decorated ostrich eggshell. Although limited younger material including pottery is overprinted, the majority is clearly mid-Holocene - a contention supported by three dates covering the period between 6000 and 4500 years ago (Pta-8496, GX-32754, GX32755). The retouched assemblage is strongly dominated by sidescrapers and backed scrapers, but backed flakes, backed bladelets, segments and denticulates also play significant roles. The beads are small with a mean diameter of $4.1 \mathrm{~mm}$ (Orton 2007b, 2008d; Orton \& Halkett 2001, 2010). JKB L is a slightly younger site with in situ deposits indicative of a small campsite and dating to 1737-1415 BC (GX-32065). Again, stone artefacts and beads were common with decorated ostrich eggshell also present. The retouched artefacts are diverse but include seven tiny quartz triangles, a type strongly characteristic of central African assemblages (Sampson 1974). The beads are small, averaging $4.5 \mathrm{~mm}$ in diameter (Orton 2007b, 2008d; Orton \& Halkett 2010). These two sites well characterise mid-Holocene lithic assemblages from the region.

Along the lower reaches of the Fish River, in southern Namibia, Robertshaw (1979) excavated a site dating within the last 200 years. It contained abundant pottery $(>700$ sherds), a few of which were decorated with single or double rows of vertical incisions. He also found a spout, a few lugs and some pieces with ground edges. Vessel shape was described as 'necked' or 'bag-shaped' with a pointed base. Glass trade beads were present, primarily associated with a burial. He lists 'red on black', 'white', 'creamy white light brown', 'black', 'opaque, light blue', 'translucent, clear' and 'opaque light green'. 
Stone artefacts, interestingly, were extremely rare. Two fragments of decorated ostrich eggshell and three unfinished beads were also recovered.

\subsubsection{Knersvlakte}

Prior to initiation of the present research, the Knersvlakte was archaeologically unknown with just one commercial survey on record. This survey found MSA surface scatters and a small rock shelter with LSA material including pottery in the north-western Knersvlakte (Goosen \& Burger 1995). Research related to the present study has revealed two important MSA sites: near the confluence of the Sout and Varsche Rivers is SFT001, a bifacial point production site (Mackay et al. 2010), while further east lies VR003, a collapsed rock shelter containing both backed and bifacial MSA artefacts likely ascribable to the Howieson's Poort and Still Bay periods respectively (Steele et al. 2010, 2012). The extent of VR003's earlier unexcavated MSA deposits remains unknown. Preliminary results of excavations carried out in two rock shelters for this thesis reveal mid- to late Holocene occupation with cultural materials broadly similar to those encountered elsewhere but with the addition of well-preserved organic artefacts and plant matter in the deposits (Orton et al. 2011). Although little work has been done in this region, recent commercial projects have documented artefact scatters of varying age across the landscape, very often associated with heuweltjies. The LSA seems least well represented (Orton 2010, 2011a, 2011b).

\subsubsection{Historical archaeology}

Nineteenth and twentieth century historical sites and ruins occur throughout Namaqualand and relate mainly to early farmers and European mission stations, the first of the latter being Leliefontein, established in 1816 (Shaw 1840). Loan farms were registered to European settlers in Namaqualand from 1750, but European pastoralists 
were certainly already living in the area (Penn 1995). Nineteenth century Contact period $^{14}$ sites are known from the central coastline (Orton 2009a) and interior (Webley 1984, 1986) as well as the Knersvlakte (Orton et al. 2011). Also represented are the remains of Second Anglo-Boer War (1899-1902) fortifications. Letterklip, near Garies, is particularly well-known, but Burke (1995) notes numerous blockhouses throughout the area, many positioned to protect the British mining interests around Okiep.

\subsubsection{Summary}

No research has been aimed at the ESA and very little at the MSA in Namaqualand; consequently, little is known of these periods. However, sporadic scatters of material pertaining to both Ages are known from various areas. Only three in situ MSA occurrences are excavated: Boegoeberg 1 (Klein et al. 1999) and Spitzkloof (Dewar \& Stewart 2012) in the far north and VR003 (Steele et al. 2010; Steele et al. 2012) in the far south.

The earliest documented LSA material comes from just north of Kleinzee where terminal Pleistocene stone artefacts were located (Orton 2008a). Spoeg River Cave and possibly Wolfkraal contain large scrapers indicative of early Holocene occupation (Webley 1984, 2002; Vogel et al. 1997), but the earliest radiocarbon date, in the mid-fourth millennium BC, comes from Seal Midden (MB2005/005B; GX-32526; Dewar 2008). The limited research in the northern and central regions allows general conclusions on the local later Holocene sequence to be drawn, but the southern area remains virtually unstudied. The limpet-dominated pre-pottery shell middens of the Namaqualand coast contain higher frequencies of retouched artefacts and cryptocrystalline silicas, while younger sites have informal, quartz-dominated assemblages. Within the former grouping, backed artefacts

\footnotetext{
${ }^{14}$ Contact here refers to LSA and Historical period contact.
} 
are more common earlier on, perhaps before about 3000 BC. Similarly the trajectory of changing ostrich eggshell bead size cannot be tracked in detail but it is known that midHolocene beads are smaller than those occurring later and that larger beads $(>6 \mathrm{~mm})$ only appear with pottery (Dewar 2008). A peculiar set of sites with stone artefact assemblages based on clear quartz has been documented occurring within approximately the last 2000 years (Dewar 2008; Orton et al. 2005).

Inland, many sites seem disturbed but occupation during the late and terminal Holocene, including evidence of herding, is most frequently encountered (Webley 1984, 1992, 2007). Just two intact deep sequences have been documented, both in the far south (Orton et al. 2011). These contain material broadly similar to open sites in Namaqualand but with improved organic preservation. They are detailed below.

In the extreme north, the excavated sites in the Richtersveld date throughout the latter half of the Holocene and support the sequence obtained from coastal sites (Orton 2007b; Orton \& Halkett 2010; A. Smith et al. 2001; Webley 1997a; Webley et al. 1993).

The overall picture of LSA archaeology in Namaqualand is still one of too little data with some areas, like the Kamiesberg, simply not yielding good stratigraphies despite the amount of research conducted. Only tentative conclusions can be drawn from a few sources spread over a vast landscape. Broad patterns of change are evident, but the lack of radiocarbon dates and sufficient analyses means that one cannot isolate particular periods of change that could indicate greater processes at work, particularly any associated with the influx of herders or commodities typically associated with them. It is clear, however, that LSA people were able to successfully inhabit even the driest reaches of the region. 


\section{Chapter 4. Methods.}

With the context set, I now turn to my own research, first examining the field methodology and then exploring issues of artefact identification and classification.

\subsection{Field survey}

With extensive commercial survey and excavation in the northern and central Sandveld already conducted, further work was not undertaken there. Similarly, as discussed in Section 3.7, the Hardeveld and Richtersveld have been well explored by Lita Webley and colleagues. By contrast, southern Namaqualand, and particularly the Knersvlakte, were poorly understood and conducive to new exploration. In the latter, certain areas were targeted for survey through the identification of archaeologically attractive landscape features on aerial photographs or from nearby roads. These features included river valleys, deflation hollows and rocky outcrops.

Owing to the variety and often ephemeral nature of the archaeology, the surveys were relatively informal: sites were recorded photographically, the presence of stone materials and diagnostic finds was noted, and GPS co-ordinates were obtained via a hand-held GPS receiver on the WGS84 datum. Of the sites recorded, four rock shelters had in situ deposits, three more had rock art and the remainder were open artefact scatters. Many of the latter are part of the background scatter covering much of the region and are best regarded as artefact exposures. My concern during survey was two fold:

1. To record the variability in type, age and distribution of sites so as to develop an understanding of the archaeological landscape; and

2. To locate sites suitable for excavation in an area about which nothing was known. 
The earlier commercial surveys targeted areas to be mined regardless of surface features. Comprehensive ground surveys were conducted, and sites were recorded through photography, GPS co-ordinates and site record forms. The spatial distribution of sites is thus dependent on mining and does not reflect prehistoric occupation patterns.

\subsection{Selection of sites for further study}

For various reasons, new excavations were conducted in southern Namaqualand only: (1) this area was least well known archaeologically; (2) it lies between the well documented Western Cape and the rest of Namaqualand - regions with seemingly contrasting archaeological signatures; (3) southern Namaqualand contains several rock shelters and small caves which, it was anticipated, would provide a good complementary sequence to that revealed by the single occupation open sites in the north; (4) good preservation was expected in the Varsche River limestone shelters; and (5) pottery at one shelter suggested a pottery-period occupation and the opportunity to explore huntergatherer and herder signatures.

Previously excavated sites selected for further analysis were those containing sufficient cultural material, specifically stone artefacts, ostrich eggshell beads and/or pottery, to allow a good understanding of their cultural signatures. Larger excavations usually contained the most material, but smaller sites with distinctive remains were included as appropriate. Low-density or artefact-poor sites do contain information, perhaps even relating to an aspect of landscape use not readily identifiable from large excavations in rich sites (Orton 2007d), but, due to limits on the number of radiocarbon dates available, such sites were not specifically included in this study. It is acknowledged that culturally rich sites might represent aggregation sites and poor ones dispersal sites (sensu Wadley 1987), or the pattern might be time-dependent. Either way, relegation of the latter to the 
status of 'unworthy of further research' would be to ignore half the Namaqualand archaeological record. Others have also lamented the loss of archaeological data from areas of low-density occupation (e.g. Wandsnider \& Camilli 1992) and this aspect should be pulled into every large-scale research project. Where possible this is done, but the limited use of such sites to the present project is inescapable.

\subsection{Excavation}

Reception Shelter and Buzz Shelter in the Knersvlakte and the KK002 rock shelter in the southernmost Hardeveld, were excavated stratigraphically, following visible depositional breaks, but with arbitrary spits used to break larger layers. Spatial units of $0.25 \mathrm{~m}^{2}$ were employed and material was collected by layer and square. Detailed piece plotting was employed at first, but was found to offer no advantages over collection by square and to significantly slow the pace of excavation. Unless specifically specified, all deposit was screened on a $3 \mathrm{~mm}$ mesh owing to the unmanageable quantities of very fine vegetal matter and/or fine gravel that accumulated in the $1.5 \mathrm{~mm}$ sieve initially employed. Bulk samples were taken from Reception Shelter for micromammals and were later screened on a $1 \mathrm{~mm}$ mesh. The open site, VR048, was deflated to a single surface and, owing to its low density and great extent, $1 \mathrm{~m}^{2}$ spatial units were used.

The commercial excavated sites in the coastal diamond mines tended to have single occupation horizons and were sometimes deflated. These were invariably dug in $1 \mathrm{~m}^{2}$ units, but with $0.25 \mathrm{~m}^{2}$ units used occasionally when good spatial patterning was present. Sieving generally proceeded on a $3 \mathrm{~mm}$ mesh, but, when appropriate, a $1.5 \mathrm{~mm}$ was used to recover small finds. In practice the latter was often tested and abandoned either due to lack of finds or excessive moisture. These techniques were born of a need to move quickly due to the large number of sites investigated during a typical field season. 


\subsection{Analysis and classification}

\subsubsection{Lithic typology}

Typological classification of flaked artefacts is generally complicated. I have been refining a system for use in southern Africa since 2001 with the long period of time being necessary to capture suitably all the subtleties of LSA assemblages from across the region. The scheme is strongly influenced by and based on that devised by Janette Deacon (1984b) for use in the southern Cape, but, by drawing on other studies from the subcontinent, it updates many definitions and applies more widely. Where possible, previously analysed Namaqualand assemblages were reanalysed following this typology to ensure consistency.

In recent years the 'chaîne opératoire' approach to lithic analysis has gained popularity, particularly among MSA and Middle Palaeolithic researchers. This method advocates an examination of all stages of the production sequence including stone procurement, technology, site and artefact function and final discard of the finished or used products (Grace 1997). However, in the present context it is not followed, since certain aspects would either extend beyond the intended scope of the research or not add meaningfully to it. The following reasons are advanced:

- Most stone in Namaqualand sites was locally sourced (within a day's walk), but some materials may have originated very far from the sites - the immensity of the study area rendered a physical search for them unfeasible;

- Technology is guided by the nature and size of the stone nodules obtained. In Namaqualand this dictates little variation in flaking techniques with the same three core types perennially present. While refitting contributes meaningfully to some studies, it is virtually impossible with microlithic quartz debitage; 
- Site function is judged through the presence or absence of various categories of finds that inform on the primary activities carried out on site, while stone artefact function is best determined through use-wear and residue analyses. The former is typically within the remit of site reports, but the latter requires far more detailed study (e.g. Binneman 1982, 1984; Williamson 1997); and

- Spatial analysis of artefact discard patterns allows a deeper understanding of specific sites but is again better suited to site reports.

Given the relatively short period covered by this research (6000 years) and the rapid change evident through time, typological analysis is considered most informative. Table 4.1 presents the flaked artefact typology, including only those classes found in the Namaqualand assemblages reported here.

Table 4.1: Stone artefact typology.

\begin{tabular}{ll}
\hline Class & Definition \\
\hline Bipolar core & $\begin{array}{l}\text { A core with removals from thin opposing platforms. Scars originate from } \\
\text { one or both ends and occur on one or more faces. Worked on an anvil, } \\
\text { their upper platform invariably forms parallel to the anvil surface and is } \\
\text { concave in shape with the lower being straight and oblique to the anvil. } \\
\text { They are often broken, preserving only one platform. }\end{array}$ \\
\hline Bipolar bladelet core & $\begin{array}{l}\text { A variably sized bipolar core characterised by long thin removals, some of } \\
\text { which may extend the entire length of the core. }\end{array}$ \\
\hline Single platform core & $\begin{array}{l}\text { A core from which at least three flakes have been removed from a single } \\
\text { platform. The platform may have been created by a split or an earlier set } \\
\text { of scars whose initiation points are not preserved. Rare examples have } \\
\text { two opposing and independently functioning platforms; the resulting flake } \\
\text { scars do not intersect. }\end{array}$ \\
\hline Single platform & $\begin{array}{l}\text { As above but often cone-shaped due to the removal of bladelets from } \\
\text { around the perimeter of the platform and displaying at least one scar of } \\
\text { bladelet core }\end{array}$ \\
bladelet proportions. \\
\hline An irregular shaped and frequently blocky core exhibiting at least three \\
flake removals from two or more platforms. \\
\hline Arregular core
\end{tabular}




\begin{tabular}{|c|c|}
\hline Class & Definition \\
\hline \multicolumn{2}{|r|}{ Retouched: Scrapers } \\
\hline Backed scraper & $\begin{array}{l}\text { A scraper invariably made on a flake with a high dorsal ridge and with } \\
\text { backing opposing the scraper retouch. The retouched edges intersect to } \\
\text { form points at each end. Although usually strongly patterned, variation in } \\
\text { form (e.g. partial natural backing or non-pointed ends) does occur. }\end{array}$ \\
\hline Sidescraper & $\begin{array}{l}\text { A scraper of } \leq 30 \mathrm{~mm} \text { and retouched on one side of the long axis of a } \\
\text { flake. The retouch can be restricted to the side or can slightly wrap around } \\
\text { onto the ends. }\end{array}$ \\
\hline Large sidescraper & As above but with a maximum length $>30 \mathrm{~mm}$. \\
\hline Double sidescraper & $\begin{array}{l}\text { A scraper of } \leq 30 \mathrm{~mm} \text { and retouched along both sides of the long axis of a } \\
\text { flake. }\end{array}$ \\
\hline Endscraper & $\begin{array}{l}\text { A scraper of } \leq 30 \mathrm{~mm} \text { and made by retouching one end of the long axis of } \\
\text { a flake. This is usually the distal end of a long, often parallel-sided flake. } \\
\text { The retouch may be restricted to the one end or may slightly wrap around } \\
\text { onto the sides. }\end{array}$ \\
\hline Double endscraper & A scraper of $\leq 30 \mathrm{~mm}$ and retouched on both ends of its long axis. \\
\hline Side-endscraper & $\begin{array}{l}\text { A scraper of } \leq 30 \mathrm{~mm} \text { and retouched on two or more adjacent sides or } \\
\text { ends. }\end{array}$ \\
\hline Thumbnail scraper & $\begin{array}{l}\text { A shape-dependant variation of an endscraper } \leq 30 \mathrm{~mm} \text { and where width } \\
\text { and length are similar (width is usually slightly greater) and the retouch } \\
\text { opposes the bulb. They grade into endscrapers and sidescrapers but } \\
\text { intermediate sized examples are rare. }\end{array}$ \\
\hline $\begin{array}{l}\text { Large thumbnail } \\
\text { scraper }\end{array}$ & As above but with a maximum dimension $>30 \mathrm{~mm}$. \\
\hline Circular scraper & $\begin{array}{l}\text { A variably but } \leq 30 \mathrm{~mm} \text { long scraper where the retouch extends around the } \\
\text { perimeter of the flake creating an approximately circular shape in plan } \\
\text { view. The tool can be shaped by the retouch or have the retouch added to } \\
\text { an already circular (and frequently cortical) flake. (Large circular scrapers } \\
\text { - not present in this study - exceed } 30 \mathrm{~mm} \text { in maximum dimension.) }\end{array}$ \\
\hline $\begin{array}{l}\text { Miscellaneous } \\
\text { backed scraper }\end{array}$ & Any scraper with backing on it that does not conform to 'backed scraper'. \\
\hline $\begin{array}{l}\text { Miscellaneous } \\
\text { scraper }\end{array}$ & $\begin{array}{l}\text { A scraper of } \leq 30 \mathrm{~mm} \text { and with enough of the shape preserved to } \\
\text { demonstrate that it does not conform to any other scraper class. }\end{array}$ \\
\hline $\begin{array}{l}\text { Large miscellaneous } \\
\text { scraper }\end{array}$ & ension $>30 \mathrm{mn}$ \\
\hline
\end{tabular}

A broken scraper or a scraper edge accidentally broken or deliberately

Scraper fragment struck off a scraper and for which the original shape (and type) can no longer be determined. 


\begin{tabular}{|c|c|}
\hline Class & Definition \\
\hline \multicolumn{2}{|r|}{ Retouched: Backed tools } \\
\hline Backed flake & A flake with backing on one long margin, usually opposing a sharp edge. \\
\hline Back & $\begin{array}{l}\text { An artefact of blade proportions with a straight backed margin opposing } \\
\text { and parallel to a straight, sharp edge. Neither end terminates in a point. }\end{array}$ \\
\hline Backed bladelet & $\begin{array}{l}\text { As for backed blade but with maximum dimension }<25 \mathrm{~mm} \text {. Broken pieces } \\
\text { retaining bladelet proportions are included, although whether they } \\
\text { originated from backed blades or bladelets will be unknown. }\end{array}$ \\
\hline Backed point & $\begin{array}{l}\text { A backed bladelet with the straight backed and opposing margins } \\
\text { intersecting to form a sharp point. Broken pieces retaining bladelet } \\
\text { proportions are included here if their edges taper towards one another }\end{array}$ \\
\hline Curve-backed flake & $\begin{array}{l}\text { A backed flake on which the distal (or occasionally proximal) portion of the } \\
\text { backed edge is slightly convex, meeting the opposing edge at between } \\
\text { approximately } 30-60^{\circ} \text {. The backing often does not extend down the entire } \\
\text { length of the piece but is focussed on the distal, pointed end. }\end{array}$ \\
\hline $\begin{array}{l}\text { Curve-backed } \\
\text { bladelet }\end{array}$ & above but the artefact retains bladelet proportions. \\
\hline $\begin{array}{l}\text { Double-backed } \\
\text { bladelet }\end{array}$ & $\mathrm{db}$ \\
\hline Double-backed point & $\begin{array}{l}\text { A backed bladelet with both laterals backed and meeting to form a sharp } \\
\text { point. }\end{array}$ \\
\hline $\begin{array}{l}\text { Backed bladelet } \\
\text { fragment }\end{array}$ & $\begin{array}{l}\text { Any backed fragment not retaining bladelet proportions but which is likely } \\
\text { to have originated from a piece of such proportions. To be a fragment and } \\
\text { not one of the discard classes described by Movius et al. (1968) and } \mathrm{H} \text {. } \\
\text { Deacon (1976), the piece should be backed along its entire length and } \\
\text { have the proximal or distal fraction and one or two breaks at its ends. }\end{array}$ \\
\hline $\begin{array}{l}\text { Backed point } \\
\text { fragment }\end{array}$ & $\begin{array}{l}\text { Essentially a subclass of 'backed bladelet fragment', this class necessarily } \\
\text { refers to distal fragments of backed points only. }\end{array}$ \\
\hline Truncated flake & $\begin{array}{l}\text { A flake that has been truncated by the application of backing in opposition } \\
\text { to the distal end. The retouch is often at an angle to the length of the flake. }\end{array}$ \\
\hline Truncated bladelet & As above but the piece has bladelet proportions. \\
\hline Borer & $\begin{array}{l}\text { A bilaterally backed bladelet tool with parallel to gently tapering sides and } \\
\text { a blunt tip. The backing usually does not extend along the entire length of } \\
\text { the artefact. Despite much variety in shape, the cross-section is generally } \\
\text { square to triangular and the tip frequently rounded and polished from use. }\end{array}$ \\
\hline Segment & $\begin{array}{l}\text { An artefact of } \leq 30 \mathrm{~mm} \text { and with a backed arc intersecting a sharp, straight } \\
\text { or very slightly curved chord at both ends. A dorsal ridge may be present. } \\
\text { The ends are pointed with the angle between the backed margin and the } \\
\text { chord (and hence the width of the piece) being variable. }\end{array}$ \\
\hline
\end{tabular}




\begin{tabular}{ll}
\hline Class & Definition \\
\hline Large segment & $\begin{array}{l}\text { As above but with a maximum length of about 30-45 mm. The lower size } \\
\text { limit is slightly flexible according to the size of other segments present. }\end{array}$ \\
\hline $\begin{array}{l}\text { Triangle } \\
\text { A triangular piece with two straight, intersecting backed edges of similar } \\
\text { length opposing a straight, sharp edge. Equilateral forms predominate. }\end{array}$ \\
$\begin{array}{l}\text { A parallel-sided artefact with opposing truncations on its ends that form } \\
\text { acute angles with one unretouched margin and obtuse angles with the } \\
\text { other. The length exceeds the width. (Differentiated from tranchets - not } \\
\text { present in this study - in which width exceeds length.) }\end{array}$ \\
$\begin{array}{l}\text { Miscellaneous } \\
\text { backed piece }\end{array}$ \\
$\begin{array}{l}\text { A deliberately backed artefact with enough of the piece preserved to } \\
\text { democked piece } \\
\text { fragment }\end{array}$ \\
$\begin{array}{l}\text { Any broken piece with backing retouch, but excluding backed bladelet and } \\
\text { point fragments, where the form (and type) of the original artefact is } \\
\text { uncertain. }\end{array}$ \\
\hline Adze & $\begin{array}{l}\text { A variable but often roughly rectangular piece with a step-flaked working } \\
\text { edge on one or both sides. These edges are typically slightly concave but } \\
\text { can be straight or very slightly convex. The scars are usually larger than } \\
\text { those on scrapers and are the cumulative result of both retouch to shape } \\
\text { the piece and use damage. }\end{array}$
\end{tabular}

Notched piece (rarely) two notches of variable size deliberately flaked into an edge. The notch is substantially smaller than that on an adze.

A piece with three or more fine, uniformly spaced notches (approximately

Denticulate 1-2 $\mathrm{mm}$ diameter) retouched into an edge to give a comb-like appearance. Notched edges can be convex or straight in plan view and can vary from less than $30^{\circ}$ to about $70^{\circ}$ in cross-section

Large chopper An artefact usually roughly flaked in a bifacial manner to produce a semisharp chopping edge. This edge should display some battering from use. The artefact is $>100 \mathrm{~mm}$ in maximum dimension. (Differentiated from small choppers - not present in this study - in which length is $\leq 100 \mathrm{~mm}$.)

\begin{tabular}{ll}
$\begin{array}{l}\text { Miscellaneous } \\
\text { retouched piece }\end{array}$ & $\begin{array}{l}\text { A piece where the retouch does not conform to any recognisable pattern } \\
\text { and the artefact can thus not be placed in any of the above classes. }\end{array}$ \\
\hline Flake & \multicolumn{1}{c}{ Debitage } \\
& $\begin{array}{l}\geq 10 \mathrm{~mm} \text { and showing a bulb of percussion and/or discernible striking } \\
\text { platform and/or recognisable dorsal and ventral surfaces. Fragments are } \\
\text { included where they fit the size criterion. }\end{array}$
\end{tabular}




\begin{tabular}{ll}
\hline Class & Definition \\
\hline Blade & A flake (as above) of $\geq 25 \mathrm{~mm}$ length with a length:breadth ratio $\geq 2$ and \\
with roughly parallel sides. Fragments are only included where, beyond \\
reasonable doubt, they would fit the size and length:breadth criteria.
\end{tabular}

It should be noted that the presence of cortext is excluded from the typology as this is usually impossible to identify on quartz quarried from veins and the CCS only very rarely exhibits cortex.Grindstones are identified by their smoothed and sometimes faceted surfaces, anvils by occasional pitting, usually in the centre of a large surface, and hammer stones by the characteristic pitting and crushing along a convex edge. Combinations and fragments are recognised as required.

\subsubsection{Stone materials}

Namaqualand is a complex and primarily metamorphic landscape, but the rocks flaked by its prehistoric inhabitants are generally sedimentary. The most commonly flaked materials are homogenous and isotropic - i.e. their mechanical properties are similar in all directions - making them ideal for flaking. Most, however, are only available in small nodules. In the Richtersveld and the southern parts of Namaqualand many materials 
were obtained in pebble form. Pebbles are always strong and durable, having already survived a river journey, and are thus particularly suited to flaking.

Archaeological classification of stone materials is very subjective. I consider three "classifications" of raw materials to exist:

1. The makers of the artefacts would have considered merely which rocks were suitable for which purposes and how they behaved during flaking. This would have mixed different rock types according to their utility;

2. Archaeologists tend to separate rocks on their physical appearance, based on a visual examination of small fragments. This is not always geologically sound; and

3. Geologists, via thin petrographic sections and/or examination of the source outcrops, will accurately classify rock types based on their formation processes.

The problems faced by archaeologists are compounded by the frequency with which different rock types grade into one another, whether geologically or visually. Because it is destructive, archaeologists seldom employ thin sections. We are thus forced to make a best estimate and, when all else fails, the 'other' category is used. What follows is a brief description of each rock type (or group of rocks) as identified archaeologically; visual and basic geological characteristics are included.

\section{$\underline{\text { Quartz }}$}

This is the most widely flaked material in the southern African LSA. Quartz is a coarse, crystalline mineral commonly encountered in other rocks, invariably as the primary constituent. Although quartz occurs in various colours, only clear and milky quartz are common archaeologically. Clear quartz ${ }^{15}$ is pure, while the white colour of milky quartz is

\footnotetext{
${ }^{15}$ The terms 'rock crystal' and 'crystal quartz' are sometimes used but should refer only to actual crystals. Most of the clear quartz in Namaqualand likely came from bedrock veins.
} 
caused by many tiny fluid inclusions (Nesse 2000). Two primary sources occur: bedrock veins and river pebbles. Crystals are unlikely to occur in the Sandveld (G. Moseley, pers. comm. 2012) but veins are ubiquitous across the study area with quarried quartz outcrops common within a few kilometres of the shore. These outcrops vary from white to translucent with thin flakes being clear. Despite its conchoidal fracture, the presence of crystal facets and cleavage planes causes a degree of unpredictability during flaking. Clear and milky quartz were not separated during analysis as they grade into one another, but the presence of retouched artefacts on clear quartz and the dominance of either variety were noted. The presence of frequent crystal facets on the clear quartz flakes at Jakkalsberg $L$ (Orton \& Hallkett 2010) shows that crystals were obtained in the far north. They are common in the Orange River Pegmatite Belt to the west of the Richtersveld (G. Moseley, pers. comm. 2012).

\section{Sandstone}

This rock type is relatively uncommon in Namaqualand. It is composed of cemented sand-sized $(0.06-2.00 \mathrm{~mm})$ grains with pore spaces. In older sandstones the pores may be partially or completely filled (Pettijohn 1975). Precipitated cements improve the quality of the rock for flaking, but the sand grains are usually still the strongest part of the rock resulting in fracture around rather than through the grains. Due to its relatively poor flaking properties it was seldom flaked during the LSA but was used for grindstones.

\section{Quartzite}

Quartzite is patchily distributed throughout Namaqualand but, despite its reasonable flaking properties, was seldom flaked in any quantity. Near Kleinzee, fragments of pale, strongly bedded quartzite from a coastal outcrop just south of the town are common in archaeological sites. This particular rock was often used for lower grindstones. Most quartzites are fairly coarse-grained, but some occur as fine-grained rocks well suited to flaking. These latter are particularly evident in southern Namaqualand where the many 
varieties originate from river cobbles. Quartzite is metamorphosed sandstone. The degree of metamorphism increases with depth causing some intergrading between the two forms. During metamorphosis, sandstone is melted and recrystallised such that the resulting quartzite is composed of a mosaic of interlocking crystals with any earlier cements usually no longer visible (Whitten \& Brooks 1972). Quartzites appearing visually similar to quartz are identified on the basis of visible crystalline structure rather than by their opacity or translucence; quartz has a smoother, glassy texture.

\section{$\underline{\text { Silcrete }}$}

Although highly variable, good quality, fine-grained silcrete is one of the best rocks for flaking. Silcrete is identified by the variably-sized granular inclusions in an otherwise homogenous background. Surface outcrops are common in the south (Du Toit 1954) and on the Knersvlakte one finds small boulders and cobbles of silcrete within the raised terraces. Roberts (2003: fig. 4.1) has mapped the known occurrences, noting the dearth in northern Namaqualand as probably being due to insufficient information. Paraphrasing Summerfield (1983), Botha (2000:137) describes silcrete as "the product of cementation, induration or replacement of bedrock or regolith with siliceous compounds by surficial or penesurficial processes". Such processes entail the mobilisation and redeposition of silica relatively close to the earth's surface and are usually associated with deep weathering profiles (Wasson et al. 1979). The great variety in appearance and quality of silcrete is due to both the wide range of host materials in which they form and the differences in geochemical conditions under which silicification takes place (Summerfield 1982). Furthermore, the degree of silicification decreases with depth so that the silcrete becomes softer and more porous as it grades into less consolidated material below (Theron 1984). Isolated clay lenses and irregular cavities can be present and differential silicification results in hard, rocky lumps of silcrete alternating with softer, poorly consolidated, sandy material. Silcrete varies in colour with red, white, grey, yellow and brown all occurring. The rock usually has a vitreous sheen and a slightly greasy feel 
(Hutton et al. 1978). The most common silcretes have more than 5\% grain content and the grains are not self-supporting (Summerfield 1982, 1983). These are also most common archaeologically. The matrix of silcrete is very fine-grained quartz, essentially similar to the CCS described below. Wagner and Merensky (1928:11) note that some of the silcretes in the northern parts of near-coastal Namaqualand are fine-grained but that "for the most part they are of the nature of breccias composed of angular fragments of quartz, quartzite and other rocks in a matrix of grey or yellowish-brown ferruginous chalcedonic silica."

\section{$\underline{\mathrm{CCS}}$}

Cryptocrystalline silica is a generic term applied by southern African archaeologists to cover a variety of fine-grained silicious rocks including chert and chalcedony. Both types are microcrystalline quartz aggregates that can be very similar in hand specimen but are distinguishable in thin section (Nesse 2000). CCS has good conchoidal fracture and is excellent for flaking but often occurs only as small nodules. In Namaqualand CCS is usually pale in colour and slightly translucent, but darker (often brown) opaque varieties are also found. In the current and palaeo-Orange River channels they occur as river pebbles presumably derived ultimately from the basalt of the Maloti-Drakensberg Mountains (Visser \& Van Riet Lowe 1955). In the Sandveld clues to its local origin come from the calcrete-like cortex on some artefacts; possible source areas in calcrete have been identified southeast of Kleinzee (Orton \& Webley 2012a). Andrefsky (2005) notes the common occurrence of chert nodules in rocks such as limestone and it is most likely that calcrete beds are the source of the Sandveld CCS. North of the Orange River they can be collected from the beach (Cornell 1920), but such cobbles are likely to be buried along South African shores (G. Moseley, pers. comm. 2012). 


\section{Fine-Grained Black Rocks (FGBR)}

This term represents all those visually similar, very dark, fine-grained rocks which are impossible to identify without a petrographic section (Orton 2004, 2006). They likely include very fine-grained quartzites, dark shales in varying states of metamorphism (including the final stage - hornfels) and possibly some very dark CCS. Such unidentifiable rocks would usually be incorporated within 'other', but it seemed sensible to separate them out due to their better quality than many other unidentifiable rocks. Encountering the same problem, Wadley (1987) used the less descriptive term 'black rock' to refer to similar materials. Generally these rocks will behave in a similar manner to CCS and all display conchoidal fracture. They are invariably obtained as pebbles and, accordingly, are often encountered close to the Orange River and its palaeo-channels.

\section{$\underline{\text { Other }}$}

This term catches all remaining rocks that for various reasons are not readily identifiable in hand specimen, or are simply too rarely encountered to merit inclusion as a separate category. Heavily patinated rocks are sometimes necessarily included here, while many others quite likely have an igneous origin.

\subsubsection{Pottery}

Information from a course ${ }^{16}$ on prehistoric pottery and from published work (Sadr \& Sampson 1999; Sampson 1988; Sampson \& Sadr 1999) was used in the classification and description of the pottery (Figure 4.1; Table 4.2). Although Rudner's (1968; table 1) work was also helpful, the kind of detail captured by him was not possible due to the general lack of reconstructed pots in my samples. Although not all proved useful for analysis, data on thickness, weight, temper (Table 4.3), colour, decoration and lip forms

\footnotetext{
${ }^{16}$ University of the Witwatersrand, South Africa, $15^{\text {th }}-18^{\text {th }}$ December 2008.
} 
were captured for each sherd as appropriate. Refitting was attempted where feasible. For each sherd a mean thickness was calculated from its maximum and minimum values (rims with their artificially thinned edges were avoided when possible). Temper was examined with a hand lens and was invariably mineral (quartz, mica and/or other rock types) with many of the smallest grains likely natural inclusions in the original clay. Grog (fragmented old potsherds used as temper; four known occurrences; Rudner 1968; Stewart 2005) and fibre-temper (one known occurrence; unpublished data) are extremely rare in far-western South Africa. Due to the strong colour variation resulting directly from weathering, only generalised colours were assigned.

Table 4.2: Terminology used in the classification of Cape coastal pottery types from oldest to youngest as proposed by Sadr and Smith (1991) and refined by Sadr and Sampson (1999).

\begin{tabular}{lll}
\hline Acronym & Name and description & $\begin{array}{l}\text { Approximate temporal } \\
\text { occurrence }\end{array}$ \\
\hline SPINC & $\begin{array}{l}\text { Spouted incised: spouted pot with incised } \\
\text { decoration. }\end{array}$ & Pre-AD 400-AD 650 \\
SPIMP & $\begin{array}{l}\text { Spouted impressed: spouted pot with } \\
\text { impressed decoration. }\end{array}$ & AD 650-AD 850 \\
LUND & $\begin{array}{l}\text { Lugged undecorated: lugged, undecorated } \\
\text { pot. } \\
\text { Lugged incised: lugged pot with incised } \\
\text { LINC }\end{array}$ & AD 850-AD 1250 \\
\hline
\end{tabular}

Decoration is either incised or impressed with various combinations of dots and long or short lines being employed. Incised is either fine or broad depending on the means of application (e.g. tip or side of a porcupine quill respectively). Rudner (1968) and Sampson (1988) refer to broad incisions as 'grooved' and 'channel' decoration respectively. Although there is certainly a continuum of groove widths, the separation between fine and broad-incised is made at about $1 \mathrm{~mm}$ width. Vessel mouth diameter, was estimated when possible from a best-fit on concentric circles of known diameter (to the nearest $20 \mathrm{~mm}$ ). Rim orientation and form are also listed. Four orientations and eight 
rim forms have been described (Figure 4.1), but Sampson and Sadr (1999) note two classification problems. Firstly, some vessels are asymmetrical, falling into two categories. Open (flared), vertical and convergent rims are likely arbitrary divisions of a single shape continuum, but wide-open vessels (platters) are still considered a discrete class. Secondly, some sherds/pots display two lip forms, indicating a degree of intravessel lip variation. Summaries of the Namaqualand pottery data are recorded in Appendix 1.

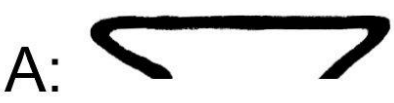

wide-open

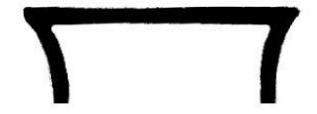

flared

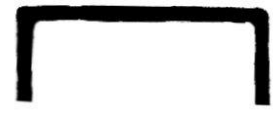

vertical

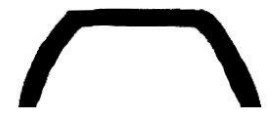

convergent

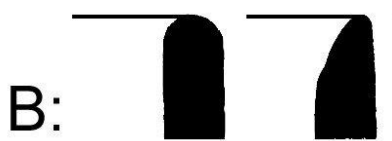

simple round

tapered

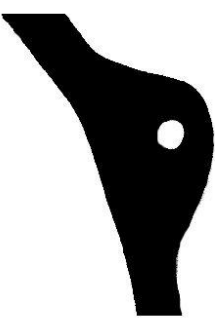

lug

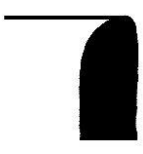

halfround

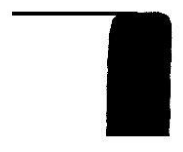

flat-top

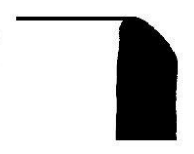

bevelled

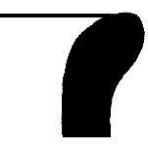

everted

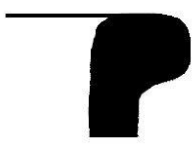

thickened round

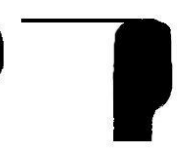

thickened flat

C.

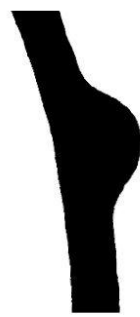

boss

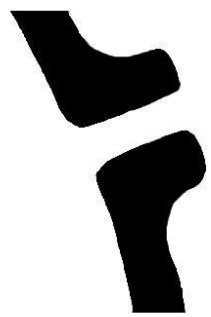

spout

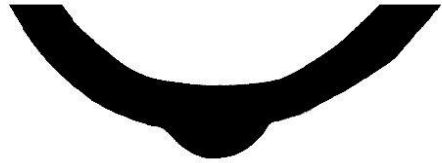

nippled base

Figure 4.1: Terminology used in the classification of pottery. A: rim orientations, B: lip forms and C: external features (redrawn from Sadr \& Sampson 1999: fig. 3; Sampson \& Sadr 1999: fig 2 \& fig. 3; Rudner 1968, table $1 \&$ fig. V). While A and B are comprehensive, C includes only features relevant to the present samples.

Table 4.3: Grain sizes of pottery temper.

\begin{tabular}{ll}
\hline Temper size & Visual description \\
\hline Very small & Texture not obviously visible \\
Small & Texture visible but grains too small to practically estimate average size \\
$0.5 \mathrm{~mm}$ & Most visible grains are approximately $0.5 \mathrm{~mm}$ in diameter \\
$1.0 \mathrm{~mm}$ & Most visible grains are approximately $1.0 \mathrm{~mm}$ in diameter; etc. \\
\hline
\end{tabular}




\subsubsection{Ostrich eggshell beads}

Following Yates (1995), the maximum external and minimum internal diameters of ostrich eggshell beads were measured. Thickness measurements were also taken and manufacturing stages follow Orton (2008d; Table 4.4). The terms small, medium, large and very large are used formally to denote bead size as follows:

- Small: $\leq 5 \mathrm{~mm}$;

- Medium: 5.01-6 mm;

- Large: $6.01-7.5 \mathrm{~mm}$; and

- Very large: $>7.5 \mathrm{~mm}$.

The lower size limit for very large beads is based on Jacobson's (1987) link between the Khoekhoen and beads of this size.

Table 4.4: Classification stages of unfinished ostrich eggshell beads as described by Orton (2008d: table 1).

\begin{tabular}{ll}
\hline Stage & Description \\
\hline- & Irregular ostrich eggshell fragment \\
I Ila, Ilb & Modified ostrich eggshell fragment \\
IIIa, IIlb & Partly drilled hole but not yet pierced \\
IVa, IVb & Partly trimmed edge \\
Va, Vb & Completely trimmed edge \\
Vla, VIb & Partly ground \\
VIlla, VIlb & Completely ground \\
\hline
\end{tabular}




\subsubsection{Glass beads}

Sizes are measured in the same manner as ostrich eggshell beads, but photographs of the glass beads were sent to Marilee Wood ${ }^{17}$ for technical identification of types.

\subsubsection{Shellfish and fauna}

I conducted shellfish species analysis for those sites not already reported by Dewar (2008), and also basic analyses on faunal remains where these were particularly sparse. Larger samples with more identifiable material were examined by faunal specialists. Most assemblages from the northern Sandveld were analysed by $\mathrm{Dr}$ Genevieve Dewar, while the remainder, as well as those from the Knersvlakte and Richtersveld areas were analysed by Prof. Richard Klein and Dr Teresa Steele. Drs Dewar and Steele are currently engaged in other research in Namaqualand.

\footnotetext{
${ }^{17}$ Dr Wood (2011a, 2011b; Robertshaw et al. 2010) has recently conducted extensive research on southern African archaeological glass beads and is presently best placed to identify them.
} 


\section{Chapter 5. Namaqualand assemblages}

This chapter describes the appearance, location and cultural materials of the analysed sites. Pottery data are summarised in Appendix 1 , subsistence data are tabulated in Appendix 2 and all dates apear in full in Appendix 3. Figure 5.1 maps the sites $^{18}$.

Since 2002, I have analysed several hundred northern Sandveld assemblages of varying size, It has become apparent, based on visual impressions of the flaked stone artefacts, that the vast majority were easily and reliably separable into four groups. Although this separation is intuitive, graphical analyses of their defining characteristics at the start of Chapter 6 demonstrate that they hold true. It should be noted that different Groups can co-occur if certain defining characteristics of each are strongly present within a single assemblage. These groups are used as the basis for the analyses that follow in Chapter 6 and are described as follows:

- Group 1: Assemblages containing a significant proportion ( 20-40\%) of CCS or finegrained silcrete and many retouched tools in these materials (it is assumed that silcrete was employed based on availability as an alternative to CCS);

- Group 2: Assemblages appearing very informal and based almost exclusively on milky quartz and quartzite;

- Group 3: Assemblages rich in backed artefacts and manufactured almost exclusively ( 95-99\%) on clear quartz; and

- Group 4: Assemblages with no or extremely few flaked artefacts.

${ }^{18}$ Note that , due to the biased distribution of excavations (dependent on mining areas and hence CRM work) and the very small number of sites considered in this research relative to all recorded sites in the region (probably close to 2000 in total distributed widely throughout the coastal landscape), the individual Groups have not been mapped. 


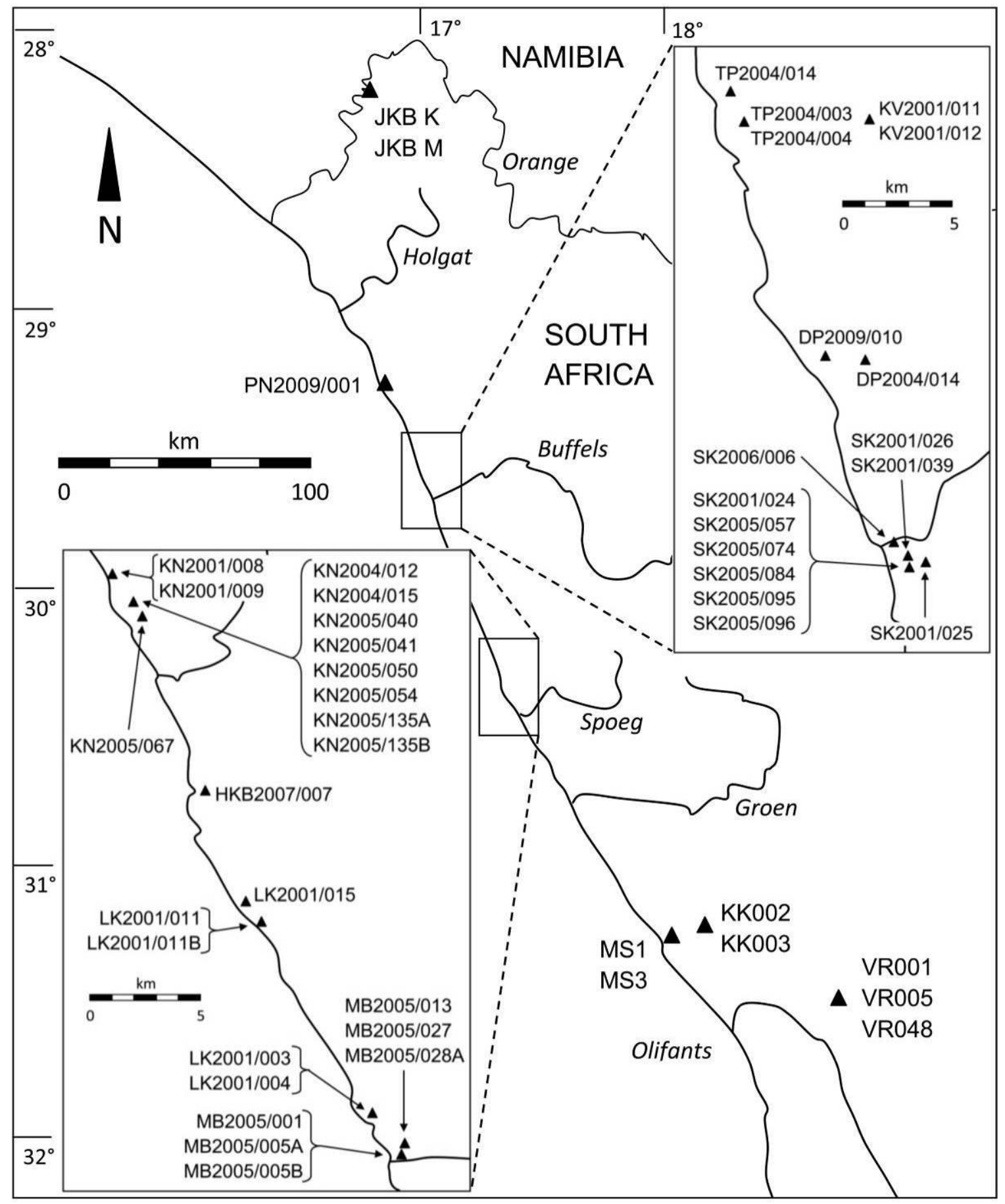

Figure 5.1: Map showing the locations of the sites discussed in Chapter 5.

Group 4 assemblages may represent a real component of the Namaqualand cultural sequence; they may have been left by particular groups of people or been the product of particular activities for which flaked stone artefacts were not required in any number. It is also possible, however, that they are the result of small excavations with biased samples, or that the people simply moved on before making any artefacts. Given this 
uncertainty and the limited cultural data they contain it was thought best to exclude most such assemblages from the project.

\subsection{Northern Sandveld}

This is the region for which we have the most archaeological data. A large number of sites have received excavations ranging in size from $1 \mathrm{~m}^{2}$ (simply for a shell sample) to $180 \mathrm{~m}^{2}$, but with the majority being in the order of $5-10 \mathrm{~m}^{2}$. Many sites in this region present as open, deflated occurrences among low sand dunes, but some are buried and in situ, betrayed only by the presence of occasional shells on the surface. The latter frequently retain vertical integrity but many sites with lower shellfish density appear to have been bioturbated. It is likely that many deeply buried sites are not located during archaeological surveys - one that was found where a mine trench had intersected a dune was some $7 \mathrm{~m}$ below the dune crest. Organic preservation is very poor on exposed sites, but buried middens often contain rich faunal assemblages. Cultural material is usually abundant, but is frequently limited to lithics, particularly in the older sites.

The sites researched for the first time here are presented in alphanumeric order, after which those sites already published elsewhere are briefly discussed. Site names from the northern and central areas follow a convention: farm name or town acronym and year of discovery/site number for that year and farm/town (e.g. KN2005/040). The farms/towns involved, from north to south, are Port Nolloth (PN), Tweepad (TP), Dreyer's Pan (DP), Mannel's Vlei (MV), Sandkop (SK), Koingnaas (KN), Hondeklipbaai (HKB), Langklip (LK) and Mitchell's Bay (MB), Sites in the south simply have an acronym followed by a site number (e.g. VR005). Sites lie on Komkans (KK), Mineral Sands Mine (MS) and Varsche Rivier Farm (VR). The Jakkalsberg (JKB) sites in the Richtersveld are named after the nearby mountain of that name. Alternative names are provided where 
these exist. Since this thesis concerns itself only with the type of cultural material present rather than its density, I do not provide full excavation details. These can usually be found in the relevant CRM reports and/or field note books, copies of which are on file with the author. Since the majority of sites are open and often deflated occurrences, density is meaningless, varying only according to the quantity of wind-blown sand incorporated in the deposit.

\subsubsection{DP2004/010}

\section{The site}

This small shell midden lay among hummock dunes at the eastern (inland) edge of a dune field, $1 \mathrm{~km}$ from the coast and some 200 m southwest of Karas Pan (29³5'54.7" S $\left.17^{\circ} 01^{\prime} 49.8^{\prime \prime} \mathrm{E}\right)$. The midden formed a small mound surrounded by lower density shell scatter, with a second scatter some $15 \mathrm{~m}$ to the south. The excavation covered $14 \mathrm{~m}^{2}$ at the main midden, Patch $\mathrm{A}$, and $5 \mathrm{~m}^{2}$ at the smaller scatter, Patch B (Orton \& Halkett 2005). Suitable dating material was absent from Patch B, but Patch $A$ has the following date:

\begin{tabular}{|c|c|c|c|c|}
\hline Lab. No. & Provenience & Material & ${ }^{14} \mathrm{C}$ date $\mathrm{BP}$ & Calibrated age (95.4\%) \\
\hline OxA-24078 & $\mathrm{H} 16$ & Charcoal (sp. unknown) & $712 \pm 24$ & AD 1282-1388 \\
\hline
\end{tabular}

It is not known whether the two patches relate to a single occupation, but activity differences could easily account for the varying signatures present. In the absence of a compelling reason to separate them, the patches are assumed to be contemporary.

\section{$\underline{\text { Cultural material }}$}

The excavation recovered a small, informal stone artefact assemblage of quartz and quartzite that can be assigned to Group 2. Table 5.1 shows the finds from Patch A, while 
in Patch B there were only four flakes, one chunk and one chip in quartz and one quartzite flake. No retouched artefacts are present. A most unusual inclusion is the milled-edge pebble in Patch A. Although not thinned by grinding on either of its surfaces, the entire perimeter is 'milled' through hammer damage (Figure 5.2). Such artefacts are typical of the south coast of South Africa with only two other examples known from the west coast (Orton 2009b, 2009c). Its $65.8 \mathrm{~mm}$ diameter and $30.4 \mathrm{~mm}$ thickness are consistent with the south coast pattern as established at Noetzie Midden (Orton 2009b: fig. 12).

Table 5.1: Stone artefacts from Patch A at DP2004/010 (Group 2).

\begin{tabular}{lccccc}
\hline & Quartz & Silcrete & Quartzite & Sandstone & Other \\
\hline Bipolar core & 1 & - & 2 & - & - \\
Irregular core & 3 & - & - & - & - \\
Bladelet & 1 & - & - & - & - \\
Flake & 31 & 1 & 44 & 3 & 3 \\
Chunk & 15 & - & 15 & - & - \\
Chip & 18 & 1 & 2 & - & - \\
Total & 69 & $\mathbf{2}$ & $\mathbf{6 3}$ & $\mathbf{3}$ & $\mathbf{3}$ \\
Stone material \% total & $\mathbf{4 9 . 3}$ & $\mathbf{1 . 4}$ & $\mathbf{4 5 . 0}$ & $\mathbf{2 . 1}$ & $\mathbf{2 . 1}$ \\
Hammer stone & - & - & 1 & - & - \\
Upper grindstone fragment & - & - & - & 1 & - \\
Lower grindstone fragment & - & - & 1 & - & - \\
Milled-edged pebble & - & - & - & 1 & - \\
\hline
\end{tabular}
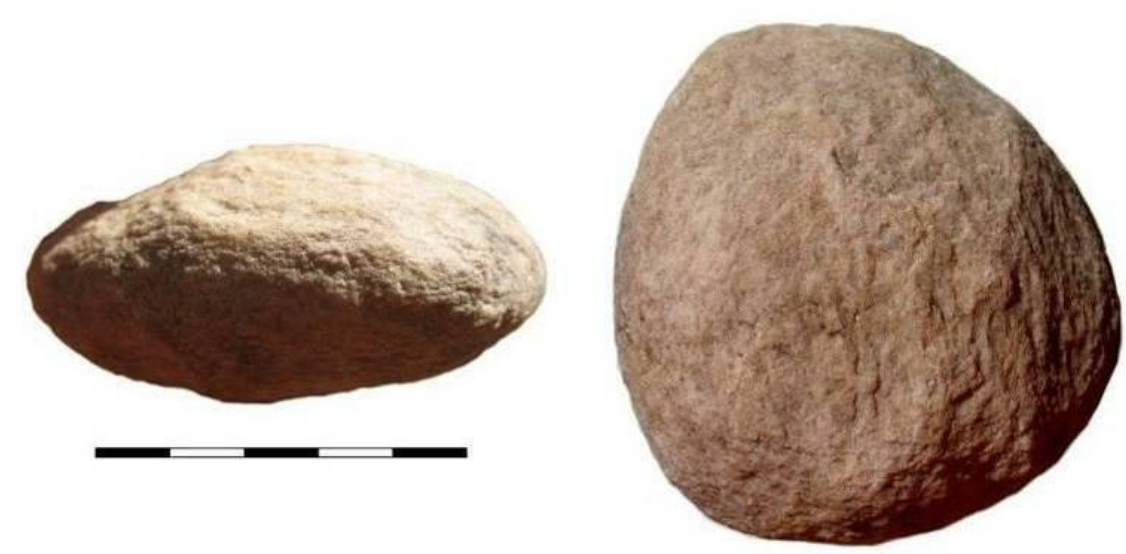

Figure 5.2: Lateral and plan views of the sandstone milled-edge pebble from Patch $A$ at DP2004/010. Scale in $10 \mathrm{~mm}$ intervals. 
Twenty ostrich eggshell beads came from Patch A (Table 5.2). The majority are large but some medium beads are also present. Although only three beads derive from Patch B, there is no reason to believe they originated from different populations (the sample is too small to meaningfully test this), though they may have come from different strings (Figure 5.3). Five flask fragments were found in the primary midden; two pairs refit.

Table 5.2: Summary statistics for finished ostrich eggshell beads from DP2004/010.

\begin{tabular}{llccc}
\hline Patch & & Outside diameter $(\mathrm{mm})$ & Aperture diameter $(\mathrm{mm})$ & Thickness $(\mathrm{mm})$ \\
\hline \multirow{3}{*}{$\mathrm{A}$} & Mean & 6.38 & 1.99 & 1.84 \\
$(\mathrm{n}=20)^{*}$ & Std Deviation & 0.70 & 0.40 & 0.12 \\
& Minimum & 5.36 & 1.48 & 1.65 \\
& Maximum & 7.26 & 2.61 & 2.14 \\
\hline \multirow{3}{*}{$\mathrm{B}(\mathrm{n}=3)$} & Mean & 6.21 & 2.63 & 1.71 \\
& Std Deviation & 0.05 & 0.28 & 0.08 \\
& Minimum & 6.16 & 2.41 & 1.65 \\
& Maximum & 6.26 & 2.95 & 1.80 \\
\hline
\end{tabular}

* Two beads were burnt and exfoliated such that for thickness $n=18$.

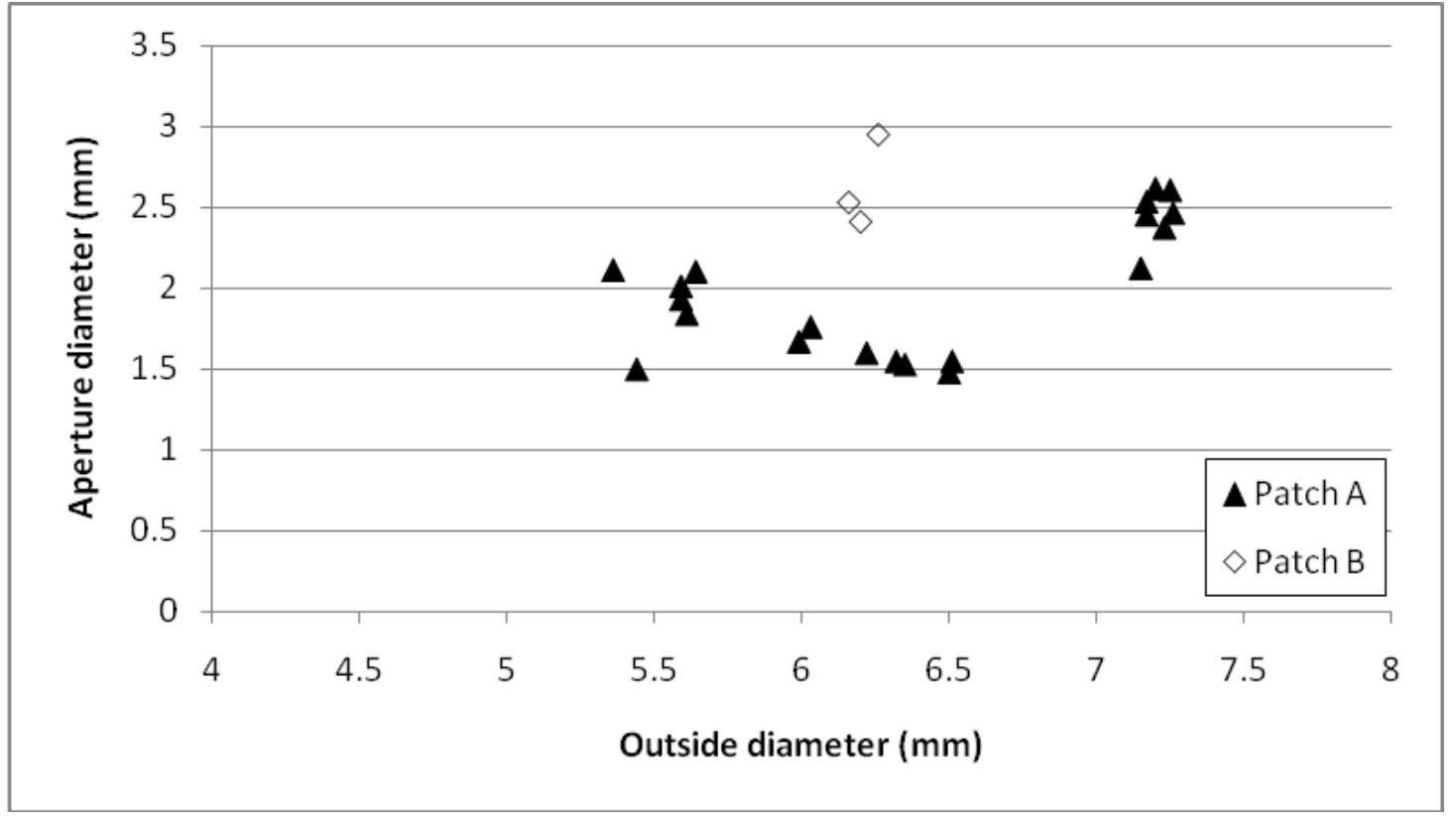

Figure 5.3: Scatter plot of ostrich eggshell bead dimensions from DP2004/010.

Four potsherds, together weighing $25.1 \mathrm{~g}$ and having a mean wall thickness of $5.51 \pm$ $0.34 \mathrm{~mm}$, were found in Patch $\mathrm{A}$, while a further 11 weighing $36.8 \mathrm{~g}$ and with a mean 
thickness of $5.09 \pm 0.18 \mathrm{~mm}$ came from Patch B. Two in Patch A refit and a third certainly comes from the same pot. All three exterior surfaces have a red slip painted on them and one is very tightly curved, perhaps originating from a spout. Another shows evidence of coil manufacture. The sherds from Patch B were heavily weathered and retained no diagnostic features.

\subsubsection{HKB2007/007}

\section{The site}

This site was a small in situ shell midden located some $170 \mathrm{~m}$ from the shore of Hondeklipbaai $\left(30^{\circ} 18^{\prime} 51.4^{\prime \prime}\right.$ S 17016'36.8" E; Orton 2007a). Twenty-six square metres were excavated (Orton 2009a). Among the fauna are many domestic bones; they are mostly sheep/goat but include one goat and one cow. The following date was obtained:

\begin{tabular}{|c|c|c|c|c|}
\hline Lab. No. & Provenience & Material & ${ }^{14} \mathrm{C}$ date BP & Calibrated age (95.4\%) \\
\hline UGAMS-5252 & Q7 \& Q8 & Charcoal (sp. unknown) & $340 \pm 30$ & AD 1497-1648 \\
\hline
\end{tabular}

Based on the abundant historical material within the midden (A. Malan, pers. comm. 2009), including a metal plate lying on the base, it is expected that this date is too old and that the site should date to the latter half of the nineteenth century. The charcoal date was obtained in a CRM context and there seemed no merit in redating the site.

\section{$\underline{\text { Cultural material }}$}

A small collection of stone artefacts (Table 5.3) comprised the only indigenous cultural finds. The assemblage does not conform well to any one group; the quartz backed flake is in clear quartz, suggesting affinity with Group 3, while the CCS component supports Group 1. The assemblage is, however, perhaps too small to judge. The associated historical material includes glass, ceramics, leather, clay pipe stems, a soapstone pipe bowl and metal items, including buttons (Orton 2009a). 
Table 5.3: Stone artefacts from HKB2007/007 (Group 1/3).

\begin{tabular}{lcccc}
\hline & Quartz & CCS & Quartzite & Other \\
\hline Bipolar core & 2 & - & - & - \\
Sidescraper & - & 1 & - & - \\
Scraper fragment & 1 & - & - & - \\
Backed flake & 1 & - & - & - \\
Bladelet & 1 & - & - & - \\
Flake & 15 & 4 & 2 & 1 \\
Edge-damaged flake & 2 & - & - & - \\
Chunk & 5 & - & - & - \\
Chip & 8 & 3 & - & - \\
Total & 35 & $\mathbf{8}$ & 2 & 1 \\
Stone material \% total & 76.1 & $\mathbf{1 7 . 4}$ & 4.3 & 2.2 \\
Stone material \% formal & 66.7 & 33.3 & - & - \\
Grindstone fragment & -- & - & - & 1 \\
\hline
\end{tabular}

\subsubsection{KN2001/009}

\section{The site}

This site was a small shell midden located some $300 \mathrm{~m}$ from the coast and $4.9 \mathrm{~km}$ north of the Swartlintjies River $\left(30^{\circ} 13^{\prime} 22.1^{\prime \prime} \mathrm{S} 17^{\circ} 14^{\prime} 23.7^{\prime \prime} \mathrm{E}\right)$. A total area of $35 \mathrm{~m}^{2}$ was excavated with the deposit sieved through a $1.5 \mathrm{~mm}$ mesh (Halkett 2003). The site consisted of two overlapping shell mounds forming a single midden. The following date was obtained:

\begin{tabular}{|c|c|c|c|c|}
\hline Lab. No. & Provenience & Material & ${ }^{14} \mathrm{C}$ date BP & Calibrated age (95.4\%) \\
\hline OxA-24516 & E11 & $\begin{array}{l}\text { Bone (Raphicerus } \\
\text { campestris) }\end{array}$ & $607 \pm 24$ & AD 1320-1423 \\
\hline
\end{tabular}

\section{$\underline{\text { Cultural material }}$}

The stone artefact assemblage is almost entirely of clear quartz with 10 of the 12 retouched items being backed (Table 5.4). This indicates an ascription to Group 3. 
Table 5.4: Stone artefacts from KN2001/009 (Group 3).

\begin{tabular}{lcccc}
\hline & Quartz & Silcrete & Quartzite & Other \\
\hline Bipolar core & 2 & - & - & - \\
Irregular core & 4 & - & - & - \\
Sidescraper & 1 & - & - & - \\
Scraper fragment & 1 & - & - & - \\
Backed flake & 1 & - & - & - \\
Backed bladelet & 1 & - & - & - \\
Backed point & 3 & - & - & - \\
Backed bladelet fragment & 2 & - & - & - \\
Backed piece fragment & 1 & - & - & - \\
Blade & 4 & - & - & - \\
Bladelet & 10 & - & - & - \\
Flake & 126 & 3 & 5 & - \\
Edge-damaged flake & 3 & - & - & - \\
Chunk & 34 & - & 2 & - \\
Chip & 375 & - & - & - \\
Edge-damaged chip & 1 & - & - & - \\
Total & $\mathbf{5 6 9}$ & $\mathbf{3}$ & $\mathbf{7}$ & $\mathbf{0}$ \\
Stone material \% total & $\mathbf{9 8 . 3}$ & $\mathbf{0 . 5}$ & $\mathbf{1 . 2}$ & - \\
Stone material \% formal & $\mathbf{1 0 0}$ & - & - & - \\
Hammer stone & - & - & - & 1 \\
\hline
\end{tabular}

One small ostrich eggshell bead was found; its diameter, aperture and thickness are 4.90, 1.65 and $1.92 \mathrm{~mm}$ respectively. Two refitting fragments of an ostrich eggshell flask mouth indicate an opening of approximately $9 \mathrm{~mm}$ (Figure 5.4). One fresh and five waterworn Conus shells were also found, but none showed signs of use. Pottery was absent.

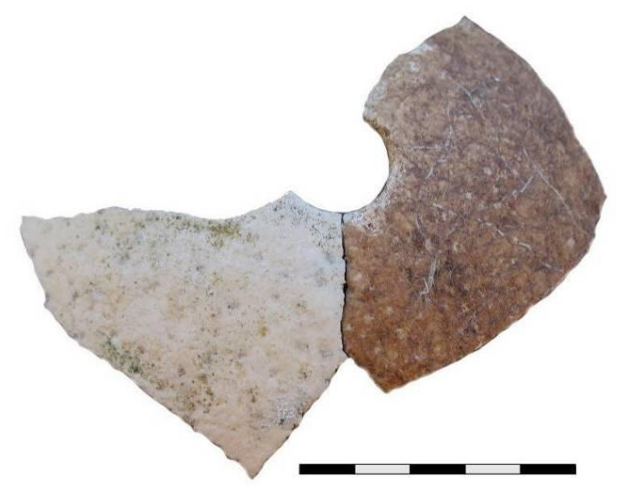

Figure 5.4: The refitting flask mouth fragments from KN2001/009. Scale in $5 \mathrm{~mm}$ intervals. 


\subsubsection{KN2004/012}

\section{The site}

This small, semi-deflated shell midden lay among hummock dunes $3.2 \mathrm{~km}$ north of the Swartlintjies River and 550 m from the sea (30¹4'09.5”S 17¹5'00.6”E). A collection was made from the surrounding surface, while $11.75 \mathrm{~m}^{2}$ were excavated. The $5-10 \mathrm{~cm}$ thick deposit overlay calcrete and, although partly deflated, several dark stains likely indicated the positions of hearths (Orton \& Halkett 2005). A background scatter of older, heavily wind-blasted items was present but easily separable from the younger, in situ material associated with the radiocarbon date. The following date was obtained:

$\begin{array}{lllll}\text { Lab. No. } & \frac{\text { Provenience }}{\text { OxA-22977 }} & \text { Material } & \frac{{ }^{14} \mathrm{C} \text { date BP }}{\text { H16 Midden }} & \text { Charcoal (sp. unknown) } \\ 1579 \pm 24 \text { BP } & \text { AD 432-606 }\end{array}$

\section{$\underline{\text { Cultural material }}$}

The small stone assemblage is informal in character, predominantly of quartz and conforms to Group 2 (Table 5.5). Three small to medium ostrich eggshell beads were present (Table 5.6). Also found were two decorated potsherds, one body and one rim. Together they weigh $2.2 \mathrm{~g}$ and have a mean wall thickness of $4.79 \pm 0.82 \mathrm{~mm}$. The rim has short diagonal lines, probably impressed, around the lip with a horizontal incised line below. The body sherd has two rows of vertical impressions one above the other (Figure 5.5). A bone tube was found and presumed to be a bead; the extensive polishing of both ends supports its long term curation (Figure 5.6).

Table 5.5: Stone artefacts from KN2004/012 (Group 2).

\begin{tabular}{lccccc}
\hline & Quartz & CCS & Silcrete & Quartzite & Other \\
\hline Bipolar core & 2 & 1 & - & - & - \\
Irregular core & 1 & - & - & - & - \\
Flake & 65 & 5 & 3 & - & 2 \\
Chunk & 26 & 1 & - & - & - \\
Edge-damaged chunk & & 1 & - & - & - \\
\hline
\end{tabular}




\begin{tabular}{lccccc}
\hline Chip & 40 & 1 & - & - & - \\
Total & 134 & 9 & 3 & 0 & 2 \\
Stone material \% total & 90.5 & 6.1 & 2.0 & - & 1.4 \\
Hammer stone fragment & - & - & - & 1 & - \\
Upper grindstone / hammer stone fragment & - & - & - & - & 1 \\
Lower grindstone & - & - & - & - & 1 \\
Lower grindstone fragment & - & - & - & - & 1 \\
\hline
\end{tabular}

Table 5.6: Summary statistics for finished ostrich eggshell beads from KN2004/012.

\begin{tabular}{llccc}
\hline & & Outside diameter $(\mathrm{mm})$ & Aperture diameter $(\mathrm{mm})$ & Thickness $(\mathrm{mm})$ \\
\hline \multirow{4}{*}{$\mathrm{n}=3$} & Mean & 4.95 & 1.73 & 1.53 \\
& Std Deviation & 0.21 & 0.06 & 0.01 \\
& Minimum & 4.72 & 1.67 & 1.52 \\
& Maximum & 5.12 & 1.79 & 1.54 \\
\hline
\end{tabular}

In addition, several heavily wind-blasted items undoubtedly formed part of a background scatter in the general area. These included seven flakes, eight chunks and six chips in quartz, one silcrete flake and three refitting fragments of an ostrich eggshell pendant plus a fourth fragment, most likely belonging to a second pendant (see Section 5.6 .3 below).

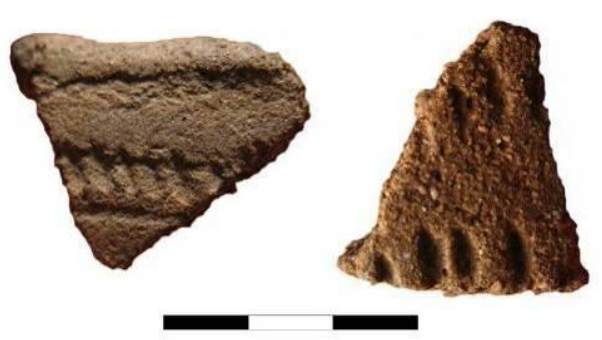

Figure 5.5: The two decorated pot sherds from KN2004/012. Scale in $5 \mathrm{~mm}$ intervals.

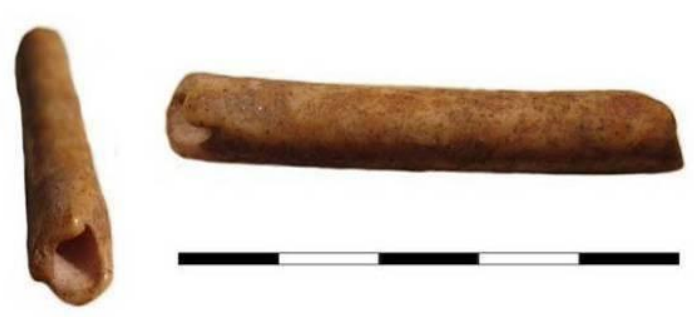

Figure 5.6: The well worn bone tube from $\mathrm{KN} 2004 / 012$. Scale in $5 \mathrm{~mm}$ intervals.

\subsubsection{KN2004/015E}

\section{The site}

This was a well deflated scatter in an area with a high density of sites (30॰14'09.4" S $\left.17^{\circ} 14^{\prime} 57.5^{\prime \prime} \mathrm{E}\right)$. A small surface collection was made around the site, while $9.5 \mathrm{~m}^{2}$ were excavated (Orton \& Halkett 2005). Many of the ostrich eggshell fragments found on the 
site, as well as most of the ostrich eggshell beads, appeared quite wind-abraded, raising the possibility that the site is a palimpsest. The shell appears typical for such sites: partially sun-bleached with only large shells remaining intact. The bone is variably preserved with some being very fragmented, although much of the tortoise bone is intact with a well preserved and unbleached cluster in one area. Whether this cluster represents a tortoise burial is unknown, but this seems unlikely given the dispersion of bone over some $3 \mathrm{~m}^{2}$. Stone artefacts, bone, pottery, flask openings and beads appear to cluster in the southern part of the excavation, while lobster mandibles are more evenly dispersed and ostrich eggshell fragments are focused to the north. Ostrich eggshell beads, which are already rounded during their manufacture, might be expected to take on a polished look through even limited exposure to wind. A few fresh ostrich eggshell fragments were also present. It seems likely that the site has been subjected to extensive wind-blasting in the deflation hollow with the result that any exposed material has become rounded and polished. Overprinting is discounted, but the presence of occasional finds related to background scatter is possible. The following date was obtained:

$\begin{array}{lllll}\text { Lab. No. } & \text { Provenience } & \text { Material } & \frac{14}{{ }^{14} \mathrm{C} \text { date BP }} & \text { Calibrated age (95.4\%) } \\ \text { OxA-22930 } & \text { WW73 Surface } & \text { Bone (Chersina angulata) } & 973 \pm 24 \text { BP } & \text { AD 1035-1174 }\end{array}$

\section{$\underline{\text { Cultural material }}$}

A small collection of flaked stone artefacts was obtained, the vast majority in quartz (Table 5.7). It was frequently difficult to tell quartz from quartzite and some could be classified incorrectly. Much of this seemed to have originated from cobbles, while other pieces were more obviously clear, including the two quartz retouched items. The CCS MRP resembles an unfinished unifacial point (Figure 5.7). A quartz boulder of $320 \times 300$ x $200 \mathrm{~mm}$ was present (but not collected). It was presumably brought to the site as a source of stone material for flaking but was unworked. Occasional reused flakes were 
noted through the presence of weathered surfaces. Various fragments of probable pigment were present, including one piece of specularite. An adze and a sidescraper, both made in CCS, were noted on the surface of unexcavated squares. The stone assemblage conforms partly to Groups 1 and 3, but the overall proportions of materials are incongruent with either ascription, particularly given the CCS retouched items.

Table 5.7: Stone artefacts from KN2004/015E (Group 1/3).

\begin{tabular}{lccc}
\hline & Quartz & CCS & Quartzite \\
\hline Irregular core & 2 & - & - \\
Sidescraper & 1 & - & - \\
Scraper fragment & - & 1 & - \\
Segment & 1 & - & - \\
Miscellaneous retouched piece & - & 1 & - \\
Bladelet & 2 & - & - \\
Flake & 96 & 4 & 2 \\
Chunk & 48 & - & - \\
Chip & 70 & 1 & - \\
Total & $\mathbf{2 2 0}$ & $\mathbf{7}$ & $\mathbf{2}$ \\
Stone material \% total & $\mathbf{9 6 . 0}$ & $\mathbf{3 . 1}$ & $\mathbf{0 . 9}$ \\
Stone material \% formal & $\mathbf{5 0 . 0}$ & $\mathbf{5 0 . 0}$ & - \\
\hline
\end{tabular}
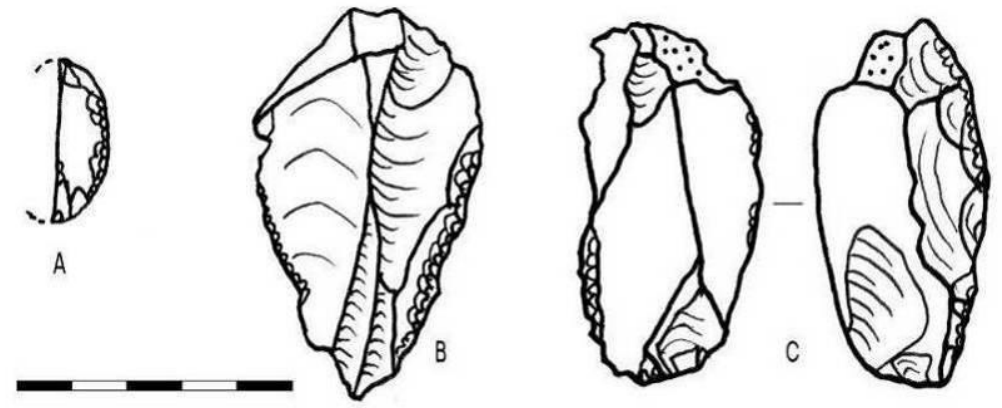

Figure 5.7: Stone artefacts from KN2004/015E. A: scraper fragment; B: miscellaneous retouched piece; C: adze. All in CCS. Scale in $5 \mathrm{~mm}$ intervals.

Seven ostrich eggshell beads of small to medium size were found (Table 5.8). Most were at least slightly wind-blasted, but, as explained above, this is not completely unexpected on a deflated scatter. Three ostrich eggshell fragments were retouched along one edge to make what appear to be wide openings. There were also nine potsherds weighing 
$29.4 \mathrm{~g}$, three of which were undecorated rims. Their mean thickness is $5.76 \pm 0.46 \mathrm{~mm}$. All have vertical necks with one rim being simple rounded and the other two tapered. Two refitting sherds have wind-blasted surfaces supporting long-term exposure to the wind. At least two pots are represented.

Table 5.8: Summary statistics for finished ostrich eggshell beads from KN2004/015E.

\begin{tabular}{llccc}
\hline & & Outside diameter $(\mathrm{mm})$ & Aperture diameter $(\mathrm{mm})$ & Thickness $(\mathrm{mm})$ \\
\hline \multirow{4}{*}{$\mathrm{n}=7$} & Mean & 4.93 & 1.73 & 1.50 \\
\cline { 3 - 5 } & Std Deviation & 0.61 & 0.27 & 0.16 \\
& Minimum & 4.36 & 1.22 & 1.28 \\
& Maximum & 6.08 & 1.97 & 1.70 \\
\hline
\end{tabular}

\subsubsection{KN2005/040}

\section{The site}

This was a fairly dense but deflated shell and artefact scatter $540 \mathrm{~m}$ from the coast and

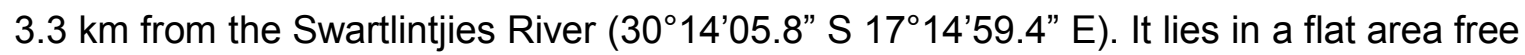
of dunes, but this may be partly due to its proximity to a mine road. A single layer was excavated from $13 \mathrm{~m}^{2}$ (Orton \& Halkett 2006). The following date was obtained:

\begin{tabular}{|c|c|c|c|c|}
\hline Lab. No. & Provenience & Material & ${ }^{14} \mathrm{C}$ date $\mathrm{BP}$ & Calibrated age $(95.4 \%)$ \\
\hline OxA-22971 & K12 Surface & Bone (Chersina angulata) & $2695 \pm 26 \mathrm{BP}$ & $895-772 \mathrm{BC}$ \\
\hline
\end{tabular}

\section{$\underline{\text { Cultural material }}$}

This site contained a good stone artefact assemblage of quartz and CCS with retouched formal tools characteristic of Group 1; most tools are scrapers (Table 5.9). Significantly, backed scrapers are absent, but one miscellaneous backed scraper looks very much like an incomplete backed scraper that broke during manufacture (Figure 5.8). Although both the backed piece fragments were in clear quartz, the vast majority of quartz in the assemblage was less clear. A variety of colours of CCS is evident and several pieces display evidence of heat-treatment, either crazing or pot-lidding (Figure 5.9). This 
practice is rare in Namaqualand and in the LSA in general. Five small to medium ostrich eggshell beads were found (Table 5.10).

Table 5.9: Stone artefacts from KN2005/040 (Group 1).

\begin{tabular}{lcccc}
\hline & Quartz & CCS & Silcrete & Other \\
\hline Bipolar core & 3 & 1 & - & - \\
Single platform core & 1 & 1 & - & - \\
Irregular core & 3 & 1 & - & - \\
Sidescraper & - & 2 & - & - \\
Miscellaneous backed scraper & - & 2 & - & - \\
Miscellaneous scraper & - & 1 & - & - \\
Scraper fragment & 1 & 3 & - & - \\
Segment & 1 & - & - & - \\
Backed piece fragment & 2 & - & - & - \\
Miscellaneous retouched piece & 1 & 1 & - & - \\
Bladelet & 2 & - & - & - \\
Flake & 150 & 24 & 1 & - \\
Edge-damaged flake & 2 & 2 & - & - \\
Chunk & 116 & 8 & - & - \\
Edge-damaged chunk & 1 & 1 & - & - \\
Chip & 172 & 7 & - & - \\
Total & $\mathbf{4 5 5}$ & $\mathbf{5 4}$ & $\mathbf{1}$ & $\mathbf{0}$ \\
Stone material \% total & $\mathbf{8 9 . 4}$ & $\mathbf{1 0 . 4}$ & $\mathbf{0 . 2}$ & - \\
Stone material \% formal & $\mathbf{3 5 . 7}$ & $\mathbf{6 4 . 3}$ & - & - \\
Upper grindstone & - & - & - & 1 \\
\hline
\end{tabular}
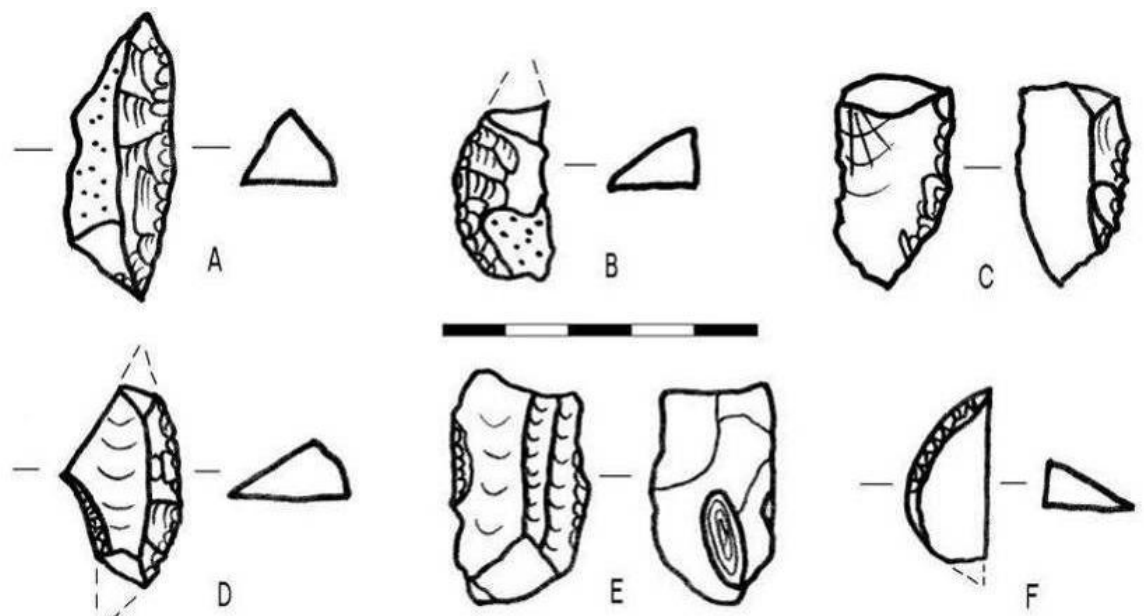

Figure 5.8: Stone artefacts from KN2005/040. A, B: sidescrapers; C: miscellaneous scraper; D, $\mathrm{E}$ : miscellaneous backed scrapers; F: segment. All in CCS. E has heat-induced crazing and a potlid fracture on its ventral surface. Scale in $5 \mathrm{~mm}$ intervals. 

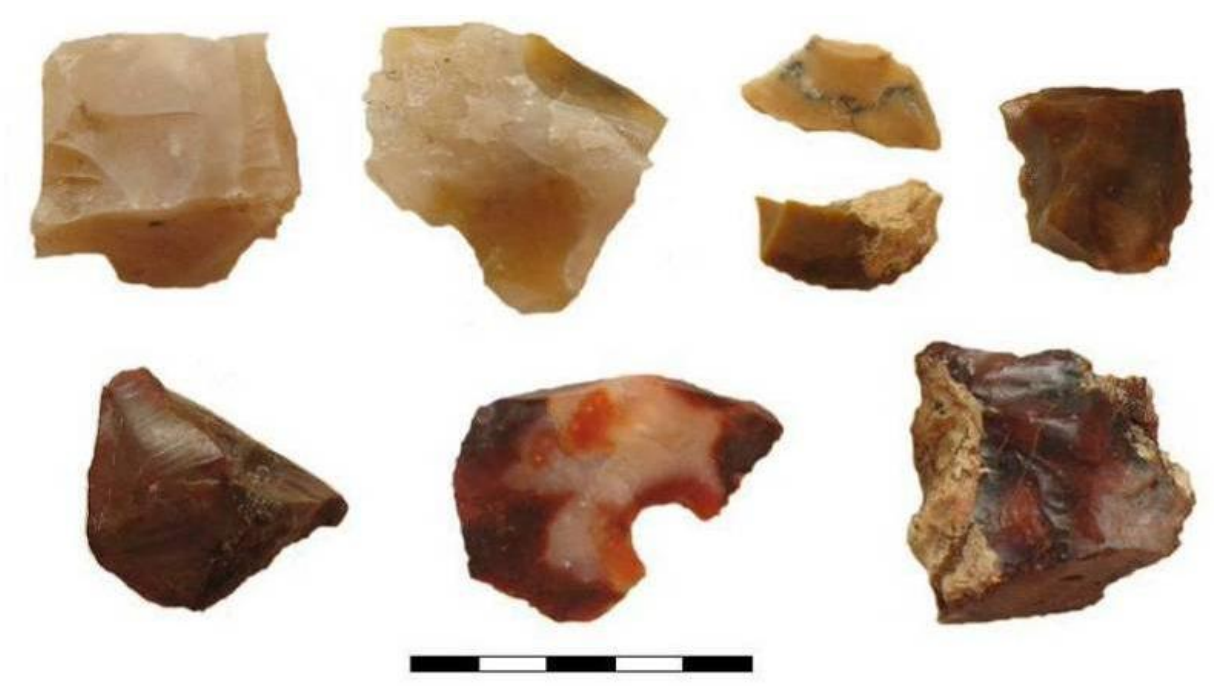

Figure 5.9: CCS artefacts from KN2005/040 showing the variety in colour from beige through yellow, mustard, brown and red. The lower right artefact has surface crazing due to heattreatment. Scale in $5 \mathrm{~mm}$ intervals.

Table 5.10: Summary statistics for finished ostrich eggshell beads from KN2005/040.

\begin{tabular}{|c|c|c|c|c|}
\hline & & Outside diameter (mm) & Aperture diameter $(\mathrm{mm})$ & Thickness (mm) \\
\hline \multirow{5}{*}{$n=5$} & Mean & 4.81 & 1.66 & 1.64 \\
\hline & Std & 056 & 020 & \\
\hline & Deviation & 0.50 & 0.20 & 0.11 \\
\hline & Minimum & 3.95 & 1.32 & 1.48 \\
\hline & Maximum & 5.49 & 1.85 & 1.77 \\
\hline
\end{tabular}

\subsubsection{KN2005/041}

\section{$\underline{\text { The site }}$}

KN2005/041 was an in situ, single layer shell midden in a fairly open area with large dunes to its southeast. It was $570 \mathrm{~m}$ from the sea and $3.3 \mathrm{~km}$ from the Swartlintjies River (30¹4'06.4" S $\left.17^{\circ} 15^{\prime} 00.0^{\prime \prime} \mathrm{E}\right)$. The midden had $10.5 \mathrm{~m}^{2}$ excavated (Orton \& Halkett 2006). A cattle horn core from this site is the oldest directly dated cow bone from South Africa (Orton et al. in press). In general, the bones were highly fragmented and impacted by carnivore chewing (G. Dewar, pers. comm. 2009). The following dates were obtained: 
Lab. No. Provenience Material

OxA-22933 E6 Midden Bone (Bos taurus)

OxA-22979 H6 Midden

Notes:
${ }^{14} \mathrm{C}$ date BP Calibrated age (95.4\%)

$1625 \pm 25 \mathrm{BP} \quad \mathrm{AD} 421-559$

Charcoal (sp. Unknown) $\quad 1631 \pm 23$ BP $\quad$ AD 418-552

- OxA-22933 is on a Bos taurus horn core (domestic cow).

\section{$\underline{\text { Cultural material }}$}

A moderately sized assemblage of flaked artefacts was obtained, but with little retouch (Table 5.11). Besides the clear quartz backed point, the only other retouched piece was a silcrete large miscellaneous scraper with a retouched edge $75 \mathrm{~mm}$ wide; it could even be a single platform core (Figure 5.10). Such large scrapers are rare. The quartz is both clear and greyish milky quartz (possibly quartzite) with the latter including many flakes larger than the customary $15-25 \mathrm{~mm}$. While the larger milky quartz flakes suggest a Group 2 component, the presence of clear quartz including a backed point shows a Group 3 contribution. Three small ostrich eggshell beads are present (Table 5.12) and limited manufacturing debris occurs in the form of four fragments in stage IIlb and one in stage IVb. There are also two $S$. argenvillei rims that must have been collected (Figure 11). One is water-worn and would have come from the beach, while the other is sandblasted and might have come from a deflated midden. No pottery was found.

Table 5.11: Stone artefacts from KN2005/041 (Group 2/3).

\begin{tabular}{lccccc}
\hline & Quartz & CCS & Silcrete & Sandstone & Other \\
\hline Bipolar core & 9 & 1 & - & - & - \\
Single platform core & 1 & - & - & - & - \\
Irregular core & 1 & - & 1 & - & - \\
Large miscellaneous scraper & - & - & 1 & - & - \\
Backed point & 1 & - & - & - & - \\
Bladelet & 5 & - & - & - & - \\
Flake & 121 & 10 & 5 & - & 1 \\
Edge-damaged flake & - & 1 & - & - & - \\
Chunk & 77 & 1 & 2 & 1 & - \\
Chip & 108 & 6 & 1 & - & - \\
Total & $\mathbf{3 2 3}$ & $\mathbf{1 9}$ & $\mathbf{1 0}$ & $\mathbf{1}$ & $\mathbf{1}$ \\
Stone material \% total & $\mathbf{9 1 . 2}$ & $\mathbf{5 . 4}$ & $\mathbf{2 . 8}$ & $\mathbf{0 . 3}$ & $\mathbf{0 . 3}$ \\
\hline
\end{tabular}




\begin{tabular}{lccccc}
\hline Stone material \% formal & $\mathbf{5 0 . 0}$ & - & $\mathbf{5 0 . 0}$ & - & - \\
Hammer stone & - & - & - & 1 & - \\
Upper grindstone & - & - & - & - & 1 \\
Grindstone fragment & - & - & - & - & 7 \\
\hline
\end{tabular}

Table 5.12: Summary statistics for finished ostrich eggshell beads from KN2005/041.

\begin{tabular}{|c|c|c|c|c|}
\hline & & $\begin{array}{l}\text { Outside diameter } \\
\qquad(\mathrm{mm})\end{array}$ & $\begin{array}{l}\text { Aperture diameter } \\
\qquad(\mathrm{mm})\end{array}$ & Thickness (mm) \\
\hline \multirow{4}{*}{$n=3$} & Mean & 4.74 & 1.28 & 1.69 \\
\hline & $\begin{array}{l}\text { Std } \\
\text { Deviation }\end{array}$ & 0.15 & 0.22 & 0.08 \\
\hline & Minimum & 4.58 & 1.08 & 1.62 \\
\hline & Maximum & 4.87 & 1.51 & 1.77 \\
\hline
\end{tabular}

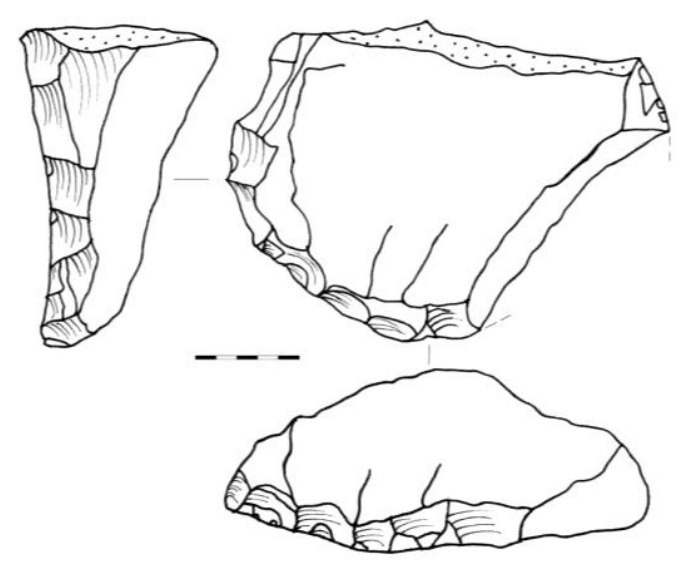

Figure 5.10: The silcrete large miscellaneous scraper from KN2005/041. Scale in $5 \mathrm{~mm}$ intervals.

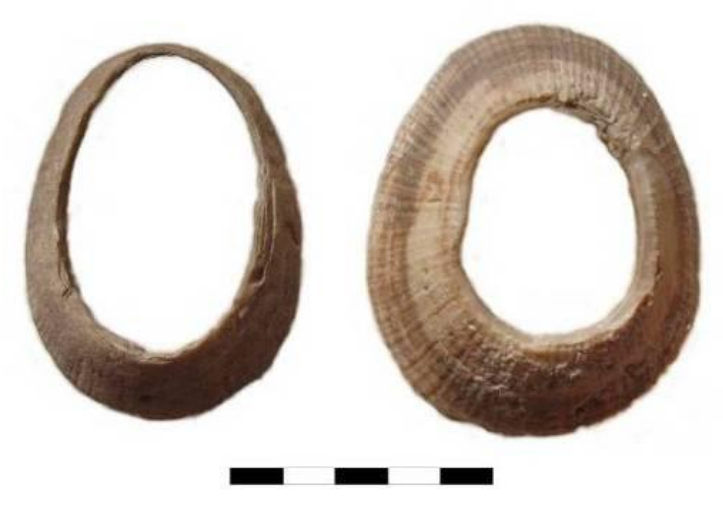

Figure 5.11: The two S. argenvillei rims from KN2005/041. The left one is water-worn and the right sand-blasted. Scale in $10 \mathrm{~mm}$ intervals.

\section{$5.1 .8 \quad \mathrm{KN} 2005 / 050$}

\section{The site}

This is a small, largely deflated site that includes about $6 \mathrm{~m}^{2}$ of in situ shell midden within a tiny dune that remained intact (Figure 5.12). It is $530 \mathrm{~m}$ from the coast and $3.3 \mathrm{~km}$ north of the Swartlintjies River (30¹4'05.0" S 17¹4'58.6" E). Although KN2005/051 lies immediately to the north, KN2005/050 is clearly a discrete occurrence. It had $21 \mathrm{~m}^{2}$ excavated (Orton \& Halkett 2006). The following date was obtained: 


\section{$\underline{\text { Cultural material }}$}

The assemblage includes many stone artefacts and just three ostrich eggshell beads. All quartz is clear. The CCS retouched tools are generally typical of older Group 1 assemblages and include two segments and two backed points (Table 5.13; Figure 5.13). The miscellaneous backed scraper is essentially a thumbnail scraper with backing applied opposite the scraper retouch. The three beads are small (Table 5.14).

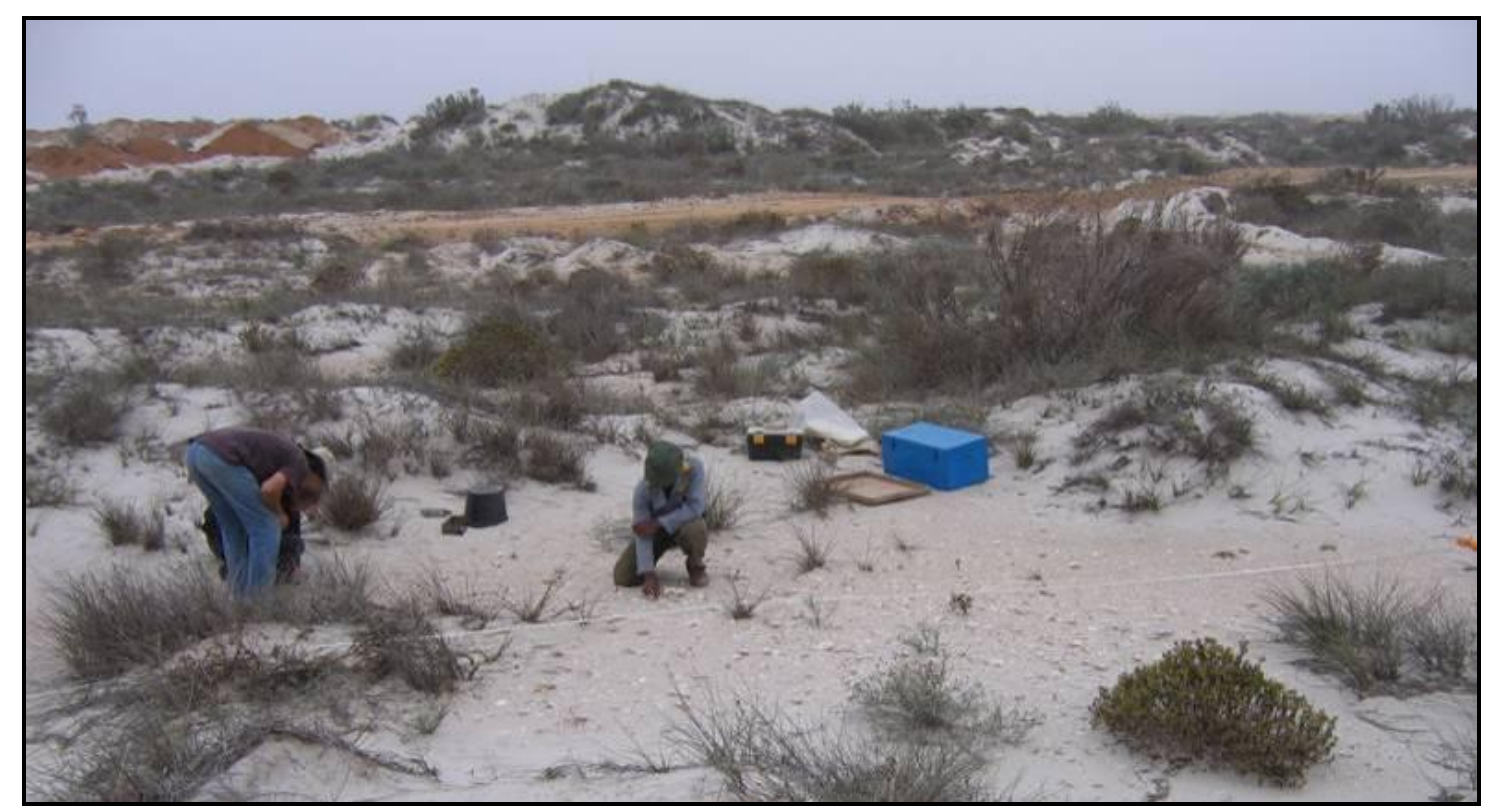

Figure 5.12: View towards the east showing the in situ midden between the figures and the deflated area in front of the toolbox.

Table 5.13: Stone artefacts from KN2005/050 (Group 1).

\begin{tabular}{lcccc}
\hline & Quartz & CCS & Quartzite & Other \\
\hline Bipolar core & 2 & - & - & - \\
Single platform core & - & 1 & - & - \\
Single platform bladelet core & - & 1 & - & - \\
Irregular core & 3 & 2 & - & - \\
Backed scraper & - & 1 & - & - \\
Sidescraper & - & 1 & - & - \\
Miscellaneous backed scraper & - & 1 & - & - \\
Scraper fragment & - & 2 & - & - \\
\hline
\end{tabular}




\begin{tabular}{lcccc}
\hline & Quartz & CCS & Quartzite & Other \\
\hline Backed flake & - & 1 & - & - \\
Backed bladelet & - & 1 & - & - \\
Backed point & - & 2 & - & - \\
Segment & - & 2 & - & - \\
Backed piece fragment & - & 1 & - & - \\
Notched piece & 1 & - & - & - \\
Bladelet & 9 & 14 & - & - \\
Edge-damaged bladelet & 1 & - & - & - \\
Flake & 102 & 83 & 16 & - \\
Edge-damaged flake & 1 & 3 & - & - \\
Chunk & 42 & 11 & 10 & - \\
Chip & 107 & 48 & 1 & - \\
Edge-damaged chip & - & 1 & - & - \\
Total & $\mathbf{2 6 8}$ & $\mathbf{1 7 6}$ & $\mathbf{2 7}$ & $\mathbf{0}$ \\
Stone material \% total & $\mathbf{5 7 . 0}$ & $\mathbf{3 7 . 2}$ & $\mathbf{5 . 7}$ & - \\
Stone material \% formal & $\mathbf{8 . 3}$ & $\mathbf{9 1 . 7}$ & - & - \\
Grindstone fragments & - & - & - & 1 \\
\hline
\end{tabular}

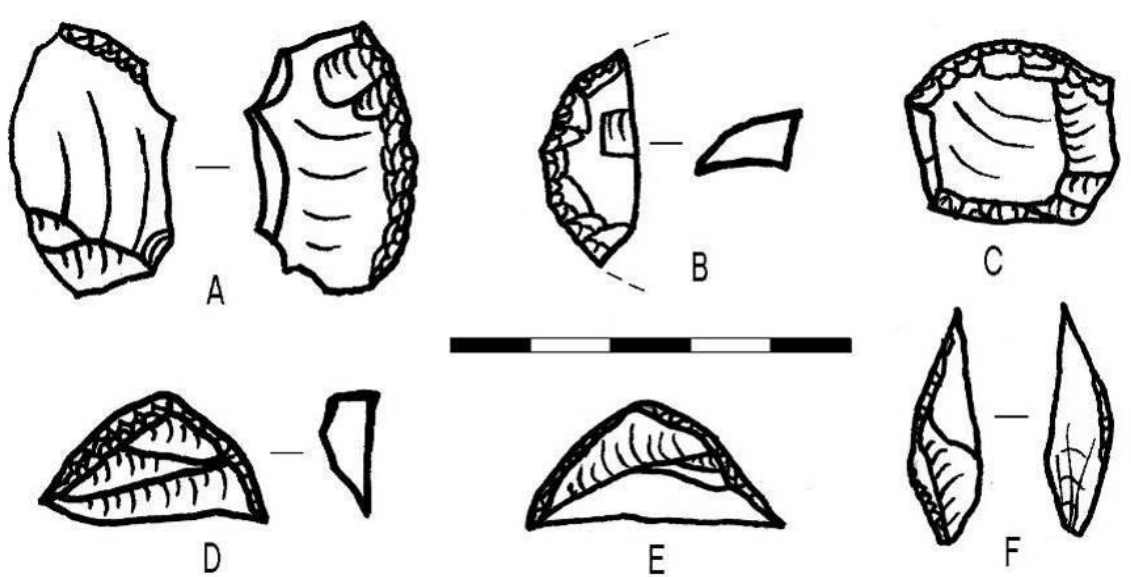

Figure 5.13: Stone artefacts from KN2005/050. A: backed scraper; B: scraper fragment; C: miscellaneous backed scraper; D, E: segments; F: backed point. All in CCS. Scale bar in $5 \mathrm{~mm}$ intervals.

Table 5.14: Summary statistics for finished ostrich eggshell beads from KN2005/050.

\begin{tabular}{llccc}
\hline & & Outside diameter $(\mathrm{mm})$ & Aperture diameter $(\mathrm{mm})$ & Thickness $(\mathrm{mm})$ \\
\hline \multirow{2}{*}{$\mathrm{n}=3$} & 4.66 & 1.75 & 1.61 \\
& Mean & & & 0.12 \\
& Deviation & 0.07 & 0.32 & 1.47 \\
& Minimum & 4.59 & 1.38 & 1.70 \\
\hline
\end{tabular}




\section{1 .9 KN2005/054}

\section{The site}

This small, dense shell midden (Figure 5.14) was located among low, partially vegetated dunes $500 \mathrm{~m}$ from the shore and $3.1 \mathrm{~km}$ north of the Swartlintjies River (S 30¹4'12.9" E 17'14'59.1"). Only $3 \mathrm{~m}^{2}$ were excavated (Orton \& Halkett 2006). The following date was obtained:

\begin{tabular}{|c|c|c|c|c|}
\hline Lab. No. & Provenience & Material & ${ }^{14} \mathrm{C}$ date $\mathrm{BP}$ & Calibrated age (95.4\%) \\
\hline OxA-22932 & D13 MS1 & Bone (Chersina angulata) & $1598 \pm 25 \mathrm{BP}$ & AD 429-584 \\
\hline
\end{tabular}

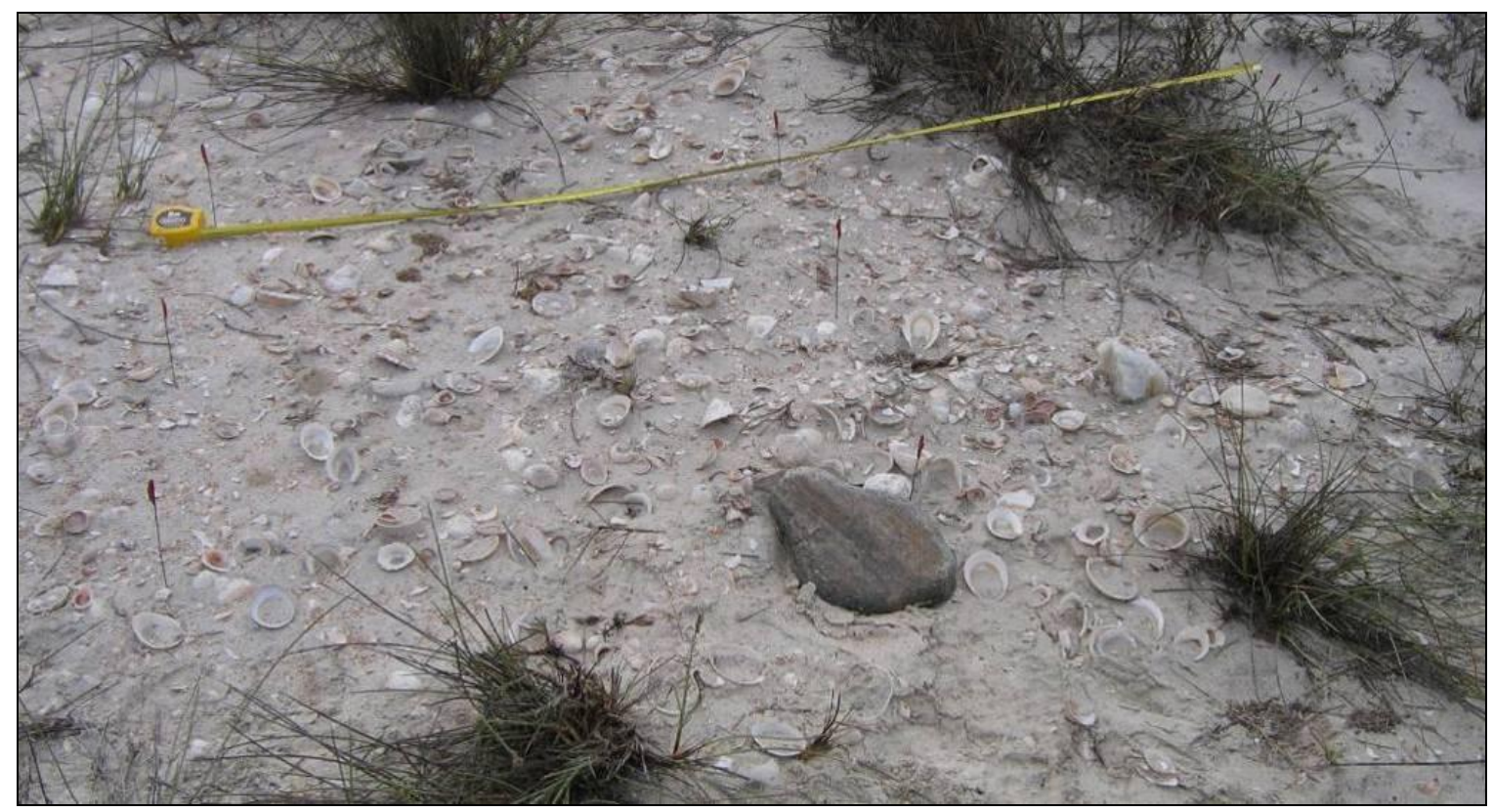

Figure 5.14: Surface appearance of the KN2005/054 shell midden.

\section{$\underline{\text { Cultural material }}$}

The site had a very high quartz frequency and yielded many clear quartz artefacts including backed tools (Table 5.15). It thus belongs to Group 3. Other cultural material included four medium-sized ostrich eggshell beads (Table 5.16) and two refitting sherds of comb-incised pottery weighing $17.1 \mathrm{~g}$ (Figure 5.15). These sherds are from the neck of a pot with one preserving part of the rim. Although damaged, it seems that the rim was 
vertically oriented and was simple rounded in form. The mean thickness of the two sherds was $7.08 \pm 0.45 \mathrm{~mm}$.

Table 5.15: Stone artefacts from KN2005/054 (Group 3).

\begin{tabular}{lccc}
\hline & Quartz & CCS & Quartzite \\
\hline Bipolar core & 8 & - & - \\
Single platform core & 1 & - & 1 \\
Irregular core & 2 & - & - \\
Backed flake & 1 & - & - \\
Backed bladelet & 2 & - & - \\
Bladelet & 2 & - & - \\
Flake & 57 & - & 4 \\
Chunk & 9 & - & 4 \\
Chip & 60 & 4 & 1 \\
Total & $\mathbf{1 4 2}$ & $\mathbf{4}$ & $\mathbf{1 0}$ \\
Stone material \% total & $\mathbf{9 1 . 0}$ & $\mathbf{2 . 6}$ & $\mathbf{6 . 4}$ \\
Stone material \% formal & $\mathbf{1 0 0 . 0}$ & - & - \\
\hline
\end{tabular}

Table 5.16: Summary statistics for finished ostrich eggshell beads from KN2005/054.

\begin{tabular}{llccc}
\hline & & Outside diameter $(\mathrm{mm})$ & Aperture diameter $(\mathrm{mm})$ & Thickness $(\mathrm{mm})$ \\
\hline \multirow{3}{*}{$\mathrm{n}=4$} & 5.34 & 1.88 & 1.80 \\
& Mean & 0.27 & 0.24 & 1.11 \\
& Deviation & 5.03 & 1.71 & 1.67 \\
& Minimum & 5.68 & 2.23 & 1.92 \\
\hline
\end{tabular}

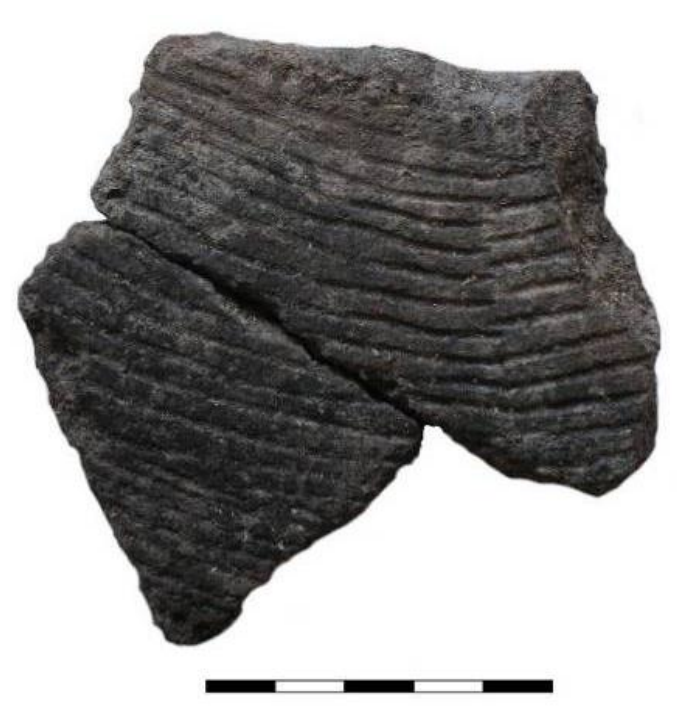

Figure 5.15: The comb-incised pot sherds from KN2005/054. Scale in $5 \mathrm{~mm}$ intervals. 


\subsubsection{KN2005/067}

\section{The site}

This is more of a site complex: it comprises several in situ shell middens with numerous ashy features, hollows and deliberately buried tortoises (Orton 2012) all occurring in a large, flat area enclosed by low dunes. It lies $700 \mathrm{~m}$ from the coast and $2.9 \mathrm{~km}$ north of the Swartlintjies River ( $\left.30^{\circ} 14^{\prime} 22.6^{\prime \prime} \mathrm{S} 17^{\circ} 15^{\prime} 03.3^{\prime \prime} \mathrm{E}\right)$. Variable areas totalling $98 \mathrm{~m}^{2}$ were excavated from several patches of deposit but with most $\left(81 \mathrm{~m}^{2}\right)$ coming from the central patches (Orton \& Halkett 2006). Figure 5.16 shows the spatial layout of the main excavation area and Figure 5.17 an example of the in situ midden deposits - this midden is typical of the vast majority of in situ middens in Namaqualand. Patch 3 lies $6 \mathrm{~m}$ north of $1 \mathrm{C}$ while Patch 2 is a further $7 \mathrm{~m}$ northwest. Patch 5 is $4 \mathrm{~m}$ south of $1 \mathrm{~B}$ and Patch 4 is $8 \mathrm{~m}$ southeast of $1 \mathrm{~A}$. Note that Patch 2 was originally recorded as KN2005/082 and Patch 5 as KN2005/083. The following dates were obtained:

\begin{tabular}{|c|c|c|c|c|}
\hline Lab. No. & Provenience & Material & ${ }^{14} \mathrm{C}$ date $\mathrm{BP}$ & Calibrated age (95.4\%) \\
\hline OxA-24521 & $\begin{array}{l}\text { Patch } 1 \text { A O5 } \\
\text { Midden }\end{array}$ & $\begin{array}{l}\text { Bone (Chersina } \\
\text { angulata) }\end{array}$ & $354 \pm 23$ & AD 1497-1640 \\
\hline OxA-24520 & $\begin{array}{l}\text { Patch 1A O5 } \\
\text { Tortoise Burial }\end{array}$ & $\begin{array}{l}\text { Bone (Chersina } \\
\text { angulata) }\end{array}$ & $339 \pm 24$ & AD 1501-1646 \\
\hline OxA-24519 & $\begin{array}{l}\text { Patch 1A L1 } \\
\text { Tortoise Burial } 3\end{array}$ & $\begin{array}{l}\text { Bone (Chersina } \\
\text { angulata) }\end{array}$ & $891 \pm 23$ & AD 1155-1261 \\
\hline OxA-24518 & $\begin{array}{l}\text { Patch 1B H-5 } \\
\text { Midden }\end{array}$ & $\begin{array}{l}\text { Bone (Chersina } \\
\text { angulata) }\end{array}$ & $321 \pm 23$ & AD 1505-1652 \\
\hline OxA-24522 & $\begin{array}{l}\text { Patch 1C R-10 } \\
\text { Midden }\end{array}$ & $\begin{array}{l}\text { Bone (Chersina } \\
\text { angulata) }\end{array}$ & $355 \pm 24$ & AD 1496-1640 \\
\hline OxA-24517 & $\begin{array}{l}\text { Patch } 3 \text { X-11 } \\
\text { Midden }\end{array}$ & $\begin{array}{l}\text { Bone (Chersina } \\
\text { angulata) }\end{array}$ & $262 \pm 23$ & AD 1637-1799 \\
\hline
\end{tabular}

The radiocarbon dates suggest that two occupations, C. AD 1200 and c. AD 1600, might have occurred. However, with the older date coming from an area not overlain by shell midden, it is likely that the vast majority of finds belong with the suite of younger dates. 


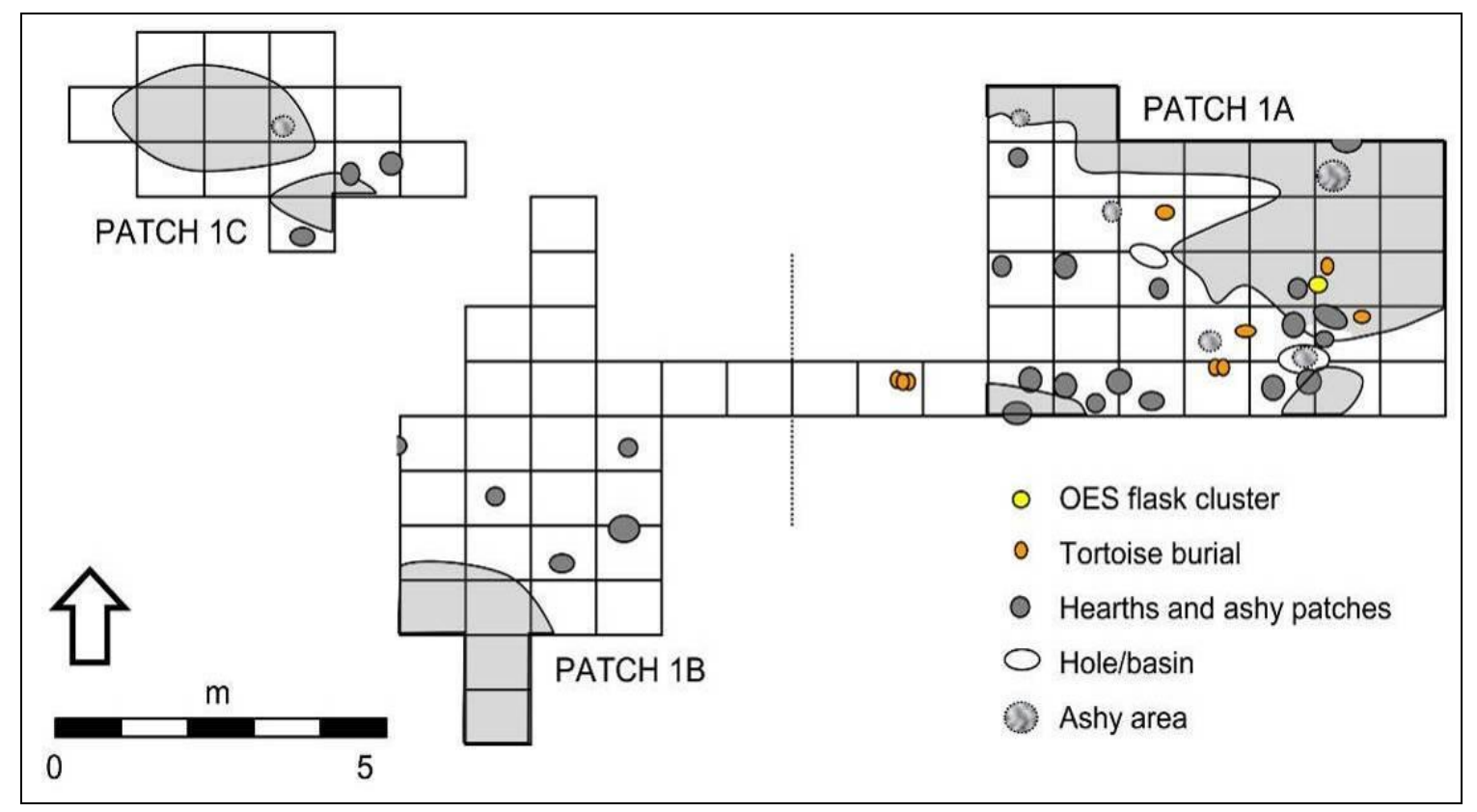

Figure 5.16: Layout of the main excavation area at KN2005/067. The separation of Patches $1 \mathrm{~A}$ and $1 \mathrm{~B}$ is arbitrary.

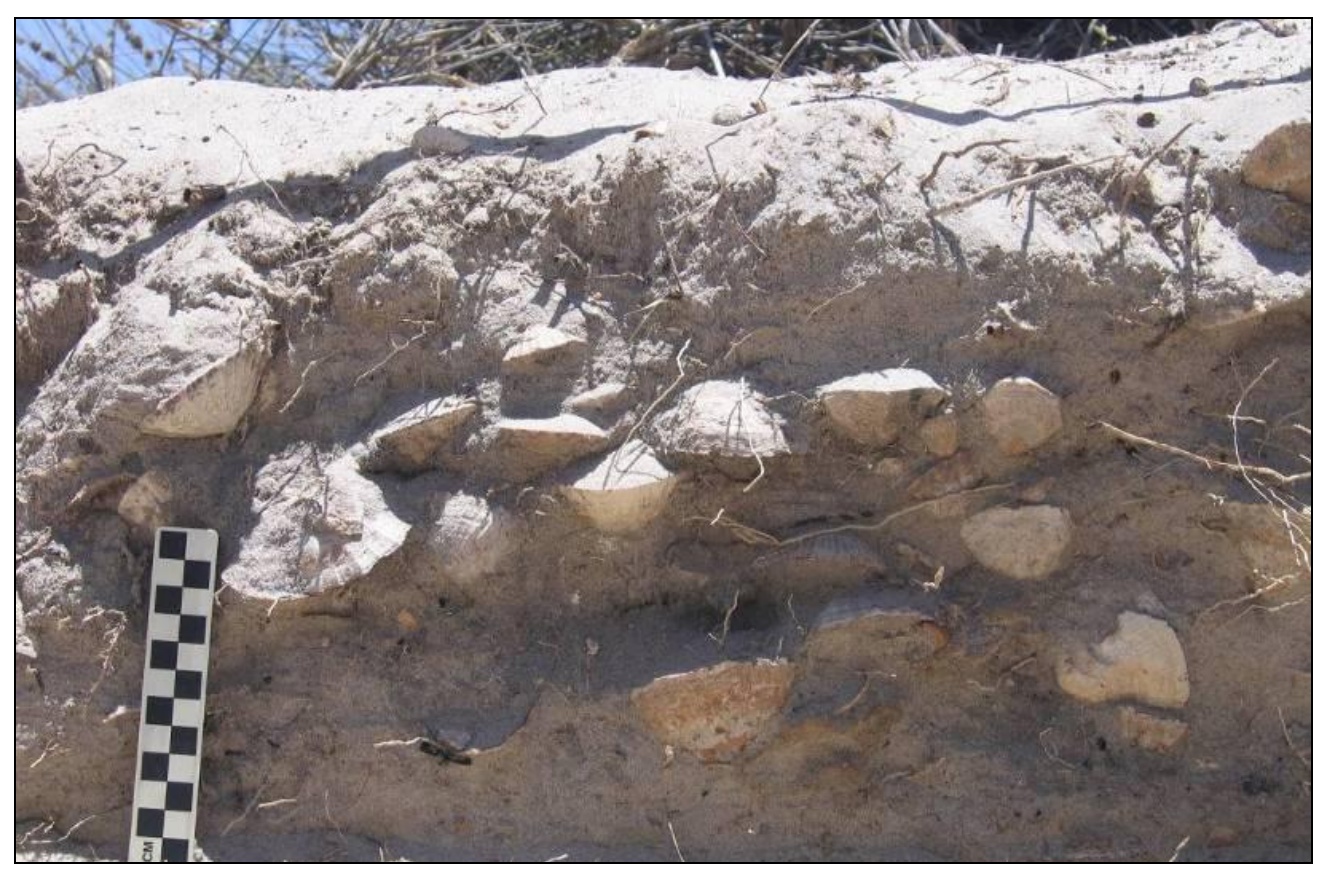

Figure 5.17: Section through the in situ midden deposits of Patch 1A. Scale in $10 \mathrm{~mm}$ intervals.

\section{$\underline{\text { Cultural material }}$}

Artefacts abraded by wind-blown sand were present throughout the site, both spatially and at all depths within the in situ midden. Due to their varying degrees of abrasion, they were at times difficult to separate from non-abraded artefacts, but most likely relate to earlier occupation of the area. Abraded retouched artefacts include a backed point 
(CCS), a backed scraper (silcrete) and a denticulate (CCS), all consistent with a prepottery age. The abraded artefacts are not considered further.

The non-abraded flaked stone artefacts in most patches are predominantly of quartz and display characteristics of the informal Group 2 assemblages (Tables 5.17-5.22). However, in Patch 1B a typical Group 3 assemblage was found and there was some evidence for the re-use of older artefacts. The sandstone upper grindstone in Patch $1 \mathrm{~A}$ retained a greasy stain on its grinding surface. Patch 1B contained a beautiful creamcoloured siliceous pebble that must have been collected as a curio and was the only patch to contain a few fragments of specularite (four) and ochre (one).

Table 5.17: Stone artefacts from KN2005/067, Patch 1A (Group 2).

\begin{tabular}{lccccc}
\hline & Quartz & CCS & Quartzite & Sandstone & Other \\
\hline Irregular core & 2 & - & - & - & - \\
Edge-damaged bladelet & - & 1 & - & - & - \\
Flake & 53 & 8 & 1 & - & 5 \\
Chunk & 4 & 1 & - & - & - \\
Chip & 24 & 4 & 1 & - & - \\
Total & $\mathbf{8 3}$ & $\mathbf{1 4}$ & $\mathbf{2}$ & $\mathbf{0}$ & $\mathbf{5}$ \\
Stone material \% total & $\mathbf{7 9 . 8}$ & $\mathbf{1 3 . 5}$ & $\mathbf{1 . 9}$ & - & 4.8 \\
Stone material \% formal & - & - & - & - & - \\
Hammer stone fragment & - & - & - & - & 1 \\
Upper grindstone & - & - & - & 1 & - \\
Grindstone fragment & - & - & 1 & - & - \\
\hline
\end{tabular}

Table 5.18: Stone artefacts from KN2005/067, Patch 1B (Group 3).

\begin{tabular}{lccccc}
\hline & Quartz & CCS & Quartzite & Sandstone & Other \\
\hline Bipolar core & 2 & - & - & - & - \\
Irregular core & 2 & - & - & - & - \\
Backed flake & 1 & - & - & - & - \\
Backed bladelet & - & 1 & - & - & - \\
Curve-backed bladelet & 2 & - & - & - & - \\
Backed bladelet fragment & 4 & - & - & - & - \\
Backed piece fragment & 1 & - & - & - & - \\
Bladelet & 4 & 1 & - & - & - \\
\hline
\end{tabular}




\begin{tabular}{lccccc}
\hline & Quartz & CCS & Quartzite & Sandstone & Other \\
\hline Flake & 97 & 6 & 3 & - & 1 \\
Edge-damaged flake & - & 1 & - & - & - \\
Chunk & 24 & - & - & - & - \\
Chip & 78 & 3 & - & - & - \\
Total & $\mathbf{2 1 5}$ & $\mathbf{1 2}$ & $\mathbf{3}$ & $\mathbf{0}$ & $\mathbf{1}$ \\
Stone material \% total & 93.1 & $\mathbf{5 . 2}$ & $\mathbf{1 . 3}$ & - & 0.4 \\
Stone material \% formal & $\mathbf{8 8 . 8 9}$ & $\mathbf{1 1 . 1 1}$ & - & - & - \\
Upper grindstone/hammer stone & - & - & - & 1 & - \\
Lower grindstone fragment & - & - & - & - & 1 \\
\hline
\end{tabular}

Table 5.19: Stone artefacts from KN2005/067, Patch 1C (Group 2).

\begin{tabular}{lcc}
\hline & Quartz & CCS \\
\hline Irregular core & 1 & - \\
Flake & 1 & 2 \\
Chunk & - & - \\
Chip & 4 & 1 \\
Total & 6 & 3 \\
Stone material \% total & 66.67 & 33.33 \\
Stone material \% formal & - & - \\
\hline
\end{tabular}

Table 5.20: Stone artefacts from KN2005/067, Patch 2 (Group 2).

\begin{tabular}{lcc}
\hline & Quartz & CCS \\
\hline Flake & - & 2 \\
Chunk & - & - \\
Chip & 1 & 1 \\
Total & $\mathbf{1}$ & $\mathbf{3}$ \\
Stone material \% total & $\mathbf{2 5 . 0}$ & $\mathbf{7 5 . 0}$ \\
Stone material \% formal & - & - \\
\hline
\end{tabular}

Table 5.21: Stone artefacts from KN2005/067, Patch 3 (Group 2).

\begin{tabular}{lc}
\hline & Quartz \\
\hline Flake & 2 \\
Chunk & 1 \\
Chip & 4 \\
Total & $\mathbf{7}$ \\
Stone material \% total & $\mathbf{1 0 0 . 0}$ \\
Stone material \% formal & - \\
\hline
\end{tabular}


Table 5.22: Stone artefacts from KN2005/067, Patch 5 (Group 2).

\begin{tabular}{lcc}
\hline & Quartz & CCS \\
\hline Flake & 4 & 1 \\
Edge-damaged flake & - & \\
Chunk & 1 & - \\
Chip & 4 & - \\
Total & 9 & 1 \\
Stone material \% total & 90.0 & $\mathbf{1 0 . 0}$ \\
Stone material \% formal & - & - \\
\hline
\end{tabular}

As with the stone, there were also variably abraded ostrich eggshell fragments throughout. Some of the ostrich eggshell beads, particularly those from Patch 1A (all from one square), were also lightly abraded showing that some degree of wind-blasting also occurred in more recent times. The Patch $1 \mathrm{~A}$ beads were all very large and similar in size, likely belonging to a single jewellery item (Table 5.23). Those from Patch $1 \mathrm{~B}$ were more variable, but with the majority being medium; two beads were between 6 and $8 \mathrm{~mm}$ and two were between 10 and $11 \mathrm{~mm}$. Patches $1 \mathrm{~A}, 1 \mathrm{~B}$ and 5 contained bead manufacturing debris. Most followed Pathway 1 (Table 5.24) but in Patch $1 \mathrm{~A}$ there was one bead from each of Stages IIIa, IIIb and IVb, while in Patch 1B there was one IVa and one IVb. Interestingly, many of the Stage Ila beads had only a very shallow 'pilot dimple', almost as if these pieces had been prepared for easier drilling later on. Flask mouth fragments were found in Patches 1A (14) and 1B (8) and, where determinable, showed mouth diameters of about 8-15 mm. Two refitting fragments of bead debris in Patch 1B were also engraved (Figure 5.18); no other engraved ostrich eggshell was present.

Table 5.23: Summary statistics for finished ostrich eggshell beads from KN2001/067.

\begin{tabular}{|c|c|c|c|c|}
\hline Patch & & Outside diameter (mm) & Aperture diameter (mm) & Thickness (mm) \\
\hline & Mean & 8.00 & 2.88 & 1.94 \\
\hline $1 \mathrm{~A}$ & Std Deviation & 0.13 & 0.36 & 0.09 \\
\hline \multirow[t]{2}{*}{$(n=5)$} & Minimum & 7.80 & 2.53 & 1.84 \\
\hline & Maximum & 8.13 & 3.31 & 2.08 \\
\hline 1B & Mean & 6.29 & 2.80 & 1.43 \\
\hline$(n=15)$ & Std Deviation & 1.80 & 0.17 & 0.28 \\
\hline
\end{tabular}




\begin{tabular}{lcccc}
\hline & Minimum & 5.24 & 2.52 & 1.07 \\
& Maximum & 10.77 & 3.21 & 1.94 \\
\hline $3(\mathrm{n}=1)$ & 4.81 & 2.74 & 1.27 \\
\hline $5(\mathrm{n}=1)$ & 8.88 & 3.09 & 1.69 \\
\hline
\end{tabular}

Table 5.24: Pathway 1 ostrich eggshell bead manufacturing debris from KN2005/067, Patch $1 \mathrm{~A}$.

\begin{tabular}{ccccccccccccc}
\hline Stage & Ila & Ilb & Illa & Illb & IVa & IVb & Va & Vb & Vla & Vlb & VIla & Vllb \\
\hline Patch 1A & 43 & 48 & 21 & 222 & & 52 & 8 & 34 & 6 & 5 & 2 \\
\hline Patch 1B & 6 & 17 & & 41 & & 10 & 3 & 61 & & 3 & 15 & \\
\hline Patch 5 & & 1 & 2 & 4 & 1 & 4 & & 2 & & 1 &
\end{tabular}
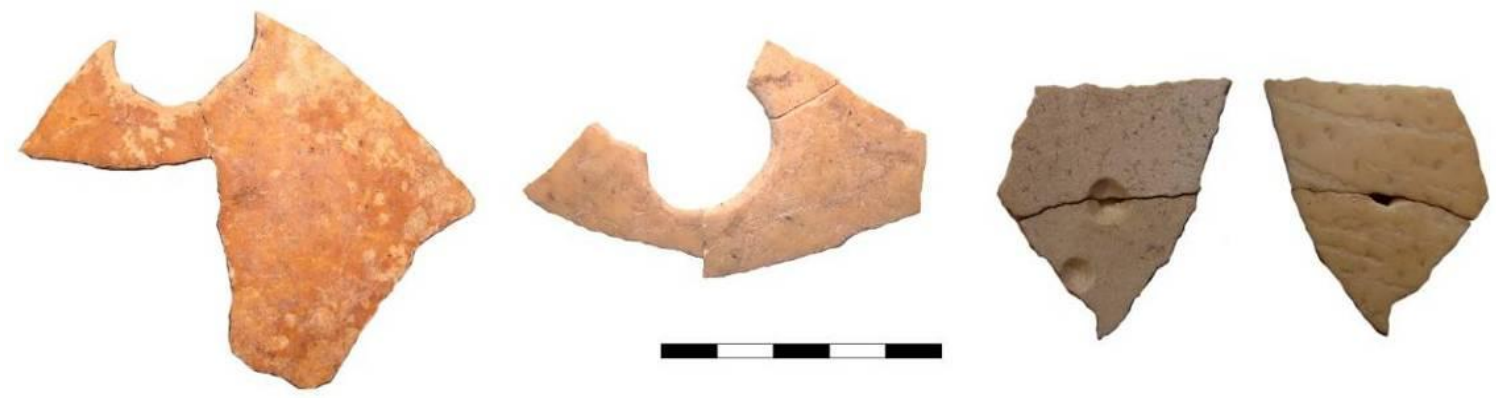

Figure 5.18: Two refitted flask mouths from Patch $1 \mathrm{~A}$ (left) and opposite sides of the engraved and refitting bead debris from Patch $1 B$. Scale in $5 \mathrm{~mm}$ intervals.

Pottery was abundant on Patches $1 \mathrm{~A}$ and $1 \mathrm{~B}$, but also occurred on Patches $1 \mathrm{C}$ and 3 . Patch $1 \mathrm{~A}$ had 37 sherds weighing $273.9 \mathrm{~g}$ and with a mean wall thickness of $6.72 \pm 0.96 \mathrm{~mm}$; many had thickly caked residue on their inner surfaces. There were no rims or decorated sherds. On patch 1B there were 35 sherds weighing $154.0 \mathrm{~g}$ and including six vertical, flat-lipped rims. Their mean thickness was $5.58 \pm 1.04 \mathrm{~mm}$. Where mouth diameters could be estimated these were $100(x 1), 120(x 3)$ and $140 \mathrm{~mm}(\mathrm{x} 1)$. Five refitting sherds, none of them rims, were decorated with small vertical impressions the upper row smaller and less regular than the lower (Figure 5.19). Both patches incorporated sherds with rounded breaks showing reuse of the pots post-breakage. Patches $1 \mathrm{C}$ and 3 had 2 plain potsherds each with weights of $3.1 \mathrm{~g}$ and $15.9 \mathrm{~g}$ and mean thicknesses of $4.43 \pm 0.39 \mathrm{~mm}$ and $7.35 \pm 0.09 \mathrm{~mm}$ respectively. 


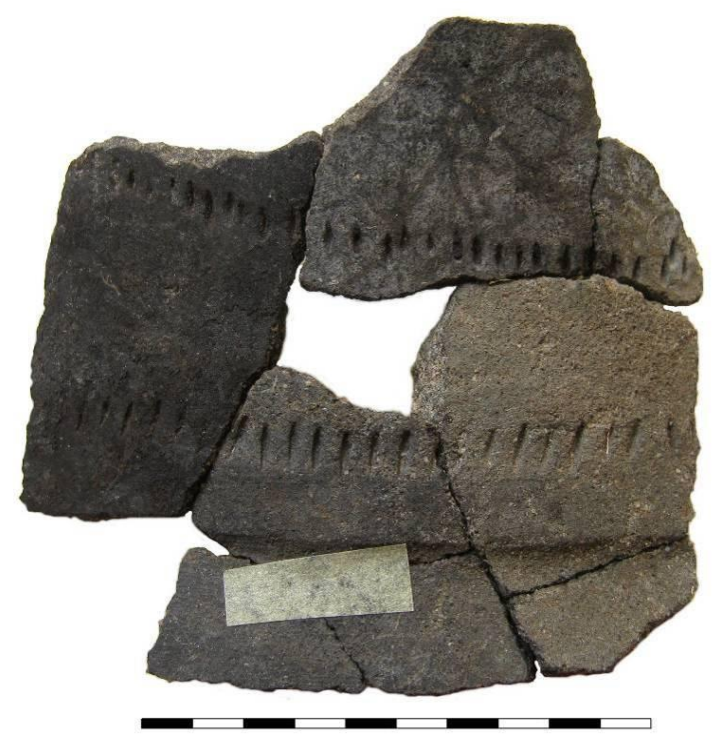

Figure 5.19: Refitting pottery from Patch 1B. The two sherds at upper right appear to have broken post-excavation. Scale in $5 \mathrm{~mm}$ intervals.

Rims of water-worn S. argenvillei shells were also present, three each on Patches 1B and $1 \mathrm{C}$. Some were not complete with two of these being fully rounded fragments (Figure 5.20). The other three were the usual rings, but two were higher than normal. A water-worn Bullia sp. shell came from Patch 1A and a Conus sp. shell from Patch 1C. Two bone artefacts were found. One was a broken 'melon knife' from Patch 1A (c.f. Budack 1977; J.H.A. Kinahan 2000: fig. 3.2) and the other a shaft bone from Patch $1 \mathrm{C}$ with one end worked obliquely (Figure 5.21).
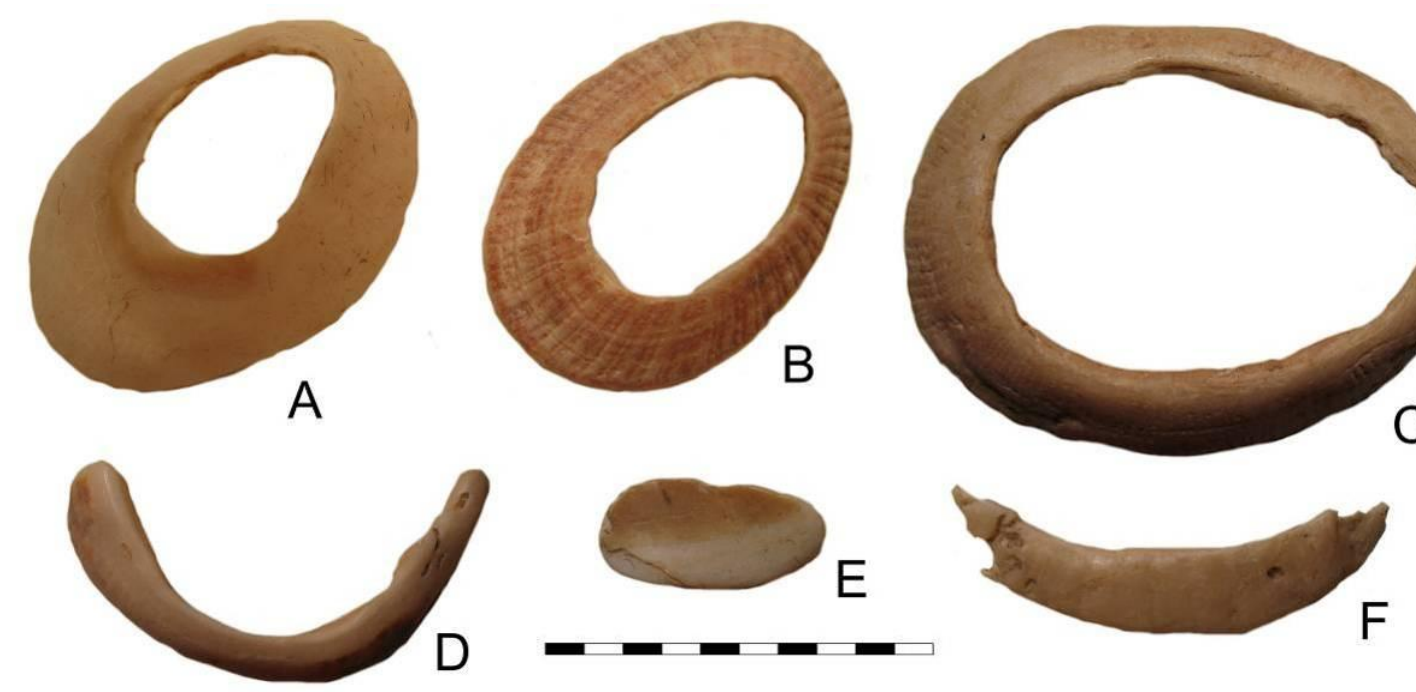

Figure 5.20: Water-worn S. argenvillei shells from KN2005/067 (A-C: Patch 1C; D-F: Patch 1B). Only F has non-abraded breaks. Scale in $5 \mathrm{~mm}$ intervals. 

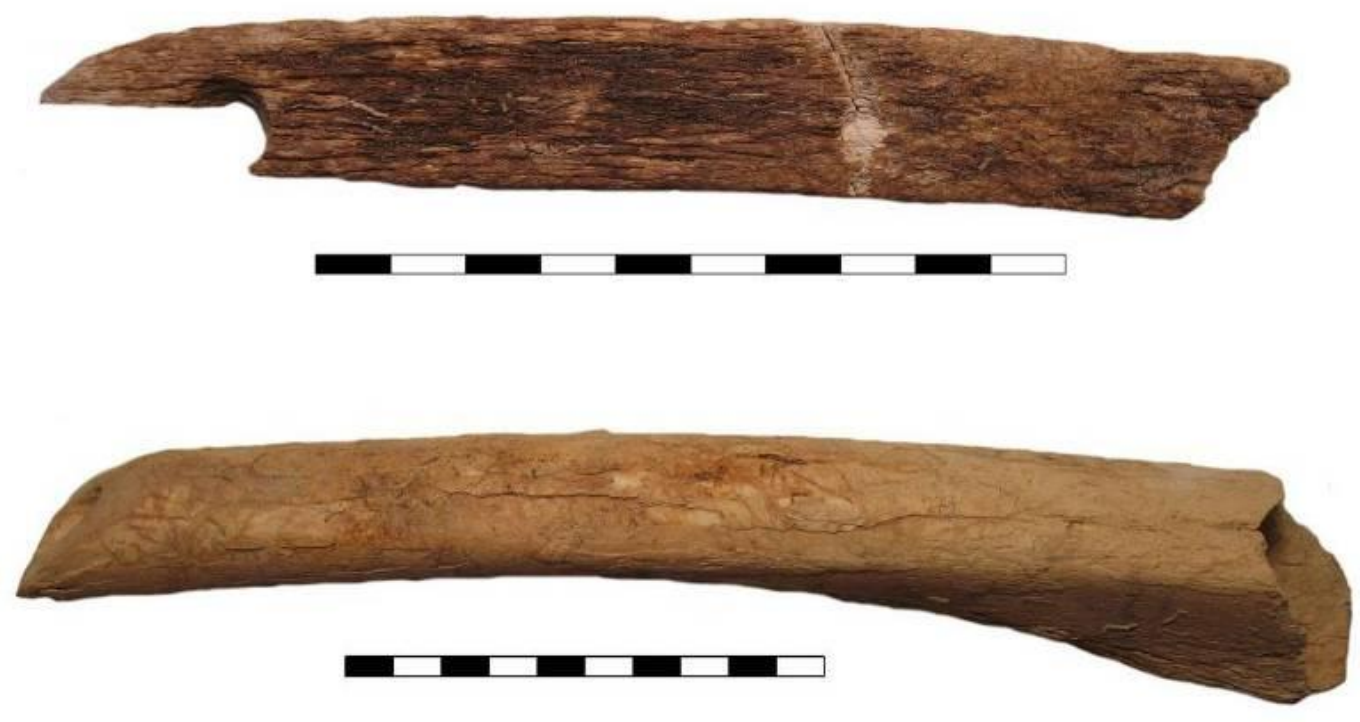

Figure 5.21: Bone artefacts from KN2005/067. Top: melon knife from Patch 1A, bottom: worked bone from Patch $1 \mathrm{C}$. Scale bars in $5 \mathrm{~mm}$ intervals.

Also included as 'material culture' are the six tortoise burials from Patch $1 \mathrm{~A}$, one of which contained two individuals and another three (Figure 5.16). These are identified through various features as follows:

- their carapace and plastron are invariably intact but separated from one another;

- parts of the animals are sometimes slightly burnt;

- some burials contain more than one individual;

- they are routinely found within sterile sand beneath intact shell middens indicating burial early on during occupation; and

- although a hole is seldom visible in the ground, occasional shells found alongside the tortoises occur on end and serve to help define the holes.

These and other tortoise burials from the region are further discussed and illustrated in Orton (2012). 


\subsubsection{KN2005/135A}

\section{The site}

This site was a small in situ shell midden extending to about $30 \mathrm{~cm}$ maximum depth. It lay in an area of small but tall hummock dunes and extended beneath one. It was $370 \mathrm{~m}$

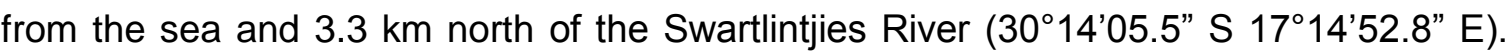
An area of $8 \mathrm{~m}^{2}$ was excavated (Orton \& Halkett 2006). The following date was obtained:

\begin{tabular}{|c|c|c|c|c|}
\hline Lab. No. & Provenience & Material & ${ }^{14} \mathrm{C}$ date $\mathrm{BP}$ & Calibrated age (95.4\%) \\
\hline OxA-22973 & K23 Top & Bone (Chersina angulata) & $2523 \pm 27 \mathrm{BP}$ & $761-414 \mathrm{BC}$ \\
\hline
\end{tabular}

\section{$\underline{\text { Cultural material }}$}

A small, distinctive Group 1 flaked assemblage was recovered (Table 5.25). There were two somewhat unconventional backed bladelets, both with a concave ventral surface; one was made on a very thick bladelet. Two rounded artefacts, a quartz flake and chunk, are not included in Table 5.25. The lower grindstone is large and has a light groove. A second similar one was noted on the surface of an unexcavated square and both were upside down (Figure 5.22). Four small to medium ostrich eggshell beads were found (Table 5.26).

Table 5.25: Stone artefacts from KN2005/135A (Group 1).

\begin{tabular}{lcccc}
\hline & Quartz & CCS & Silcrete & Other \\
\hline Sidescraper & - & 1 & - & - \\
Scraper fragment & - & 1 & - & - \\
Backed bladelet & - & 2 & - & - \\
Blade & 1 & - & - & - \\
Flake & 12 & 9 & - & - \\
Chunk & 7 & 3 & - & - \\
Chip & 13 & 4 & 1 & - \\
Total & 33 & $\mathbf{2 0}$ & $\mathbf{1}$ & $\mathbf{0}$ \\
Stone material \% total & $\mathbf{6 1 . 1}$ & $\mathbf{3 7 . 0}$ & $\mathbf{1 . 9}$ & - \\
Stone material \% formal & - & $\mathbf{1 0 0 . 0}$ & - & - \\
\hline
\end{tabular}




\begin{tabular}{lcccc}
\hline & Quartz & CCS & Silcrete & Other \\
\hline Hammer stone & - & - & - & 2 \\
Hammer stone / Upper grindstone & - & - & - & 1 \\
Upper grindstone & - & - & - & 1 \\
Lower grindstone & - & - & - & 1 \\
Grindstone fragment & - & - & - & 1 \\
\hline
\end{tabular}

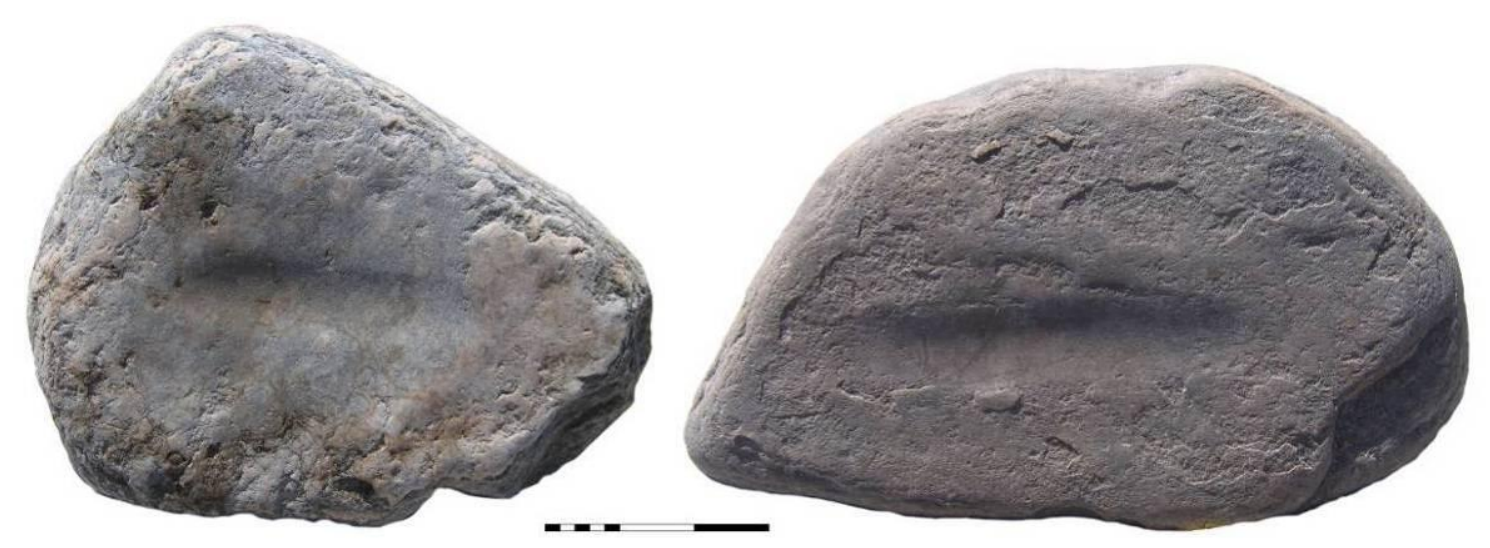

Figure 5.22: The two lower grindstones from KN2005/135A. Scale in 10 and $50 \mathrm{~mm}$ intervals.

Table 5.26: Summary statistics for finished ostrich eggshell beads from KN2005/135A.

\begin{tabular}{llccc}
\hline & Outside diameter $(\mathrm{mm})$ & Aperture diameter $(\mathrm{mm})$ & Thickness $(\mathrm{mm})$ \\
\hline \multirow{3}{*}{$\mathrm{n}=4$} & Mean & 4.88 & 1.75 & 1.64 \\
& Std Deviation & 0.39 & 0.30 & 0.15 \\
& Minimum & 4.61 & 1.32 & 1.46 \\
& Maximum & 5.45 & 2.00 & 1.81 \\
\hline
\end{tabular}

\subsubsection{KN2005/135B}

\section{The site}

This small deflated scatter lay in a bay between tall hummock dunes, $370 \mathrm{~m}$ from the coast and $3.3 \mathrm{~km}$ north of the Swartlintjies River (3005.5” S 1714'52.8” E). The site was within 10 m of KN2005/135A but the two were quite discrete. At KN2005/135B, $16 \mathrm{~m}^{2}$ were excavated (Orton \& Halkett 2006). The following date was obtained:

$\begin{array}{lllll}\text { Lab. No. } & \text { Provenience } & \text { Material } & \frac{{ }^{14} \mathrm{C} \text { date BP }}{\text { OxA-22931 }} & \text { Calibrated age (95.4\%) } \\ \text { D30 Surface } & \text { Bone (Chersina angulata) } & 368 \pm 23 \text { BP } & \text { AD 1482-1634 }\end{array}$




\section{$\underline{\text { Cultural material }}$}

A collection of 234 stone artefacts was excavated along with 18 ostrich eggshell beads.

The stone includes a CCS thumbnail scraper (Table 5.27). Given the scraper, one is tempted to argue for overlap with KN2005/135A. However, that site contains a sidescraper and two backed tools, items typical for its age and absent from 135B. The CCS frequency at KN2005/135B is expected for a site where this material was used and, given the lack of backed elements and side- or backed scrapers, it seems uncontaminated and likely part of Group 1. An extremely well-worn upper grindstone may have been a treasured possession (Figure 5.23). The beads are almost all very large 16 are tightly clustered in the $8-10 \mathrm{~mm}$ range (Table 5.28 ; Figures $5.24 \& 5.25$ ). The two small ones may have originated from KN2005/135A. There are also two fragments of ostrich eggshell flask mouth. No pottery was found.

Table 5.27: Stone artefacts from KN2005/135B (Group 1).

\begin{tabular}{lccccc}
\hline & Quartz & CCS & Quartzite & Sandstone & Other \\
\hline Bipolar core & 2 & - & - & - & - \\
Single platform core & 1 & - & - & - & - \\
Irregular core & 3 & - & 1 & - & - \\
Thumbnail scraper & - & 1 & - & - & - \\
Miscellaneous retouched piece & - & 1 & - & - & - \\
Blade & 1 & - & - & - & - \\
Bladelet & 1 & 3 & - & - & - \\
Flake & 62 & 17 & 4 & - & - \\
Edge-damaged flake & - & 1 & - & - & - \\
Chunk & 35 & 11 & 8 & - & - \\
Chip & 65 & 16 & 1 & - & - \\
Total & $\mathbf{1 7 0}$ & $\mathbf{5 0}$ & $\mathbf{1 4}$ & $\mathbf{0}$ & $\mathbf{0}$ \\
Stone material \% total & $\mathbf{7 2 . 6}$ & $\mathbf{2 1 . 4}$ & $\mathbf{6 . 0}$ & - & - \\
Stone material \% formal & - & $\mathbf{1 0 0 . 0}$ & - & - & - \\
Hammer stone / Upper grindstone & - & - & 1 & - & - \\
Upper grindstone & - & - & 1 & - & - \\
Lower grindstone & - & - & - & 1 & - \\
Grindstone fragment & - & - & - & - & 1 \\
\hline
\end{tabular}




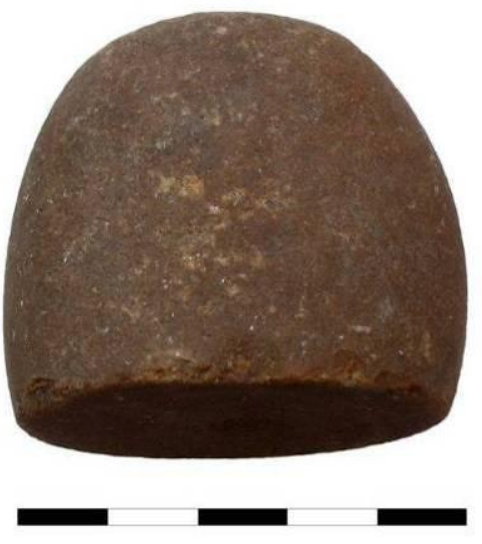

Table 5.28: Summary statistics for finished ostrich eggshell beads from KN2005/135B.

\begin{tabular}{clccc}
\hline & Outside diameter $(\mathrm{mm})$ & Aperture diameter $(\mathrm{mm})$ & Thickness $(\mathrm{mm})$ \\
\hline \multirow{2}{*}{$\mathrm{n}=18$} & 8.50 & 2.53 & 1.73 \\
\cline { 3 - 4 } & Mean & 1.50 & 0.58 & 0.19 \\
& Minimum & 4.47 & 1.62 & 1.27 \\
& Maximum & 9.64 & 3.00 & 1.97
\end{tabular}

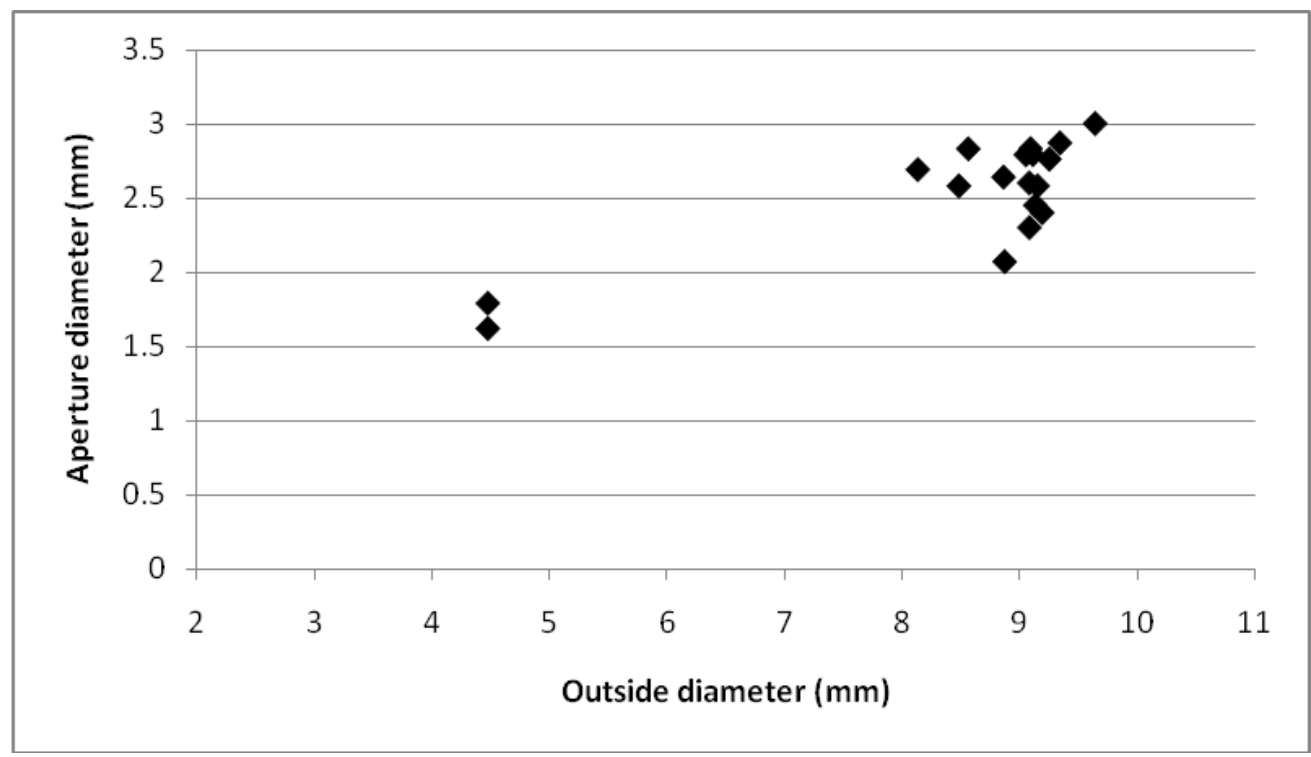

Figure 5.24: Scatter plot of ostrich eggshell bead dimensions from KN2005/135B.
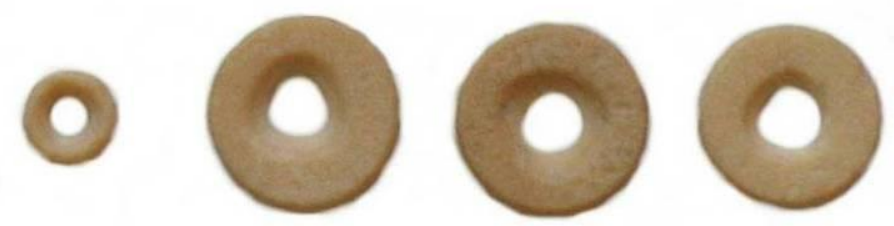

Figure 5.25: Ostrich eggshell beads from KN2005/135B. Scale in 1 and $5 \mathrm{~mm}$ intervals. 


\subsubsection{KV2001/012}

\section{The site}

This site was truncated, exposed and deflated at the edge of a mine trench. As such, the material was found on a sloping surface but with three patches clearly discernible. It was once deposited within a small red sand dune field overlooking the Kareedoringvlei Pan $600 \mathrm{~m}$ to the southwest and $6.3 \mathrm{~km}$ from the coast (29 $\left.30^{\prime} 04.7^{\prime \prime} \mathrm{S} 17^{\circ} 03^{\prime} 19.2^{\prime \prime} \mathrm{E}\right)$. From Areas A, B and C respectively $44 \mathrm{~m}^{2}, 55 \mathrm{~m}^{2}$ and $17 \mathrm{~m}^{2}$ were excavated (Figure 5.26; Halkett 2003). A remnant shell lens was visible in the section above the scatter indicating the original position of the material but too little remained to merit excavation of these in situ deposits. The distribution of finds suggests that deflation had concentrated material on the lower part of the slope. Marked variation in shellfish frequencies supports the presence of three separate occupations. The following dates were obtained:

$\begin{array}{llllll}\text { Lab. No. } & \text { Provenience } & \text { Material } & \frac{14 \text { C date BP }}{3760 \pm 25} & & \text { Calibrated age (95.4\%) } \\ \text { UGAMS-8870 } & \text { Area A, F14 } & \text { Marine shell } & 360 \text { BC } \\ \text { OxA-22984 } & \text { Area B, G24 } & \text { OES (Struthio camelus) } & 1219 \pm 23 \text { BP } & \text { AD 717-1282 } \\ \text { UGAMS-9707 } & \begin{array}{l}\text { Area B, N26 } \\ \text { \& M27 }\end{array} & \text { Marine shell } & 1380 \pm 20 \text { BP } & \text { AD 960-1331 }\end{array}$

Notes:

- OxA-22984: Stage VIIb OES bead with external diameter 9.11, aperture 3.71 and thickness $2.03 \mathrm{~mm}$

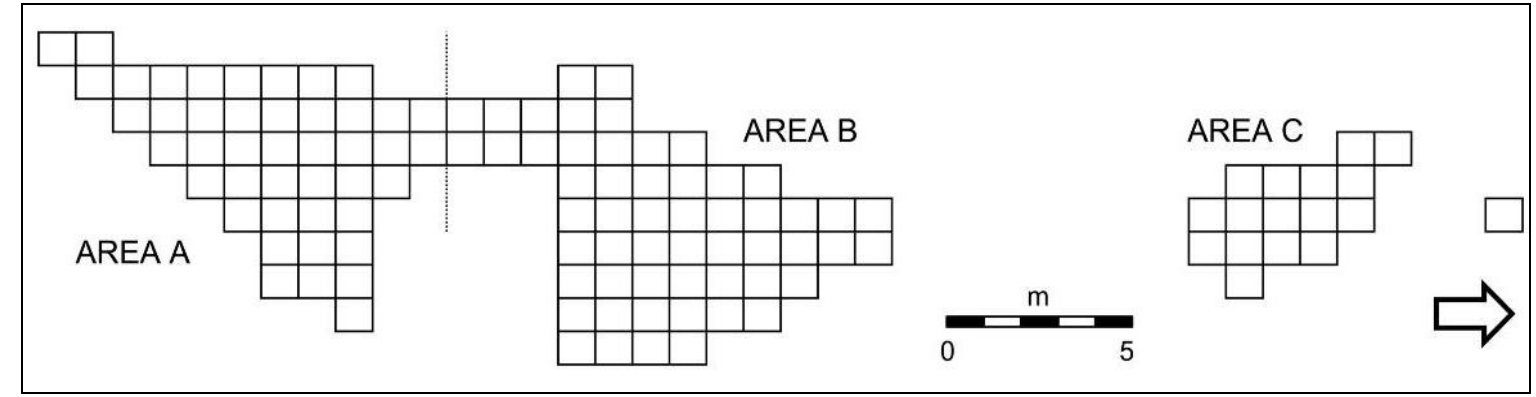

Figure 5.26: Schematic diagram of the excavation at KV2001/012. The division between Areas A and $B$ is arbitrary. The mine trench lay to the east. 


\section{$\underline{\text { Cultural material }}$}

Moderate-sized flaked artefact assemblages were present in Areas A and B, while C had only a small collection (Tables 5.29-5.31). Although some partially transparent quartz occurs on both Areas A and B, it is undoubtedly all of vein origin. Area $\mathrm{C}$ has exclusively milky quartz. In Area A (Group 1) one of the three notched pieces and the MRP seem rather adze-like but they are small (Figure 5.27). The MRP might even have a single, very wide and ill-defined notch. In Area B (probable Group 1) the miscellaneous backed piece looks like an unfinished backed bladelet and has backing running diagonally across the tool. In Area C (Group 1) the thumbnail scraper could be a sidescraper, but its overall morphology slightly favours the former.

Table 5.29: Stone artefacts from KV2001/012, Area A (Group 1).

\begin{tabular}{lccccc}
\hline & Quartz & CCS & Silcrete & Quartzite & Other \\
\hline Bipolar core & - & 2 & - & - & - \\
Single platform core & - & 1 & - & - & - \\
Irregular core & 2 & 1 & - & - & - \\
Notched piece & - & 3 & - & - & - \\
Miscellaneous retouched piece & - & 1 & - & - & - \\
Blade & 1 & 3 & - & - & - \\
Bladelet & 3 & 3 & - & - & - \\
Flake & 110 & 80 & 25 & 13 & 1 \\
Edge-damaged flake & - & 1 & - & - & - \\
Chunk & 66 & 11 & 3 & 12 & - \\
Edge-damaged chunk & - & 1 & - & - & - \\
Chip & 30 & 4 & - & 1 & - \\
Total & $\mathbf{2 1 2}$ & $\mathbf{1 1 1}$ & $\mathbf{2 8}$ & $\mathbf{2 6}$ & $\mathbf{1}$ \\
Stone material \% total & $\mathbf{5 6 . 1}$ & $\mathbf{2 9 . 4}$ & $\mathbf{7 . 4}$ & $\mathbf{6 . 9}$ & $\mathbf{0 . 3}$ \\
Stone material \% formal & - & $\mathbf{1 0 0 . 0}$ & - & - & - \\
Lower grindstone / anvil fragment & - & - & - & - & 1 \\
\hline
\end{tabular}

Table 5.30: Stone artefacts from KV2001/012, Area B (Group 1).

\begin{tabular}{lcccccc}
\hline & Quartz & CCS & Silcrete & Quartzite & Sandstone & Other \\
\hline Bipolar core & 1 & 1 & - & - & - & - \\
Single platform core & - & - & 1 & - & - & - \\
Side-endscraper & - & 1 & - & - & - & - \\
\hline
\end{tabular}




\begin{tabular}{lcccccc}
\hline & Quartz & CCS & Silcrete & Quartzite & Sandstone & Other \\
\hline Miscellaneous backed piece & 1 & - & - & - & - & - \\
Miscellaneous retouched piece & - & - & 1 & - & - & - \\
Blade & - & 1 & 2 & - & - & - \\
Bladelet & - & - & 1 & - & - & - \\
Flake & 86 & 8 & 94 & 6 & 1 & - \\
Edge-damaged flake & 1 & - & 2 & - & - & - \\
Chunk & 69 & 3 & 27 & 2 & - & - \\
Chip & 33 & - & 4 & - & - & - \\
Total & $\mathbf{1 9 1}$ & $\mathbf{1 4}$ & $\mathbf{1 3 2}$ & $\mathbf{8}$ & $\mathbf{1}$ & $\mathbf{0}$ \\
Stone material \% total & $\mathbf{5 5 . 2}$ & $\mathbf{4 . 0}$ & $\mathbf{3 8 . 2}$ & $\mathbf{2 . 3}$ & $\mathbf{0 . 3}$ & - \\
Stone material \% formal & $\mathbf{3 3 . 3}$ & $\mathbf{3 3 . 3}$ & $\mathbf{3 3 . 3}$ & - & - & - \\
\hline
\end{tabular}

Table 5.31: Stone artefacts from KV2001/012, Area C (Group 1).

\begin{tabular}{lcccccc}
\hline & Quartz & CCS & Silcrete & Quartzite & Sandstone & Other \\
\hline Sidescraper & - & - & 1 & - & - & - \\
Thumbnail scraper & - & - & 1 & - & - & - \\
Blade & 1 & - & - & - & - & - \\
Edge-damaged blade & - & - & 1 & - & - & - \\
Bladelet & - & - & 1 & - & - & - \\
Flake & 28 & 4 & 10 & 1 & - & - \\
Chunk & 31 & 2 & 8 & 1 & - & - \\
Chip & 5 & - & - & - & - & - \\
Total & 65 & $\mathbf{6}$ & $\mathbf{2 2}$ & $\mathbf{2}$ & $\mathbf{0}$ & 0 \\
Stone material \% total & $\mathbf{6 8 . 4}$ & $\mathbf{8 . 4}$ & $\mathbf{2 1 . 1}$ & $\mathbf{2 . 1}$ & - & - \\
Stone material \% formal & - & - & $\mathbf{1 0 0 . 0}$ & - & - & - \\
Upper grindstone fragment & - & - & - & - & 1 & - \\
\hline
\end{tabular}

Silcrete is generally rare in Holocene sites along this coastline and the prominence of silcrete across all three scatters may suggest proximity to a source of good material. In all three areas the silcrete appears to be the same beige-colour as present on the ridge inland of the site, but the artefacts are slightly finer-grained. Both Area C scrapers are made from an extremely fine-grained silcrete and are the only two examples of this material from the site. Some reuse of older silcrete flakes is evident and, with some larger flakes also present, it may be the case that people simply collected old flakes from the vicinity of the outcrop - KV2005/002 is at this outcrop (see Section 3.7.1). The lower 
grindstone fragment in Area A has a fairly deep groove on both sides, each of which is accompanied by pecking marks characteristic of use as an anvil.
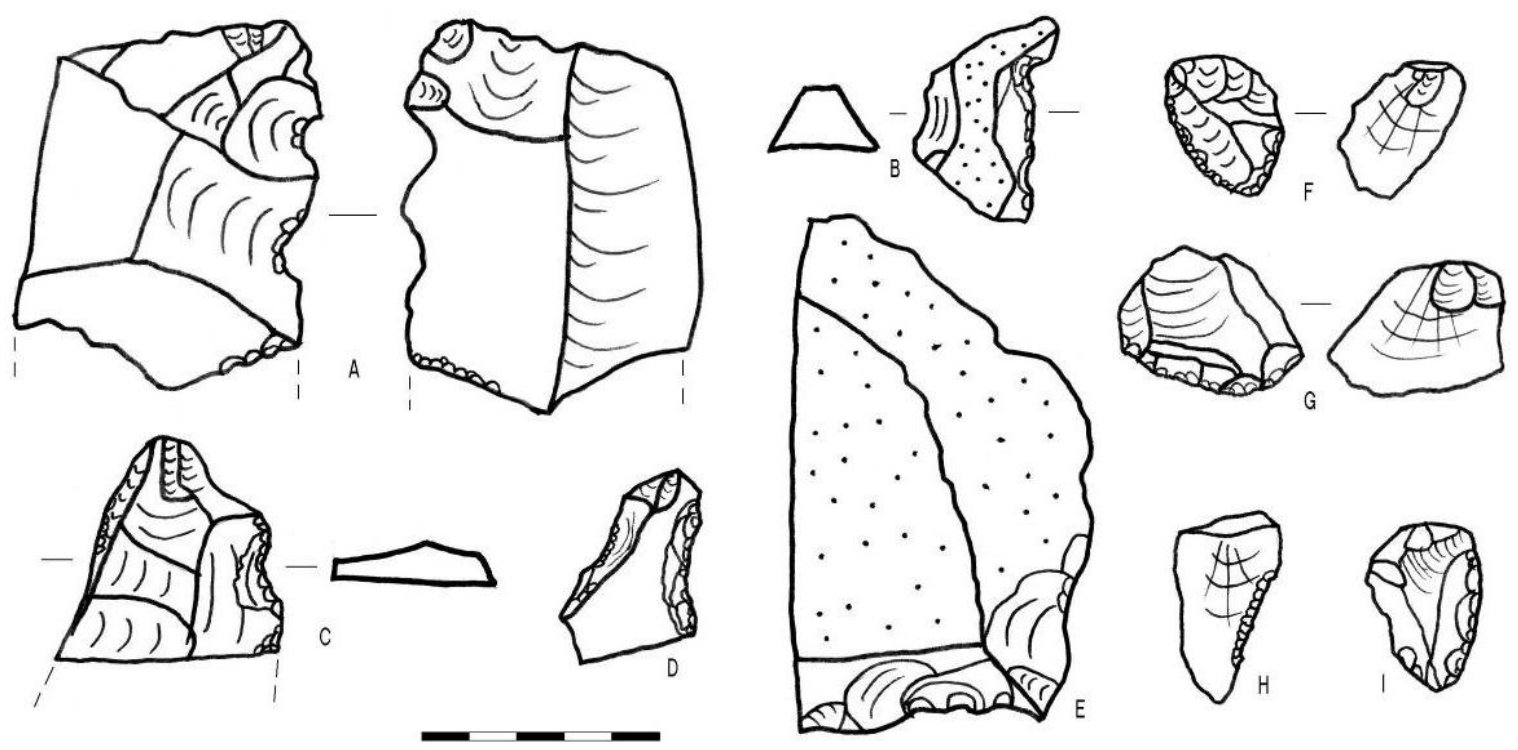

Figure 5.27: Stone artefacts from KV2001/012 Area A (A-D), Area B (E-G) and Area C (H-I). AC: notched pieces; D, E: miscellaneous retouched pieces; F: side-endscraper; G: thumbnail scraper; H: miscellaneous backed piece; I: sidescraper. All in CCS except E: silcrete; F: quartz. Scale in $5 \mathrm{~mm}$ intervals.

One ostrich eggshell bead was found in Area A and 44 in Area B. The latter comprise one small, two medium, one large and 40 very large beads (Table 5.32; Figure 5.28). Furthermore, Area A has a broken bead of approximately $4.5 \mathrm{~mm}$ diameter and a partly made bead in stage $\mathrm{Va}$, while Area $\mathrm{B}$ has two broken beads of about $10 \mathrm{~mm}$ and two of about $9 \mathrm{~mm}$ diameter. There were nine flask mouth fragments in Area $A$ and two in Area B (Figure 5.29). From Area A two sets of two mouths were refitted and with the massive quantities of ostrich eggshell found in this area (1749 fragments weighing c. 1.2 $\mathrm{kg}=5$ whole eggs) a cache of flasks was almost certainly present. 
Table 5.32: Summary statistics for finished ostrich eggshell beads from KV2001/012.

\begin{tabular}{|c|c|c|c|c|}
\hline \multicolumn{2}{|l|}{ Area } & Outside diameter (mm) & Aperture diameter $(\mathrm{mm})$ & Thickness (mm) \\
\hline \multicolumn{2}{|l|}{$A(n=1)$} & 4.45 & 1.58 & 1.51 \\
\hline \multirow{4}{*}{$\begin{array}{c}B \\
(n=44)\end{array}$} & Mean & 9.37 & 3.79 & 1.76 \\
\hline & Std Deviation & 1.36 & 0.48 & 0.19 \\
\hline & Minimum & 3.65 & 1.55 & 1.35 \\
\hline & Maximum & 10.38 & 4.35 & 2.13 \\
\hline
\end{tabular}

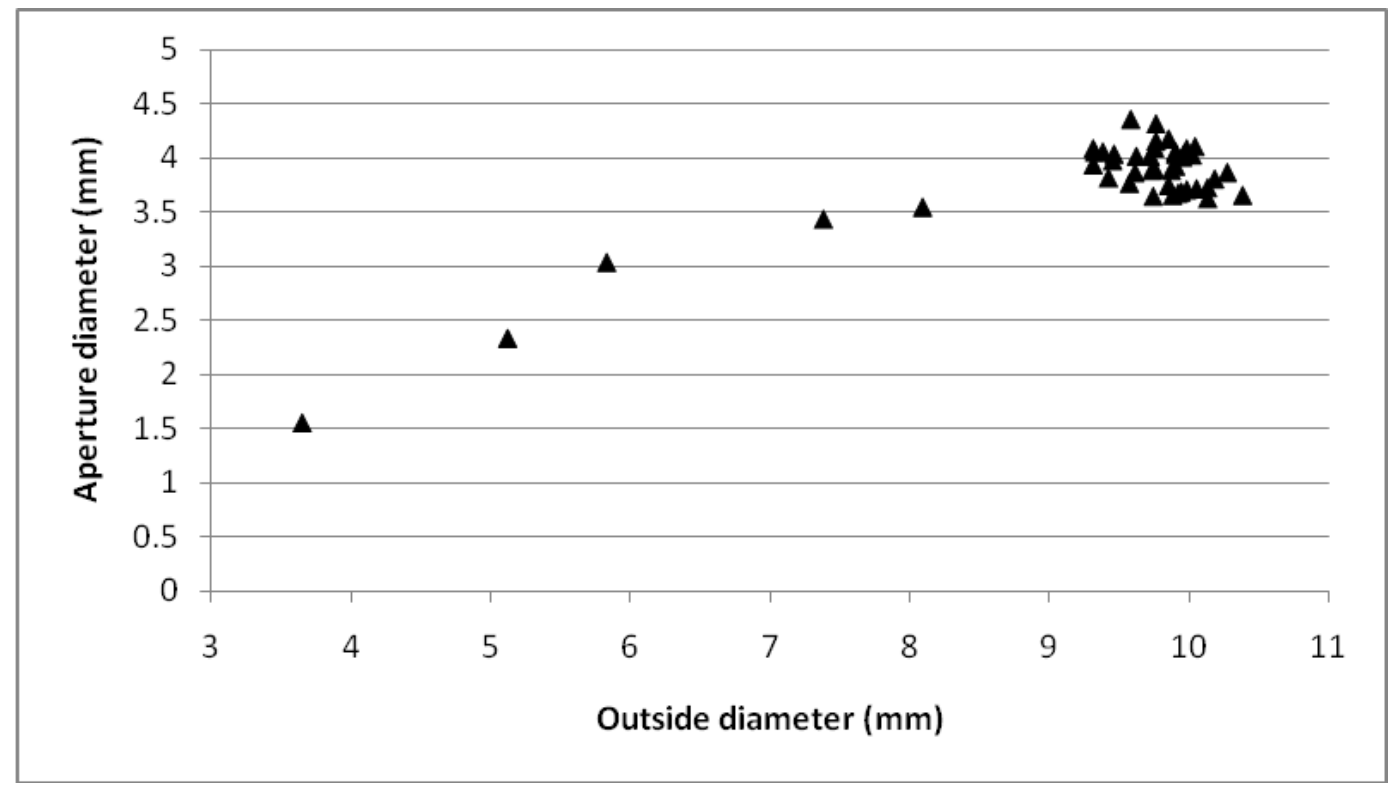

Figure 5.28: Scatter plot of ostrich eggshell bead dimensions from Area B of KV2001/012.

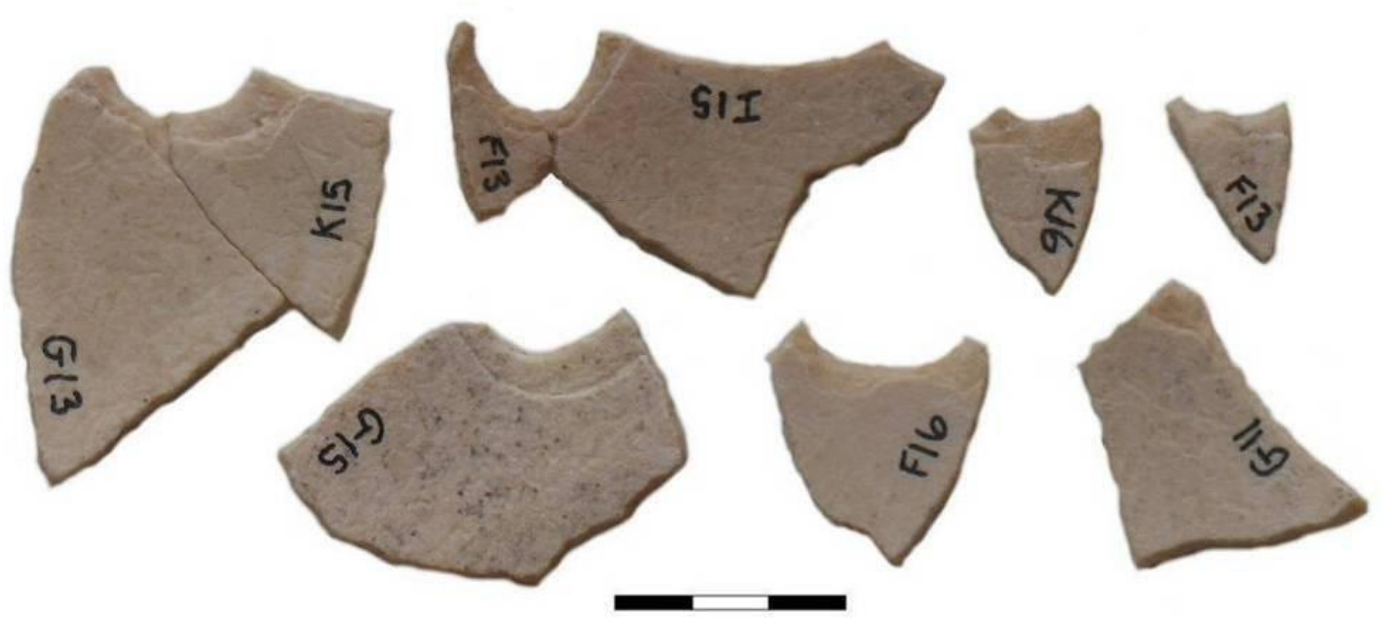

Figure 5.29: Ostrich eggshell flask mouth fragments from KV2001/012, Area A. Scale in $5 \mathrm{~mm}$ intervals.

Also on the site were five fragments of green bottle glass, one in Area A and four in Area B. These are unworked and clearly a modern intrusion 


\subsubsection{LK2001/015}

\section{The site}

LK2001/015 lay between a large dune cordon and the coast, some $300 \mathrm{~m}$ from the latter $\left(30^{\circ} 21^{\prime} 38.0^{\prime \prime} \mathrm{S} 17^{\circ} 17^{\prime} 36.0^{\prime \prime} \mathrm{E}\right)$ and $10.8 \mathrm{~km}$ from the Swartlintjies River mouth. On the surface, many patches of shell occurred in a limited area. The strong spatial relationship between them suggested they were likely all part of the same site. Between $1 \mathrm{~m}^{2}$ and $12 \mathrm{~m}^{2}$ were excavated from each for a total of $44 \mathrm{~m}^{2}$ (Figure 5.30 ). The deposit was passed through a $1.5 \mathrm{~mm}$ sieve (Halkett 2003). The following dates were obtained:

\begin{tabular}{|c|c|c|c|c|}
\hline Lab. No. & Provenience & Material & ${ }^{14} \mathrm{C}$ date $\mathrm{BP}$ & Calibrated age (95.4\%) \\
\hline \multirow[t]{2}{*}{ OxA-24557 } & Patch Chi: J29 & Bone (Raphicerus & $394 \pm 24$ & AD 1457-1626 \\
\hline & Lower & campestris) & & \\
\hline \multirow{2}{*}{ OxA-24558 } & Patch Cii: N32 & Bone (Chersina & \multirow{2}{*}{$420 \pm 24$} & \multirow{2}{*}{ AD 1448-1622 } \\
\hline & Hearth/Ash & angulata) & & \\
\hline OxA-24560 & Patch D: ZA35 & $\begin{array}{l}\text { Bone (Chersina } \\
\text { angulata) }\end{array}$ & $401 \pm 22$ & AD 1455-1625 \\
\hline OxA-24561 & Patch D: ZA35 & $\begin{array}{l}\text { Bone (Chersina } \\
\text { angulata) }\end{array}$ & $442 \pm 24$ & AD 1442-1615 \\
\hline OxA-24562 & Patch F: ZE32 & $\begin{array}{l}\text { Bone (? Raphicerus } \\
\text { campestris) }\end{array}$ & $398 \pm 25$ & AD 1456-1626 \\
\hline \multirow[t]{2}{*}{ OxA-24559 } & Patch I: J6 & Bone (Raphicerus & \multirow[t]{2}{*}{$403 \pm 24$} & \multirow{2}{*}{ AD 1454-1625 } \\
\hline & Lower & campestris) & & \\
\hline
\end{tabular}

Notes:

- OxA-24560 \& OxA-24561 were run on the same sample.

The dates suggest the scatters to be contemporary and support the idea that the site is a large camp with each patch representing domestic dumps from different huts.

\section{Cultural material}

Just 29 flaked stone artefacts were found across the entire excavation but with 59\% coming from Patch D alone (Tables 5.33 to 5.35). Patches, $A, B, C i, G$ and $H$ have no flaked artefacts. Patch F has just one artefact, a CCS bipolar core. Individual 
assemblages are tiny, but Patch D may belong to Group 1, Patch Cii to Group 2 and Patch I to Group 3, with the rest belonging in Group 4. Given the similar age of all patches, these finds likely represent occasional use of stone artefacts over a very short period of time.

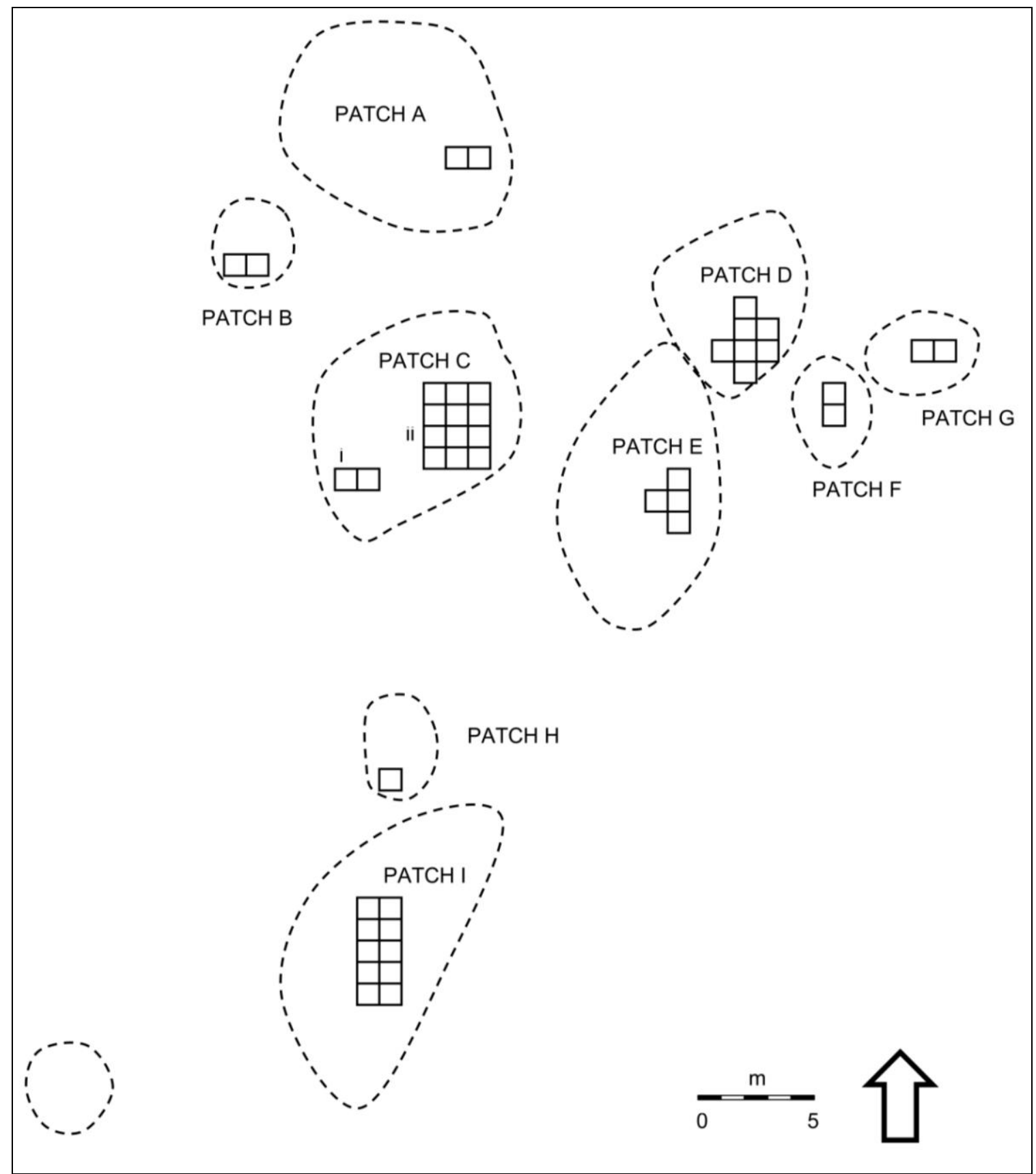

Figure 5.30: Schematic map of the excavation at LK2001/015. The dashed circles indicate approximate limits of visible surface shell scatter at each patch. 
Table 5.33: Stone artefacts from LK2001/015, Patch Cii Group 2).

\begin{tabular}{lcc}
\hline & Quartz & Quartzite \\
\hline Bipolar core & 1 & - \\
Flake & 2 & 1 \\
Chunk & 1 & - \\
Total & 4 & $\mathbf{1}$ \\
Stone material \% total & $\mathbf{8 0}$ & $\mathbf{2 0}$ \\
\hline
\end{tabular}

Table 5.34: Stone artefacts from LK2001/015, Patch D (Group 1).

\begin{tabular}{lcccc}
\hline & Quartz & CCS & Quartzite & Other \\
\hline Sidescraper & - & 1 & - & - \\
Bladelet & 1 & - & - & - \\
Flake & 6 & - & 3 & - \\
Chunk & - & - & 1 & - \\
Chip & 3 & - & 2 & - \\
Total & 10 & $\mathbf{1}$ & $\mathbf{6}$ & $\mathbf{0}$ \\
Stone material \% total & $\mathbf{5 8 . 8}$ & $\mathbf{5 . 9}$ & $\mathbf{3 5 . 3}$ & - \\
Stone material \% formal & - & $\mathbf{1 0 0 . 0}$ & - & - \\
Grindstone fragment & - & - & - & 2 \\
\hline
\end{tabular}

Table 5.35: Stone artefacts from LK2001/015, Patch I (Group 3).

\begin{tabular}{lcc}
\hline & Quartz & Quartzite \\
\hline Backed flake & 1 & - \\
Backed bladelet fragment & 1 & - \\
Flake & 1 & 1 \\
Chunk & - & 1 \\
Chip & 1 & - \\
Total & $\mathbf{4}$ & $\mathbf{2}$ \\
Stone material \% total & $\mathbf{6 6 . 7}$ & $\mathbf{3 3 . 3}$ \\
Stone material \% formal & $\mathbf{1 0 0 . 0}$ & - \\
\hline
\end{tabular}

Ostrich eggshell beads were found only in Patches $\mathrm{Ci}$, Cii and I. In Cii the two whole beads were of two completely different sizes (small and large) so no mean values are given (Table 5.36). In Patch I the six whole beads all came from a single square and were of similar size (Table 5.37). Several unfinished beads were found in Patches $\mathrm{Ci}$ and Cii only (Table 5.38). Two fragments of pottery weighing $8.1 \mathrm{~g}$ were found in Patch F. One has a rounded break indicating reuse of the sherd after initial breakage. Their mean 
wall thickness was $4.07 \pm 0.25 \mathrm{~mm}$. A single Marginella sp. shell was found on Patch I. Being water-worn, it was obviously collected from the beach.

Table 5.36: Measurements of the two finished ostrich eggshell beads from LK2001/015, Patch Cii.

\begin{tabular}{ccc}
\hline Outside diameter $(\mathrm{mm})$ & Aperture diameter $(\mathrm{mm})$ & Thickness $(\mathrm{mm})$ \\
\hline 3.28 & 1.71 & 1.06 \\
7.02 & 2.54 & 1.56 \\
\hline
\end{tabular}

Table 5.37: Summary statistics for finished ostrich eggshell beads from LK2001/015, Patch I.

\begin{tabular}{clccc}
\hline & Outside diameter $(\mathrm{mm})$ & Aperture diameter $(\mathrm{mm})$ & Thickness $(\mathrm{mm})$ \\
\hline \multirow{3}{*}{$\mathrm{n}=6^{*}$} & 8.33 & 2.10 & 1.79 \\
\cline { 3 - 4 } & Std Deviation & 0.13 & 0.19 & 0.13 \\
& Minimum & 8.21 & 1.90 & 1.61 \\
& Maximum & 8.58 & 2.38 & 1.91 \\
\hline
\end{tabular}

${ }^{*}$ One bead had exfoliated such that thickness could not be measured.

Table 5.38: Unfinished ostrich eggshell beads from LK2001/015.

\begin{tabular}{lccc}
\hline Stage & Ila & Illb & IVb \\
\hline Patch $\mathrm{Ci}$ & - & 1 & - \\
Patch Cii & 1 & 2 & 1 \\
\hline
\end{tabular}

The most interesting cultural find from this site, and unique in Namaqualand, is part of a decorated seal scapula from Patch Ci (Figure 5.31). It has one edge rounded and smoothed and the decoration is in the form of small impressions seemingly created by drilling into the bone surface. The back has also been smoothed. No other seal bone occurs in Patches $\mathrm{Ci}$ and Cii. The only other known instance of this type of decoration is on an ivory knife from De Hangen (Parkington \& Poggenpoel 1971). 


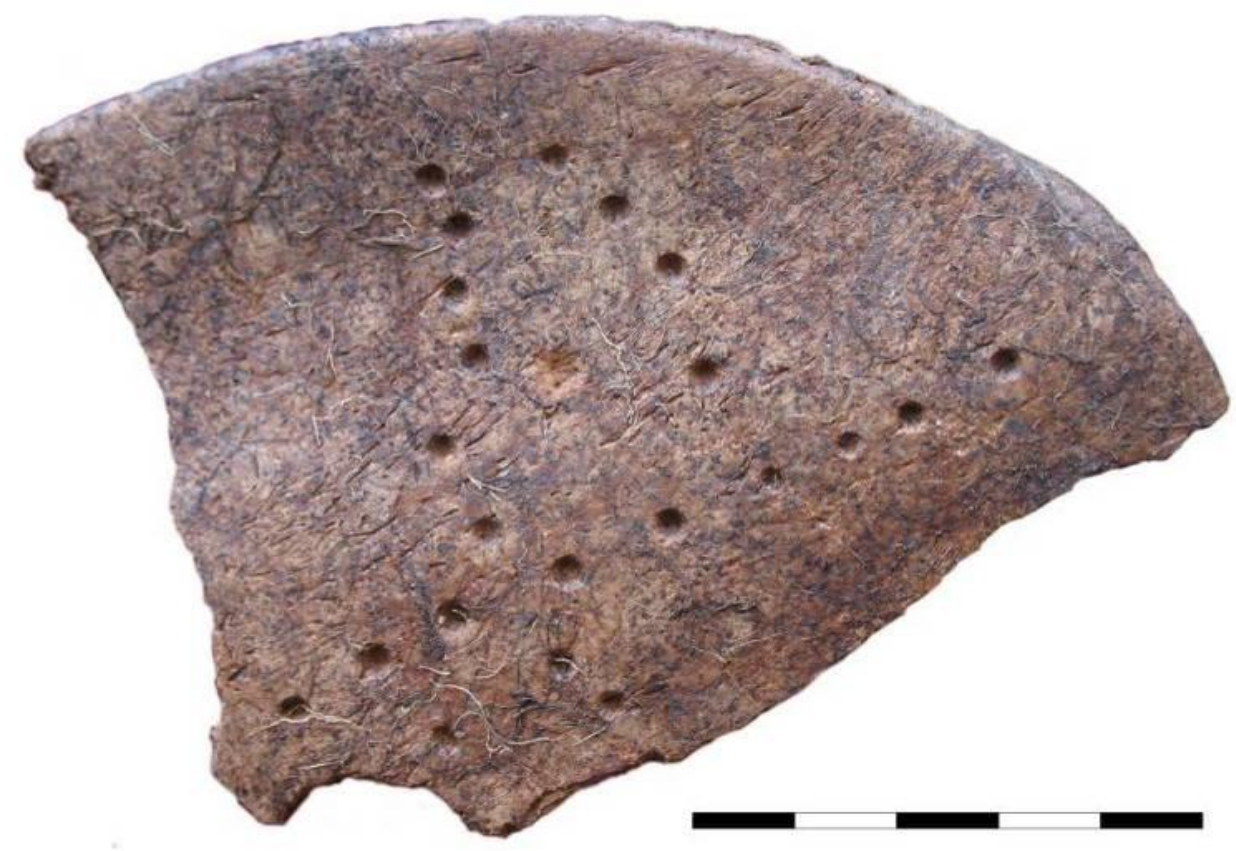

Figure 5.31: The decorated seal scapula from LK2001/015, Patch Ci. Scale in $5 \mathrm{~mm}$ intervals.

\subsubsection{LK2004/011B}

\section{The site}

LK2004/011B was found eroding out of the side of a mine trench some $90 \mathrm{~m}$ from the shore and midway between the Spoeg and Swartlintjies Rivers, $12.5 \mathrm{~km}$ from each $\left(30^{\circ} 22^{\prime} 10.9^{\prime \prime} \mathrm{S} 17^{\circ} 18^{\prime} 01.4^{\prime \prime} \mathrm{E}\right)$. Much of its immediate context was lost, but the site was probably deposited within a hollow between the large aeolian dunes of the area. While only $2.75 \mathrm{~m}^{2}$ of in situ midden could be excavated from the side of the trench (Figure 5.32), a large collection was taken from the slope below. The slumped material was collected via a $1.5 \mathrm{~mm}$ sieve, while the wetter in situ material was from a $3 \mathrm{~mm}$ sieve. Three human leg bones $(\mathrm{MNI}=1)$ were collected from the slope $10 \mathrm{~m}$ west of the excavated squares but cannot reliably be associated with the midden (Orton \& Halkett 2005). One was radiocarbon dated to $800 \pm 70 \mathrm{BP}$ (GX-32523; Dewar 2008). The adjacent site of Penguin Midden (LK2004/011) was reported by Dewar (2008) and lies some $10 \mathrm{~m}$ to the east. The following dates have been obtained for the $011 \mathrm{~B}$ site: 
Lab. No.

GX-32064

Provenience

Q28d

OxA-22980 R27b

Notes:
${ }^{14} \mathrm{C}$ date BP Calibrated age (95.4\%)

Marine shell

Charcoal (sp. unknown)
$1250 \pm 60$ BP AD 1055-1447

$924 \pm 22 \mathrm{BP} \quad$ AD 1050-1218

- Given these results and the uncertainties associated with marine calibration, the charcoal date is taken as more reliable and is used as the age for the site.

\section{$\underline{\text { Cultural material }}$}

Most stone artefacts (91.9\%) come from the slope of the trench but those obtained from the in situ deposits appear to be representative of the slumped portion. All are thus taken together as one assemblage. A large collection of clear quartz artefacts with many tiny backed artefacts was recovered (Group 3). Other materials were rare (Table 5.39). The assemblage is typical of similar ones from other sites (e.g. Orton et al. 2005), but the inclusion of two segments in such a recent site is interesting. One is whole, somewhat irregular in shape (Figure 5.33), and measures $8.88 \mathrm{~mm}$ long, $5.62 \mathrm{~mm}$ wide and 2.15 $\mathrm{mm}$ thick, while the other would have been about $12 \mathrm{~mm}$ long before breaking.

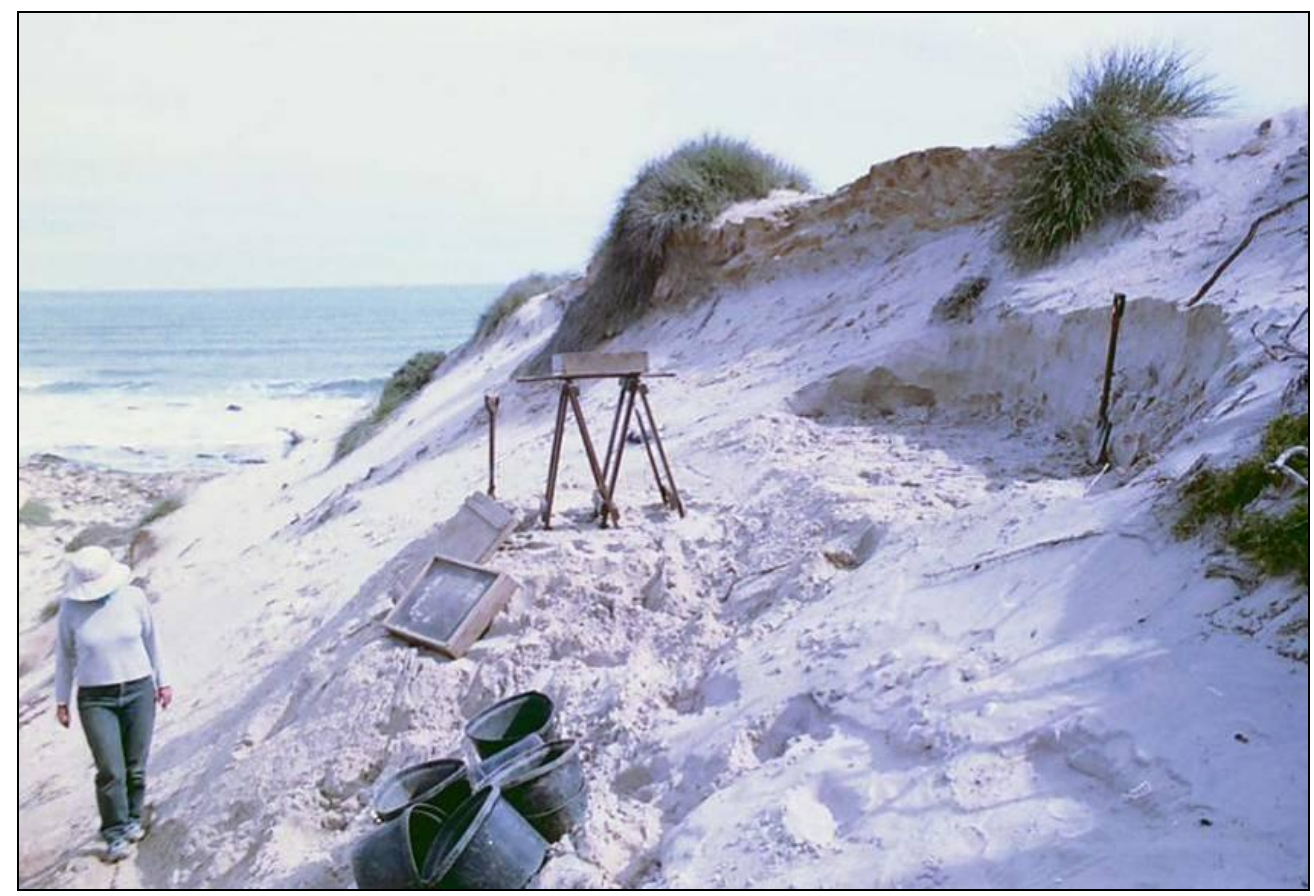

Figure 5.32: View westwards showing the position of the in situ shell midden (at the base of the spade) in the side of a mine trench. 
Table 5.39: Stone artefacts from LK2004/011B (Group 3).

\begin{tabular}{|c|c|c|c|c|c|}
\hline & Quartz & CCS & Silcrete & Quartzite & Other \\
\hline Bipolar core & 18 & - & - & - & - \\
\hline Single platform core & 2 & - & - & - & - \\
\hline Irregular core & 3 & - & - & - & - \\
\hline Sidescraper & 1 & - & - & - & - \\
\hline Backed flake & 17 & - & - & - & - \\
\hline Backed bladelet & 39 & - & - & - & - \\
\hline Curve-backed flake & 1 & - & - & - & - \\
\hline Backed bladelet fragment & 6 & - & - & - & - \\
\hline Backed point fragment & 1 & - & - & - & - \\
\hline Segment & 2 & - & - & - & - \\
\hline Backed piece fragment & 5 & - & - & - & - \\
\hline Miscellaneous retouched piece & 6 & - & - & - & - \\
\hline Blade & - & - & - & 1 & - \\
\hline Bladelet & 33 & - & - & - & - \\
\hline Edge-damaged bladelet & 5 & - & - & - & - \\
\hline Flake & 240 & - & - & 33 & - \\
\hline Edge-damaged flake & 7 & - & 1 & - & - \\
\hline Chunk & 101 & - & - & 11 & - \\
\hline Edge-damaged chunk & 1 & - & - & - & - \\
\hline Chip & 672 & 1 & - & 3 & - \\
\hline Edge-damaged chip & 2 & - & - & - & - \\
\hline Total & 1162 & 1 & 1 & 48 & 0 \\
\hline Stone material \% total & 95.9 & 0.1 & 0.1 & 4.0 & - \\
\hline Stone material \% formal & 100 & - & - & - & - \\
\hline Hammer stone / Upper grindstone & - & - & - & - & 1 \\
\hline Hammer stone / Upper grindstone fragment & - & - & - & - & 2 \\
\hline
\end{tabular}

This is the largest Group 3 assemblage from Namaqualand so it is useful to present size data for the common backed elements (Table 40). Figure 5.34 shows that backed flakes and bladelets do separate into two groups but that backed flakes tend to be quite elongate, probably suggesting that they were all one type as far as their makers were concerned. The hammer stone/upper grindstone is well worn with two adjoining facets. 
Table 5.40: Size data of unbroken backed artefacts from LK2004/011B.

\begin{tabular}{llccc}
\hline & & Length & Breadth & Thickness \\
\hline \multirow{2}{*}{ Backed } & Mean & 13.83 & 5.63 & 2.66 \\
bladelets & Standard deviation & 2.84 & 1.41 & 0.67 \\
$\mathrm{n}=16$ & Maximum & 23.36 & 10.28 & 4.24 \\
& Minimum & 10.59 & 4.02 & 1.92 \\
\hline \multirow{2}{*}{ Backed } & Mean & 9.51 & 5.61 & 2.17 \\
flakes & Standard deviation & 1.86 & 0.98 & 0.35 \\
$\mathrm{n}=10$ & Maximum & 14.35 & 8.13 & 2.77 \\
& Minimum & 7.91 & 4.66 & 1.58 \\
\hline
\end{tabular}
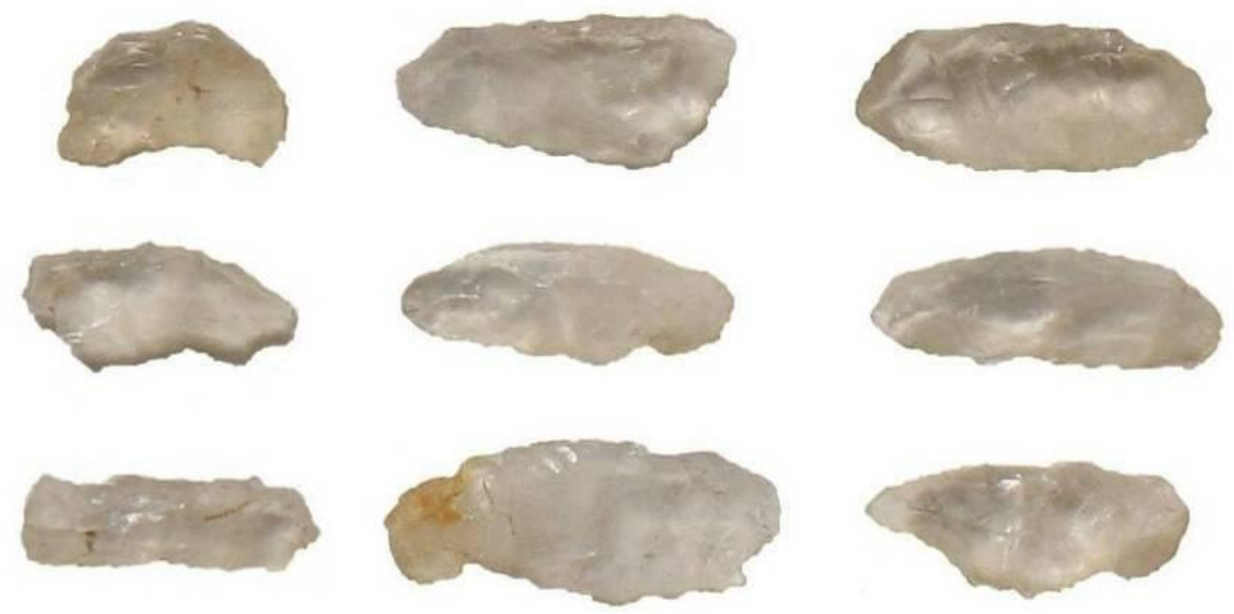

Figure 5.33: A segment (upper left) and eight backed bladelets from LK2004/011B. All have their backed edges towards the top of the page. Scale in 1 and $5 \mathrm{~mm}$ intervals.

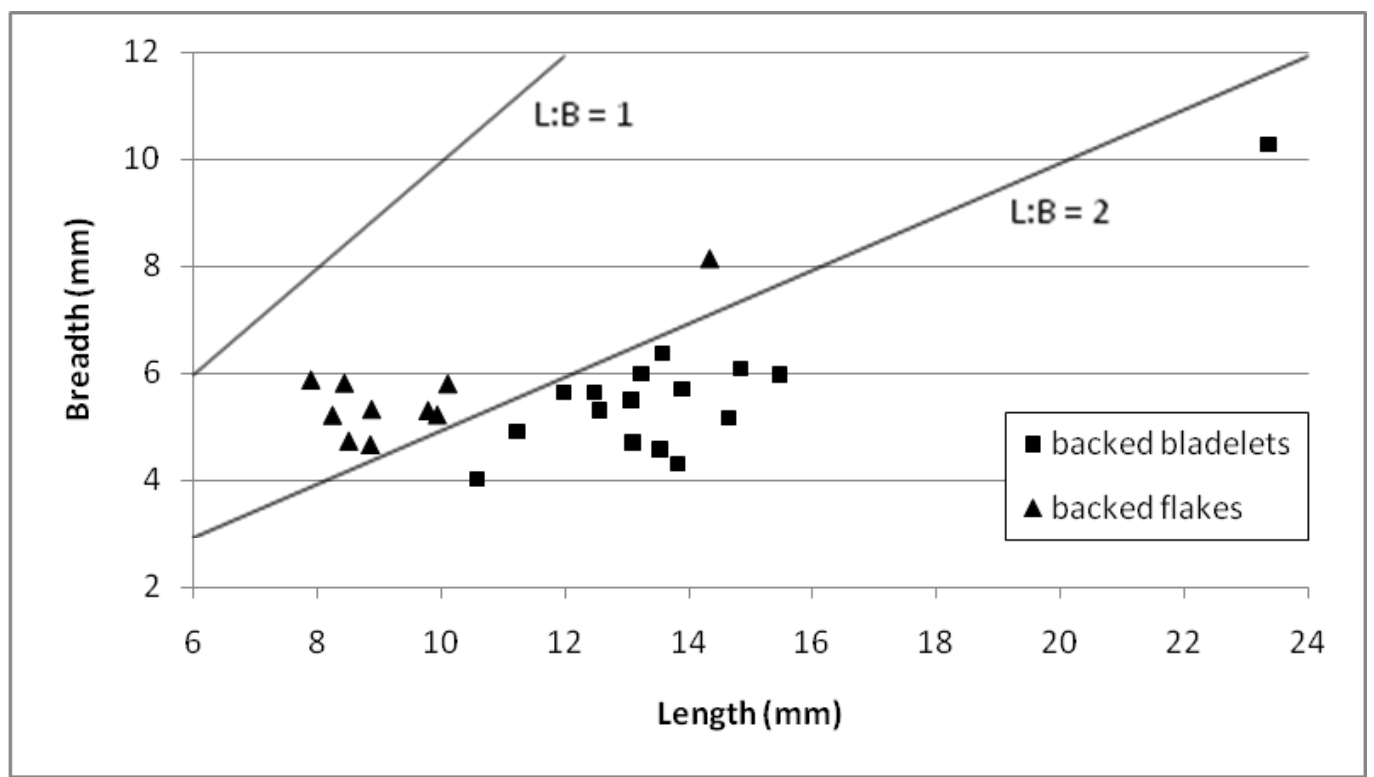

Figure 5.34: Plot of length to breadth for whole backed flakes and bladelets from LK2004/011B. 
The site also produced a collection of sixteen whole and two broken ostrich eggshell beads. The five in situ beads were medium and large, while all sizes were found in the slump; two populations are not readily isolated (Figure 5.35; Table 5.41). The broken beads are c. 6.6 and $5.0 \mathrm{~mm}$ in diameter respectively. Two refitting ostrich eggshell flask mouth fragments were also found in the slumped material along with one plain body potsherd $(3.3 \mathrm{~g})$.

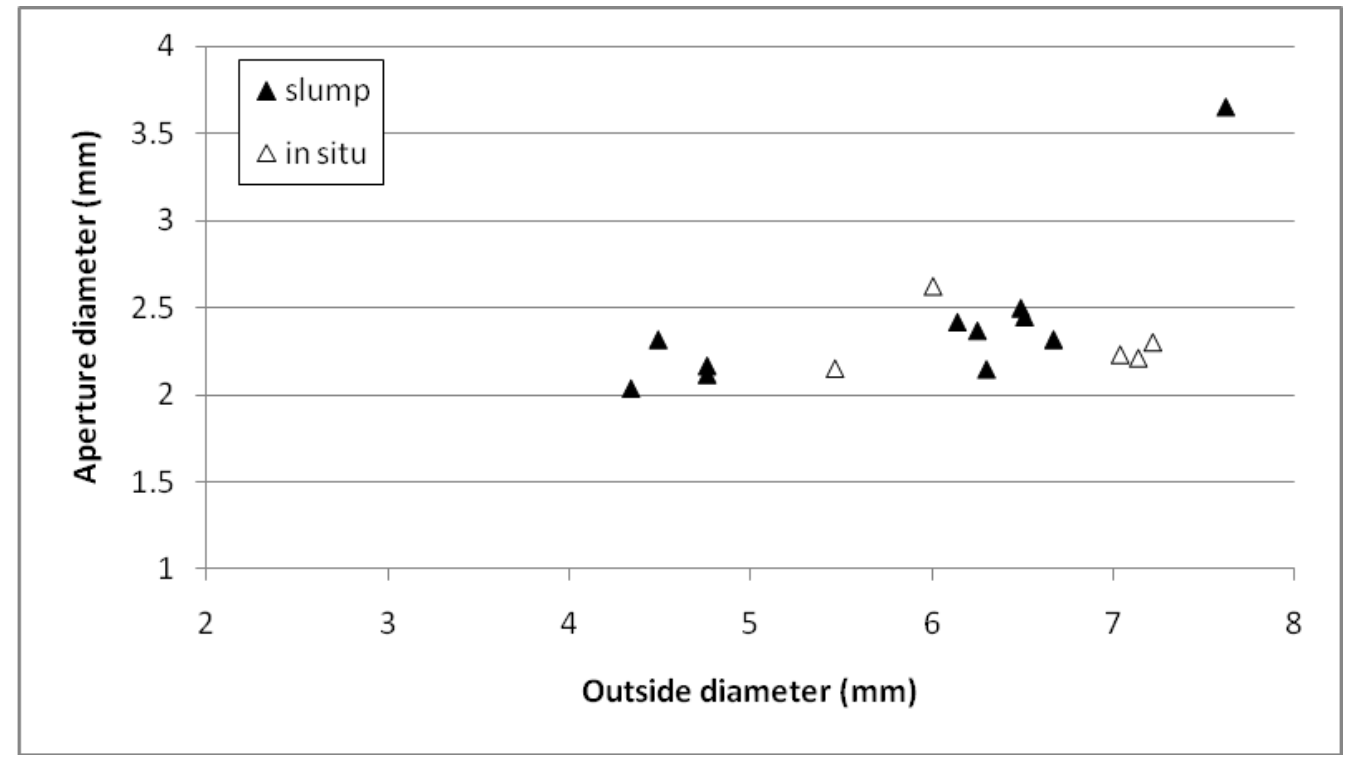

Figure 5.35: Scatter plot of ostrich eggshell bead dimensions from LK2004/011B.

Table 5.41: Summary statistics for finished ostrich eggshell beads from LK2004/011B.

\begin{tabular}{|c|c|c|c|c|}
\hline & & Outside diameter (mm) & Aperture diameter (mm) & Thickness (mm) \\
\hline \multirow{4}{*}{$\mathrm{n}=16$} & Mean & 6.08 & 2.38 & 1.49 \\
\hline & Std Deviation & 1.03 & 0.37 & 0.26 \\
\hline & Minimum & 4.34 & 2.04 & 1.04 \\
\hline & Maximum & 7.62 & 3.65 & 1.90 \\
\hline
\end{tabular}

\subsubsection{MB2005/001E}

\section{The site}

This site lay near the northern end of the barrier sand dunes at the mouth of the Spoeg River $\left(30^{\circ} 28^{\prime} 07.4^{\prime \prime} \mathrm{S} 17^{\circ} 21^{\prime} 38.6^{\prime \prime} \mathrm{E}\right)$. Despite their close proximity, the two excavated areas revealed very different occupation events (Figure 5.36). The modern dune surface 
slopes downhill towards the north, while the archaeological layers were found to be fairly horizontal. Square H43 was $27 \mathrm{~cm}$ deep at its northern edge and $32 \mathrm{~cm}$ at the south, while F43 was approximately $55 \mathrm{~cm}$ deep. Square A40 revealed $82 \mathrm{~cm}$ of archaeological deposits. The deposits are also younger towards the south. It is assumed that the dune was formed differently in the past such that the older occupation to the north was buried at the time of the southern occupation and is now becoming exposed through deflation (Orton \& Halkett 2006). The following dates were obtained:

\begin{tabular}{|c|c|c|c|c|}
\hline Lab. No. & Provenience & Material & ${ }^{14} \mathrm{C}$ date $\mathrm{BP}$ & Calibrated age $(95.4 \%)$ \\
\hline OxA-24552 & $\begin{array}{l}\text { Layer } 1, \text { A39 } \\
2^{\text {nd }} \text { Layer }\end{array}$ & Bone (Chersina angulata) & $2190 \pm 27$ & $353-52 \mathrm{BC}$ \\
\hline OxA-24553 & $\begin{array}{l}\text { Layer } 1, \text { A39 } \\
4^{\text {th }} \text { Layer }\end{array}$ & Bone (Chersina angulata) & $2176 \pm 27$ & $349-46 \mathrm{BC}$ \\
\hline OxA-24554 & $\begin{array}{l}\text { Layer 2, A39 } \\
8^{\text {th }} \text { Layer }\end{array}$ & Bone (Chersina angulata) & $2796 \pm 27$ & $975-812 \mathrm{BC}$ \\
\hline GX-32756 & $\begin{array}{l}\text { Layer } 3, \mathrm{H} 43 \\
\text { TOP }\end{array}$ & Marine shell & $3810 \pm 145$ & $2121-1226 \mathrm{BC}$ \\
\hline GX-32757 & $\begin{array}{l}\text { Layer } 4, \mathrm{H} 43 \\
\text { Layer } 6\end{array}$ & Marine shell & $4180 \pm 90$ & $2470-1751 \mathrm{BC}$ \\
\hline
\end{tabular}

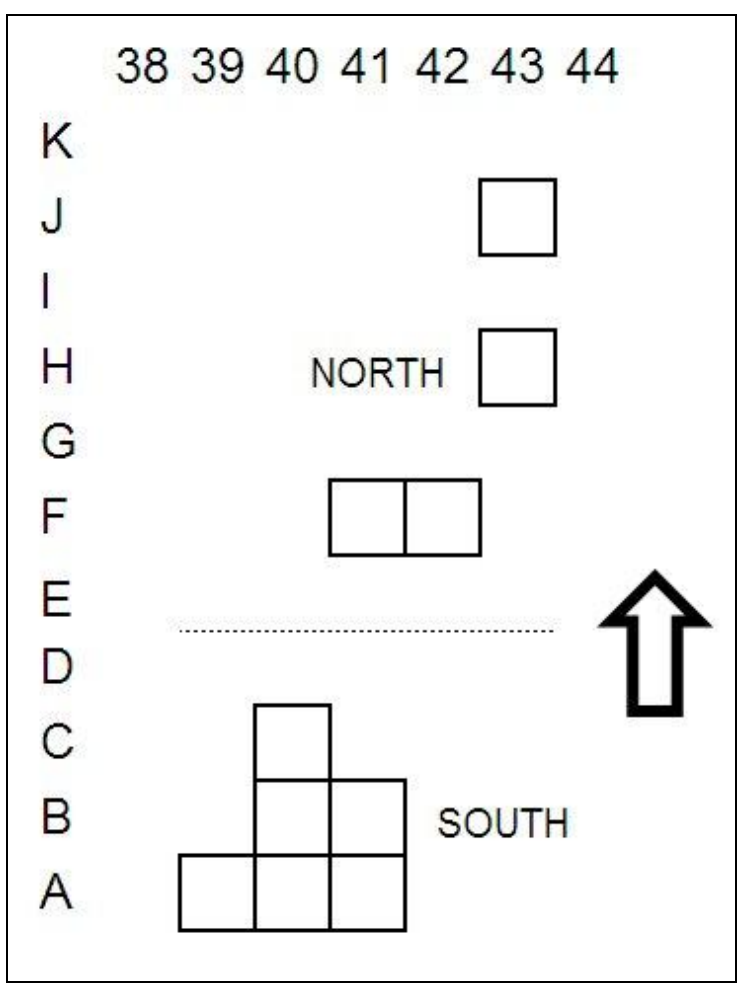

Figure 5.36: Plan of the excavation at MB2005/001E. 
For the purposes of analysis the excavation levels have been combined into four layers as shown in Table 5.42.

Table 5.42: Stratigraphic groupings at MB2005/001E.

\begin{tabular}{ll}
\hline Analytical layer & Excavation rows and levels \\
\hline Layer 1 & Rows A-C: Surf, 2 $^{\text {nd }}$ layer-5 ${ }^{\text {th }}$ layer \\
\hline Layer 2 & Rows A-C: $7^{\text {th }}$ layer-8 ${ }^{\text {th }}$ layer \\
\hline \multirow{2}{*}{ Layer 3 } & Row F: Top, Layer 2-Layer 4 \\
& Row H: Top, Layer 2-Layer 3 \\
& Row J: Top \\
\hline \multirow{2}{*}{ Layer 4 } & Row F: Layer 5-Layer 9 \\
& Row H: Layer 4-Layer 6 \\
& Row J: Lower \\
\hline
\end{tabular}

\section{$\underline{\text { Cultural material }}$}

Stone artefacts were found in variable density throughout the site (Tables 5.43-5.46). Although density was clearly reduced in the lower part of the south excavation, the very low artefact numbers are due to the small area excavated. The quartz is all clear and, despite the dominance of scrapers, Layer 1 is considered to represent an early manifestation of Group 3. Although quartz consistently comprises more than $90 \%$ of the assemblages, the presence of CCS retouched tools in the older levels, albeit minimal but in the absence of quartz tools, supports a likely assignation to Group 1.

Table 5.43: Stone artefacts from MB2005/001E, Layer 1 (Group 3).

\begin{tabular}{lccccc}
\hline & Quartz & CCS & Silcrete & Quartzite & Other \\
\hline Bipolar core & 3 & 1 & - & - & - \\
Single platform core & 2 & - & - & - & - \\
Irregular core & 4 & - & - & - & - \\
Sidescraper & 3 & - & - & - & - \\
Backed bladelet & 1 & - & - & - & - \\
Bladelet & 12 & - & - & - & - \\
Flake & 116 & 10 & 1 & 2 & 1 \\
Edge-damaged flake & 2 & - & - & - & - \\
Chunk & 21 & - & - & - & - \\
Chip & 193 & 8 & - & - & - \\
\hline
\end{tabular}




\begin{tabular}{lccccc}
\hline Total & 357 & 19 & 1 & 2 & 1 \\
Stone material \% total & 93.9 & 5.0 & 0.3 & 0.5 & 0.3 \\
Stone material \% formal & 100.0 & - & - & - & - \\
\hline
\end{tabular}

Table 5.44: Stone artefacts from MB2005/001E, Layer 2 (Group 1).

\begin{tabular}{lcc}
\hline & Quartz & CCS \\
\hline Flake & - & 1 \\
Chunk & - & - \\
Chip & 3 & - \\
Total & 3 & 1 \\
Stone material \% total & $\mathbf{7 5 . 0}$ & $\mathbf{2 5 . 0}$ \\
Stone material \% formal & - & - \\
\hline
\end{tabular}

Table 5.45: Stone artefacts from MB2005/001E, Layer 3 (Group 1).

\begin{tabular}{lccc}
\hline & Quartz & CCS & Other \\
\hline Bipolar core & 1 & 1 & - \\
Single platform core & 1 & - & 1 \\
Irregular core & 1 & - & - \\
Thumbnail scraper & - & 1 & - \\
Bladelet & 2 & - & - \\
Flake & 28 & 6 & 1 \\
Chunk & 17 & - & 2 \\
Chip & 104 & 1 & - \\
Total & $\mathbf{1 5 4}$ & $\mathbf{9}$ & $\mathbf{4}$ \\
Stone material \% total & $\mathbf{9 2 . 2}$ & $\mathbf{5 . 4}$ & $\mathbf{2 . 4}$ \\
Stone material \% formal & - & $\mathbf{1 0 0 . 0}$ & - \\
\hline
\end{tabular}

Table 5.46: Stone artefacts from MB2005/001E, Layer 4 (Group 1).

\begin{tabular}{lccc}
\hline & Quartz & CCS & Other \\
\hline Bipolar core & 2 & - & - \\
Scraper fragment & - & 1 & - \\
Bladelet & 1 & - & - \\
Flake & 24 & 3 & - \\
Chunk & 5 & 1 & - \\
Chip & 37 & - & - \\
Total & 49 & $\mathbf{5}$ & $\mathbf{0}$ \\
Stone material \% total & $\mathbf{9 3 . 2}$ & $\mathbf{6 . 8}$ & - \\
Stone material \% formal & - & $\mathbf{1 0 0 . 0}$ & - \\
Hammer stone/upper grindstone & - & - & 1 \\
Lower grindstone & - & - & 1 \\
\hline
\end{tabular}


Three small ostrich eggshell beads are present, one in each of Layers 1, 3 and 4 (Table 5.47). The only other cultural item is a water-worn Bullia sp. shell in Layer 1.

Table 5.47: Measurement of the three finished ostrich eggshell beads from MB2005/001E.

\begin{tabular}{lccc}
\hline & Outside diameter $(\mathrm{mm})$ & Aperture diameter $(\mathrm{mm})$ & Thickness $(\mathrm{mm})$ \\
\hline Layer 1 & 3.71 & 1.26 & 1.77 \\
Layer 3 & 4.93 & 1.52 & 1.75 \\
Layer 4 & 4.35 & 1.38 & 1.72 \\
\hline
\end{tabular}

\subsubsection{MB2005/013}

\section{The site}

This dense shell midden lay on the east-facing slope of a low hill north of the Spoeg River estuary, $750 \mathrm{~m}$ from the river and some $550 \mathrm{~m}$ from the coastline $\left(30^{\circ} 27^{\prime} 52.9^{\prime \prime} \mathrm{S}\right.$ $\left.17^{\circ} 21^{\prime} 40.6^{\prime \prime} \mathrm{E}\right)$. The midden was buried beneath approximately $130 \mathrm{~mm}$ of nearly sterile sand. While $12 \mathrm{~m}^{2}$ were excavated from the main midden area to the east, only $4 \mathrm{~m}^{2}$ had the upper deposits sieved and sorted - the remainder was shovelled off due to its extremely sparse content. A second part of the site to the west had $8 \mathrm{~m}^{2}$ taken from the surface with no midden found below. It too had minimal content (Orton \& Halkett 2006). Internal consistency suggests all to be one site. The following date was obtained:

\begin{tabular}{|c|c|c|c|c|}
\hline Lab. No. & Provenience & Material & ${ }^{14} \mathrm{C}$ date $\mathrm{BP}$ & Calibrated age (95.4\%) \\
\hline OxA-24555 & I24 Lower & Bone (Chersina angulata) & $717 \pm 25$ & AD 1281-1387 \\
\hline
\end{tabular}

\section{$\underline{\text { Cultural material }}$}

A small collection of flaked stone artefacts was recovered (Table 5.48). Most was in quartz with all of this being clear. CCS accounts for a small proportion only, yet all three retouched pieces are in this material. All are thumbnail scrapers with one made on a bipolar core. Although the CCS frequency is very low, the scrapers support assignation to Group 1. Two hammer stones and a lower grindstone fragment were also found. The 
latter artefact is unusual in that it is a very small piece of an unusually deeply grooved grindstone.

Table 5.48: Stone artefacts from MB2005/013 (Group 1).

\begin{tabular}{lccccc}
\hline & Quartz & CCS & Silcrete & Quartzite & Other \\
\hline Bipolar core & 2 & - & - & - & - \\
Thumbnail scraper & - & 3 & - & - & - \\
Blade & 2 & - & - & - & - \\
Bladelet & 4 & - & - & - & - \\
Flake & 56 & 3 & 2 & 7 & - \\
Edge-damaged flake & 2 & - & - & - & - \\
Chunk & 6 & - & - & - & - \\
Chip & 54 & 1 & - & 3 & - \\
Total & 126 & 7 & 2 & 10 & - \\
Stone material \% total & $\mathbf{8 6 . 9}$ & $\mathbf{4 . 8}$ & $\mathbf{1 . 4}$ & $\mathbf{6 . 9}$ & - \\
Stone material \% formal & - & $\mathbf{1 0 0 . 0}$ & - & - & - \\
Hammer stone & - & - & - & 2 & - \\
Lower grindstone fragment & - & - & - & - & 1 \\
\hline
\end{tabular}

Also present were eight ostrich eggshell beads, four from each excavation (Table 5.49). All were medium or large. Five fragments of ostrich eggshell flask mouth were found in two neighbouring squares with only one possible refit. Three collected shells were found, two of Marginella sp. and one a fragment of cowrie (Figure 5.37). The former are not threadable and were thus not collected for use as pendants. Ten potsherds weighing $38.5 \mathrm{~g}$ were recovered, one a plain rim. Nine came from two neighbouring squares and the tenth was collected from the surface a few metres away. Some were quite weathered but there was little to distinguish the nine found in the excavation. Only that collected from the surface may be a different vessel. The rim is a simple rounded rim, but its orientation cannot be determined. The mean thickness of the walls was found to be $5.36 \pm 1.02 \mathrm{~mm}$. 
Table 5.49: Summary statistics for finished ostrich eggshell beads from MB2005/013.

\begin{tabular}{|c|c|c|c|c|}
\hline & & Outside diameter $(\mathrm{mm})$ & Aperture diameter $(\mathrm{mm})$ & Thickness (mm) \\
\hline \multirow{4}{*}{$\mathrm{n}=8$} & Mean & 6.02 & 2.25 & 1.67 \\
\hline & Std Deviation & 0.52 & 0.29 & 0.14 \\
\hline & Minimum & 5.26 & 1.73 & 1.5 \\
\hline & Maximum & 6.60 & 2.56 & 1.95 \\
\hline
\end{tabular}

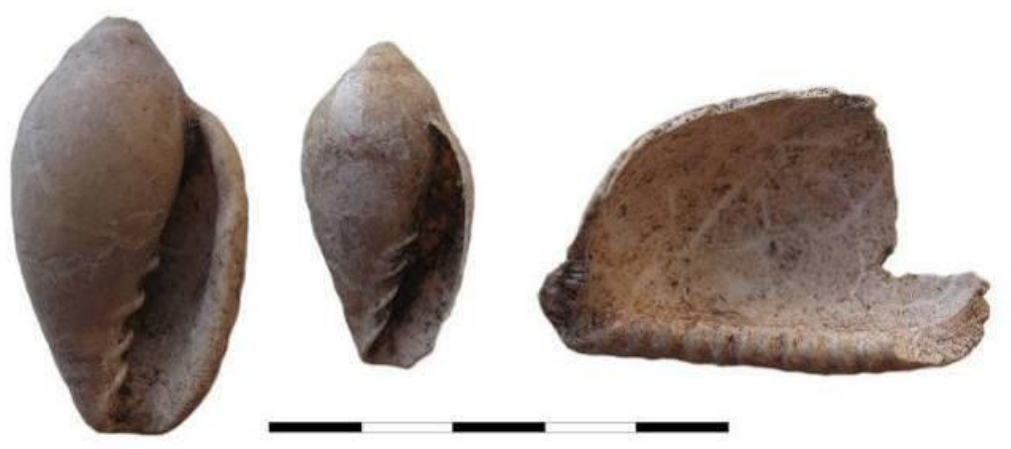

Figure 5.37: The three collected shells from MB2005/013, two Marginella sp. on the left and a cowrie fragment on the right. Scale in $5 \mathrm{~mm}$ intervals.

\subsubsection{MB2005/027}

\section{The site}

This site was some distance up the slope of the hill forming the north bank of the Spoeg River estuary $\left(30^{\circ} 27^{\prime} 54.4^{\prime \prime} \mathrm{S} 17^{\circ} 21^{\prime} 41.6^{\prime \prime} \mathrm{E}\right)$. It was $550 \mathrm{~m}$ from the beach and $700 \mathrm{~m}$ north of the river. Although appearing sparse on the surface, a thin but dense shell midden with charcoal-rich hearths was present below (Figure 5.38). The site was excavated in two levels over $11 \mathrm{~m}^{2}$, but these clearly represent a single occupation event (Orton \& Halkett 2006). The following date was obtained:

Lab. No. Provenience Material OxA-22978 G13 Hearth 1 Charcoal (sp. unknown)
${ }^{14} \mathrm{C}$ date BP $\quad$ Calibrated age $(95.4 \%)$

$650 \pm 22$ BP AD 1304-1402 


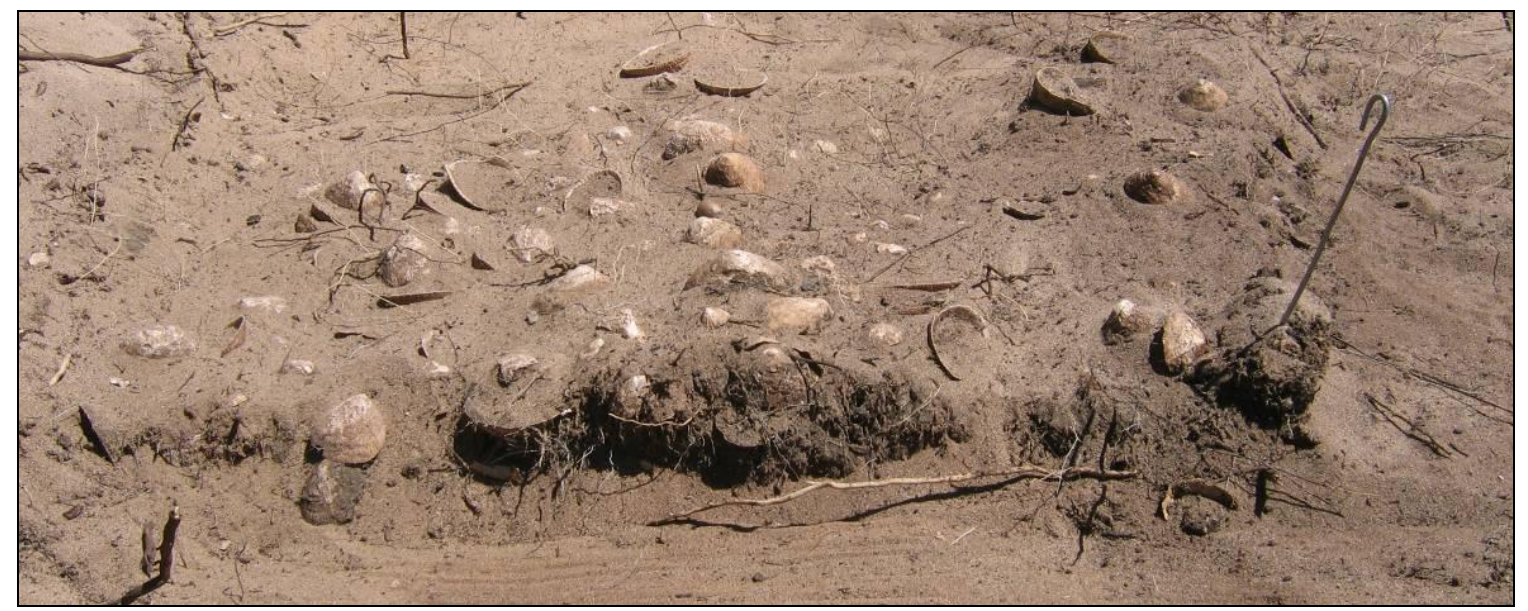

Figure 5.38: The MB2005/027 shell midden as revealed from above and in section.

\section{$\underline{\text { Cultural material }}$}

Cultural material consisted solely of a small assemblage of stone artefacts of which the vast majority was clear quartz (Table 5.50). The collection of backed artefacts in the absence of scrapers is typical of Group 3.

Table 5.50: Stone artefacts from MB2005/027 (Group 3).

\begin{tabular}{lccccc}
\hline & Quartz & CCS & Silcrete & Quartzite & Other \\
\hline Bipolar core & 4 & - & - & - & - \\
Single platform core & 1 & - & - & - & - \\
Backed flake & 1 & - & - & - & - \\
Backed bladelet & 1 & - & - & - & - \\
Backed bladelet fragment & 4 & - & - & - & - \\
Backed point fragment & 1 & - & - & - & - \\
Miscellaneous backed piece & 2 & - & - & - & - \\
Backed piece fragment & 1 & - & - & - & - \\
Bladelet & 6 & - & - & - & - \\
Flake & 83 & 5 & 3 & 6 & 1 \\
Edge-damaged flake & - & - & - & 1 & - \\
Chunk & 21 & 1 & - & 1 & - \\
Chip & 55 & 1 & 2 & 2 & - \\
Total & $\mathbf{1 8 0}$ & $\mathbf{7}$ & $\mathbf{5}$ & $\mathbf{1 0}$ & $\mathbf{1}$ \\
Stone material \% total & $\mathbf{8 8 . 7}$ & $\mathbf{3 . 4}$ & $\mathbf{2 . 5}$ & $\mathbf{4 . 9}$ & $\mathbf{0 . 5}$ \\
Stone material \% formal & $\mathbf{1 0 0 . 0}$ & - & - & - & - \\
\hline
\end{tabular}




\subsubsection{MB2005/028A}

\section{The site}

The site lay $700 \mathrm{~m}$ north of the Spoeg River estuary and $450 \mathrm{~m}$ from the coast $\left(30^{\circ} 27\right.$ $55.3^{\prime \prime} S 17^{\circ} 21^{\prime} 40.3^{\prime \prime}$ E). Although two patches of deposit were evident, only Patch A is incorporated here. Just $4 \mathrm{~m}^{2}$ were excavated and sieved on a $1.5 \mathrm{~mm}$ mesh (Halkett \& Dewar 2007). The following date was obtained:

\begin{tabular}{|c|c|c|c|c|}
\hline Lab. No. & Provenience & Material & ${ }^{14} \mathrm{C}$ date $\mathrm{BP}$ & Calibrated age (95.4\%) \\
\hline OxA-24626 & C11 Lower & Bone (Chersina angulata) & $680 \pm 25$ & AD 1296-1392 \\
\hline
\end{tabular}

\section{Cultural material}

A small assemblage of clear quartz artefacts with backed tools was recovered from the site (Table 5.51). Although a few quartzite flaked artefacts were also present, the assemblage is clearly Group 3. A remarkable and very large lower grindstone with multiple grooves was found (Figure 5.39). The down-facing surface had five grooves and the other three. Such artefacts are extremely rare with just one other similar one found in Namaqualand to date. One small ostrich eggshell bead was found; its external, aperture and thickness dimensions are 4.72, 1.72 and $1.58 \mathrm{~mm}$ respectively. The two remaining cultural items are a fragment of tortoise plastron ground on one edge and on its outer surface, and a water-worn but freshly broken piece of cowrie shell. Pottery was absent.

Table 5.51: Stone artefacts from MB2005/028A (Group 3).

\begin{tabular}{lcccc}
\hline & Quartz & CCS & Quartzite & Other \\
\hline Bipolar core & 3 & - & - & - \\
Single platform core & 1 & - & - & - \\
Irregular core & 1 & - & 1 & - \\
Backed bladelet & 2 & - & - & - \\
Backed piece fragment & 1 & - & - & - \\
Blade & 1 & - & - & - \\
Bladelet & 1 & - & - & - \\
Flake & 38 & 1 & 4 & - \\
\hline
\end{tabular}




\begin{tabular}{lcccc}
\hline & Quartz & CCS & Quartzite & Other \\
\hline Chunk & 5 & - & 1 & - \\
Chip & 41 & - & - & - \\
Total & 94 & $\mathbf{1}$ & $\mathbf{6}$ & $\mathbf{0}$ \\
Stone material \% total & 93.1 & $\mathbf{1 . 0}$ & $\mathbf{5 . 9}$ & - \\
Stone material \% formal & $\mathbf{1 0 0 . 0}$ & - & - & - \\
Lower grindstone & - & - & - & 1 \\
Upper grindstone & - & - & - & 3 \\
Hammer stone/upper grindstone & - & - & - & 2 \\
\hline
\end{tabular}

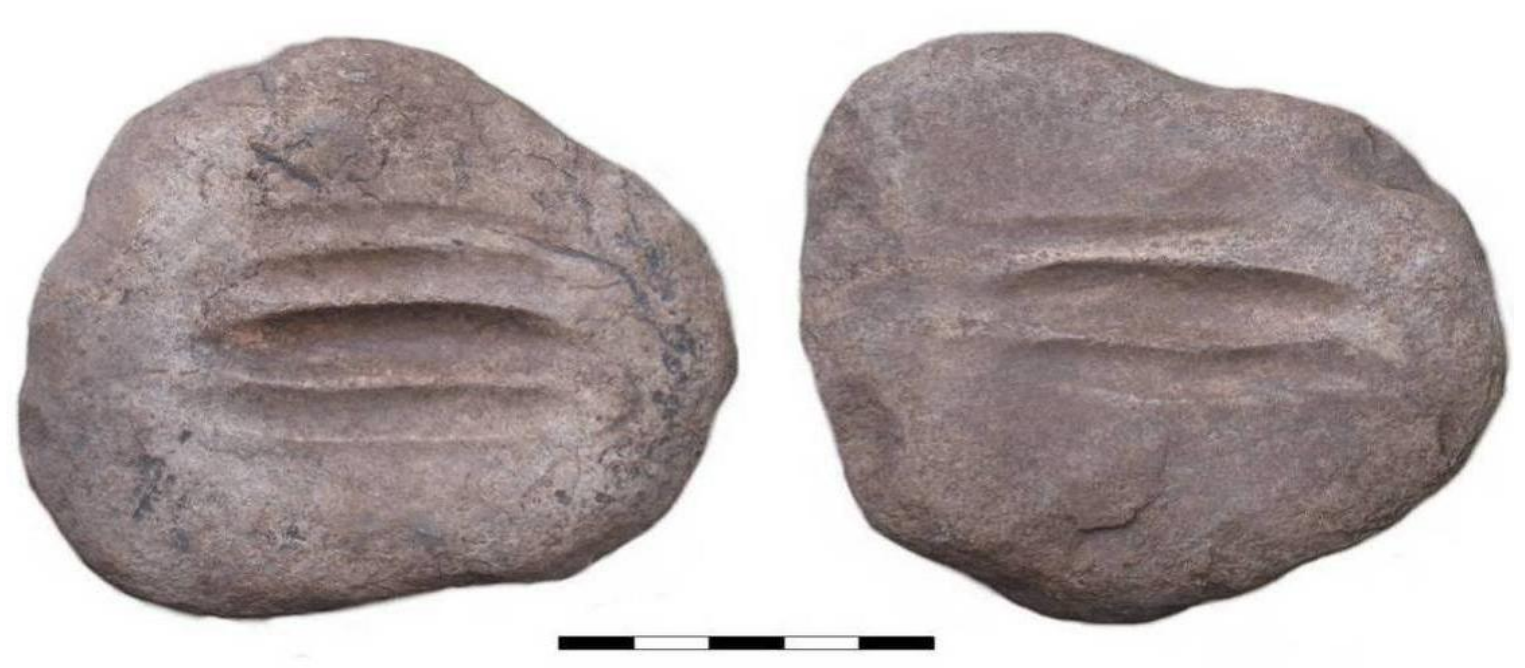

Figure 5.39: The grooved lower grindstone found at MB2005/028A. The left view was facing down. Scale in $50 \mathrm{~mm}$ intervals.

\subsubsection{MB2005/059}

\section{The site}

MB2005/059 was a deflated shell scatter on a low dune ridge overlooking the Spoeg River estuary $800 \mathrm{~m}$ to its north and $550 \mathrm{~m}$ from the coast $\left(30^{\circ} 27^{\prime} 51.2^{\prime \prime} \mathrm{S} 17^{\circ} 21^{\prime} 40.2^{\prime \prime} \mathrm{E}\right)$. Two patches $19 \mathrm{~m}$ apart had a combined total of $19 \mathrm{~m}^{2}$ excavated from them with the material sieved on a $1.5 \mathrm{~mm}$ sieve (Halkett \& Dewar 2007). Whether the two patches are related is unknown, but the peculiar and very similar shellfish frequencies make this likely (Appendix 1). The following date has been obtained from Patch $A$ of the site: 


\section{$\underline{\text { Cultural material }}$}

A small assemblage dominated by clear quartz, but including CCS, was found. Retouched artefacts on CCS came from both patches (Tables 5.52-5.53). The lower grindstone was used on both sides. Aside from the lack of pottery on Patch $B$, there is no evidence to suggest that two entirely separate sites are present. The differing tool types may suggest activity differences. The artefacts suggest a combination of Groups 1 and 3 .

Table 5.52: Stone artefacts from MB2005/059, Patch A (Group 1/3).

\begin{tabular}{lcccc}
\hline & Quartz & CCS & Quartzite & Other \\
\hline Bipolar core & 1 & - & 1 & - \\
Single platform core & 1 & - & - & - \\
Irregular core & - & - & 1 & - \\
Miscellaneous retouched piece & - & 1 & - & - \\
Bladelet & 1 & - & - & - \\
Flake & 13 & - & - & - \\
Chunk & 3 & - & 1 & - \\
Chip & 10 & 1 & - & - \\
Total & 29 & 2 & 3 & 0 \\
Stone material \% total & 85.3 & 5.9 & $\mathbf{8 . 8}$ & - \\
Stone material \% formal & - & $\mathbf{1 0 0 . 0}$ & - & - \\
Upper grindstone & - & - & 1 & 1 \\
Hammer stone / upper grindstone & - & - & - & 1 \\
Lower grindstone & - & - & - & 1 \\
\hline
\end{tabular}

Table 5.53: Stone artefacts from MB2005/059, Patch B (Group 1/3).

\begin{tabular}{lcccc}
\hline & Quartz & CCS & Quartzite & Other \\
\hline Thumbnail scraper & - & 1 & - & - \\
Denticulate & - & 1 & - & - \\
Flake & 14 & - & - & - \\
Chunk & - & - & - & - \\
Chip & 7 & - & - & - \\
Total & 21 & 2 & 0 & 0 \\
Stone material \% total & $\mathbf{9 1 . 3}$ & $\mathbf{8 . 7}$ & - & - \\
\hline
\end{tabular}




\begin{tabular}{lcccc}
\hline Stone material \% formal & - & $\mathbf{1 0 0 . 0}$ & - & - \\
Hammer stone & - & - & - & 1 \\
\hline
\end{tabular}

There were no ostrich eggshell beads, but two flask mouth fragments were found, one indicating an opening of c. $9 \mathrm{~mm}$. Quite a large pottery assemblage of 32 sherds (196.5 g) was recovered from Patch $A$ and enough pieces could be refitted to establish that a large, round pot of about $280 \mathrm{~mm}$ maximum width was present. Only a few millimetres of the neck was preserved so no information on rim form could be obtained, but the diameter at the neck was about $140 \mathrm{~mm}$. The outside of the pot was ochred and the lower part was darkened, presumably from use on a fire (Figure 5.40). The mean thickness of the potsherds was $5.69 \pm 0.61 \mathrm{~mm}$.
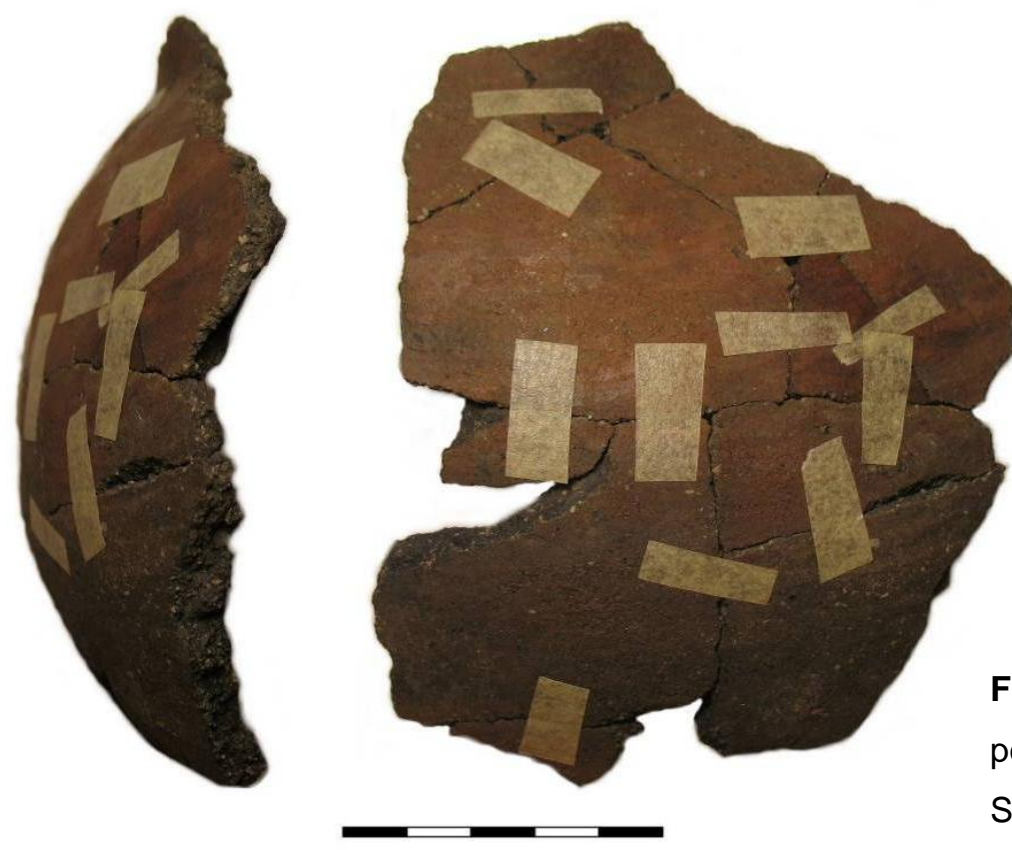

Figure 5.40: The refitted pottery from MB2005/059. Scale in $10 \mathrm{~mm}$ intervals.

Given the deflated nature of the site, its pottery content, and the radiocarbon date (predates the appearance of pottery to South Africa by at least five centuries), it is concluded that the site is a palimpsest. 


\subsubsection{MV2007/005}

\section{The site}

This very low density artefact scatter was found in a shallow deflation bay of some $25 \mathrm{~m}$ by $50 \mathrm{~m}$ in size (Figure 5.41). It lies in a zone of dunes and deflations $1.1 \mathrm{~km}$ south of the Buffels River and $19.7 \mathrm{~km}$ from the coast (29³6'03.2" S $\left.17^{\circ} 14^{\prime} 07.2^{\prime \prime} \mathrm{E}\right)$. The density of finds was too low to merit excavation so all visible material was collected from the deflated surface (Orton 2007c). Owing to a lack of suitable material, no date was run for this site.

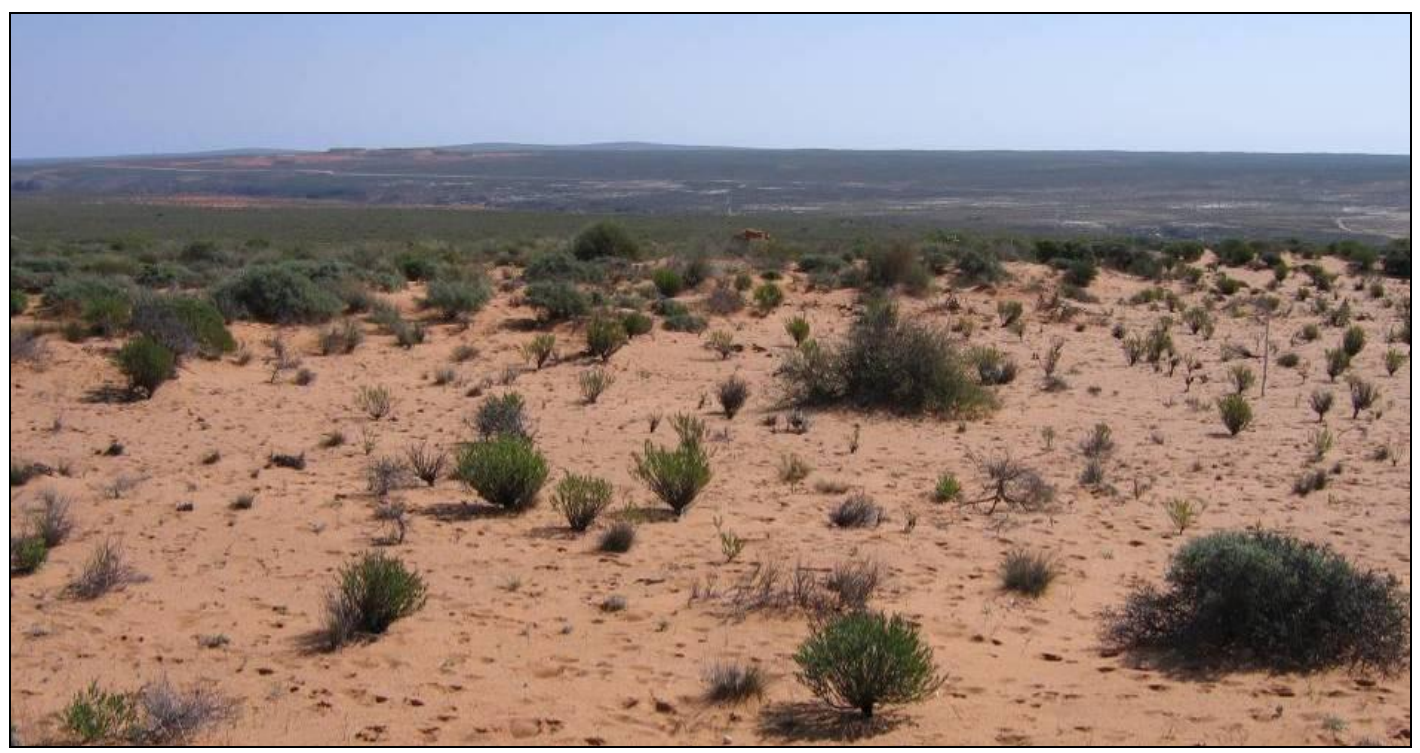

Figure 5.41: View towards the northwest across the deflated area containing MV2007/005.

\section{Cultural material}

Stone artefacts are limited to 19 flakes, seven chunks and one chip in quartz, one quartzite flake and one CCS adze-like MRP. Despite the MRP, the assemblage is likely Group 2. The only other artefact was a single decorated rim sherd (3.6 g) with a row of irregularly spaced oblong impressions about $10 \mathrm{~mm}$ below the lip of the vessel (Figure 5.42). The rim orientation is vertical and its form is simple rounded. It has a thickness of $5.94 \mathrm{~mm}$. 


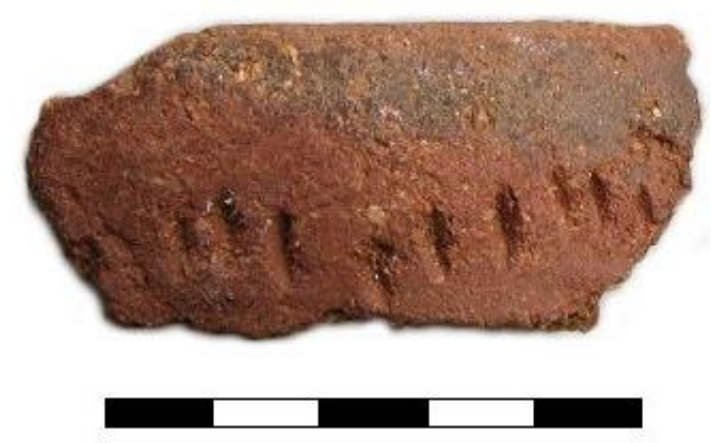

Figure 5.42: The impressed rim sherd from MV2007/005. Scale in $5 \mathrm{~mm}$ intervals.

\subsubsection{MV2007/009}

\section{$\underline{\text { The site }}$}

This very low density artefact scatter was found in the central part of a large, shallow deflation in an inland dune system $1.4 \mathrm{~km}$ south of the Buffels River and $19.6 \mathrm{~km}$ inland $\left(29^{\circ} 36^{\prime} 02.3^{\prime \prime} \mathrm{S} 17^{\circ} 14^{\prime} 10.7^{\prime \prime} \mathrm{E}\right)$. Due to the ephemeral but extensive nature of the archaeological material no formal excavation was carried out. Instead, the site was divided into four discrete areas with all material collected from each. A small, dense scatter of potsherds within Area 1 was collected separately (Orton 2007c). Owing to a lack of suitable material, no date was run for this site.

\section{$\underline{\text { Cultural material }}$}

A small collection of stone artefacts was obtained from each area of the deflation (Tables 5.54-5.57). The quartz appeared yellow from light exposure, very fractured and heavily weathered; on occasions it was difficult to be certain about whether each piece was actually flaked. Other materials were rarer and less problematic. The assemblages are very informal in character and can be assigned to Group 2.

Table 5.54: Stone artefacts from MV2007/009, Area 1 (Group 2).

\begin{tabular}{lcc}
\hline & Quartz & Sandstone \\
\hline Bipolar core & 1 & - \\
Flake & 10 & - \\
Chunk & 4 & - \\
\hline
\end{tabular}




\begin{tabular}{lcc}
\hline Chip & 1 & - \\
Total & 16 & 0 \\
Stone material \% total & 100.0 & - \\
Stone material \% formal & - & - \\
Hammer stone & - & 1 \\
\hline
\end{tabular}

Table 5.55: Stone artefacts from MV2007/009, Area 2 (Group 2).

\begin{tabular}{lcc}
\hline & Quartz & Quartzite \\
\hline Single platform core & - & 1 \\
Flake & 16 & 1 \\
Edge-damaged flake & 1 & - \\
Chunk & 4 & 1 \\
Chip & 3 & - \\
Total & $\mathbf{2 4}$ & $\mathbf{3}$ \\
Stone material \% total & $\mathbf{8 8 . 9}$ & $\mathbf{1 1 . 1}$ \\
Stone material \% formal & -- & - \\
\hline
\end{tabular}

Table 5.56: Stone artefacts from MV2007/009, Area 3 (Group 2).

\begin{tabular}{lcccc}
\hline & Quartz & CCS & Silcrete & Quartzite \\
\hline Irregular core & 1 & - & - & - \\
Blade & 1 & - & - & - \\
Flake & 48 & 1 & 1 & 1 \\
Edge-damaged flake & - & - & 1 & - \\
Chunk & 17 & - & - & - \\
Chip & 3 & - & - & - \\
Total & 70 & 1 & 2 & 1 \\
Stone material \% total & $\mathbf{9 4 . 6}$ & $\mathbf{1 . 4}$ & $\mathbf{2 . 7}$ & $\mathbf{1 . 4}$ \\
Stone material \% formal & - & - & - & - \\
\hline
\end{tabular}

Table 5.57: Stone artefacts from MV2007/009, Area 4 (Group 2).

\begin{tabular}{lcccc}
\hline & Quartz & CCS & Quartzite & Sandstone \\
\hline Flake & 39 & - & 4 & 2 \\
Edge-damaged flake & - & - & - & - \\
Chunk & 9 & 1 & - & - \\
Chip & 2 & - & - & - \\
Total & 50 & $\mathbf{1}$ & $\mathbf{4}$ & $\mathbf{2}$ \\
Stone material \% total & $\mathbf{8 7 . 7}$ & $\mathbf{1 . 8}$ & $\mathbf{7 . 0}$ & $\mathbf{3 . 5}$ \\
Stone material \% formal & - & - & - & - \\
\hline
\end{tabular}

Four ostrich eggshell beads were found in Area 1. All are very large and surprisingly thin (Table 5.58). A peculiarity noted at this site was that unworked ostrich eggshell fragments were also very thin. A sample of 45 yielded a mean thickness of 
$1.61 \pm 0.11 \mathrm{~mm}$. It is commonplace to find a bimodal distribution with modes of approximately 1.65 and $1.90 \mathrm{~mm}$ (own data), but this was not the case here with the range being $1.27-1.75 \mathrm{~mm}$. Whether the beads were old or made from thin eggshell thus remains unknown.

Table 5.58: Summary statistics for finished ostrich eggshell beads from MV2007/009.

\begin{tabular}{|c|c|c|c|c|}
\hline & & Outside diameter (mm) & Aperture diameter (mm) & Thickness (mm) \\
\hline \multirow{4}{*}{$\mathrm{n}=4$} & Mean & 9.23 & 2.10 & 1.69 \\
\hline & Std Deviation & 0.26 & 0.15 & 0.09 \\
\hline & Minimum & 8.94 & 1.93 & 1.56 \\
\hline & Maximum & 9.53 & 2.25 & 1.75 \\
\hline
\end{tabular}

This site contained one of the largest pottery collections from the area. Forty-three sherds weighing $428.5 \mathrm{~g}$ were recovered. Most came from Area 1 with one each from Areas 2 and 3 . It seems likely that three vessels are represented, but with most sherds probably originating from a single large, wide vessel with a nippled base (Figure 5.43). Also found in this deflation was a horizontally pierced lug which would have been part of a tall jar (Figure 5.43). Its temper is rich in mica. No decorated or painted sherds occurred. Not all sherds had their thicknesses calculated, but those measured indicated a thickness range from 5.64 to $6.67 \mathrm{~mm}$.
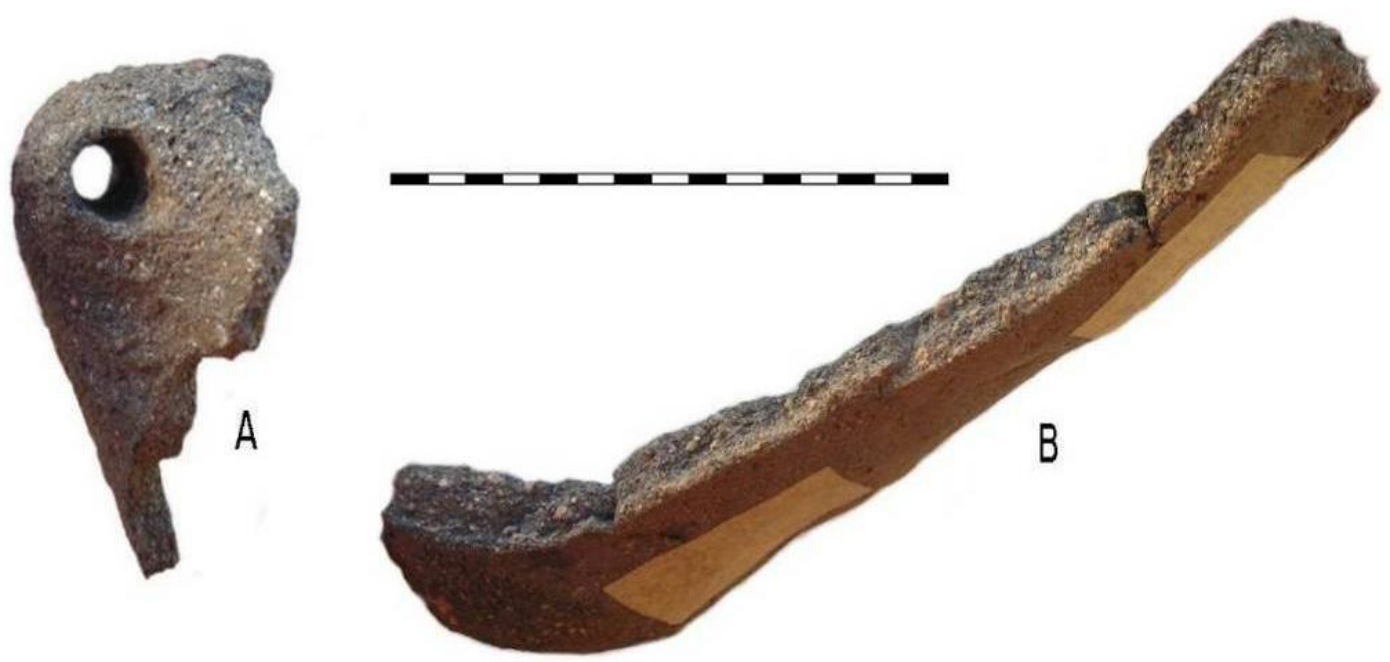
Figure 5.43: Pottery from MV2007/009, Area 1(A). A: lug; B: base of a large vessel. Scale in $5 \mathrm{~mm}$ intervals.

\subsubsection{PN2009/001}

\section{The site}

This site was located on the western edge of the salt pan that lies on the north-eastern outskirts of Port Nolloth, some $800 \mathrm{~m}$ from the sea (29 $\left.14^{\prime} 46.6^{\prime \prime} \mathrm{S} 16^{\circ} 52^{\prime} 27.7^{\prime \prime} \mathrm{E}\right)$. It presented as a series of deflated shell and artefact scatters draped across the surface of low dunes (Webley 2009). During excavation one small area of in situ shell midden was found and it was from there that a dating sample was selected. Spread over multiple patches, $133 \mathrm{~m}^{2}$ were excavated to depths varying between $2 \mathrm{~cm}$ and $10 \mathrm{~cm}$, although one patch was somewhat deeper $(14 \mathrm{~cm})$ and also revealed a $21 \mathrm{~cm}$ deep hollow filled with shell and some ash. A $1.5 \mathrm{~mm}$ sieve was used throughout (Webley \& Orton 2010). Figure 5.44 maps the site. The following date was obtained:

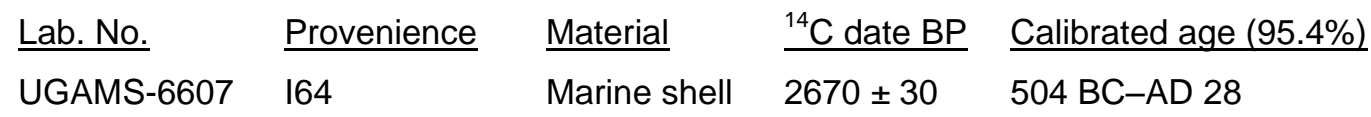

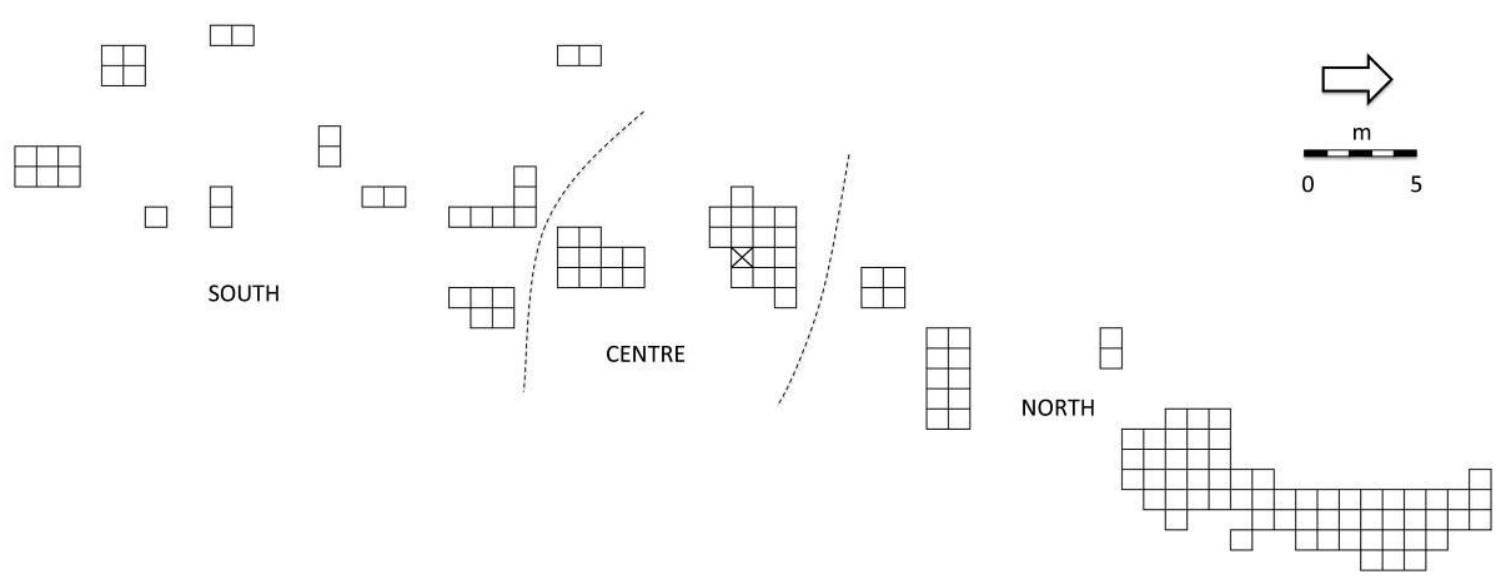

Figure 5.44: Layout of the excavated areas at PN2009/001. The X marks the origin of the date sample.

$\underline{\text { Cultural material }}$ 
Aside from a scatter of glass and iron fragments relating to twentieth century use of the dune area, the cultural material included a rich assemblage of stone artefacts, ostrich eggshell beads and engraved ostrich eggshell. The stone artefact assemblage is unusual in that, after quartz, silcrete was the next most important material. The silcrete is extremely fine-grained and, given the coarse silcretes generally available to the south, it is no doubt for this reason that it was used above CCS. Its source is unknown, but Roberts (2003) maps a silcrete outcrop some $10 \mathrm{~km}$ inland of the site. Taken together, silcrete and CCS comprise almost half the assemblage which is unusually high. The assemblage is of Group 1 character. Although scrapers dominate strongly, some backed tools are present along with a few denticulates and notched pieces (Table 5.59, Figure 5.45-5.46). The excavated area is large but little spatial variation was evident. Of note, perhaps, is the ratio of sidescrapers to backed scrapers (Table 5.60). The northern area has more backed scrapers which may suggest a slightly different age there. However, all artefact types appear to occur throughout the excavated area.

Table 5.59: Stone artefacts from PN2009/001 (Group 1).

\begin{tabular}{lcccccc}
\hline & Quartz & CCS & Silcrete & Quartzite & Sandstone & Other \\
\hline Bipolar core & 24 & 3 & 2 & - & - & - \\
Single platform core & 7 & 1 & 6 & - & - & - \\
Irregular core & $18^{*}$ & 3 & 14 & - & - & - \\
Radial core & 1 & - & - & - & - & - \\
Backed scraper & - & 1 & 19 & - & - & - \\
Sidescraper & 1 & 1 & 36 & - & - & - \\
Endscraper & - & - & 1 & - & - & - \\
Thumbnail scraper & - & 1 & - & - & - & - \\
Miscellaneous backed scraper & - & - & 5 & - & - & - \\
Large miscellaneous scraper & - & 1 & - & - & - & - \\
Miscellaneous scraper & - & 1 & 2 & - & - & - \\
Scraper fragment & - & 1 & 7 & - & - & - \\
Backed flake & - & - & 2 & - & - & - \\
Curve-backed bladelet & - & 1 & - & - & - & - \\
Backed bladelet fragment & - & - & 1 & - & - & - \\
Large segment & - & - & 1 & - & - & - \\
\hline
\end{tabular}




\begin{tabular}{lcccccc}
\hline & Quartz & CCS & Silcrete & Quartzite & Sandstone & Other \\
\hline Miscellaneous backed piece & - & - & 1 & - & - & - \\
Backed piece fragment & 2 & - & 9 & - & - & - \\
Notched piece & - & 3 & 1 & - & - & - \\
Denticulate & - & 2 & - & - & - & - \\
Miscellaneous retouched piece & - & 1 & 6 & - & - & - \\
Blade & 17 & 2 & 16 & - & - & - \\
Bladelet & 77 & 6 & 83 & - & - & - \\
Edge-damaged bladelet & 1 & - & 1 & - & - & - \\
Flake & 1050 & 104 & 842 & 5 & 2 & - \\
Edge-damaged flake & 19 & & 21 & - & - & - \\
Chunk & 330 & 26 & 126 & 2 & - & - \\
Edge-damaged chunk & - & 1 & - & - & - & - \\
Chip & 327 & 30 & 281 & 1 & - & - \\
Total & $\mathbf{1 8 7 4}$ & $\mathbf{1 8 9}$ & $\mathbf{1 4 8 3}$ & $\mathbf{8}$ & $\mathbf{2}$ & - \\
Stone material \% total & $\mathbf{5 2 . 6}$ & $\mathbf{5 . 4}$ & $\mathbf{4 1 . 6}$ & $\mathbf{0 . 2}$ & $\mathbf{0 . 1}$ & - \\
Stone material \% formal & $\mathbf{2 . 8}$ & $\mathbf{1 1 . 3}$ & $\mathbf{8 5 . 8}$ & - & - & - \\
Hammer stone & 1 & - & - & 1 & - & - \\
Hammer stone fragment & - & - & - & - & 1 & - \\
Hammer stone/upper grindstone & - & - & - & 2 & 4 & - \\
Lower grindstone & - & - & - & 1 & - & - \\
Lower grindstone fragment & - & - & - & - & - & 1 \\
Upper grindstone & - & - & - & 1 & 1 & - \\
Upper grindstone fragment & - & - & - & 1 & 1 & - \\
\hline *One iregular core is also the hamm & & - & & & - \\
\end{tabular}

${ }^{*}$ One irregular core is also the hammer stone

Table 5.60: Ratio of sidescrapers to backed scrapers at PN2009/001.

\begin{tabular}{lccc}
\hline & North & Centre & South \\
\hline Sidescrapers & 13 & 14 & 10 \\
Backed scrapers & 12 & 4 & 4 \\
Ratio & 1.08 & 3.5 & 2.5 \\
\hline
\end{tabular}



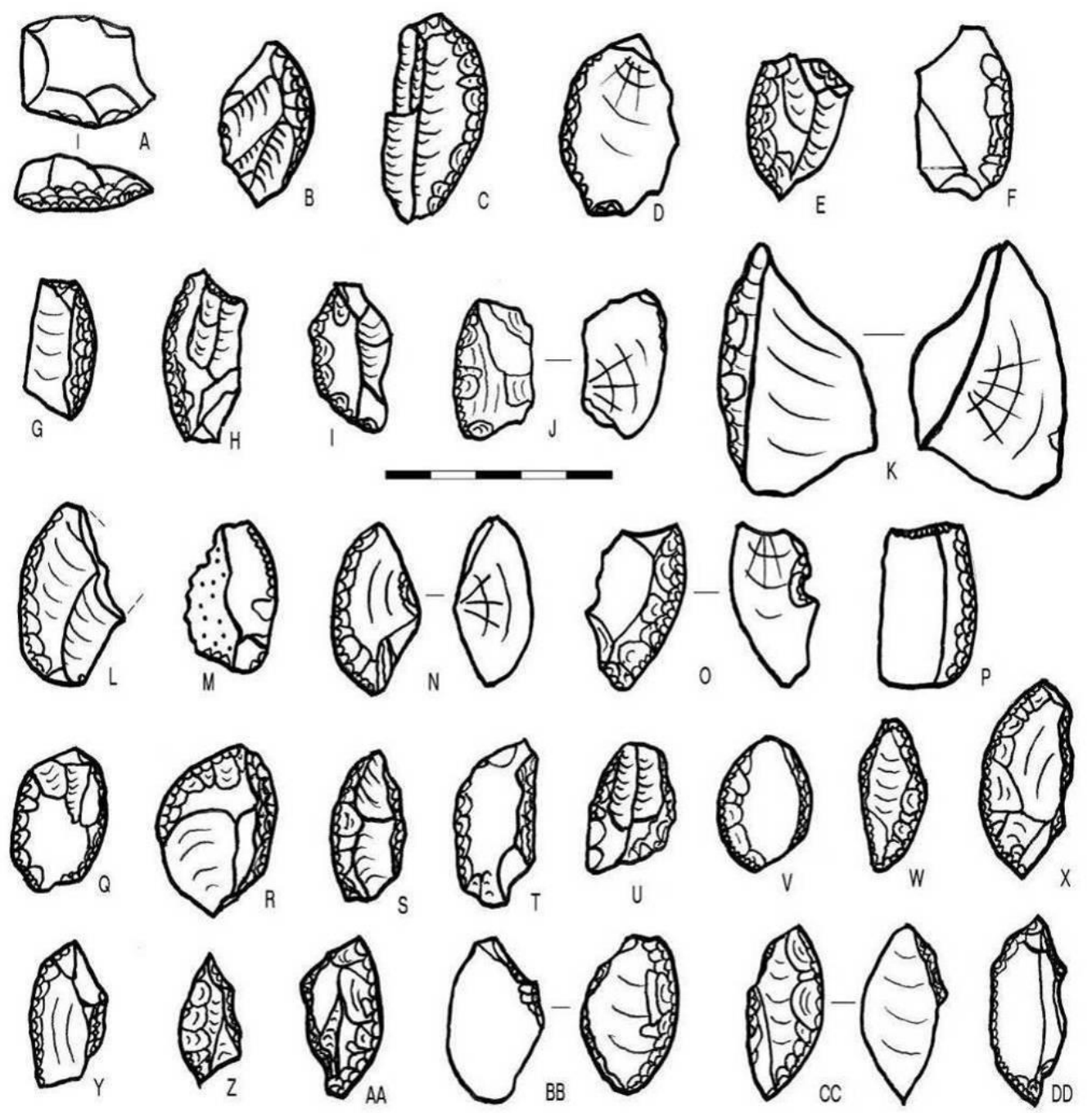

Figure 5.45: Stone artefacts from PN2009/001. A-P: sidescrapers; Q-DD: backed scrapers. All in silcrete except $A$ : CCS \& $K$ : quartz. $O$ has a notch opposite the scraper retouch, $P$ has a truncation with the platform removed. Scale in $5 \mathrm{~mm}$ intervals.

A collection of 36 ostrich eggshell beads was found, the majority of which were small; just one medium bead occurred (Table 5.61). They are spread throughout the site but with about half (17) from the dated patch. Some spatial variation seems present: using the same northern, central and southern areas one finds mean external dimensions of $4.50 \mathrm{~mm}(\mathrm{n}=7), 4.29 \mathrm{~mm}(\mathrm{n}=19)$ and $3.89 \mathrm{~mm}(\mathrm{n}=10)$ respectively. It is acknowledged, however, that the southern area is comprised of ten small excavated patches and that two of its beads are unusually small. Just one broken bead and six unfinished beads were found. The latter included three in Stage IIIb and one each in Stages $\mathrm{Va}, \mathrm{Vb}$ and Vlb. 


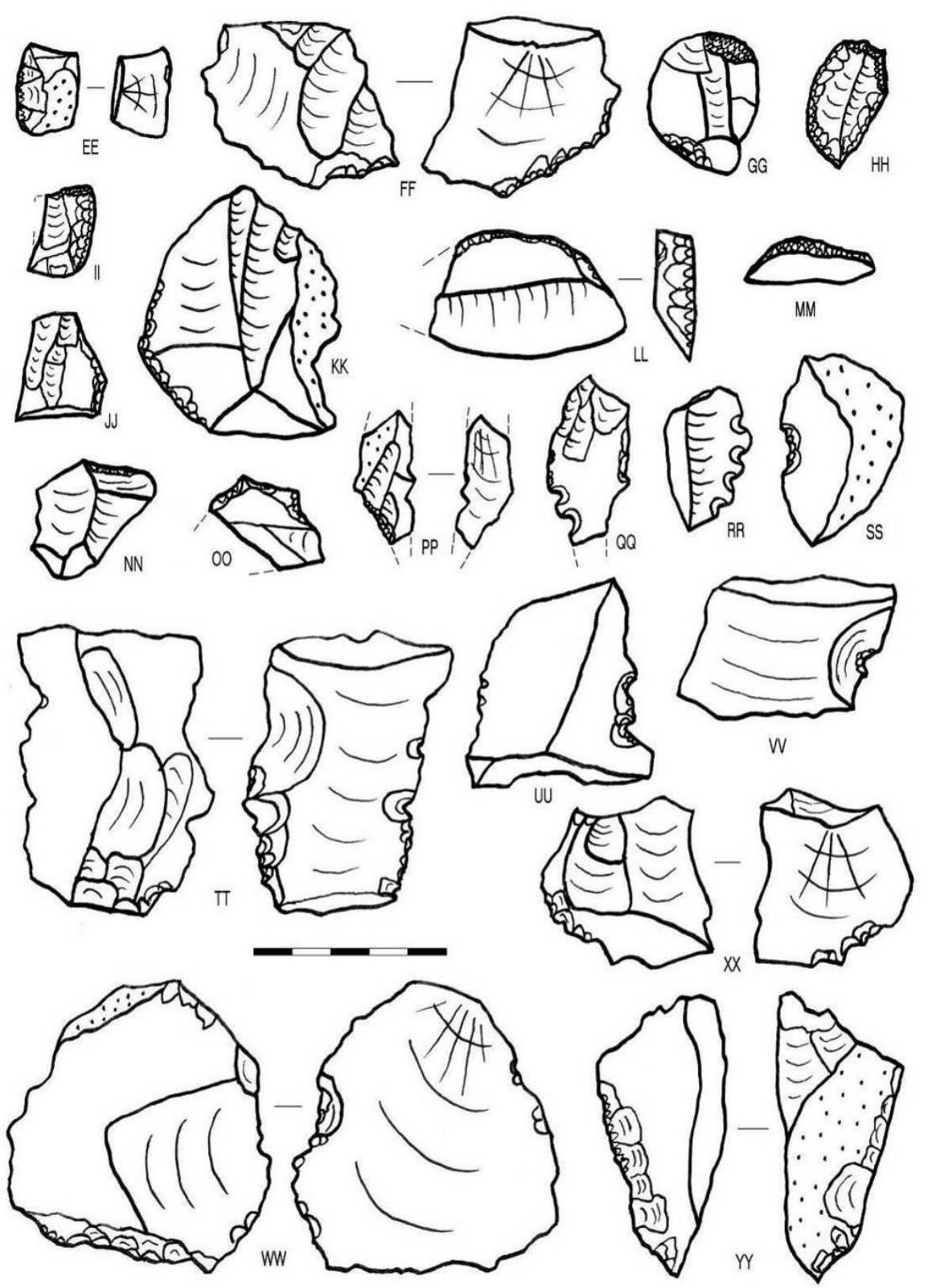

Figure 5.46: Stone artefacts from PN2009/001. EE: thumbnail scraper; FF: endscraper; GG-II: miscellaneous backed scrapers; JJ-KK: miscellaneous scraper; LL: large segment; MM: curvebacked bladelet; NN: miscellaneous backed piece; OO-PP: backed piece fragments; QQ-RR: denticulates; SS-VV: notched pieces; WW-YY: miscellaneous retouched pieces. All in silcrete except PP: quartz \& EE, JJ, KK, MM, QQ, RR, SS, UU, VV: CCS. Scale in $5 \mathrm{~mm}$ intervals.

Table 5.61: Summary statistics for finished ostrich eggshell beads from PN2009/001.

\begin{tabular}{llccc}
\hline & Outside diameter $(\mathrm{mm})$ & Aperture diameter $(\mathrm{mm})$ & Thickness $(\mathrm{mm})$ \\
\hline \multirow{3}{*}{$\mathrm{n}=36^{*}$} & 4.22 & 1.61 & 1.51 \\
& Mean & 0.50 & 0.26 & 0.14 \\
& Minimum & 2.50 & 0.88 & 1.14 \\
& Maximum & 5.16 & 2.19 & 1.77 \\
\hline
\end{tabular}

${ }^{*}$ One bead was burnt and exfoliated such that for thickness $n=35$. 
Three flask mouth fragments and 17 engraved ostrich eggshell fragments were also recovered. Twelve of the latter came from the central area but all areas had some. Most consist of parallel lines, sometimes wavy, while ladder designs were also present. Some were wind-abraded and this is no doubt a product of variable exposure (Figure 5.47).

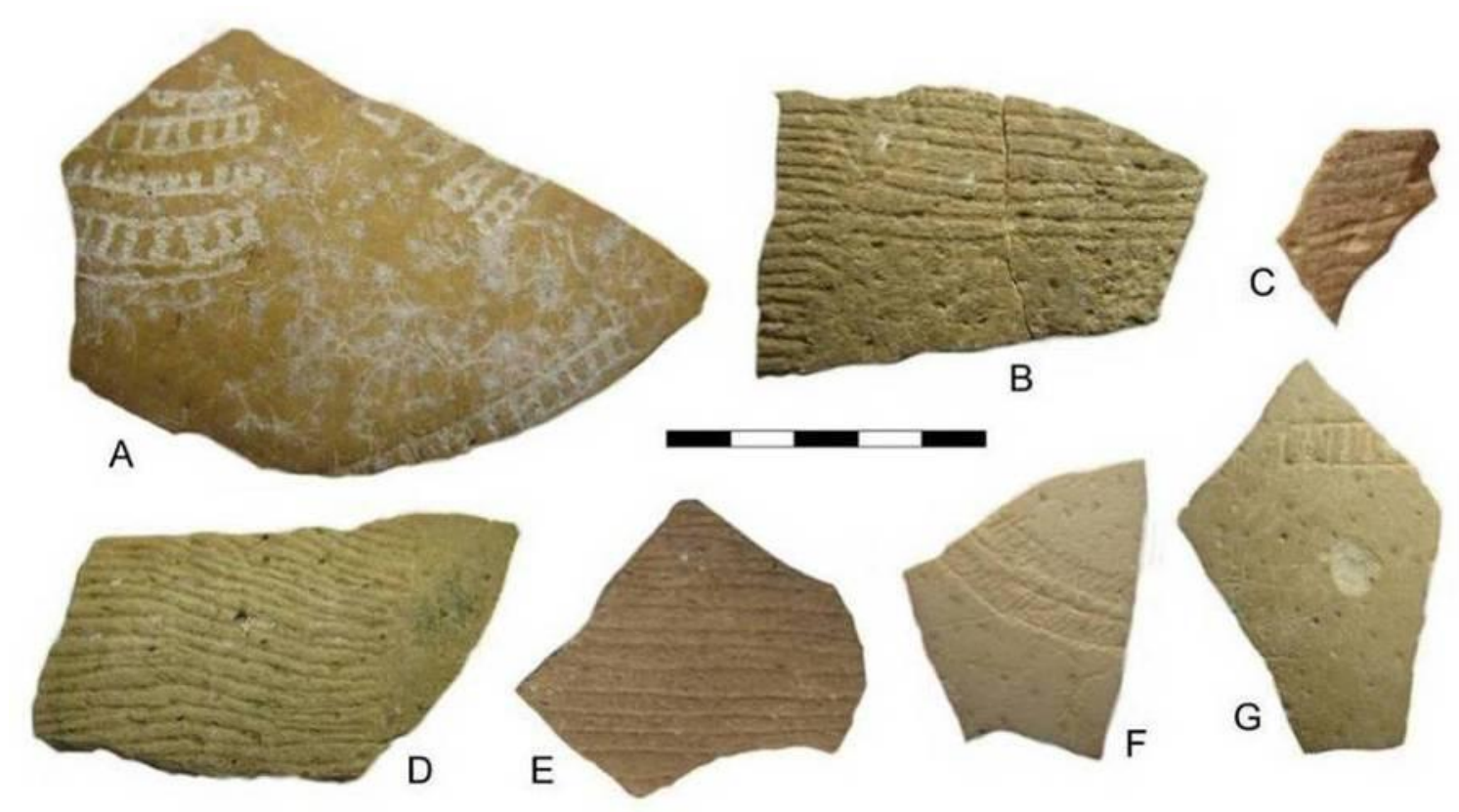

Figure 5.47: Engraved ostrich eggshell fragments from PN2009/001. Scale in $5 \mathrm{~mm}$ intervals.

\subsubsection{SK2001/024}

\section{The site}

The site lay among very low dunes $1 \mathrm{~km}$ from the shoreline and $1.6 \mathrm{~km}$ south of the Buffels River $\left(29^{\circ} 41^{\prime} 12.5^{\prime \prime S} 17^{\circ} 03^{\prime} 56.5^{\prime \prime E}\right)$. Fourteen discrete shell dumps were spread over an area of approximately $80 \mathrm{~m}$ diameter. Each midden probably relates to a single family, perhaps indicating the approximate positions of huts in the camp (Figure 5.48; Halkett 2003). Four were sampled, with one having $3 \mathrm{~m}^{2}$ excavated (Patch A) and the rest $1 \mathrm{~m}^{2}$ each (Patches $\mathrm{B}, \mathrm{C}$ and $\left.\mathrm{M}\right)$. The following date was obtained:

$\begin{array}{lllll}\text { Lab. No. } & \frac{\text { Provenience }}{\text { OxA-24523 }} & \text { Material } & \frac{{ }^{14} \mathrm{C} \text { date BP }}{{ }^{2} \text { Patch A, F10 }} & \text { Calibrated age (95.4\%) } \\ \text { Bone (Chersina angulata) } & 570 \pm 25 & \text { AD 1393-1440 }\end{array}$




\section{$\underline{\text { Cultural material }}$}

A very limited stone artefact assemblage was recovered, but this displayed a very informal character with quartzite markedly present (Tables 5.62-5.64). The assemblage likely belongs in Group 2. Patch C had just one quartz chip. No ostrich eggshell beads occur. Three large potsherds $(73.5 \mathrm{~g})$ came from Patch $\mathrm{M}$, two of which refitted to leave two fragments of undecorated rim (Figure 5.49). Both reflect a vertically oriented neck and everted lip; they seem likely to originate from the same pot. The mean wall thickness was $5.90 \pm 0.22 \mathrm{~mm}$.

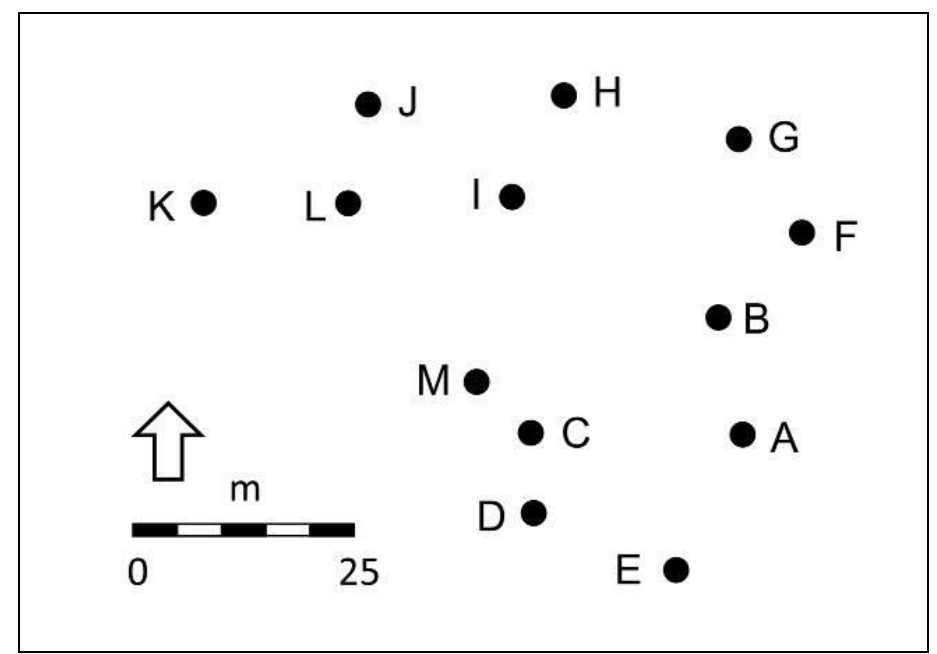

Figure 5.48: Schematic map of the patches at SK2001/024.

Table 5.62: Stone artefacts from SK2001/024, Patch A (Group 2).

\begin{tabular}{lccc}
\hline & Quartz & Silcrete & Quartzite \\
\hline Flake & 16 & 1 & 8 \\
Edge-damaged flake & - & - & 1 \\
Chunk & 2 & - & 7 \\
Chip & 8 & - & 2 \\
Total & $\mathbf{2 6}$ & $\mathbf{1}$ & $\mathbf{1 8}$ \\
Stone material \% total & $\mathbf{5 7 . 8}$ & $\mathbf{2 . 2}$ & $\mathbf{4 0 . 0}$ \\
Stone material \% formal & - & - & - \\
\hline
\end{tabular}

Table 5.63: Stone artefacts from SK2001/024, Patch B (Group 2).

\begin{tabular}{lcc}
\hline & Quartz & Quartzite \\
\hline Flake & 3 & 1 \\
Chunk & 1 & - \\
Chip & 2 & -
\end{tabular}




\begin{tabular}{lcc}
\hline Total & 6 & 1 \\
Stone material \% total & 85.7 & 14.3 \\
Stone material \% formal & - & - \\
\hline
\end{tabular}

Table 5.64: Stone artefacts from SK2001/024, Patch M (Group 2).

\begin{tabular}{lcc}
\hline & Quartz & Quartzite \\
\hline Flake & 6 & 1 \\
Chunk & - & 2 \\
Chip & 1 & - \\
otal & 7 & 3 \\
Stone material \% total & $\mathbf{7 0 . 0}$ & $\mathbf{3 0 . 0}$ \\
Stone material \% formal & - & - \\
\hline
\end{tabular}

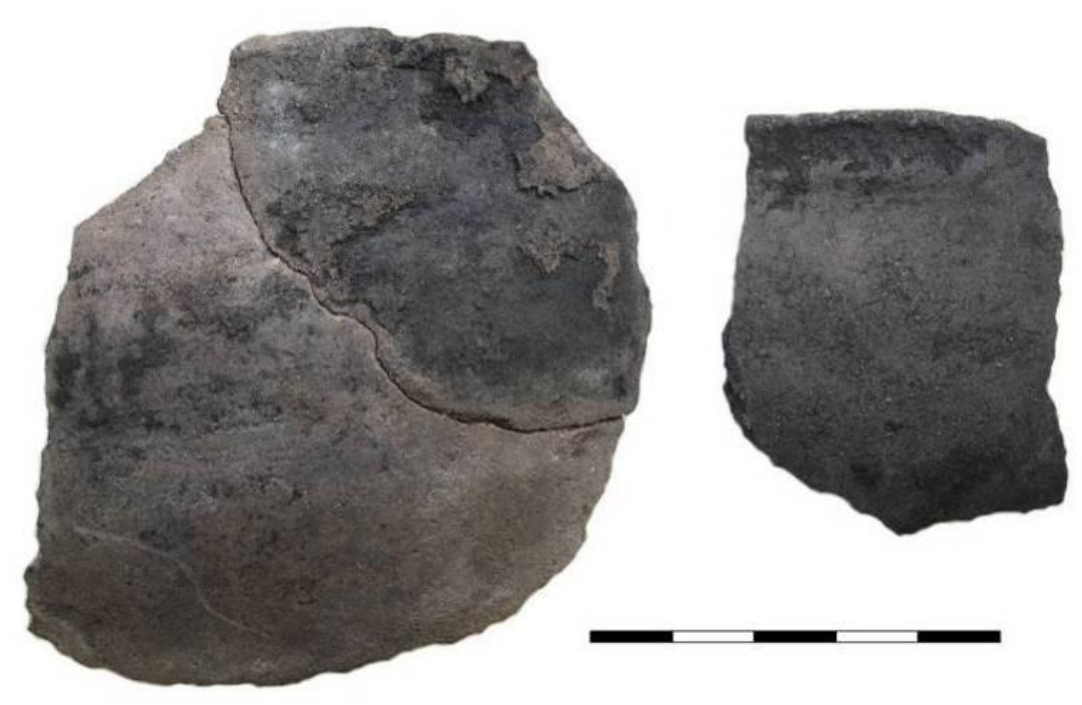

Figure 5.49: Pottery rims from SK2001/024, Patch M. Scale in $10 \mathrm{~mm}$ intervals.

\subsubsection{SK2001/025}

\section{$\underline{\text { The site }}$}

This site was spread out along the crest of an ephemeral dune cordon some $1.6 \mathrm{~km}$ inland and $1.9 \mathrm{~km}$ south of the Buffels River (29 $\left.41^{\prime} 08.0^{\prime \prime} \mathrm{S} 17^{\circ} 04^{\prime} 15.2^{\prime \prime} \mathrm{E}\right)$. Several patches of shell lay exposed in deflations and hollows along the cordon (Figure 5.50). The south-westernmost of the six excavated areas was heavily deflated, seemingly due to mining-related disturbance. It was from this area that the very poorly preserved 
remains of a human burial (a few cranial and vertebral fragments) were recovered. The burial, dating earlier in the mid-first millennium BC (Dewar 2008), is older than the occupation debris. The other patches exhibited variable preservation with only Area $\mathrm{C}$ well enough preserved to be called a proper shell midden. The excavations were mostly conducted in units of $0.25 \mathrm{~m}^{2}$, but the single square from Area $E$ and much of the heavily deflated Area F were taken in $1 \mathrm{~m}^{2}$ units. A total area of $149.75 \mathrm{~m}^{2}$ was excavated (Table 5.65) and a $1.5 \mathrm{~mm}$ sieve was employed throughout (Halkett 2003). The following dates were obtained:

\begin{tabular}{|c|c|c|c|c|c|}
\hline Lab. No. & Area & $\underline{\text { Provenience }}$ & Material & ${ }^{14} \mathrm{C}$ date $\mathrm{BP}$ & Calibrated age (95.4\%) \\
\hline Pta-9310 & Area C & Unknown & Marine shell & $2640 \pm 60$ & 497 BC-AD 84 \\
\hline OxA-22976 & Area C & $\begin{array}{l}\text { P197 } \\
\text { Midden }\end{array}$ & $\begin{array}{l}\text { Bone (Raphicerus } \\
\text { campestris) }\end{array}$ & $2172 \pm 25$ & $346-47 \mathrm{BC}$ \\
\hline $\begin{array}{l}\text { UGAMS- } \\
9708\end{array}$ & Area $\mathrm{F}$ & $\begin{array}{l}\text { YC/YD } \\
119 / 120\end{array}$ & Marine shell & $2320 \pm 25$ & 65 BC-AD 428 \\
\hline
\end{tabular}

Notes:

- Pta-9310 Genevieve Dewar, pers. comm. 2006.

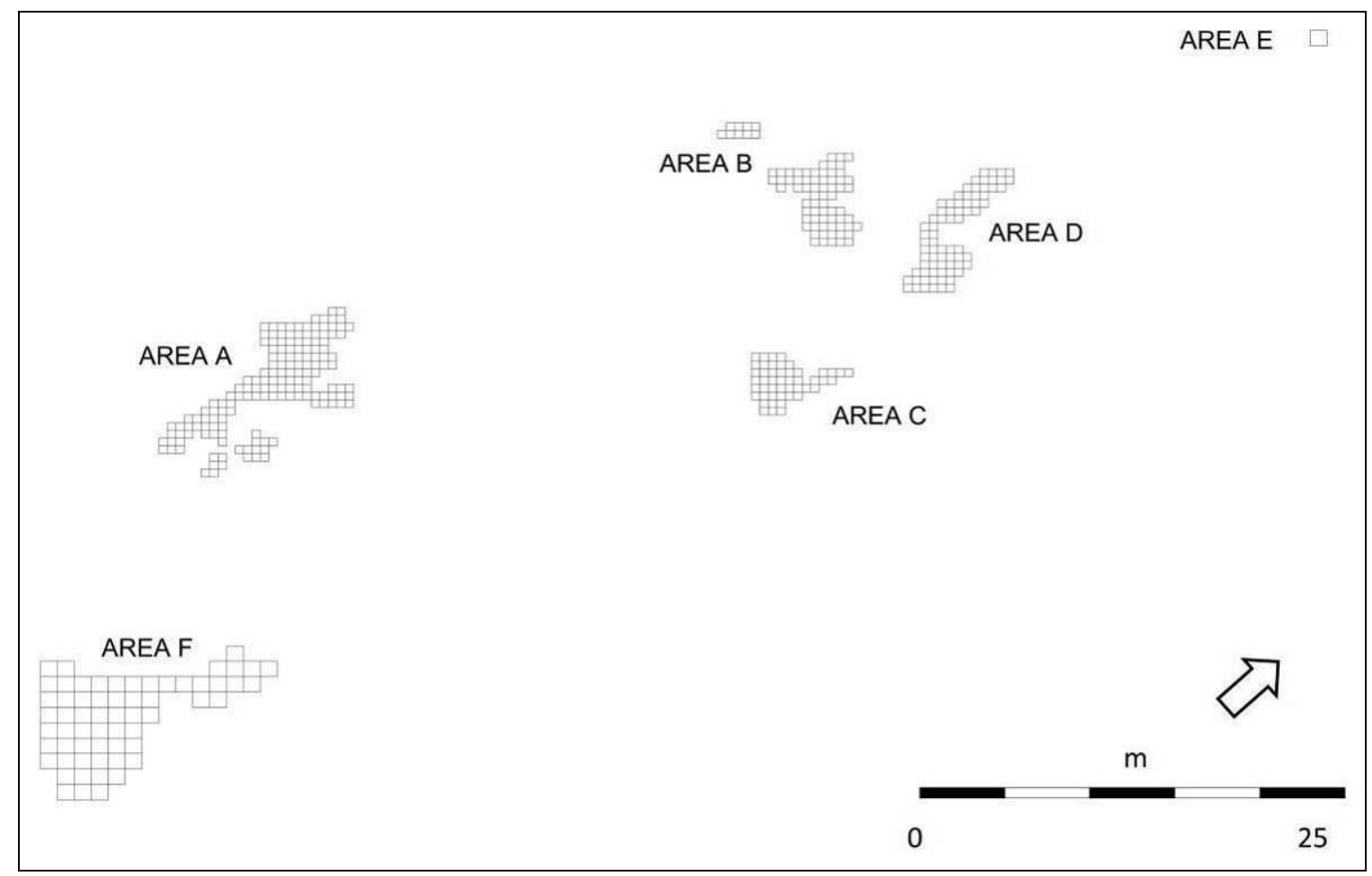

Figure 5.50: Layout of the excavated areas at SK2001/025. 
Table 5.65: Excavated areas at SK2001/025.

\begin{tabular}{cc}
\hline Area A & $38.5 \mathrm{~m}^{2}$ \\
Area B & $18.75 \mathrm{~m}^{2}$ \\
Area C & $12.0 \mathrm{~m}^{2}$ \\
Area D & $18.5 \mathrm{~m}^{2}$ \\
Area E & $1.0 \mathrm{~m}^{2}$ \\
Area F & $61.0 \mathrm{~m}^{2}$ \\
\hline
\end{tabular}

$\underline{\text { Cultural material }}$

Stone artefacts were recovered from all areas (Tables 5.66-5.71). Areas A to D are all dominated by scrapers, while only Area F has a good selection of backed artefacts including the only segment. Among its scrapers it also has the only backed scraper. The two denticulates from Area F are both atypical; one is on a blade, while the other is quite minimal and made on a fragment of a large flake. Stone material frequencies are fairly consistent across the six areas although Area E has too few artefacts to be meaningful. The rest have approximately two-thirds quartz and one-third CCS. Some pieces of CCS have cortex supporting an origin within calcrete. All the assemblages are Group 1.

Table 5.66: Stone artefacts from SK2001/025 Area A (Group 1).

\begin{tabular}{lcccccc}
\hline & Quartz & CCS & Silcrete & Quartzite & Sandstone & Other \\
\hline Bipolar core & 4 & - & - & - & - & - \\
Single platform core & 1 & - & - & - & - & - \\
Irregular core & 3 & 1 & - & - & - & - \\
Sidescraper & - & 2 & - & - & - & - \\
Miscellaneous scraper & - & 2 & - & - & - & - \\
Scraper fragment & - & 3 & - & - & - & - \\
Backed piece fragment & - & 2 & - & - & - & - \\
Miscellaneous retouched piece & - & 2 & - & - & - & - \\
Blade & 2 & - & - & - & - & - \\
Bladelet & 4 & 7 & - & - & - & - \\
Flake & 96 & 34 & 3 & 3 & 1 & 3 \\
Edge-damaged flake & 2 & 2 & - & - & - & - \\
Chunk & 29 & 4 & - & - & - & 1 \\
Chip & 87 & 31 & - & - & - & - \\
Edge-damaged chip & - & 1 & - & - & - & - \\
Total & $\mathbf{2 2 8}$ & $\mathbf{9 1}$ & $\mathbf{3}$ & $\mathbf{3}$ & $\mathbf{1}$ & $\mathbf{3}$ \\
\hline
\end{tabular}




\begin{tabular}{lcccccc}
\hline & Quartz & CCS & Silcrete & Quartzite & Sandstone & Other \\
\hline Stone material \% total & 69.1 & 27.6 & 0.9 & 0.9 & 0.3 & 1.2 \\
Stone material \% formal & - & $\mathbf{1 0 0 . 0}$ & - & - & - & - \\
Lower grindstone fragment & - & - & - & - & - & 1 \\
Upper grindstone fragment & - & - & - & 1 & - & - \\
\hline
\end{tabular}

Table 5.67: Stone artefacts from SK2001/025 Area B (Group 1).

\begin{tabular}{lcccccc}
\hline & Quartz & CCS & Silcrete & Quartzite & Sandstone & Other \\
\hline Bipolar core & 2 & - & - & - & - & - \\
Single platform core & 1 & 1 & - & 1 & - & - \\
Irregular core & 1 & - & - & - & - & - \\
Sidescraper & - & 7 & - & - & - & - \\
Thumbnail scraper & - & 3 & - & - & - & - \\
Scraper fragment & - & 1 & - & - & - & - \\
Backed point & - & 1 & - & - & - & - \\
Miscellaneous backed piece & - & 1 & - & - & - & - \\
Backed piece fragment & - & 1 & - & - & - & - \\
Notched piece & 1 & 1 & - & - & - & - \\
Blade & - & 2 & - & - & - & - \\
Bladelet & 11 & 3 & - & 1 & - & - \\
Flake & 91 & 51 & 1 & 11 & - & - \\
Edge-damaged flake & - & 3 & - & - & - & - \\
Chunk & 23 & 7 & - & 3 & - & - \\
Edge-damaged chunk & 1 & - & - & - & - & - \\
Chip & 116 & 14 & - & 6 & - & - \\
Total & $\mathbf{2 4 7}$ & $\mathbf{9 6}$ & $\mathbf{1}$ & $\mathbf{2 2}$ & $\mathbf{0}$ & $\mathbf{0}$ \\
Stone material \% total & $\mathbf{6 7 . 3}$ & $\mathbf{2 6 . 4}$ & $\mathbf{0 . 3}$ & $\mathbf{6 . 0}$ & - & - \\
Stone material \% formal & $\mathbf{5 . 9}$ & $\mathbf{9 4 . 1}$ & - & - & - & - \\
Upper grindstone & - & - & - & - & 1 & - \\
Lower grindstone & - & - & - & - & - & 1 \\
Lower grindstone fragment & - & - & - & - & - & 1 \\
\hline
\end{tabular}

Table 5.68: Stone artefacts from SK2001/025 Area C (Group 1).

\begin{tabular}{lcccccc}
\hline & Quartz & CCS & Silcrete & Quartzite & Sandstone & Other \\
\hline Bipolar core & 2 & 3 & - & - & - & - \\
Single platform core & 1 & 1 & - & 3 & - & - \\
Irregular core & 6 & 3 & - & 3 & - & - \\
Sidescraper & - & 5 & - & - & - & - \\
Thumbnail scraper & - & 1 & - & - & - & - \\
Miscellaneous backed scraper & - & 1 & - & - & - & - \\
Backed piece fragment & 1 & - & - & - & - & - \\
\hline
\end{tabular}




\begin{tabular}{lcccccc}
\hline & Quartz & CCS & Silcrete & Quartzite & Sandstone & Other \\
\hline Notched piece & - & 1 & - & - & - & - \\
Miscellaneous retouched piece & - & 1 & - & - & - & - \\
Blade & 3 & 1 & - & 1 & - & - \\
Bladelet & 13 & 8 & - & 2 & - & - \\
Flake & 231 & 96 & - & 50 & - & 5 \\
Edge-damaged flake & 1 & 4 & - & - & - & - \\
Chunk & 85 & 11 & - & 30 & - & 1 \\
Chip & 195 & 26 & - & 9 & - & - \\
Total & $\mathbf{5 3 8}$ & $\mathbf{1 6 2}$ & $\mathbf{0}$ & $\mathbf{9 8}$ & $\mathbf{0}$ & $\mathbf{6}$ \\
Stone material \% total & $\mathbf{6 7 . 0}$ & $\mathbf{2 0 . 1}$ & - & $\mathbf{1 2 . 2}$ & - & $\mathbf{0 . 7}$ \\
Stone material \% formal & $\mathbf{1 8 . 2}$ & $\mathbf{8 1 . 8}$ & - & - & - & - \\
Hammer stone & - & - & - & 1 & - & 1 \\
Hammer stone/upper & - & - & - & - & 1 & - \\
grindstone fragment & - & - & - & - & - & 3 \\
Lower grindstone fragment & - & - & - & - & - & 3 \\
Grindstone fragment & - & & & & & \\
\hline
\end{tabular}

Table 5.69: Stone artefacts from SK2001/025 Area D (Group 1).

\begin{tabular}{lcccccc}
\hline & Quartz & CCS & Silcrete & Quartzite & Sandstone & Other \\
\hline Bipolar core & - & 3 & - & - & - & - \\
Single platform core & - & - & - & 1 & - & - \\
Irregular core & 1 & 3 & 1 & - & - & - \\
Sidescraper & - & 2 & - & - & - & - \\
Miscellaneous scraper & - & 1 & - & - & - & - \\
Bladelet & 7 & 3 & - & - & - & - \\
Flake & 75 & 26 & - & 5 & 1 & - \\
Chunk & 16 & 7 & - & - & - & - \\
Chip & 62 & 9 & - & 1 & - & - \\
Total & $\mathbf{1 6 1}$ & $\mathbf{5 4}$ & $\mathbf{1}$ & $\mathbf{7}$ & $\mathbf{1}$ & $\mathbf{0}$ \\
Stone material \% total & $\mathbf{7 1 . 9}$ & $\mathbf{2 4 . 1}$ & $\mathbf{0 . 4}$ & $\mathbf{3 . 1}$ & $\mathbf{0 . 4}$ & - \\
Stone material \% formal & - & $\mathbf{1 0 0 . 0}$ & - & - & - & - \\
\hline
\end{tabular}

Table 5.70: Stone artefacts from SK2001/025 Area E (Group 1).

\begin{tabular}{lcccccc}
\hline & Quartz & CCS & Silcrete & Quartzite & Sandstone & Other \\
\hline MBP & - & 1 & - & - & - & - \\
Bladelet & - & 1 & - & - & - & - \\
Flake & 2 & 2 & - & - & - & - \\
Chunk & 1 & 1 & - & - & - & - \\
Chip & 1 & - & - & - & - & - \\
\hline
\end{tabular}




\begin{tabular}{lcccccc}
\hline & Quartz & CCS & Silcrete & Quartzite & Sandstone & Other \\
\hline Total & $\mathbf{4}$ & $\mathbf{5}$ & $\mathbf{0}$ & $\mathbf{0}$ & $\mathbf{0}$ & $\mathbf{0}$ \\
Stone material \% total & $\mathbf{4 4 . 4}$ & $\mathbf{5 5 . 6}$ & - & - & - & - \\
Stone material \% formal & - & $\mathbf{1 0 0 . 0}$ & - & - & - & - \\
Lower grindstone fragments & - & - & - & 1 & - & - \\
\hline
\end{tabular}

Table 5.71: Stone artefacts from SK2001/025 Area F (Group 1).

\begin{tabular}{|c|c|c|c|c|c|c|}
\hline & Quartz & CCS & Silcrete & Quartzite & Sandstone & Other \\
\hline Bipolar core & 9 & 1 & - & - & - & - \\
\hline Bipolar bladelet core & - & 1 & - & - & - & - \\
\hline Single platform core & 1 & - & - & - & - & - \\
\hline Irregular core & 10 & 10 & - & - & - & - \\
\hline Backed scraper & - & 1 & - & - & - & - \\
\hline Sidescraper & - & 3 & - & - & - & - \\
\hline Thumbnail scraper & - & 4 & - & - & - & - \\
\hline Miscellaneous backed scraper & - & 1 & - & - & - & - \\
\hline Miscellaneous scraper & - & 1 & - & - & - & - \\
\hline Scraper fragment & - & 3 & - & - & - & - \\
\hline Backed bladelet & - & 1 & - & - & - & - \\
\hline Segment & - & 1 & - & - & - & - \\
\hline Miscellaneous backed piece & - & 1 & - & - & - & - \\
\hline Backed piece fragment & 1 & 3 & - & - & - & - \\
\hline Adze & - & 1 & - & - & - & - \\
\hline Notched piece & - & 3 & - & - & - & - \\
\hline Denticulate & - & 2 & - & - & - & - \\
\hline Miscellaneous retouched piece & 1 & - & - & - & - & - \\
\hline Blade & 5 & - & - & 1 & 1 & - \\
\hline Bladelet & 13 & 15 & - & - & - & - \\
\hline Flake & 254 & 123 & 2 & 22 & 6 & 1 \\
\hline Edge-damaged flake & 8 & 16 & - & 1 & $1^{*}$ & - \\
\hline Chunk & 58 & 15 & - & 7 & - & - \\
\hline Edge-damaged chunk & 1 & 2 & - & - & - & - \\
\hline Chip & 146 & 99 & - & 8 & - & - \\
\hline Total & 507 & 307 & 2 & 39 & 8 & 1 \\
\hline Stone material \% total & 58.5 & 35.9 & 0.2 & 4.5 & 0.8 & 0.1 \\
\hline Stone material \% formal & 6.5 & 93.5 & - & - & - & - \\
\hline Lower grindstone & - & - & - & - & - & 1 \\
\hline Lower grindstone fragments & - & - & - & 1 & 2 & - \\
\hline Grindstone fragments & - & - & - & - & 3 & - \\
\hline
\end{tabular}

${ }^{*}$ MSA artefact excluded from material frequencies. 
Two fragments of ostrich eggshell appeared to be engraved. One (from Area B) is heavily burnt and the engraving, two fine, parallel lines, may not be real. The second (from Area C) is weathered but bears a single clear line incised across its face. One flask mouth fragment was found in Area E. Ostrich eggshell beads were found only in Areas A, C and F. Their size data are given in Table 5.72. All the beads are small, with none bigger than $4.5 \mathrm{~mm}$ external diameter (Figure 5.51).

Table 5.72: Summary statistics for finished ostrich eggshell beads from SK2001/025.

\begin{tabular}{|c|c|c|c|c|}
\hline Area & & Outside diameter $(\mathrm{mm})$ & Aperture diameter $(\mathrm{mm})$ & Thickness $(\mathrm{mm})$ \\
\hline & Mean & 3.71 & 1.69 & 1.01 \\
\hline A & Std Deviation & 0.29 & 0.05 & 0.14 \\
\hline \multirow[t]{2}{*}{$(n=3)$} & Minimum & 3.39 & 1.66 & 0.92 \\
\hline & Maximum & 3.94 & 1.75 & 1.19 \\
\hline \multirow[t]{2}{*}{$C(n=1)$} & & 3.24 & 1.18 & 1.67 \\
\hline & Mean & 4.20 & 1.77 & 1.57 \\
\hline $\mathrm{F}$ & Std Deviation & 0.35 & 0.28 & 0.12 \\
\hline \multirow[t]{2}{*}{$(n=12)$} & Minimum & 3.50 & 1.01 & 1.41 \\
\hline & Maximum & 4.50 & 2.11 & 1.76 \\
\hline
\end{tabular}

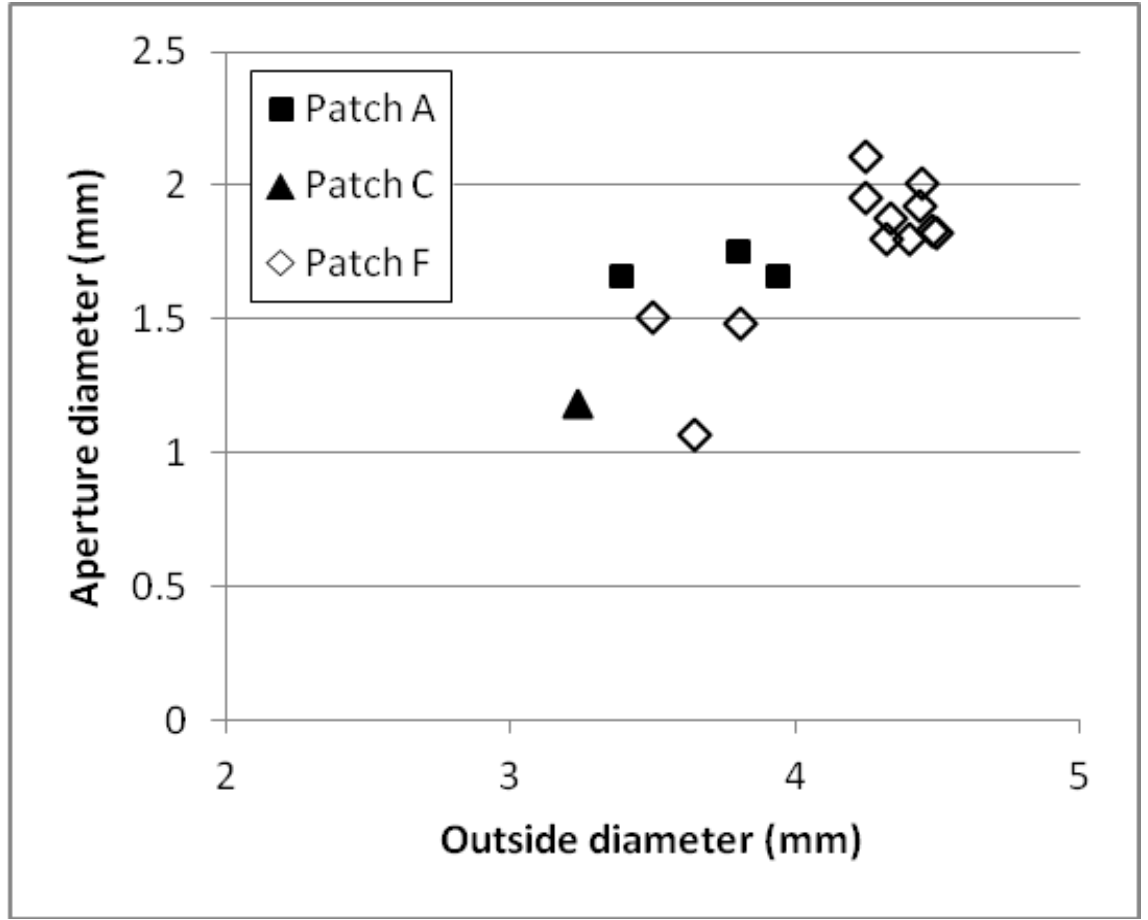

Figure 5.51: Scatter plot of ostrich eggshell bead dimensions from SK2001/025. 


\subsubsection{SK2001/039}

\section{The site}

This small site lay on the west side of a low dune, $1.2 \mathrm{~km}$ south of the Buffels River and $1.05 \mathrm{~km}$ from the coast $\left(29^{\circ} 40^{\prime} 59.8^{\prime \prime} \mathrm{S} 17^{\circ} 03^{\prime} 51.2^{\prime \prime} \mathrm{E}\right)$. While most of the site was shell scatter, part of the $8 \mathrm{~m}^{2}$ excavated was in situ shell midden (Halkett 2003). The following dates were obtained:

\begin{tabular}{|c|c|c|c|c|}
\hline -ab. No. & Provenience & Material & ${ }^{14} \mathrm{C}$ date BP & Calibrated age (95.4\%) \\
\hline 4 & J33 & (Chersina angulata) & 606 & 1425 \\
\hline$x A-24525$ & J33 & Bone (Chersina angulata) & $609 \pm 25$ & AD 1319-1422 \\
\hline
\end{tabular}

Notes:

- OxA-24524 \& OxA-24525 were run on the same sample.

\section{$\underline{\text { Cultural material }}$}

A moderate assemblage of flaked stone artefacts was recovered with the majority being quartz (Table 5.73). Most of this was clear quartz, including one backed bladelet, although the presence of CCS and particularly some retouched artefacts in that material suggest Groups 1 and 3. The thumbnail scraper, unusually, was retouched on its ventral surface. Interestingly, the silcrete was all of a very fine-grained, pale brown type, similar to that noted at PN2009/001, some $52 \mathrm{~km}$ to the north. Three fragments of ochre were also present.

Table 5.73: Stone artefacts from SK2001/039 (Group 1/3).

\begin{tabular}{lccccc}
\hline & Quartz & CCS & Silcrete & Quartzite & Other \\
\hline Bipolar core & 2 & - & - & - & - \\
Irregular core & 1 & 1 & - & - & - \\
Thumbnail scraper & - & 1 & - & - & - \\
Scraper fragment & - & 1 & - & - & - \\
Backed bladelet & 1 & - & - & - & - \\
Backed piece fragment & - & 1 & - & - & - \\
Blade & 1 & - & - & - & - \\
Bladelet & 4 & 1 & - & - & - \\
\hline
\end{tabular}




\begin{tabular}{lccccc}
\hline & Quartz & CCS & Silcrete & Quartzite & Other \\
\hline Flake & 82 & 15 & 6 & 28 & - \\
Chunk & 20 & 1 & - & 8 & - \\
Edge-damaged chunk & 1 & - & - & 8 & - \\
Chip & 115 & 6 & - & - & - \\
Total & 227 & $\mathbf{2 7}$ & $\mathbf{6}$ & $\mathbf{4 4}$ & $\mathbf{0}$ \\
Stone material \% total & $\mathbf{7 4 . 7}$ & $\mathbf{8 . 9}$ & $\mathbf{2 . 0 0}$ & $\mathbf{1 4 . 5}$ & - \\
Stone material \% formal & $\mathbf{2 5 . 0}$ & $\mathbf{7 5 . 0}$ & - & - & - \\
Upper grindstone fragment & - & - & - & 1 & - \\
Grindstone fragments & - & - & - & - & 1 \\
\hline
\end{tabular}

No ostrich eggshell beads were present but two fragments of ostrich eggshell flask mouth were noted. Twenty-nine potsherds weighing $174 \mathrm{~g}$ and having a mean thickness of $5.71 \pm 0.61 \mathrm{~mm}$ were found. Some of the body sherds showed an external surface with numerous striations, presumably reflecting the method of finishing employed (Figure 5.52). Four refitting sherds with a heavy residue on the outside form a flared neck with a variably tapered and simple rounded lip. It is decorated with small impressions (Figure 5.52). This set reflects a mouth diameter of c. $100 \mathrm{~mm}$. A further decorated fragment seemed to have slightly different shaped impressions. Two sherds show evidence of coil manufacture.
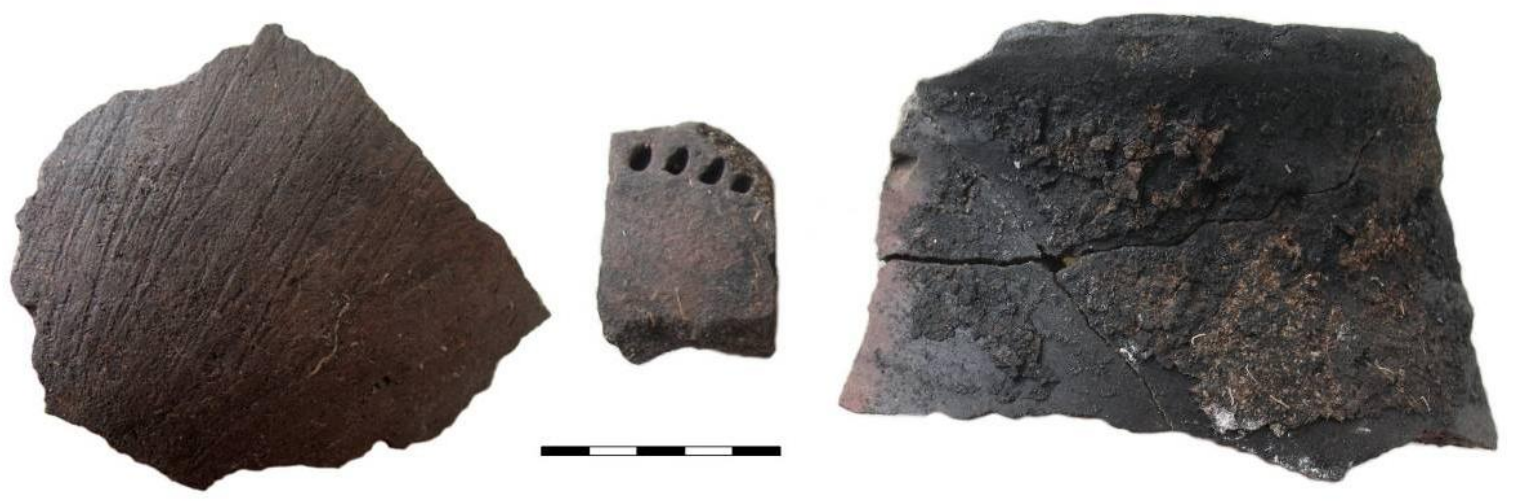

Figure 5.52: The striated body sherd and decorated rims from SK2001/039. Scale in $5 \mathrm{~mm}$ intervals. 


\subsubsection{SK2005/057A}

\section{The site}

This site lay atop a prominent vegetated sand dune $1.8 \mathrm{~km}$ south of the Buffels River estuary and $780 \mathrm{~m}$ from the sea $\left(29^{\circ} 41^{\prime} 19.0^{\prime \prime} \mathrm{S} 17^{\circ} 03^{\prime} 48.7^{\prime \prime} \mathrm{E}\right)$. It is on the eastern (inland) side of the dune with older occupations present to the west and northwest. Although a small part of the site was disturbed, most was in pristine condition beneath 30 $\mathrm{cm}$ of sterile dune sand and consisted of a string of small middens extending northsouth. A hearth was found in the southern part of the site. A single layer was excavated over $54 \mathrm{~m}^{2}$ with some of this area being dense shell midden (Orton \& Halkett 2006). The following date was obtained:

\begin{tabular}{|c|c|c|c|c|}
\hline$b$ & Provenience & Material & ${ }^{14} \mathrm{C}$ date $\mathrm{B}$ & ted \\
\hline & earth & Charcoal (sp. unknown) & $400 \pm 22$ & 625 \\
\hline
\end{tabular}

\section{$\underline{\text { Cultural material }}$}

A rich assemblage of flaked artefacts, worked ostrich eggshell and pottery was recovered. The stone includes a variety of materials and types suggesting overprinting of material of different ages (Table 5.74). The vast majority, however, belongs to this site and represents a Group 2 assemblage. The older artefacts, particularly those in CCS, are focussed in the north-western part of the site and no doubt originate from the nearby Group 1 site of SK2005/074A (185 BC-AD 85; see below). One single platform core is a large, possibly ESA, flake that was collected and further flaked from its ventral surface. The large chopper is made on a flat slab of quartzite (Figure 5.53). Twelve small ochre fragments were found clustered in the northern part of the site. 
Table 5.74: Stone artefacts from SK2005/057A (Group 2).

\begin{tabular}{lccccc}
\hline & Quartz & CCS & Quartzite (brown) & Quartzite (other) & Other \\
\hline Bipolar core & 3 & - & - & - & - \\
Single platform core & - & - & 2 & - & - \\
Irregular core & 3 & - & - & - & - \\
Backed scraper & - & 1 & - & - & - \\
Sidescraper & - & 1 & - & - & - \\
Scraper fragment & - & 1 & - & 1 & - \\
Large chopper & - & - & - & - & - \\
Blade & 3 & - & - & - & - \\
Bladelet & 2 & 1 & - & 2 & 1 \\
Flake & 137 & 22 & 26 & 3 & 1 \\
Chunk & 62 & 3 & 6 & - & - \\
Chip & 164 & 7 & 13 & 6 & $\mathbf{2}$ \\
Total & 374 & 36 & $\mathbf{4 7}$ & $\mathbf{1 . 3}$ & $\mathbf{0 . 4}$ \\
Stone material \% total & $\mathbf{8 0 . 4}$ & $\mathbf{7 . 7}$ & $\mathbf{1 0 . 1}$ & $\mathbf{2 5 . 0}$ & - \\
Stone material \% formal & - & $\mathbf{7 5 . 0}$ & - & - & 2 \\
Upper grindstone & - & - & - & - & 4 \\
Upper grindstone fragment & - & - & - & - & 1 \\
Lower grindstone fragment & - & - & - & - & 2 \\
Grindstone fragments & - & - & - & & \\
\hline
\end{tabular}

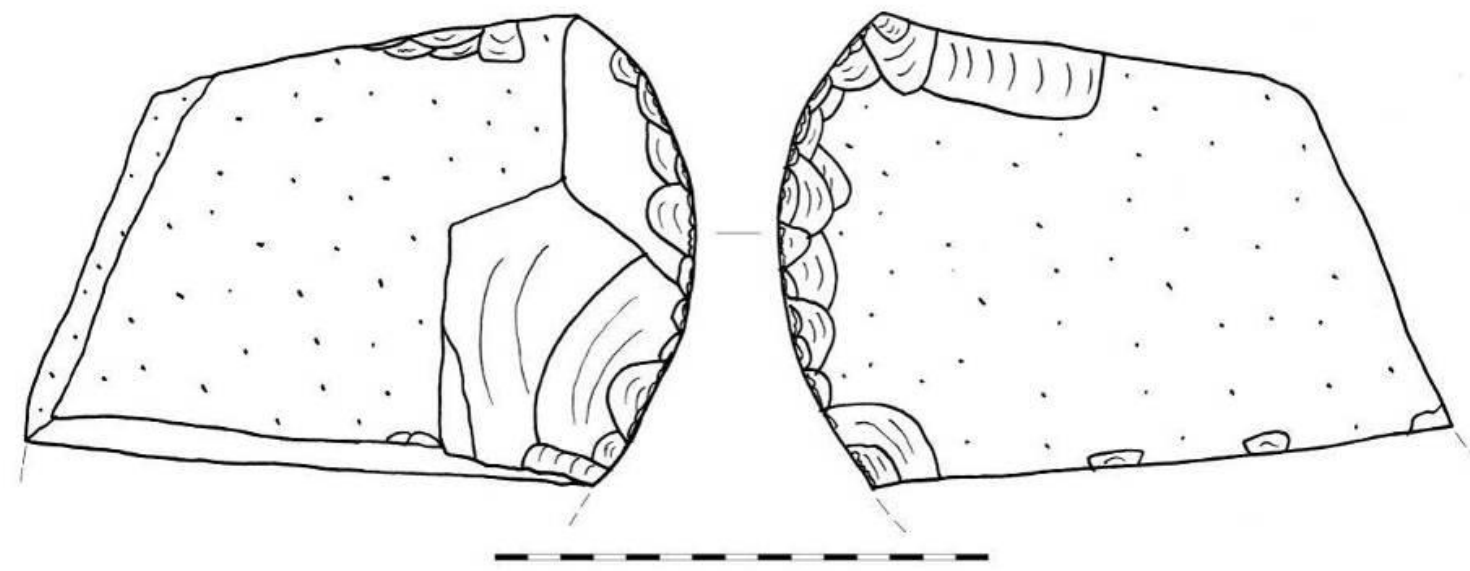

Figure 5.53: The quartzite large chopper from SK2005/057A. Stippling denotes cortex. Scale in 5 $\mathrm{mm}$ intervals.

The worked ostrich eggshell includes two refitting flask mouth fragments with an opening of just less than $10 \mathrm{~mm}$ that were found a few metres from the main concentration of ostrich eggshell fragments. Also present were a good collection of ostrich eggshell beads 
and manufacturing fragments. Small unworked fragments, probably off-cuts, were concentrated in a similar area to the manufacturing debris. The bead production debris is tabulated in Table 5.75, while summary statistics for the finished beads appear in Table 5.76. The only small bead $(4.11 \mathrm{~mm}$ diameter) comes from the northern part of the site and likely originated from SK2005/074A. The other 25 beads are all medium to large, clustering between 5.1 and $6.4 \mathrm{~mm}$. A single large bead of $12.4 \mathrm{~mm}$ external diameter was found in a disturbed area some $10 \mathrm{~m}$ east of the excavation and has not been included in the data presented here.

Table 5.75: Ostrich eggshell bead manufacturing debris from SK2005/057A.

\begin{tabular}{ccccccccccccc}
\hline Stage & Ila & Ilb & Illa & IIlb & IVa & IVb & Va & Vb & Vla & VIb & VIla & VIlb \\
\hline & - & 18 & 9 & 73 & - & 16 & - & 2 & - & - & 26 & 3 \\
\hline
\end{tabular}

Table 5.76: Summary statistics for finished ostrich eggshell beads from SK2005/057A.

\begin{tabular}{llccc}
\hline & Outside diameter $(\mathrm{mm})$ & Aperture diameter $(\mathrm{mm})$ & Thickness $(\mathrm{mm})$ \\
\hline \multirow{3}{*}{$\mathrm{n}=26$} & 5.58 & 1.98 & 1.79 \\
\cline { 2 - 4 } & Mean & 0.41 & 0.50 & 0.18 \\
& Minimum & 4.11 & 1.10 & 1.47 \\
& Maximum & 6.39 & 2.80 & 2.05 \\
\hline
\end{tabular}

Eighty-six potsherds weighing $317.1 \mathrm{~g}$ were clustered in two main areas of the site. In the north a single rim fragment with two rows of impressions (Figure 5.54) and a plain rim suggest two vessels, while in the south a cluster of very fine-grained and thinner-walled sherds suggest a third. The decorated rim has a mouth diameter of about $100 \mathrm{~mm}$. The mean wall thickness was $6.32 \pm 1.12 \mathrm{~mm}$. Half a water-worn ring of $C$. granatina was also present, along with many other collected shells (14 Conus mozambicus, 10 Bullia digitalis, 1 Marginella rosea). Some Bullia shells showed possible signs of threading, but none were convincing. 


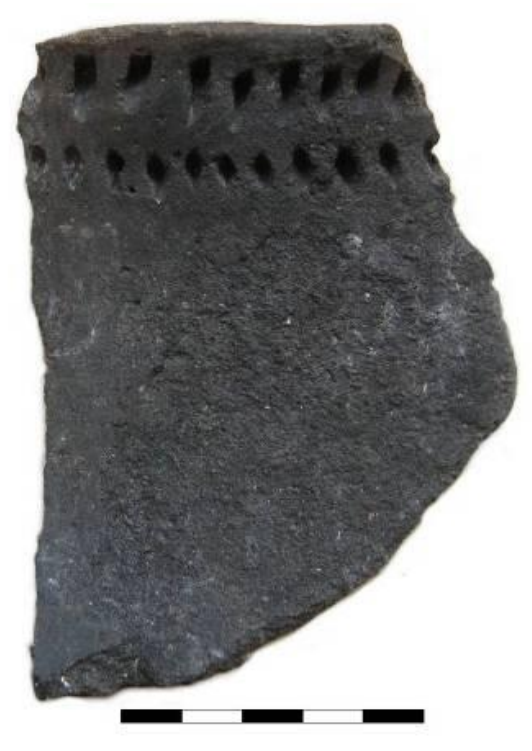

Figure 5.54: The decorated rim sherd from SK2005/057A. Scale in $5 \mathrm{~mm}$ intervals.

\subsubsection{SK2005/074A}

\section{The site}

This site lies immediately north of SK2005/057A, on the northern part of the same sand dune $\left(29^{\circ} 41^{\prime} 18.5^{\prime \prime} \mathrm{S} 17^{\circ} 03^{\prime} 49.0^{\prime \prime} \mathrm{E}\right)$. It is $1.8 \mathrm{~km}$ south of the Buffels River and $770 \mathrm{~m}$ from the beach. Four layers were identified with variable areas of each being excavated (Table 5.77; Orton \& Halkett 2006). The total depth at the base of Layer 4 was approximately $50 \mathrm{~cm}$. The following dates were obtained:

\begin{tabular}{|c|c|c|c|c|}
\hline Lab. No. & Provenience & Material & ${ }^{14} \mathrm{C}$ date BP & Calibrated age (95.4\%) \\
\hline OxA-24526 & $\begin{array}{l}\text { Layer 1, N24 } \\
\text { Surface }\end{array}$ & $\begin{array}{l}\text { Bone (Raphicerus } \\
\text { campestris) }\end{array}$ & $2132 \pm 27$ & $185 \mathrm{BC}-\mathrm{AD} 1$ \\
\hline OxA-24527 & $\begin{array}{l}\text { Layer 2, M24 } \\
\text { M1/L1 }\end{array}$ & $\begin{array}{l}\text { Bone (Chersina } \\
\text { angulata) }\end{array}$ & $2052 \pm 34$ & 107 BC-AD 85 \\
\hline
\end{tabular}

Bone from Layer 3 yielded too little collagen for a date and Layer 4 remains undated. The dates and stone artefacts support all but Layer 4 being of similar age. Layer 3 had extremely low density shell and effectively represents the gap between the two primary occupation periods (and shell middens) at the site. 
Table 5.77: Excavated areas and artefact densities at SK2005/074A. Surface, L1 and L2 are shell scatter, while M1 and M2 are midden levels.

\begin{tabular}{cccc}
\hline Layer & Excavation levels & Area excavated & Flaked artefacts $/ \mathrm{m}^{2}$ \\
\hline 1 & Surface & $17 \mathrm{~m}^{2}$ & 21.8 \\
2 & M1 \& L1 & $9 \mathrm{~m}^{2}$ & 54.6 \\
3 & L2 & $2 \mathrm{~m}^{2}$ & 20.5 \\
4 & M2 & $2 \mathrm{~m}^{2}$ & 0.5 \\
\hline
\end{tabular}

\section{$\underline{\text { Cultural material }}$}

Due primarily to the larger excavated areas, most flaked stone artefacts occur in Layers 1 and 2 (Tables 5.78-5.79). Artefacts in Layer 3 (Table 5.80) are assumed to have filtered down from above and Layer 4 contains just one quartz flake. The curve-backed flake and truncated bladelet are rare forms. The proportions of stone materials used remains fairly consistent with CCS always comprising about one quarter. This figure, and the presence of CCS retouched pieces, places the assemblages within Group 1 (Figure 5.55). Most of the quartz is clear, but some was difficult to distinguish from quartzite. Manuports were fairly common in Layers 1 and 2 and ochre fragments were present in all Layer 1 (one fragment), Layer 2 (five fragments) and Layer 3 (one fragment).

Table 5.78: Stone artefacts from SK2005/074A, Layer 1 (Group 1).

\begin{tabular}{lccccc}
\hline & Quartz & CCS & Silcrete & Quartzite & Other \\
\hline Bipolar core & 2 & - & - & 1 & - \\
Irregular core & 2 & 2 & - & - & - \\
Backed scraper & - & 1 & - & - & - \\
Sidescraper & - & 2 & - & - & - \\
Thumbnail scraper & - & 1 & - & - & - \\
Backed flake & - & 1 & - & - & - \\
Truncated bladelet & - & 1 & - & - & - \\
Backed piece fragment & - & 1 & - & - & - \\
Notched piece & 1 & - & - & - & - \\
Blade & 1 & - & - & - & - \\
Bladelet & 6 & 4 & - & - & - \\
Flake & 117 & 51 & 3 & 21 & 3 \\
Edge-damaged flake & - & 1 & - & - & - \\
Chunk & 35 & 6 & - & 5 & - \\
\hline
\end{tabular}




\begin{tabular}{lccccc}
\hline & Quartz & CCS & Silcrete & Quartzite & Other \\
\hline Chip & 78 & 18 & - & 4 & - \\
Total & 242 & 89 & 3 & 31 & 3 \\
Stone material \% total & 65.4 & $\mathbf{2 4 . 6}$ & $\mathbf{0 . 8}$ & $\mathbf{8 . 4}$ & $\mathbf{0 . 8}$ \\
Stone material \% formal & $\mathbf{1 2 . 5}$ & $\mathbf{8 7 . 5}$ & - & - & - \\
\hline
\end{tabular}

Table 5.79: Stone artefacts from SK2005/074A, Layer 2 (Group 1).

\begin{tabular}{lcccccc}
\hline & Quartz & CCS & Silcrete & Quartzite & Sandstone & Other \\
\hline Bipolar core & 3 & - & - & - & - & - \\
Single platform core & - & - & - & 1 & - & - \\
Irregular core & 4 & 1 & - & - & - & - \\
Large thumbnail scraper & 1 & - & - & - & - & - \\
Scraper fragment & - & 1 & - & - & - & - \\
Backed blade & - & 1 & - & - & - & - \\
Curve-backed flake & - & 1 & - & - & - & - \\
Segment & - & 1 & - & - & - & - \\
Backed piece fragment & - & 3 & - & - & - & - \\
Miscellaneous retouched piece & - & 1 & - & - & - & - \\
Blade & 1 & 3 & - & - & - & - \\
Bladelet & 6 & 4 & - & 1 & - & 1 \\
Flake & 132 & 63 & - & 32 & - & - \\
Edge-damaged flake & 2 & 2 & - & - & - & - \\
Chunk & 32 & 6 & 1 & 16 & - & - \\
Chip & 111 & 32 & - & 19 & - & - \\
Total & $\mathbf{2 9 2}$ & $\mathbf{1 1 9}$ & $\mathbf{1}$ & $\mathbf{6 9}$ & $\mathbf{0}$ & $\mathbf{1}$ \\
Stone material \% total & $\mathbf{6 0 . 6}$ & $\mathbf{2 4 . 7}$ & $\mathbf{0 . 2}$ & $\mathbf{1 4 . 3}$ & - & $\mathbf{0 . 2}$ \\
Stone material \% formal & $\mathbf{1 0 . 0}$ & $\mathbf{9 0 . 0}$ & - & - & - & - \\
Upper grindstone/hammer stone & - & - & - & - & 2 & 1 \\
Lower grindstone fragment & - & - & - & - & 1 & - \\
\hline & & & & & & \\
\hline & & & & - & - & \\
\end{tabular}

Table 5.80: Stone artefacts from SK2005/074A, Layer 3 (Group 1).

\begin{tabular}{lccc}
\hline & Quartz & CCS & Quartzite \\
\hline Bladelet & - & - & 1 \\
Flake & 13 & 4 & 3 \\
Edge-damaged flake & - & 1 & - \\
Chunk & 3 & - & - \\
Chip & 9 & 4 & 2 \\
Total & $\mathbf{2 5}$ & $\mathbf{9}$ & $\mathbf{6}$ \\
Stone material \% total & $\mathbf{6 2 . 5}$ & $\mathbf{2 2 . 5}$ & $\mathbf{1 5 . 0}$ \\
Stone material \% formal & - & - & - \\
\hline
\end{tabular}




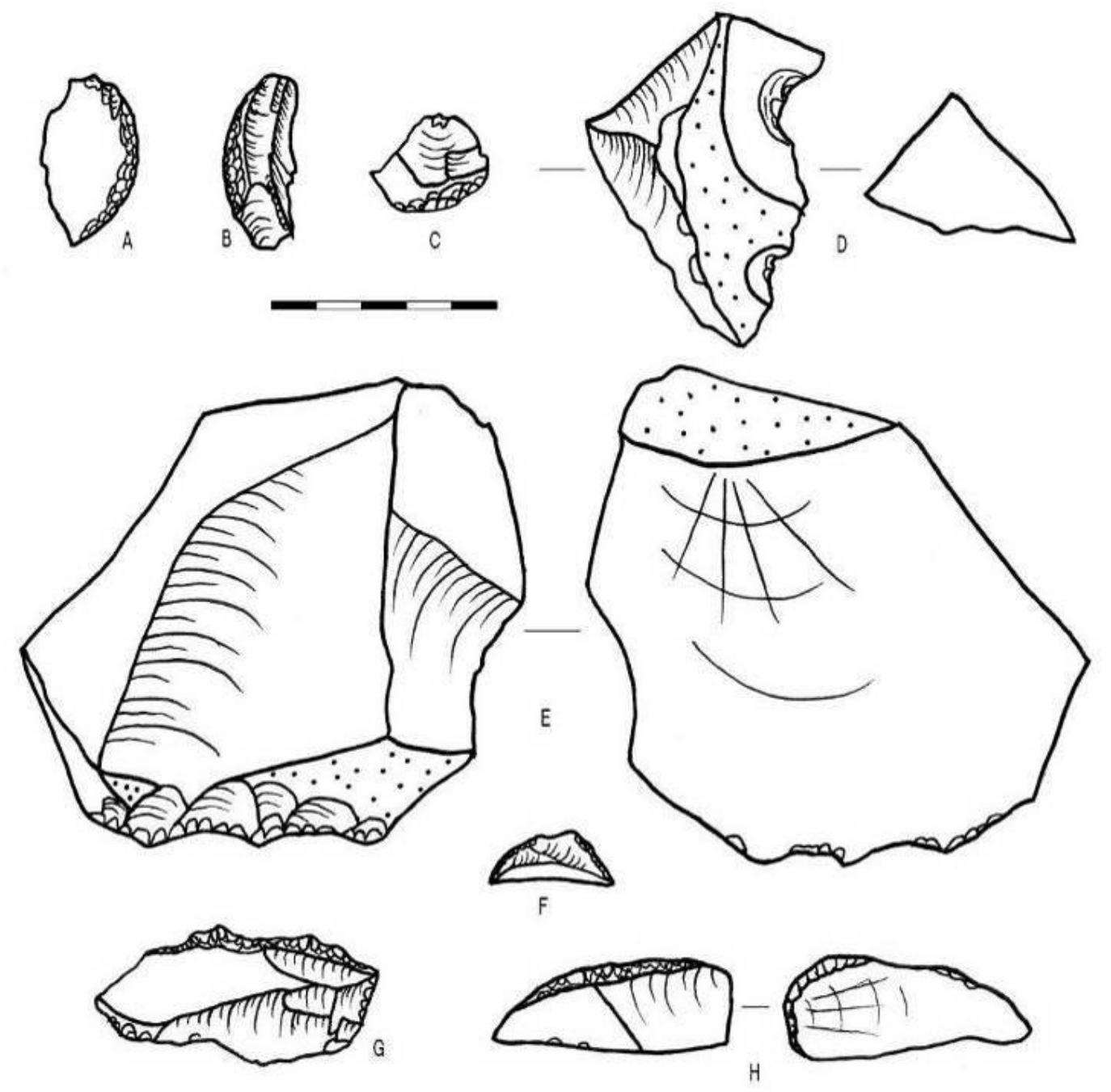

Figure 5.55: Stone artefacts from SK2005/074. All from M1/L1 except D: Surface. A, B: sidescrapers; C: thumbnail scraper; D: notched piece; E: large thumbnail scraper; F: segment; G: backed blade; $\mathrm{H}$ : curve-backed bladelet. All in CCS except $\mathrm{D} \& \mathrm{E}$ : quartz. Scale in $5 \mathrm{~mm}$ intervals.

Only three ostrich eggshell beads were found, two in Layer 1 and one in Layer 2. All are small and, given the similar ages, I have grouped them in Table 5.81. Two flask mouth fragments from Layer 1 refit to give a mouth diameter of $8.8 \mathrm{~mm}$. One plain potsherd (weight $=3.3 \mathrm{~g}$, thickness $=4.20 \mathrm{~mm}$ ) was found on the surface and is assumed to relate to a later occupation of the hill, perhaps even to SK2005/057A described above.

Table 5.81: Summary statistics for finished ostrich eggshell beads from SK2005/074A.

\begin{tabular}{llccc}
\hline Layer & & Outside diameter $(\mathrm{mm})$ & Aperture diameter $(\mathrm{mm})$ & Thickness $(\mathrm{mm})$ \\
\hline \multirow{3}{*}{$1 \& 2$} & Mean & 4.46 & 1.67 & 1.79 \\
$(\mathrm{n}=3)$ & Std Deviation & 0.08 & 0.20 & 0.2 \\
& Minimum & 4.39 & 1.55 & 1.63 \\
& Maximum & 4.55 & 1.90 & 2.01 \\
\hline
\end{tabular}




\subsubsection{SK2005/084}

\section{The site}

This deflated shell scatter lay in a flat, open area some $820 \mathrm{~m}$ from the coast and $1.5 \mathrm{~km}$ south of the Buffels River (Figure 5.56; 2941'11.4" S 1703'48.8” E). It was excavated over an area of $17 \mathrm{~m}^{2}$ (Orton \& Halkett 2006). The following date was obtained:

\begin{tabular}{|c|c|c|c|c|}
\hline Lab. No. & Provenience & Material & ${ }^{14} \mathrm{C}$ date BP & Calibrated age (95.4\%) \\
\hline UGAMS-6608 & S3 & Marine shell & $2420 \pm 30$ & 196 BC-AD 325 \\
\hline
\end{tabular}

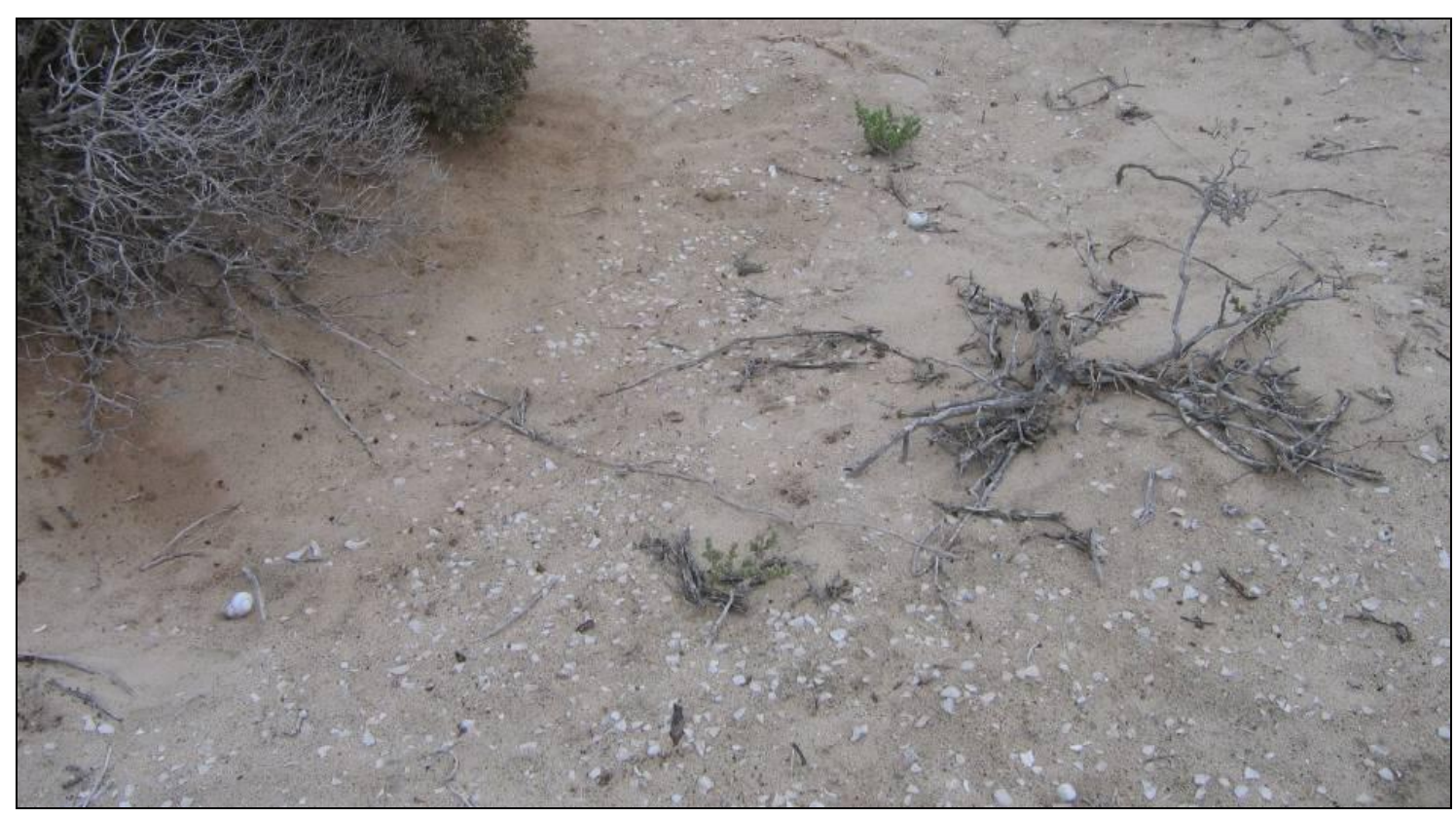

Figure 5.56: Surface appearance of the deflated shell scatter at SK2005/084.

\section{$\underline{\text { Cultural material }}$}

The 458 flaked stone artefacts are dominated by quartz and include a quartz segment that likely broke during manufacture and two CCS miscellaneous backed scrapers (Table 5.82). The assemblage appears to be quite typical of Group 1 (Figure 5.57). Four ostrich eggshell beads are present, one small, one medium and two large (Table 5.83). A most interesting find is a piece of engraved ostrich eggshell with a unique design (Figure 5.58). Six potsherds weighing $6.0 \mathrm{~g}$ are also present, three of which are undecorated rims. Two of the latter are vertical tapered rims, while the third is flaring and tapered. The mean wall thickness was $3.56 \pm 0.45 \mathrm{~mm}$. The ostrich eggshell (worked and unworked) 
and pottery is all very weathered owing to wind exposure and all is assumed to be the same age.

Table 5.82: Stone artefacts from SK2005/084 (Group 1).

\begin{tabular}{lccc}
\hline & Quartz & CCS & Quartzite \\
\hline Bipolar core & 2 & - & - \\
Miscellaneous backed scraper & - & 2 & - \\
Miscellaneous scraper & - & 1 & - \\
Segment & 1 & - & - \\
Miscellaneous retouched piece & - & 2 & - \\
Blade & 1 & - & - \\
Bladelet & 2 & 3 & - \\
Flake & 154 & 40 & 9 \\
Edge-damaged flake & 1 & 1 & - \\
Chunk & 58 & 5 & 8 \\
Chip & 143 & 25 & - \\
Total & $\mathbf{3 6 2}$ & $\mathbf{7 9}$ & $\mathbf{1 7}$ \\
Stone material \% total & $\mathbf{7 9 . 0}$ & $\mathbf{1 7 . 2}$ & $\mathbf{3 . 7}$ \\
Stone material \% formal & $\mathbf{1 6 . 7}$ & $\mathbf{8 3 . 3}$ & - \\
\hline
\end{tabular}

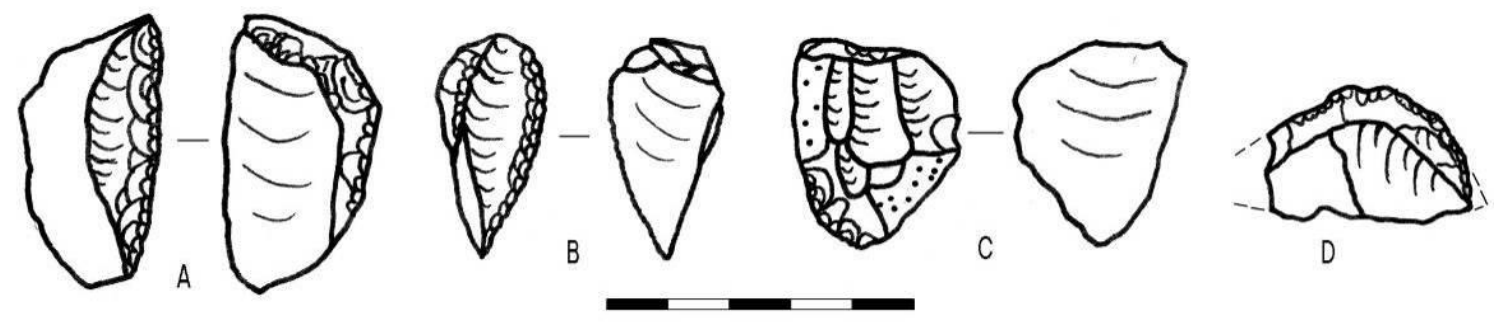

Figure 5.57: Stone artefacts from SK2005/084. A, B: miscellaneous backed scrapers; C: miscellaneous scraper; D: segment. All in CCS except D: quartz. Scale in $5 \mathrm{~mm}$ intervals.

Table 5.83: Summary statistics for finished ostrich eggshell beads from SK2005/084.

\begin{tabular}{llccc}
\hline & & Outside diameter $(\mathrm{mm})$ & Aperture diameter $(\mathrm{mm})$ & Thickness $(\mathrm{mm})$ \\
\hline \multirow{3}{*}{$\mathrm{n}=6$} & Mean & 5.51 & 1.82 & 1.79 \\
& Std Deviation & 1.10 & 0.18 & 0.10 \\
& Minimum & 3.91 & 1.57 & 1.68 \\
& Maximum & 6.28 & 1.98 & 1.87 \\
\hline
\end{tabular}


Figure 5.58: The engraved ostrich eggshell fragment from SK2005/084. Scale in $5 \mathrm{~mm}$ intervals.

\subsubsection{SK2005/095}

\section{$\underline{\text { The site }}$}

This site comprised five patches (Figure 5.59). The north-western one, Patch A, was richer than the rest that are cumulatively taken as Patch B. The site lay in an open area

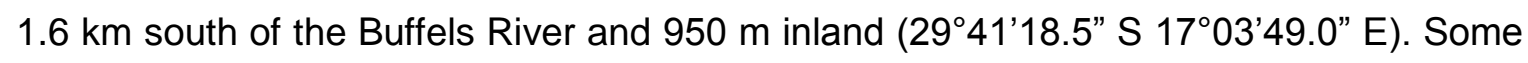
disturbed shell patches to the north were not sampled and may also have belonged to the site (Orton \& Halkett 2006). Whether the patches are related is unknown, they exhibit both differences and similarities, and the dating does not help. Although the site was all a single layer, the presence of wind-blasted stone artefacts shows that the area was previously occupied. The following dates were obtained:

\begin{tabular}{|c|c|c|c|c|}
\hline Lab. No. & Provenience & Material & ${ }^{14} \mathrm{C}$ date $\mathrm{BP}$ & Calibrated age $(95.4 \%)$ \\
\hline OxA-24551 & $\begin{array}{l}\text { Patch A, F29 } \\
\text { Midden }\end{array}$ & Bone (Chersina angulata) & $468 \pm 25$ & AD 1429-1497 \\
\hline OxA-24550 & $\begin{array}{l}\text { Patch B, S20 } \\
\text { L2 }\end{array}$ & Bone (?medium bovid) & $389 \pm 24$ & AD 1459-1626 \\
\hline
\end{tabular}

\section{$\underline{\text { Cultural material }}$}

Small stone artefact assemblages, based mostly on clear quartz, were recovered from both the main excavation (Patch A) and the remainder (Patch B) (Tables 5.84-5.85). The only retouched item in Patch A was a large thumbnail scraper on either calcrete or 
silcrete, though the former seems more likely (Figure 5.60). A CCS adze occurs in Patch B. Neither piece is typical of any Group and, on the strength of the clear quartz component, this site is allocated to Group 3.

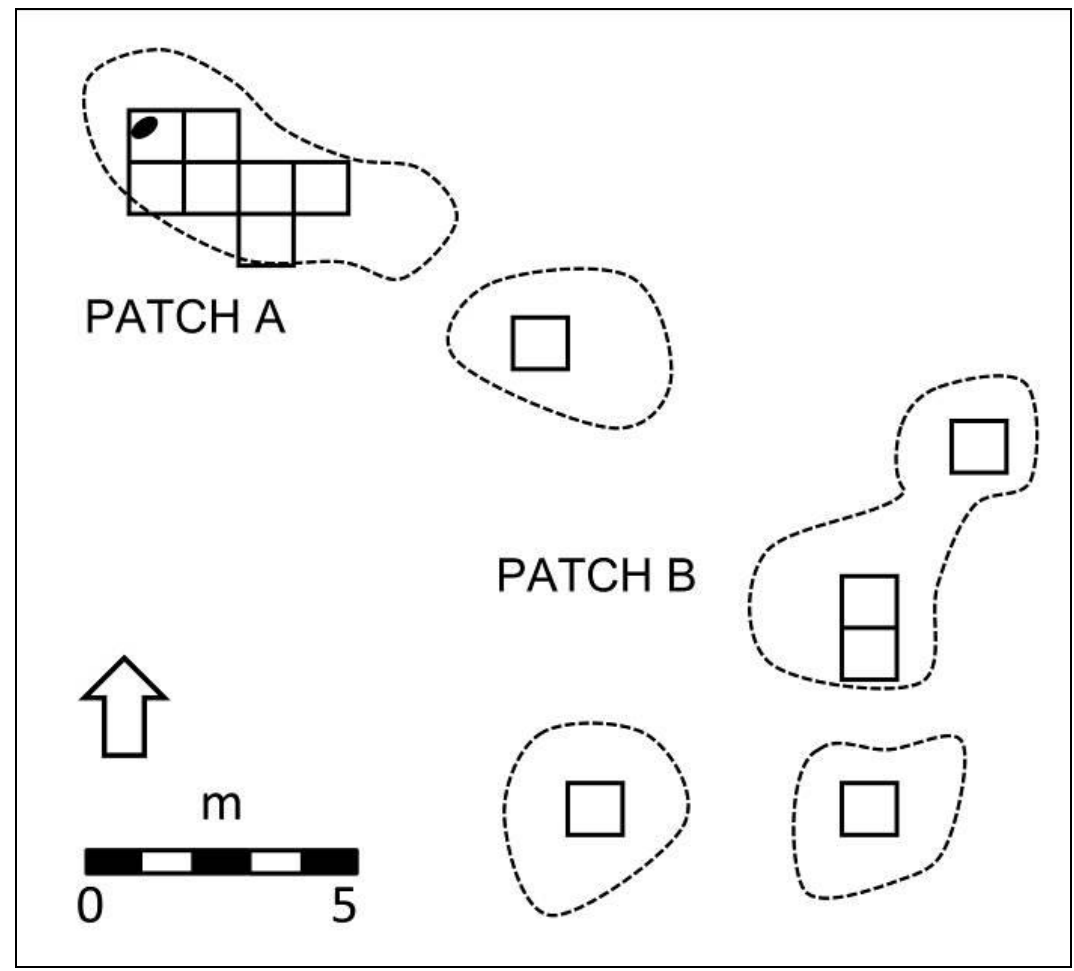

Figure 5.59: Layout of SK2005/095. The dotted lines indicate visible surface shell scatter and the small black oval in Patch A is a tortoise burial.

Table 5.84: Stone artefacts from SK2005/095, Patch A (Group 3).

\begin{tabular}{lccc}
\hline & Quartz & Calcrete & Other \\
\hline Bipolar core & 2 & - & - \\
Large thumbnail scraper & - & 1 & - \\
Bladelet & 7 & - & - \\
Flake & 67 & - & - \\
Edge-damaged flake & 3 & - & - \\
Chunk & 18 & - & - \\
Chip & 38 & - & - \\
Total & $\mathbf{1 3 5}$ & $\mathbf{1}$ & $\mathbf{0}$ \\
Stone material \% total & 99.3 & $\mathbf{0 . 7}$ & - \\
Stone material \% formal & - & $\mathbf{1 0 0 . 0}$ & - \\
Grindstone fragments & - & - & 2 \\
\hline
\end{tabular}


Table 5.85: Stone artefacts from SK2005/095, Patch B.

\begin{tabular}{lccc}
\hline & Quartz & CCS & Quartzite \\
\hline Adze & - & 1 & - \\
Flake & 10 & 1 & 2 \\
Edge-damaged flake & 2 & - & - \\
Chunk & 4 & - & 1 \\
Chip & 12 & - & - \\
Total & $\mathbf{2 8}$ & $\mathbf{2}$ & $\mathbf{3}$ \\
Stone material \% total & $\mathbf{8 4 . 8}$ & $\mathbf{6 . 1}$ & $\mathbf{9 . 1}$ \\
Stone material \% formal & - & $\mathbf{1 0 0 . 0}$ & - \\
Hammer stone/grindstone fragment & - & - & 1 \\
\hline
\end{tabular}

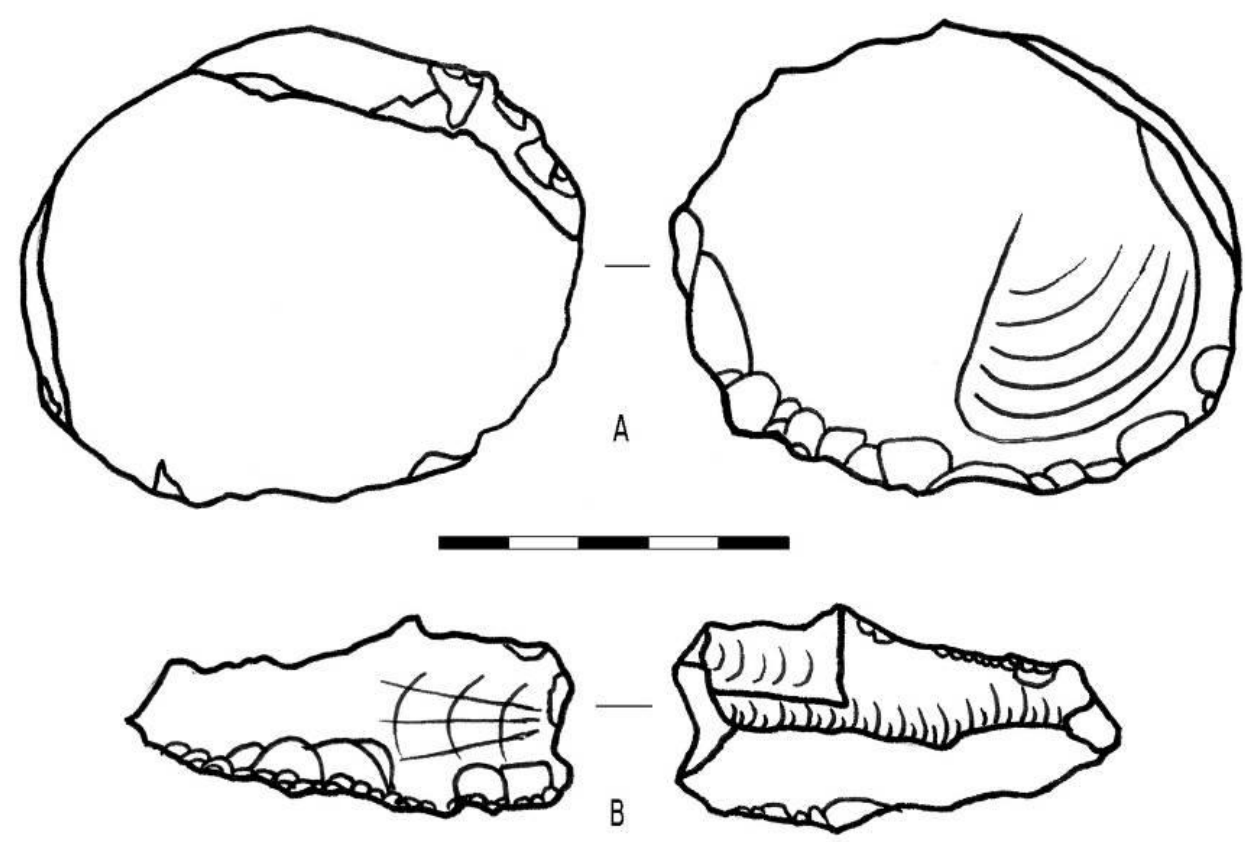

Figure 5.60: Stone artefacts from SK2005/095. A: calcrete large thumbnail scraper (Patch A); B: CCS adze (Patch B). Scale in $5 \mathrm{~mm}$ intervals.

Patch A contained eight whole large and very large ostrich eggshell beads (Table 5.86) and a significant collection of bead manufacturing debris (Table 5.87), while on Patch B square N16 contained one whole bead $(7.24 \mathrm{~mm}$ diameter, $2.20 \mathrm{~mm}$ aperture, $1.85 \mathrm{~mm}$ thickness) and some manufacturing debris. Three potsherds (weight $=18.7 \mathrm{~g}$, thickness $=5.95 \pm 0.37 \mathrm{~mm}$ ) were found on Patch B with one of the two in M25 almost certainly the same pot as a sherd collected from the surface of U22. A number of waterworn shells of various species were also found in both areas (Table 5.88). 
Table 5.86: Summary statistics for finished ostrich eggshell beads from SK2005/095.

\begin{tabular}{|c|c|c|c|c|}
\hline & & Outside diameter (mm) & Aperture diameter (mm) & Thickness (mm) \\
\hline \multirow{4}{*}{$\mathrm{n}=8$} & Mean & 6.99 & 2.33 & 1.93 \\
\hline & Std Deviation & 0.80 & 0.24 & 0.19 \\
\hline & Minimum & 6.11 & 2.05 & 1.74 \\
\hline & Maximum & 8.00 & 2.67 & 2.04 \\
\hline
\end{tabular}

Table 5.87: Ostrich eggshell bead manufacturing debris from SK2005/095.

\begin{tabular}{ccccccccccccc}
\hline Stage & Ila & Ilb & Illa & Illb & IVa & IVb & Va & Vb & Vla & VIb & VIla & Vllb \\
\hline Patch A & 1 & 65 & 4 & 273 & & 28 & & 11 & 1 & 1 & 8 & 2 \\
\hline Square N16 & 3 & & 24 & 1 & 2 & & & 1 & \\
\hline
\end{tabular}

Table 5.88: Water-worn shells from SK2005/095.

\begin{tabular}{ccccc}
\hline & $\begin{array}{c}\text { Conus mozambicus } \\
\text { (whole) }\end{array}$ & $\begin{array}{c}\text { Conus mozambicus } \\
\text { (fragments) }\end{array}$ & Bullia sp. & Unknown \\
\hline Patch A & 5 & 3 & 11 & \\
Patch B & 1 & & 1 & $1^{*}$ \\
\hline
\end{tabular}

* Likely Marginella sp., Volvarina sp. or Prunum capensis.

\subsubsection{SK2005/096}

\section{The site}

This site included multiple patches of archaeological material some $800 \mathrm{~m}$ from the sea and $1.9 \mathrm{~km}$ south of the Buffels River (2941'19.9" S 1703'51.4" E). Patch A was a small, in situ shell midden with two areas of dense shell. A single layer was excavated over an area of $20 \mathrm{~m}^{2}$ and passed through a $3 \mathrm{~mm}$ sieve, while a second, deflated patch (096B) had $13 \mathrm{~m}^{2}$ excavated with a $1.5 \mathrm{~mm}$ sieve employed (Orton \& Halkett 2006). The following dates were obtained:

\begin{tabular}{|c|c|c|c|c|}
\hline Lab. No. & Provenience & Material & ${ }^{14} \mathrm{C}$ date $\mathrm{BP}$ & Calibrated age ( \\
\hline OxA-22974 & Patch A, G28 & \multirow{2}{*}{ Bone (Chersina angulata) } & $611 \pm 23$ & AD 1319-1420 \\
\hline OxA-22975 & Surface & & $654 \pm 23$ & AD 1301-1401 \\
\hline UGAMS-8871 & Patch B, F15 & Marine shell & $2740 \pm 25$ & $648-60 \mathrm{BC}$ \\
\hline
\end{tabular}

Notes:

- OxA-22974 \& OxA-22975 were run on the same sample. 


\section{$\underline{\text { Cultural material }}$}

The Patch A stone artefact assemblage is primarily of quartz and CCS with the vast majority of the former being clear. Both clear quartz backed tools and other non-backed types in CCS are present (Table 5.89). The quartz backed tools are of the types expected of a Group 3 assemblage but their small size and often quite informal shapes made identification difficult at times; the sidescraper resembles a backed bladelet, while the miscellaneous backed scraper could easily be a heavily utilised backed bladelet. One of the CCS sidescrapers also had a notch retouched into its distal end and the CCS tools indicate a Group 1 component (Figure 5.61). Not included in the inventory is a heavily weathered clear quartz flake which must have been collected elsewhere for its novelty value. Its frosted surface was likely the result of much sand-blasting. Three fragments each of ochre and another darker pigment were also present. A large lower grindstone with three parallel grooves was found upside down on the surface of the midden (Figure 5.62). The central and deepest groove measures about $30 \times 170 \mathrm{~mm}$.

Table 5.89: Stone artefacts from SK2005/096A (Group 1/3).

\begin{tabular}{lccccc}
\hline & Quartz & CCS & Silcrete & Quartzite & Sandstone \\
\hline Bipolar core & 2 & 1 & - & - & - \\
Irregular core & 5 & - & - & - & - \\
Radial core & 3 & - & - & - & - \\
Sidescraper & 1 & 4 & - & - & - \\
Thumbnail scraper & - & 2 & - & - & - \\
Miscellaneous backed scraper & 1 & - & - & - & - \\
Backed bladelet & 1 & - & - & - & - \\
Backed bladelet fragment & 1 & - & - & - & - \\
Backed piece fragment & 1 & - & - & - & - \\
Notched piece & - & 1 & - & - & - \\
Miscellaneous retouched piece & - & 1 & - & - & - \\
Bladelet & 8 & 3 & - & - & - \\
Flake & 116 & 42 & 1 & 6 & - \\
Edge-damaged flake & 1 & - & - & - & - \\
Chunk & 45 & 2 & - & 2 & - \\
Chip & 120 & 13 & - & 3 & - \\
Total & $\mathbf{3 0 5}$ & $\mathbf{6 9}$ & $\mathbf{1}$ & $\mathbf{1 1}$ & $\mathbf{0}$ \\
\hline
\end{tabular}




\begin{tabular}{lccccc}
\hline & Quartz & CCS & Silcrete & Quartzite & Sandstone \\
\hline Stone material \% total & $\mathbf{7 9 . 0}$ & $\mathbf{1 7 . 9}$ & $\mathbf{0 . 3}$ & $\mathbf{2 . 9}$ & - \\
Stone material \% formal & $\mathbf{3 8 . 5}$ & $\mathbf{6 1 . 5}$ & - & - & - \\
Lower grindstone & - & - & - & - & 1 \\
Upper grindstone fragment & - & - & - & - & 1 \\
\hline
\end{tabular}

Patch B represents a typical Group 1 assemblage with a high proportion of CCS and retouched artefacts in this material (Table 5.90). The quartz is again almost entirely clear but, importantly, the lack of clear quartz backed tools in Patch B supports the presence of a different phenomenon there. Five fragments of ochre were also found.

Table 5.90: Stone artefacts from SK2005/096B (Group 1).

\begin{tabular}{lcccc}
\hline & Quartz & CCS & Quartzite & Other \\
\hline Single platform core & 1 & - & - & - \\
Sidescraper & 1 & 2 & - & - \\
Thumbnail scraper & - & 2 & - & - \\
Blade & - & 1 & - & - \\
Bladelet & 1 & - & - & - \\
Flake & 33 & 17 & - & - \\
Edge-damaged flake & - & 1 & - & - \\
Chunk & 6 & 5 & 1 & - \\
Chip & 76 & 44 & - & - \\
Total & $\mathbf{1 1 8}$ & $\mathbf{7 2}$ & $\mathbf{1}$ & $\mathbf{0}$ \\
Stone material \% total & $\mathbf{6 1 . 8}$ & $\mathbf{3 7 . 7}$ & $\mathbf{0 . 5}$ & - \\
Stone material \% formal & $\mathbf{2 0 . 0}$ & $\mathbf{8 0 . 0}$ & - & - \\
Hammer stone fragment & - & - & - & 1 \\
\hline
\end{tabular}
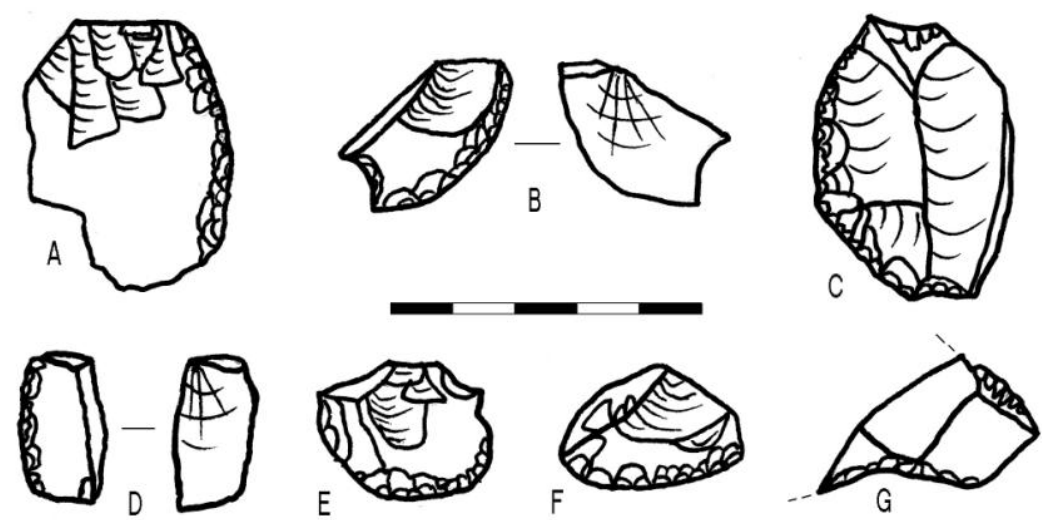

Figure 5.61: Stone artefacts from SK2005/096A. A-D: sidescrapers; E-F: thumbnail scrapers; G: notched piece. All in CCS. Scale in $5 \mathrm{~mm}$ intervals. 


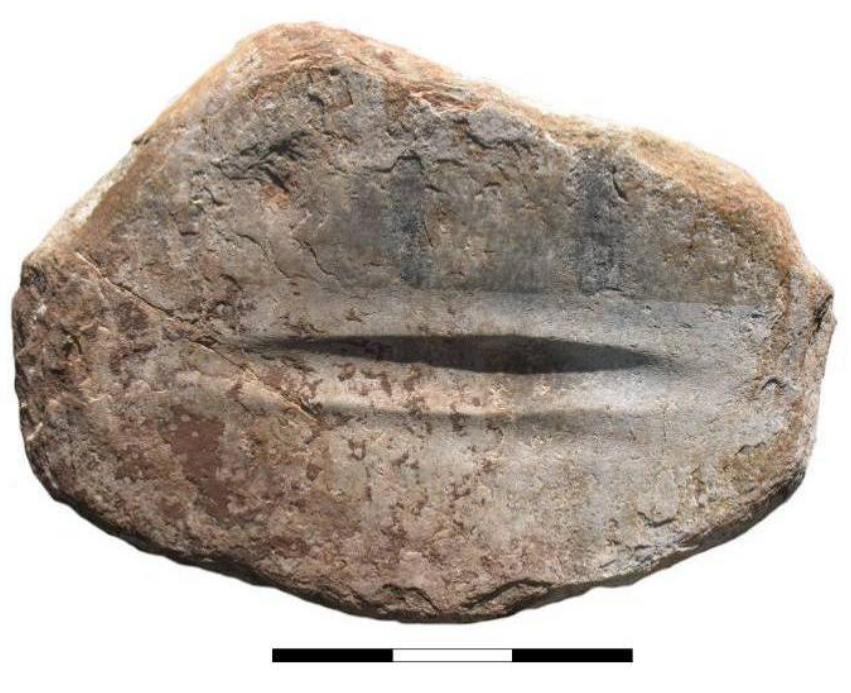

Figure 5.62: The unusually deeply grooved lower grindstone from SK2006/096A. Scale in $50 \mathrm{~mm}$ intervals.

Whether the CCS component at SK2006/096A belongs with the site or is part of a background scatter relating to the far older SK2006/096B cannot be proven. Evidence points both ways (Table 5.91), but given the occurrence of similar assemblages elsewhere the Patch A collection is assumed to be uncontaminated.

Table 5.91: Evidence for the origin of the CCS retouched tools in SK2006/096.

\begin{tabular}{lll}
\hline CCS tools originate from 096A & CCS tools originate from 096B \\
\hline - Greater density of CCS tools in 096A than in & - CCS tools all in northern part of 096A, \\
096B, while total CCS density is lower in 096A. & closest to 096B. \\
- Scrapers, and particularly thumbnail scrapers, & - Notched pieces are absent from other \\
occur in other late sites. & sites dating within the last 2000 years. \\
- Generally large number of CCS artefacts in what & - The same scraper types occur in both \\
would otherwise be a Group 3 assemblage. & assemblages. \\
\hline
\end{tabular}

A single fragment of an ostrich eggshell flask mouth, one engraved fragment and two ostrich eggshell beads, one large and one medium, were found in Patch A (Table 5.92). The engraved fragment has just one line across it. Eight probable Bullia pendants were found in five contiguous squares (Figure 5.63). All are water-worn and it is not possible to tell whether the holes were formed as a result of natural degradation in the ocean or if they are anthropogenic. All are well worn and some seem to display slightly greater wear at the end from which they would hang had the holes been threaded. Just one small bead (3.62 $\mathrm{mm}$ diameter, $1.56 \mathrm{~mm}$ aperture, $1.45 \mathrm{~mm}$ thickness) was found in Patch B. 
Table 5.92: Summary statistics for finished ostrich eggshell beads from SK2005/096A.

\begin{tabular}{|c|c|c|c|c|}
\hline & & Outside diameter (mm) & Aperture diameter (mm) & Thickness (mm) \\
\hline \multirow{4}{*}{$n=2$} & Mean & 6.04 & 1.81 & 1.68 \\
\hline & Std Deviation & 0.83 & 0.28 & 0.00 \\
\hline & Minimum & 5.45 & 1.61 & 1.68 \\
\hline & Maximum & 6.62 & 2.01 & 1.68 \\
\hline
\end{tabular}

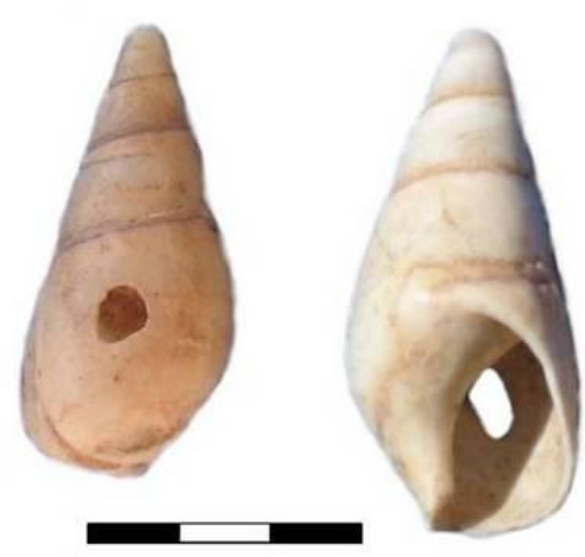

Figure 5.63: Two perforated Bullia shells from SK2005/096A. Scale in $5 \mathrm{~mm}$ intervals.

A collection of ten potsherds $(73.6 \mathrm{~g})$ was found in Patch A. All are body sherds with nine, all from the same square, likely originating from a single vessel. One seems to be from the neck area and the other eight all have a thick residue adhering to their inner surfaces. These eight refit to form two sets. The tenth sherd has a very smooth surface that may have been burnished. The mean wall thickness was $5.92 \pm 0.47 \mathrm{~mm}$.

\subsubsection{SK2006/006}

\section{The site}

Three patches of shell were excavated surrounding a dune $480 \mathrm{~m}$ from the coast and

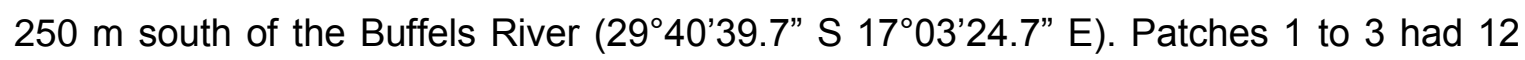
$\mathrm{m}^{2}, 13 \mathrm{~m}^{2}$ and $8 \mathrm{~m}^{2}$ excavated from them respectively, but at Patch 2 the deeper levels were sampled over a smaller area. All three had a shell midden just beneath the surface, but Patch 2 had a second one further down. A $1.5 \mathrm{~mm}$ sieve was used throughout 
(Halkett \& Dewar 2007). The two middens at Patch 2 are referred to as Upper and Lower. Differential abrasion of ostrich eggshell (fragments and beads) and stone artefacts throughout the site suggests the possibility of mixing of different aged assemblages, but the dating supports one general period of occupation. The following dates were obtained:

\begin{tabular}{|c|c|c|c|c|}
\hline Lab. No. & $\underline{\text { Provenience }}$ & Material & ${ }^{14} \mathrm{C}$ date $\mathrm{BP}$ & Calibrated age $(95.4 \%)$ \\
\hline OxA-24077 & $\begin{array}{l}\text { Patch 2, Upper, } \\
\text { S39 Lower } 2\end{array}$ & Charcoal (sp. unknown) & $377 \pm 24$ & AD 1465-1630 \\
\hline OxA-25329 & $\begin{array}{l}\text { Patch 2, Lower, } \\
\text { S39 Lower } 2 A\end{array}$ & Charcoal (sp. unknown) & $401 \pm 25$ & AD1455-1625 \\
\hline OxA-24076 & Patch 3, B53 & Charcoal (sp. unknown) & $425 \pm 24$ & AD 1446-1621 \\
\hline
\end{tabular}

\section{$\underline{\text { Cultural material }}$}

Patch 1 yielded a small, undiagnostic assemblage (Table 5.93) possibly ascribable to Group 1. Patch 2 contains a larger assemblage including both scrapers and backed tools (Tables 5.94-5.95). Despite the dating, there were enough differences in the two layers to support retention of two assemblages. Although numbers are small, it seems that CCS backed tools are more frequent in Lower. The miscellaneous backed scraper in Upper is unusual and essentially a truncated scraper. In Lower the borer is unconventional being rather flat and having a truncation opposite the tip (Figure 5.64). Local silcrete is typically very coarse-grained and seldom flaked. All the silcrete in Patch 2 , however, is very finegrained, resembling that from PN2009/001. Both layers have Group 1 components but the quartz backed tools are all clear suggesting Group 3 contributions as well. Pigment occurs on Patch 2 with specularite (one fragment in Upper), mica (three fragments in Lower), ochre (one fragment in Upper and nine on Lower) and other dark pigment (one fragment in Upper) present. The Patch 3 assemblage seems more characteristic of Group 1 (Table 5.96). Although scraper-dominated, its tools are atypical. The side 
scraper's retouched edge tends towards backing in one part and the MRP has both scraper and denticulate retouch opposing a backed edge (Figure 5.65).

Table 5.93: Stone artefacts from SK2006/006, Patch 1 (Group 1).

\begin{tabular}{lccc}
\hline & Quartz & CCS & Quartzite \\
\hline Bipolar core & 1 & - & - \\
Irregular core & 1 & - & - \\
Bladelet & 1 & - & - \\
Flake & 17 & 3 & 1 \\
Edge-damaged flake & - & 1 & - \\
Chunk & 6 & - & - \\
Chip & 6 & 1 & - \\
Total & $\mathbf{3 2}$ & $\mathbf{5}$ & $\mathbf{1}$ \\
Stone material \% total & $\mathbf{8 4 . 2}$ & $\mathbf{1 3 . 2}$ & $\mathbf{2 . 6}$ \\
Stone material \% formal & - & - & - \\
Upper grindstone & - & - & 1 \\
\hline
\end{tabular}

Table 5.94: Stone artefacts from SK2006/006, Patch 2 Upper (Group 1/3).

\begin{tabular}{lccccc}
\hline & Quartz & CCS & Silcrete & Quartzite & Other \\
\hline Bipolar core & 2 & 1 & - & - & - \\
Sidescraper & - & 1 & - & - & - \\
Thumbnail scraper & - & 1 & - & - & - \\
Miscellaneous backed scraper & - & 1 & - & - & - \\
Backed piece fragment & 2 & - & - & - & - \\
Bladelet & 2 & - & - & 1 & - \\
Flake & 54 & 21 & 4 & 8 & - \\
Edge-damaged flake & - & 1 & - & - & - \\
Chunk & 13 & 1 & - & 3 & - \\
Chip & 88 & 11 & - & 1 & - \\
Total & $\mathbf{1 6 1}$ & $\mathbf{3 8}$ & $\mathbf{4}$ & $\mathbf{1 3}$ & - \\
Stone material \% total & $\mathbf{7 4 . 5}$ & $\mathbf{1 7 . 6}$ & $\mathbf{1 . 9}$ & $\mathbf{6 . 0}$ & - \\
Stone material \% formal & $\mathbf{4 0 . 0}$ & $\mathbf{6 0 . 0}$ & - & - & - \\
Hammer stone/upper grindstone & - & - & - & - & 1 \\
\hline
\end{tabular}

Table 5.95: Stone artefacts from SK2006/006, Patch 2 Lower (Group 1/3).

\begin{tabular}{lccccc}
\hline & Quartz & CCS & Silcrete & Quartzite & Other \\
\hline Single platform core & 1 & - & - & - & - \\
Irregular core & - & - & - & 1 & - \\
Double endscraper & - & 1 & - & - & - \\
\hline
\end{tabular}




\begin{tabular}{lccccc}
\hline & Quartz & CCS & Silcrete & Quartzite & Other \\
\hline Thumbnail scraper & - & 1 & - & - & - \\
Scraper fragment & - & 1 & - & - & - \\
Backed bladelet & 1 & 1 & - & - & - \\
Backed point & 1 & - & - & - & - \\
Borer & - & 1 & - & - & - \\
Miscellaneous backed piece & - & 1 & - & - & - \\
Backed piece fragment & 1 & - & - & - & - \\
Notched piece & - & 1 & - & - & - \\
Blade & - & 1 & - & - & - \\
Bladelet & 5 & 5 & - & - & - \\
Flake & 38 & 41 & 3 & 5 & - \\
Edge-damaged flake & - & 2 & - & - & - \\
Chunk & 15 & 3 & - & 1 & - \\
Chip & 57 & 21 & - & 1 & - \\
Total & $\mathbf{1 1 9}$ & $\mathbf{8 0}$ & $\mathbf{3}$ & $\mathbf{8}$ & $\mathbf{0}$ \\
Stone material \% total & $\mathbf{5 6 . 3}$ & $\mathbf{3 8 . 5}$ & $\mathbf{1 . 4}$ & $\mathbf{3 . 8}$ & - \\
Stone material \% formal & $\mathbf{3 0 . 0}$ & $\mathbf{7 0 . 0}$ & - & - & - \\
Lower grindstone fragment & - & - & - & 1 & - \\
Hammer stone/upper grindstone fragment & - & - & - & 1 & - \\
\hline
\end{tabular}

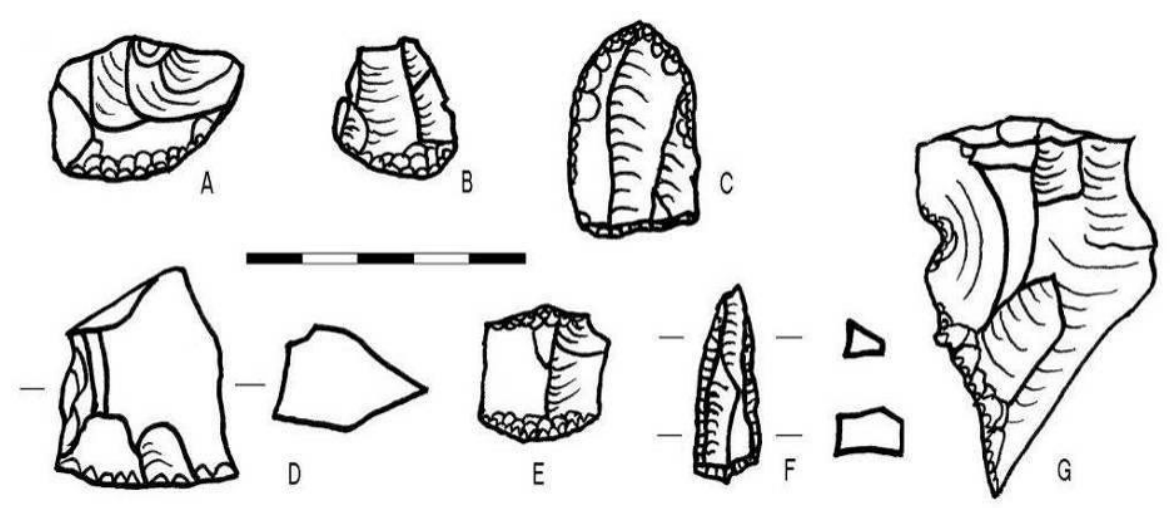

Figure 5.64: Stone artefacts from SK2006/006 Patch 2 Upper (A-C) and Lower (D-G). A: sidescraper; B, D: thumbnail scrapers; C: miscellaneous backed scraper; E: double endscraper; F: borer; G: notched piece. All in CCS. Scale in $5 \mathrm{~mm}$ intervals.

Table 5.96: Stone artefacts from SK2006/006, Patch 3 (Group 1).

\begin{tabular}{lccccc}
\hline & Quartz & CCS & Silcrete & Quartzite & Other \\
\hline Sidescraper & - & 1 & - & - & - \\
Scraper fragment & - & 1 & - & - & - \\
Miscellaneous retouched piece & - & 1 & - & - & - \\
Bladelet & 1 & 2 & - & - & - \\
\hline
\end{tabular}




\begin{tabular}{lccccc}
\hline & Quartz & CCS & Silcrete & Quartzite & Other \\
\hline Flake & 17 & 4 & 1 & 2 & - \\
Edge-damaged flake & - & 2 & - & - & - \\
Chunk & 2 & 1 & - & - & - \\
Chip & 12 & 1 & - & 1 & - \\
Total & $\mathbf{3 2}$ & $\mathbf{1 3}$ & $\mathbf{1}$ & $\mathbf{3}$ & $\mathbf{0}$ \\
Stone material \% total & $\mathbf{6 5 . 3}$ & $\mathbf{2 6 . 5}$ & $\mathbf{2 . 0}$ & $\mathbf{6 . 1}$ & - \\
Stone material \% formal & - & $\mathbf{1 0 0 . 0}$ & - & - & - \\
\hline
\end{tabular}
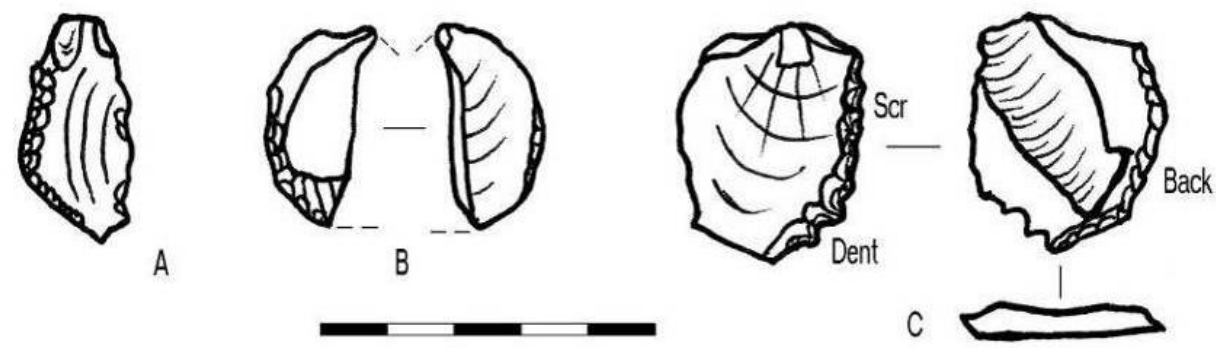

Figure 5.65: Stone artefacts from SK2006/006 Patch 3. A: sidescraper; B: scraper fragment; C: miscellaneous retouched piece with scraper, denticulate and backing retouch all present as indicated. All in CCS. Scale in $5 \mathrm{~mm}$ intervals.

Patches 1 and 2 contained ostrich eggshell beads (Tables 5.97). On the former there were just three - two large and one small. In Patch 2 Upper the very large $(8.20 \mathrm{~mm})$ bead may well be intrusive since the rest are all medium and small (the second largest bead is $5.31 \mathrm{~mm}$ in diameter). With the largest bead excluded the mean drops to $4.69 \pm 0.58 \mathrm{~mm}$. The beads from Lower are more homogenous $(\mathrm{SD}=0.55 \mathrm{~mm})$ with nine small and only two medium beads. Also on Patch 2 Upper was a single weathered fragment of engraved ostrich eggshell with several parallel lines on it. A single flask mouth fragment with a diameter of approximately $20 \mathrm{~mm}$ came from Patch 3.

Table 5.97: Summary statistics for finished ostrich eggshell beads from SK2006/006.

\begin{tabular}{lllll}
\hline $\begin{array}{l}\text { Patch / } \\
\text { Layer }\end{array}$ & Outside diameter $(\mathrm{mm})$ & Aperture diameter $(\mathrm{mm})$ & Thickness $(\mathrm{mm})$ \\
\hline \multirow{4}{*}{$1(\mathrm{n}=3)$} & Mean & 6.07 & 1.84 & 1.68 \\
& Std Deviation & 1.63 & 0.28 & 0.10 \\
& Minimum & 4.25 & 1.52 & 1.58 \\
& Maximum & 7.40 & 2.02 & 1.78 \\
\hline 2 Upper & Mean & 5.19 & 1.67 & 1.76 \\
\hline
\end{tabular}




\begin{tabular}{|c|c|c|c|c|}
\hline $\begin{array}{l}\text { Patch / } \\
\text { Layer }\end{array}$ & & Outside diameter (mm) & Aperture diameter $(\mathrm{mm})$ & Thickness (mm) \\
\hline \multirow[t]{4}{*}{$(n=7)$} & Std Deviation & 1.43 & 0.44 & 0.14 \\
\hline & Minimum & 3.68 & 1.16 & 1.53 \\
\hline & Maximum & 8.20 & 2.53 & 1.95 \\
\hline & Mean & 4.32 & 1.52 & 1.62 \\
\hline 2 Lower & Std Deviation & 0.55 & 0.26 & 1.16 \\
\hline \multirow[t]{2}{*}{$(n=11)$} & Minimum & 3.54 & 1.10 & 1.33 \\
\hline & Maximum & 5.09 & 1.98 & 1.87 \\
\hline
\end{tabular}

A single undiagnostic potsherd (weight $=1.5 \mathrm{~g}$, thickness $=5.61 \mathrm{~mm}$ ) was present on Patch 1. The Upper layer of Patch 2 produced 12 sherds weighing $68.9 \mathrm{~g}$ and with a mean thickness of $6.12 \pm 0.37 \mathrm{~mm}$. Four refit to produce a horizontally-pierced lug (Figure 5.66), while four more clearly belong to the same pot. These eight were in the bottom part of the layer, while the other four sherds from above were somewhat weathered. No pottery occurred in Lower. Patch 3 had eight plain sherds weighing $26.4 \mathrm{~g}$ and with a mean thickness of $5.34 \pm 0.31 \mathrm{~mm}$.

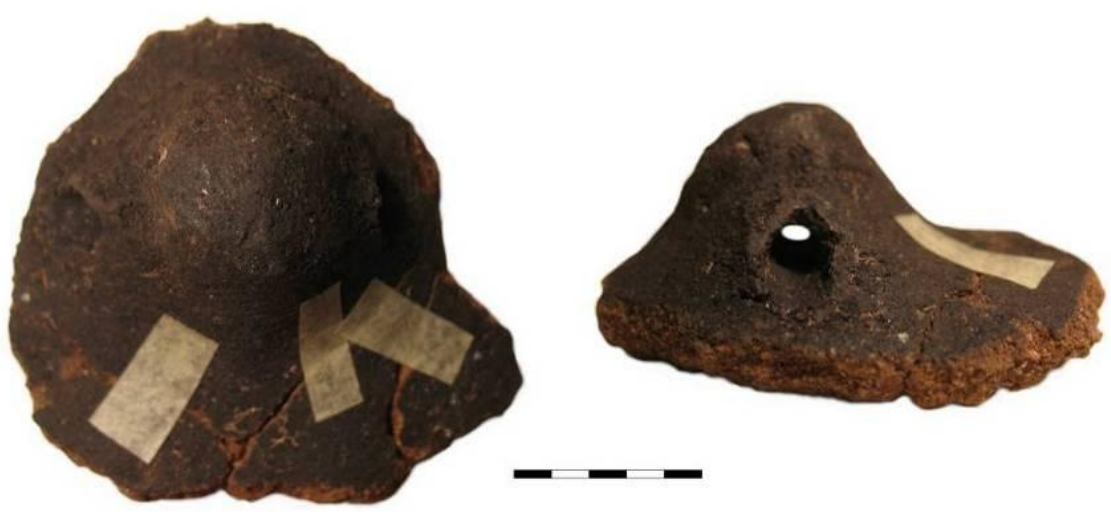

Figure 5.66: The pot lug from SK2006/006, Patch 2, Upper. Scale in $5 \mathrm{~mm}$ intervals.

\subsubsection{TP2004/003}

\section{The site}

This large shell scatter lay in a depression along the western side of a low, vegetated dune ridge $1.4 \mathrm{~km}$ from the coast (S 29²9'52.7" E 1659'55.8"). The site was well 
deflated and, except for the stone artefacts, all material was in very poor condition. Various patches were sampled over a total area of $9 \mathrm{~m}^{2}$ (Orton \& Halkett 2005). The following date was obtained:

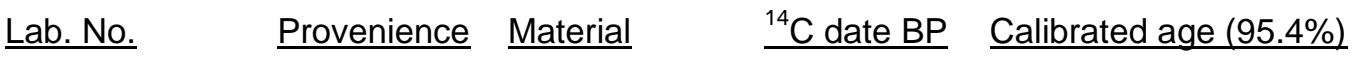

UGAMS-8424 S20 Marine shell $2230 \pm 25 \quad$ AD 52-539

\section{$\underline{\text { Cultural material }}$}

The small assemblage is exclusively of clear quartz and includes two backed tools (Table 5.98). The site is thus in Group 3. Two engraved ostrich eggshell fragments with grid-type designs on them were also recovered (Figure 5.67).

Table 5.98: Stone artefacts from TP2004/003 (Group 3).

\begin{tabular}{lc}
\hline & Quartz \\
\hline Backed flake & 1 \\
Backed bladelet & 1 \\
Bladelet & 1 \\
Flake & 26 \\
Edge-damaged flake & 1 \\
Chunk & 3 \\
Chip & 20 \\
Total & $\mathbf{5 3}$ \\
Stone material \% total & $\mathbf{1 0 0 . 0}$ \\
Stone material \% formal & $\mathbf{1 0 0 . 0}$ \\
\hline
\end{tabular}




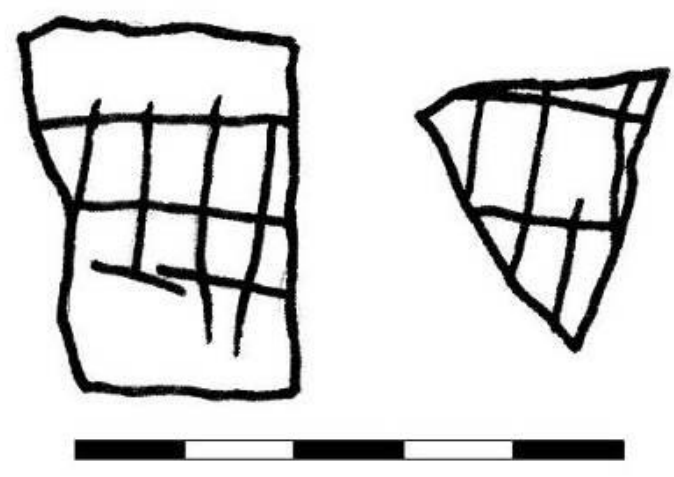

Figure 5.67: The two engraved ostrich eggshell fragments from TP2004/003. Scale in $5 \mathrm{~mm}$ intervals.

\subsubsection{TP2004/014}

\section{The site}

This site was $900 \mathrm{~m}$ inland in a gently undulating area (29²9'06.7" S 1659'33.8” E). Various scatters were evident and sampled with two containing pottery. Only Area A is of concern here and this lacked pottery. Two spits were removed, the first from $6 \mathrm{~m}^{2}$ and the second from $2 \mathrm{~m}^{2}$. Most artefacts (79.9\%) were located between 8 and $15 \mathrm{~cm}$ below the surface in the lower spit. Unfortunately the site was only briefly sampled and, since mining did not proceed there, no further excavation was carried out. The deposits were screened on a $1.5 \mathrm{~mm}$ sieve (Orton \& Halkett 2005). The following date was obtained:

\begin{tabular}{|c|c|c|c|c|}
\hline Lab. No. & Provenience & Material & ${ }^{14} \mathrm{C}$ date BP & Calibrated age (95.4\%) \\
\hline UGAMS-8425 & H44 Lower & Marine shell & $3430 \pm 25$ & $1417-908 \mathrm{BC}$ \\
\hline
\end{tabular}

\section{$\underline{\text { Cultural material }}$}

Aside from a single broken ostrich eggshell bead in stage IVb (Orton 2008d) the only cultural material in this excavation was a rich lithic assemblage. Although some of the lithics came from above the main layer it is likely that they are of broadly similar age and are dispersed through bioturbation. The stone artefacts are presented in Table 5.99 and the types are typical of Group 1 and include a rare truncated bladelet (Figure 5.68). 
Table 5.99: Stone artefacts from TP2004/014 (Group 1).

\begin{tabular}{lcc}
\hline & Quartz & CCS \\
\hline Bipolar core & - & - \\
Single platform core & 2 & 2 \\
Edge-damaged single platform core & - & 1 \\
Irregular core & 4 & 1 \\
Backed scraper & - & 2 \\
Sidescraper & - & 1 \\
Miscellaneous scraper & - & 1 \\
Backed bladelet & - & 2 \\
Curve-backed bladelet & - & 1 \\
Truncated flake & - & 1 \\
Segment & - & 1 \\
Backed piece fragment & - & 1 \\
Notched piece & - & 1 \\
Miscellaneous retouched piece & 1 & 2 \\
Blade & - & 1 \\
Edge-damaged blade & - & 1 \\
Bladelet & - & 1 \\
Flake & 36 & 20 \\
Edge-damaged flake & 2 & 2 \\
Chunk & 24 & 7 \\
Chip & 134 & 32 \\
Total & $\mathbf{2 0 3}$ & $\mathbf{8 1}$ \\
Stone material \% total & $\mathbf{7 1 . 5}$ & $\mathbf{2 8 . 5}$ \\
\hline & $\mathbf{9 3 . 3}$ \\
\hline
\end{tabular}
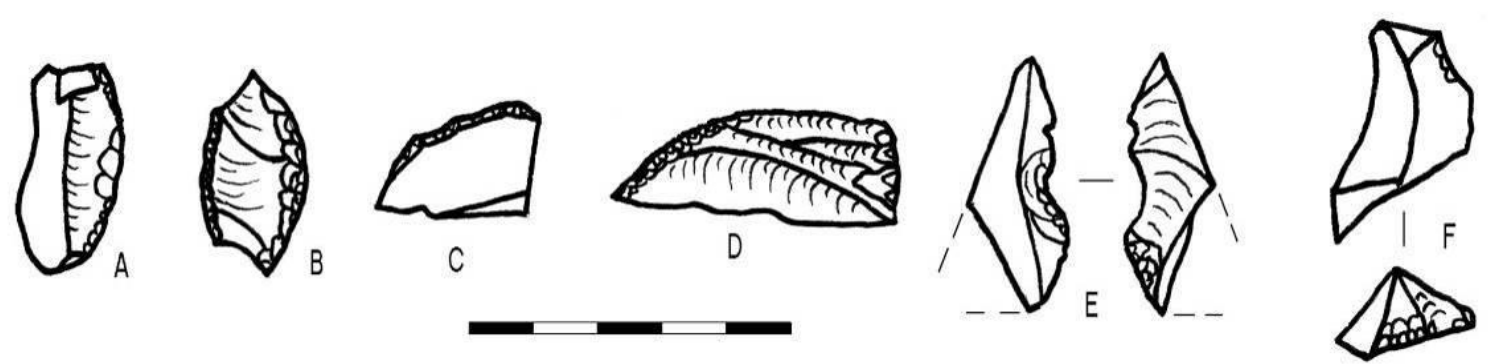

Figure 5.68: Stone artefacts from TP2004/014. A: sidescraper; B: backed scraper; C: segment; D: curve-backed bladelet; E: notched piece; F: truncated bladelet. All in CCS. Scale in $5 \mathrm{~mm}$ intervals. 


\subsubsection{Assemblages described elsewhere}

Here I very briefly describe the sites incorporated within my Sandveld cultural sequence but published elsewhere. With two exceptions, detailed data are omitted, since these are available in the relevant publications. Although other categories of finds occur, I refer only to stone artefacts, ostrich eggshell beads and pottery as it is these three that are of concern to my research. Note that for the sake of standardisation all radiocarbon dates have been recalibrated and their full details are presented in Appendix 2.

\section{$\underline{\text { DP2004/014 }}$}

This in situ shell midden dates to AD 1287-1666 (GX-32060; Dewar 2008). A large, mostly informal stone artefact collection was recovered. Most was quartz with a very small proportion of it clear. The latter included one backed piece fragment, while two backed bladelets in clear quartz were found in a disturbed area. The assemblage thus includes Group 2 and Group 3 components. Since spatial data are not important here, material from the disturbed area is included and the full stone data set is presented in Table 5.100. Ostrich eggshell bead manufacturing took place on site and the whole beads were variable in external diameter ranging from 4.40 to $7.90 \mathrm{~mm}$ and with a mean diameter of $5.50 \pm 0.8 \mathrm{~mm}$. Pottery was rare with just one plain rim sherd found.

Table 5.100: Stone artefacts from DP2004/014 (Group 2/3).

\begin{tabular}{lcccc}
\hline & Quartz & CCS & Quartzite & Other \\
\hline Bipolar core & 15 & - & - & - \\
Single platform core & 1 & - & 1 & - \\
Irregular core & 5 & - & - & - \\
Backed bladelet & 2 & - & - & - \\
Backed piece fragment & 1 & - & - & - \\
Blade & 2 & - & - & - \\
Bladelet & 7 & - & - & - \\
Flake & 385 & 2 & 44 & - \\
Chunk & 217 & - & 16 & - \\
\hline
\end{tabular}




\begin{tabular}{lcccc}
\hline Chip & 211 & - & 5 & - \\
Total & 846 & 2 & 66 & 0 \\
Stone material \% total & 92.6 & 0.2 & 7.2 & - \\
Stone material \% formal & 100.0 & - & - & - \\
Lower grindstone fragment & - & - & 1 & - \\
Upper grindstone fragment & - & - & - & 3 \\
Upper grindstone/hammer stone & - & - & - & 6 \\
Upper grindstone/hammer stone fragment & - & - & - & 2 \\
Hammer stone & - & - & - & 1 \\
\hline
\end{tabular}

\section{$\underline{\mathrm{KN} 6-3 \mathrm{C}(\mathrm{KN} 2001 / 008 \mathrm{C})}$}

This large site has two contemporary middens, North and South, but with an older occupation beneath the North Midden and extending eastwards into an unexcavated area. The levels are here termed Upper and Lower. Three dates were obtained by Dewar (2008) and a fourth has been added (see below). A rich and unusual stone artefact collection was recovered and, owing to errors in Dewar (2008, table 9.2), the details are presented again here (Table 5.101-5.102). The assemblage is remarkable and unique along this coastline for the many borers present, though these tools are reported from Elizabeth Bay on the Namibian coastline (Rudner \& Grattan-Bellew 1964). A variety of scrapers and other backed artefacts also occur. There were 40 ostrich eggshell beads, all in the upper layer, with a mean external diameter of $4.20 \pm 0.5 \mathrm{~mm}$ (Dewar 2008). The vast majority are small. Engraved ostrich eggshell is also present in both levels. The dates are as follows:

\begin{tabular}{|c|c|c|c|c|c|}
\hline Lab. No. & Midden & $\underline{\text { Provenience }}$ & Material & ${ }^{14} \mathrm{C}$ date $\mathrm{BP}$ & Calibrated age $(95.4 \%)$ \\
\hline Pta-9335 & North & M18 SMU & Marine shell & $3720 \pm 45$ & $1813-1272 \mathrm{BC}$ \\
\hline Pta-9325 & North & M18 Surf 1 & Marine shell & $3740 \pm 60$ & $1862-1293$ BC \\
\hline Pta-9316 & North & M18 Surf 3 & Marine shell & $4630 \pm 70$ & $3036-2401 \mathrm{BC}$ \\
\hline OxA-22970 & South & G16 Surface & $\begin{array}{l}\text { Bone (Chersina } \\
\text { angulata) }\end{array}$ & $3355 \pm 28$ & $1681-1498$ BC \\
\hline
\end{tabular}

Notes:

- Pta-9335, Pta-9325 \& Pta-9316 obtained by Dewar (2008) all from the North Midden.

- Pta-9335 was incorrectly reported with M18 SMU being the correct provenience.

- Given the overlap between bone and shell dates, OxA-22970 is used for the age of 'Upper'. 
Table 5.101: Stone artefacts from KN2001/008C, Upper (Group 1).

\begin{tabular}{|c|c|c|c|c|c|}
\hline & Quartz & $\operatorname{ccs}$ & Quartzite & Sandstone & Other \\
\hline Bipolar core & 12 & 10 & & & \\
\hline Edge-damaged bipolar core & - & 2 & & & \\
\hline Single platform core & 3 & 1 & & & \\
\hline Irregular core & $24^{*}$ & 4 & & & \\
\hline Backed scraper & - & 7 & & & \\
\hline Sidescraper & - & 8 & & & \\
\hline Double sidescraper & - & 1 & & & \\
\hline Thumbnail scraper & - & 5 & & & \\
\hline Miscellaneous backed scraper & 1 & 5 & & & \\
\hline Miscellaneous scraper & 1 & 4 & & & \\
\hline Backed flake & 1 & 4 & & & \\
\hline Backed bladelet & 1 & 10 & - & - & - \\
\hline Backed point & 3 & 3 & - & - & - \\
\hline Backed bladelet fragment & - & 1 & - & - & - \\
\hline Borer & - & 27 & - & - & - \\
\hline Segment & 4 & 2 & - & - & - \\
\hline Miscellaneous backed piece & 2 & 15 & - & - & - \\
\hline Backed piece fragment & 2 & 15 & - & - & - \\
\hline Notched piece & - & 1 & - & - & - \\
\hline Miscellaneous retouched piece & 2 & 13 & - & - & - \\
\hline Blade & 6 & 2 & - & - & - \\
\hline Bladelet & 26 & 13 & - & - & - \\
\hline Edge-damaged bladelet & 2 & 1 & - & - & - \\
\hline Flake & 544 & 252 & 3 & - & 8 \\
\hline Edge-damaged flake & 22 & 20 & - & - & - \\
\hline Chunk & 322 & 99 & 7 & - & 3 \\
\hline Edge-damaged chunk & 2 & 6 & - & - & - \\
\hline Chip & 1623 & 502 & 4 & - & 4 \\
\hline Edge-damaged chip & 2 & 3 & - & - & - \\
\hline Total & 2605 & 1036 & 14 & 0 & 15 \\
\hline Stone material \% total & 71.0 & 28.2 & 0.4 & - & 0.4 \\
\hline Stone material \% formal & 12.3 & 87.7 & - & - & - \\
\hline Upper grindstone & 1 & - & - & - & 1 \\
\hline Hammer stone/upper grindstone & - & - & 1 & 1 & 1 \\
\hline Hammer stone & - & - & 1 & 1 & 3 \\
\hline Lower grindstone & - & - & - & 2 & 1 \\
\hline
\end{tabular}

* One irregular core is also the upper grindstone 
Table 5.102: Stone artefacts from KN2001/008C, Lower (Group 1).

\begin{tabular}{lccccc}
\hline & Quartz & CCS & Quartzite & Sandstone & Other \\
\hline Single platform core & 1 & - & - & - & - \\
Irregular core & 1 & - & - & - & - \\
Sidescraper & - & 1 & - & - & - \\
Thumbnail scraper & - & 1 & - & - & - \\
Miscellaneous scraper & - & 2 & - & - & - \\
Baked flake & - & 1 & - & - & - \\
Backed bladelet & 1 & - & - & - & - \\
Miscellaneous backed piece & - & 4 & - & - & - \\
Backed piece fragment & - & 1 & - & - & - \\
Flake & 24 & 17 & - & 1 & - \\
Edge-damaged flake & - & 1 & - & - & - \\
Chunk & 19 & 5 & - & - & - \\
Chip & 121 & 125 & - & - & - \\
Total & $\mathbf{1 6 7}$ & $\mathbf{1 5 8}$ & $\mathbf{0}$ & $\mathbf{1}$ & $\mathbf{0}$ \\
Stone material \% total & $\mathbf{5 1 . 2}$ & $\mathbf{4 8 . 5}$ & - & $\mathbf{0 . 3}$ & - \\
Stone material \% formal & $\mathbf{9 . 1}$ & $\mathbf{9 0 . 9}$ & - & - & - \\
\hline
\end{tabular}

\section{$\underline{\text { KV502 (KV2001/011) }}$}

This deflated shell midden yielded an age of 826-339 BC (Pta-9306; Dewar 2008). It has a collection of stone artefacts based primarily on milky quartz, but including fine-grained materials as well, from which most of the retouched tools are made. Silcrete is included, with both very fine-grained and coarser material present. Retouched artefacts are on both CCS and fine silcrete and most are scrapers. The assemblage falls within Group 1. Ostrich eggshell beads and pottery are absent.

\section{Rooiwal Midden (LK2001/003)}

This small midden lay near the Spoeg River estuary atop a small but high dune field on the north edge of Rooiwal Bay. It was dated to AD 1196-1581 (Pta-8910) and revealed an assemblage of clear quartz artefacts belonging to Group 3. The 21 ostrich eggshell beads are mostly medium in size, but range from 4.5 to $7.95 \mathrm{~mm}$ in external diameter with a mean of $5.70 \pm 1.01 \mathrm{~mm}$. Twenty-one small potsherds $(18.8 \mathrm{~g})$ suggest two pots. 
Although the eight rims sherds are very small, they appear to be undecorated (Orton et al. 2005).

\section{$\underline{\text { Rooiwal Hollow (LK2001/004) }}$}

This site lay in a large deflation hollow at the foot of the dune field containing Rooiwal Midden. Dates from two areas suggest ages of 331 BC-AD 180 (Pta-8915) and 156 BCAD 410 (Pta-8909). The flaked stone assemblage is of clear quartz with backed tools (Group 3) and the eight ostrich eggshell beads are all small, their mean external diameter being $3.77 \pm 0.37 \mathrm{~mm}$. Pottery was absent (Orton et al. 2005).

\section{$\underline{\text { LK2004/011 }}$}

This midden was found partially deflated and partially in situ and two radiocarbon dates from the latter part suggested an age of AD 1241-1481 (GX-32057, GX-32059; Dewar 2008). All quartz was clear, prompting assignation to Group 3. However, the assemblage is somewhat atypical, since only one of the three retouched pieces was backed, and quartzite and a peculiar dark-coloured CCS comprised a larger than usual proportion of the materials. Three medium-sized ostrich eggshell beads yielded a mean diameter of $5.3 \pm 0.17 \mathrm{~mm}$ (calculated from Dewar 2008).

\section{$\underline{\mathrm{MB} 2005 / 005 \mathrm{~A}}$}

This in situ shell midden yielded two strongly overlapping radiocarbon ages calibrating to 383 BC-AD 118 (GX-32524, GX-32525; Dewar 2008). The very large assemblage of clear quartz artefacts included many retouched items, both scrapers and backed tools (Group 3). A small collection of CCS also included both tool types. Five ostrich eggshell beads, mostly small, had a mean external diameter of $3.30 \pm 1.10 \mathrm{~mm}$ and there was no pottery. 


\section{MB2005/005B}

This site was largely deflated but part was preserved in situ beneath MB2005/005A. A single date from the in situ midden provided an age of 3932-3383 BC (GX-32526; Dewar 2008). The stone artefacts included mostly quartz, but some CCS was also present. The majority of backed tools were in quartz and scrapers were mostly in CCS. The assemblage is an atypical Group 1 assemblage. The collection of 38 ostrich eggshell beads was mostly small with a mean external diameter of $4.20 \pm 0.60 \mathrm{~mm}$.

\section{SK400 (SK2001/026)}

This midden contained a rich assemblage of springbok (Antidorcas marsupialis; $\mathrm{MNI}=123$ ) bone that was interpreted to represent a mass-kill site (Dewar 2008; Dewar et al. 2006). Two almost identical dates place the site at AD 1438-1627 (Pta 9099, Pta9105). The stone assemblage is highly informal, based largely on milky quartz, and has no retouched items (Group 2). The 182 ostrich eggshell beads were mostly large with a mean external diameter of $7.40 \pm 1.4 \mathrm{~mm}$, but the range included beads from 2.90 to $10.50 \mathrm{~mm}$. Pottery was abundant and included four plain rims and one with a double row of impressions. A spout fragment was also present.

\section{$\underline{\text { TP2004/004 }}$}

This site had two spatially discrete middens on it that were assumed to be related. A date from the northern midden, from which almost all the cultural material originates, places the site at AD 1300-1680 (GX-32058; Dewar 2008). Although the quartz in the tiny assemblage was all clear, the very low artefact density and its informal nature prompted a Group 2 assignation. One unfinished ostrich eggshell bead was found. The primary significance of this site is the large pottery assemblage which includes two plain rims and seven rims with elongated impressions below the lip. 


\subsection{Hardeveld assemblages}

Two newly documented sites from opposite sides of the Groot Goeraap River in the southernmost Hardeveld are presented here. The surroundings are really more typical of the rolling hills of the inland Sandveld, but the valley has been carved into the underlying hard geology to reveal the granite.

\subsubsection{KK002}

\section{$\underline{\text { The site }}$}

This shallow rock shelter was located on the northern side of a small rocky valley in the south-western extremity of the Hardeveld, $17 \mathrm{~km}$ from the sea (31'14'32.9" $\mathrm{S}$ $18^{\circ} 03^{\prime} 05.8^{\prime \prime} \mathrm{E}$; Figure 3.4). An excavation of $7.5 \mathrm{~m}^{2}$ was conducted (Figure 5.69 ) and the in situ deposits, including a layer of bedding grass, were found to vary from 0 to $9 \mathrm{~cm}$ deep over bedrock. Towards the front of the shelter poorer contexts were encountered with a depth of $21 \mathrm{~cm}$ where the bedrock dips gently downwards (Figure 5.70). It appears that the shelter was largely empty prior to the final occupation, but there may have been residual deposits on the bedrock when the grass layer was introduced. The shelter is south-facing and overlooks a small river valley (Figure 5.71). The following dates were obtained:

\begin{tabular}{|c|c|c|c|c|}
\hline Lab. No. & Provenience & Material & ${ }^{14} \mathrm{C}$ date $\mathrm{BP}$ & Calibrated age (95.4\%) \\
\hline OxA-25346 & $\begin{array}{l}\text { I11 NW L2/4 } \\
\text { interface }\end{array}$ & Bone (Chersina angulata) & $701 \pm 23$ & AD 1285-1390 \\
\hline OxA-25347 & I11 NW L4B & Bone (Chersina angulata) & $334 \pm 23$ & AD 1503-1647 \\
\hline OxA-25348 & G10 NE L6 & Bone (Chersina angulata) & $175 \pm 23$ & AD 1671-1954 \\
\hline OxA-25349 & I12 SE L5B & Bone (Chersina angulata) & $1462 \pm 24$ & AD 597-666 \\
\hline OxA-25350 & I8 NE L3 & Bone (Chersina angulata) & $932 \pm 24$ & AD 1046-1218 \\
\hline OxA-25351 & I8 NE L3C & Bone (Chersina angulata) & $644 \pm 23$ & AD 1305-1404 \\
\hline
\end{tabular}


Using the dates and finds it is possible to envisage an occupation sequence. Rare retouched tools typical of the mid-Holocene were present in levels close to bedrock and suggest some mid-Holocene occupation; this deposit was probably washed out of the shelter during a period of non-occupation. A mid-first millennium AD occupation is represented by the $\mathrm{L} 5$ deposits against the back wall with the remainder perhaps also having washed out. Sporadic occupation then took place throughout the second millennium $A D$ until the start of the twentieth century. For the purposes of analysis, L5 and $\mathrm{L} 5 \mathrm{~B}$ are together regarded as a layer and termed 'Lower', while the remaining deposits are grouped as 'Upper'.

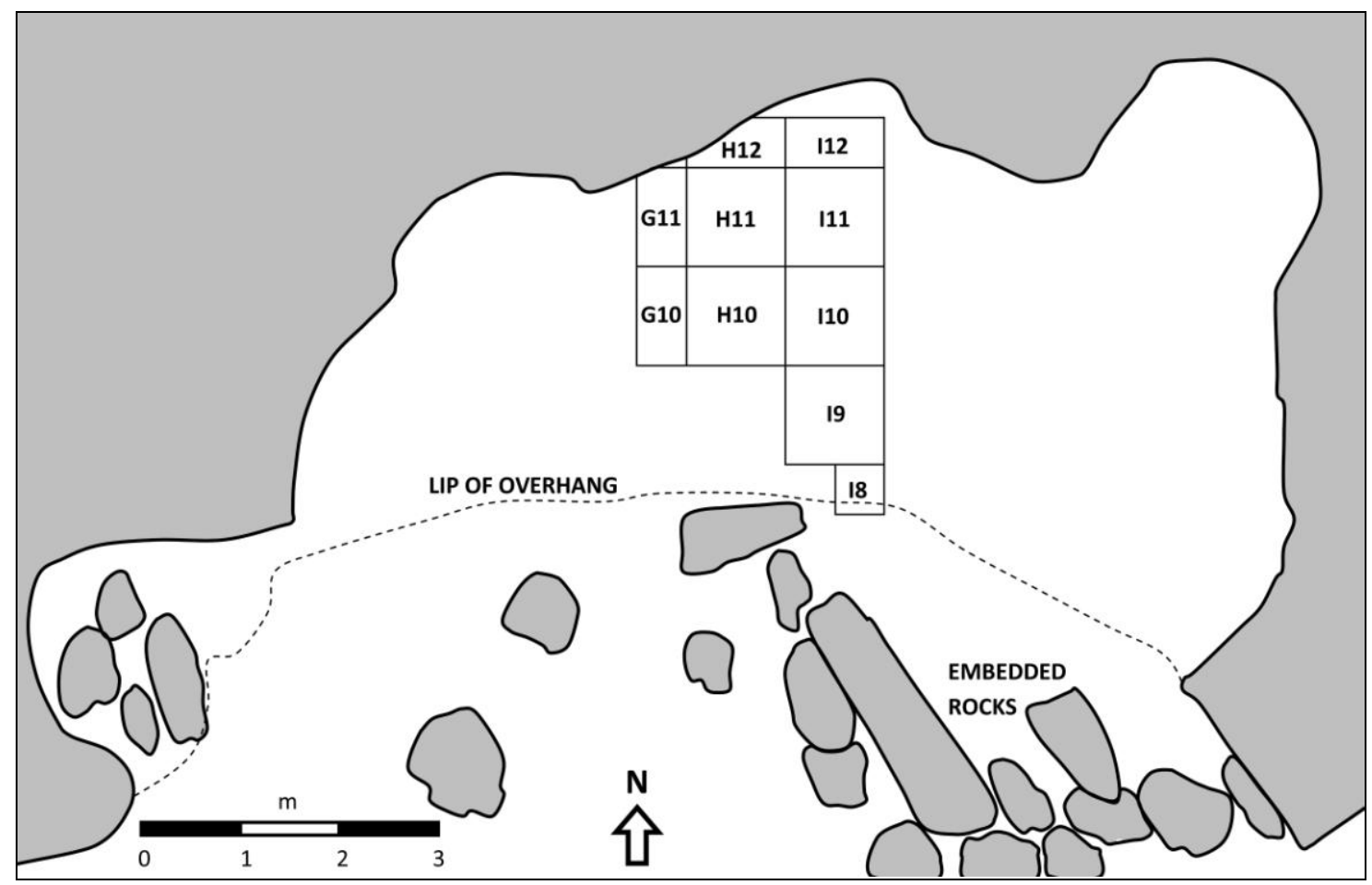

Figure 5.69: Floor plan of KK002.

\section{$\underline{\text { Cultural material }}$}

The Upper occupation contained a large flaked stone artefact assemblage very strongly dominated by quartz but with various other materials present. A variety of retouched artefacts was found, but most were backed and made from clear quartz (Group 3; Table 5.103; Figure 5.72). Of the 38 quartz retouched pieces, 29 are clear $(76.3 \%)$ indicating a strong Group 3 component. 


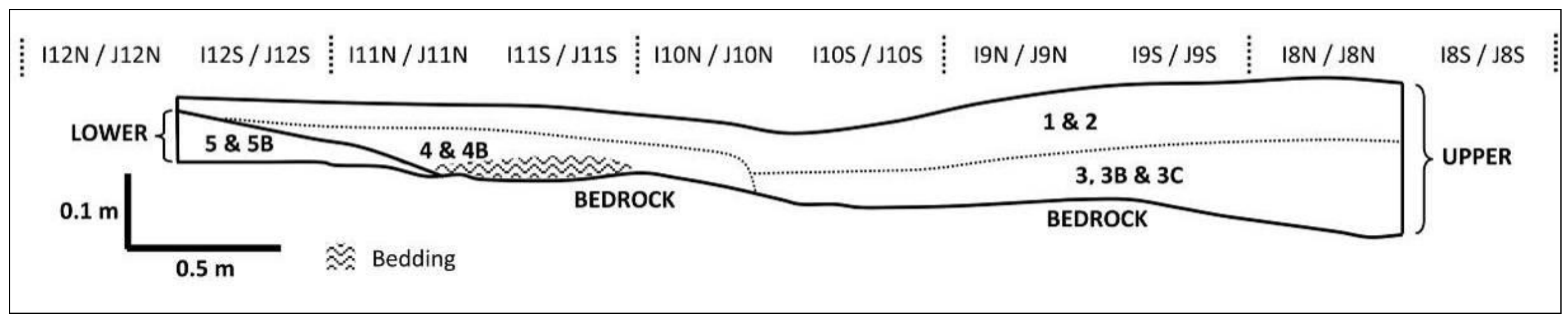

Figure 5.70: Section through the KK002 deposits facing east.

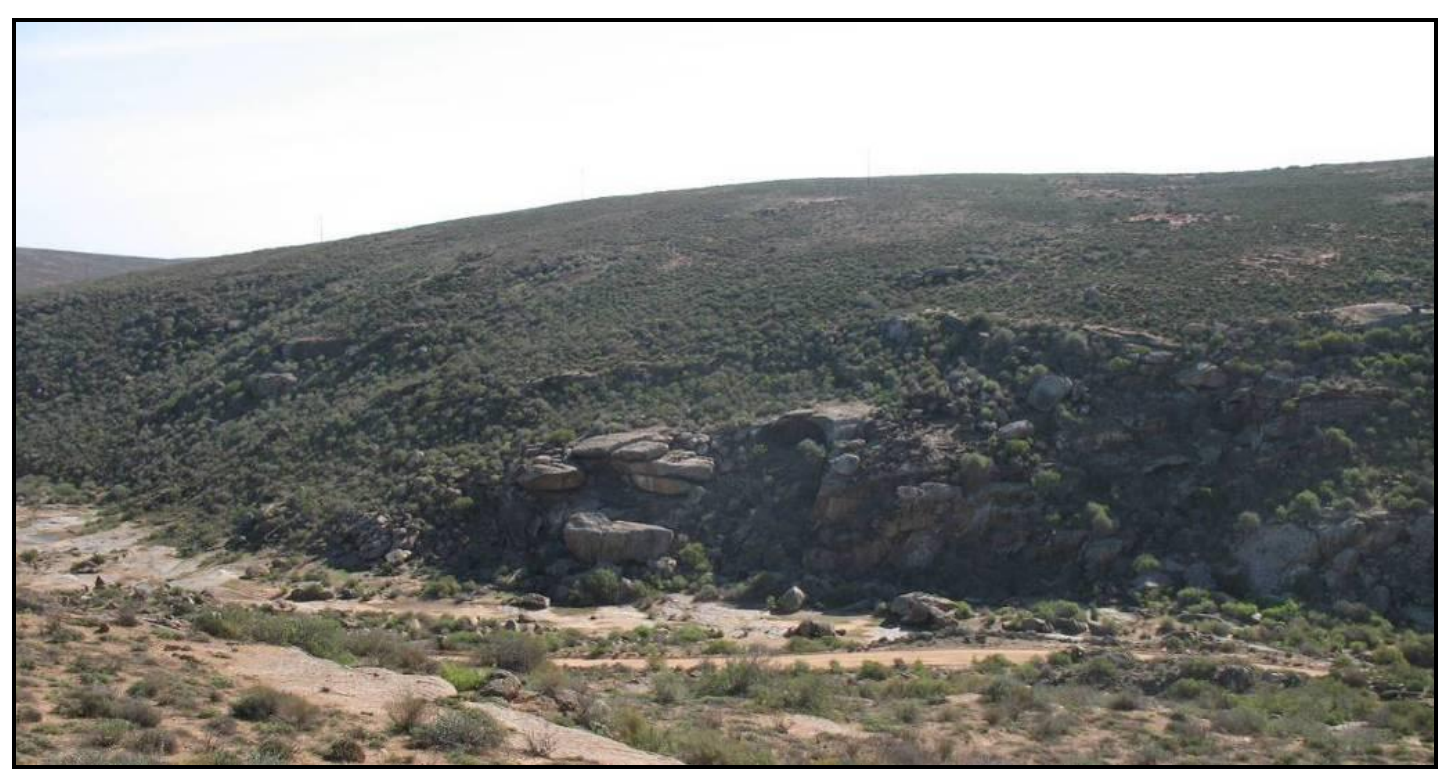

Figure 5.71: Northwest view towards KK002 (dome-shaped shelter in mid-picture). 
Segments and triangles are typically expected in mid-Holocene occupations (Orton \& Halkett 2010) but, given the two segments at LK2004/011B and these finds here, it may be that they are simply rare occurrences in late sites. The three silcrete and CCS tools, however, are more likely to be mid-Holocene Group 1 remnants. Four small grindstone fragments and one hammer stone were found, along with minimal specularite (one fragment) and black pigment (two fragments) and 32 fragments of ochre.

Table 5.103: Stone artefacts from KK002, Upper (Group 3, with residual Group 1).

\begin{tabular}{|c|c|c|c|c|c|c|c|}
\hline & 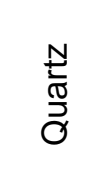 & D & $\begin{array}{l}\frac{0}{0} \\
\frac{\overline{0}}{\bar{\omega}}\end{array}$ & $\begin{array}{l}\stackrel{\Upsilon}{0} \\
\mathbb{0} \\
\mathbb{1} \\
\mathbb{1}\end{array}$ & 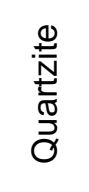 & 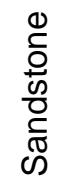 & $\frac{\bar{\Phi}}{\frac{\Phi}{\square}}$ \\
\hline Bipolar core & 64 & - & - & - & - & - & - \\
\hline Single platform core & 6 & - & - & 1 & $1^{*}$ & - & - \\
\hline Irregular core & 16 & - & 1 & - & - & - & - \\
\hline Sidescraper & 2 & - & - & - & - & - & - \\
\hline Miscellaneous scraper & 1 & - & - & - & - & - & - \\
\hline Scraper fragment & 1 & - & - & - & - & - & - \\
\hline Baked flake & 1 & - & - & - & - & - & - \\
\hline Backed bladelet & 9 & - & - & - & - & - & - \\
\hline Backed point & 6 & - & 1 & - & - & - & - \\
\hline Curve-backed bladelet & 1 & - & - & - & - & - & - \\
\hline Backed bladelet fragment & 6 & - & - & - & - & - & - \\
\hline Backed point fragment & 2 & - & - & - & - & - & - \\
\hline Borer & - & 1 & - & - & - & - & - \\
\hline Segment & 1 & - & 1 & - & - & - & - \\
\hline Triangle & 3 & - & - & - & - & - & - \\
\hline Backed piece fragment & 3 & 1 & - & - & - & - & - \\
\hline Notched piece & 1 & - & - & - & - & - & - \\
\hline Adze & - & - & - & - & - & - & - \\
\hline Miscellaneous retouched piece & 1 & 1 & - & - & - & - & - \\
\hline Blade & 13 & - & - & 1 & 2 & - & - \\
\hline Bladelet & 213 & 4 & 5 & 2 & 7 & - & - \\
\hline Edge-damaged bladelet & 1 & - & 3 & - & - & - & - \\
\hline Flake & 2167 & 42 & 63 & 21 & 232 & 3 & 9 \\
\hline Edge-damaged flake & 17 & 3 & 3 & - & - & - & - \\
\hline Chunk & 739 & 9 & 4 & 7 & 49 & - & 4 \\
\hline
\end{tabular}




\begin{tabular}{|c|c|c|c|c|c|c|c|}
\hline & $\begin{array}{l}\frac{N}{\pi} \\
\stackrel{0}{J} \\
0\end{array}$ & S & $\frac{\frac{\Phi}{\omega}}{\frac{\bar{\omega}}{\bar{\omega}}}$ & $\begin{array}{l}\mathbb{q} \\
\mathbb{0} \\
\mathbb{1} \\
\end{array}$ & 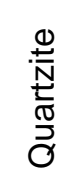 & 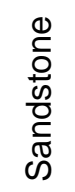 & $\begin{array}{l}\bar{\Phi} \\
\stackrel{ \pm}{\Xi}\end{array}$ \\
\hline Edge-damaged chunk & 3 & - & - & - & - & - & - \\
\hline Chip & 4956 & 32 & 10 & 3 & 47 & - & 1 \\
\hline Total & 8233 & 93 & 91 & 35 & 338 & 3 & 14 \\
\hline Stone material \% total & 93.5 & 1.1 & 1.0 & 3.8 & 0.4 & 0.0 & 0.2 \\
\hline Stone material \% formal & 88.4 & 7.0 & 4.7 & - & - & - & - \\
\hline Lower grindstone fragment & - & - & - & - & 2 & - & - \\
\hline Grindstone fragment & - & - & - & - & 2 & - & - \\
\hline Hammer stone & - & - & - & - & 1 & - & - \\
\hline
\end{tabular}

* The quartzite single platform core is also a lower grindstone fragment.
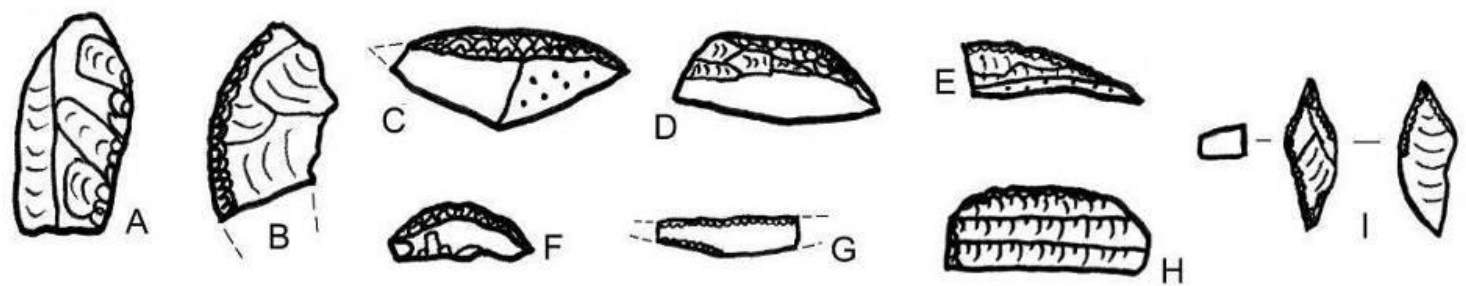

禹

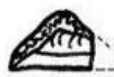

$\mathrm{K}$
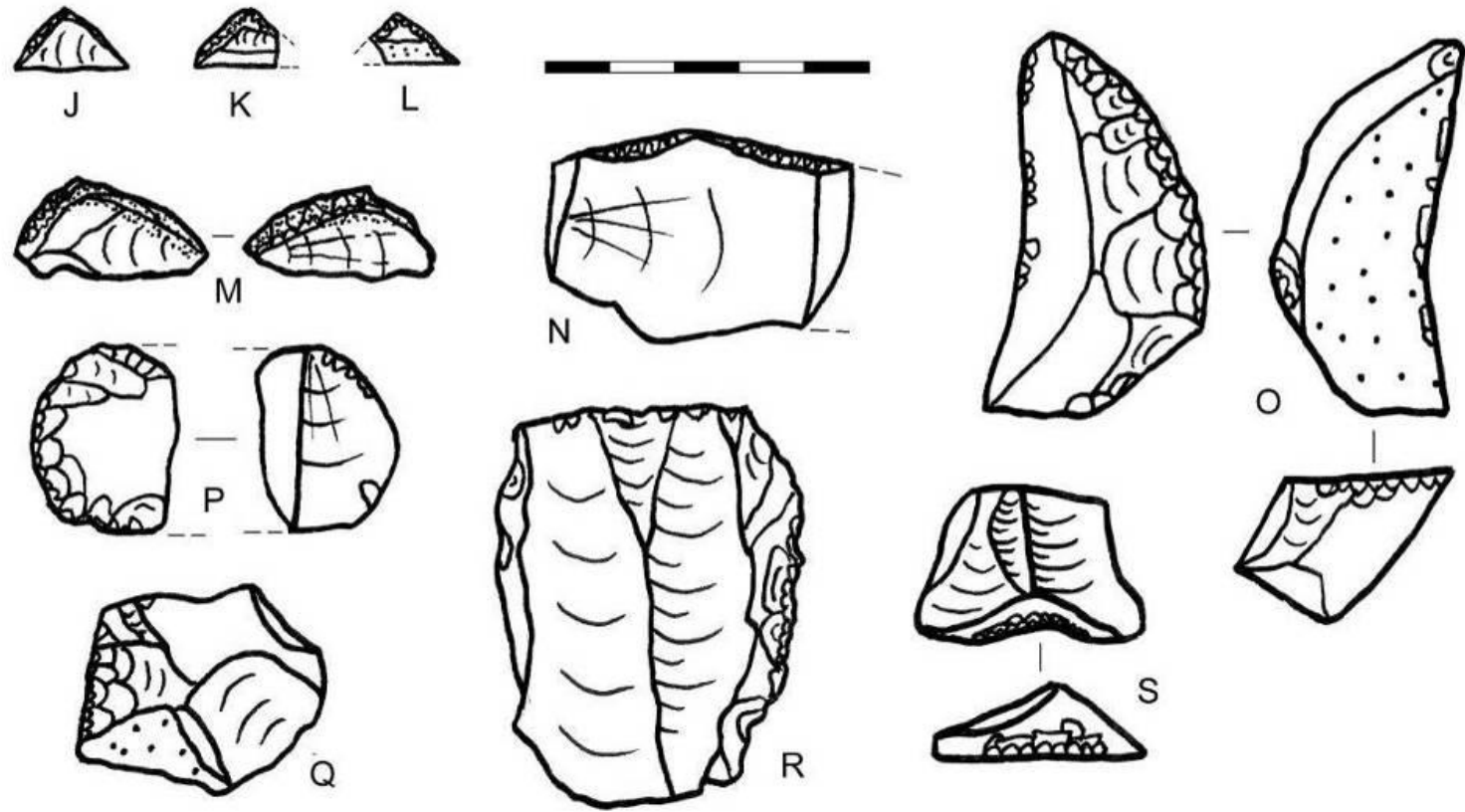

Figure 5.72: Stone artefacts from KK002, Upper. A, B: sidescrapers; C, G, H: backed bladelet; D: curve-backed bladelet; E: backed point; F: segment; I: borer; J-L: triangles; M: segment with red mastic stain (stippled); $\mathrm{N}$ : backed piece fragment; $\mathrm{O}, \mathrm{R}$ : miscellaneous retouched piece; $\mathrm{P}$ : scraper fragment; Q: miscellaneous scraper; S: notched piece. A, D, M, N, Q, R: quartz; B, C, E, J-L, P, S: clear quartz; G, I, O: CCS. F, H: silcrete. Scale in $5 \mathrm{~mm}$ intervals. 
A large assemblage was also present in the considerably smaller excavated volume of Lower (Table 5.104). Material frequencies are virtually identical and $73.3 \%$ of the quartz retouched tools are clear indicating Group 3. The silcrete adze is not well developed but, as sometimes occurs in south-western Cape assemblages (J. Kaplan 1987), appears to be made on a MSA blade, in this case broken. No ground artefacts were found but two fragments of ochre and one fragment of specularite were present.

Table 5.104: Stone artefacts from KK002, Lower (Group 3).

\begin{tabular}{|c|c|c|c|c|c|c|}
\hline & 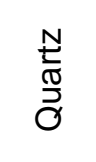 & O & $\frac{\frac{\Phi}{\Phi}}{\frac{\bar{U}}{\bar{\omega}}}$ & $\begin{array}{l}\stackrel{⿰}{0} \\
\mathbb{0} \\
\mathbb{1}\end{array}$ & 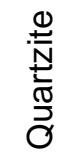 & 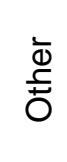 \\
\hline Bipolar core & 5 & - & - & - & - & - \\
\hline Irregular core & 1 & - & - & - & - & - \\
\hline Backed flake & 1 & - & - & - & - & - \\
\hline Backed bladelet & 6 & - & - & - & - & - \\
\hline Backed point & 3 & - & - & - & - & - \\
\hline Backed point fragment & 1 & - & - & - & - & - \\
\hline Backed piece fragment & 2 & - & - & - & - & - \\
\hline Segment & 1 & - & - & - & - & - \\
\hline Adze & - & - & 1 & - & - & - \\
\hline Miscellaneous retouched piece & 1 & - & - & - & - & - \\
\hline Blade & 2 & 1 & - & - & - & - \\
\hline Bladelet & 29 & - & 1 & 1 & 5 & - \\
\hline Edge-damaged bladelet & - & - & - & - & - & - \\
\hline Flake & 242 & 9 & 10 & 2 & 28 & 1 \\
\hline Edge-damaged flake & 5 & 1 & - & - & - & - \\
\hline Chunk & 78 & 1 & 4 & - & 13 & - \\
\hline Edge-damaged chunk & - & - & - & - & - & - \\
\hline Chip & 532 & 2 & 1 & 1 & 4 & - \\
\hline Total & 909 & 14 & 17 & 4 & - & 1 \\
\hline Stone material \% total & 91.4 & 1.4 & 1.7 & 5.0 & 0.4 & 0.1 \\
\hline Stone material \% formal & 93.8 & - & 6.3 & - & - & - \\
\hline
\end{tabular}

That both segments were in milky quartz and came from the base of the deposits may support an older age for them. One of these and a backed bladelet in Lower had mastic 
stains along their backed edges, one red and one yellow-green (Figure $5.73 \mathrm{G} \mathrm{\& H}$ ). Ochre has been shown to be a good additive to mastic (Wadley et al. 2009).

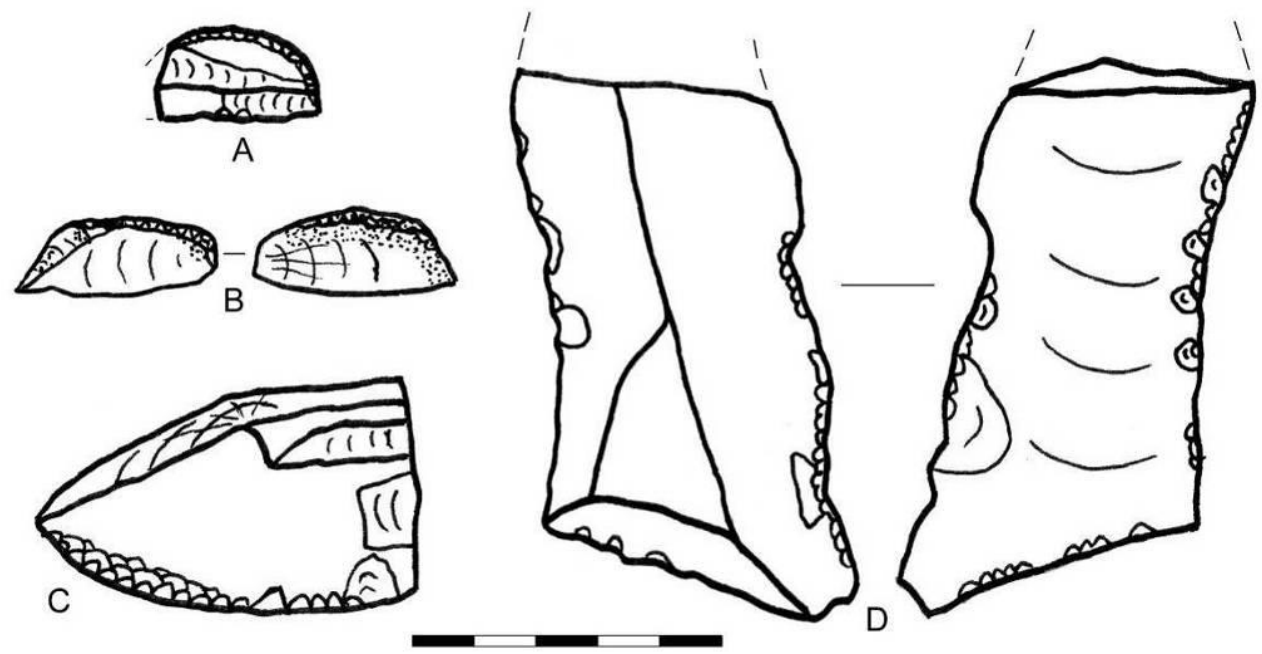

Figure 5.73: Stone artefacts from KK002, Lower. A: segment; B: backed bladelet with yellowgreen mastic stain (stippled); C: miscellaneous retouched piece; D: adze. A-C: quartz; D: silcrete. Scale in $5 \mathrm{~mm}$ intervals.

Twenty-four whole ostrich eggshell beads were recovered from Upper and seven from Lower (Table 5.105). Although a wide range of diameters is represented, a scatter plot does not show two distinct populations and also reveals a similar pattern for both layers (Figure 5.74). When the diameters of the 25 broken beads from Upper are examined in the same way, however, it seems clear that a separate population of far larger beads is present. Add to this 21 further bead fragments falling between 9.0 and $12.5 \mathrm{~mm}$, but whose remaining proportions were too small to allow reliable estimation, and the pattern is even stronger (although some of the latter undoubtedly refit with the first set of 25 broken beads). There is a clear pattern of large beads being broken and small beads being whole. What this signifies is unknown, though one might speculate on the possibilities of ritual given the association of small and large beads with hunter-gatherers and herders respectively. Another way of looking at this is via thickness. All whole beads have a mean thickness of $1.57 \pm 0.21 \mathrm{~mm}(\mathrm{n}=26)$, while broken beads average $1.85 \pm$ $0.16(n=45)$, almost identical to the thickness of unmodified ostrich eggshell fragments from Upper of $1.86 \pm 0.15 \mathrm{~mm}(n=142)$. Although larger beads can be expected to wear 
down more slowly, these data present a strong case for the broken beads being quite newly made.

Table 5.105: Summary statistics for finished ostrich eggshell beads from KK002.

\begin{tabular}{|c|c|c|c|c|}
\hline \multicolumn{2}{|l|}{ Layer } & Outside diameter $(\mathrm{mm})$ & Aperture diameter $(\mathrm{mm})$ & \multirow{2}{*}{$\begin{array}{c}\text { Thickness }(\mathrm{mm}) \\
1.60\end{array}$} \\
\hline & Mean & 5.32 & 1.89 & \\
\hline Upper & Std Deviation & 1.14 & 0.57 & 0.22 \\
\hline \multirow[t]{3}{*}{$\left(n=24^{*}\right)$} & Minimum & 3.05 & 0.93 & 1.13 \\
\hline & Maximum & 7.31 & 3.38 & 1.96 \\
\hline & Mean & 5.73 & 2.57 & 1.50 \\
\hline Lower & Std Deviation & 1.11 & 0.67 & 0.15 \\
\hline \multirow[t]{2}{*}{$\left(\mathrm{n}=7^{\star \star}\right)$} & Minimum & 3.59 & 1.47 & 1.29 \\
\hline & Maximum & 6.82 & 3.38 & 1.68 \\
\hline
\end{tabular}

${ }^{*}$ Four beads were burnt and exfoliated such that for thickness $n=20$.

${ }^{* *}$ One bead was burnt and exfoliated such that for thickness $n=6$.

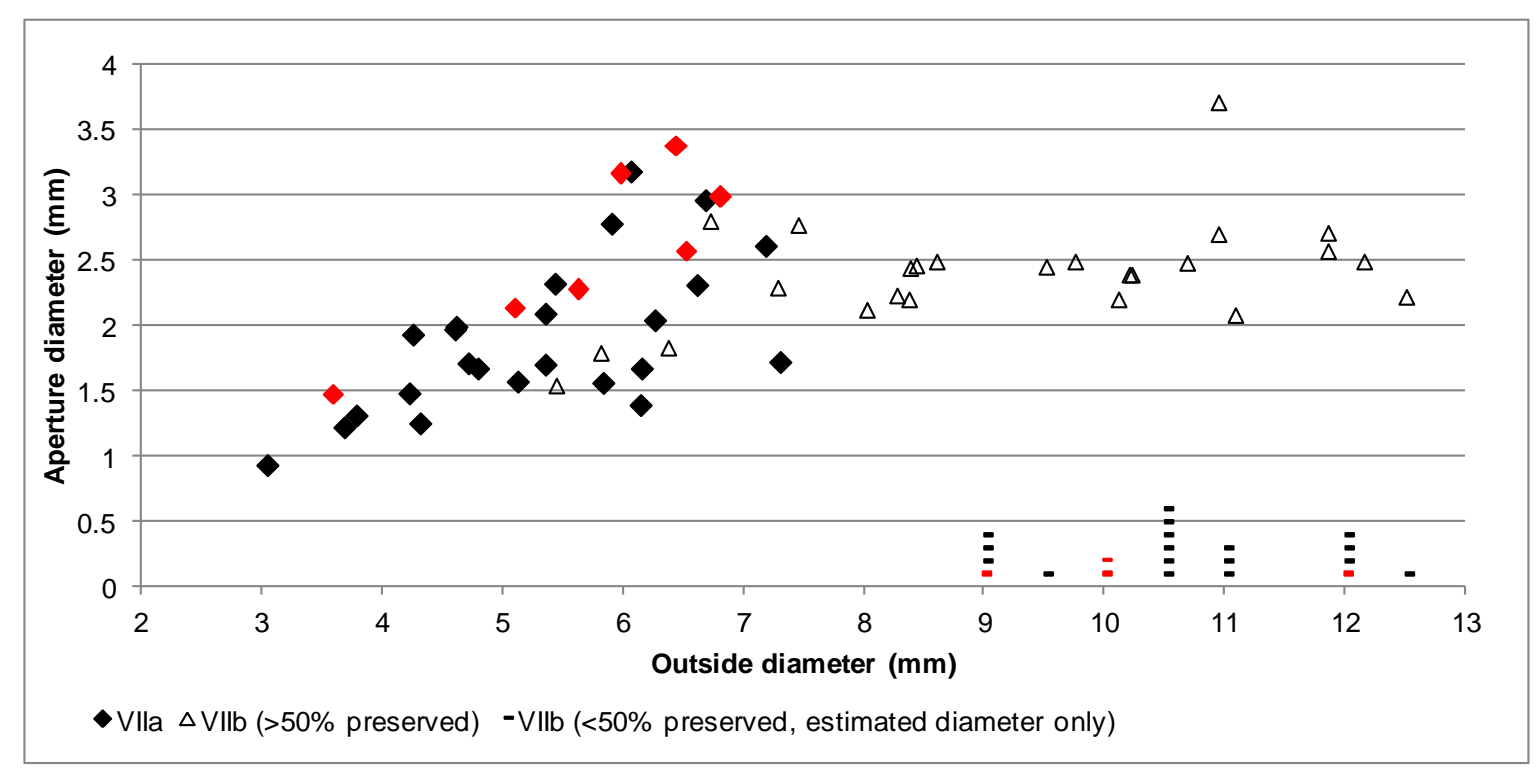

Figure 5.74: Scatter plot of ostrich eggshell bead dimensions from KK002. Upper are in black (whole beads) and white (broken beads with $>50 \%$ preserved), Lower are in red.

Nineteen potsherds weighing $52.0 \mathrm{~g}$ (mean thickness $5.59 \pm 0.71 \mathrm{~mm}$ ) were recovered from Upper, while one weighing $1.6 \mathrm{~g}$ (thickness $=5.96 \mathrm{~mm}$ ) came from Lower. Among the former three had red slip painted on them with one being a plain rim sherd. Average sherd thickness for Upper is $5.59 \pm 0.71 \mathrm{~mm}$ with a range of $3.84-6.68 \mathrm{~mm}$. The sherd from Lower is $5.96 \mathrm{~mm}$ thick. 
Other categories of cultural material from the Upper occupation include a single broken Conus shell, probably collected for decorative purposes, 289 wood shavings, seven pieces of worked wood, 12 cut reeds and one possible seed bead. One wooden item is the blunt end of a small peg, while another, judging by its very well-worn appearance, may have been a handle of sorts (Figure 5.75). Also found were a $12.4 \mathrm{~mm}$ long and $c$. 2-3 mm wide fragment of copper wire, a very tiny clear glass fragment, a small iron rod of $93.4 \mathrm{~mm}$ length and $5.6 \times 4.5 \mathrm{~mm}$ at its thickest part (Figure 5.76), a brass pendant of the sort made from a Dutch button (Figure 5.77; Miller et al. 1998), and six glass trade beads (Table 5.106). The iron rod may be a link shaft; it was found within the bedding grass and is definitely not intrusive. Thin section examination revealed that it originated as a flat sheet that was rolled and hammered into shape; it is definitely not from a modern blast furnace (F. Bandama, pers. comm. 2012). Miller and Markell (1993) noted that the upper domes of Dutch brass buttons were frequently perforated for use as pendants, while Miller et al. (1998) describe a number of examples from Western Cape LSA sites. Such buttons were available from at least the late seventeenth century as testified by their presence on the wreck of the Oosterland which sank in Table Bay, Cape Town, 1697 (Werz 1994). The glass beads are European, and probably Venetian, in origin and likely date to the late nineteenth or early twentieth centuries (M. Wood, pers. comm. 2011). That all were found in the uppermost levels rather than in the bedding supports this contention.

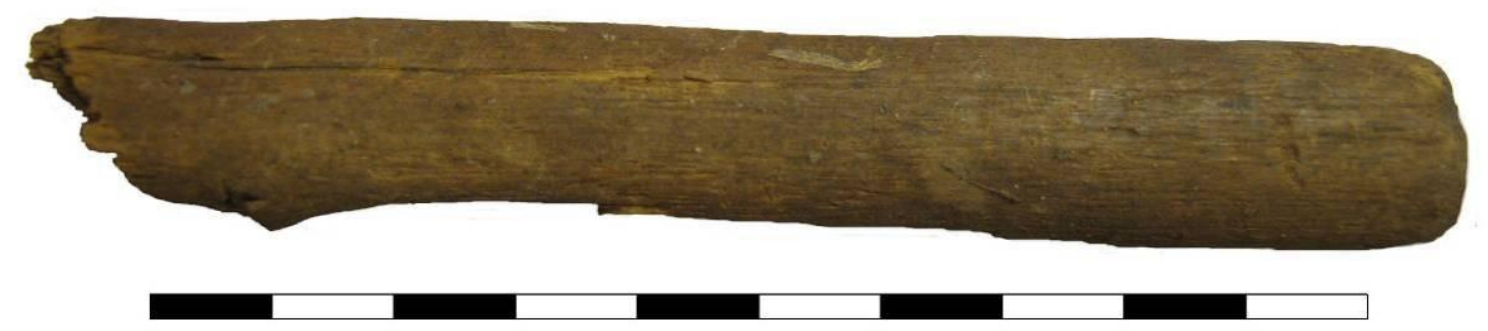

Figure 5.75: A wooden artefact from the bedding layer in Upper at KK002. Scale in $5 \mathrm{~mm}$ intervals. 
Table 5.106: K002 glass bead attributes.

\begin{tabular}{|c|c|c|c|c|c|c|}
\hline Provenance & Colour & Translucency & $\begin{array}{l}\text { Outside } \\
\text { diameter } \\
(\mathrm{mm})\end{array}$ & $\begin{array}{c}\text { Aperture } \\
\text { diameter } \\
(\mathrm{mm})\end{array}$ & $\begin{array}{l}\text { Thickness } \\
\text { (mm) }\end{array}$ & Photograph \\
\hline $\begin{array}{c}\text { H10 SE } \\
\text { L.1-2 }\end{array}$ & $\begin{array}{l}\text { Brownish- } \\
\text { red on red }\end{array}$ & Opaque & 3.51 & 1.19 & 1.81 & \\
\hline $\begin{array}{c}\text { H10 SW } \\
\text { L.1-2 }\end{array}$ & Pale blue & $\begin{array}{l}\text { Opaque- } \\
\text { translucent }\end{array}$ & 2.9 & 1.14 & 2.43 & \\
\hline $\begin{array}{c}\text { H11 NW } \\
\text { L. } 1\end{array}$ & Black & Opaque & 5.1 & 1.77 & 3.21 & \\
\hline $\begin{array}{c}\text { H11 SW } \\
\text { L.2 }\end{array}$ & $\begin{array}{l}\text { Black/very } \\
\text { dark blue }\end{array}$ & Opaque & 4.42 & 1.43 & 4 & \\
\hline I11 SW L.2 & $\begin{array}{l}\text { Oyster } \\
\text { white }\end{array}$ & $\begin{array}{l}\text { Opaque- } \\
\text { translucent }\end{array}$ & 4.11 & 1.13 & 2.61 & \\
\hline I11 NW L.2 & $\begin{array}{c}\text { Blue } \\
\text { (medium) }\end{array}$ & $\begin{array}{l}\text { Opaque- } \\
\text { translucent }\end{array}$ & 3.65 & 0.92 & 1.9 & \\
\hline
\end{tabular}

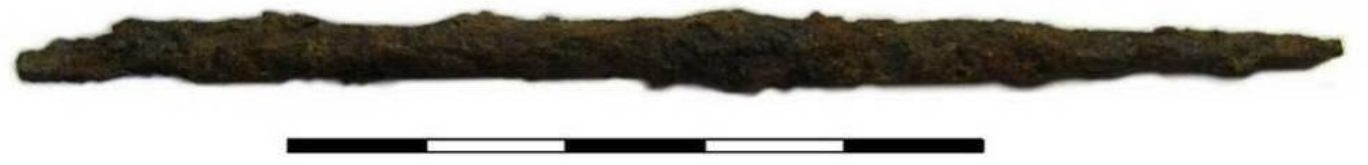

Figure 5.76: The iron rod from the bedding layer in Upper at KK002. Scale in $10 \mathrm{~mm}$ intervals.
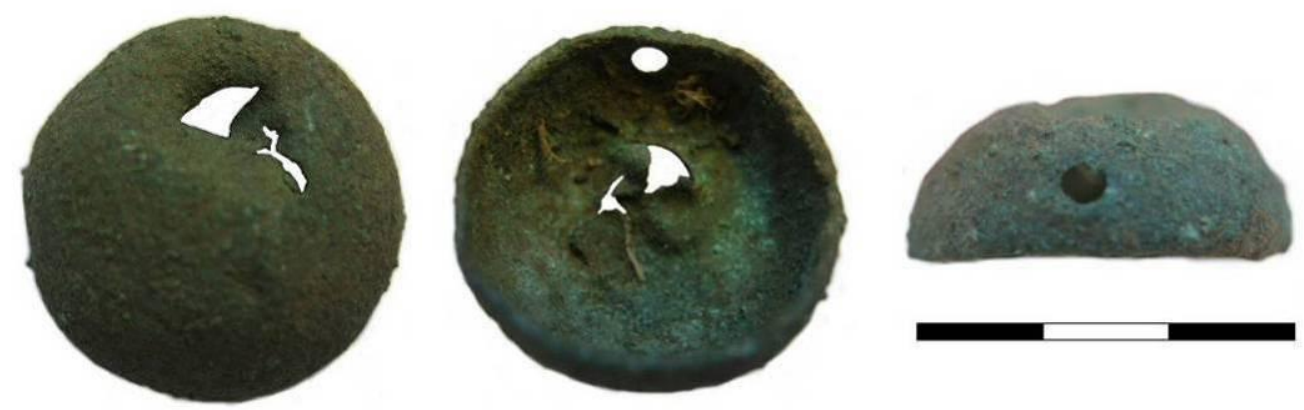

Figure 5.77: The brass pendant from Upper in KK002. Scale in $5 \mathrm{~mm}$ intervals. 


\subsubsection{KK003}

\section{The site}

This site is located around a large boulder on the southern side of a small, rocky valley in the south-western extremity of the Hardeveld, $17 \mathrm{~km}$ from the sea and overlooking the

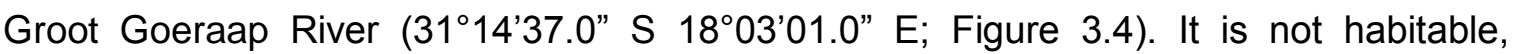
although a tiny alcove behind the boulder houses rock paintings (Figure 5.78) and an extensive scatter of archaeological material lies on the talus. The talus is mostly of exposed bedrock (Figure 5.79). Nothing in good context could be dated and no attempt was made to directly date the remaining paint.

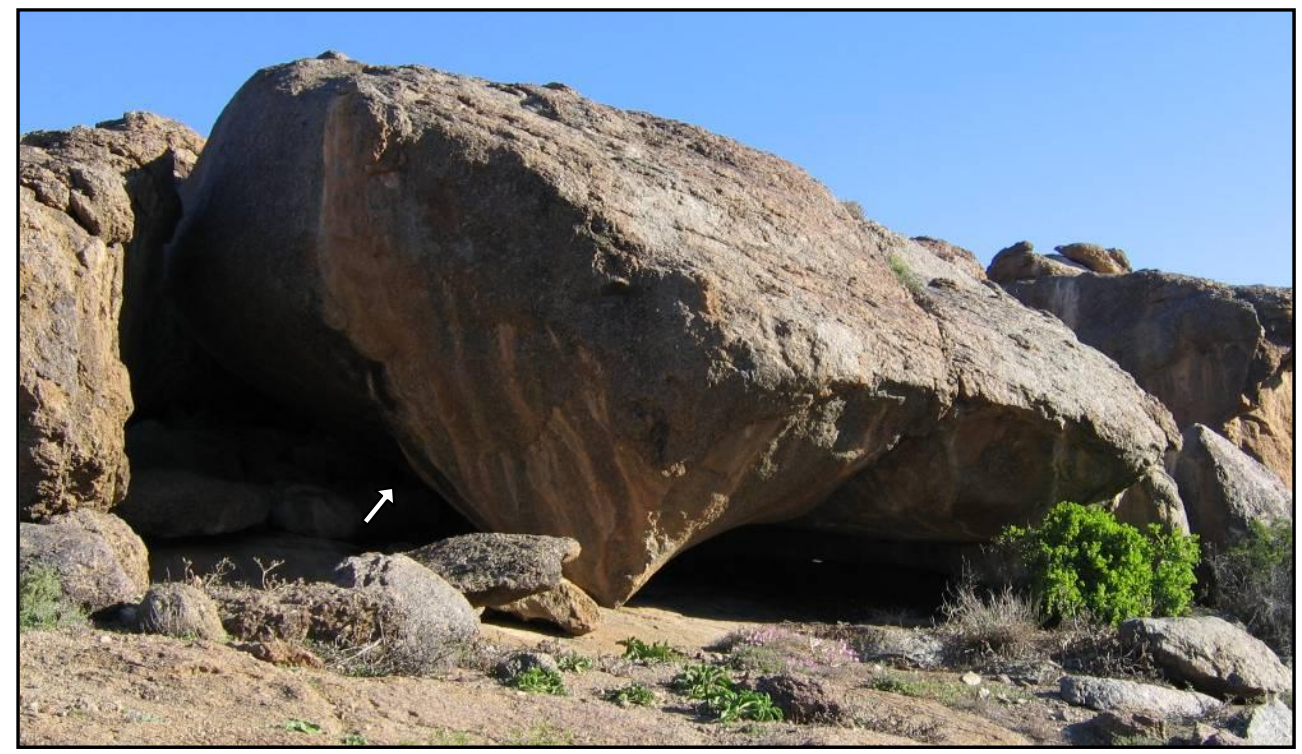

Figure 5.78: View of KK003 showing the location of the primary painted panel (arrow) and the knee-high cavity beneath the boulder.

\section{$\underline{\text { Cultural material }}$}

The primary significance of this site is its rock art. It is of the type described by Eastwood and Smith (2005; Eastwood 2003; B. Smith \& Ouzman 2004) from the Central Limpopo Basin in the northern part of South Arica and ascribed by them to the Khoekhoen. The paintings are bold, red and white finger-painted images emphasizing circles, grids and 
dots (Figures $5.80 \& 5.81$ ). Owing to a precipitate emanating from a seam above the panel, the images are poorly preserved. The circular motifs along the top of the panel are particularly badly affected and it seems likely that the remaining visible paint reflects only part of each.

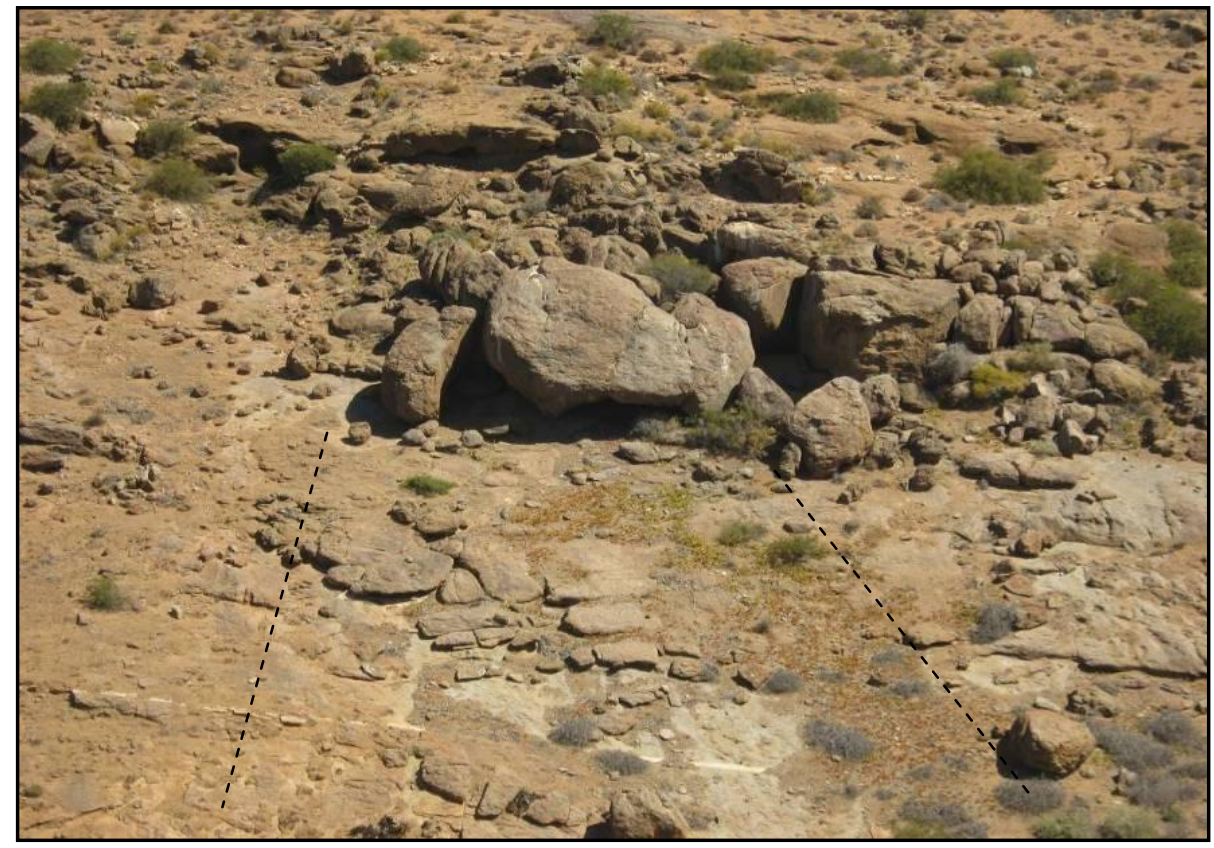

Figure 5.79: Oblique aerial view of KK003 showing the approximate extent of the artefact-bearing talus (between the dashed lines).
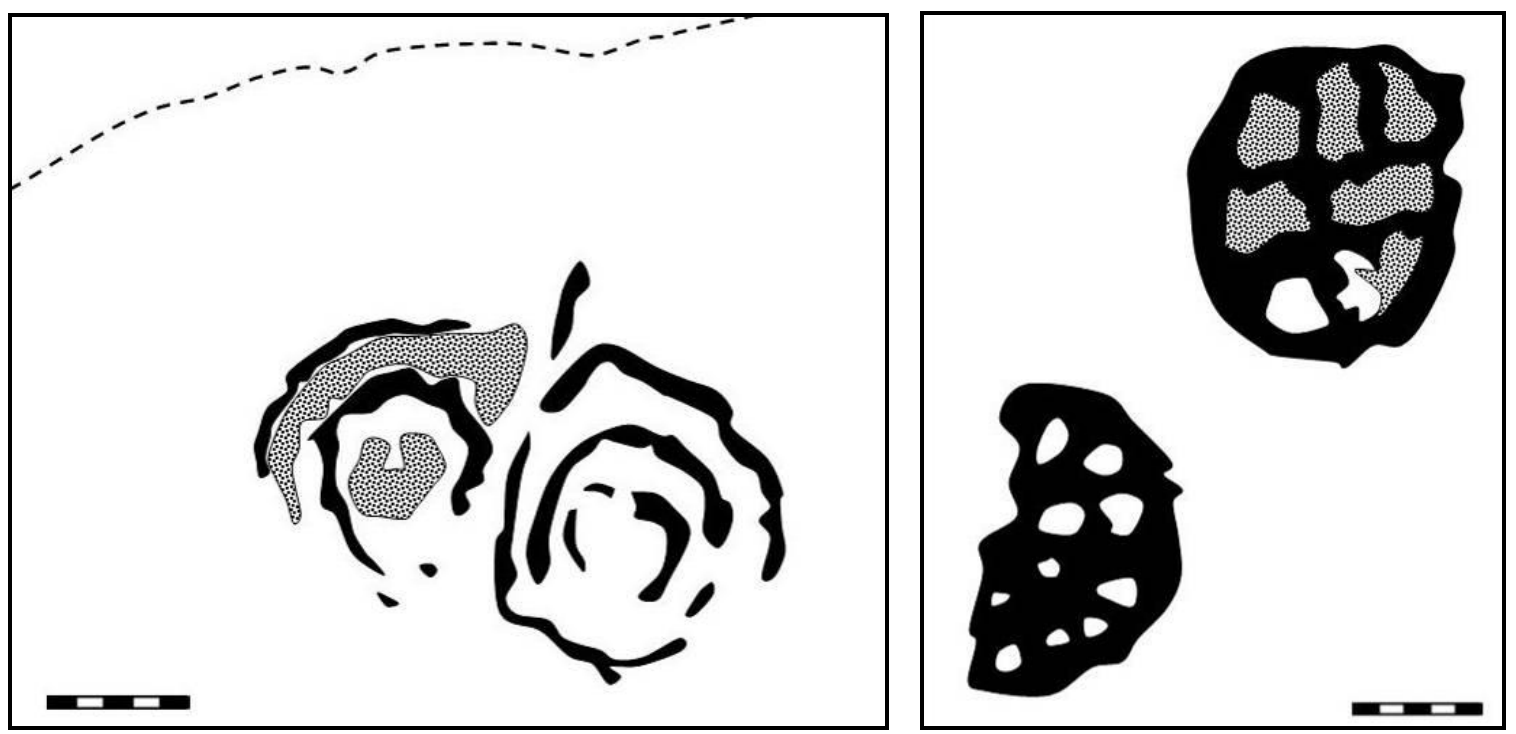

Figure 5.80: Circular motifs in the upper left and upper right parts of the main panel. The dotted line at top left represents the position of a seam in the boulder from which precipitate has flowed. Black denotes red paint and the stippled areas are white. Scales in $10 \mathrm{~mm}$ intervals. 


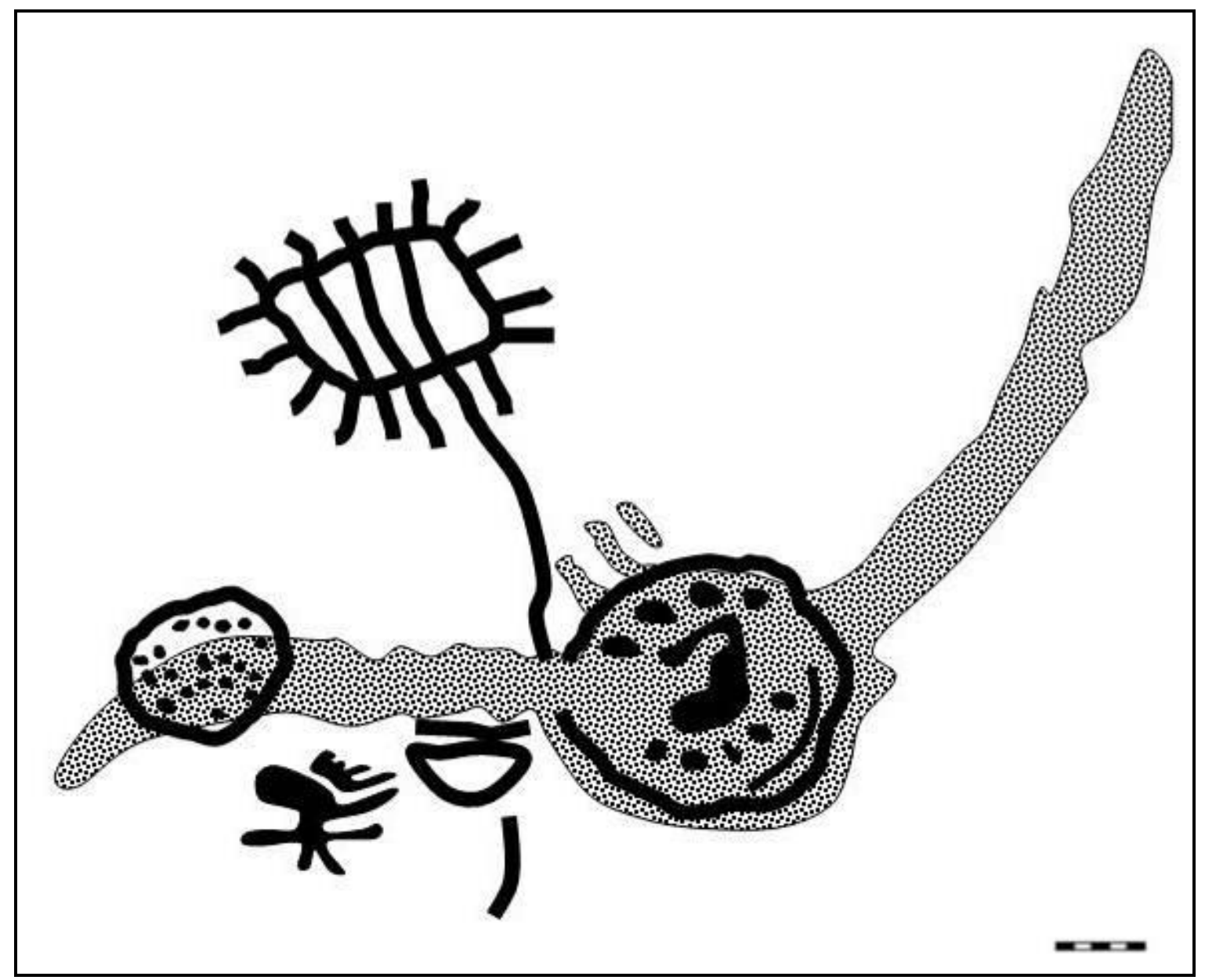

Figure 5.81: The lower group of images on the main panel. The right hand motifs in Figure 5.80 lie just above the right hand side of this image. Black denotes red paint and the stippled areas are white. Scale in $10 \mathrm{~mm}$ intervals.

Scattered over the talus slope was a large number of stone artefacts, marine shells, bone and ostrich eggshell fragments and one piece of undiagnostic pottery $5.85 \mathrm{~mm}$ thick. The stone artefacts are tabulated in Table 5.107, but, with no secure context, it is unknown whether these relate to the art or not. The lithics are probably a mixture of Groups with Group 1 the only one that can be confidently identified

Table 5.107: Stone artefacts from KK003 (Group 1 \& possibly others).

\begin{tabular}{|c|c|c|c|c|c|c|c|}
\hline & $\begin{array}{l}\frac{N}{\sigma} \\
\frac{\pi}{2}\end{array}$ & D & $\frac{\frac{0}{0}}{\frac{0}{\omega}}$ & $\begin{array}{l}\frac{0}{N} \\
\frac{\pi}{N} \\
\frac{0}{0}\end{array}$ & $\begin{array}{l}\stackrel{⿰}{0} \\
\mathbb{1} \\
\stackrel{\sim}{\longleftarrow}\end{array}$ & 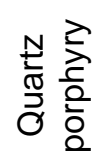 & $\begin{array}{l}\bar{\Phi} \\
\bar{\Xi} \\
\end{array}$ \\
\hline Bipolar core & 5 & - & - & - & - & 1 & - \\
\hline Single platform core & 3 & - & 1 & 1 & - & 1 & 1 \\
\hline
\end{tabular}




\begin{tabular}{|c|c|c|c|c|c|c|c|}
\hline & $\begin{array}{l}\frac{N}{\mathbb{T}} \\
\stackrel{0}{\sigma}\end{array}$ & ల్ & $\frac{\frac{\Phi}{0}}{\frac{\bar{\omega}}{\bar{\omega}}}$ & $\begin{array}{l}\frac{0}{N} \\
\frac{N}{N} \\
\frac{0}{0}\end{array}$ & $\begin{array}{l}\stackrel{⿰}{0} \\
\mathbb{0} \\
\mathbb{w}\end{array}$ & 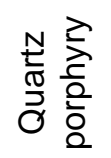 & $\frac{\grave{\Phi}}{\stackrel{ \pm}{0}}$ \\
\hline Irregular core & 12 & - & - & 4 & - & 1 & - \\
\hline Sidescraper & 1 & - & - & - & - & - & - \\
\hline Thumbnail scraper & - & 1 & - & - & - & - & - \\
\hline Backed piece fragment & - & 1 & - & - & - & - & - \\
\hline Blade & 1 & - & - & - & - & - & - \\
\hline Bladelet & 10 & - & - & - & - & - & - \\
\hline Flake & 262 & 1 & 6 & 23 & - & 1 & 6 \\
\hline Edge-damaged flake & 1 & - & 1 & - & - & - & - \\
\hline Chunk & 45 & - & 2 & 8 & 1 & - & 1 \\
\hline Chip & 24 & 1 & - & - & - & - & - \\
\hline Total & 364 & 4 & 10 & 36 & 1 & 4 & 8 \\
\hline Stone material $\%$ total & 85.2 & 0.9 & 2.3 & 8.4 & 0.2 & 0.9 & 1.9 \\
\hline Stone material \% formal & 33.3 & 66.7 & - & - & - & - & - \\
\hline Hammer stone & - & - & - & 1 & - & - & - \\
\hline
\end{tabular}

\subsection{Southern Sandveld assemblages}

\subsubsection{MS3}

This site was a deflated shell and artefact scatter found in a shallow deflation hollow $\left(31^{\circ} 15^{\prime} 52.8^{\prime \prime} \mathrm{S} 17^{\circ} 54^{\prime} 39.0^{\prime \prime} \mathrm{E}\right)$. It produced only shell and stone artefacts and all material was recovered from a $1.5 \mathrm{~mm}$ mesh sieve (Hart \& Halkett 1994). The following date was obtained by ACO (unpublished):

$\begin{array}{lllll}\text { Lab. No. } & \text { Provenience } & \text { Material } & \frac{{ }^{14} \mathrm{C} \text { date BP }}{\text { GX-32062 }} & \text { Calibrated age (95.4\%) } \\ \text { Unknown } & \text { Marine shell } & 3160 \pm 70 & \frac{966-492 \mathrm{BC}}{960}\end{array}$

\section{$\underline{\text { Cultural material }}$}

Table 5.108 presents the stone analysis. The vast majority of flaked artefacts were in quartz and most of this was yellowed from sun exposure. Backed tools dominate strongly and the single truncated flake had the appearance of an unfinished triangle or trapezium. 
Occasional pebble cortex was evident on the quartz while some CCS had calcrete cortex present. The two 'other' chunks were both calcrete and no doubt originally came in with CCS attached. A number of small ochreous nodules were present but these may have been naturally occurring.

Table 5.108: Stone artefacts from MS3 (Group 1).

\begin{tabular}{|c|c|c|c|c|c|c|}
\hline & $\begin{array}{l}\frac{N}{U} \\
\frac{\pi}{3} \\
0\end{array}$ & D & $\frac{\frac{\Phi}{\omega}}{\frac{\bar{\omega}}{\bar{\omega}}}$ & 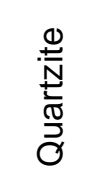 & 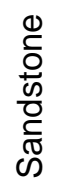 & $\begin{array}{l}\bar{\Phi} \\
\stackrel{ \pm}{0}\end{array}$ \\
\hline Bipolar core & 3 & - & - & - & - & - \\
\hline Single platform core & 4 & - & - & 1 & - & - \\
\hline Irregular core & 8 & - & 1 & 1 & - & - \\
\hline Radial core & - & - & - & 1 & - & - \\
\hline Sidescraper & - & 1 & 1 & - & - & - \\
\hline Backed flake & 1 & 2 & - & - & - & - \\
\hline Backed bladelet & 3 & - & - & - & - & - \\
\hline Backed point & 2 & 1 & - & - & - & - \\
\hline Curve-backed flake & 1 & - & - & - & - & - \\
\hline Backed point fragment & 1 & - & - & - & - & - \\
\hline Truncated flake & - & 1 & - & - & - & - \\
\hline Segment & 4 & 1 & - & - & - & - \\
\hline Miscellaneous backed piece & - & 2 & - & - & - & - \\
\hline Miscellaneous retouched piece & - & 1 & - & 1 & - & - \\
\hline Blade & 1 & - & - & 1 & - & - \\
\hline Bladelet & 54 & - & 2 & 6 & - & - \\
\hline Flake & 719 & 3 & 19 & 98 & 3 & 2 \\
\hline Edge-damaged flake & 2 & - & - & - & - & - \\
\hline Chunk & 190 & 3 & 4 & 12 & - & 2 \\
\hline Chip & 1059 & 3 & 9 & 45 & - & - \\
\hline Total & 2052 & 18 & 36 & 166 & 3 & 4 \\
\hline Stone material \% total & 90.0 & 0.8 & 1.6 & 7.3 & 0.1 & 0.2 \\
\hline Stone material \% formal & 52.2 & 39.1 & 4.3 & 4.3 & - & - \\
\hline Hammer stone & - & - & - & $1^{*}$ & - & - \\
\hline
\end{tabular}

* The hammer stone is also a chunk 


\subsubsection{Assemblages described elsewhere}

Two sets of sites have been commercially excavated in the southern Sandveld and are recorded only in grey literature (Halkett et al. 1993; Hart \& Halkett 1994). They come from coastal and near-coastal contexts respectively, $50 \mathrm{~km}$ northwest of the Olifants River mouth. Unfortunately, limited dating and analytical detail precluded the coastal set from further consideration. While MS3 was reanalysed and presented above, Hart and Halkett's (1994) analysis from the MS1 was deemed consistent enough with the present research to merit direct use.

\section{$\underline{\text { MS1 }}$}

This deflated shell and artefact scatter was located on the east side of a silcrete outcrop (31 $\left.15^{\circ} 52.8^{\prime \prime} \mathrm{S} 17^{\circ} 54^{\prime} 39.0^{\prime \prime} \mathrm{E}\right)$. The excavation produced only shell and stone artefacts with the latter including both the remains of earlier (ESA) silcrete quarrying activities and overprinted LSA material. These were separated based on patina prior to analysis (Hart \& Halkett 1994). One date puts the LSA component at 1842-1407 BC (GX-32063; ACO, unpublished). The coarse-grained silcrete is commonly encountered as outcrops in the area. Note that in MS3 reanalysis suggested the coarse silcrete to be quartzite. Table 5.109 presents the LSA stone analysis.

Table 5.109: Stone artefacts from MS1 (Group 1; source: Hart \& Halkett 1994).

\begin{tabular}{|c|c|c|c|c|}
\hline & $\frac{N}{\stackrel{\frac{\pi}{2}}{2}}$ & ల & 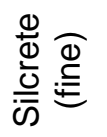 & 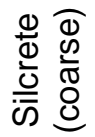 \\
\hline Bipolar core & 5 & - & - & - \\
\hline Single platform core & 1 & - & - & 1 \\
\hline Irregular core & 21 & - & - & 5 \\
\hline Backed bladelet & 2 & 1 & - & - \\
\hline Backed point & 2 & 2 & - & - \\
\hline Segment & 9 & 2 & - & - \\
\hline
\end{tabular}




\begin{tabular}{|c|c|c|c|c|}
\hline & $\begin{array}{l}\frac{N}{0} \\
\stackrel{0}{0}\end{array}$ & OS & 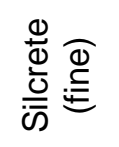 & 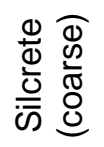 \\
\hline Miscellaneous backed piece & 4 & - & - & - \\
\hline Miscellaneous retouched piece & 4 & - & - & 1 \\
\hline Blade & - & - & - & - \\
\hline Bladelet & 37 & 2 & 1 & 23 \\
\hline Flake & 708 & 5 & 1 & 777 \\
\hline Chunk & 224 & 12 & 2 & 145 \\
\hline Chip & 1325 & 3 & 1 & 709 \\
\hline Total & 2342 & 27 & 5 & 1661 \\
\hline Stone material \% total & 58.5 & 0.7 & 0.1 & 41.2 \\
\hline Stone material \% formal & 77.8 & 18.5 & - & 3.7 \\
\hline Hammer stone & - & - & 1 & - \\
\hline
\end{tabular}

\subsection{Knersvlakte assemblages}

This section presents two newly excavated rock shelters from along the Varsche River in the Knersvlakte. A proximate open site at which research is ongoing is also briefly discussed. It was sampled in order to determine whether occupation had occurred in the open at the same time as in the shelters, since open LSA sites have been found to be extremely rare in the Knersvlakte.

\subsubsection{Reception Shelter (VR001)}

\section{The site}

Reception Shelter (VR001) is located in a small cave in partly metamorphosed limestone

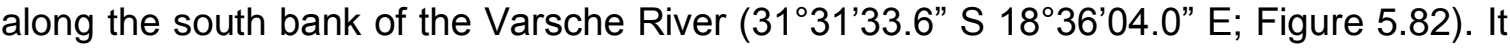
is $43 \mathrm{~km}$ from the coast and $16.5 \mathrm{~km}$ from the Olifants River. A full description of the site and its deposits is contained in Orton et al. (2011). However, since that publication, further excavations and dating have resulted in minor restructuring of the analytical 
groups. Table 5.110 shows the grouping of excavation levels now employed and the total area excavated inside the shelter is $3 \mathrm{~m}^{2}$ (Figure 5.83). Just two major bedding layers were located (Figure 5.84). The first, forming the upper part of Layer $4 \mathrm{~A}$, seemed to be composed primarily of hay, perhaps brought in to feed livestock penned in the shelter. The second occupied a hollow against the cave wall and was part of the only typical LSA cave deposit found in the site. Layers 9 and 10, although containing typical LSA material, were affected by moisture such that the expected organic material was not preserved. A strange concentration of rocks was found occurring between excavation levels 17 (lower Layer 6) and 20 (upper Layer 8) in the southern part of the excavation. They were densely packed and appeared to form a mound in the middle of the cave, but their function could not be determined. The present study concerns itself primarily with the better resolved deposits from inside the rock shelter and only these are presented, although the talus slope was also sampled.

Table 5.110: Stratigraphic grouping of levels at Reception Shelter. Layer numbers follow Orton et al. (2011) but Layers 4 and 9 are newly divided.

\begin{tabular}{|c|c|c|}
\hline Layer & Excavation levels & Brief description \\
\hline 1 & 1,2 & Crusty dung. \\
\hline 2 & 3,4 & $\begin{array}{l}\text { Crusty dung on top, softer with grass/wheat } \& \text { ash patches } \\
\text { below. }\end{array}$ \\
\hline 3 & 5 & $\begin{array}{l}\text { Grass bedding that thickens away from the cave wall and } \\
\text { includes a hearth in a pit. }\end{array}$ \\
\hline $4 \mathrm{~A}$ & 6 & Patches of bedding in a hard, compact deposit. \\
\hline 4B & 7,8 & $\begin{array}{l}\text { Ashy and dusty with vegetation. Dense accumulation ash } \\
\text { covering multiple levels in the south. }\end{array}$ \\
\hline 5 & $9,10,11,12,13,14$ & $\begin{array}{l}\text { Organic-rich with dense bedding layer (11) and ashy patches. } \\
\text { Dense ash covering multiple levels in the south. }\end{array}$ \\
\hline 6 & $\begin{array}{l}15,15 \mathrm{~A}, 15 \mathrm{~B}, 15 \mathrm{C}, 16 \\
16 \mathrm{~A}, 16 \mathrm{~B}, 17\end{array}$ & $\begin{array}{l}\text { Decomposed bedding with corm casings, silty deposits } \\
\text { below. Several hearths to the south. }\end{array}$ \\
\hline 7 & $18,19(A-D)$ & Silty deposit with spalls near the cave wall. \\
\hline 8 & $\begin{array}{l}20,20 \mathrm{AR}, 21,21 \mathrm{~A} \\
21 \mathrm{~B}, 22,23,23 \mathrm{~B}, 23 \mathrm{C}\end{array}$ & $\begin{array}{l}\text { Powdery, silty, snail-rich deposit with spalls near the cave } \\
\text { wall. Hearths in the south. }\end{array}$ \\
\hline $9 \mathrm{~A}$ & $24,24 \mathrm{~A}, 24 \mathrm{~B}$ & Powdery, silty deposit. Hearths in the south. \\
\hline $9 B$ & $25,25 \mathrm{~A}, 25 \mathrm{~B}, 25 \mathrm{C}$ & Powdery, silty deposit with some ash. Hearths in the south. \\
\hline
\end{tabular}


Important additions from the new excavations are a suite of four tortoise burials containing seven or eight tortoises (Orton 2012) and a new basal lens (L25C).

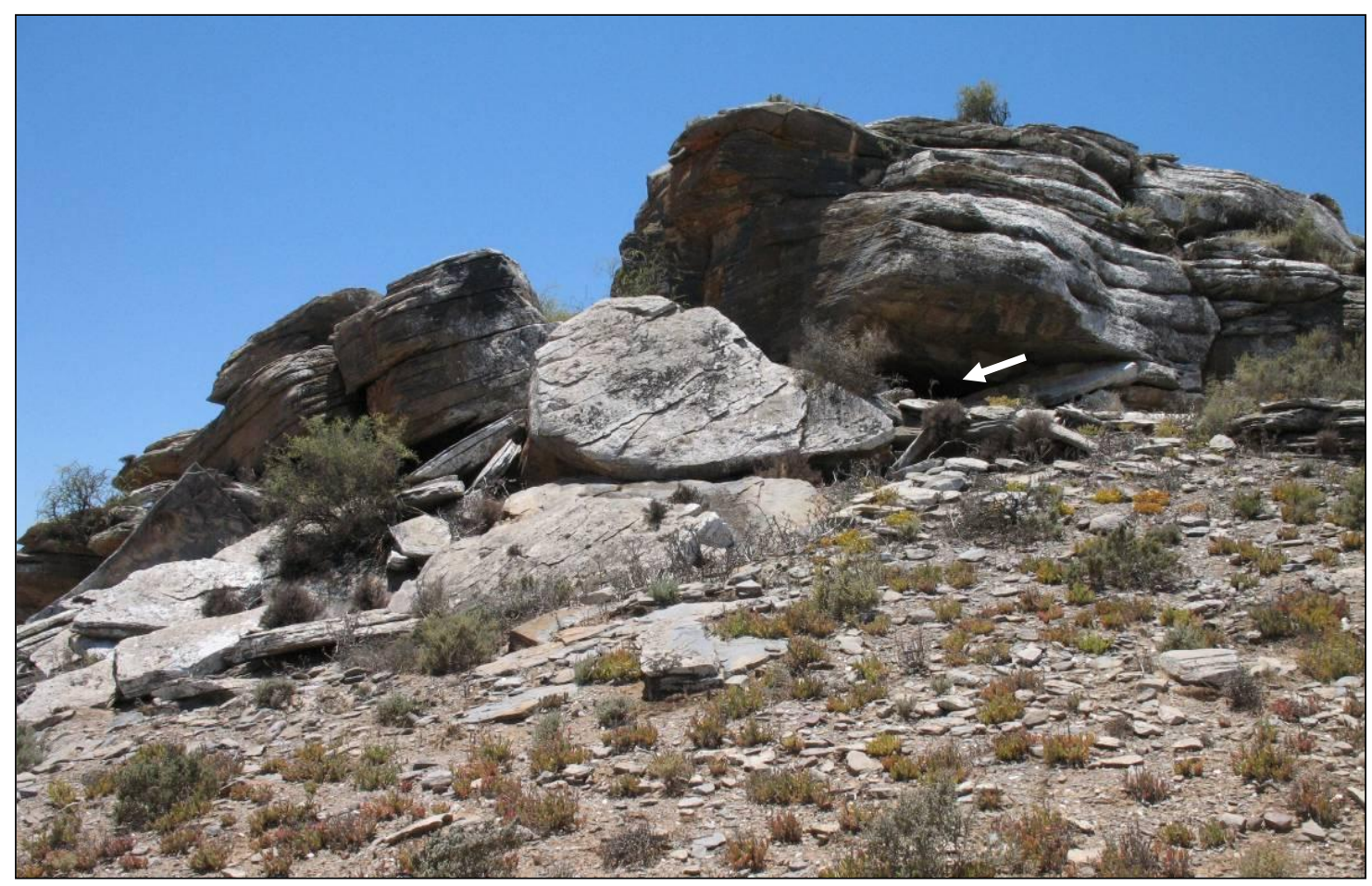

Figure 5.84: View of Reception Shelter and its talus facing east. Its tiny entrance is arrowed.

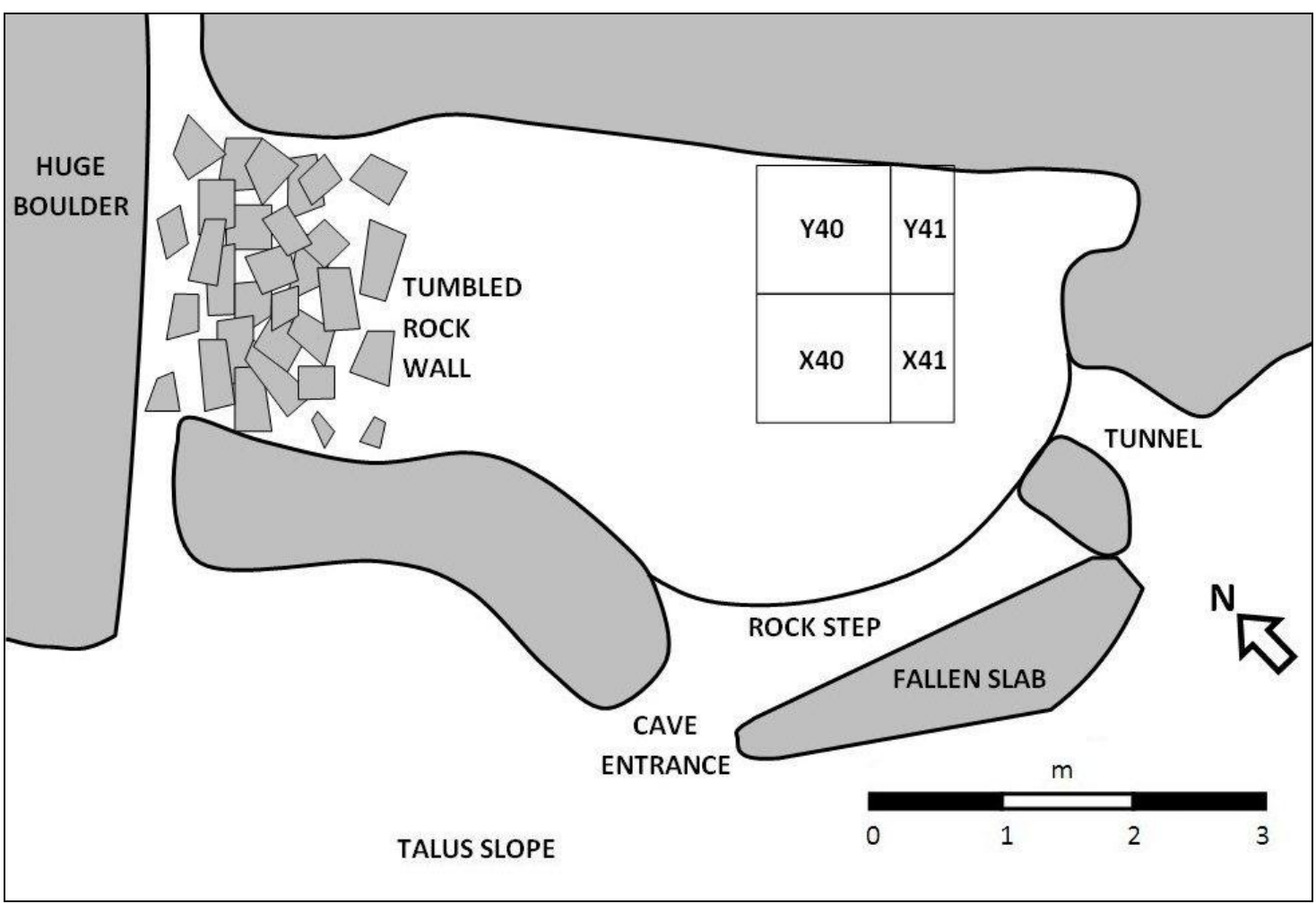

Figure 5.83: Floor plan of the interior of Reception Shelter. 


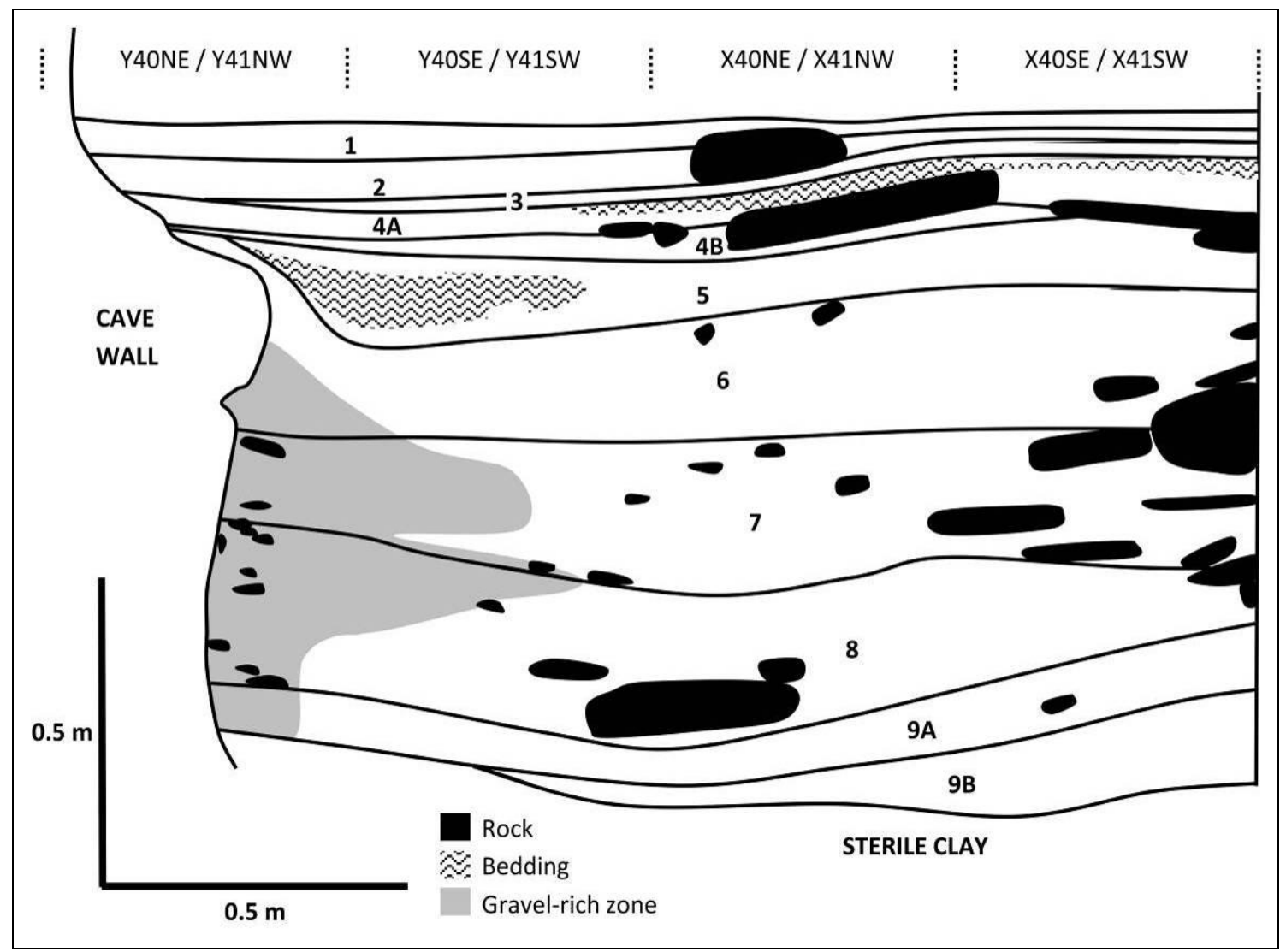

Figure 5.84: Section through the Reception Shelter deposits along the 40/41 line.

The following dates were obtained:

\begin{tabular}{|c|c|c|c|c|}
\hline Lab. No. & Provenience & Material & ${ }^{14} \mathrm{C}$ date $\mathrm{BP}$ & Calibrated age (95.4\%) \\
\hline OxA-24513 & $\begin{array}{l}\text { Layer } 4 \text {, top (X40 } \\
\text { L6) }\end{array}$ & Bone (Chersina angulata) & $589 \pm 23$ & AD 1326-1422 \\
\hline OxA-22876 & $\begin{array}{l}\text { Layer 4, middle } \\
\text { (Y40 L7) }\end{array}$ & Charcoal (sp. unknown) & $622 \pm 21$ & AD 1318-1411 \\
\hline OxA-22982 & $\begin{array}{l}\text { Layer 5, middle } \\
\text { (Y40 L11) }\end{array}$ & Sticks (sp. unknown) & $474 \pm 22$ & AD 1429-1483 \\
\hline AA-89909 & $\begin{array}{l}\text { Layer 6, top (X40 } \\
\text { NW L15A) }\end{array}$ & Bone (Chersina angulata) & $828 \pm 44$ & AD 1177-1293 \\
\hline OxA-22983 & $\begin{array}{l}\text { Layer 7, top (Y40 } \\
\text { L18) }\end{array}$ & Charcoal (sp. unknown) & $2578 \pm 25$ & 794-539 BC \\
\hline OxA-25353 & $\begin{array}{l}\text { Layer 8, middle } \\
\text { (Y40 L22) }\end{array}$ & Bone (Chersina angulata) & $1897 \pm 25$ & AD 85-292 \\
\hline OxA-25354 & $\begin{array}{l}\text { Layer 9A (Y40 } \\
\text { L24) }\end{array}$ & Bone (Bos taurus) & $1840 \pm 26$ & AD 133-336 \\
\hline AA-89910 & $\begin{array}{l}\text { Layer 9B (Y40 } \\
\text { SW L25) }\end{array}$ & Bone (Chersina angulata) & $2560 \pm 49$ & 793-416 BC \\
\hline
\end{tabular}




\begin{tabular}{|c|c|c|c|c|}
\hline Lab. No. & Provenience & Material & ${ }^{14} \mathrm{C}$ date BP & Calibrated age (95.4\%) \\
\hline OxA-24514 & U47 SW Spit 2 & Bone (Chersina angulata) & $394 \pm 23$ & AD 1457-1626 \\
\hline AA-89907 & $\begin{array}{l}\text { P43 NW Level } 1 \\
\text { (5 cm bel surf) }\end{array}$ & OES (Struthio camelus) & $679 \pm 44$ & AD 1220-1951 \\
\hline AA-89908 & $\begin{array}{l}\text { Q43 SW Level } 6 \\
\text { (105 cm bel surf) }\end{array}$ & OES (Struthio camelus) & $\begin{array}{l}21,900 \pm \\
120\end{array}$ & out of range \\
\hline
\end{tabular}

Notes:

- OxA-22892: small sticks taken from bedding material.

- OxA-22876 \& OxA-22983: possibly Acacia karoo and seem to be old wood.

- OxA-24514 from test hole on terrace outside cave mouth.

- $\mathrm{AA-89907,} \mathrm{AA-89908:} \mathrm{from} \mathrm{test} \mathrm{hole} \mathrm{in} \mathrm{talus} \mathrm{slope.}$

\section{$\underline{\text { Cultural material }}$}

By rock shelter standards, this site was relatively poor in cultural finds, although a diverse collection was recovered. Altogether, 1664 flaked stone artefacts were found with just 19 being retouched (Tables 5.111-5.16). Layers 5 and 6 contained $50.5 \%$ of all flaked artefacts and $36.8 \%$ of retouched pieces. Nine out of fourteen quartz backed artefacts are in clear quartz and are spread throughout the sequence. They presumably indicate a Group 3 input to the assemblages, although the lower overall quartz frequencies indicate other influences as well. It should, of course, be remembered that a Group 3 assemblage may look rather different in an environment abundant in cobbles of milky quartz, fine-grained quartzite, silcrete and other rocks. Whether Group 1 is represented by the milky quartz retouched items in Layers $8-9 \mathrm{~A}$ is unknown, but the rarity of retouched items in fine-grained materials may argue against this. Overall, because of the mixing that occurs within rock shelters, the assemblages here cannot be assigned to specific groups. Ochre was rare through much of the sequence (Layers 1-4A have one fragment, Layers 4B-5 have two, Layer 6 has four and Layer 7 has one), but far more common in Layers 8-9A (twenty-three fragments) and Layer 9B (seven fragments). Included in Layer 8 was a large lump of very hard ochre exhibiting grinding striations. Layer 5 contained a small slab of rock with an ochre stain on it, while a lower grindstone in Layer 7 was heavily ochred and found upside down. It is intriguing that 
Layers 1 to $4 \mathrm{~A}$, representing the historical occupation of the cave, contain a prehistoric stone artefact assemblage essentially unchanged from those below.

Table 5.111: Stone artefacts from Reception Shelter, Layers 1-4A. Clear quartz artefacts are summed in parentheses in the quartz column.

\begin{tabular}{|c|c|c|c|c|c|c|}
\hline & $\begin{array}{l}\frac{N}{\pi} \\
\stackrel{0}{\partial} \\
0\end{array}$ & O্ & 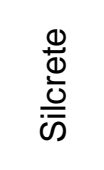 & $\begin{array}{l}\frac{0}{N} \\
\frac{\pi}{0} \\
\frac{0}{0}\end{array}$ & 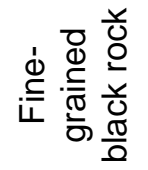 & $\frac{\bar{\Phi}}{\stackrel{ \pm}{\Xi}}$ \\
\hline Bipolar core & 1 & - & - & - & - & - \\
\hline Irregular core & 2 & - & 1 & - & - & - \\
\hline Backed bladelet & $1(1)$ & 1 & - & - & - & - \\
\hline MRP & 1 & - & - & - & - & - \\
\hline Blade & - & - & - & 1 & - & - \\
\hline Bladelet & 3 & - & - & 1 & - & - \\
\hline Flake & 49 & 1 & 13 & 11 & 6 & 1 \\
\hline Edge-damaged flake & 5 & 1 & 2 & - & - & - \\
\hline Chunk & 17 & $3^{*}$ & 3 & - & 1 & 2 \\
\hline Edge-damaged chunk & 1 & - & - & - & - & - \\
\hline Chip & 51 & 1 & 2 & - & - & - \\
\hline Total & 131 & 7 & 21 & 13 & 7 & 3 \\
\hline Stone material \% total & 72.0 & 3.8 & 11.5 & 7.1 & 3.8 & 1.6 \\
\hline Stone material \% formal & 66.7 & 33.3 & - & - & - & - \\
\hline Hammer stone & - & 1 & - & - & - & - \\
\hline
\end{tabular}

${ }^{*}$ One chunk is also the hammer stone.

Table 5.112: Stone artefacts from Reception Shelter, Layers 4B-5. Clear quartz retouched artefacts are indicated in parentheses in the quartz column.

\begin{tabular}{|c|c|c|c|c|c|c|}
\hline & 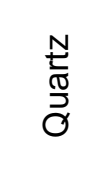 & ల) & $\frac{\frac{d}{0}}{\frac{\overline{0}}{\bar{\omega}}}$ & 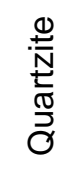 & 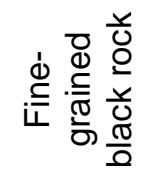 & $\begin{array}{l}\bar{\Phi} \\
\bar{\Xi}\end{array}$ \\
\hline Bipolar core & 14 & - & - & - & - & - \\
\hline Single platform core & - & - & - & 1 & *1 & 1 \\
\hline Irregular & 3 & - & 1 & - & - & - \\
\hline Backed bladelet & $3(2)$ & - & - & - & - & - \\
\hline Backed piece fragment & $1(1)$ & - & - & - & - & - \\
\hline Blade & - & - & 2 & - & 1 & 1 \\
\hline Bladelet & 14 & - & 2 & 1 & - & - \\
\hline Flake & 173 & 7 & 41 & 43 & 37 & 11 \\
\hline
\end{tabular}




\begin{tabular}{|c|c|c|c|c|c|c|}
\hline & $\begin{array}{l}\stackrel{N}{t} \\
\stackrel{0}{3} \\
0\end{array}$ & O্ & $\frac{\frac{\Phi}{ \pm}}{\frac{\bar{\omega}}{\bar{\omega}}}$ & 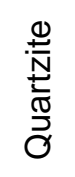 & 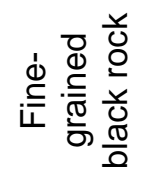 & $\begin{array}{l}\bar{\Phi} \\
\bar{\Xi}\end{array}$ \\
\hline Edge-damaged flake & 5 & - & - & - & - & - \\
\hline Chunk & 47 & 2 & 7 & 2 & 7 & 5 \\
\hline Chip & 178 & - & 3 & 1 & 1 & 2 \\
\hline Total & 438 & 9 & 56 & 48 & 47 & 20 \\
\hline Stone material \% total & 70.9 & 1.5 & 9.1 & 7.8 & 7.6 & 3.3 \\
\hline Stone material \% formal & 100.0 & - & - & - & - & - \\
\hline Hammer stone & - & - & - & - & 1 & - \\
\hline Lower grindstone & - & - & - & - & - & 2 \\
\hline Lower grindstone fragment & - & - & - & - & - & 1 \\
\hline Grindstone fragment & - & - & - & - & - & 1 \\
\hline
\end{tabular}

${ }^{*}$ The single platform core is also the hammer stone.

Table 5.113: Stone artefacts from Reception Shelter, Layer 6. Clear quartz retouched artefacts are indicated in parentheses in the quartz column.

\begin{tabular}{|c|c|c|c|c|c|c|}
\hline & $\begin{array}{l}\frac{N}{ \pm} \\
\stackrel{\sigma}{J} \\
0\end{array}$ & O্ & $\frac{\frac{\Phi}{ \pm}}{\frac{\bar{\omega}}{\bar{\omega}}}$ & $\begin{array}{l}\frac{9}{N} \\
\frac{N}{0} \\
\frac{\pi}{0} \\
0\end{array}$ & 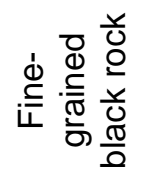 & $\frac{\grave{\Phi}}{\bar{\Xi}}$ \\
\hline Bipolar core & 4 & - & - & - & - & - \\
\hline Single platform core & 2 & - & - & - & - & - \\
\hline Backed bladelet & $1(1)$ & - & - & - & - & - \\
\hline Curve-backed bladelet & $1(1)$ & - & - & - & - & - \\
\hline Backed piece fragment & $1(1)$ & - & - & - & - & - \\
\hline Adze & - & 1 & - & - & - & - \\
\hline Miscellaneous retouched piece & - & - & - & - & 2 & - \\
\hline Blade & 1 & 1 & - & 1 & - & - \\
\hline Bladelet & 6 & - & - & - & 1 & - \\
\hline Edge-damaged bladelet & 1 & - & - & - & - & - \\
\hline Flake & 72 & 1 & 20 & 32 & 37 & 9 \\
\hline Edge-damaged flake & 4 & 1 & - & 1 & 1 & - \\
\hline Chunk & 29 & - & 2 & 4 & 2 & 4 \\
\hline Edge-damaged chunk & - & - & - & - & - & 1 \\
\hline Chip & 95 & - & 3 & 3 & 3 & - \\
\hline Total & 217 & 4 & 25 & 41 & 46 & 14 \\
\hline Stone material \% total & 62.5 & 1.2 & 7.2 & 11.8 & 13.3 & 4.0 \\
\hline Stone material \% formal & 50 & 16.7 & - & - & 33.3 & - \\
\hline Hammer stone fragment & - & - & - & 2 & - & - \\
\hline
\end{tabular}


Table 5.114: Stone artefacts from Reception Shelter, Layer 7. Clear quartz retouched artefacts are indicated in parentheses in the quartz column.

\begin{tabular}{|c|c|c|c|c|c|c|}
\hline & $\begin{array}{l}\frac{N}{t} \\
\stackrel{0}{J} \\
\sigma\end{array}$ & O & $\frac{\frac{\Phi}{ \pm}}{\frac{\bar{d}}{\bar{\omega}}}$ & 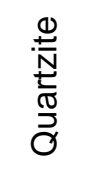 & 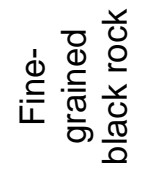 & $\begin{array}{l}\bar{\Phi} \\
\stackrel{\Phi}{0}\end{array}$ \\
\hline Bipolar core & 1 & - & - & - & - & - \\
\hline Single platform core & - & - & 1 & - & - & - \\
\hline Irregular core & 2 & - & - & - & $1^{*}$ & - \\
\hline Backed bladelet & $1(1)$ & - & - & - & - & - \\
\hline MSA retouched flake & - & - & - & - & $1^{* *}$ & - \\
\hline Bladelet & 3 & - & 1 & - & - & - \\
\hline Flake & 29 & 1 & 2 & 3 & - & 3 \\
\hline Edge-damaged flake & - & 1 & - & - & - & - \\
\hline Chunk & 10 & 4 & - & - & - & - \\
\hline Chip & 50 & 4 & - & - & 1 & - \\
\hline Total & 96 & 10 & 4 & 3 & 3 & 3 \\
\hline Stone material $\%$ total & 81.4 & 8.5 & 3.4 & 2.5 & 2.5 & 2.5 \\
\hline Stone material \% formal & 100.0 & - & - & - & - & - \\
\hline Lower grindstone & - & - & - & - & - & 1 \\
\hline Upper grindstone/anvil & - & - & - & - & 1 & - \\
\hline Upper grindstone/hammer stone & - & - & - & 1 & - & - \\
\hline
\end{tabular}

* Irregular core is also the upper grindstone/anvil.

${ }^{* \star}$ Excluded from material frequencies.

Table 5.115: Stone artefacts from Reception Shelter, Layers 8-9A.

\begin{tabular}{|c|c|c|c|c|c|c|}
\hline & $\begin{array}{l}\frac{N}{\sigma} \\
\stackrel{0}{0}\end{array}$ & ల్ & $\frac{\frac{d}{0}}{\frac{\bar{\omega}}{\dot{\omega}}}$ & 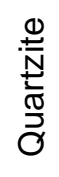 & 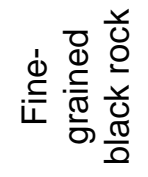 & $\frac{\grave{\Phi}}{\stackrel{ \pm}{\square}}$ \\
\hline Bipolar core & 3 & - & - & - & - & - \\
\hline Single platform core & 2 & - & 1 & 2 & $1^{*}$ & - \\
\hline Irregular core & 4 & 1 & 2 & - & - & - \\
\hline Backed point & 1 & - & - & - & - & - \\
\hline Segment & 1 & - & - & - & - & - \\
\hline Trapezium & 1 & - & - & - & - & - \\
\hline Backed piece fragment & 1 & - & - & - & - & - \\
\hline Blade & - & 1 & - & - & - & - \\
\hline Edge-damaged blade & 1 & - & - & - & - & - \\
\hline Bladelet & 5 & 1 & - & - & - & - \\
\hline Flake & 61 & 10 & 3 & 3 & - & 6 \\
\hline
\end{tabular}




\begin{tabular}{|c|c|c|c|c|c|c|}
\hline & 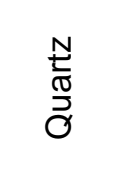 & D্ & $\frac{\frac{\Phi}{\omega}}{\frac{\bar{U}}{\bar{\omega}}}$ & 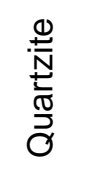 & 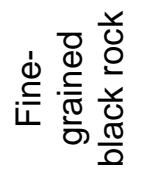 & 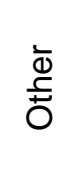 \\
\hline Edge-damaged flake & 5 & 1 & - & - & 1 & - \\
\hline Chunk & 23 & 4 & 4 & 1 & 1 & 7 \\
\hline Edge-damaged chunk & 1 & - & - & - & - & - \\
\hline Chip & 70 & 3 & 2 & - & - & 1 \\
\hline Total & 179 & 21 & 12 & 7 & 3 & 14 \\
\hline Stone material \% total & 76.5 & 9.0 & 5.1 & 2.6 & 0.9 & 6.0 \\
\hline Stone material \% formal & 100.0 & - & - & - & - & - \\
\hline Hammer stone & - & - & - & - & 1 & $2^{* *}$ \\
\hline Upper grindstone/hammer stone & - & - & - & 3 & - & - \\
\hline Upper grindstone & - & - & - & 2 & - & - \\
\hline Lower grindstone & - & - & - & - & - & 1 \\
\hline Lower grindstone fragment & - & - & - & 1 & - & 1 \\
\hline Grindstone fragment & - & - & - & 1 & - & - \\
\hline
\end{tabular}

*Single platform core is also the hammer stone.

${ }^{* *}$ Both hammer stones are in sandstone.

Table 5.116: Stone artefacts from Reception Shelter, Layer 9B. Clear quartz artefacts are summed in parentheses in the quartz column.

\begin{tabular}{|c|c|c|c|c|c|c|}
\hline & $\begin{array}{l}\stackrel{N}{\mathbb{N}} \\
\stackrel{0}{\partial}\end{array}$ & ల్ & $\frac{\frac{\Phi}{0}}{\frac{\bar{\omega}}{\bar{\omega}}}$ & $\begin{array}{l}\stackrel{0}{\stackrel{N}{N}} \\
\frac{0}{0} \\
\frac{0}{0}\end{array}$ & 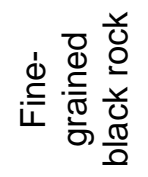 & $\frac{\grave{\Phi}}{\stackrel{\check{D}}{\Xi}}$ \\
\hline Bipolar core & 3 & - & - & - & - & - \\
\hline Irregular core & 2 & 1 & 1 & - & - & - \\
\hline Sidescraper & $1(1)$ & - & - & - & - & - \\
\hline Backed point & $1(1)$ & - & - & - & - & - \\
\hline MRP & 1 & - & - & - & - & - \\
\hline Blade & 1 & 1 & - & - & - & - \\
\hline Bladelet & 6 & - & - & - & - & - \\
\hline Flake & 72 & 4 & 7 & 1 & 2 & 3 \\
\hline Edge-damaged flake & 2 & - & 1 & - & - & - \\
\hline Chunk & 13 & 1 & - & - & 1 & 1 \\
\hline Edge-damaged chunk & 1 & 1 & - & - & - & - \\
\hline Chip & 32 & 2 & 1 & - & - & - \\
\hline Total & 135 & 10 & 10 & 1 & 3 & 4 \\
\hline Stone material $\%$ total & 82.8 & 6.1 & 6.1 & 0.6 & 1.8 & 2.5 \\
\hline
\end{tabular}




\begin{tabular}{|c|c|c|c|c|c|c|}
\hline & $\underset{\stackrel{N}{\frac{T}{2}}}{\stackrel{0}{0}}$ & U & $\begin{array}{l}\frac{\Phi}{\Delta} \\
\frac{d}{\bar{D}}\end{array}$ & 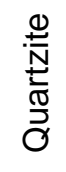 & 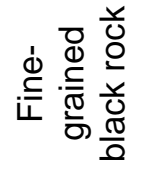 & $\frac{\grave{d}}{\stackrel{ \pm}{0}}$ \\
\hline Stone material \% formal & 100.0 & - & - & - & - & - \\
\hline Upper grindstone & - & - & - & 1 & - & - \\
\hline Lower grindstone/anvil & - & - & - & - & - & 1 \\
\hline
\end{tabular}

Ostrich eggshell beads remain small to medium throughout the occupation of the shelter with mean external diameters ranging between 3.80 and $5.80 \mathrm{~mm}$ (Table 5.117). Interestingly, very large beads are completely absent from the sample of 84 reflected in Figure 5.85. It should be noted that 15 of the beads from Layer $9 \mathrm{~A}$ came from a single bucket of deposit and almost all bore ochre traces; they probably came from a single item of jewellery. Evidence of bead manufacture is entirely absent. Another form of worked ostrich eggshell is in the form of fragments, often triangular in shape, that have been 'retouched' along an inner margin (Figure 5.86). They came from Layers 5 (1), 6 (3) and 7 (1). Webley (1992b) reports similar artefacts from Frummel Bakkies and assumes they had a utilitarian function. Fragments of painted ostrich eggshell were found in Layers 3, 5 and 6 with twelve of the fifteen examples from the latter (Figure 5.86). Such finds are rarely reported but include one similar fragment from Apollo 11 in Namibia (Wendt 1972) and those from Buzz Shelter reported below.

Table 5.117: Summary statistics for finished ostrich eggshell beads from Reception Shelter.

\begin{tabular}{|c|c|c|c|c|}
\hline Layers & & Outside diameter (mm) & Aperture diameter (mm) & Thickness (mm) \\
\hline \multirow{4}{*}{$1-4 A(n=2)$} & Mean & 4.90 & 1.55 & 1.77 \\
\hline & Std Deviation & 0.76 & 0.22 & 0.06 \\
\hline & Minimum & 4.36 & 1.39 & 1.73 \\
\hline & Maximum & 5.43 & 1.70 & 1.81 \\
\hline \multirow{4}{*}{$\begin{array}{l}\text { 4B-5 } \\
\left(n=17^{*}\right)\end{array}$} & Mean & 5.85 & 2.15 & 1.57 \\
\hline & Std Deviation & 0.95 & 0.38 & 0.23 \\
\hline & Minimum & 4.24 & 1.21 & 1.27 \\
\hline & Maximum & 7.29 & 2.76 & 1.92 \\
\hline
\end{tabular}




\begin{tabular}{|c|c|c|c|c|}
\hline Layers & & Outside diameter (mm) & Aperture diameter $(\mathrm{mm})$ & Thickness $(\mathrm{mm})$ \\
\hline \multirow{4}{*}{$6\left(n=7^{* *}\right)$} & Mean & 4.44 & 1.82 & 1.38 \\
\hline & Std Deviation & 0.73 & 0.47 & 1.12 \\
\hline & Minimum & 3.56 & 1.27 & 1.13 \\
\hline & Maximum & 5.42 & 2.47 & 1.75 \\
\hline \multirow{4}{*}{$7\left(n=6^{\dagger}\right)$} & Mean & 3.86 & 1.49 & 1.43 \\
\hline & Std Deviation & 0.25 & 0.14 & 0.15 \\
\hline & Minimum & 3.52 & 1.23 & 1.27 \\
\hline & Maximum & 4.18 & 1.59 & 1.67 \\
\hline \multirow{4}{*}{$\begin{array}{l}8-9 A \\
\left(n=48^{\dagger \dagger}\right)\end{array}$} & Mean & 4.93 & 1.86 & 1.49 \\
\hline & Std Deviation & 0.94 & 0.40 & 0.18 \\
\hline & Minimum & 3.18 & 0.84 & 1.03 \\
\hline & Maximum & 6.48 & 2.67 & 1.82 \\
\hline \multirow{4}{*}{$9 B(n=4)$} & Mean & 4.27 & 1.56 & 1.47 \\
\hline & Std Deviation & 0.47 & 0.28 & 0.19 \\
\hline & Minimum & 3.68 & 1.34 & 1.23 \\
\hline & Maximum & 4.82 & 1.94 & 1.66 \\
\hline
\end{tabular}

*Two beads were burnt and exfoliated such that for thickness $n=15$.

${ }^{* *}$ One bead was burnt and exfoliated such that for thickness $n=6$.

${ }^{\dagger}$ One bead was split laterally such that for thickness $n=5$.

${ }^{t+}$ Six beads were burnt and exfoliated such that for thickness $n=42$.

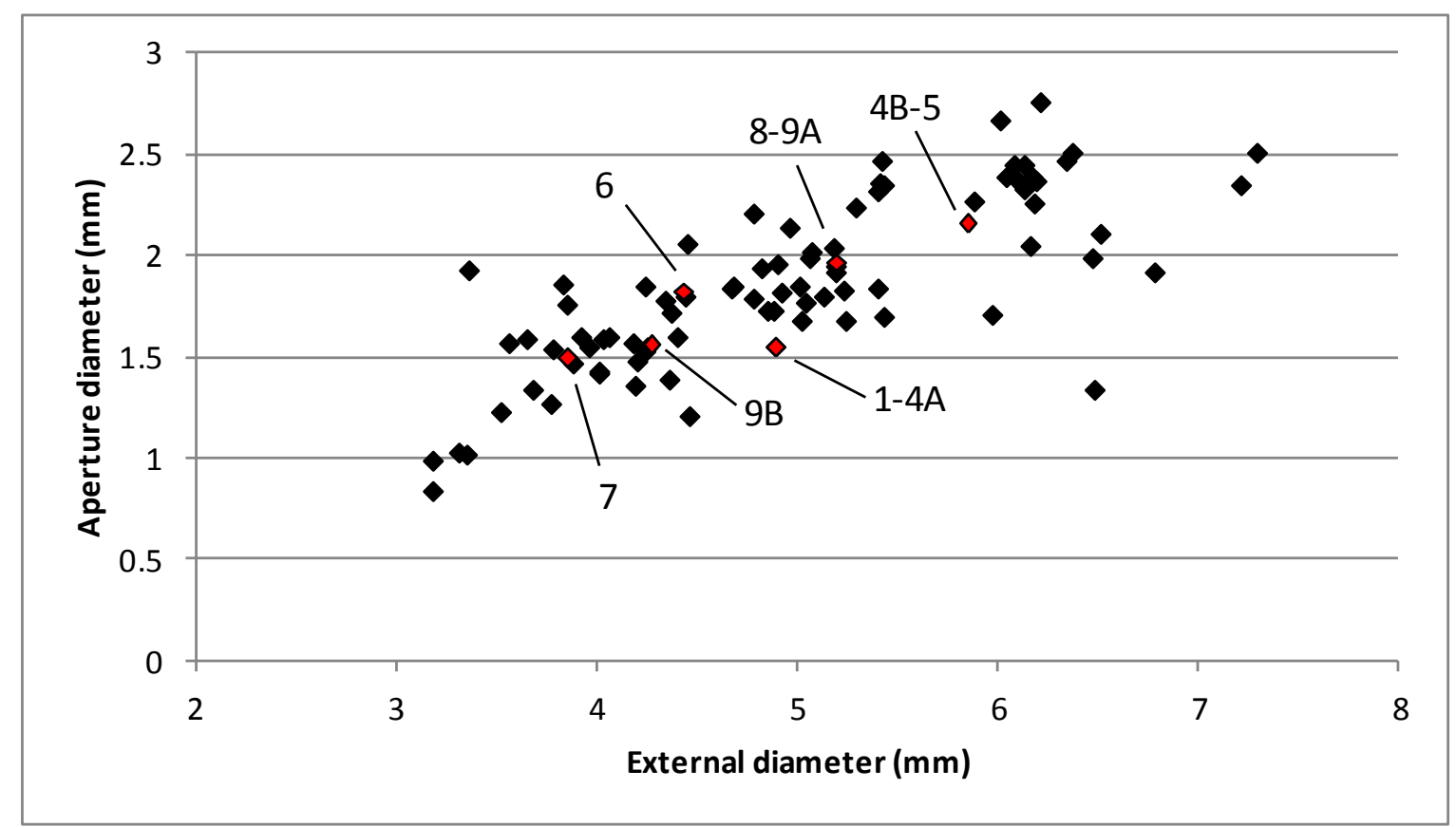

Figure 5.85: Scatter plot of ostrich eggshell bead dimensions from Reception Shelter. Red symbols represent layer means as labelled. 


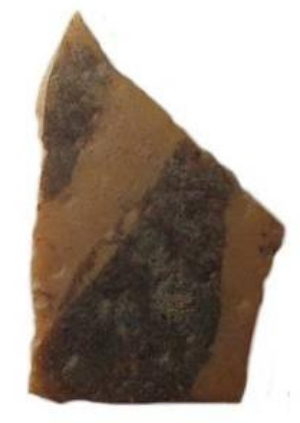

A

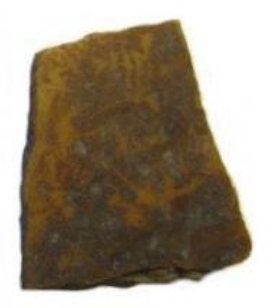

D

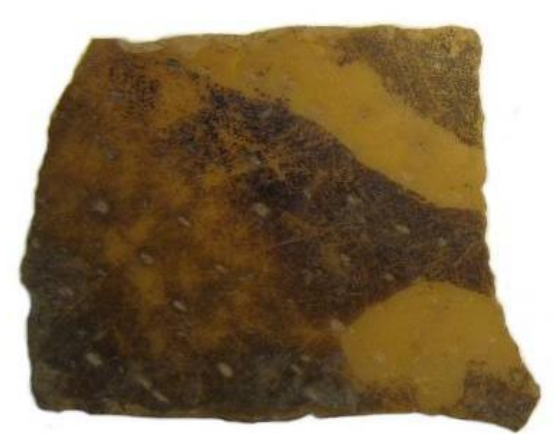

B

E

$\mathrm{F}$
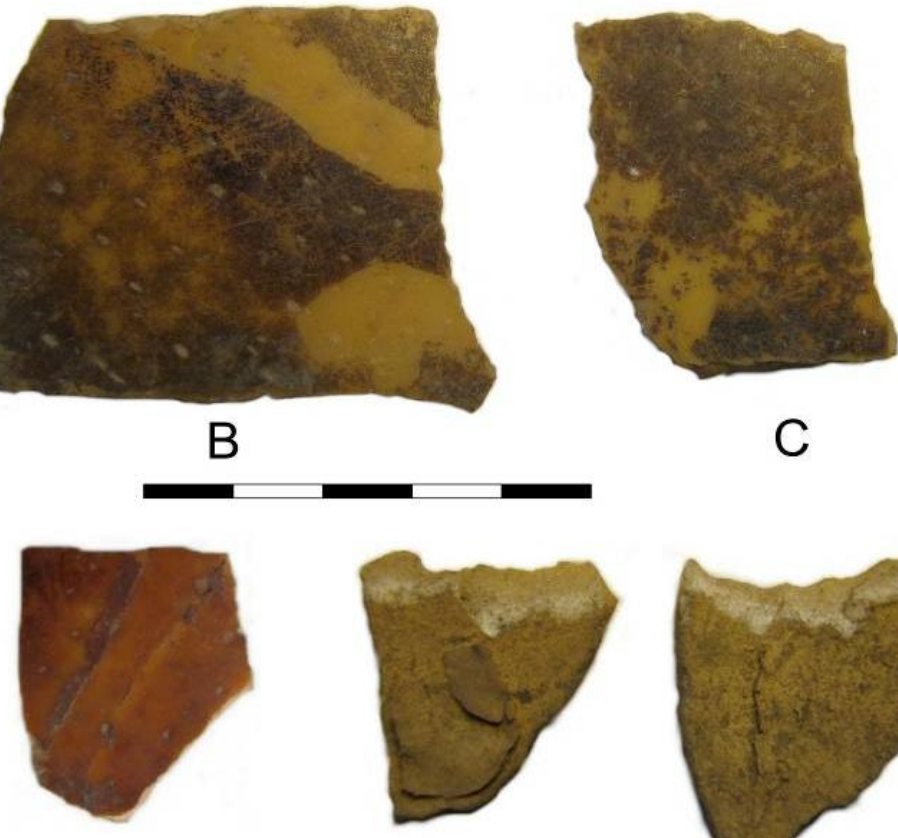

C

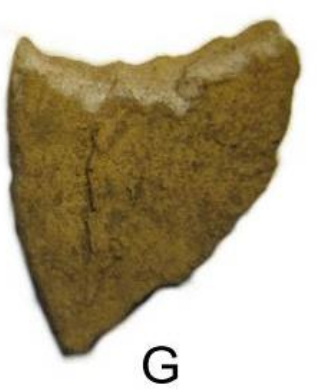

Figure 5.86: Painted (A-E) and worked (F-G) ostrich eggshell fragments from Reception Shelter Layer 6 . Scale in $5 \mathrm{~mm}$ intervals.

Pottery is present throughout the sequence but is very sparse in the upper layers. The uppermost sherds in fact lie in Layer 3, possibly suggesting that by the time historical use of the shelter commenced indigenous pottery was no longer being used there. Although a handful of sherds came from the middle layers of the site, dating to the fourteenth and fifteenth centuries $A D$, the majority of sherds originate from Layers 8 ( 6 sherds) and $9 A$ (32 sherds) where the domestic animal bones are also concentrated. Layer 5 includes a vertical or possibly flared rim with a simple rounded form and a diameter of approximately $140 \mathrm{~mm}$. In Layer 6 a small rim sherd has an everted lip form and is painted red to just below the lip. This layer is the only one to include ochred sherds with three of the eleven being painted. A vertically oriented rim with a thickened flat and slightly bevelled lip occurs in Layer 8. No decorated sherds were found. Pottery thickness increases progressively through time: in Layers 8-9A mean thickness is $5.21 \pm$ $0.71 \mathrm{~mm}$, in Layer 6 it is $6.01 \pm 1.63 \mathrm{~mm}$, in Layers $4 \mathrm{~B}-5$ it is $7.59 \pm 1.45 \mathrm{~mm}$ and in Layers $1-4 \mathrm{~A}$ it is $8.24 \pm 2.64 \mathrm{~mm}$. 
The talus slope was rich in pottery with decorated sherds found there and on the platform above the cave. These include: two refitting sherds with broad-incised decoration in a basket-weave pattern; a tiny sherd with parallel, very closely spaced, fine-incised lines that may have been dragged with a comb; another with similar but more widely spaced lines that could have been etched into the already dry sherd (cf. Bakoond, Orton 2009b); a sherd with a row of small, circular impressions; and a rim with multiple fine-incised lines below the lip (Figure 5.87).

A few items from the upper four layers are historical. These include fragments of thread and of a glass mirror, a bone button, a match stick, wire and other metal fragments, a rusted adze or axe head, several wheat grains and part of a leather shoe sole $80 \mathrm{~mm}$ long. The button, which comes from Layer 1, has four holes and a recessed centre. It appears to be a 19th-century British-turned bone button (Peacock 1978: fig. 13). The upper levels of the excavation were dominated by dense dung with bedding layers immediately below. The shoe sole is certain to be in place. The Layer 4 date of AD 1326-1422 (OxA-24513) presumably reflects the surface on which the historical occupation began. The fact that historical items occur in tandem with Stone Age material in these levels opens up the possibility of indigenous people working for European colonists in the nineteenth century. Archival records show that the Varsrivier farm was first owned in quitrent from 1843 and the ruined buildings are thus likely to date between then and 1899 when the farm was subdivided (N. Amschwand, pers. comm. 2011). This age matches that of the button. 


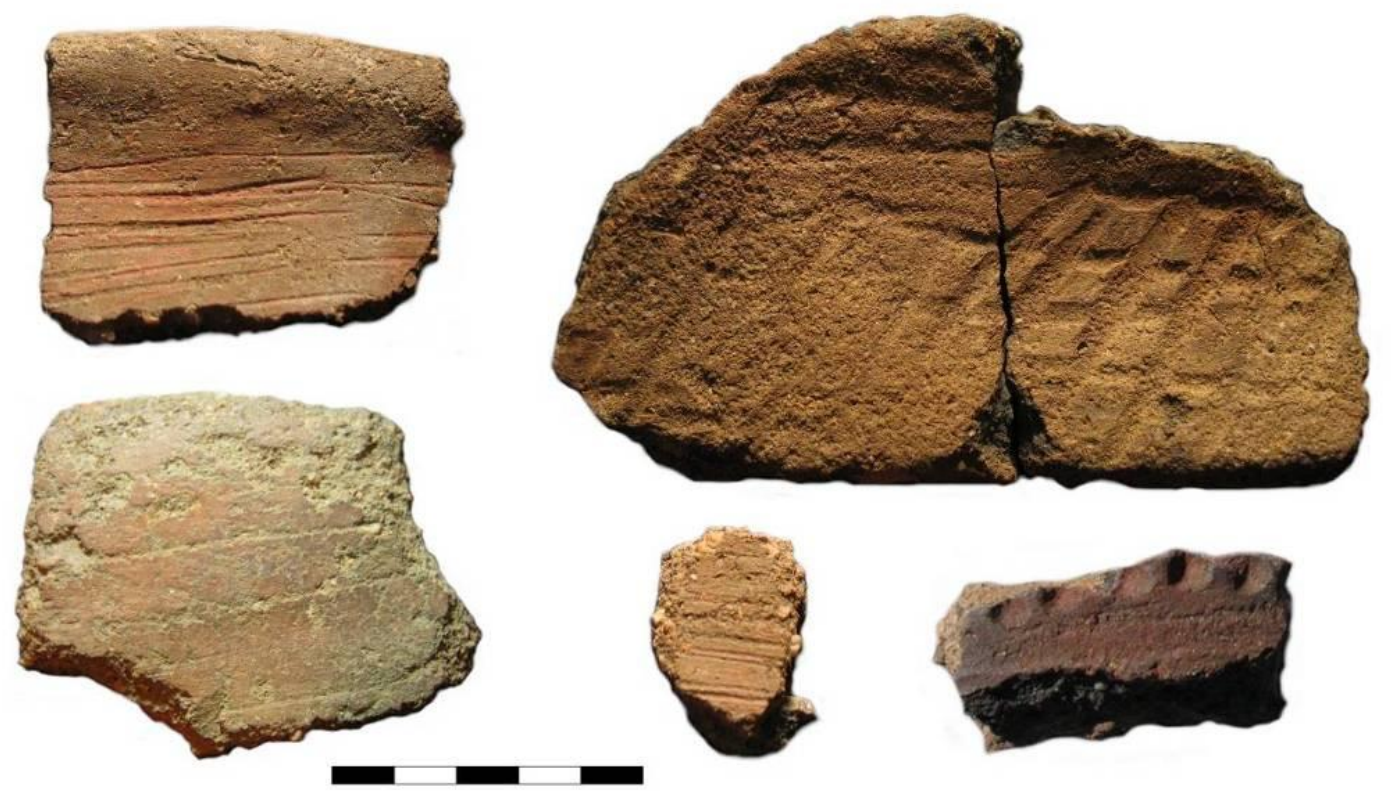

Figure 5.87: Decorated potsherds from the Reception Shelter talus. Scale in $5 \mathrm{~mm}$ intervals.

\subsubsection{Buzz Shelter (VR005)}

\section{The site}

Buzz Shelter (VR005) is located in a small cave in partly metamorphosed limestone along the north bank of the Varsche River ( $\left.31^{\circ} 31^{\prime} 25.1^{\prime \prime} \mathrm{S} 18^{\circ} 36^{\prime} 01.0^{\prime \prime} \mathrm{E}\right)$. It is $43 \mathrm{~km}$ from the coast and $16.5 \mathrm{~km}$ from the Olifants River. A full description of the site and its deposits is contained in Orton et al. (2011) but the excavation inside the shelter has now been expanded to $4 \mathrm{~m}^{2}$ - only this excavation is considered here (Figure 5.88), since those outside are poorly stratified. The grouping of excavation levels is shown in Table 5.118. The roof of the cave is formed from a thin layer of limestone which has been eroding back with time (Figure 5.89). As such, earlier occupations appear to have been focused towards the south and as the lip migrated northwards so did the habitable floor space inside the shelter. Significantly, this site has yielded early, but as yet not directly dated caprine teeth from Layer 3. 


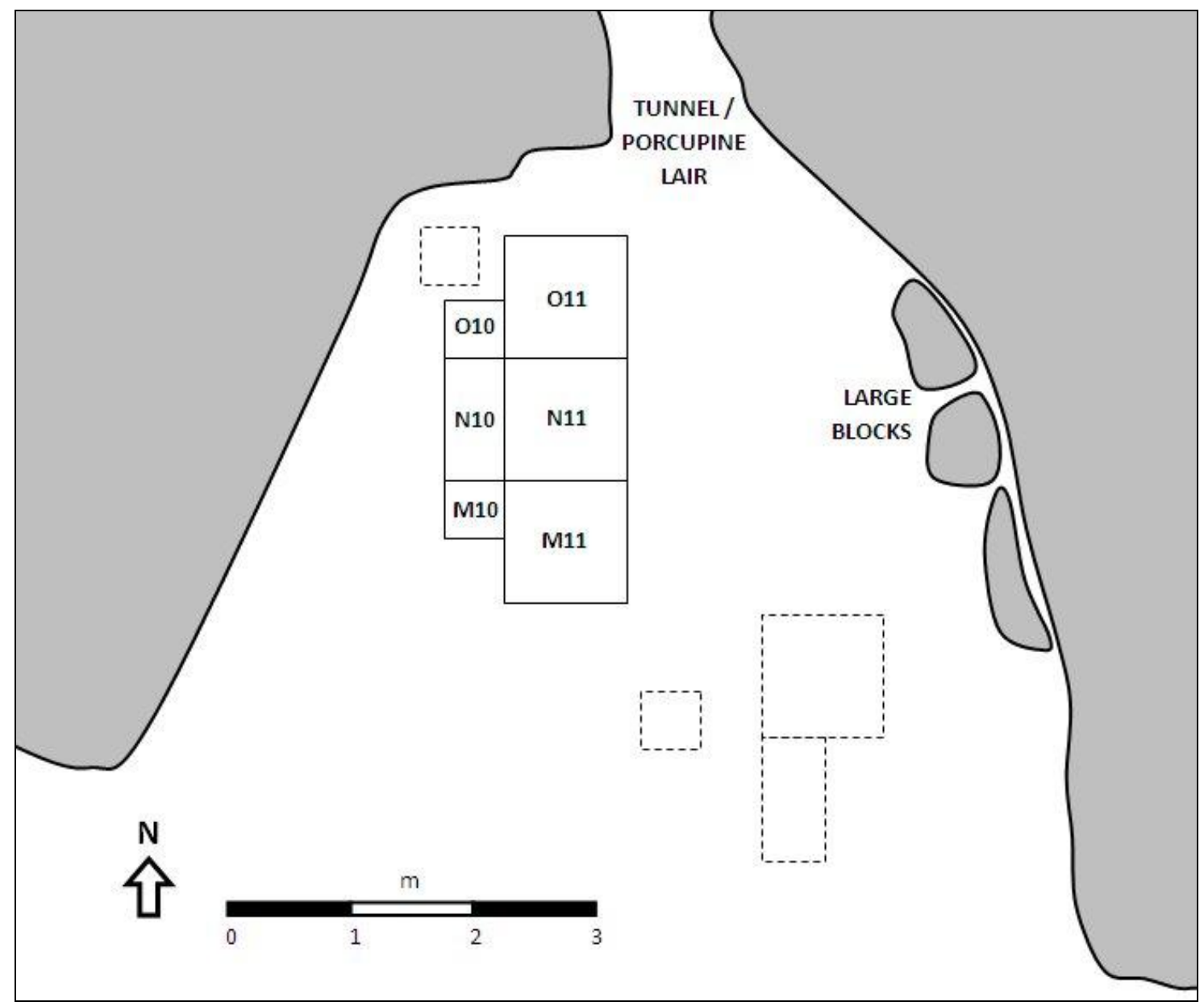

Figure 5.88: Floor plan of the interior of Buzz Shelter. The dashed outlines denote other test excavations.

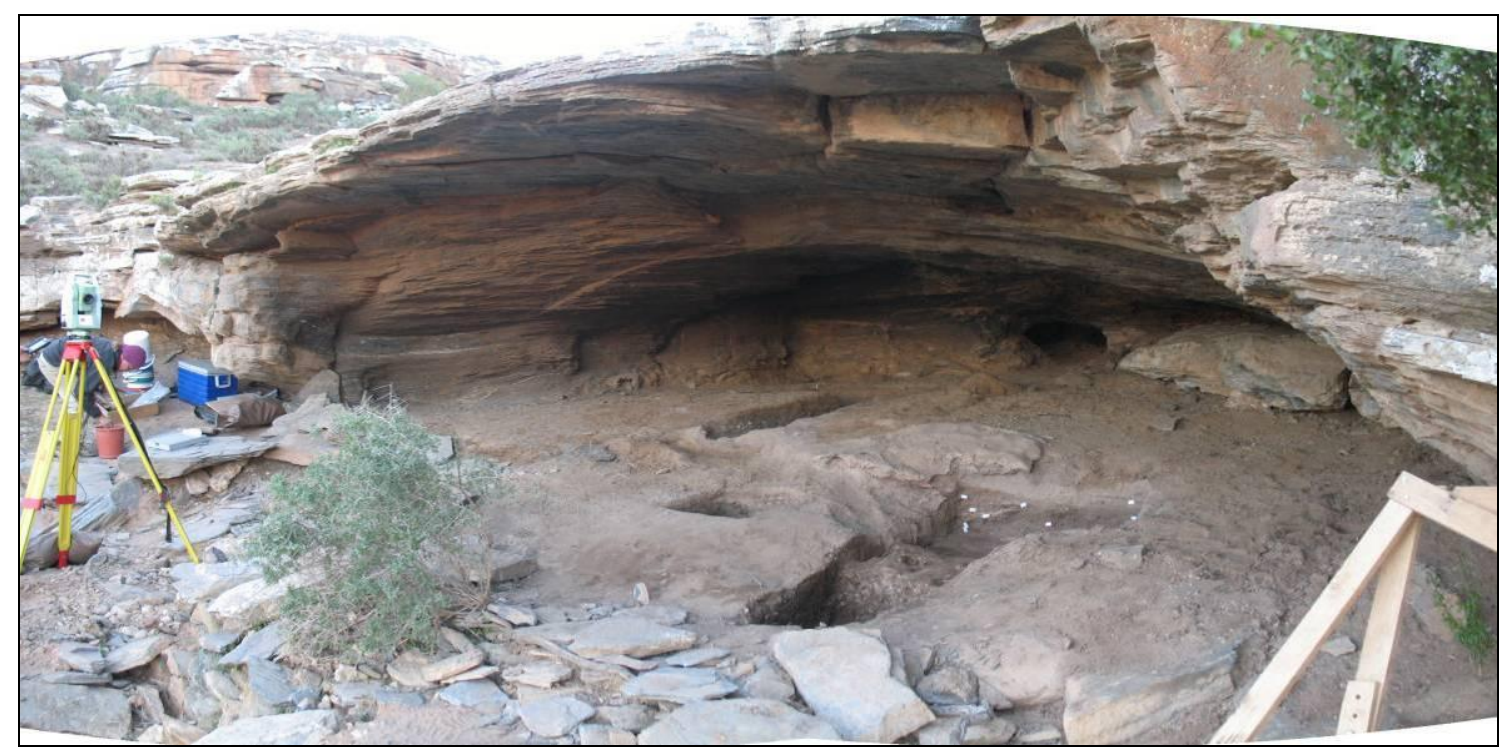

Figure 5.89: View into Buzz Shelter looking towards the northwest. The excavation described here is the rear trench. 
Table 5.118: Stratigraphic grouping of levels at Buzz Shelter. Layer numbers follow Orton et al. (2011).

\begin{tabular}{|c|c|c|}
\hline Layer & Excavation levels & Brief description \\
\hline 1 & $1,1 a, 1 b, 2,2 a$ & $\begin{array}{l}\text { Crusty dung with animal hairs. Becomes looser lower down but } \\
\text { towards the north it has many sticks and spalls (like Layer 2). }\end{array}$ \\
\hline 2 & $3,3 a, 3 b, 3 c$ & $\begin{array}{l}\text { Poorly stratified and variable layer of round droppings (mostly in the } \\
\text { south), roof spalls, and sticks (mostly in the north). Overlies a clear } \\
\text { base throughout. }\end{array}$ \\
\hline 3 & $\begin{array}{l}8,4,4 \mathrm{a}, 4 \mathrm{~b}, 4 \mathrm{GH} \\
5,5 \mathrm{ASH}, 6,6 \mathrm{~b}, 7 \\
7 \mathrm{NTR}\end{array}$ & $\begin{array}{l}\text { Finer deposits with well-preserved bedding grass and few droppings. } \\
\text { Generally excellent organic preservation. (7NTR = O10SE only) }\end{array}$ \\
\hline 4 & $\begin{array}{l}\text { 9, 9a, 9aii, 9aiii, } \\
\text { 9b, 9c, 9d, 10, } \\
\text { 10a, 10b, } 11\end{array}$ & $\begin{array}{l}\text { Pit deposits are unconsolidated with dense, variably preserved } \\
\text { grass. Stratified deposits are powdery with decomposing grass } \\
\text { layers. Possibly multiple overlapping hollows. Grass sometimes } \\
\text { extends from stratified deposits into pit. }\end{array}$ \\
\hline 5 & 12,13 & Fine, ashy deposits with small amounts of decomposing grass. \\
\hline 6 & $\begin{array}{l}\text { 14, 14a, 14b, 14c, } \\
15,15 a, 15 b, 15 c \\
7 N T R\end{array}$ & $\begin{array}{l}\text { Fine, ashy deposits with variably preserved but mostly well } \\
\text { decomposed grass. Overlies decomposing bedrock. (7NTR = all } \\
\text { squares except O10SE) }\end{array}$ \\
\hline 7 & 16 & Fine, moist, clay-rich, dark brown deposit with little content. \\
\hline
\end{tabular}

The following dates were obtained:

\begin{tabular}{|c|c|c|c|c|}
\hline Lab. No. & Provenience & Material & ${ }^{14} \mathrm{C}$ date $\mathrm{BP}$ & Calibrated age (95.4\%) \\
\hline OxA-22984 & Layer 2 (M11NE L3) & $\begin{array}{l}\text { Charcoal (species } \\
\text { unknown) }\end{array}$ & $3327 \pm 26$ & $1627-1455 \mathrm{BC}$ \\
\hline OxA-25352 & $\begin{array}{l}\text { Layer } 2 \text { (011 SW } \\
\text { L3a) }\end{array}$ & $\begin{array}{l}\text { Bone (Chersina } \\
\text { angulata) }\end{array}$ & $1646 \pm 25$ & AD 410-543 \\
\hline OxA-24515 & $\begin{array}{l}\text { Layer } 3 \text { top (011 SW } \\
\text { L4a) }\end{array}$ & $\begin{array}{l}\text { Bone (Chersina } \\
\text { angulata) }\end{array}$ & $1921 \pm 25$ & AD 76-232 \\
\hline OxA-22985 & $\begin{array}{l}\text { Layer } 3 \text { middle } \\
\text { (N11NW L5) }\end{array}$ & $\begin{array}{l}\text { Charcoal (species } \\
\text { unknown) }\end{array}$ & $12770 \pm 50$ & out of range \\
\hline OxA-24722 & $\begin{array}{l}\text { Layer } 3 \text { middle } \\
\text { (N11NW L5) }\end{array}$ & $\begin{array}{l}\text { Charcoal (species } \\
\text { unknown) }\end{array}$ & $12955 \pm 60$ & out of range \\
\hline OxA-22877 & $\begin{array}{l}\text { Layer } 3 \text { base } \\
\text { (N11NW L7) }\end{array}$ & $\begin{array}{l}\text { Grass (species } \\
\text { unknown) }\end{array}$ & $324 \pm 22$ & AD 1505-1650 \\
\hline AA-89911 & $\begin{array}{l}\text { Layer } 4 \text { top (M11 } \\
\text { NE/NW L9a) }\end{array}$ & Bone & $4551 \pm 54$ & 3366-2945 BC \\
\hline
\end{tabular}




\begin{tabular}{|c|c|c|c|c|}
\hline Lab. No. & Provenience & Material & ${ }^{14} \mathrm{C}$ date $\mathrm{BP}$ & Calibrated age $(95.4 \%$ \\
\hline $\begin{array}{l}\text { UGAMS- } \\
11683\end{array}$ & $\begin{array}{l}\text { Layer } 4 \text { pit (N11 SE } \\
\text { L10) }\end{array}$ & Grass & $3890 \pm 20$ & $2458-2155 B C$ \\
\hline OxA-22986 & Layer 5 (M11NE L12) & $\begin{array}{l}\text { Charcoal (species } \\
\text { unknown) }\end{array}$ & $4185 \pm 31$ & $2872-2580 \mathrm{BC}$ \\
\hline AA-89912 & $\begin{array}{l}\text { Layer } 6 \text { (M11 SE/SW } \\
\text { L15c) }\end{array}$ & Bone & $5452 \pm 54$ & $4347-4053 \mathrm{BC}$ \\
\hline Votes: & & & & \\
\hline
\end{tabular}

- OxA-22877: Grass clump taken from floor of shelter beneath roof collapse. The date seems inexplicably young.

- OxA-22984, OxA-22985 \& OxA-22986 are possibly Acacia karoo.

- While OxA-22984 is likely old wood, OxA-22985 is inexplicably old and indicates contamination. The sample was redated to produce OxA-24722.

The dating at Buzz Shelter was problematic. The presence of historical material as far down as the top of Layer 3 supports a recent component and, despite a first millennium $A D$ age in Layer 2, the loose nature of its deposits no doubt facilitated migration of artefacts. This was exacerbated towards the rear of the cave where Layer 1 was similarly loose. The better stratified deposits below the clear Layer 2 base appeared more typical of LSA cave deposits. Although the OxA-22877 grass sample was trapped between an apparent roof fall and bedrock, and no disturbance was evident in this area, the very late date it produced for the base of Layer 3 is inexplicable in light of the overlying early to mid-first millennium AD ages and has been disregarded. In Layer 4 there seems to have been a period during which disturbance of the deposits took place, perhaps through excavation and infilling of multiple bedding hollows in the centre of the cave. These were not readily separable from the better stratified deposits of similar age and all are therefore lumped in Layer 4 (Figure 5.90). The inversion of dates in Layer 4 may reflect the AA-89911 bone having been excavated from the hollows with UGAMS-11683 dating their subsequent infill. Layer 5, with a younger radiocarbon date, is likely of broadly similar age to Layer 4. Layers 6 and 7 are older and were split based on their texture. 


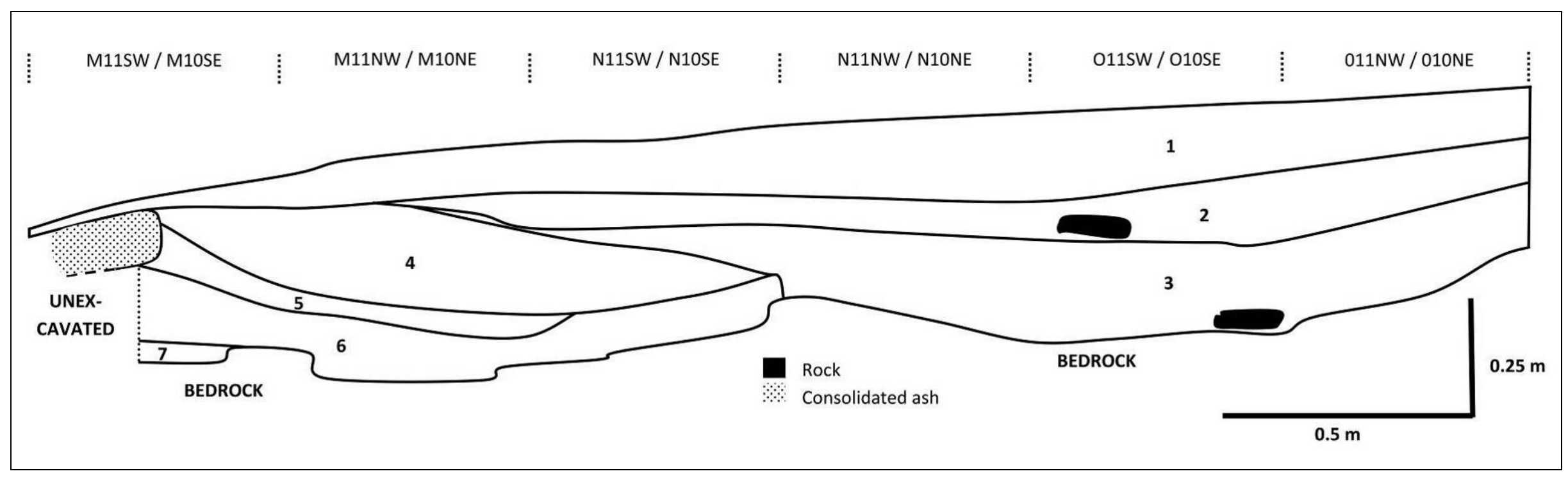

Figure 5.90: Section through the deposits inside Buzz Shelter along the 10/11 line. Aside from the disturbed area which does not intersect this section (see Orton et al. 2011, fig. 6 for a section further east), there are several thinner bedding layers which are not indicated. 


\section{$\underline{\text { Cultural material }}$}

Buzz Shelter contained a rich collection of 3721 flaked stone artefacts with 39 retouched items (Tables 5.119-5.125). Quartz is typically dominant, although the mid-Holocene levels contain higher frequencies of CCS and silcrete. They also contain more retouched items. Just four retouched pieces (from Layers 2 to 4 ) are in clear quartz indicating very limited inputs from Group 3 with much of the rest likely Group 2. Layers 4 to 6 are typically characteristic of Group 1, since they include many backed artefacts in CCS (none occur in layers 1 to 3 ) and many scrapers ( 7 of the total of 8 for the site). Layer 4 specifically includes a clear quartz triangle, two curve-backed flakes (quartz and CCS), a truncated flake (CCS) and three truncated points (CCS). The various Layers show characteristics of different Groups and it is not possible to assign specific Layers to specific Groups. Layer 4 also includes artefacts with mastic on them: a quartz blade with probable white mastic, a CCS adze with dark, bubbly mastic opposite the working edge and a CCS backed point with dark mastic on its butt. Whether occupation pre-dating the mid-Holocene is present seems unlikely, although an MSA quartzite flake was found in Layer 6 overlying bedrock and a quartz flake from Layer 7 was probably MSA.

Utilised manuports were generally rare but Layer 4 included a //khom stone, used for scraping skins (Nienaber \& Raper 1977; Webley 1990), and a small pebble of finegrained black rock with a groove on one side and a notch in one edge (Figure 5.91). Ochre occurred throughout but was particularly common in Layer $4(61.7 \%$ of the total by number) which included one round fragment. The seven layers had two, three, twentyeight, ninety-five, six, seventeen and three fragments respectively. The presence of ochre powder in the deposit (particularly in Layer 3) was noted and it may have lined one of the grass-filled hollows. 
Table 5.119: Stone artefacts from Buzz Shelter, Layer 1 (Group 2).

\begin{tabular}{|c|c|c|c|c|c|}
\hline & $\begin{array}{l}\frac{N}{ \pm} \\
\frac{\pi}{2} \\
O\end{array}$ & D & $\frac{\frac{\Phi}{ \pm}}{\frac{\bar{\omega}}{\bar{\omega}}}$ & 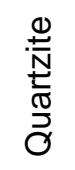 & 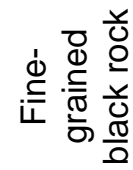 \\
\hline Bipolar core & 3 & - & - & - & - \\
\hline Bladelet & 1 & - & - & - & - \\
\hline Flake & 40 & 6 & 2 & 3 & 2 \\
\hline Chunk & 21 & 1 & - & 2 & - \\
\hline Chip & 39 & - & - & - & - \\
\hline Total & 104 & 7 & 2 & 5 & 2 \\
\hline Stone material \% total & 86.7 & 5.8 & 1.7 & 4.2 & 1.7 \\
\hline Stone \% formal & - & - & - & - & - \\
\hline
\end{tabular}

Table 5.120: Stone artefacts from Buzz Shelter, Layer 2. Clear quartz retouched artefacts are indicated in parentheses in the quartz column.

\begin{tabular}{|c|c|c|c|c|c|c|}
\hline & $\frac{\stackrel{N}{E}}{\frac{\pi}{2}}$ & U్ & $\frac{\frac{\Phi}{\frac{\omega}{\omega}}}{\frac{\bar{\omega}}{\bar{\omega}}}$ & 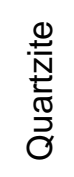 & 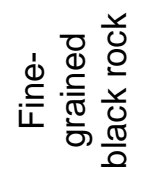 & $\begin{array}{l}\bar{\Phi} \\
\frac{ \pm}{0}\end{array}$ \\
\hline Bipolar core & 3 & - & - & - & - & - \\
\hline Single platform core & 3 & - & 1 & - & 1 & - \\
\hline Backed bladelet fragment & $1(1)$ & - & - & - & - & - \\
\hline Miscellaneous retouched piece & - & 1 & - & - & - & 1 \\
\hline Blade & 1 & - & - & - & 1 & - \\
\hline Bladelet & 5 & 1 & - & - & - & - \\
\hline Flake & 60 & 16 & 6 & 8 & 5 & - \\
\hline Edge-damaged flake & 2 & - & 1 & - & 1 & - \\
\hline Chunk & 18 & 1 & - & 1 & 2 & 1 \\
\hline Chip & 66 & 5 & 1 & 1 & - & - \\
\hline Total & 159 & 24 & 9 & 10 & 10 & 2 \\
\hline Stone material $\%$ total & 74.3 & 11.2 & 4.2 & 4.7 & 4.7 & 0.9 \\
\hline Stone material \% formal & 33.0 & 33.0 & - & - & - & 33.0 \\
\hline
\end{tabular}


Table 5.121: Stone artefacts from Buzz Shelter, Layer 3. Clear quartz retouched artefacts are indicated in parentheses in the quartz column.

\begin{tabular}{|c|c|c|c|c|c|c|}
\hline & $\begin{array}{l}\frac{N}{\pi} \\
\frac{\pi}{\sigma}\end{array}$ & S్ & $\frac{\frac{d}{0}}{\frac{\bar{d}}{\bar{\omega}}}$ & 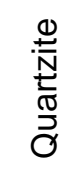 & 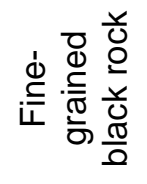 & $\frac{\bar{\Phi}}{\frac{ \pm}{\Xi}}$ \\
\hline Bipolar core & 2 & - & - & - & - & - \\
\hline Single platform core & 1 & - & - & - & - & $1^{*}$ \\
\hline Irregular core & 2 & - & - & - & - & - \\
\hline Thumbnail scraper & - & - & 1 & - & - & - \\
\hline Backed point fragment & $1(1)$ & - & - & - & - & - \\
\hline Segment & $1(1)$ & - & - & - & - & - \\
\hline Backed piece fragment & 1 & - & - & - & - & - \\
\hline Adze & - & 1 & - & - & - & - \\
\hline Blade & - & 1 & - & 1 & - & - \\
\hline Bladelet & 14 & 3 & 3 & - & - & - \\
\hline Edge-damaged bladelet & 2 & - & - & - & - & - \\
\hline Flake & 103 & 42 & 26 & 19 & 7 & 1 \\
\hline Edge-damaged flake & 3 & 3 & 2 & - & - & - \\
\hline Chunk & 31 & 4 & 2 & 5 & 3 & - \\
\hline Chip & 122 & 15 & 3 & 1 & 1 & - \\
\hline Total & 283 & 69 & 37 & 26 & 11 & 2 \\
\hline Stone material \% total & 66.1 & 16.1 & 8.6 & 6.1 & 2.6 & 0.5 \\
\hline Stone material \% formal & 60.0 & 20.0 & 20.0 & - & - & - \\
\hline Grindstone & - & - & - & - & - & 1 \\
\hline Upper grindstone fragment & - & - & - & 2 & - & - \\
\hline Lower grindstone & - & - & - & 1 & - & - \\
\hline Lower grindstone fragment & - & - & - & 1 & - & - \\
\hline
\end{tabular}

${ }^{*}$ Single platform core is also the grindstone (sandstone cobble)

Table 5.122: Stone artefacts from Buzz Shelter, Layer 4. Clear quartz retouched artefacts are indicated in parentheses in the quartz column.

\begin{tabular}{|c|c|c|c|c|c|c|}
\hline & $\begin{array}{l}\frac{N}{t} \\
\frac{\pi}{3} \\
0\end{array}$ & S్ & $\frac{\frac{d}{d}}{\frac{\frac{d}{\omega}}{\bar{\omega}}}$ & $\begin{array}{l}\frac{0}{N} \\
\frac{ \pm}{N} \\
\frac{\pi}{0}\end{array}$ & 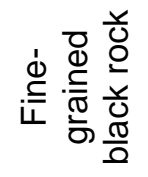 & $\begin{array}{l}\bar{亠} \\
\stackrel{ \pm}{ \pm}\end{array}$ \\
\hline Bipolar core & 6 & 1 & - & - & - & - \\
\hline Bipolar bladelet core & 1 & - & - & - & - & - \\
\hline Single platform core & 2 & 2 & - & - & - & - \\
\hline Single platform bladelet core & - & 1 & 2 & - & - & - \\
\hline Irregular core & 4 & 4 & - & 1 & - & - \\
\hline
\end{tabular}




\begin{tabular}{|c|c|c|c|c|c|c|}
\hline & $\begin{array}{l}\frac{N}{t} \\
\stackrel{0}{\sigma} \\
\sigma\end{array}$ & D্ & $\frac{\frac{\Phi}{\omega}}{\frac{\bar{\omega}}{\omega}}$ & 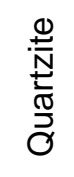 & 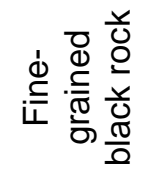 & $\begin{array}{l}\bar{\emptyset} \\
\stackrel{ \pm}{0}\end{array}$ \\
\hline Thumbnail scraper & - & 1 & - & - & - & - \\
\hline Large sidescraper & - & - & - & 1 & - & - \\
\hline Backed bladelet & 2 & - & - & - & - & - \\
\hline Backed point & - & 2 & 1 & - & - & - \\
\hline Curve-backed flake & 1 & 1 & - & - & - & - \\
\hline Double-backed point & - & 3 & - & - & - & - \\
\hline Truncated flake & - & 1 & - & - & - & - \\
\hline Triangle & $1(1)$ & - & - & - & - & - \\
\hline Adze & - & 1 & - & - & - & - \\
\hline Miscellaneous retouched piece & 1 & - & - & - & - & - \\
\hline Blade & 4 & 4 & 6 & 1 & 1 & - \\
\hline Bladelet & 31 & 16 & 7 & 1 & - & - \\
\hline Flake & 317 & 115 & 111 & 38 & 33 & 13 \\
\hline Edge-damaged flake & 4 & 2 & 2 & - & - & - \\
\hline Chunk & 85 & 25 & 7 & 8 & 5 & 3 \\
\hline Edge-damaged chunk & 1 & - & - & - & - & - \\
\hline Chip & 485 & 36 & 22 & 14 & 4 & - \\
\hline Total & 945 & 215 & 158 & 64 & 43 & 16 \\
\hline Stone material $\%$ total & 65.6 & 14.9 & 11.0 & 4.4 & 3.0 & 1.1 \\
\hline Stone material \% formal & 31.3 & 56.3 & 6.3 & 6.3 & - & - \\
\hline //Khom stone & - & - & - & - & - & $1^{*}$ \\
\hline Grooved \& notched stone & - & - & - & - & 1 & - \\
\hline
\end{tabular}

Table 5.123: Stone artefacts from Buzz Shelter, Layer 5.

\begin{tabular}{|c|c|c|c|c|c|c|}
\hline & $\begin{array}{l}\frac{N}{\mathbb{T}} \\
\stackrel{0}{\partial}\end{array}$ & ల్ & 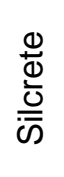 & $\begin{array}{l}\frac{0}{\stackrel{N}{N}} \\
\frac{0}{0} \\
\frac{0}{0}\end{array}$ & 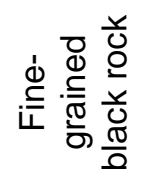 & 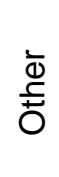 \\
\hline Bipolar core & 4 & - & - & - & - & - \\
\hline Single platform core & 1 & 1 & - & - & 1 & - \\
\hline Side-endscraper & - & - & 1 & - & - & - \\
\hline Backed flake & - & 1 & - & - & - & - \\
\hline Backed bladelet & 1 & 2 & - & - & - & - \\
\hline Blade & - & - & 1 & - & - & - \\
\hline Bladelet & 7 & 6 & 2 & 3 & - & - \\
\hline
\end{tabular}




\begin{tabular}{|c|c|c|c|c|c|c|}
\hline & $\begin{array}{l}\frac{N}{\mathbb{T}} \\
\stackrel{0}{0}\end{array}$ & ల్ & $\begin{array}{l}\frac{\Phi}{0} \\
\frac{\stackrel{\omega}{\omega}}{\bar{\omega}}\end{array}$ & 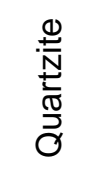 & 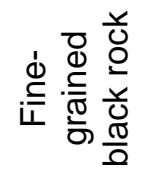 & $\frac{\bar{\Phi}}{\stackrel{ \pm}{0}}$ \\
\hline Flake & 79 & 29 & 17 & 35 & 8 & 2 \\
\hline Edge-damaged flake & 1 & - & - & - & - & - \\
\hline Chunk & 15 & 5 & 3 & 3 & 1 & 1 \\
\hline Edge-damaged chunk & 1 & - & - & - & - & - \\
\hline Chip & 128 & 21 & 6 & 11 & 1 & - \\
\hline Total & 237 & 65 & 30 & 52 & 11 & 3 \\
\hline Stone material \% total & 59.5 & 16.3 & 7.5 & 13.1 & 2.8 & 0.8 \\
\hline Stone material \% formal & 20.0 & 60.0 & 20.0 & - & - & - \\
\hline
\end{tabular}

Table 5.124: Stone artefacts from Buzz Shelter, Layer 6.

\begin{tabular}{|c|c|c|c|c|c|c|}
\hline & $\begin{array}{l}\frac{N}{t} \\
\frac{\pi}{3} \\
0\end{array}$ & ల్ & $\frac{\frac{\Phi}{0}}{\frac{\bar{U}}{\bar{\omega}}}$ & 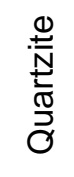 & 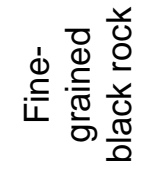 & 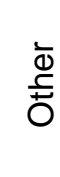 \\
\hline Bipolar core & 7 & - & - & 1 & - & - \\
\hline Single platform core & 3 & 1 & 1 & - & - & - \\
\hline Irregular core & 1 & - & 1 & - & - & - \\
\hline Double endscraper & 1 & - & - & - & - & - \\
\hline Thumbnail scraper & - & - & 1 & - & - & - \\
\hline Scraper fragment & 1 & - & - & - & - & - \\
\hline Backed point & - & 1 & 1 & - & - & - \\
\hline Double-backed bladelet & - & 1 & - & - & - & - \\
\hline Backed piece fragment & - & - & 1 & - & - & - \\
\hline Miscellaneous retouched piece & 1 & 1 & - & - & - & - \\
\hline Blade & - & - & 1 & 1 & - & - \\
\hline Bladelet & 18 & 8 & 8 & 2 & - & - \\
\hline Edge-damaged bladelet & - & - & 1 & - & - & - \\
\hline Flake & 185 & 55 & 84 & 67 & 11 & 9 \\
\hline Edge-damaged flake & 3 & - & 2 & 1 & - & - \\
\hline Chunk & 67 & 3 & 9 & 5 & 4 & 7 \\
\hline Chip & 406 & 14 & 32 & 17 & 8 & - \\
\hline Edge-damaged chip & - & - & 1 & - & - & - \\
\hline Total & 693 & 84 & 143 & 94 & 23 & 16 \\
\hline Stone material \% total & 65.8 & 8.0 & 13.6 & 8.9 & 2.2 & 1.5 \\
\hline Stone material \% formal & 33.3 & 33.3 & 33.3 & - & - & - \\
\hline Grindstone fragment & - & - & - & - & - & 1 \\
\hline
\end{tabular}


Table 5.125: Stone artefacts from Buzz Shelter, Layer 7.

\begin{tabular}{|c|c|c|c|c|c|c|}
\hline & 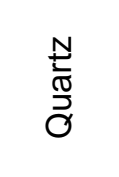 & D্ & $\frac{\frac{\Phi}{0}}{\frac{\bar{\omega}}{\bar{\omega}}}$ & 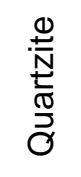 & 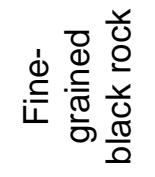 & $\frac{\grave{\Phi}}{\stackrel{ \pm}{0}}$ \\
\hline Bipolar core & 1 & - & - & - & - & - \\
\hline Single platform core & 1 & - & - & - & - & - \\
\hline Circular scraper & 1 & - & - & - & - & - \\
\hline Blade & 2 & 1 & - & - & - & - \\
\hline Bladelet & 1 & 2 & - & - & - & - \\
\hline Flake & 17 & 2 & 2 & 4 & 1 & - \\
\hline Edge-damaged flake & 2 & - & - & - & - & - \\
\hline Chunk & 7 & 2 & - & - & - & 1 \\
\hline Chip & 19 & 2 & - & - & - & - \\
\hline Total & 51 & 9 & 2 & 4 & 1 & 1 \\
\hline Stone material $\%$ total & 75.0 & 13.2 & 2.9 & 5.9 & 1.5 & 1.5 \\
\hline Stone material \% formal & 100.0 & - & - & - & - & - \\
\hline Upper grindstone fragment & - & - & - & 1 & - & - \\
\hline Hammer stone & - & - & - & - & - & 1 \\
\hline
\end{tabular}

Figure 5.91: Grooved and notched stone from Layer 4 in Buzz Shelter.

Throughout the Buzz Shelter deposits the mean external diameter of ostrich eggshell beads is small with individual beads larger than $5 \mathrm{~mm}$ only present in Layers 3 and 4 (Table 5.126); none fall into the very large class (Figure 5.92). It is interesting to note how tightly clustered the beads are with only $0.38 \mathrm{~mm}$ separating the smallest and largest means. There is no evidence for an influx of larger beads at any time with just one whole bead surpassing $6 \mathrm{~mm}$ (in layer 3 ) and Layer 1 actually having the smallest 
mean. This contrasts markedly with the beads from Reception Shelter (Figure 5.85).

Oddly, the one broken bead present, in Layer 3, is approximately $9.5 \mathrm{~mm}$ in diameter.

Table 5.126: Summary statistics for finished ostrich eggshell beads from Buzz Shelter.

\begin{tabular}{|c|c|c|c|c|}
\hline Layer & & Outside diameter $(\mathrm{mm})$ & Aperture diameter (mm) & Thickness (mm) \\
\hline \multirow{4}{*}{$1(n=10)$} & Mean & 3.94 & 1.71 & 1.20 \\
\hline & Std Deviation & 0.35 & 0.13 & 0.20 \\
\hline & Minimum & 3.25 & 1.39 & 1.07 \\
\hline & Maximum & 4.20 & 1.79 & 1.48 \\
\hline \multirow{4}{*}{$2(n=12)$} & Mean & 4.20 & 1.53 & 1.52 \\
\hline & Std Deviation & 0.34 & 0.25 & 0.24 \\
\hline & Minimum & 3.84 & 1.25 & 1.10 \\
\hline & Maximum & 4.93 & 2.06 & 1.76 \\
\hline \multirow{4}{*}{$3\left(n=35^{\star}\right)$} & Mean & 4.10 & 1.52 & 1.57 \\
\hline & Std Deviation & 0.64 & 0.36 & 0.24 \\
\hline & Minimum & 2.62 & 1.01 & 1.03 \\
\hline & Maximum & 6.50 & 2.84 & 2.00 \\
\hline \multirow{4}{*}{$4(n=32)$} & Mean & 4.24 & 1.48 & 1.52 \\
\hline & Std Deviation & 0.44 & 0.29 & 0.17 \\
\hline & Minimum & 3.35 & 0.99 & 1.16 \\
\hline & Maximum & 5.45 & 2.12 & 1.86 \\
\hline \multirow{4}{*}{$5(n=10)$} & Mean & 4.11 & 1.56 & 1.54 \\
\hline & Std Deviation & 0.57 & 0.28 & 0.19 \\
\hline & Minimum & 3.32 & 1.15 & 1.08 \\
\hline & Maximum & 4.92 & 1.98 & 1.81 \\
\hline \multirow{4}{*}{$6\left(n=19^{* \star}\right)$} & Mean & 4.32 & 1.67 & 1.45 \\
\hline & Std Deviation & 0.44 & 0.29 & 0.20 \\
\hline & Minimum & 3.35 & 1.13 & 1.06 \\
\hline & Maximum & 4.98 & 2.10 & 1.84 \\
\hline \multirow{4}{*}{$7(n=5)$} & Mean & 4.10 & 1.71 & 1.43 \\
\hline & Std Deviation & 0.06 & 0.23 & 0.03 \\
\hline & Minimum & 4.01 & 1.47 & 1.40 \\
\hline & Maximum & 4.15 & 1.97 & 1.46 \\
\hline
\end{tabular}

*Two beads were strung and could not have their apertures measured $(n=33)$, while one bead was burnt and exfoliated such that for thickness $n=34$.

${ }^{* *}$ Two beads were burnt and exfoliated such that for thickness $n=17$.

Evidence for the manufacture of ostrich eggshell beads occurred, but was too minimal to suggest that active manufacture ever took place at the site (Table 5.127). Two beads 
were found strung with a seed bead in Layer 3, while an ochre-coated bead was found tied on the end of a loop of string in Layer 4, providing evidence for the irregular wear sometimes found on beads (Figure 5.93). Several fragments of engraved, painted and 'retouched' ostrich eggshell and two pendant blanks were also recovered (Figure 5.94). Engraved eggshell occurs in Layers 3, 4 and 6, while 'retouched' fragments come from Layers 3 and 4 only. The vast majority of painted fragments are from Layer 3 but they also occur in Layers 2 and 4. Flask mouth fragments are present in Layers 3 and 4 . Just two potsherds were recovered from Buzz Shelter, one in Layer 2 (4.69 $\mathrm{mm}$ thick) and the other at the top of Layer 3 (5.60 mm thick). Both were plain body sherds.

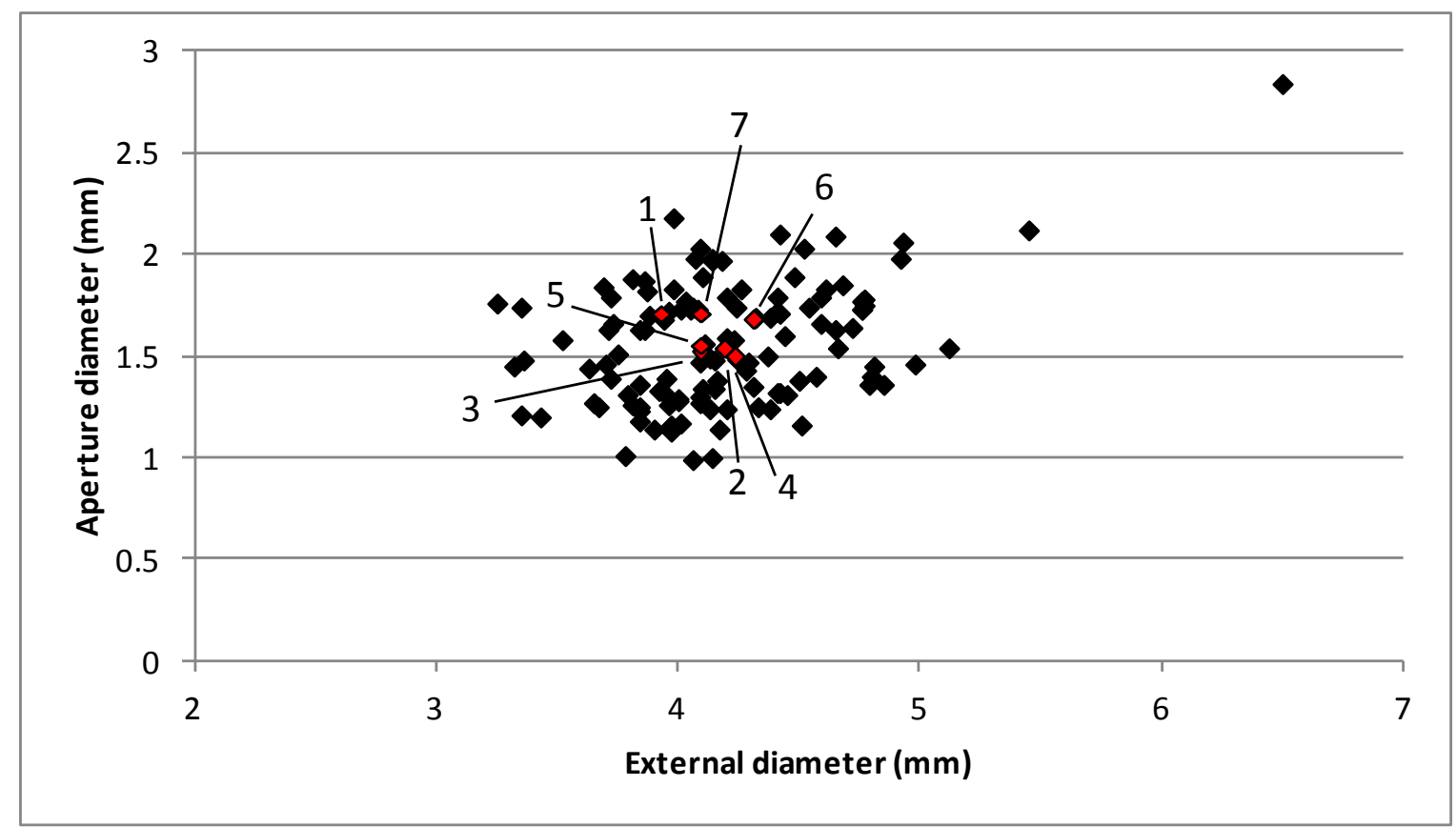

Figure 5.92: Scatter plot of ostrich eggshell bead dimensions from Buzz Shelter. Red symbols represent layer means as labelled.

Table 5.127: Ostrich eggshell bead manufacturing debris from Buzz Shelter.

\begin{tabular}{ccccccccccccc}
\hline Stage & Ila & IIb & IIIa & IIIb & IVa & IVb & Va & Vb & VIa & VIb & VIIa & VIIb \\
\hline Layer 1 & - & - & - & - & - & - & - & - & - & - & 5 & - \\
Layer 2 & - & - & - & 1 & - & - & - & - & - & - & 12 & - \\
Layer 3 & - & - & 4 & 1 & - & - & - & - & - & - & 35 & 1 \\
Layer 4 & - & - & 5 & 1 & - & - & - & - & - & - & 32 & - \\
Layer 5 & - & - & 1 & 2 & - & - & - & - & - & - & 10 & -
\end{tabular}




\begin{tabular}{ccccccccccccc}
\hline Stage & Ila & Ilb & Illa & Illb & IVa & IVb & Va & Vb & Vla & Vlb & Vlla & Vllb \\
\hline Layer 6 & - & - & 2 & 4 & 1 & 2 & - & - & - & - & 19 & - \\
Layer 7 & - & - & - & - & - & - & - & - & - & - & 5 & - \\
\hline
\end{tabular}

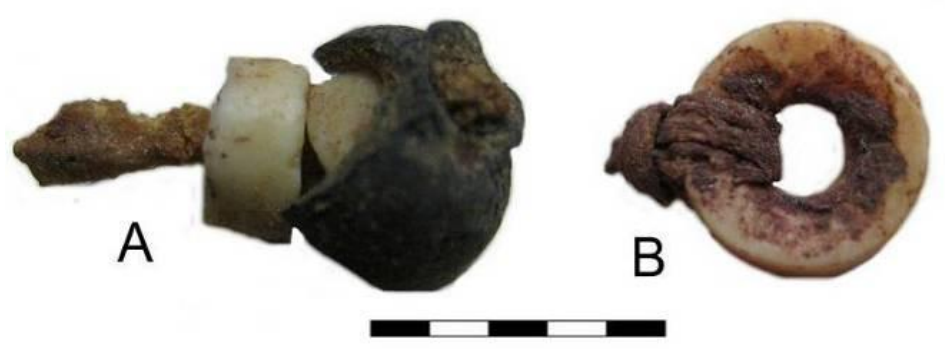

Figure 5.93: Ostrich eggshell and seed beads strung with sinew from Layer $3(A)$ and an ochred bead tied on a loop of string from Layer 4 (B) of Buzz Shelter. Scale in $1 \mathrm{~mm}$ intervals.

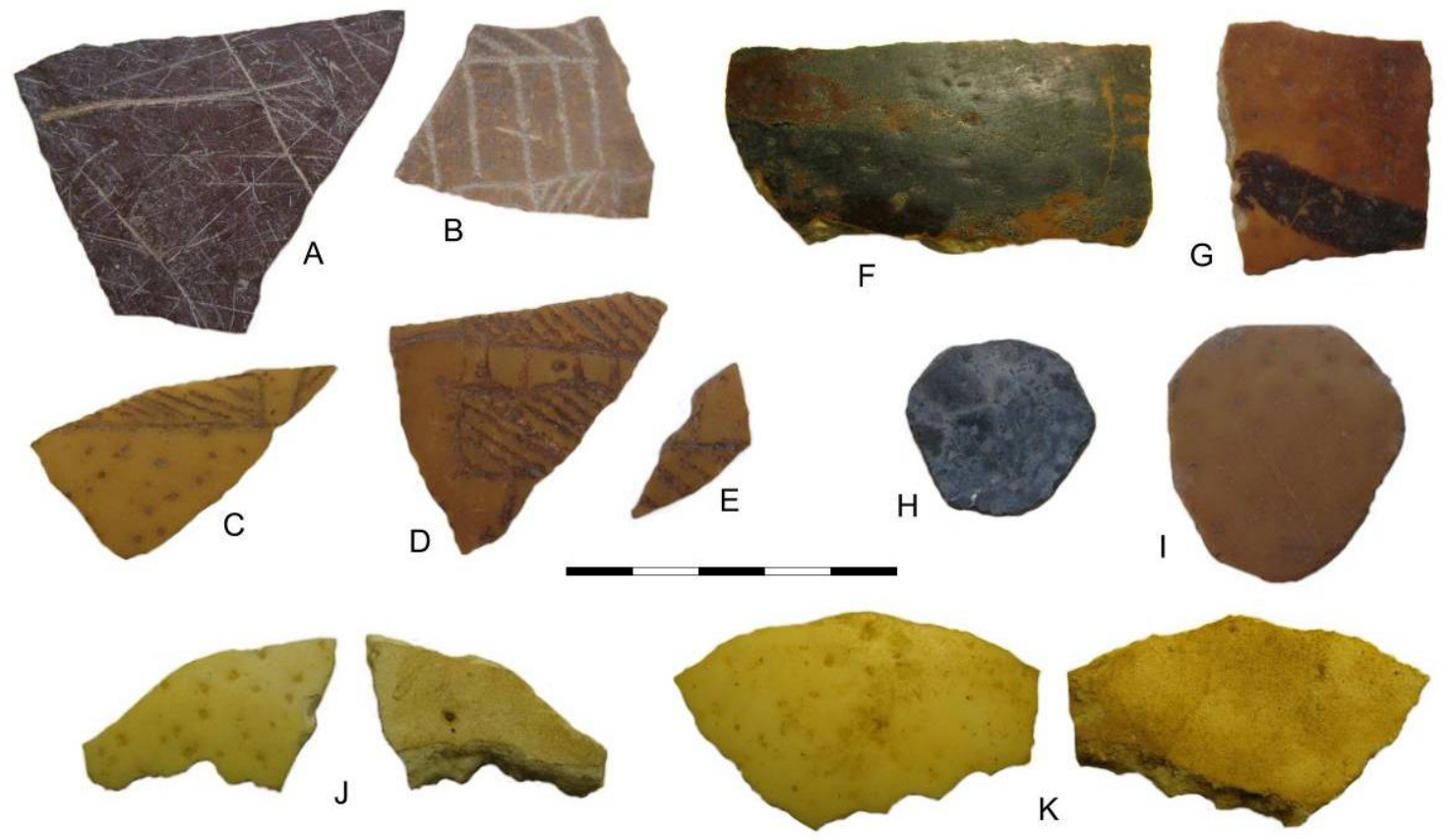

Figure 5.94: Ostrich eggshell artefacts from Buzz Shelter. Engraved fragments from Layers 3 (A \& $B$ ) and $6 A(C-E)$, painted fragments from Layer $3(F)$ and Layer $4(G)$, pendant blanks from Layers $4(\mathrm{H})$ and $5(\mathrm{I})$ and 'retouched' fragments from Layer $3(\mathrm{~J} \& \mathrm{~K})$. Scale in $5 \mathrm{~mm}$ intervals.

The excellent preservation of organic materials in Buzz Shelter has resulted in a wonderful record of other non-lithic artefacts. Space precludes a detailed description of other organic finds but these include wooden artefacts, wood shavings, string and netting, cut and split reeds, worked bone (including one tortoise bowl fragment), 
estuarine shell beads (Nassarius krausianus, some strung) and two marine shell pendants (Turbo sarmaticus and Cypraea sp.). Some of these were discussed in Orton et al. (2011).

Several historical artefacts were also found. These include three used matches from Layer 1 and one from the top of Layer 3, two small fragments of fabric (10 and $55 \mathrm{~mm}$ long respectively), two short threads and a metal loop from Layer 2 and a tiny green bottle glass fragment from the top of Layer 3. As with Reception Shelter, these items likely relate to $19^{\text {th }}$ century use of the cave.

\subsubsection{Varsche Rivier 048 (VR048)}

Research at this site is ongoing and, as such, only a general discussion of the site and its character is presented here.

\section{The site}

VR048 is located on an island between braids on the Varsche River flood plain $\left(31^{\circ} 31^{\prime} 43.9^{\prime \prime} \mathrm{S} 18^{\circ} 35^{\prime} 07.4^{\prime \prime} \mathrm{E}\right)$, which at this point is $240 \mathrm{~m}$ wide; the main channel runs to the south of VR048. The site has had $646 \mathrm{~m}^{2}$ excavated to date. The actual area of discrete artefact scatter is some $4900 \mathrm{~m}^{2}$, but with density varying greatly (Figure 5.95); virtually nothing is evident in the immediate surrounding area and similar mud flats just downstream were found to be sterile suggesting this location to have been particularly desirable for settlement. The assemblages consist of material of mixed age and no dates have been obtained. 


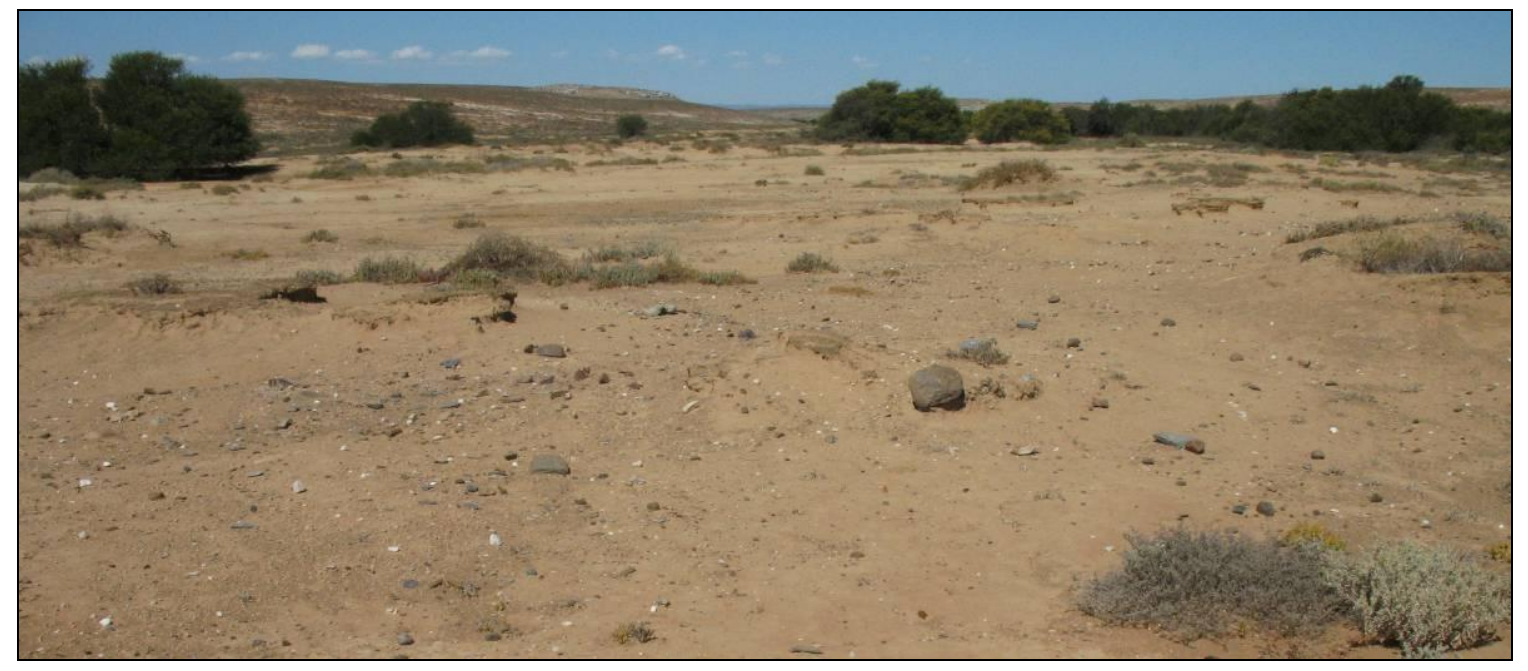

Figure 5.95: View to the east showing a dense patch of artefact scatter on VR048.

\section{$\underline{\text { Cultural material }}$}

The large stone artefact assemblage (9417 artefacts) includes 107 retouched tools from which both Group 1 and Group 3 components can be identified. Scrapers and backed tools on CCS and silcrete typify Group 1, while Group 3 is marked by the many clear quartz backed bladelets, points and flakes. Just eight ostrich eggshell beads have been found and their diameters range from small $(3.11 \mathrm{~mm})$ to very large $(8.23 \mathrm{~mm})$. Pottery was abundant with 264 sherds weighing $760 \mathrm{~g}$. The wall thicknesses vary greatly between 3.9 and $10.4 \mathrm{~mm}$ with a mean of $5.97 \pm 1.37 \mathrm{~mm}$. Lugs were present and the only decoration evident was broad-incised parallel lines. All rim sherds were vertically oriented with simple round lips, and red slip was found on about $43 \%$ of all sherds.

\subsection{Richtersveld assemblages}

Two pottery period sites from the vicinity of Sendelingsdrif on the left bank of the Orange River are presented here. Several other sites from this area, some $65 \mathrm{~km}$ from the coast, have already been published (Brink \& Webley 1996; Miller \& Webley 1994; Webley 1997a; Orton \& Halkett 2010). 


\subsubsection{Jakkalsberg K (JKB K)}

\section{The site}

JKB K lay on the bank of the Orange River, beneath the strip of large trees bordering the river in this area $\left(28^{\circ} 10^{\prime} 56.1^{\prime \prime} \mathrm{S} 16^{\circ} 52^{\prime} 55.9^{\prime \prime} \mathrm{E}\right)$. The site was deflated and $67 \mathrm{~m}^{2}$ were excavated on a $0.25 \mathrm{~m}^{2}$ grid, while two areas demonstrating poorer context were collected individually in bulk (Halkett 2001). Although the fauna was poorly preserved, two bones were identified as probable sheep (R. Klein \& T. Steele, pers. comm. 2006). The following dates were obtained:

\begin{tabular}{|c|c|c|c|c|}
\hline Lab. No. & Provenience & Material & ${ }^{14} \mathrm{C}$ date $\mathrm{BP}$ & Calibrated age (95.4\%) \\
\hline GX-32761 & $\begin{array}{l}\text { Alongside } \\
\text { Hearth A1 }\end{array}$ & Charcoal (sp. unknown) & $660 \pm 100$ & AD 1212-1459 \\
\hline OxA-24528 & K60 & $\begin{array}{l}\text { Bone (Raphicerus } \\
\text { campestris) }\end{array}$ & $358 \pm 26$ & AD 1488-1640 \\
\hline
\end{tabular}

Note:

- Possibly Acacia karoo which is abundant along the river and could return old dates.

OxA-24528 is thus taken as the most reliable age for the site.

\section{$\underline{\text { Cultural material }}$}

The site yielded a large, informal stone artefact assemblage dominated by quartz. However, various other local materials were also flaked (Table 5.128). Retouch was entirely absent prompting a Group 2 ascription. Ochre fragments were abundant on the site (195 fragments being found) and strongly concentrated in one area. Ostrich eggshell beads were mostly large and medium, but small and very large beads also occurred (Table 5.129; Figure 5.96). Seven broken complete beads were found and, interestingly, five with at least half retained were all between 4.85 and $5.35 \mathrm{~mm}$ in external diameter. One manufacturing fragment in stage IVb was found. Whether larger beads had already been removed from this site, as occurred at JKB A (Webley 1997a), is unknown. Two flask mouth fragments were present and refit to make an opening of approximately 8.5 mm diameter. 
Table 5.128: Stone artefacts from JKB K (Group 2).

\begin{tabular}{lccccc}
\hline & Quartz & CCS & Quartzite & Sandstone & Other \\
\hline Bipolar core & 2 & 1 & - & - & - \\
Single platform core & - & 1 & - & - & - \\
Irregular core & 6 & - & - & - & - \\
Blade & 4 & - & 1 & - & - \\
Bladelet & 8 & - & 4 & - & - \\
Flake & 207 & 1 & 164 & 31 & 10 \\
Edge-damaged flake & 2 & 1 & 1 & - & - \\
Chunk & 209 & - & 85 & 22 & 6 \\
Edge-damaged chunk & - & - & 1 & - & - \\
Chip & 319 & 1 & 23 & 7 & - \\
Total & 757 & $\mathbf{5}$ & $\mathbf{2 7 9}$ & $\mathbf{6 0}$ & $\mathbf{1 6}$ \\
Stone material \% total & $\mathbf{6 7 . 7 7}$ & $\mathbf{0 . 4 5}$ & $\mathbf{2 4 . 9 8}$ & $\mathbf{5 . 3 7}$ & $\mathbf{1 . 4 3}$ \\
Stone material \% formal & - & - & - & - & - \\
Upper grindstone & 1 & - & - & - & - \\
Upper grindstone fragment & - & - & - & - & 1 \\
Lower grindstone fragment & - & - & - & - & 1 \\
Upper grindstone/hammer stone & - & - & 1 & - & - \\
Hammer stone & - & - & - & - & 1 \\
\hline
\end{tabular}

Table 5.129: Summary statistics for finished ostrich eggshell beads from JKB K.

\begin{tabular}{|c|c|c|c|c|}
\hline & & Outside diameter $(\mathrm{mm})$ & Aperture diameter $(\mathrm{mm})$ & Thickness (mm) \\
\hline \multirow{4}{*}{$\mathrm{n}=14$} & Mean & 6.16 & 1.86 & 1.79 \\
\hline & Std Deviation & 1.38 & 0.24 & 0.14 \\
\hline & Minimum & 4.02 & 1.29 & 1.52 \\
\hline & Maximum & 8.90 & 2.14 & 2.00 \\
\hline
\end{tabular}




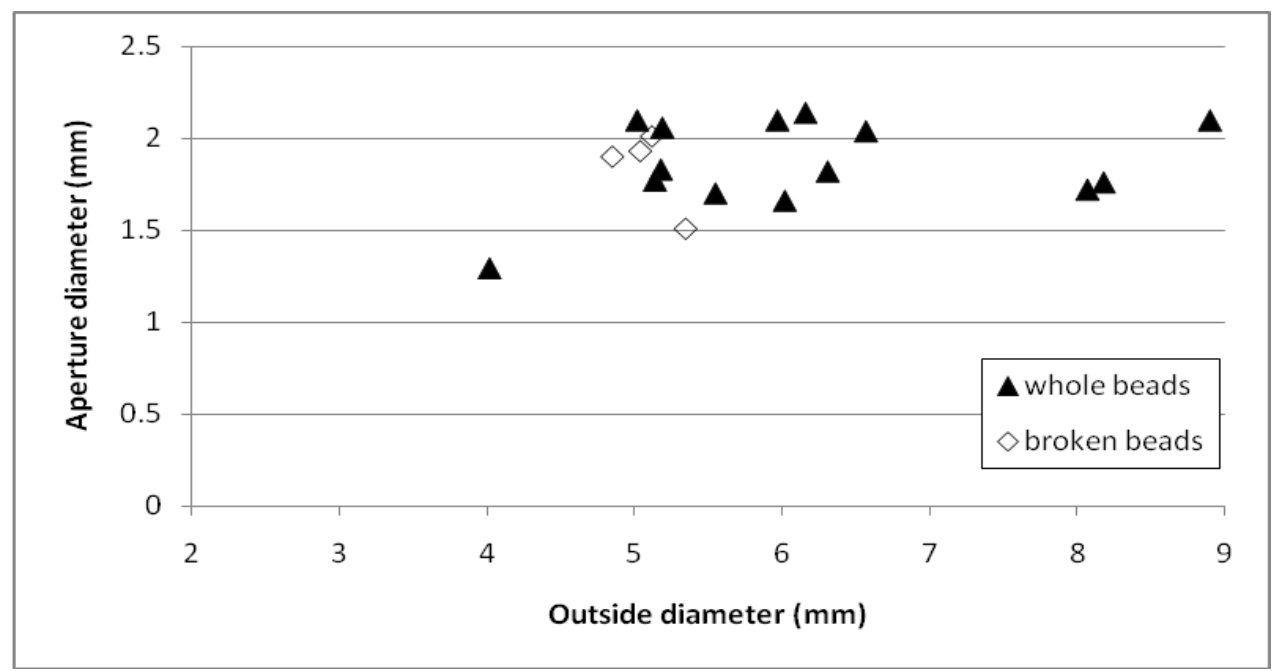

Figure 5.96: Scatter plot of ostrich eggshell bead dimensions from JKB K.

The most significant aspect of this site is its very large pottery assemblage. Altogether, the 798 sherds weigh $1667 \mathrm{~g}$. Twenty-four rim sherds were found with all being plain (Figure 5.97). Those with enough preserved all display a flared orientation, while most are tapered in form. There are two lugs present and one sherd may come from the base of a spout. Where rim diameters could be estimated these varied, with some being 80 $100 \mathrm{~mm}$, others $140 \mathrm{~mm}$ and one about $200 \mathrm{~mm}$. Just one sherd has red slip on the outside and another has a burnished surface. Two holes of the sort made for mending pots (Rudner 1968) are present, but both are broken. One displays damage on the inner surface indicating boring through from the outside. While all sherds have mineral temper, a few may have included some organic temper. This may, of course, have been an accidental inclusion. Wall thickness averages $5.22 \pm 0.94 \mathrm{~mm}$. Although difficult to tell, there may be up to nine individual pots represented. Webley (1997a) stated that a local herder had collected pottery from nearby Jakkalsberg $A$ and $B$, and it seems quite possible that JKB K was also pillaged in this way. The few shells present included two Corbicula fluminalis (freshwater) and four Bullia sp. (marine) and may have been collected or exchanged as curios. A few historical artefacts were also found, but such items occur widely across the area, having been collected in other proximate excavations as well (Orton \& Halkett 2010; Webley 1997a). 


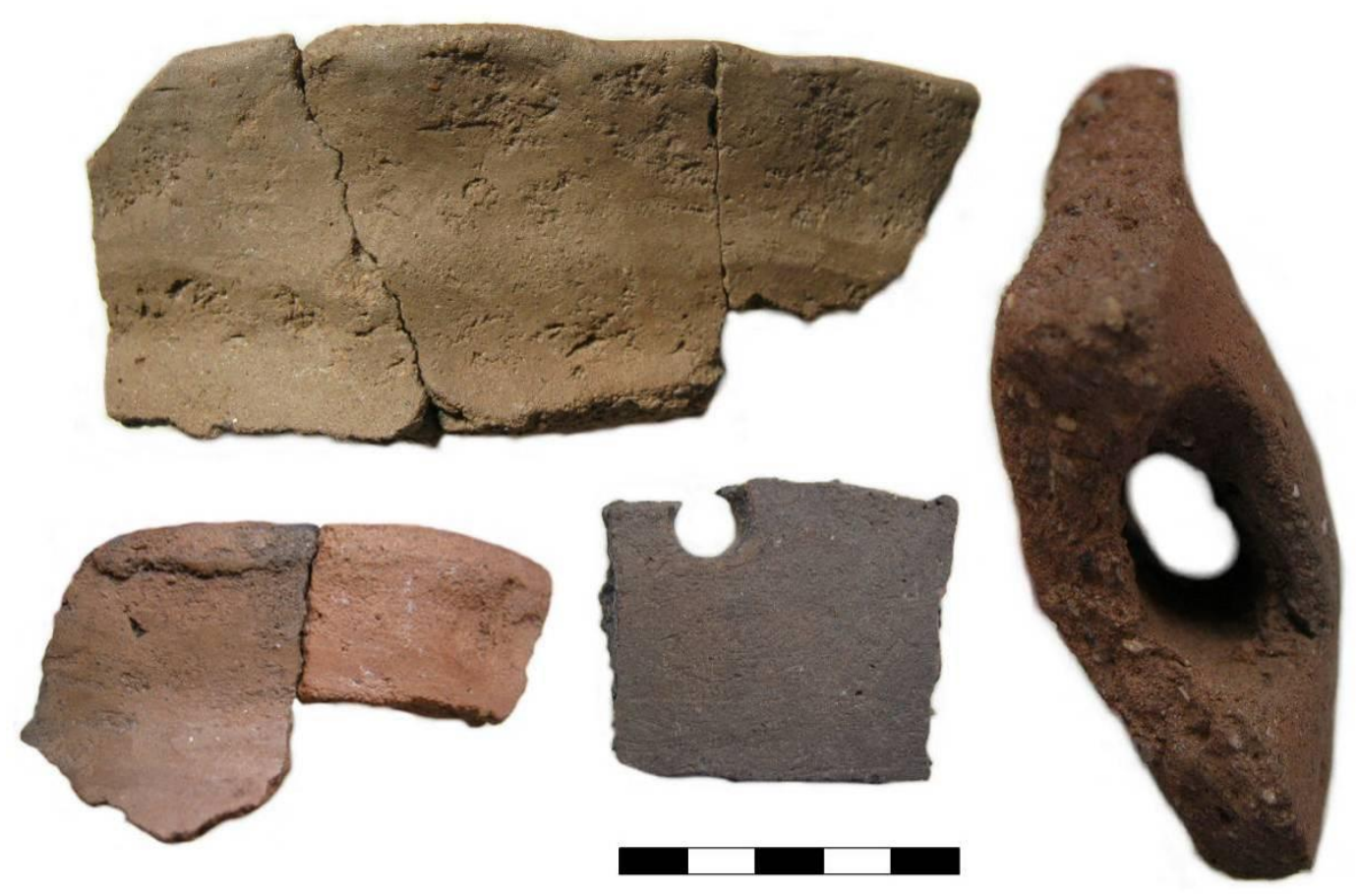

Figure 5.97: Pottery from JKB K. Scale in $5 \mathrm{~mm}$ intervals.

\subsubsection{Jakkalsberg M (JKB M)}

\section{The site}

JKB M lay on the edge of a tributary stream some $200 \mathrm{~m}$ from the Orange River $\left(28^{\circ} 10^{\prime} 50.5^{\prime \prime} \mathrm{S} 1653^{\prime} 13.0^{\prime \prime} \mathrm{E}\right)$. It was exposed in a deep deflating area between eroding stacks of silts (Halkett 2001b). The poorly preserved faunal assemblage includes two sheep limb bones and one tooth identifiable to caprine (R. Klein \& T. Steele, pers. comm. 2006). The following date was obtained:

$\begin{array}{lllll}\text { Lab. No. } & \text { Provenience } & \frac{\text { Material }}{\text { GX-32760 }} & \frac{{ }^{14} \mathrm{C} \text { date BP }}{1740 \pm 75} & \text { Calibrated age (95.4\%) } \\ \text { L32, L33, M33 83-943 } & \begin{array}{l}\text { OES (Struthio } \\ \text { camelus) }\end{array} & 170\end{array}$

Sadr (2003) notes that no pierced pottery lugs are reliably dated to before about 1200 years ago and it is perhaps prudent to regard JKB $\mathrm{M}$ as dating to the late first millennium AD. Dating was thus important here and it is unfortunate that two further samples, on bovid and sheep bones respectively, both failed due to poor collagen preservation. 


\section{$\underline{\text { Cultural material }}$}

A small, quartz-dominated flaked stone assemblage was found with no retouch present (Table 5.130). It is no doubt a Group 2 assemblage. Hammer stones and grindstones occur and one upper grindstone/hammer stone was ochre-stained. Seven ochre fragments and two 'ochre cakes' were found. The 'cakes' contain ferruginous gravel, quartz fragments, occasional bone fragments and much ochre, and were made by patting muddy lumps into shape and allowing them to dry on a flat surface. They are fragile but one that was recovered whole measures about $260 \times 180 \times 70 \mathrm{~mm}$ (Figure 5.98). An unusual find was a collection of small pebbles, not unlike marbles in size and shape, of which 48 are white quartz, 21 are variable-coloured agates, three are black and two are red. Although most were concentrated in the western part of the site, a few were scatterd over the rest of the excavated area. Twenty complete and four broken ostrich eggshell beads were found (Table 5.131), along with a collection of manufacturing debris (Table 5.132; Orton 2008). The beads range widely in size but no very large beads occur. Their small mean thickness indicates that most were well worn at the time of their loss. As before, it is unknown whether larger beads were removed from this site, but the small size of the partly made beads (Orton 2008d) argues against this.

Table 5.130: Stone artefacts from JKB M.

\begin{tabular}{lccccc}
\hline & Quartz & CCS & Quartzite & Sandstone & Other \\
\hline Single platform core & - & - & 1 & - & - \\
Irregular core & 1 & - & - & - & - \\
Flake & 39 & 1 & 11 & 4 & 3 \\
Chunk & 53 & 1 & 11 & - & 2 \\
Chip & 89 & & 2 & 1 & - \\
Total & $\mathbf{1 8 2}$ & $\mathbf{2}$ & $\mathbf{2 5}$ & $\mathbf{5}$ & $\mathbf{5}$ \\
Stone material \% total & $\mathbf{8 3 . 1}$ & $\mathbf{0 . 9}$ & $\mathbf{1 1 . 4}$ & $\mathbf{2 . 3}$ & $\mathbf{2 . 3}$ \\
Stone material \% formal & - & - & - & - & - \\
Upper grindstone/hammer stone & - & - & - & 2 & - \\
Lower grindstone & - & - & 3 & - & - \\
Lower grindstone fragment & - & - & 1 & - & - \\
Hammer stone & - & - & 1 & - & 1 \\
\hline
\end{tabular}




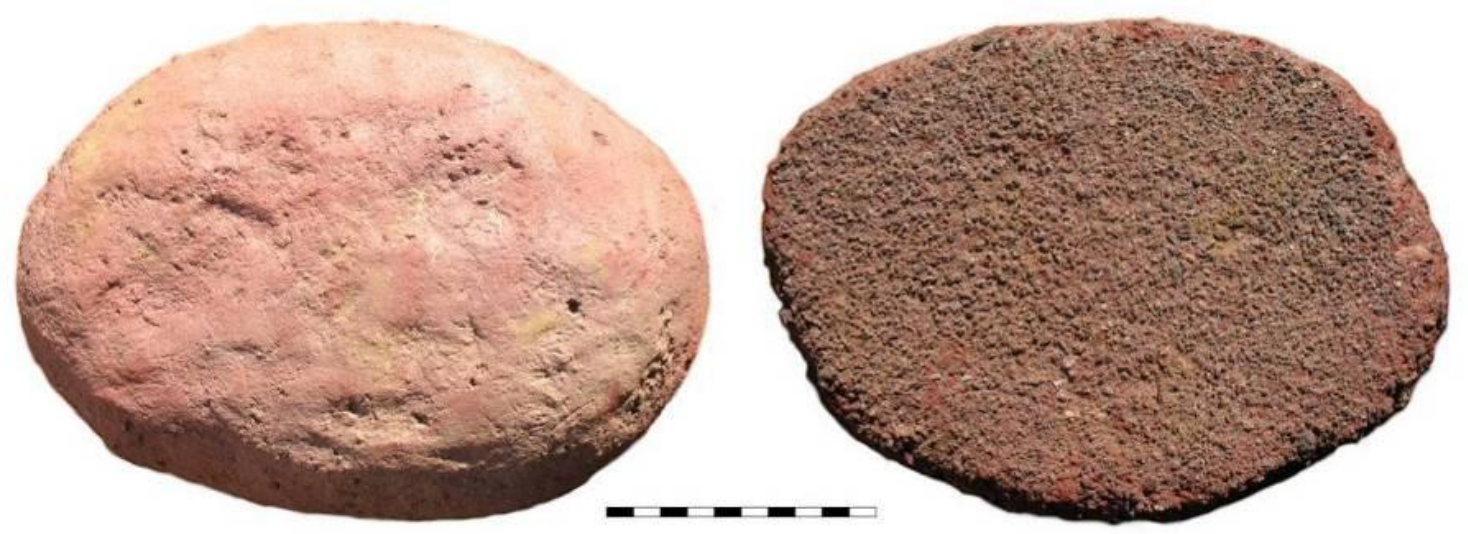

Figure 5.98: Upper and lower surfaces of one of the 'ochre cakes' from JKB M. Scale in $10 \mathrm{~mm}$ intervals.

Table 5.131: Summary statistics for finished ostrich eggshell beads from JKB M.

\begin{tabular}{llccc}
\hline & Outside diameter $(\mathrm{mm})$ & Aperture diameter $(\mathrm{mm})$ & Thickness $(\mathrm{mm})$ \\
\hline \multirow{3}{*}{$\mathrm{n}=20$} & Mean & 4.90 & 2.20 & 1.50 \\
\cline { 3 - 4 } & Std Deviation & 0.97 & 0.41 & 0.24 \\
& Minimum & 3.64 & 1.36 & 1.09 \\
& Maximum & 7.10 & 3.07 & 1.96 \\
\hline
\end{tabular}

Table 5.132: Ostrich eggshell bead manufacturing debris from JKB M.

\begin{tabular}{ccccccccccccc}
\hline Stage & Ila & Ilb & Illa & Illb & IVa & IVb & Va & Vb & Vla & Vlb & VIla & VIllb \\
\hline & 4 & 8 & 4 & 29 & - & 8 & - & 5 & - & - & 20 & 4 \\
\hline
\end{tabular}

The pottery collection includes 202 sherds weighing $393 \mathrm{~g}$. Six, and possibly seven, sherds are rims, with all but one displaying horizontal incised decoration (Figure 5.99) the last is plain. In total, 19 decorated sherds were found, all incised. One rim is possibly flared in orientation, while all are either everted or thickened round in form. Three lugs and two small bosses are present. All sherds have mineral temper but a few cavities suggest possible, and probably incidental, fibre inclusions. The mean wall thickness is $5.38 \pm 1.04 \mathrm{~mm}$. Red slip on the outside is common (115 sherds) and some had noticeable inclusions of shiny specularite ground into the paint. A few rims had red paint on their inner surfaces as well. At least five sherds have edges ground smooth, possibly to facilitate reuse of a broken pot. One, however, was ground around some $75 \%$ of its 
edge suggesting an alternative function. Collected shells include three Corbicula fluminalis and two Unio sp. fragments (freshwater), and one piece of an unidentifiable whelk (marine).
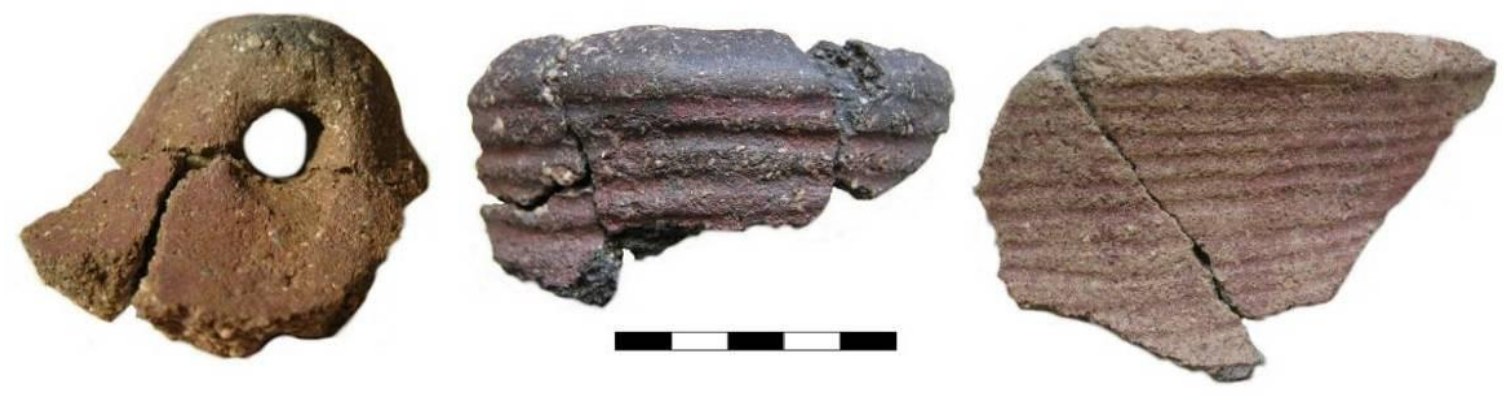

Figure 5.99: Pottery from JKB M. Scale in $5 \mathrm{~mm}$ intervals.

\subsection{Other material culture}

Although this thesis necessarily focuses on lithics, ostrich eggshell beads and pottery, which preserve best on west coast sites, other categories of material culture do exist. These are now briefly discussed for the sake of completeness but, owing to their rarity, are not examined any further in the following chapters. Undoubtedly, other aspects of material culture existed but have failed to survive the ravages of time.

\subsubsection{Shell beads}

Shell beads are known from just one site in Namaqualand, AK2001/002 (Figure 100; Halkett 2003). They were probably made on Unio caffer (freshwater mussel; G. Avery, G. Branch \& D. Herbert, pers. comm. 2005) which occurs commonly in many South African rivers (Appleton 2002). Whether the beads were imported from some distance or the shell obtained from the Buffels River estuary cannot be known. The site is undated and its context unfortunately poor, but pottery (with bosses) indicates an age within the last 2000 years. The AK2001/002 beads are remarkably consistent in size with all being in the range of 8.4-9.6 mm external diameter (Figure 101). 


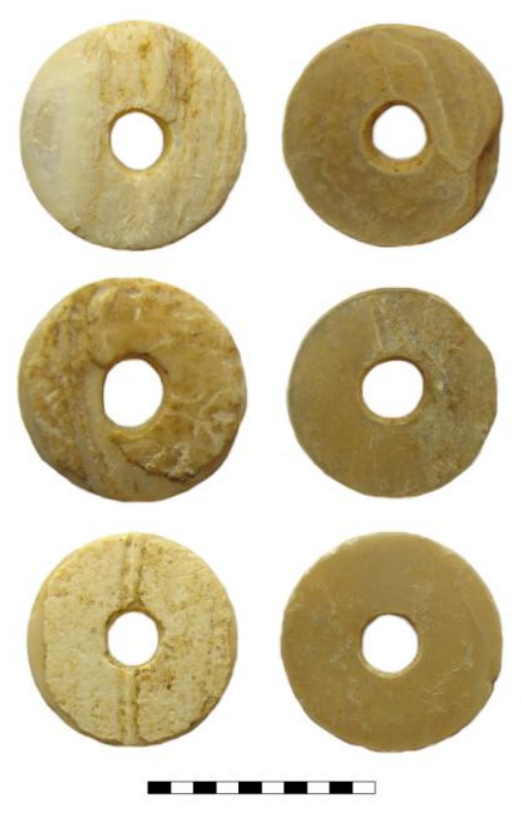

Figure 5.100: Outer (left) and inner (right) surfaces of shell beads from AK2001/002 showing. Scale in $1 \mathrm{~mm}$ intervals.

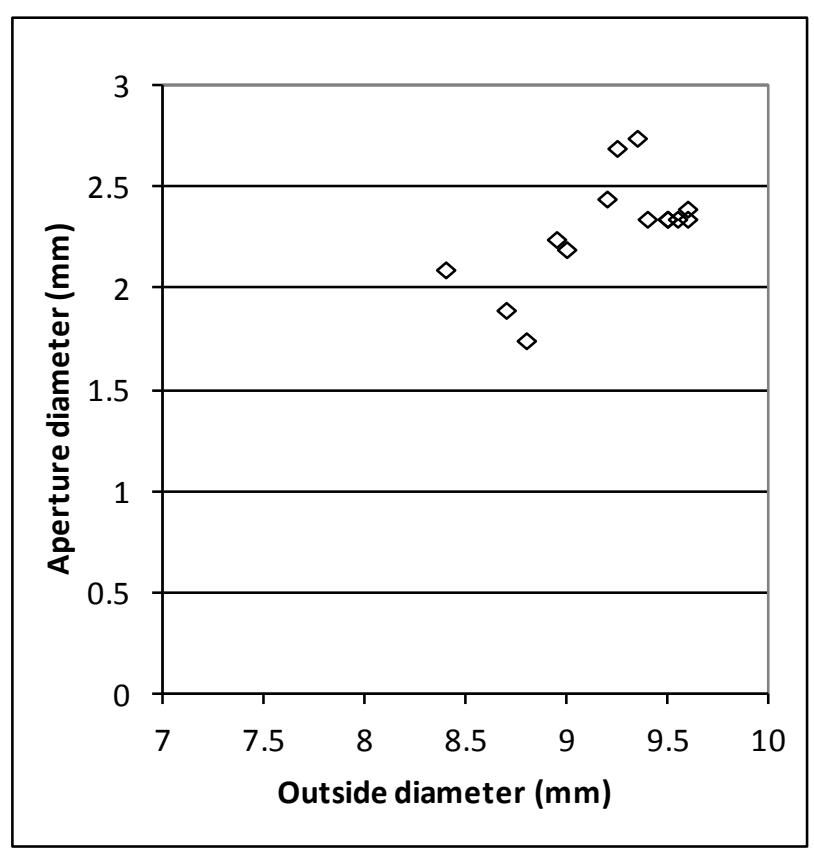

Figure 5.101: External and aperture diameters of the shell beads from AK2001/002.

Freshwater shell beads and pendants are rare but found throughout southern Africa. Mitchell (1993b) reports Achatina sp. (land snail) beads and a pendant fragment on $U$. caffer from Tloutle in Lesotho, and another pendant from nearby Ha Makotoko (Mitchell 1993a), both from early Holocene contexts. Mazel (1999) found two land snail beads at iNkolimahashi Shelter in Kwazulu-Natal, while Laidler (1936) found freshwater shell beads associated with pottery in an Eastern Cape cave. A worked freshwater mussel fragment and a land snail bead from Balerno Main Shelter in the Limpopo area date to the first millennium AD (Van Doornum 2008), while a single shell bead (not described further) was found at Geduld in Namibia (A. Smith \& Jacobson 1995).

\subsubsection{Bone beads}


Bone beads are seldom encountered. Two types exist: flat beads resembling those on ostrich eggshell can be made on a flat bone or sidewall fragment of a shaft, while tubular beads are made from a section of hollow bone, usually bird. These items are rare in Namaqualand. In the Sandveld two broken flat bone beads were found at KN2001/008C (Dewar 2008), while in the Richtersveld two whole beads were recorded at JKB N (Orton \& Halkett 2010) and one at Spitzkloof from an MSA context (Dewar \& Stewart 2012) (Table 5.133). Just one bone tube is known - from KN2004/012 described above.

Table 5.133: Dimensions of flat bone beads from Namaqualand. Source data from Dewar (2008:82), Dewar \& Stewart (2012) and Orton and Halkett (2010:15).

\begin{tabular}{lccc}
\hline Site & Diameter $(\mathrm{mm})$ & Aperture $(\mathrm{mm})$ & Thickness $(\mathrm{mm})$ \\
\hline KN2001/008C & $\sim 9.1$ & $\sim 3.1$ & 2.4 \\
KN2001/008C & $\sim 9.1$ & $\sim 3.3$ & 2.4 \\
JKB N & $11.58^{*}$ & 2.5 & 4.5 \\
JKB N & 4.24 & 1.75 & 1.52 \\
Spitzkloof & 4.2 & 2.1 & 1.5 \\
\hline * Value is the average of maximum and minimum diameters.
\end{tabular}

The south coast of South Africa generally reveals far richer worked bone assemblages and tubular beads are common there. A survey of the literature on many important sites failed to reveal many flat beads; Robey (1987) notes their presence at Tortoise Cave. Inskeep (1987) reports a collection of what he termed 'bone rings' from Nelson Bay Cave, while another was found at Matjies River Rock Shelter (Louw 1960: fig. 34). That these latter items are not beads is perhaps demonstrated by their far larger apertures (Figure 5.102). Given the prevalence of ostrich eggshell across much of southern Africa there seems little reason to make beads of bone and this is probably the main reason for their considerable scarcity. 


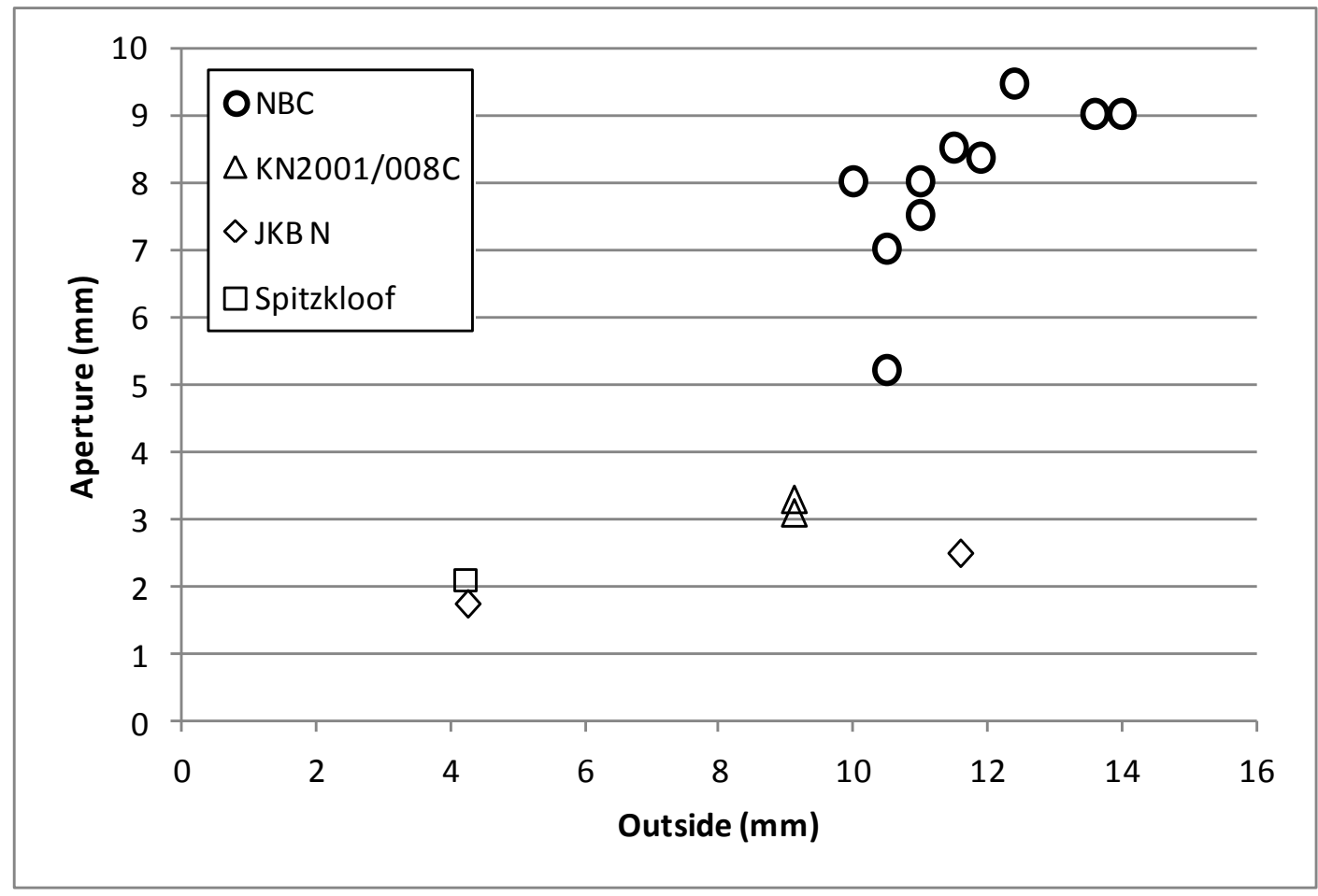

Figure 5.102: Graph showing the ratio of external to aperture diameters of bone beads from Namaqualand and bone rings from Nelson Bay Cave. Source data as in Table 5.133 above and NBC from Inskeep (1987: appendix 35).

\subsubsection{Ostrich eggshell pendants}

Ostrich eggshell pendants are rare in Namaqualand but are occasionally found (Orton \& Halkett 2005, 2006). Although broken, that from AK2005/001 is a fine example (Figure 5.103). The small nicks around the edge are a typical decorative feature, but many Namaqualand examples are plain, like the wind-blasted one from KN2004/012 (Figure 5.104). Stylistic continuity is demonstrated by the presence of an identical example to the AK2005/001 pendant from Noetzie on the south coast (Orton \& Halkett 2007b: fig. 4a). 


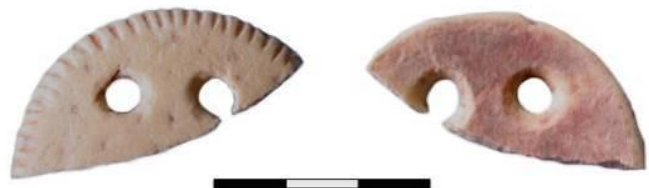

Figure 5.103: Front (left) and back (right) of the ostrich eggshell pendant fragment from site AK2005/001. The rear is ochred. Scale in $5 \mathrm{~mm}$ intervals.

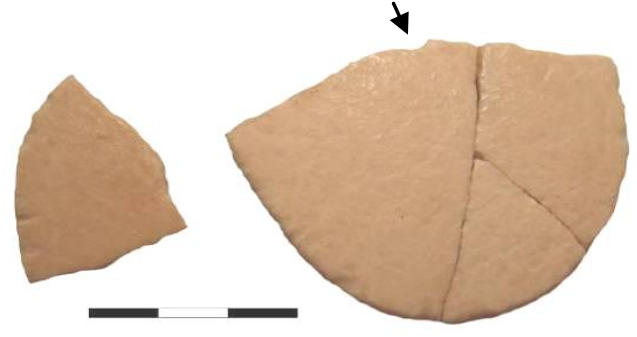

Figure 5.104: The wind-blasted ostrich eggshell pendant fragments from the background scatter at KN2004/012. The right hand one has part of a hole visible (arrowed). Scale in $5 \mathrm{~mm}$ intervals.

\subsubsection{Marine shell pendants}

Several types of marine shell pendants have been identified in Namaqualand. The first are broken cowrie shells ${ }^{19}$ which might have been threaded through their openings (Dewar 2008: fig. 11.10). Cowries are usually assumed to originate in the Indian Ocean but one species, Cypraea iutsui (Shikama 1974), does occur in deep water off the coast south of the Olifants River mouth (Liltved 2000). It is unknown what species is present in the archaeological sites and, although none are whole, comparison with the various southern African species presented in Liltved's (2000) photographic catalogue suggests they are most likely to be $C$. iutsui. The second type of shell pendants are Conus shells that have their apices missing, enabling them to be threaded through their openings (Dewar 2008: fig. 5.12 and 8.13). It should be noted that on the south coast these shells receive perforations on their basal ends (e.g. Henshilwood 2008; Louw 1960; Orton \& Halkett 2007). Although water-worn Bullia shells are common in Namaqualand, intentionally perforated examples are unknown. Further south, however, several were recovered from Tortoise Cave (Robey 1984). One example each of pendants made on Haliotis midae (Webley 1984) and Turbo sarmaticus (Orton et al. 2011) are known from

\footnotetext{
${ }^{19}$ Dewar referred to them as beads but I prefer pendants
} 
central and southern Namaqualand respectively. Both artefacts must have travelled more than $200 \mathrm{~km}$ from the natural home ranges of the species from which they were made.

\subsubsection{Bone points}

These artefacts are uncommon but are found from time to time. They consist of a variety of ground points and awls. Examples have come from AK2006/006 (Orton 2007c), DP2004/014, LK2004/011, MB2005/005 (Dewar 2008), Rooiwal Hollow (Orton et al. 2005) and SK2001/033 (Halkett 2003).

\subsubsection{Other worked bone}

Aside from the items already discussed, the only other bone artefacts recovered from the study area are two pendant fragments from AK2006/006, one of which has small punctures decorating the edges of its upper surface (Figure 5.105; Orton 2007c). This site also contained an unbroken melon knife which is shown here (Figure 5.103). Just one other probable melon knife has been found in Namaqualand from MB2005/043 near the Spoeg River mouth (Halkett \& Dewar 2006).

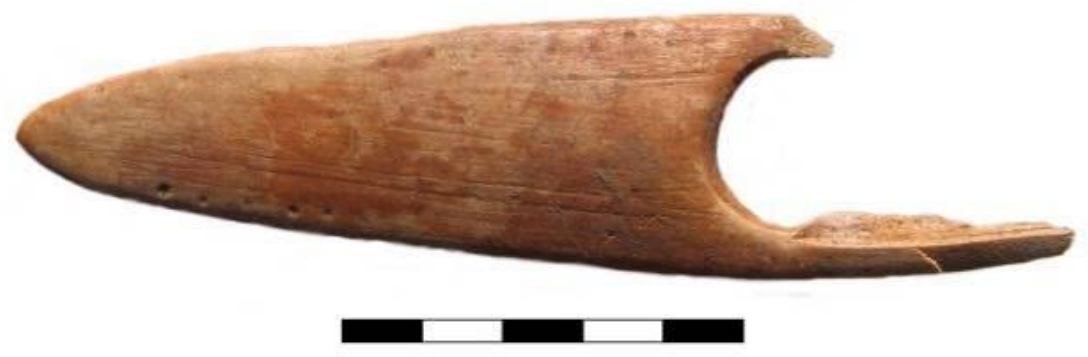

\section{O}

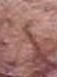

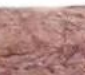
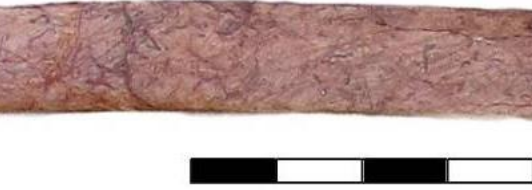

Figure 105: Bone pendant (top; scale in $5 \mathrm{~mm}$ intervals) and melon knife (bottom; scale in $10 \mathrm{~mm}$ intervals) from AK2006/006. 
Tortoise shell bowls are found throughout South Africa (J. Deacon 1984a). Despite the large number found at Dunefield Midden 1, to the south of Namaqualand (Stewart et al. 2011), very few fragments have been recovered from Namaqualand. They may be bowl fragments.

\subsubsection{Huts}

A cluster of whale bone huts was recorded on the Namibian coastline (A. Smith \& J. Kinahan 1984), while a single probable example is known from Samsons Bak 5 in central Namaqualand (Halkett \& Hart 1997). The remnants of these structures present as a loose circle of whale ribs, sometimes still standing erect. While such huts were identified historically (Gordon 1779 cited in A. Smith \& Kinahan 1984; J. Kinahan \& J.H.A. Kinahan 1984; Paterson 1789), the antiquity of their use is unknown and no radiocarbon dating has yet been attempted.

The usual mode of making huts was through the erection of a framework of poles which was covered by branches in the case of the Bushmen and by mats in the case of the Khoekhoen (J. Deacon 1984a; Godee Molsbergen 1916), hence the terms matjieshuis ${ }^{20}$. The mats were made from reeds placed parallel to one another and fastened tightly together with sinews or thread, the latter in more recent times obtained from Europeans (Sparrman 1785).

\footnotetext{
${ }^{20}$ An Afrikaans word literally translated as 'mat house'.
} 


\subsubsection{Tortoise burials}

Deliberate tortoise burials have been found in several sites in Namaqualand. The tortoises appear to have been cooked and eaten then generally buried without any bones besides the carapace and plastron. They are found beneath intact shell middens in coastal sites and may indicate some sort of consecration ritual. Further description is provided in Orton (2012)

\subsubsection{Glass trade beads}

The only glass trade bead yet found in coastal Namaqualand comes from LK2001/010a (Figure 5.106; Halkett \& Dewar 2007). This type of bead (Indian red on green - IROG) was not made before AD 1600 (M. Wood, pers. comm. 2011). The likely age of this example is provided by the fact that in Namibia such beads were only found on Kuiseb Delta historical sites dating between the 1780s and 1840s (J.H.A. Kinahan 2000). LK2001/010a also contains clear quartz backed artefacts and pottery, as is the case at KK002, the only site in this thesis to include glass beads. Inland, Webley (1984) found glass beads at Bethelsklip, along with a metal and a ceramic bead. The source of these beads is unclear, however, since the site was regularly used in historic times for church services.

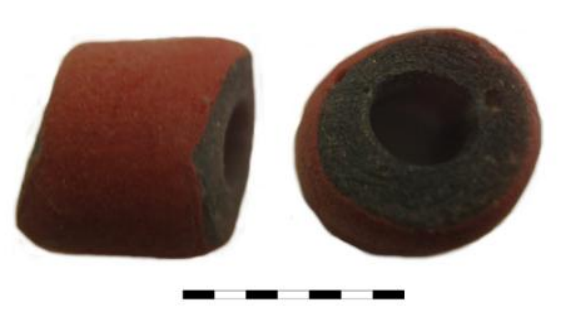

Figure 5.106: Glass bead from LK2001/010A. Scale in $1 \mathrm{~mm}$ intervals. 


\section{Chapter 6. Archaeological signatures in Namaqualand}

This chapter analyses the cultural material and shellfish assemblages from the core study area, the central and northern Namaqualand coastline. The analyses are both temporal and by assigned lithic group with data presented graphically. The analyses have two aims:

- To describe the characteristics of Namaqualand assemblages and their overall sequence of change;

- To attempt to determine if any of these characteristics can help to inform on socio-economic grouping (i.e. hunter-gatherer or herder).

The dated assemblages are numbered consecutively from oldest to youngest with those numbers used in the graphs to avoid clutter. The reader is requested to fold out the key page from inside the back cover for easy identification of the assemblages. For the purposes of the graphical analyses, stone artefact assemblages with $<50$ artefacts were omitted as were ostrich eggshell bead assemblages with $<3$ stage VIla beads. Due to the obvious discordance between age and pottery presence, MB2005/059 was disregarded completely, as were the undated assemblages.

In assemblages with two or more $\mathrm{C} 14$ determinations ages were assigned as follows:

- When the dates came from multiple layers or discrete parts of a site which could not be guaranteed contemporaneous but, for various reasons, the data from which were conflated, the maximum age range covered by both dates at $95.4 \%$ was used. There were two exceptions where lower ages post-dated those above them in which case the minimum range (period of overlap) was used; 
- When the dates came from one layer or area and represented one archaeological occupation the range was taken as the period of overlap in the 2 sigma calibrated ranges;

- On one occasion (KN2005/067, Patch 1A) one date was significantly older than two others and, being away from the main excavation, was assumed to represent an intrusion.

Although the detailed analysis focuses on the coastal samples, reliable assemblages from other parts of Namaqualand are also discussed and related to the coastal data.

\subsection{Stone artefacts}

With stone artefacts being the most persistent artefact types found in archaeological sites of all ages, their technology and typology have routinely been used to define periods of time, sometimes refered to as culture-stratigraphic units. This section seeks to identify some of the patterning in coastal Namaqualand and hence identify changes occurring within the periods referred to as the 'Holocene microlithic' (post-dating c. 8000 BP) and 'Late Holocene assemblages' (post-dating c. 3000 BP; Orton 2006). Some of tis patterning is inherent in the lithic groups which is where I begin.

Figures 6.1 and 6.2 illustrate the principal characteristics of the assigned lithic groups. The categories generally hold true but do incorporate some variety. Aside from MB2005/005B (Assemblage 1), exceptions occur in either the overall or retouched material frequencies but never in both. Dating to the mid- $4^{\text {th }}$ millennium BC, MB2005/005B is far older than the next oldest assemblage (KN2001/008C; early to mid$3^{\text {rd }}$ millennium $\mathrm{BC}$ ) and its higher quartz frequencies may signal an earlier pattern. 


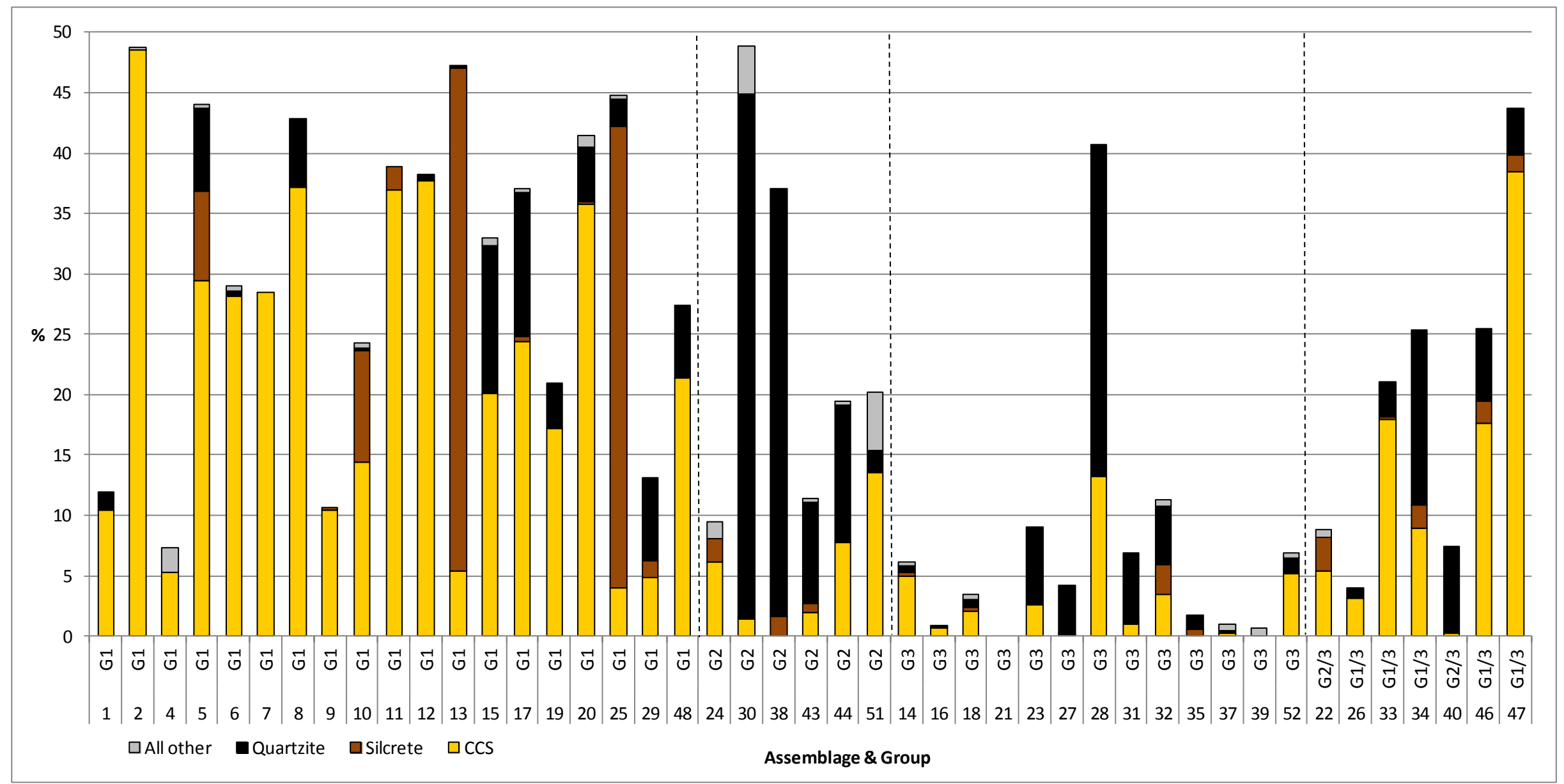

Figure 6.1: Stone material composition of the assemblages by assigned Group. Quartz is excluded and comprises the remaining amount in each assemblage. 
$\begin{array}{llllllllllllllllllllllllllllllllllllllllllllllllllllll}39 & 11 & 1 & 4 & 136 & 14 & 13 & 14 & 4 & 28 & 5 & 10 & 107 & 17 & 6 & 27 & 3 & 3 & 2 & 0 & 0 & 0 & 2 & 4 & 0 & 4 & 51 & 35 & 2 & 3 & 78 & 3 & 10 & 10 & 3 & 19 & 1 & 9 & 2 & 4 & 13 & 4 & 5 & 10 & 3\end{array}$

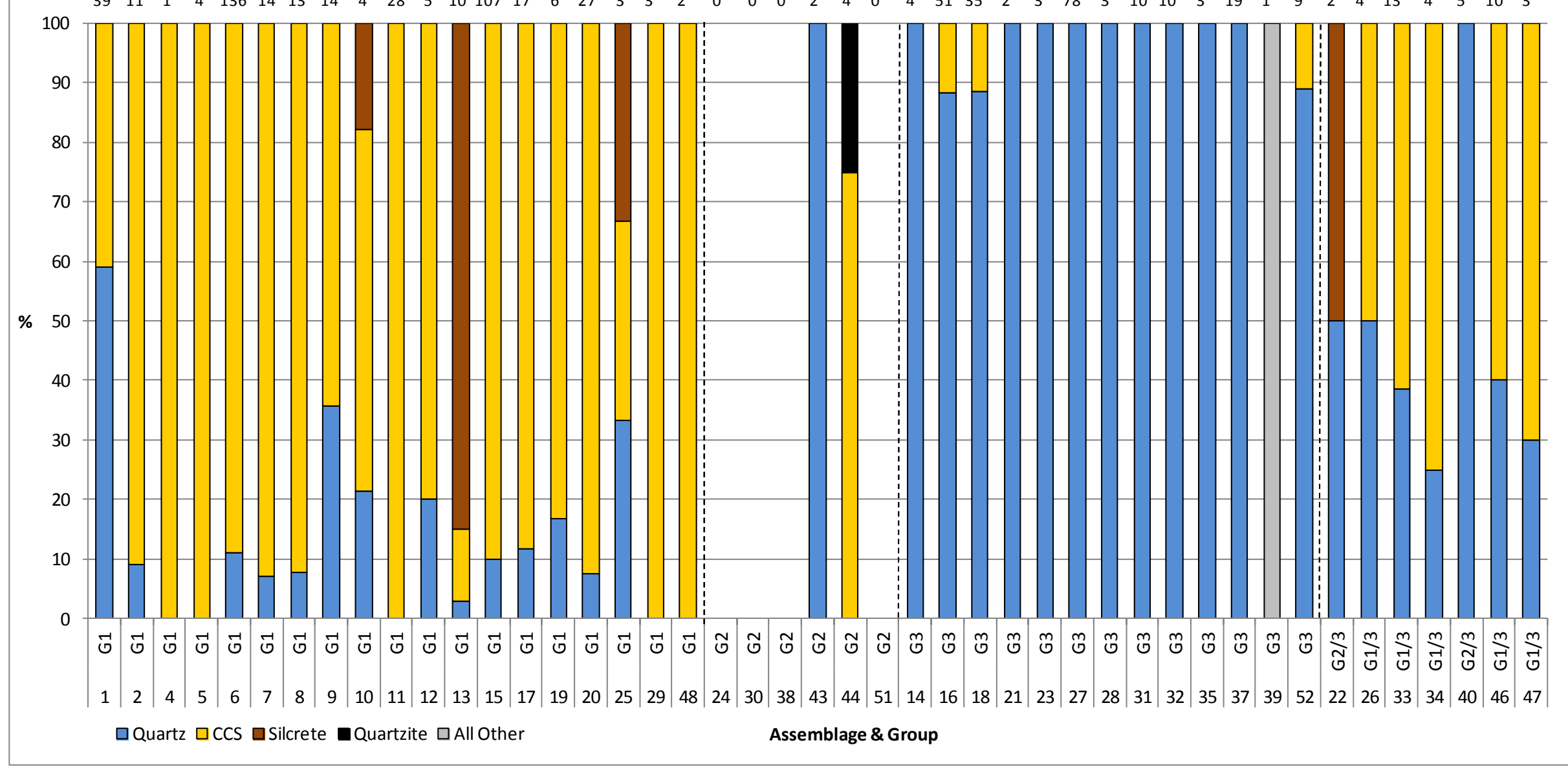

Figure 6.2: Stone material frequencies among all retouched tools by assigned group. The number of retouched tools per assemblage is indicated above each column. 
The informal Group 2 assemblages are quartz-dominated, but two make opportunistic use of good local quartzite (Figure 6.1). Group 2 includes few retouched items with the main exception, SK2005/057A (Assemblage 44), no doubt including items from SK2005/074 (Assemblage 17), an immediately proximate older site (Figure 6.2). Group 3 sites are distinguished by very high quartz frequencies in either or both of the total assemblage and the retouched component. The primary exception in Figure 6.1 is LK2004/011 (Assemblage 28) which included much quartzite, but the lack of milky quartz militated against a Group 2 influence.

Placing the assemblages in temporal order is not overly helpful but shows that the general use of CCS declined rapidly about 2000 years ago (Figure 6.3); this reflects the abrupt drop in frequency of Group 1 assemblages. Plotting the same for materials used in retouch reflects a similar pattern, but emphasises the interchangeability between Group 3 and other assemblages through time (Figure 6.4).

Analysis of cores can only be undertaken for those in quartz, since too few are present in other materials. Figure 6.5 shows that all three primary core types are present in Groups 1 and 3 and that single platform cores are entirely absent from Group 2. Overall core frequencies in quartz vary up to about $7 \%$ but Group 2 frequencies are no different to the rest. Andrefsky (2005) differentiates between formalised and informal cores with the latter requiring little or no preparation. The lack of single platform cores in Group 2 thus indicates that simpler, unstandardised core technology was favoured for the expedient production of flakes. Single platform cores require greater preparation and provide more predictably sized and shaped flakes as might be required in the more formalised Group 1 and Group 3 industries.

The overall frequency of retouched items has often been cited as a means of distinguishing hunter-gatherer from herder sites (Sadr 1997; A. Smith 2006a; A. Smith et 
al. 1991, 2001). A plot of retouch frequencies in Namaqualand shows (1) that Group 1 and 3 assemblages contain higher frequencies, (2) that little retouch occurs in Group 2 assemblages, and (3) that - largely owing to the addition of Group 2 assemblages to the mix - the overall trend is decreasing (Figure 6.6). Sadr (1997) considered the relationship between 'Formal Tool Index' (FTI; percentage of retouched tools in an assemblage) and 'Pottery Index' (PI; percentage of potsherds in the sum of all potsherds and stone artefacts) to be a potential means of identifying hunter and herder sites. Figure 6.7 plots this for the present Namaqualand sample. In theory, assemblages on the lower right would be herder, while those to the upper left would be hunter-gatherer. All Group 1 pre-AD1 assemblages without pottery are omitted, since all would lie on the y-axis and hence be in the upper left (hunter-gatherer) as expected. Two clear patterns emerge: firstly, all Group 2 (red) and Group 2 combination (yellow) assemblages lie close to the bottom of the graph $(\mathrm{FTI}<1)$ (they can be separated from the remaining assemblages by a straight line), and, secondly, Group 2 assemblages are the ones most likely to have high pottery indices. SK2005/057A (Assemblage 44) is known to include three retouched items from nearby SK2005/074A so its FTI can be taken as 0.22 . Two excluded Group 2 sites would also fall below the line, further reinforcing the pattern (Assemblage 36: $\mathrm{FTI}=$ $0, \mathrm{Cl}=86.46$; Assemblage 53: $\mathrm{FTI}=0, \mathrm{Cl}=22.22$ ). Also omitted, LK2005/015, with its multiple coeval but spatially discrete middens, complicates matters by showing that assemblages belonging to all four Groups can potentially be deposited during a single occupation. The very tiny assemblage sizes, however, significantly reduce the reliability of any conclusions that may be drawn from this observation. Several other assemblages (on Figure 6.6) have similarly been adjudged to have two Groups, and hence cultural signatures, present. Interestingly, Sadr et al.'s (2003) proposed index of $>60 \%$ for herders seldom applies, while indices $<20 \%$ for hunter-gatherers encompass the vast majority of all assemblages. Their figures are thus not suited to use in Namaqualand and, in all likelihood, region-specific figures would need to be devised as appropriate. 
When the primary categories of retouch are plotted one finds the already perceived view (see Section 3.7.1) to hold true: earlier assemblages (older than $1000 \mathrm{BC}$ ) tend to have more backed items than scrapers which in turn dominate during the subsequent millennium (Figure 6.8). Within the last two millennia Group 1 assemblages became more variable and Group 3 assemblages were strongly dominated by backed items but there is no obvious change around the transition to the pottery period.

Whether arguments around the influence of mobility on technology can be generally applied to Namaqualand seems uncertain. Kelly (1992) notes that the reconstruction of mobility patterns from technology is limited by many factors. Space precludes a full discussion but nevertheless some arguments are reviewed in Table 6.1 and the implications for Namaqualand considered. The evidence is contrasting and perhaps of limited use with Andrefsky's (1994) observation, which suggests that stone materials may be of little use in determining mobility, likely the most pertinent.

Assemblage richness, however, is worth considering further, since obvious patterning exists. Herders are well-known for their high mobility and, along the Namaqualand coast, they may have been far more mobile than hunter-gatherers due to pasture requirements. Given the expectation that hunter-gatherer assemblages should have many retouched items (A. Smith et al. 1991), as is usually the case with pre-pottery hunter-gatherer assemblages, we may expect the retouched assemblages with the lowest richness to be those of herders. Figure 6.9 shows that a wide range of retouched tool richness is represented within Groups 1 and 3, with the highest values falling into Group 1. Group 2 is informal with extremely low richness. Assemblage 44 (SK2005/057A) has four retouched items, three of which come from nearby SK2005/074A, with the fourth being a large chopper (richness =1). Assemblage 43 (SK2001/026) has only miscellaneous retouched pieces (richness $=1$ ). In temporal order we find a general decrease in tool richness with time (Figure 6.10). It is noticeable that within the last 2000 years 
(approximately Assemblages 20 to 51) richness fails to pass nine and that lower values $(<3)$ are frequent occurrences in both Groups 1 and 3. Therefore, although the Group 2 assemblages have the low richness values expected by A. Smith et al. (1991) on herder sites, Table 6.1 shows that assemblage richness does not really help in the discernment of more or less mobile groups and certainly contributes little to the huntergatherer/herder debate. 


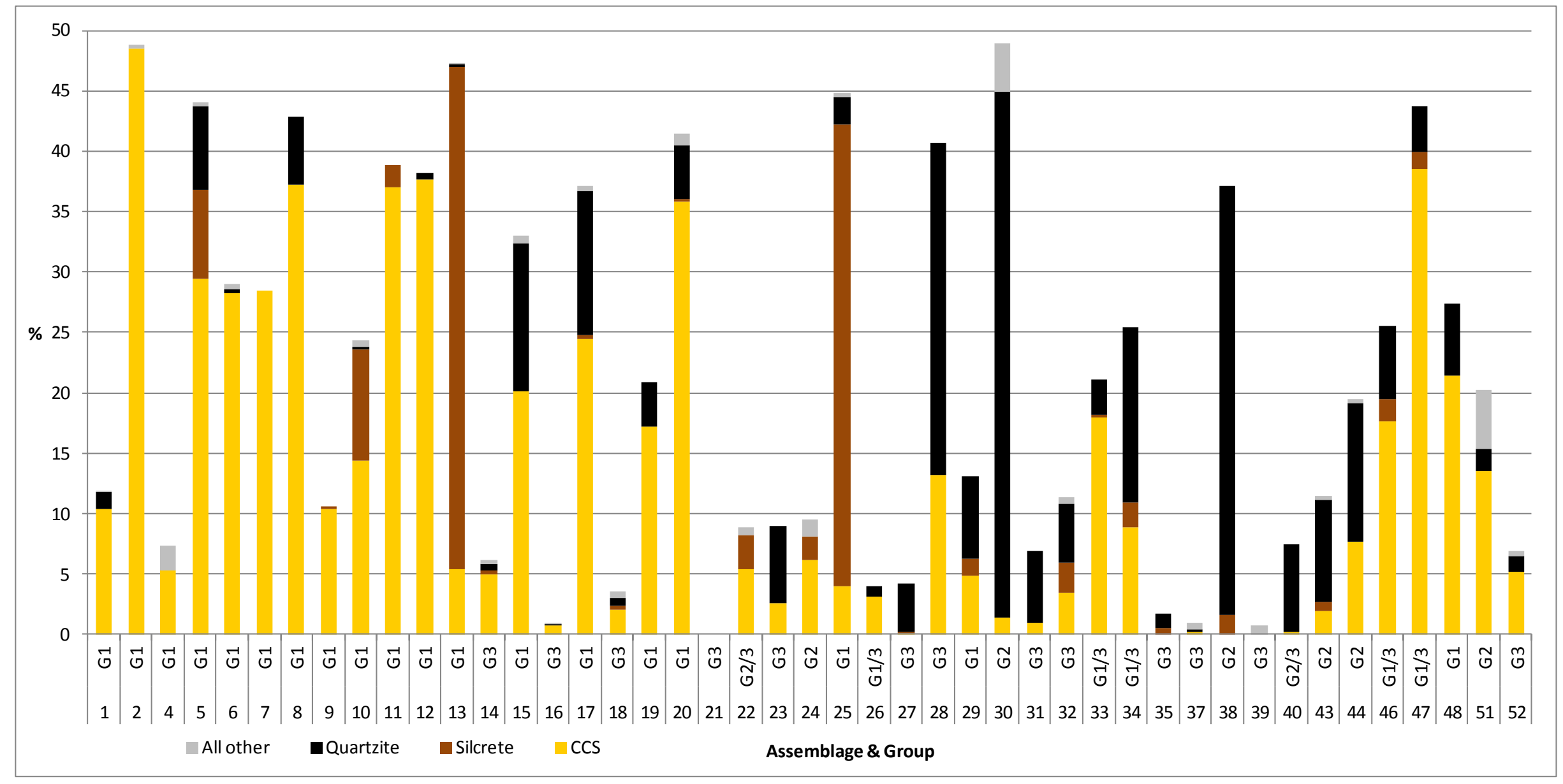

Figure 6.3: Stone material composition of the assemblages in temporal order. Quartz is excluded and comprises the remaining amount in each assemblage. 
$\begin{array}{lllllllllllllllllllllllllllllllllllllllllllllllllllll}39 & 11 & 1 & 4 & 136 & 14 & 13 & 14 & 28 & 4 & 5 & 107 & 4 & 10 & 51 & 17 & 35 & 6 & 27 & 2 & 2 & 3 & 0 & 3 & 4 & 78 & 3 & 3 & 0 & 3 & 10 & 13 & 4 & 10 & 19 & 0 & 1 & 3 & 2 & 4 & 10 & 5 & 2 & 0 & 9\end{array}$

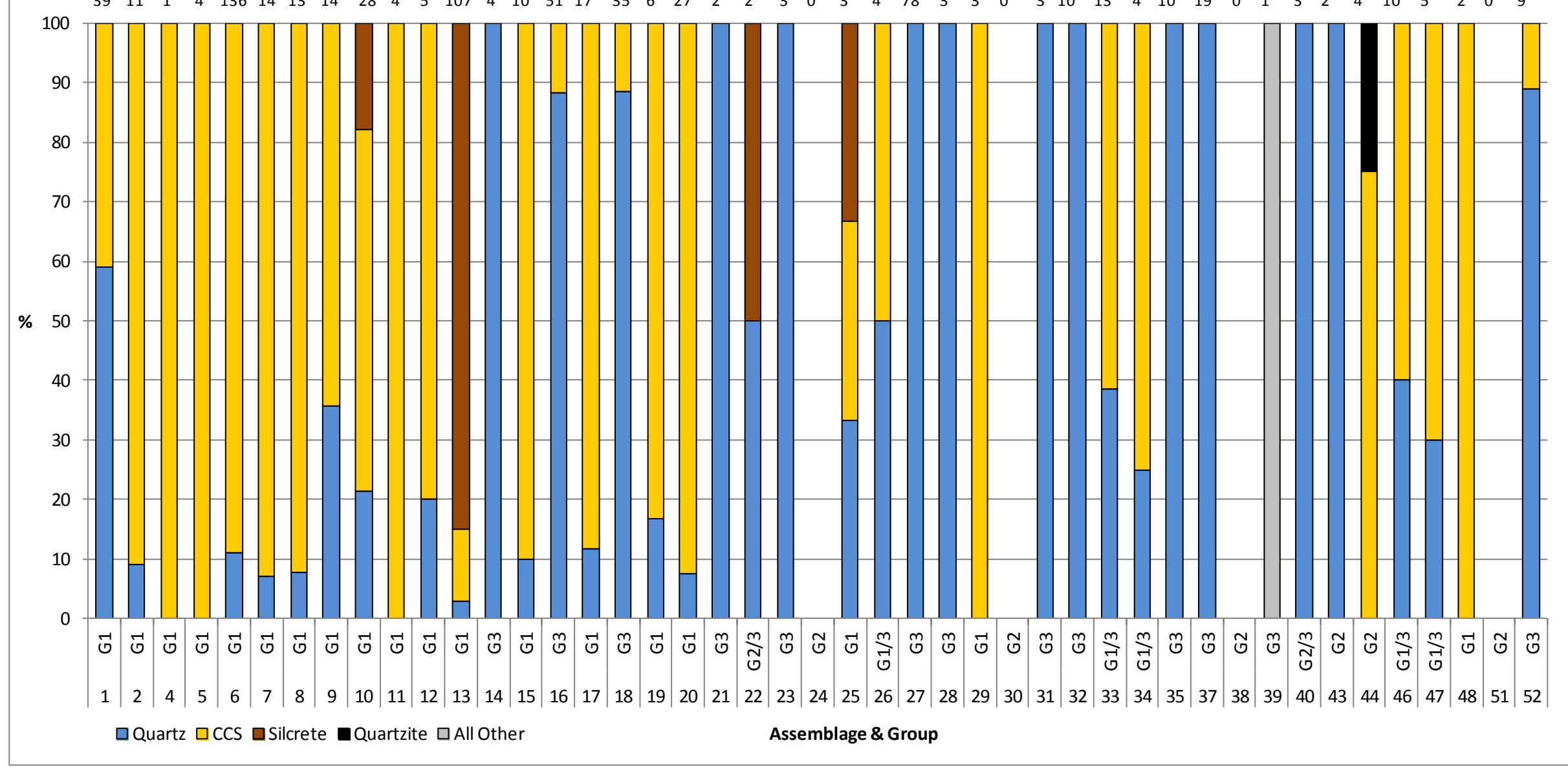

Figure 6.4: Stone material frequencies among all retouched tools in temporal order. The number of retouched tools per assemblage is indicated above each column. 


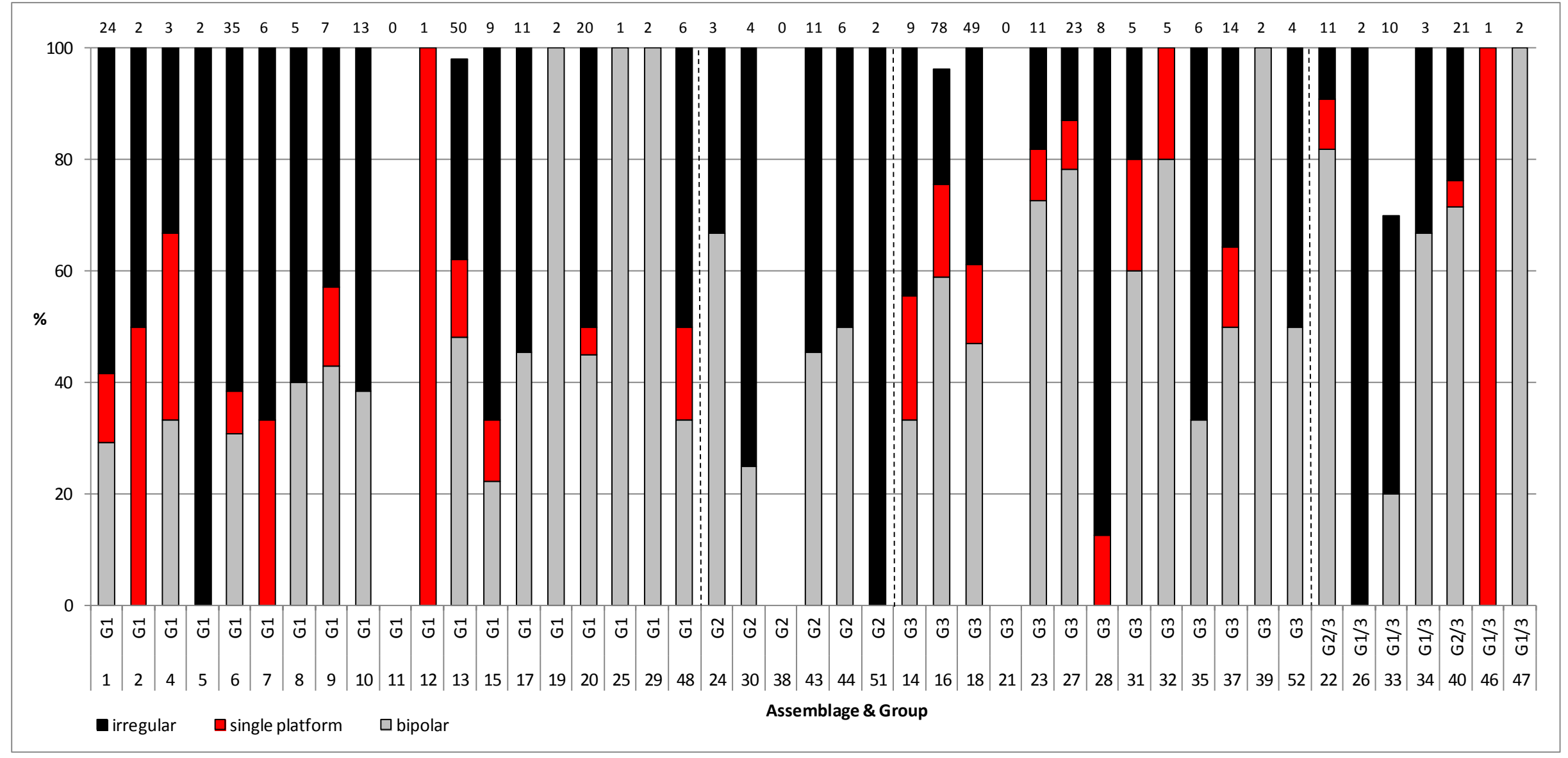

Figure 6.5: Primary core type frequencies among all quartz cores by assigned group. Minor types are omitted and the number of quartz cores per assemblage is indicated above each column. 


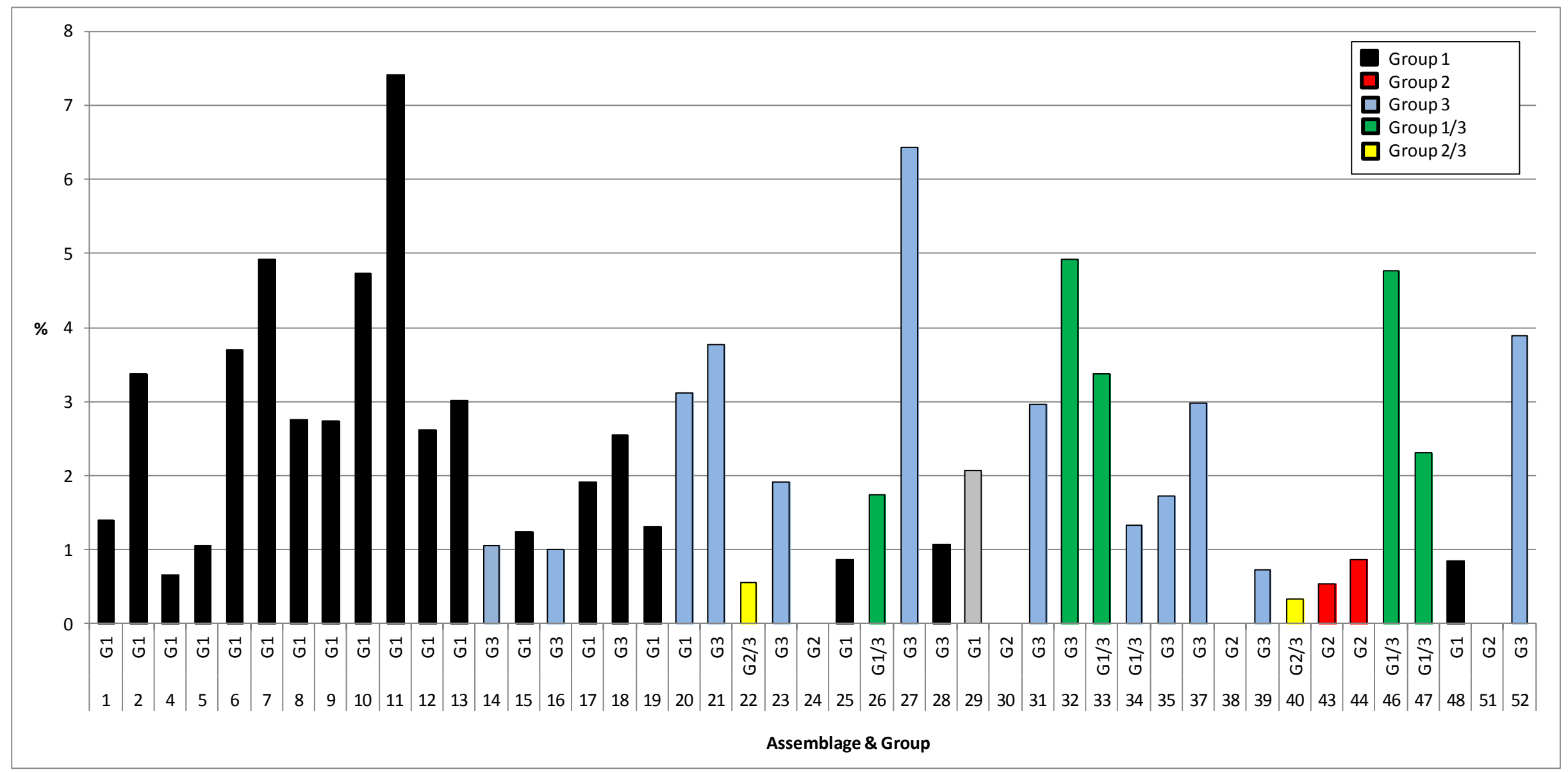

Figure 6.6: Retouch frequency in temporal order. 


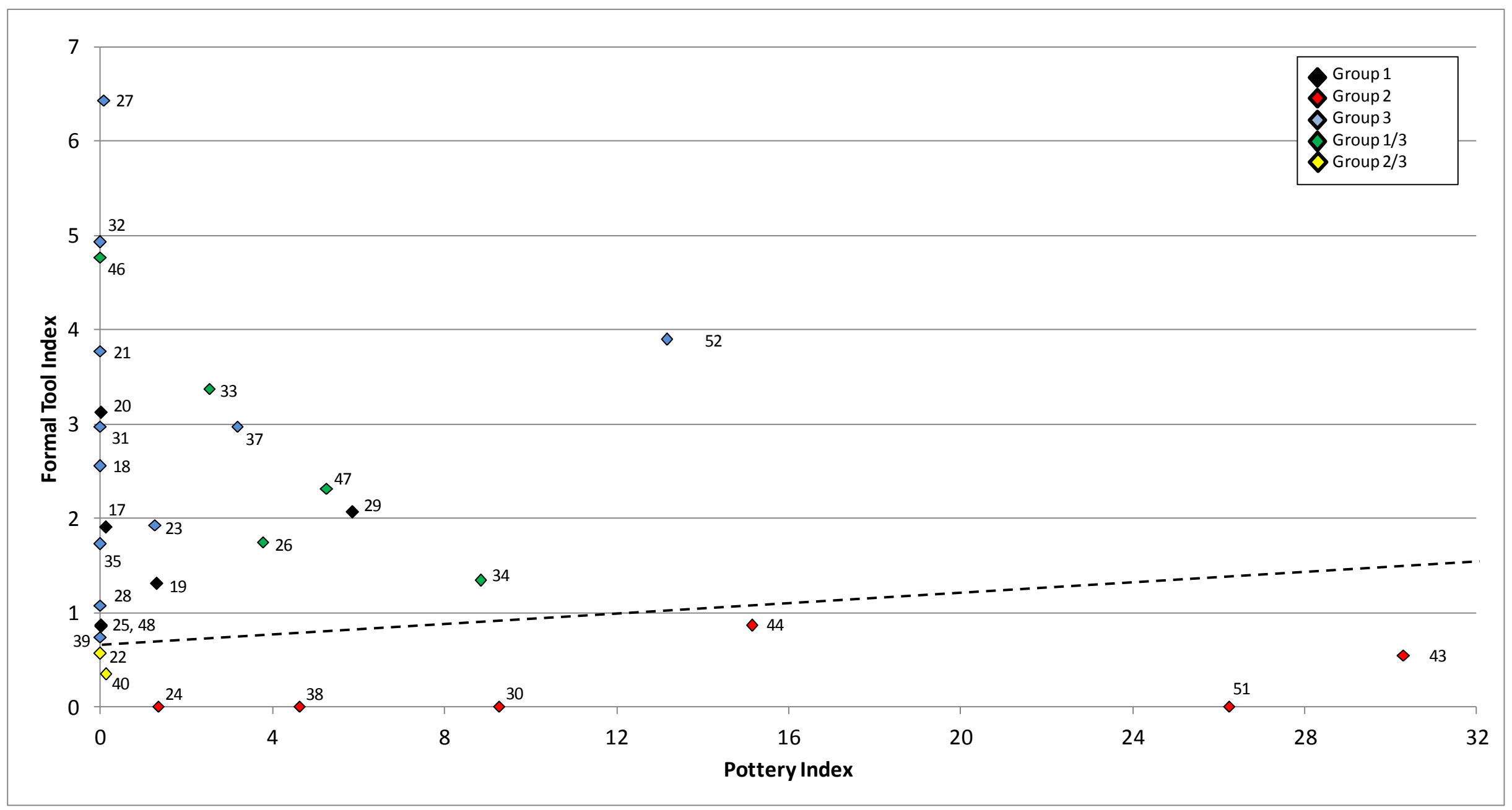

Figure 6.7: Scatter plot of formal tool index against pottery index. Assemblage numbers are indicated. For the sake of clarity, all sites older than 2000 years and with no pottery are excluded, since all would fall on the $y$-axis. The dashed line indicates the separation between Group 2 and Group 2/3 assemblages and the rest. 


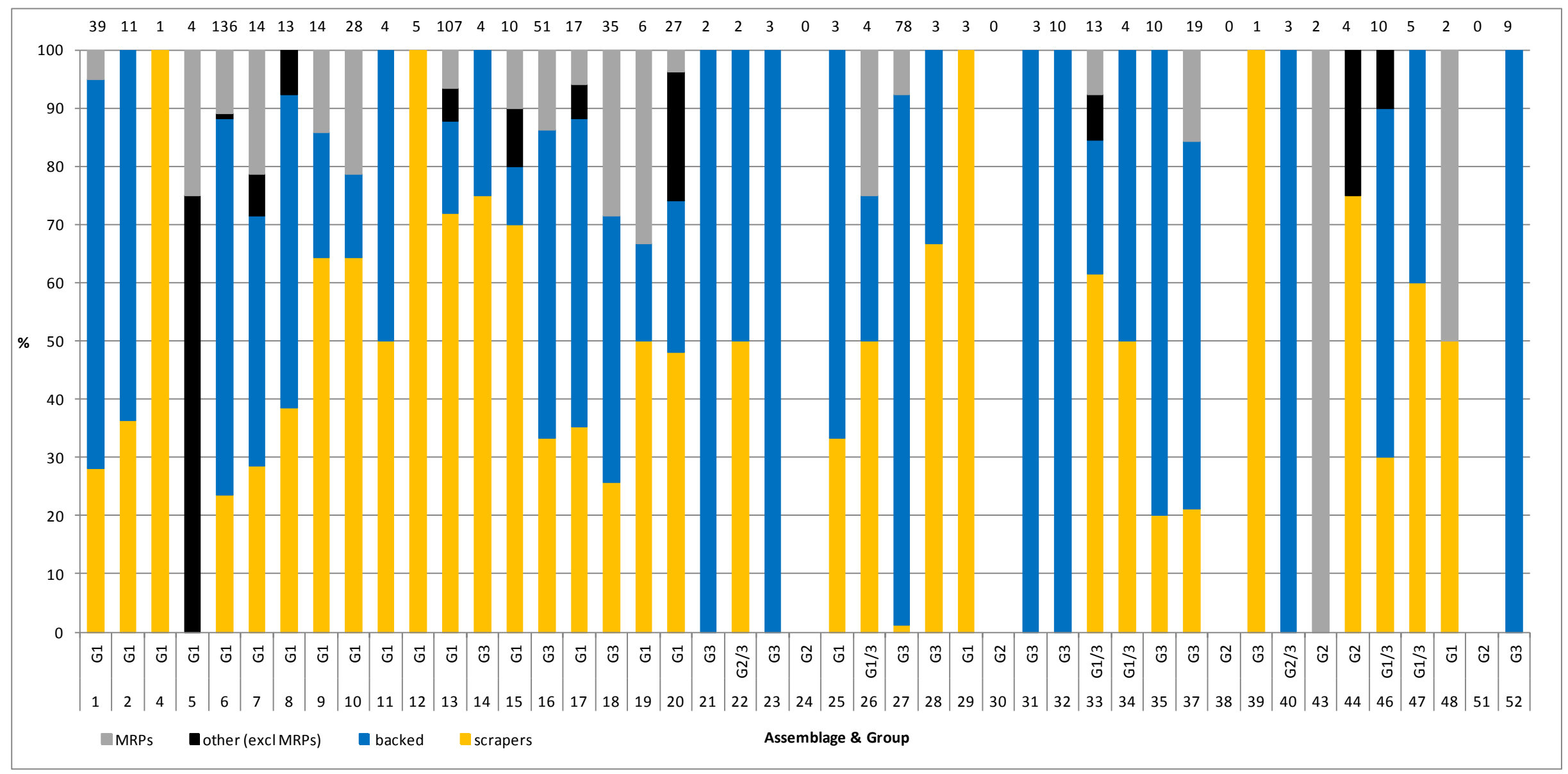

Figure 6.8: Retouch types in temporal order. 
Table 6.1: Relationships between technology and mobility and implications for Namaqualand assemblages.

\begin{tabular}{|c|c|c|}
\hline \multirow{2}{*}{ Criteria } & \multicolumn{2}{|c|}{ Namaqualand assemblages } \\
\hline & High mobility & Low mobility \\
\hline $\begin{array}{l}\text { Mobility is affected by "the time available for tool production and the } \\
\text { amount of stone which can be transported from place to place" } \\
\text { (Bamforth 1987:98). Sedentism thus encourages storage of stone } \\
\text { material and reduced expenditure of time and energy on artefact } \\
\text { production. Artefacts are thus more expedient (Parry \& Kelly 1987). } \\
\text { Expedient artefacts are technologically simple and less patterned than } \\
\text { curated ones (Bamforth 1986) because they are made to serve an } \\
\text { immediate need (Binford 1979). }\end{array}$ & $\begin{array}{l}\text { Group } 1 \text { and Group } 3 \text { have curated } \\
\text { stone tools made on materials thought } \\
\text { to have been collected from the local } \\
\text { environment. }\end{array}$ & $\begin{array}{l}\text { Group } 2 \text { is highly expedient (although } \\
\text { storage is not necessarily required } \\
\text { given abundant supplies of milky } \\
\text { quartz in the local environment). } \\
\text { Group } 3 \text { assemblages may reflect } \\
\text { expedient production of backed } \\
\text { bladelets for frequent replacement } \\
\text { from local material sources (c.f. Orton } \\
2002 \text { ). }\end{array}$ \\
\hline $\begin{array}{l}\text { High group mobility limits both the number of tools that can be carried } \\
\text { around and the degree of specialisation of those tools (Torrence } \\
\text { 1983). Mobility thus results in the need for smaller, lighter, multi- } \\
\text { functional tools that are readily transportable (Shott } 1986 \text { and } \\
\text { references therein). }\end{array}$ & $\begin{array}{l}\text { The scrapers and backed artefacts } \\
\text { (Hiscock 2006; Robertson et al. 2009) } \\
\text { commonly found in Group } 1 \text { and } \\
\text { Group } 3 \text { assemblages are small, light } \\
\text { and multi-functional. }\end{array}$ & $\begin{array}{l}\text { The expedient flakes of Group } 2 \text { were } \\
\text { likely produced as required and not } \\
\text { transported. }\end{array}$ \\
\hline $\begin{array}{l}\text { Less mobile groups will have a focus on bipolar reduction (Parry \& } \\
\text { Kelly 1987). }\end{array}$ & \multicolumn{2}{|c|}{$\begin{array}{l}\text { Bipolar cores are equally common in all assemblage types (Figure } 6.5 \text { ) and } \\
\text { likely do not inform on mobility. Although expedient assemblages typically focus } \\
\text { on bipolar reduction, it is quite likely that other prepared cores, when } \\
\text { exhausted, would have been further reduced via the bipolar technique (Downey } \\
\text { 2010; Parry \& Kelley 1987). }\end{array}$} \\
\hline
\end{tabular}




\begin{tabular}{|l|l|l|}
\hline \multicolumn{1}{|c|}{ Criteria } & \multicolumn{2}{c|}{ Namaqualand assemblages } \\
\cline { 2 - 3 } $\begin{array}{l}\text { Highly mobile groups should have less diverse toolkits (Shott 1986: } \\
\text { fig. 2). (Shott uses 'diverity' where 'richness' is more correct.) }\end{array}$ & $\begin{array}{l}\text { Group 2 has low richness (negligible } \\
\text { retouch present). }\end{array}$ & $\begin{array}{l}\text { Group 1 \& Group 3 have high } \\
\text { richness (many retouched classes). }\end{array}$ \\
\hline $\begin{array}{l}\text { Using three dichotomies, Cribb (1991:68) suggests that nomadic } \\
\text { material culture in the archaeological record would consist of 'fixtures' } \\
\text { (equatable with Binford's (1980) site furniture), 'durables' and }\end{array}$ & $\begin{array}{l}\text { Although with some variation, fixtures (large grindstones), portables (small } \\
\text { flaked artefacts), durables (stone artefacts, pottery, ostrich eggshell fragments } \\
\text { 'expendables' with the opposite, 'portables', 'perishables' and } \\
\text { 'valuables' generally absent. }\end{array}$ & $\begin{array}{l}\text { artefacts, ostrich eggshell fragments) and valuables (beads) occur equally in all } \\
\text { assemblage types post-AD 1. This suggests their deposition by mobile people. }\end{array}$ \\
\cline { 2 - 3 } & $\begin{array}{l}\text { Group 2 and Group 3 stone artefacts } \\
\text { may be considered more expendable } \\
\text { in that they have low acquisition or }\end{array}$ & $\begin{array}{l}\text { Group 1 stone artefacts are more } \\
\text { valuable in that CCS can be seen as } \\
\text { having a high acquisition or } \\
\text { replacement cost. }\end{array}$ \\
\hline $\begin{array}{l}\text { Both mobile and sedentary people may have needed curated tools } \\
\text { when abundance and quality of materials was restricted, while both } \\
\text { groups might have focused on expedient production when materials } \\
\text { were readily to hand (Andrefsky 1994). }\end{array}$ & $\begin{array}{l}\text { Given the short geological time span and thus unchanged access to stone } \\
\text { materials, and the fact that expedient and curated technologies are present } \\
\text { side-by-side suggesting similar material access, technology may not inform on } \\
\text { mobility at all in Namaqualand. }\end{array}$ \\
\hline
\end{tabular}




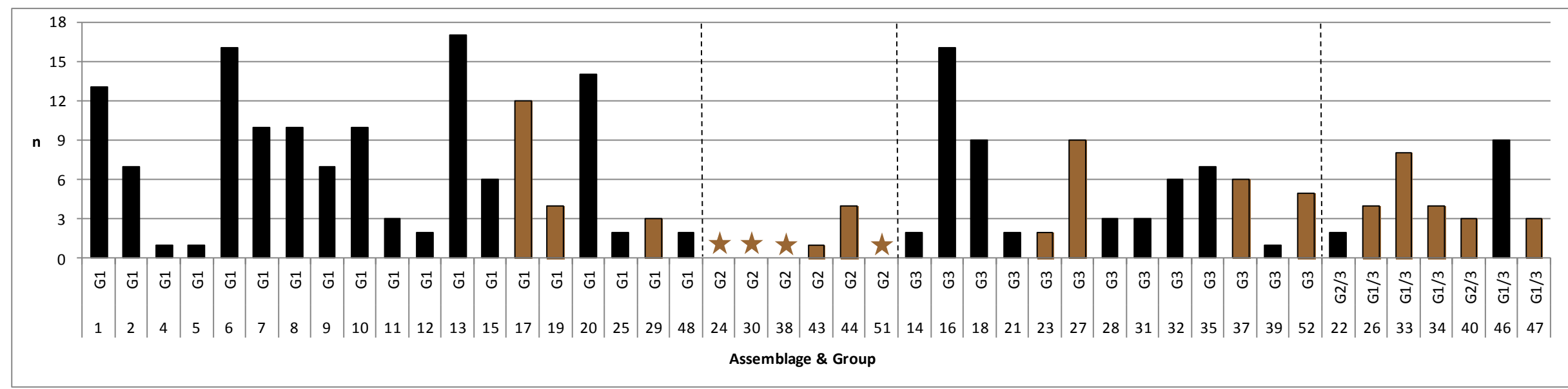

Figure 6.9: Number of retouched tool classes by assigned assemblage group. Brown bars are assemblages with pottery and stars indicate pottery but no retouch.

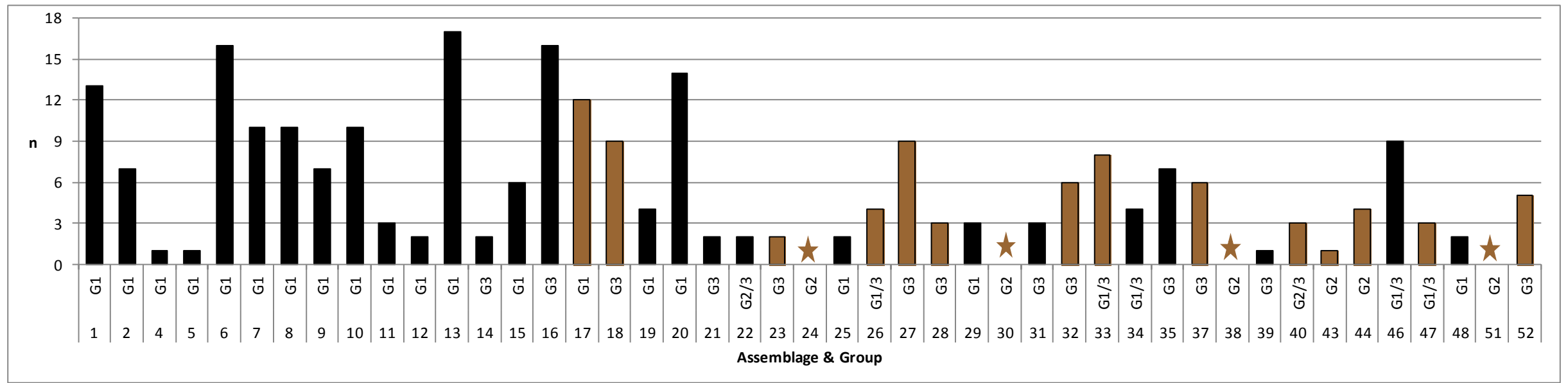

Figure 6.10: Number of retouched tool classes in temporal order. Brown bars are assemblages with pottery and stars indicate pottery but no retouch. 
I turn now to a brief discussion of other Namaqualand sites and how their stone assemblages relate to the coastal samples.

Spoeg River Cave contains the most significant excavated Holocene deposit in Namaqualand. However, being a cave site, its assemblages will be mixed to some degree and cannot offer the clear windows of single occupation open sites. This is borne out by the consistency of stone material frequencies in the cave (Webley 2002: tables 3 \& 6), while open sites show much fluctuation. Little detail on retouch materials is provided in Webley (2002) but, in common with the open sites, fine-grained materials appear to be more frequent pre-AD1 with quartz dominating strongly later on. Although Webley (1992b, 2002) offers no comment on clear and milky quartz, the high frequencies of both quartz and backed artefacts in later assemblages may well indicate the presence of Group 3 assemblages. The expected retouch pattern (Figure 6.8) does not occur at Spoeg River Cave (Table 6.2). There, scrapers and backed tools are fairly evenly represented pre-1000 BC and during the subsequent millennium (ratios of 7:5 and 18:16 in favour of scrapers for Layers $14-12$ and 11-7 respectively). Whether this is due to differential class identification or other factors is unknown. The late Holocene is clearer and, as already noted, seems to be Group 3 focused. Webley (2002) considers the lack of scrapers post-AD 1 to be due to their replacement by large //khom scrapers. One was found in the Spoeg River Cave deposits, but they are absent from open sites in Namaqualand, the only other archaeological example known being from Buzz Shelter (reported above) and Renosterkop 1, near Kakamas (Morris \& Beaumont 1991). While Webley (2002) remains fairly open on what occurred in the cave during the first millennium AD, Vogel et al. (1997) seem more convinced that either herders were present or that local hunter-gatherers had begun herding. Should Vogel et al. be correct then Group 3 assemblages could signify herding in one way or another. 
Table 6.2: Retouch types at Spoeg River Cave (ages calibrated and data calculated from Webley 2002: tables $2 \& 4)$.

\begin{tabular}{|c|c|c|c|c|c|c|}
\hline Layer & Ages & $\mathbf{n}$ & $\begin{array}{c}\text { Scrapers } \\
\%\end{array}$ & $\begin{array}{c}\text { Backed } \\
\%\end{array}$ & $\begin{array}{c}\text { Other (excl. } \\
\text { MRPs) \% }\end{array}$ & $\begin{array}{c}\text { MRPs } \\
\%\end{array}$ \\
\hline 16 & Early Holocene & 10 & 70 & 20 & 10 & \\
\hline 15 & Early Holocene & 4 & 100 & & & \\
\hline 14 & & 5 & 60 & & 20 & 20 \\
\hline 13 & $1921-1636 \mathrm{BC}$ & 12 & 8.3 & 33.3 & & 58.3 \\
\hline 12 & $2457-1980 \mathrm{BC}$ & 7 & 42.9 & 14.3 & & 42.9 \\
\hline 11 & & 7 & 14.3 & 28.6 & 14.3 & 42.9 \\
\hline 10 & $\begin{array}{l}518-366 \text { BC } \\
\text { AD 55-325 }\end{array}$ & 4 & 50 & & & 50 \\
\hline 9 & $\begin{array}{l}\text { AD 62-333 } \\
\text { AD 55-325 }\end{array}$ & 10 & 40 & 40 & & 20 \\
\hline 8 & & 8 & 37.5 & 12.5 & & 50 \\
\hline 7 & $\begin{array}{l}\text { AD 685-961 } \\
\text { AD 469-680 }\end{array}$ & 19 & 42.1 & 47.4 & & 10.5 \\
\hline $6 b$ & AD 6-313 & 4 & 25 & 25 & & 50 \\
\hline $6 a$ & & 4 & 75 & 25 & & \\
\hline 5 & & 9 & & 55.6 & 11.1 & 33.3 \\
\hline 4 & AD 554-766 & 1 & & 100 & & \\
\hline 3 & & 2 & & 100 & & \\
\hline 2 & & 6 & & 66 & 16.7 & 16.7 \\
\hline 1 & & 2 & & 100 & & \\
\hline
\end{tabular}

No reliable observations can be drawn from the Hardeveld area but, to the north, assemblages from the Richtersveld are in general agreement with those from the Sandveld. Although JKB N is scraper-dominated, JKB L (Orton \& Halkett 2010) and Die Toon (Webley et al. 1993) are dominated by backed tools as expected pre-1000 BC. Despite a few retouched items at JKB A (Webley 1997a), the four first and second millennium $A D$ sites at Jakkalsberg all have informal stone artefact assemblages dominated by quartz and quartzite (Group 2) and low FTI and PI values. Further downstream, Bloeddrift 23 also shows an informal, quartz-dominated assemblage in the second millennium AD. Although the seemingly mixed assemblages at /hei-/khomas (see 3.7.3 above) offer the possibility of Group 1 assemblages occurring in this area post-AD 
1, it seems that Group 2 assemblages dominate the Richtersveld landscape during this period.

In the far southern Sandveld contrasting signatures occur before 1000 BC: scrapers dominate at BSB2 (Halkett et al. 1993) and backed artefacts at MS1. Given the many backed artefacts at MS3, it likely dates in the early part of its calibrated range, before 1000 BC. Sites post-dating AD 1 are all informal assemblages, likely falling in Group 2.

Slightly inland, KK002 has a strong Group 3 signature throughout its occupation during the last 1500 years, while in the Knersvlakte Group 3 is well represented throughout the Reception Shelter Late Holocene deposits and also at VR048. The mid-Holocene assemblages from Buzz Shelter are Group 1, but the later material may represent a mixture of groups, possibly due to natural mixing of the rock shelter deposits. VR048 also shows evidence of Group 1 out in the open.

The above analysis shows that in Namaqualand temporally-based change among lithic assemblages is limited before 2000 years ago. All assemblages are typical of the Holocene microlithic with the only obvious change being a shift from backed tool to scraper domination between about 1100 and 800 BC. After this time change is limited but variation is strongly conditioned by the lithic Groups which have strongly differing characteristics. While Group 1 must belong to hunter-gatherers due to its existence before AD 1, the presence of two other assemblage types (Groups 2 and 3) complicates matters and they thus do not inform on issues of socio-economic grouping as well as they are said to do on the Vredenburg Peninsula where just two types are identified (see 2.1.1 above; A. Smith 2006; A. Smith et al. 1991). However, it does seem possible that the strikingly different Group 2 assemblages with their consistent pottery presence might be those of herders. Group 1 assemblages, particularly those predating AD 1, must 
belong to hunter-gatherers, while Group 3 remains enigmatic and will be further explored below.

\subsection{Ostrich eggshell beads}

Based on size change after the introduction of domestic stock, bead size has often been linked to socio-economic grouping (Jacobson 1987; A. Smith 2006; A. Smith et al. 1991). When the Namaqualand beads are examined by Group it becomes evident that lithic group has no bearing on bead size; size dominance varies within each group and similar ratios between different sizes occur in all three Groups (Figure 6.11). Similar to the present lithic groups, Jacobson (1987) proposed three assemblage types: typical microlithic LSA pre-herder with beads smaller than $7.5 \mathrm{~mm}$; the same with the addition of some pottery and larger beads; and typical herder sites lacking retouch but with much pottery and generally larger beads. His Types I and II correspond broadly with early and late Group 1 assemblages respectively, while his Type III seems to correspond with Group 2. It has already been noted that bead size is not a respecter of lithic group in Namaqualand and, as such, not all of Jacobson's (1987) patterns apply there: in particular, late Group 1 assemblages are highly variable and contain very few small beads (Figure 6.11). It is quite clear that bead size is not conditioned in any way by lithic group. The Group 2 assemblages identified in Figure 6.7 as being different to the rest display no consistency in bead size. Comparison of Assemblages 24 (small-medium), 30 (medium-large), 43 (small-very large), 44 (small-large) and 51 (very large) makes this clear. Figure 6.12 presents the data in temporal order highlighting the general increase in size, while Figure 6.13 separates the bead sizes, clarifying the size shift. Reorganising the data into time periods shows the increase starting during the first millennium $A D$ and consolidating strongly post-AD 1000 (Figure 6.14). The very strong consistency in bead size leading up to $A D 1$ is obvious. Figure 6.15 shows that, overall, mean external 
diameter increases from $<5$ to $>6 \mathrm{~mm}$ during the period examined but that the pattern is not a clear-cut one - variation exists.

Yates et al. (1994) commented that a shift in aperture diameter was culturally significant in the south-western Cape, particularly so at the coast, with the apertures of both large and small beads increasing from about 650-1000 AD onwards. Although apertures are not studied in great detail here, comparison of Figures 6.15 and 6.16 demonstrates that in coastal Namaqualand mean aperture size is strongly related to external diameter and that when the external diameter remains small, so does the aperture. Plotting all beads in the sample together shows this relationship to be fairly consistent (Figure 6.17). I consider the main driver of this pattern to be that heavier beads will wear faster and thus develop larger apertures than equivalent aged small beads. That $r^{2}$ (which shows the degree to which aperture diameter relies on external diameter) is not higher than $52 \%$ is probably due to two factors: (1) variation in the as-drilled apertures and (2) the presence of older, well worn beads within the assemblages (these would be the outliers above the regression line). It thus seems clear that apertures are not culturally significant in Namaqualand.

In sum, mean ostrich eggshell bead size has little relationship to stone artefact group (Figure 6.18) or, by implication, to socio-economic group with temporal change occurring similarly in each lithic group. Although Group 3 lacks mean bead sizes exceeding $7.5 \mathrm{~mm}$, individual beads in this size class do occur. 


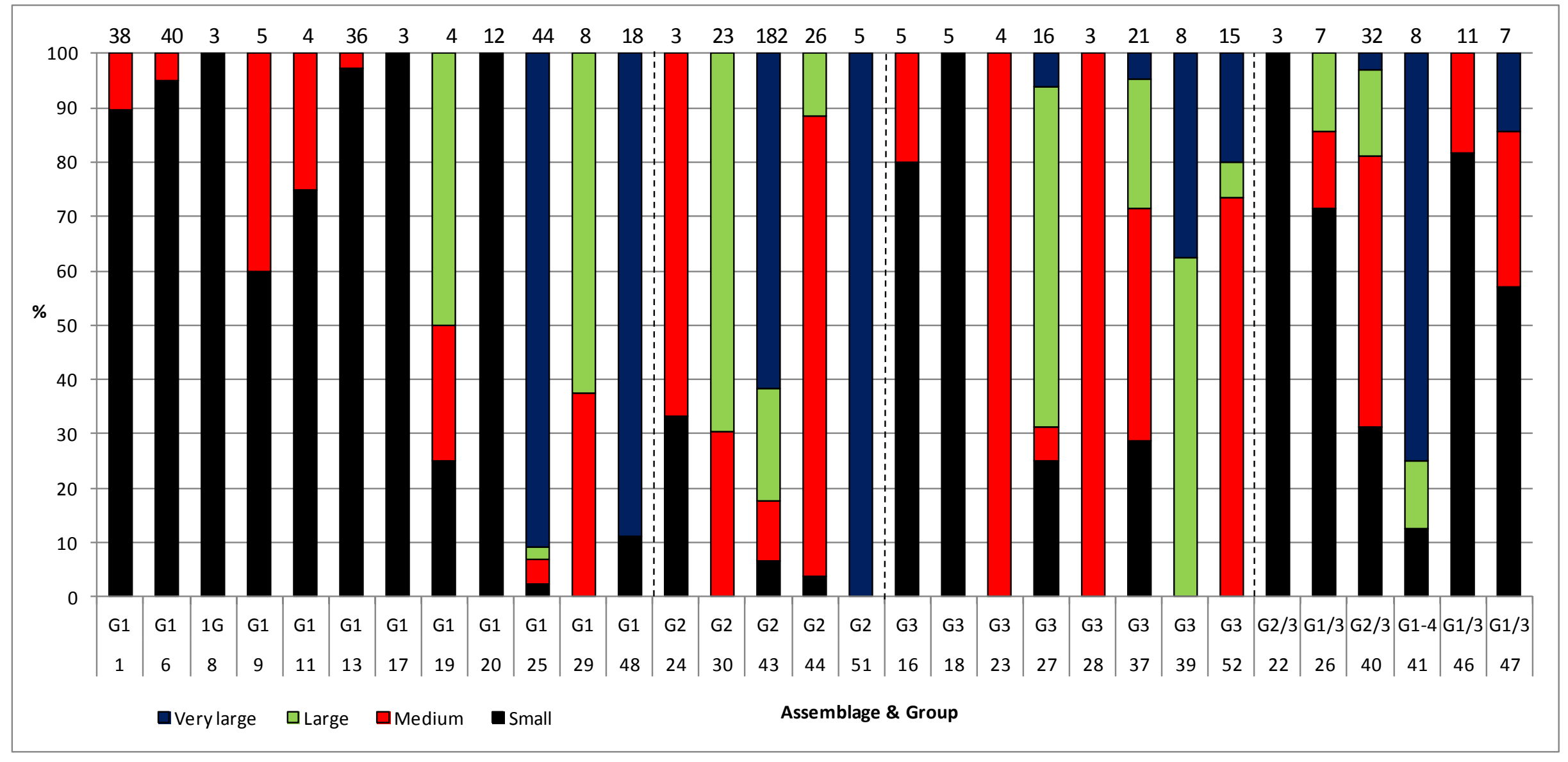

Figure 6.11: Ostrich eggshell bead size by assigned group. 


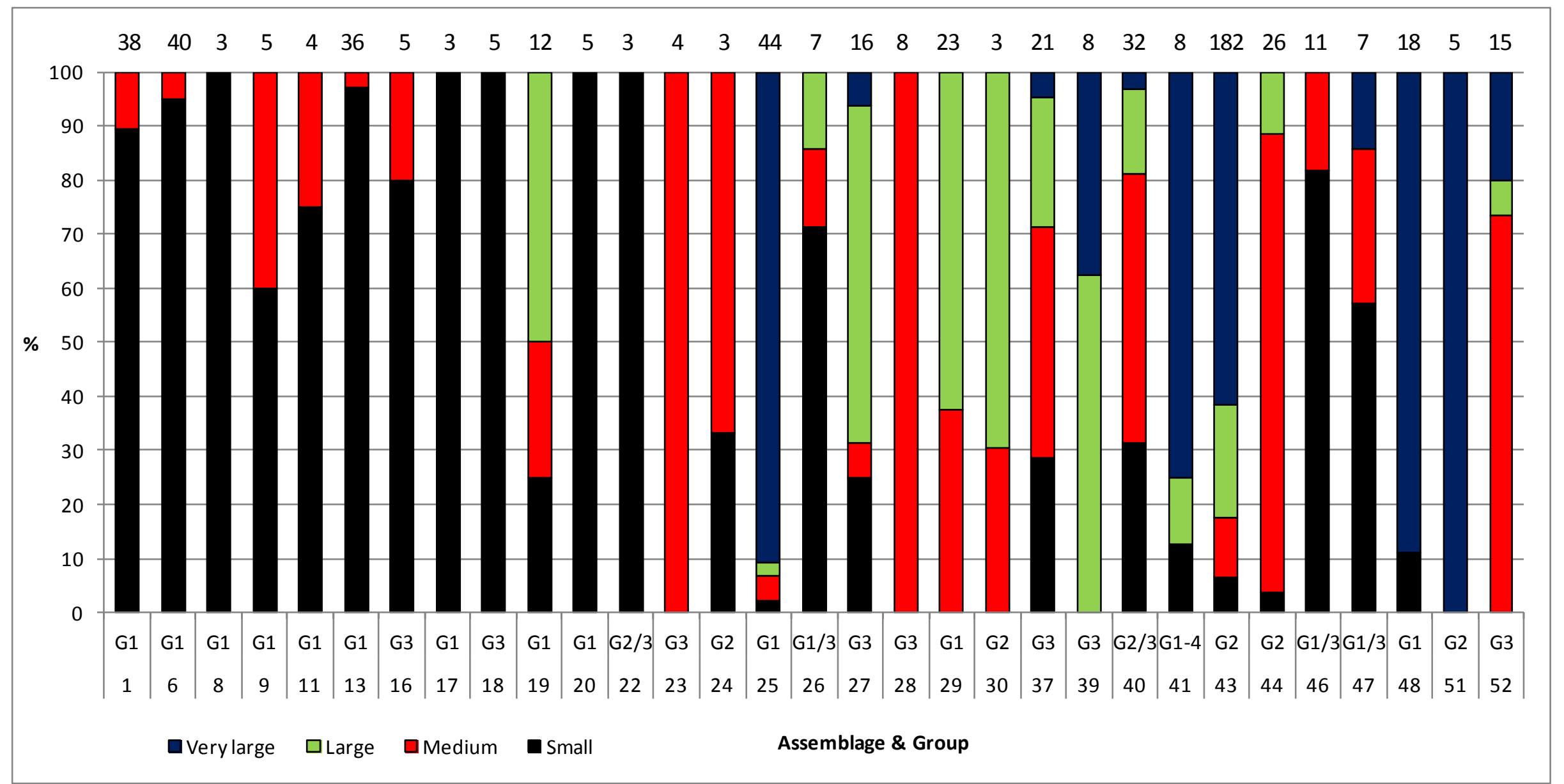

Figure 6.12: Ostrich eggshell bead size in temporal order showing the relative contributions of the various size categories to each assemblage. 

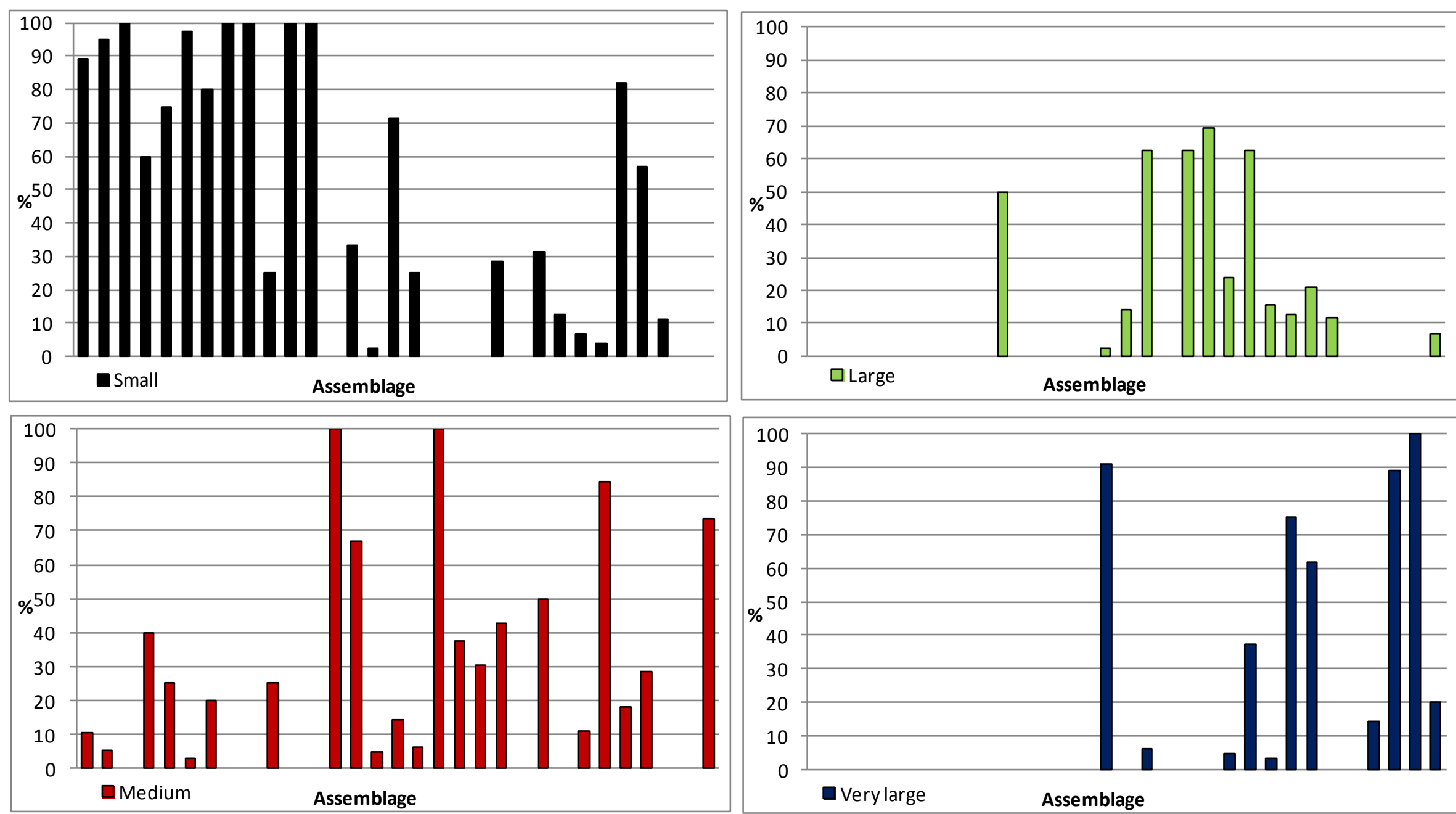

Figure 6.13: Ostrich eggshell bead size in temporal order for each size category based on the data in Figure 6.12 (from which assemblage numbers, groups and bead counts can be obtained). 

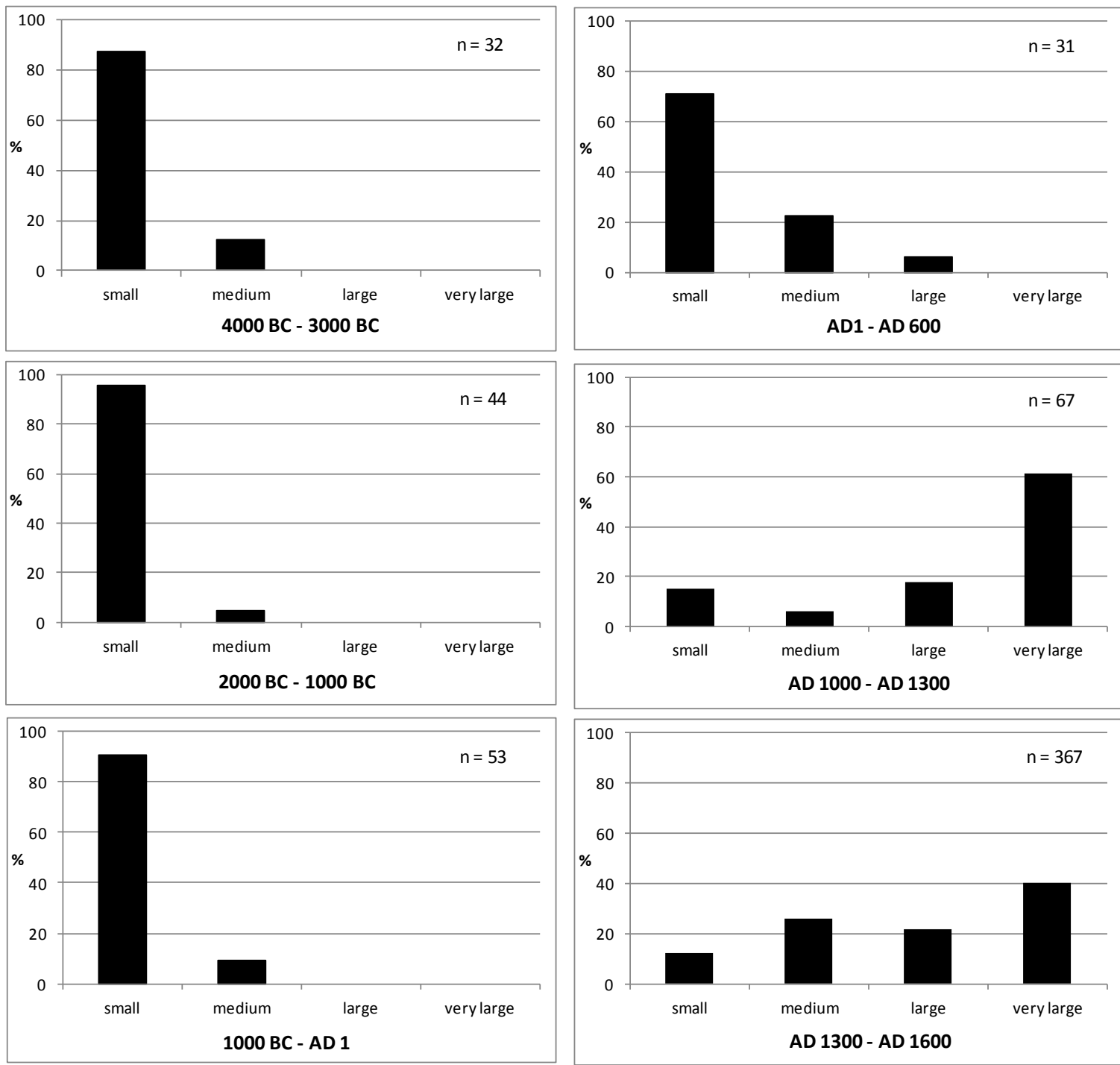

Figure 6.14 Histograms showing the change in ostrich eggshell bead size classes through time. Intervening periods that are not represented have no data available. 


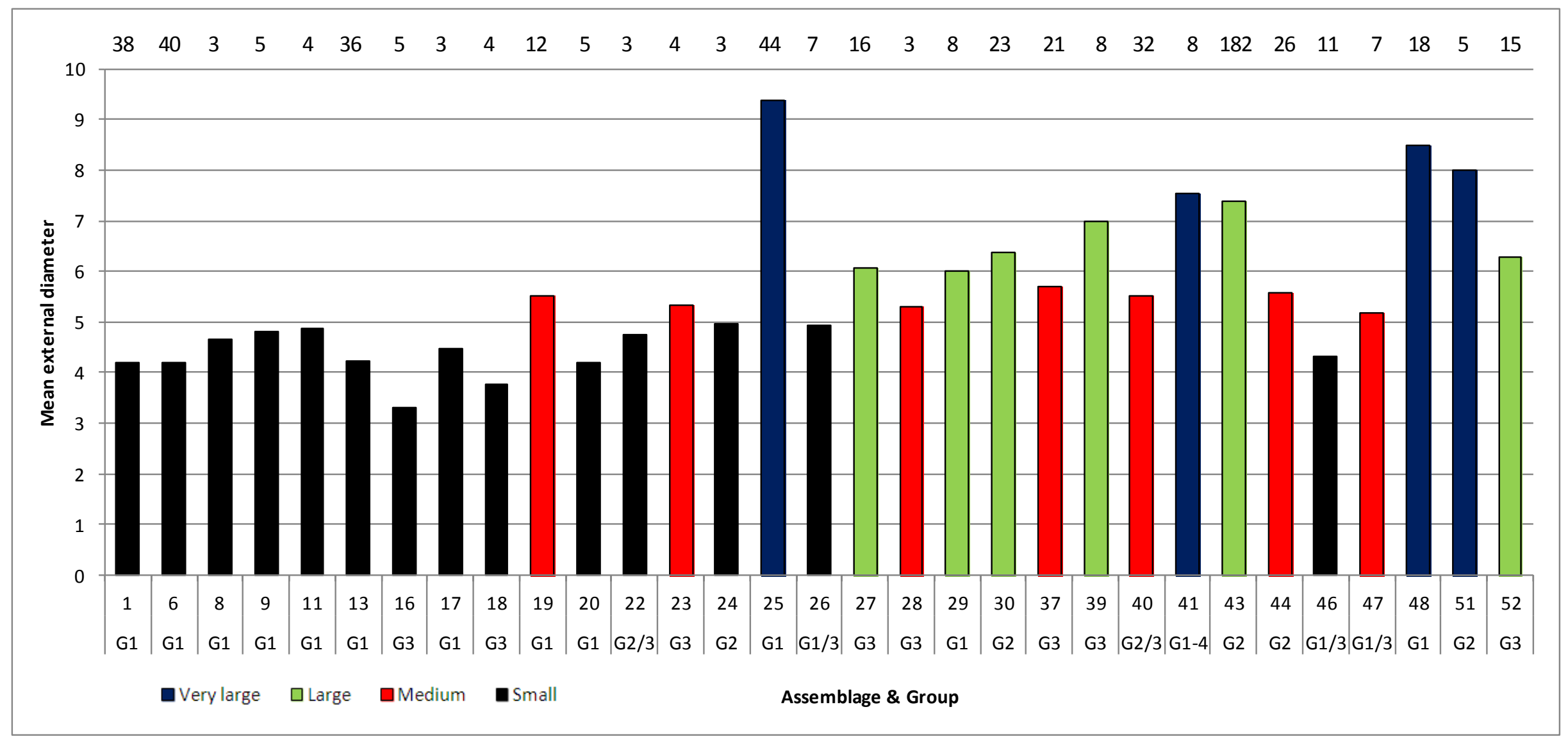

Figure 6.15: Ostrich eggshell bead mean external diameter in temporal order. 


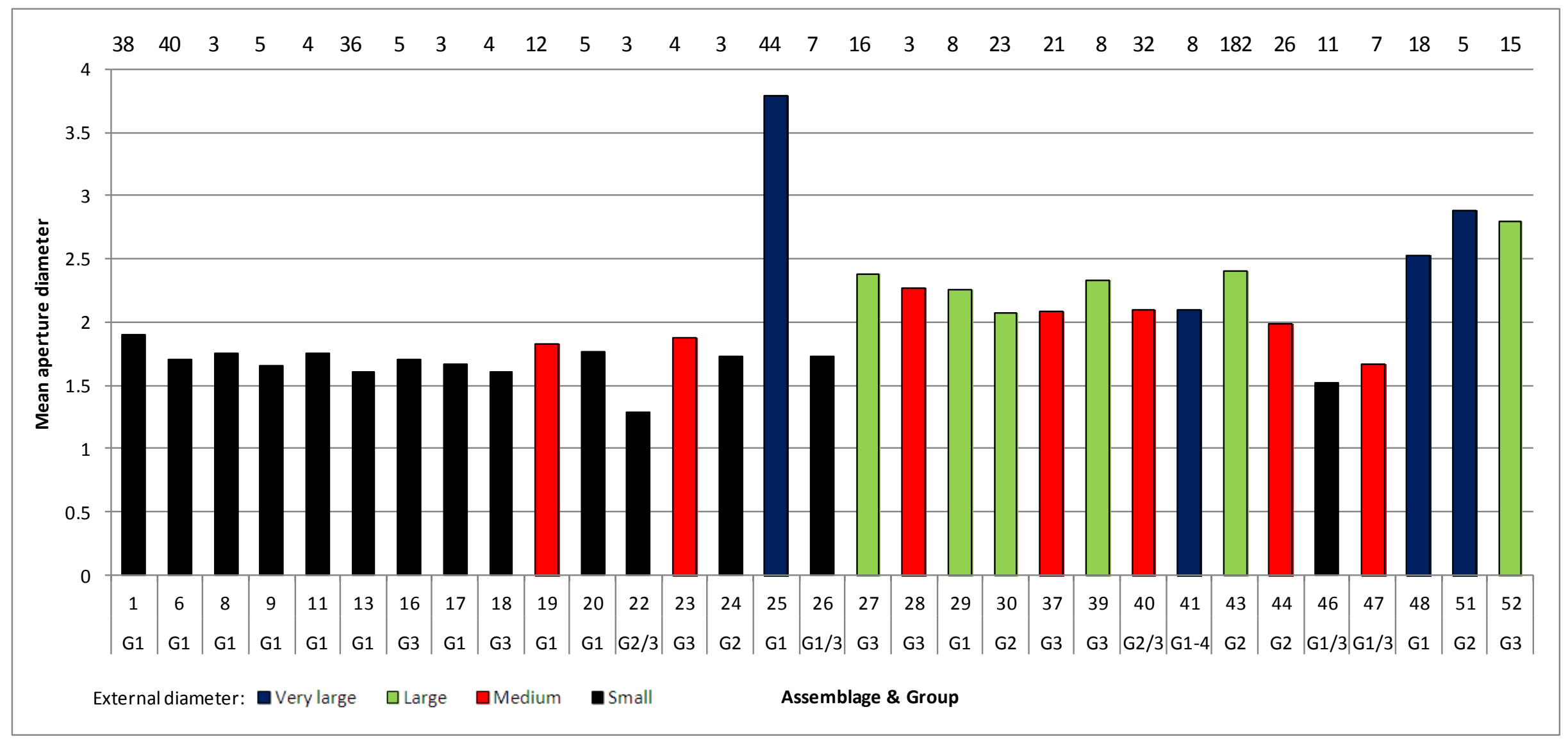

Figure 6.16: Ostrich eggshell bead mean aperture diameter in temporal order. 


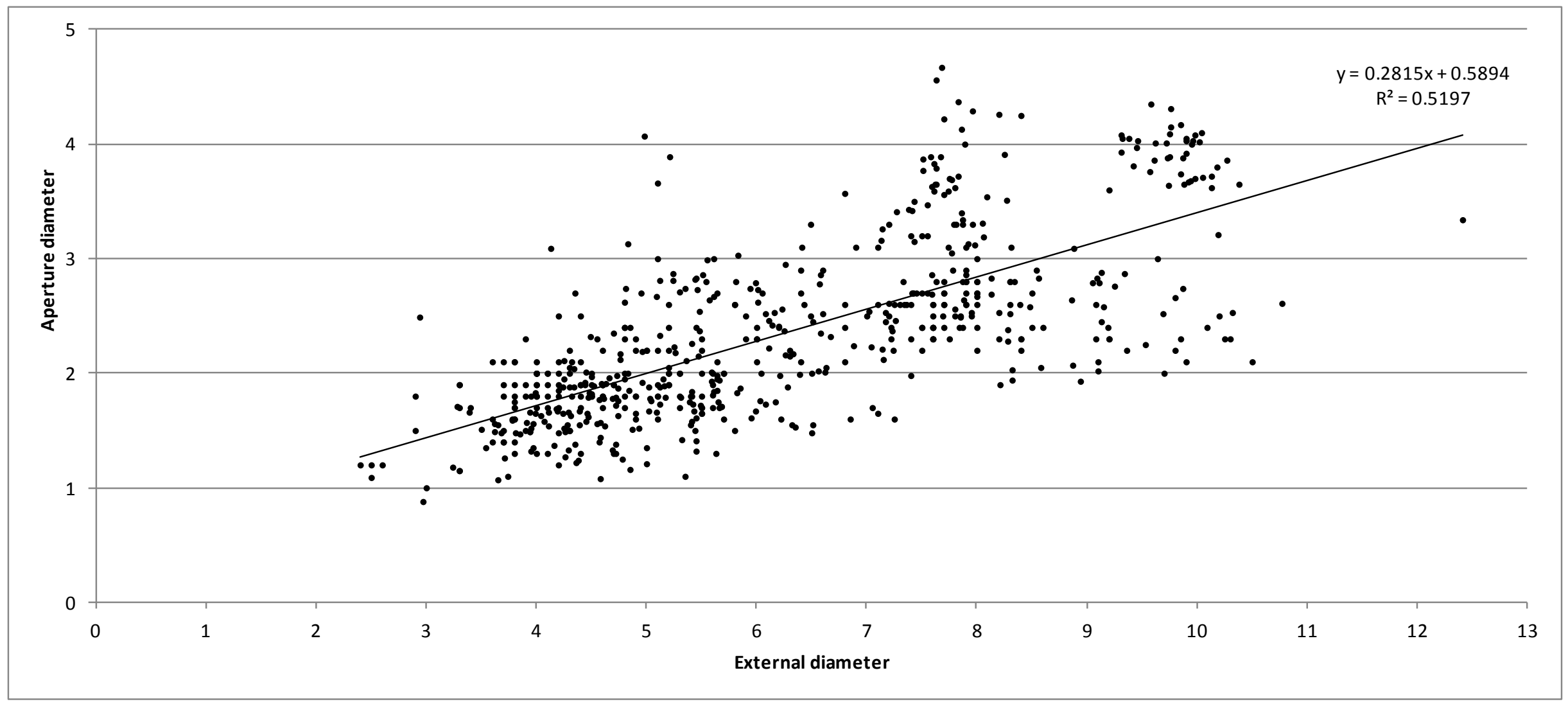

Figure 6.17: Scatter plot of all ostrich eggshell bead external and aperture diameters showing the relationship between them as a linear regression. 


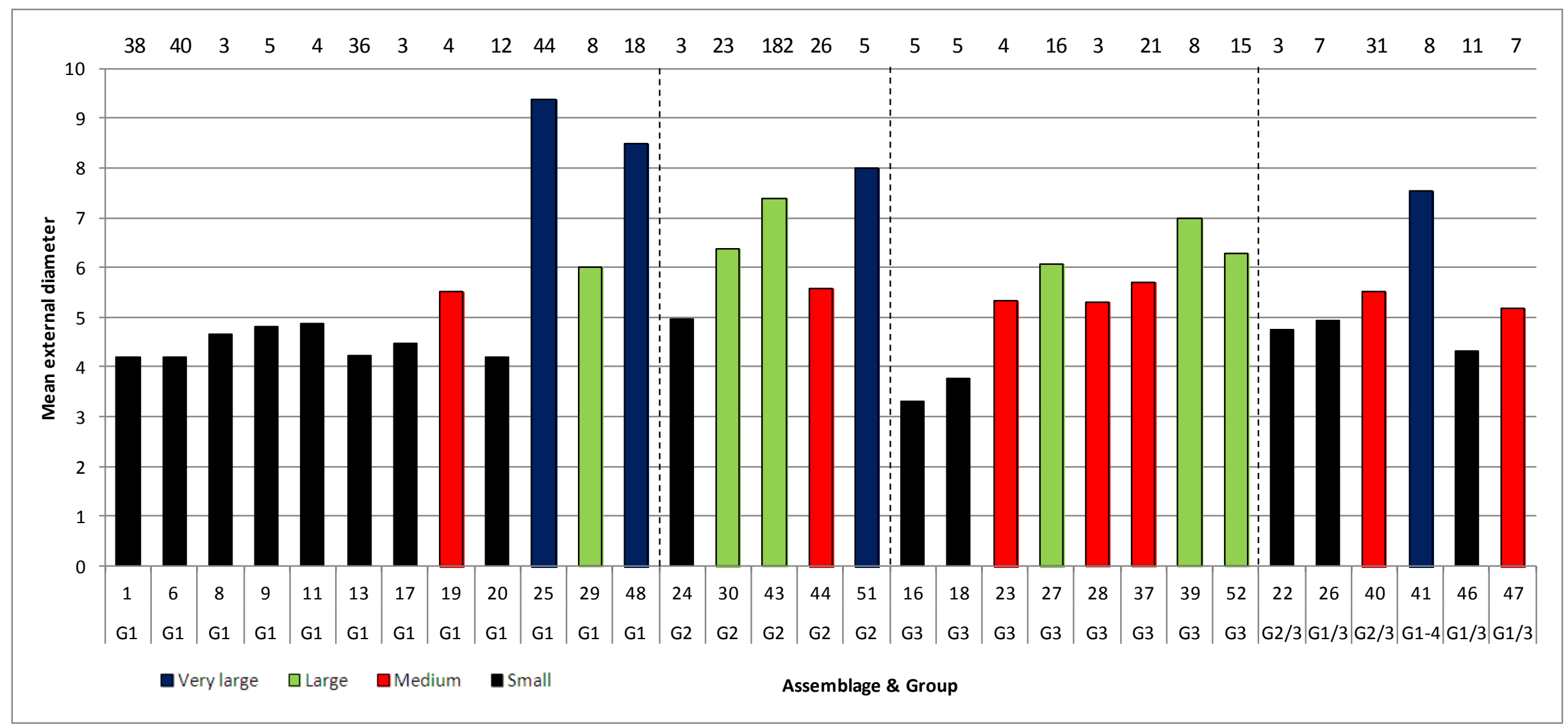

Figure 6.18: Mean ostrich eggshell bead size according to assigned lithic group. 
Webley (2002: table 12) provides ostrich eggshell bead diameters for Spoeg River Cave. Graphing these shows a similar pattern to the open assemblages (Figure 6.19), the only difference being that bead size increases more rapidly during the early first millennium $A D$ in the cave (Layers $6 b$ to 1 ) than in the open sites (Assemblages 21 to 24). The marked reduction in variation (as compared to Figure 6.15) is likely due to the mixing effect in the rock shelter deposits. I now turn to an examination of beads from other parts of Namaqualand.

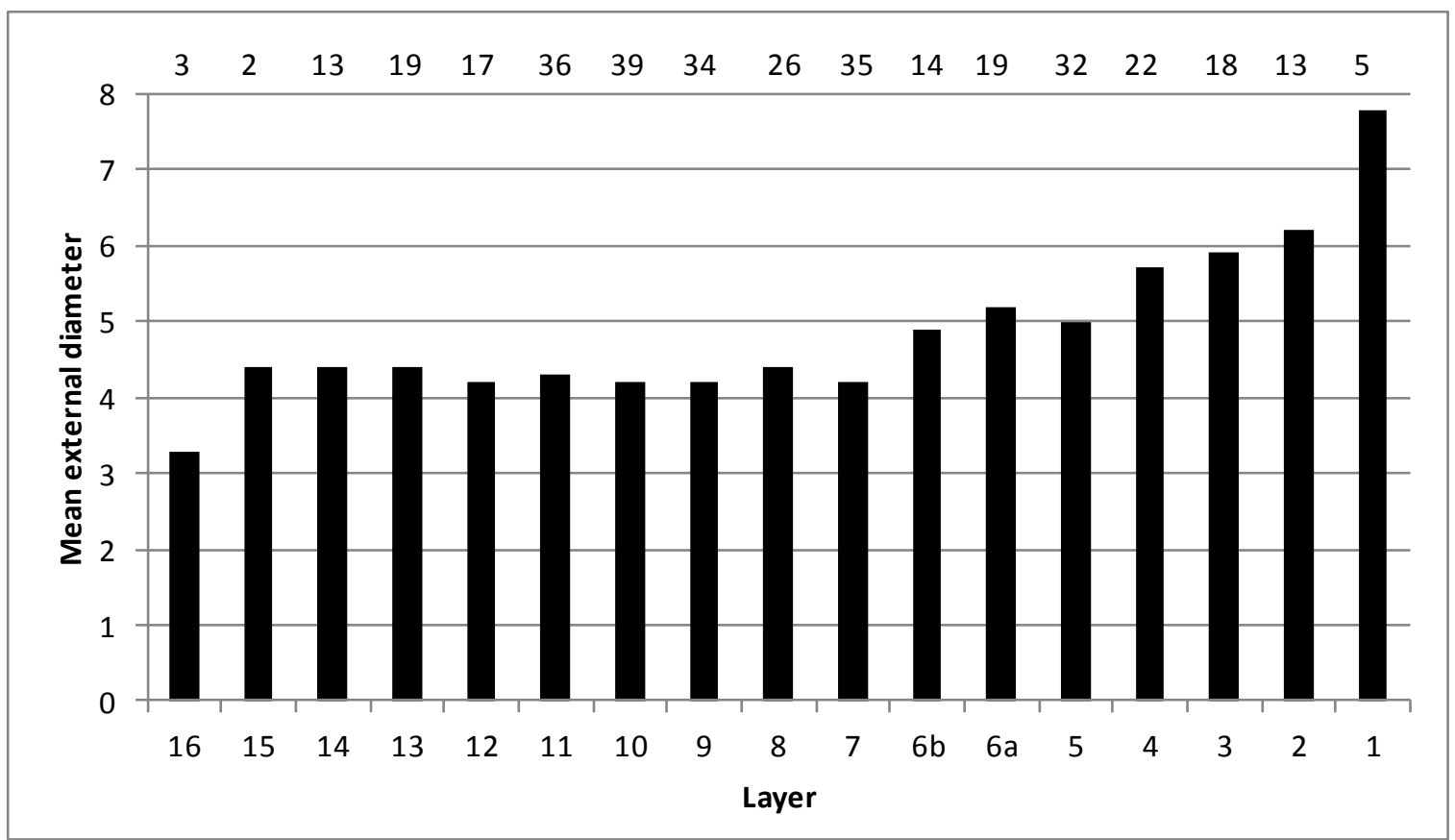

Figure 6.19: Mean ostrich eggshell bead size change through time at Spoeg River Cave (base don Webley 2002: table 12).

The earliest ostrich eggshell bead samples from the Richtersveld are from JKB N, JKB L and Die Toon. At all three the beads are focused between $3.0 \mathrm{~mm}$ and $5.5 \mathrm{~mm}$ (Orton \& Halkett 2010; Webley et al. 1993). JKB M has small to medium beads during the first millennium AD, while JKB A and JKB B have medium beads (Webley 1997a). Later assemblages show the characteristic larger beads expected: JKB K and Bloeddrift 23 (A. Smith et al. 2001) have mean values exceeding $6 \mathrm{~mm}$ and $7 \mathrm{~mm}$ respectively. 
In the south, Buzz Shelter has small beads throughout its mid- to late Holocene occupation. The late Holocene Reception Shelter deposits contain larger beads but lack very large ones. Nearer the coast, the late Holocene KK002 has a broad range of bead sizes, but with very large beads again noticeably absent. This, of course, assumes the broken very large beads to have been introduced deliberately for purposes other than domestic use.

\subsection{Flasks and engraved ostrich eggshell}

Flask mouth fragments are common and flasks were used throughout the period under examination and by the makers of all lithic groups (Figure 6.20). Engraved ostrich eggshell, on the other hand, belongs only to Groups 1 and 3. Although temporal patterning could be an artefact of small sample size, it does appear that while early assemblages contain various patterns, the later period, after AD 1000, contains only parallel lines (Table 6.3).

The Richtersveld sites contain many engraved ostrich eggshell fragments. Those predating $A D 1000$ contain the expected variety (Figure 6.21), but the dating resolution at /hei-/khomas is too poor to understand the temporal patterning of engraved designs there. Further north, at Rosh Pinah in Namibia, in a second millennium AD context, Sievers (1984) found decorated ostrich eggshell with multiple intersecting lines but no chevron-type patterns. At Reception Shelter, in the Knersvlakte, one tiny engraved fragment has three intersecting lines but the remainder have single lines each. Buzz Shelter has greater variety with parallel lines and more complicated designs occurring throughout its pre-AD 1000 sequence (Figure 6.22). 


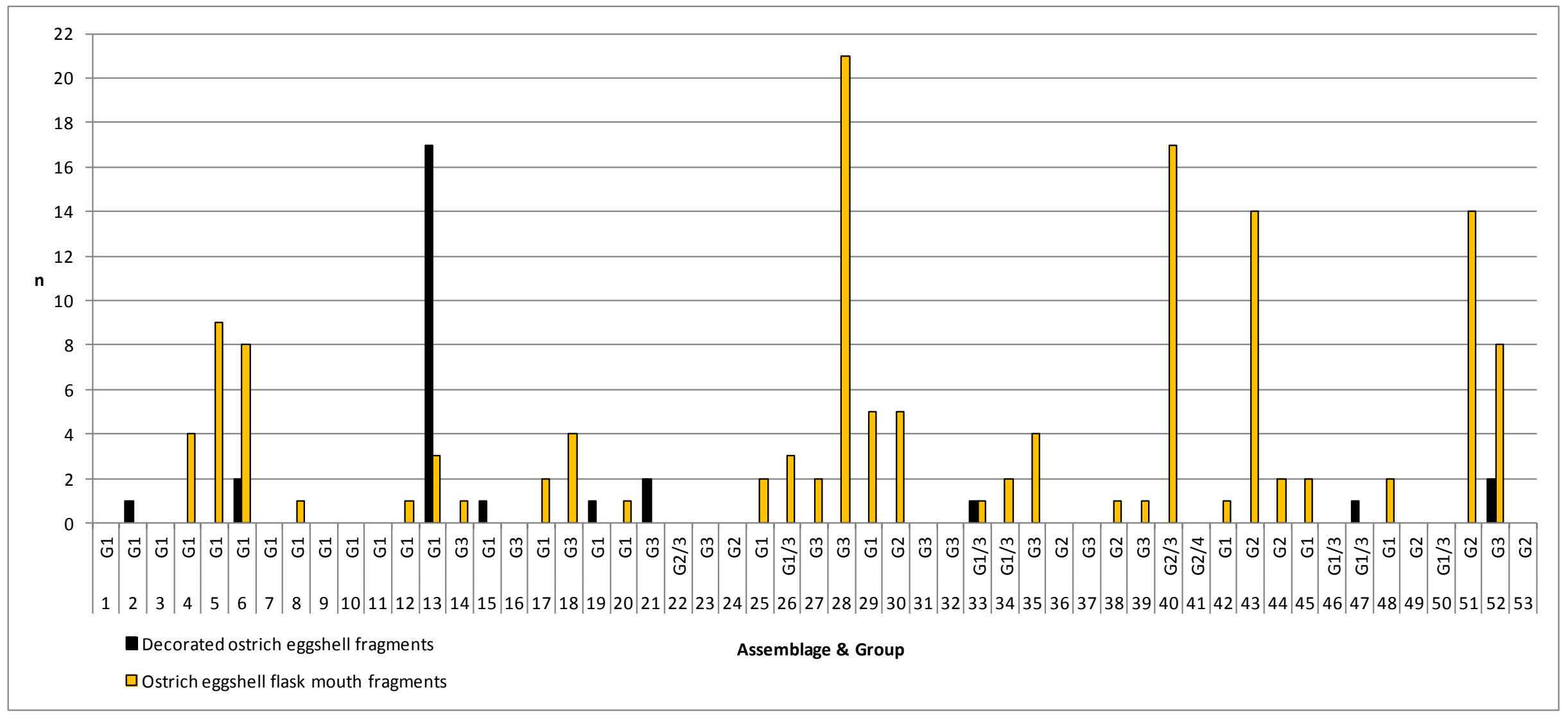

Figure 6.20: Frequency of engraved fragments and flask mouth fragments among all ostrich eggshell fragments excluding bead manufacturing debris. 


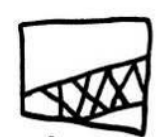

A

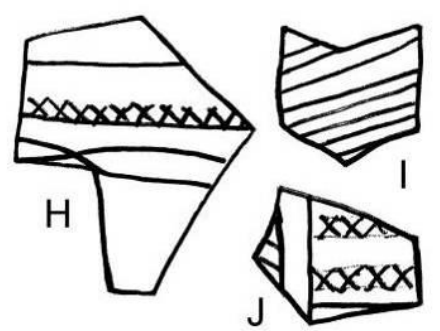

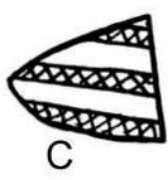
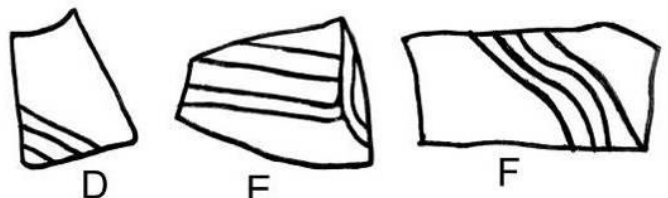

$\mathrm{F}$

Figure 6.21: Engraved ostrich eggshell from the Richtersveld. A-G: Jakkalsberg N, fourth-third millennia BC (Orton \& Halkett 2010, fig. 2); H-K: Jakkalsberg L, second millennium BC (Orton \& Halkett 2010, fig. 7); L-M: Jakkalsberg A, first millennium AD (Webley 1997a: fig. 10); N-Q: /hei/khomas, first \& second millennia AD (Webley 2001: fig. 12). D, K \& P are flask mouths.
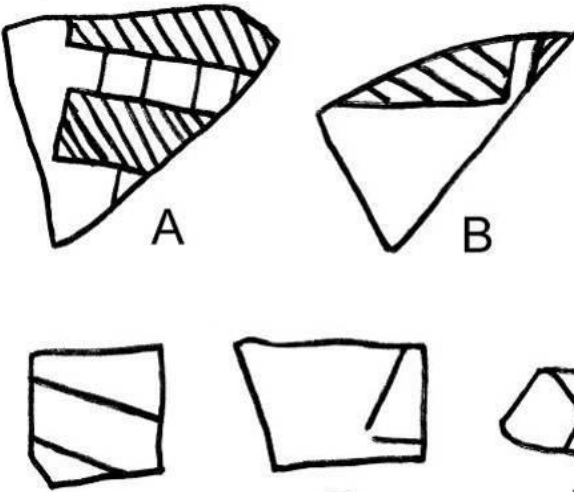

$\mathrm{F}$

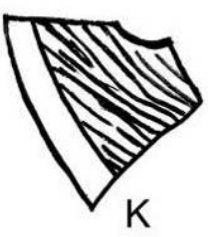

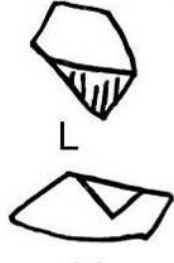

$\mathrm{M}$

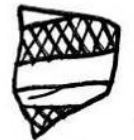

$\mathrm{N}$

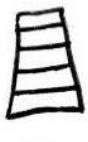

$\mathrm{O}$
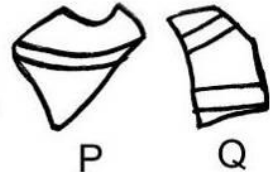

G

Figure 6.22: Engraved ostrich eggshell from the Knersvlakte. A: Buzz Shelter, c. fourth millennium BC; B-H: Buzz Shelter, first millennium AD; I-J: Reception Shelter talus excavation, second millennium $A D$. 
Table 6.3: Engraved ostrich eggshell patterns as they appear in the coastal Namaqualand archaeological record.

\begin{tabular}{|c|c|c|c|c|c|}
\hline Assemblage & $\begin{array}{c}\text { Assemblage } \\
\text { Number }\end{array}$ & Date & Illustration & Lithic Group & Reference \\
\hline KN2001/008C, Lower & 2 & $3036-2401 \mathrm{BC}$ & & G1 & Dewar 2008 \\
\hline Spoeg River Cave, Layer 14 & - & $?>2000 \mathrm{BC}$ & & unknown & Webley 2002: fig. 17 \\
\hline KN2001/008C, Upper & 6 & $1862-1272 \mathrm{BC}$ & & G1 & Dewar 2008 \\
\hline PN2009/001 & 13 & 504 BC-AD 28 & & G1 & \\
\hline Spoeg River Cave, Layer 11 & - & 2000 BC-?AD1 & 8 & unknown & Webley 2002: fig. 17 \\
\hline SK2001/025, Area C & 15 & $346 \mathrm{BC}-47 \mathrm{BC}$ & & G1 & \\
\hline
\end{tabular}


Table 6.3 continued.

\begin{tabular}{|c|c|c|c|c|c|}
\hline Assemblage & $\begin{array}{c}\text { Assemblage } \\
\text { Number }\end{array}$ & Date & Illustration & Lithic Group & Reference \\
\hline SK2005/084 & 18 & 196 BC-AD 325 & & G1 & \\
\hline TP2004/003 & 20 & AD 52-539 & & G3 & \\
\hline Spoeg River Cave, Layer 7 & - & AD 469-961 & & unknown & Webley 2002: fig. 17 \\
\hline SK2005/096, Patch A & 32 & AD 1319-1401 & & $\mathrm{G} 1 / 3$ & \\
\hline SK2006/006, Patch 2 Upper & 47 & AD 1465-1630 & & $\mathrm{G} 1 / 3$ & \\
\hline KN2005/067, Patch 1B & 51 & AD 1505-1652 & & G3 & \\
\hline ZD6 & - & undated & \& & unknown & Halkett \& Hart 1997: plate 5 \\
\hline
\end{tabular}




\subsection{Pottery}

This section includes all dated pottery samples available from the core study area as well as others with diagnostic features. Pottery first appears in the Sandveld at or just after 2000 years ago, but only becomes commonplace after about AD 500. Given the small size of the pottery collections, the analysis is generally qualitative, examining the presence and absence of various characteristics. Rudner (1968) conducted an extensive collection and description of pottery from the west coast, but, being undated, his samples do not aid the determination of sequence. While features such as lugs, bosses, basal nipples and ochred walls occur, they were too rare for meaningful analysis, others, such as wall thickness and decoration style, however, could be temporally examined.

Figure 6.23 plots pottery indices. Two observations emerge: (1) pottery index increases with time, but some assemblages still contain no pottery; and (2) with one exception (Assemblage 38), Group 2 assemblages stand proud of their neighbours throughout. The implication is that people making informal stone artefacts had access to and/or used the most pottery but that with time pottery availability generally increased for everyone on the landscape.

Decorated sherds, although forming a very small proportion of the total number, are frequent enough for meaningful discussion. Halkett and Hart (1997), in their extensive survey, noted the dominance of three decoration styles: rows of rounded impressions, horizontal incised lines and small crescent-shaped impressions. While the latter are absent from the present study, rows of impressions of varying shape were found to dominate strongly - consistent with Rudner's (1968) observation that they were most frequent on the west coast. Ordering the various styles temporally shows that fine-and broad-incised decoration occurs in the company of impressed decoration during the first 
millennium $A D$, while second millennium $A D$ assemblages show only impressions (Table 6.4). Unfortunately, most incised pots are from undated occurrences. It is tempting to presume that the lack of decorated sherds pre-dating the mid-first millennium AD means that early pottery was undecorated. There is, however, too little evidence for this. One can only label pots undecorated when rims are present since body sherds are frequently adiagnostic. In any case, plain rims were recorded throughout the sequence, sometimes accompanying impressed sherds.

Sadr (1998) contends that lugs appeared in the southern African archaeological record around $A D 700$ and may have signified the arrival of the Khoekhoen, since they occur throughout the western part of the subcontinent along their likely routes of spread. Although only one dated assemblage (SK2006/006, Patch 2 Upper from the mid-second millennium $A D$ ) includes a lug, others are known in combination with broad-incised (MB2005/135; Orton \& Halkett 2006) and fine-incised sherds (ZD27; Halkett \& Hart 1997) and may thus be earlier.

Comparison with the well-established south-western Cape and Karoo sequence (see Table 4.2 above) is merited. KN2004/012 (Assemblage 24) seems, on comparison with Sadr and Sampson (1999: fig. 6), to be spouted-incised (SPINC) ware. Spouts are rare in Namaqualand. Dewar (2008) reported just one, from a late site (SK2001/026, Assemblage 43), while Rudner (1968: fig. V:4), too, found only one spouted vessel - at Kleinzee. The latter was undecorated and, of course, undated. Although the SK2001/026 sample includes impressions and a spout, it is quite clear from Sadr and Sampson's (1999) description that it should not be termed spouted-incised (SPINC) ware on either stylistic or temporal grounds. With lugs so rare, lugged-undecorated (LUND) and luggedincised (LINC) cannot be properly assessed except to say that the latter may occur, as noted above, at MB2005/135 and ZD27. While one impressed sherd also originates from KN2004/012, this form of decoration proliferated in Namaqualand after AD 1300 (Table 
6.4). This is the most obvious indicator that the Namaqualand pottery sequence is different to that in the south-western Cape and Karoo where, at this time, a rich assortment of fine and broad lines was incised either vertically or diagonally and occasionally in conjunction with impressions (Sadr \& Sampson 1999: fig. 12). In Namibia, Albrecht et al. (2001) show a variety of sherds from the late first millennium $A D$ at Oruwanje 95/1 all with multiple incised lines, Jacobson (1977) describes pots with combined incised lines and circular impressions but with no horizontal bands, while at Big Elephant Shelter (Wadley 1979) and Geduld (A. Smith \& Jacobson 1995) we find crescentic impressions similar to those noted in Namaqualand by Halkett and Hart (1997). Also like Namaqualand, Sievers (1984) found rows of vertical impressions at Rosh Pinah in the second millennium AD. Despite some commonalities between Namaqualand and Namibian pottery, the apparent absence of rows of circular impressions from the latter suggests at least one prominent difference. Overall, the differences between pottery decoration in Namaqualand and areas to the north, east and south could suggest that the variety is more cultural than temporal in nature.

Jacobson (1987) noted that in Namibia pottery wall thickness increased during the early second millennium AD but provided no dimensions. Rudner (1968:450) divided pottery walls into 'very thin' (<6 mm), 'thin' $(6-8 \mathrm{~mm})$ and 'thick' $(>8 \mathrm{~mm})$, although he changed this terminology in his Table 8 from which the following data originates. While very thin walls comprised some $20 \%$ to $40 \%$ of sherds in all areas, thin walls were most frequent from Namibia and the Saldanha Bay area (c. $75 \%$ of sherds) and reduced in frequency to the east. Namaqualand is listed as having $60 \%$ of its sherds as thin walled. Thick walls were rare, passing $10 \%$ of sherds only on the southeast coast and being entirely absent north of Saldanha Bay. Figure 6.24 plots mean wall thickness. A general increase through time is evident but with no obvious early second millennium $A D$ change as suggested by Jacobson. In contrast with Rudner's observation, the majority of values are less than $6 \mathrm{~mm}$ (very thin). What is perhaps significant is that the earliest pottery 
assemblage (excluding Assemblage 17 with its intrusive pottery), although based on very few sherds, is the thinnest. Although three of its four measureable sherds are rims, the body sherd is still the second thinnest.

Broad incised horizontal lines strongly dominate the Spoeg River Cave pottery assemblage with impressed decoration very rare (Webley 1992: fig. 8; 2002: fig. 13). The former style occurs only in the oldest of the open assemblages with decorated pottery (KN2005/054) and thus seems to be expected for the early first millennium AD in Namaqualand. In keeping with the open sequence, a combination style also occurs as is the case at the other early open site, KN2004/012 (Table 6.4). Wall thickness is consistent with the finds from the open sites: sherds from Layers 7 and 6 are the thinnest $(<5 \mathrm{~mm})$ and the mean sherd thicknesses for the overlying layers all fall in the 5.1$6.1 \mathrm{~mm}$ range (Webley 2002: table 7). Lugs, bosses and spouts are absent (Webley 2007). 


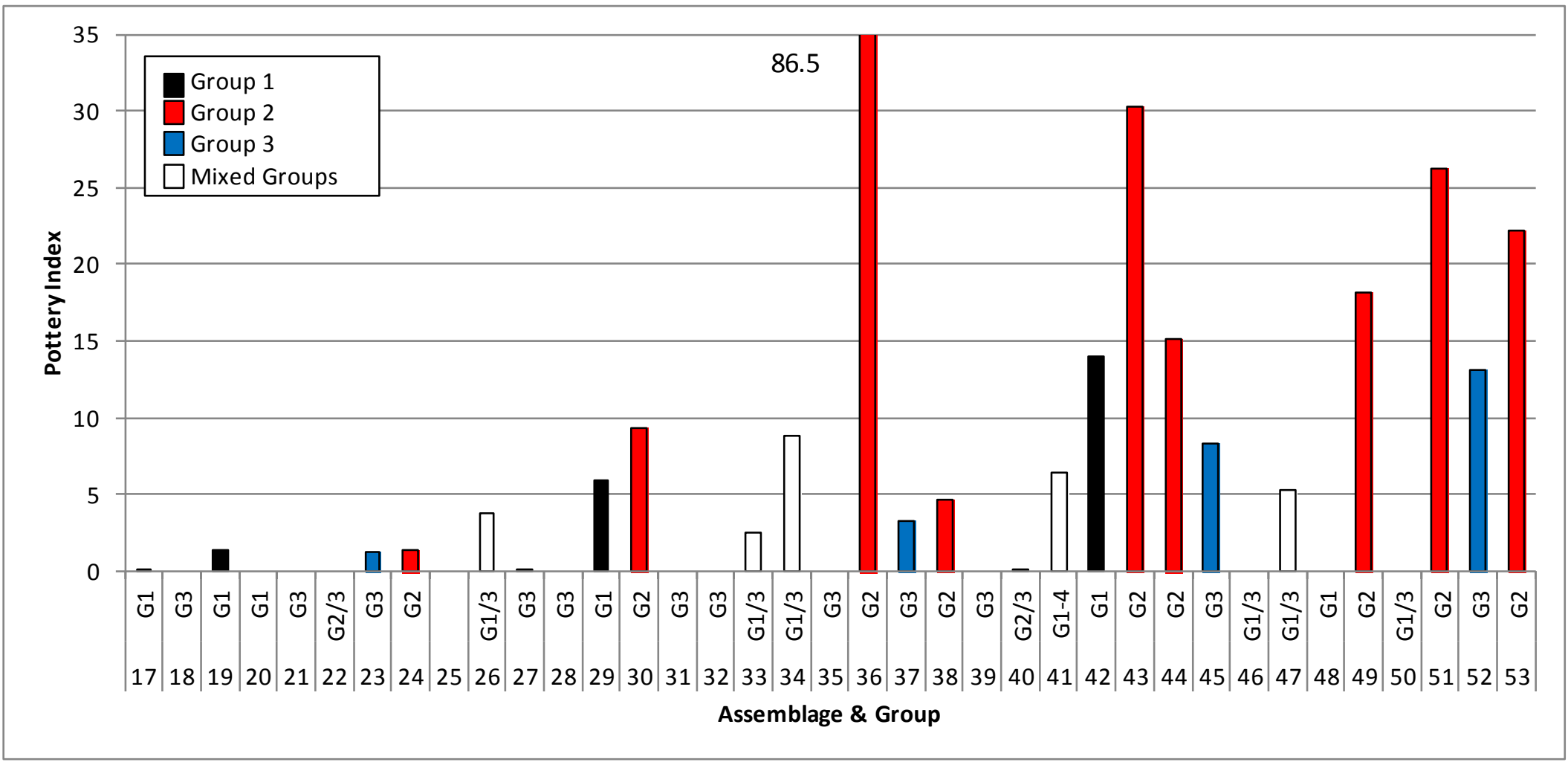

Figure 6.23: Pottery Index in temporal order. 
Table 6.4: Pottery decoration styles as they appear in the coastal Namaqualand archaeological record. Rim sherds are indicated. Not to scale.

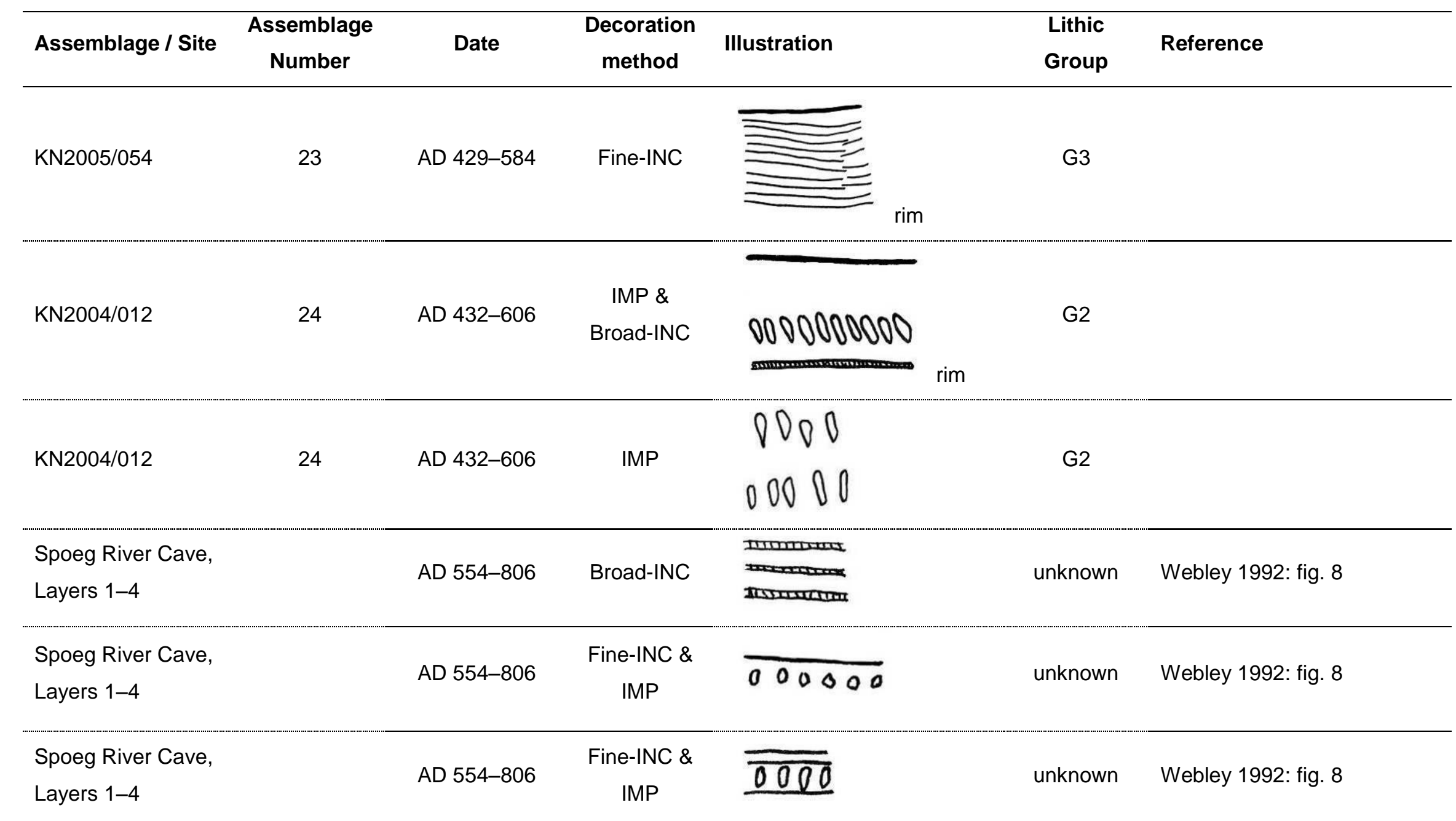


Table 6.4 continued

\begin{tabular}{|c|c|c|c|c|c|c|}
\hline Assemblage / Site & $\begin{array}{l}\text { Assemblage } \\
\text { Number }\end{array}$ & Date & $\begin{array}{l}\text { Decoration } \\
\text { method }\end{array}$ & Illustration & $\begin{array}{l}\text { Lithic } \\
\text { Group }\end{array}$ & Reference \\
\hline SK2001/039 & 33 & AD 1319-1422 & IMP & $\overline{0 \Delta \Delta 0}$ rim & $\mathrm{G} 1 / 3$ & \\
\hline SK2001/039 & 33 & AD 1319-1422 & IMP & $\begin{array}{llllll}0 & 0 & 0 & 0 & \text { rim }\end{array}$ & $\mathrm{G} 1 / 3$ & \\
\hline TP2004/004 & 36 & AD 1300-1680 & IMP & $00000000_{\text {rim }}$ & G2 & $\begin{array}{l}\text { Dewar 2008: fig. 7.9; Orton \& } \\
\text { Halkett 2005: fig. } 3.12\end{array}$ \\
\hline TP2004/004 & 36 & AD 1300-1680 & IMP & 00000000 rim & G2 & $\begin{array}{l}\text { Dewar 2008: fig. } 7.9 \text {; Orton \& } \\
\text { Halkett 2005: fig. } 3.12\end{array}$ \\
\hline SK2001/026 & 43 & AD 1445-1627 & IMP & $\begin{array}{l}0000000000 \\
00000000000 \mathrm{rim}\end{array}$ & G2 & Dewar 2008: fig. 5.9 \\
\hline SK2005/057A & 44 & AD 1455-1625 & IMP & $\begin{array}{l}00000000 \\
000000000 \mathrm{rim}\end{array}$ & G2 & \\
\hline KN2005/067 & 51 & AD 1505-1652 & IMP & $\begin{array}{l}000000000000000 \\
000000000000000\end{array}$ & G3 & \\
\hline
\end{tabular}


Table 6.4 continued

\begin{tabular}{|c|c|c|c|c|c|c|}
\hline Site & $\begin{array}{l}\text { Assemblage } \\
\text { Number }\end{array}$ & Date & $\begin{array}{l}\text { Decoration } \\
\text { method }\end{array}$ & Illustration & $\begin{array}{l}\text { Lithic } \\
\text { Group }\end{array}$ & Reference \\
\hline AK2006/006 & - & undated & IMP & $0 \Delta \Delta 0^{0 \Delta} \mathrm{rim}$ & $\mathrm{G} 2 / 3$ & Own data \\
\hline AK2006/006 & - & undated & IMP & 000000 rim & G2/3 & Own data \\
\hline AK2006/006 & - & undated & IMP & 80000 rim & G2/3 & Own data \\
\hline AK2006/006 & - & Undated & IMP & 00000 rim & $\mathrm{G} 2 / 3$ & Own data \\
\hline SK2005/077 & - & Undated & IMP & $000000 \mathrm{rim}$ & Unknown & $\begin{array}{l}\text { Orton \& Halkett 2006: plate } \\
3.47\end{array}$ \\
\hline KN2005/006 & - & Undated & Broad-INC & 1 & Unknown & Own data \\
\hline MB2005/135 & - & Undated & Broad-INC & rim & G4 & $\begin{array}{l}\text { Orton \& Halkett 2006: plate } \\
3.122\end{array}$ \\
\hline Port Nolloth & - & Undated & IMP & 000000 rim & Unknown & Rudner 1968: fig. XXXI (13) \\
\hline
\end{tabular}


Table 6.4 continued

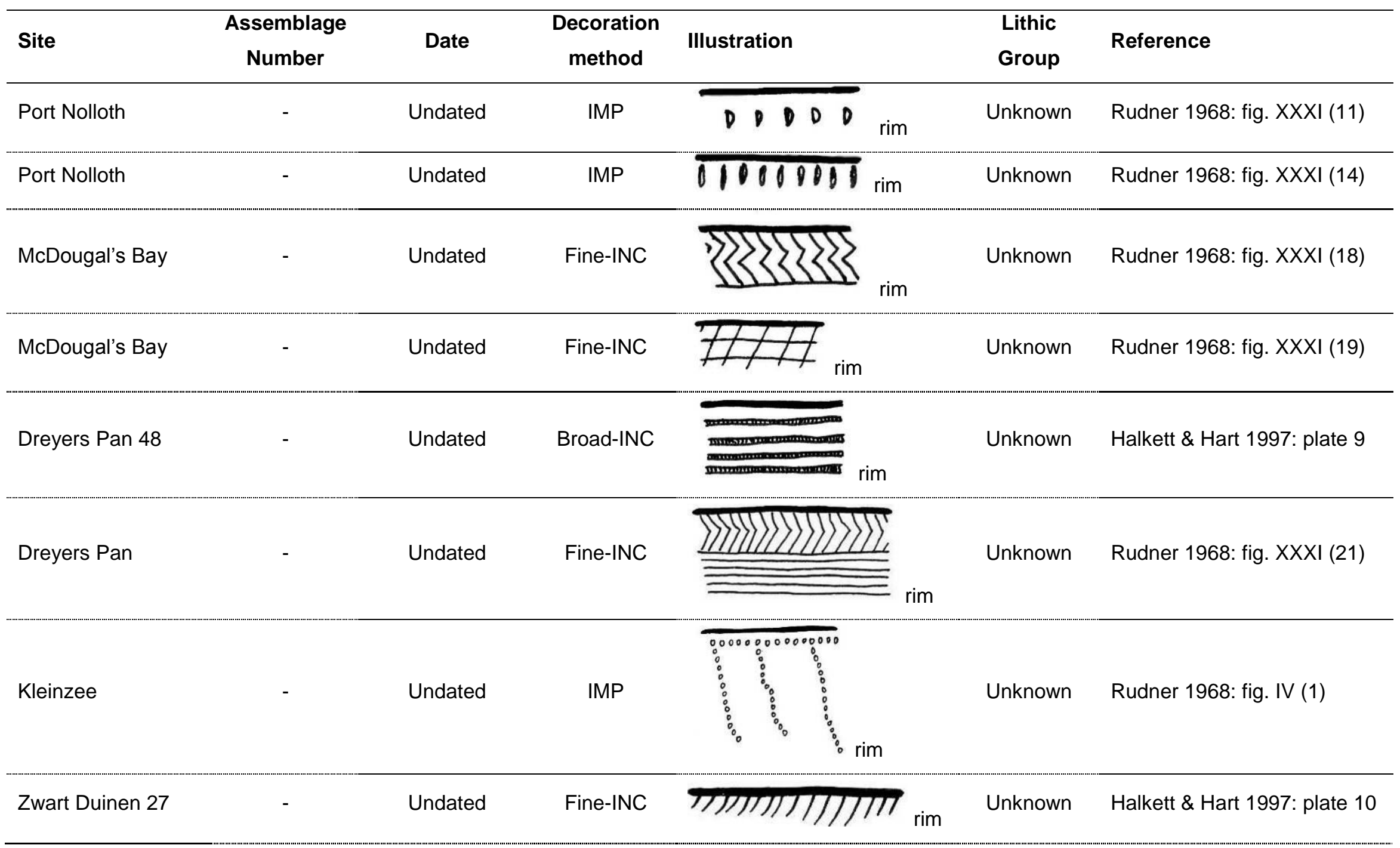




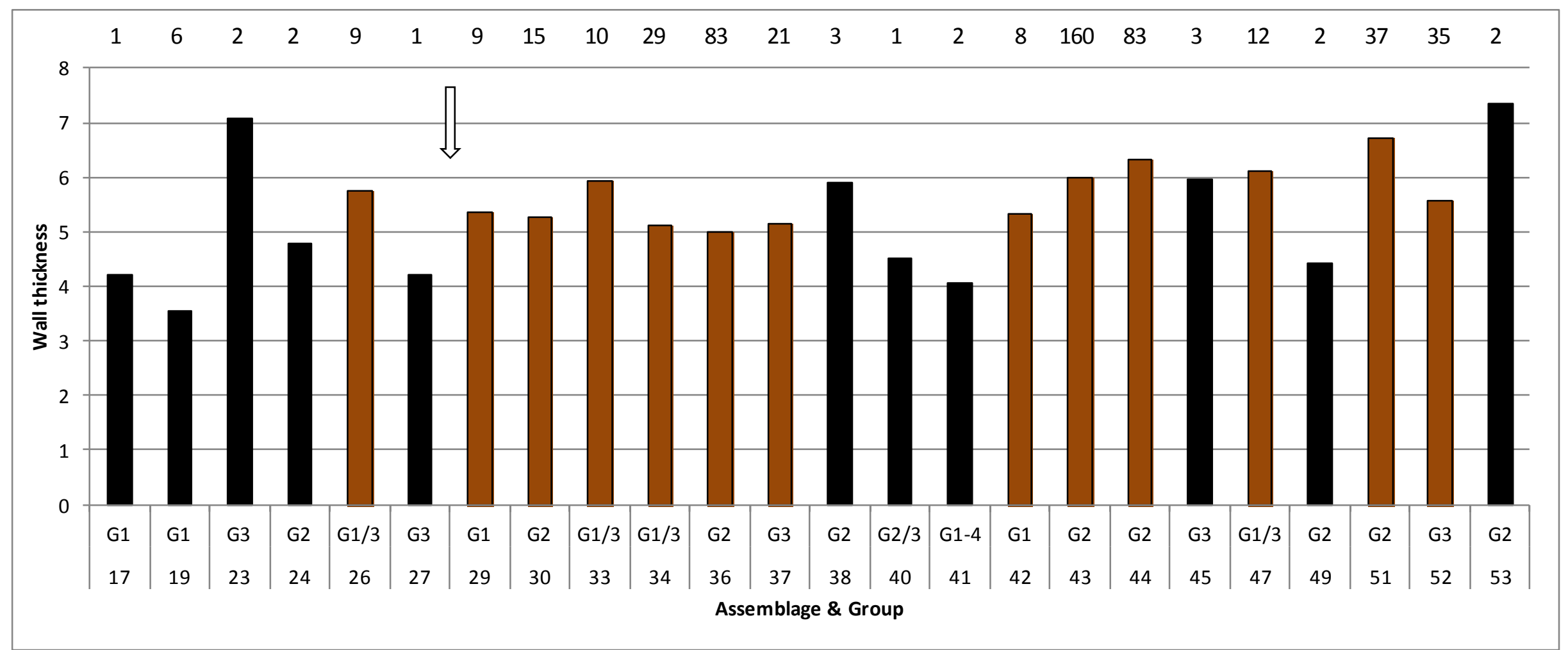

Figure 6.24: Pottery wall thickness in temporal order. Collections with eight or more sherds are shown in brown and assumed to be more reliable. Numbers along the top indicate number of sherds and the white arrow shows AD 1200. 
In the Richtersveld between AD 600 and 900 we find richly decorated pottery with broadand fine-incised lines occurring together with rarer oval impressions at Jakkalsberg $A$ and B. Fine incisions also occur on the lip of some rim sherds, and bosses and a spout are present (Webley 1997a). Jakkalsberg M, dated only to the first millennium AD, has broad-incised horizontal lines in the presence of lugs. Bloeddrift 23 has only impressed decoration and is thus in keeping with similarly aged Sandveld assemblages. It also has lugs (A. Smith et al. 2001). A small undated pottery collection from elsewhere in the Bloeddrift area contains richly decorated sherds reminiscent of the JKB A and B pottery (Figure 6.25; D. Halkett, pers. comm. 2012). Unfortunately, sherds with decoration or other diagnostic features are absent from the dated southern Namaqualand deposits. Nevertheless, the central and northern Namaqualand assemblages show that during the first millennium $A D$ both incised and impressed decoration was made, while during the second millennium AD only impressions were produced. The decorated sherds from the Reception Shelter talus demonstrate that fine-incised and impressed decoration occurs throughout Namaqualand; the broad-incised basket-weave-type decoration is rare in Namaqualand, occurring at just one site to the north (KN2005/006; Table 6.4). Stewart (2005: fig. 2) documents it at DFM1, near Elands Bay, while Rudner (1968) found a similar example at Modderrivier $50 \mathrm{~km}$ north of Cape Town, but with 'fine' rather than 'channelled' lines.
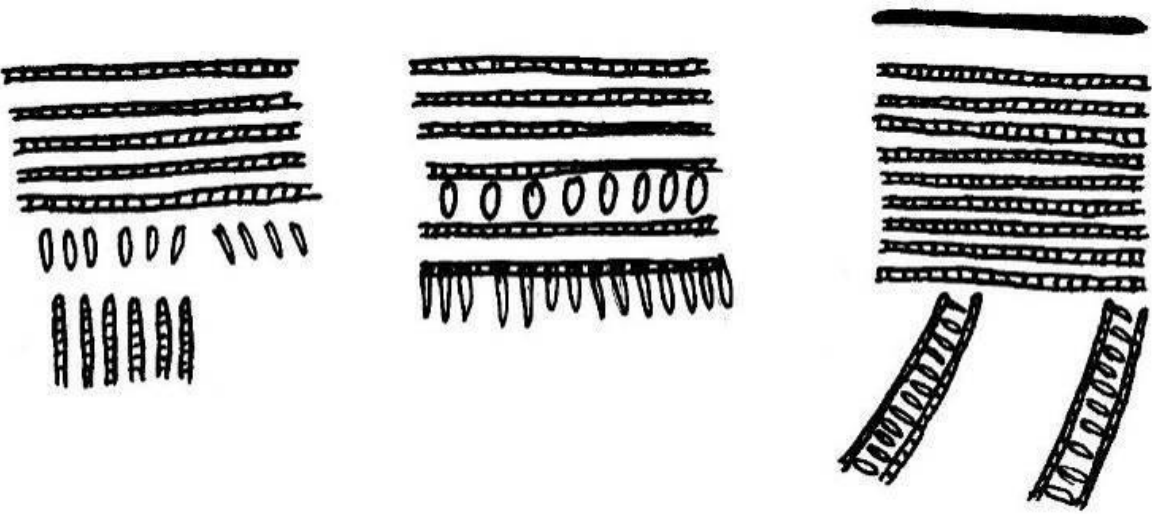

Figure 6.25: Unpublished decorated pottery from the Bloeddrift area of the Richtersveld (D. Halkett, pers. comm. 2012). No date is available. Bold line above right hand sherd is the rim. 


\subsection{Other material culture}

Waterworn shells collected from the beach and carved bone melon knives occur in Namaqualand assemblages (Table 6.5). The collected shells were almost certainly ornamental, and, among the Bushmen, J. Wood (1870) saw cowrie shells hanging from womens' hair and noted their alternate use as a form of currency ${ }^{21}$. Among various other items, Barrow (1801) saw shells included as decoration on the aprons of Namaqua women. Mitchell (2002a) notes that, with the exception of Welgeluk in the Eastern Cape (S. Hall 1990), cowrie shells appear to post-date AD 1 in southern African sites. In Namaqualand they, and all other waterworn shells, are later, all post-dating AD 1300. Might shell ornamentation be linked to the advent of herding and indicate a diversification of ornamentation in general? This seems likely, though with the lack of observations between this time and AD 500 it cannot be proved.

Budack (1977) describes melon knives made by the $\neq$ Aonin, a Khoekhoe group with domestic stock who still live near Walvis Bay on the Namibian coast. They are specialised tools for harvesting and processing !nara melons. Although !nara melons are not known from south of the Orange River (Klopatek \& Stock 1994), three melon knives are known from Namaqualand, one from a midden near the Spoeg River (MB2005/043; Group 3; Halkett \& Dewar 2006), one from AK2006/006 near the Buffels River (Orton 2007c) and the one from KN2005/067. This wide distribution could reflect alternative functions for these artefacts and/or, if they were exclusively used by the Khoekhoen, could reflect cultural and ethnic continuity throughout the region.

\footnotetext{
${ }^{21}$ Wood's appears to be a generic description and gives no location for the observation.
} 
Table 6.5: Occurrence of water-worn shells and melon knives from Sandveld assemblages. Numbers in parentheses indicate additional fragments.

\begin{tabular}{|c|c|c|c|c|c|c|c|c|c|}
\hline Assemblage & $\begin{array}{l}\text { 음 } \\
\frac{0}{0}\end{array}$ & $\begin{array}{l}0 \\
\text { के } \\
\text { के } \\
\text { ठ } \\
0\end{array}$ & 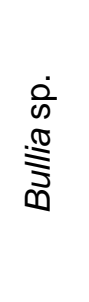 & $\begin{array}{l}\frac{y}{0} \\
\frac{c}{3} \\
\frac{1}{\Phi} \\
\frac{D}{J} \\
\end{array}$ & $\frac{0}{3}$ & 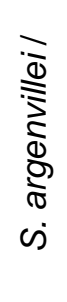 & 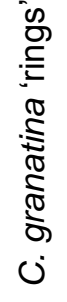 & 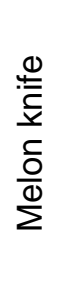 & Reference \\
\hline LK2004/011 (28) & 3 & & & & 2 & & & & Dewar 2008 \\
\hline MB2005/013 (29) & 1 & & & 2 & (1) & & & & \\
\hline MB2005/028A (31) & 3 & & & & $(1)$ & & & & \\
\hline SK2005/096A (33) & $1 / 3$ & & $8(1)$ & & & & & & \\
\hline KN2001/009 (35) & 3 & $6^{*}$ & & & & & & & \\
\hline SK2005/095A (39) & 3 & $5(3)$ & 11 & & & & & & \\
\hline DP2004/014 (40) & 2 & 5 & & & & & & & Dewar 2008 \\
\hline SK2001/026 (43) & 2 & 2 & & & & & & & Dewar 2008 \\
\hline SK2005/057A (44) & 2 & 14 & 10 & 1 & & & 1 & & \\
\hline SK2005/095B (45) & 3 & 1 & 1 & 1 & & & & & \\
\hline KN2005/067, Patch 1C (49) & 2 & 1 & & & & & 3 & & \\
\hline KN2005/067, Patch 1A (51) & 2 & & 1 & & & & & 1 & \\
\hline KN2005/067, Patch 1B (52) & 3 & & & & & & 3 & & \\
\hline AK2006/006 ( - ) & 3 & $8(5)$ & 1 & 3 & (7) & & & 1 & Own data \\
\hline MB2005/043 ( - ) & 3 & & & unknc & & & & 1 & $\begin{array}{l}\text { Halkett \& } \\
\text { Dewar } 2006\end{array}$ \\
\hline
\end{tabular}

${ }^{*}$ One of these was fresh.

Beads of metal and glass are well documented among the historical Khoekhoen but are virtually absent from the archaeology. A. Smith and Pheiffer's (1993:32 \& 42) translations of early eighteenth century Dutch texts describing the Cape Khoekhoen reveal that despite copper beads being favoured, the Khoekhoen had more glass beads and they were of many colours. Goodwin (1952) related a late $17^{\text {th }}$ century account of the Namaqua wearing vast numbers of copper and iron beads, bracelets and chains. The absence of these materials from the Namaqualand Sandveld is curious: aside from KK002 which has glass beads and copper and iron artefacts, just one glass bead is on record, from LK2001/010A (Halkett \& Dewar 2007), and this despite their great frequency on recent coastal sites in Namibia (J.H.A. Kinahan 2000). A. Smith and Pheiffer (1993) 
consider the archaeological rarity of copper to be because it was such a precious commodity that it was treated with great care and seldom lost. While this seems plausible for larger items, it seems unlikely for the tiny glass trade beads: if dropped, they would be difficult to recover from sandy substrates. They also considered iron to be 'virtually unobtainable' in the west during prehistory and thus when brought by Europeans it commanded very high trading value. That it was present prehistorically is attested by the artefacts from Jakkalsberg (Miller \& Webley 1994) and the iron rod at KK002 (F. Bandama, pers. comm. 2012). While the source of pre-colonial iron is unknown, Cornell (1920) notes the occurrence of prehistoric copper mining in the Richtersveld

\subsection{Domestic stock and the 'herder package'}

The presence of domestic animal bones can indicate various things (as described in Section 2.1.2 above) but they are less informative in coastal Namaqualand than in areas to the south: too few sites contain domesticates (Appendix 2, Table A2.4) and, when they do, they usually have exceedingly few bones. The three assemblages on Figure 6.6 to include domestic animal bones occur in the upper left (Assemblage 27; Group 3), lower left (Assemblage 22; Group 2/3) and lower right (Assemblage 44; Group 2), thus demonstrating no consistency with regards to stone retouch and pottery. Ostrich eggshell bead size has been shown to relate to time and those assemblages containing stock and beads have mean bead diameters, in temporal order, of $4.74 \mathrm{~mm}$ (Assemblage 22), 6.08 $\mathrm{mm}$ (Assemblage 27), $6.99 \mathrm{~mm}$ (Assemblage 39) and $5.58 \mathrm{~mm}$ (Assemblage 44). Again, consistency is absent with small, medium and large means present, although, following A. Smith et al. (1991; A. Smith 2005), the latter three would be large enough to reflect herders in the context of the Vredenburg Peninsula. Perhaps significantly, very large means are not represented at all among sites with stock. 
Spoeg River Cave is the only coastal site with many sheep bones (Webley 2002). Among the sheep-bearing deposits, Layers 11 to 7 appear to (and should) be Group 1dominated, while the overlying layers are all dominated by either Group 1 or Group 3. From the formal tool and pottery indices (Table 6.6), Layers 1, 3 and 4 could nevertheless be accommodated beneath the dashed line in Figure 6.6. It may well be that with the blurring of fine stratigraphic distinctions expected in cave deposits we are seeing mixed assemblages containing Groups 1, 2 and 3. Webley (2002) does not list materials for the various artefact types, but from her Figure 7 caption we may deduce that the majority of backed items were of quartz. Whether these are milky or clear remains unknown. The mean bead diameters for the pottery-bearing layers conform to the A. Smith ideal for herders, but only Layers 1 and 2 surpass $6.0 \mathrm{~mm}$. Again it appears that time is the major determinant of bead size.

Table 6.6: Formal tool index (FTI), pottery index ( $\mathrm{PI})$ and mean external ostrich eggshell bead diameter for Namaqualand assemblages associated with domestic stock (sheep, goats or cattle). For deep sites appropriate surrounding layers without stock are included for comparison. (SRC = Spoeg River Cave; JKB = Jakkalsberg; VR001 = Reception Shelter; VR005 = Buzz Shelter; NISP = number of identified specimens).

\begin{tabular}{|c|c|c|c|c|c|c|}
\hline Layer & Ages & FTI & PI & $\begin{array}{l}\text { OES } \\
\text { bead }\end{array}$ & $\begin{array}{l}\text { Stock } \\
\text { NISP }\end{array}$ & References \\
\hline $\begin{array}{c}\text { SRC Layer } \\
11\end{array}$ & & 1.53 & 0 & 4.3 & 4 & \multirow{9}{*}{$\begin{array}{l}\text { Ages calibrated and } \\
\text { indices calculated from } \\
\text { Webley }(2002)^{*} \\
\text { Beads: Webley (2002) } \\
\text { Sheep: Webley (2002) }\end{array}$} \\
\hline $\begin{array}{c}\text { SRC Layer } \\
10\end{array}$ & $\begin{array}{l}518-366 \text { BC } \\
A D 55-325\end{array}$ & 1.55 & 0 & 4.2 & 0 & \\
\hline SRC Layer 9 & $\begin{array}{l}\text { AD 62-333 } \\
\text { AD 55-325 }\end{array}$ & 5.43 & 0 & 4.2 & 2 & \\
\hline SRC Layer 8 & & 1.55 & 0 & 4.4 & 1 & \\
\hline SRC Layer 7 & $\begin{array}{l}\text { AD 685-961 } \\
\text { AD 469-680 }\end{array}$ & 2.66 & 0.70 & 4.2 & 14 & \\
\hline $\begin{array}{c}\text { SRC Layer } \\
6 b\end{array}$ & $A D$ 6-313 & 3.45 & 4.92 & 4.9 & \multirow{2}{*}{21} & \\
\hline $\begin{array}{c}\text { SRC Layer } \\
6 a\end{array}$ & & 2.61 & 6.71 & 5.2 & & \\
\hline SRC Layer 5 & & 3.73 & 18.03 & 5.0 & 38 & \\
\hline SRC Layer 4 & AD 554-766 & 0.83 & 35.14 & 5.7 & 2 & \\
\hline
\end{tabular}




\begin{tabular}{|c|c|c|c|c|c|c|}
\hline Layer & Ages & FTI & PI & $\begin{array}{c}\text { OES } \\
\text { bead }\end{array}$ & $\begin{array}{l}\text { Stock } \\
\text { NISP }\end{array}$ & References \\
\hline SRC Layer 3 & & 0.90 & 39.45 & 5.9 & 15 & \multirow{3}{*}{ As above. } \\
\hline SRC Layer 2 & & 2.50 & 19.19 & 6.2 & 4 & \\
\hline SRC Layer 1 & & 1.16 & 14.85 & 7.8 & 7 & \\
\hline JKB A & AD 653-970 & 0.06 & 8.84 & $5.97^{* *}$ & 21 & \multirow{2}{*}{$\begin{array}{l}\text { Ages calibrated and } \\
\text { indices calculated from } \\
\text { Webley (1997a) } \\
\text { Beads: Webley (1997a) } \\
\text { Fauna: Brink \& Webley } \\
\text { (1996) }\end{array}$} \\
\hline JKB B & AD 610-855 & 0 & 13.25 & 5.7 & 27 & \\
\hline JKB M & AD 83-943 & 0 & 47.74 & 4.90 & 2 (or 3 ) & $\begin{array}{l}\text { Fauna: R. Klein \& T. } \\
\text { Steele, pers. comm. } \\
2006\end{array}$ \\
\hline JKB K & AD 1488-1640 & 0 & 26.95 & 6.16 & $? 2$ & $\begin{array}{l}\text { Fauna: R. Klein \& T. } \\
\text { Steele, pers. comm. } \\
2006\end{array}$ \\
\hline $\begin{array}{c}\text { VR001 Layer } \\
\text { 9B }\end{array}$ & 793-416 BC & 1.84 & 2.40 & 4.27 & 0 & \multirow{6}{*}{$\begin{array}{l}\text { Fauna: R. Klein \& T. } \\
\text { Steele (pers. comm. } \\
\text { 2012) }\end{array}$} \\
\hline $\begin{array}{c}\text { VR001 Layer } \\
\text { 8-9A }\end{array}$ & AD 85-336 & 1.70 & 13.91 & 4.93 & 1 & \\
\hline $\begin{array}{c}\text { VR001 Layer } \\
7\end{array}$ & & 0.84 & 0 & 3.86 & 0 & \\
\hline $\begin{array}{c}\text { VR001 Layer } \\
6\end{array}$ & AD 1177-1293 & 1.73 & 3.07 & 4.44 & 0 & \\
\hline $\begin{array}{c}\text { VR001 Layer } \\
\text { 4B-5 }\end{array}$ & AD 1318-1483 & 0.65 & 2.06 & 5.85 & 1 & \\
\hline $\begin{array}{c}\text { VR001 Layer } \\
\text { 1-4A }\end{array}$ & & 1.65 & 1.62 & 4.90 & 0 & \\
\hline $\begin{array}{c}\text { VR005 Layer } \\
3\end{array}$ & $\begin{array}{c}\text { Problematic, } \\
\text { but AD 76-232 } \\
\text { most likely }\end{array}$ & 1.01 & 0.20 & 4.10 & 2 & \multirow{3}{*}{$\begin{array}{l}\text { Fauna: R. Klein \& T. } \\
\text { Steele (pers. comm. } \\
\text { 2011) }\end{array}$} \\
\hline $\begin{array}{c}\text { VR005 Layer } \\
2\end{array}$ & $\begin{array}{l}\text { Problematic, } \\
\text { but AD 410- } \\
543 \text { most likely }\end{array}$ & 1.32 & 0 & 4.20 & 0 & \\
\hline $\begin{array}{c}\text { VR005 Layer } \\
1\end{array}$ & & 0 & 0 & 3.94 & 0 & \\
\hline
\end{tabular}

* Value calculated from all 375 beads in Webley (1997a: table 7).

${ }^{* *}$ Webley (2002; table 8) calculated PI following Yates \& Smith (1993) but I have recalculated following Sadr et al. (2003). 
In the Richtersveld first millennium AD domestic animal bones have been found at Jakkalsberg A and B (Brink \& Webley 1996) and also at JKB M. The younger JKB K has probable sheep. All appear to be Group 2 assemblages and, with their low formal tool indices and high pottery indices (Table 6.6), all would fall below the dashed line in Figure 6.6. Bead size again relates well to time with the four mean sizes increasing in temporal order. At Reception Shelter in the Knersvlakte only the second youngest layer grouping, with one domestic bone, would sneak below the Figure 6.6 line, while the only other layer with a domesticate has the highest pottery index but also a fairly high formal tool index. Bead sizes are variable and offer no further assistance here. Buzz Shelter appears more like a hunter-gatherer site with very few potsherds and very small, desite two stock bones in Layer 3.

It thus seems that the Richtersveld assemblages offer the best possibility of a "herder package' but, as explored in Section 2.1.1, the picture is far from clear. It may be, of course, that those sites really do represent herders and that many of the others throughout the region relate either to hunter-gatherers who obtained stock as food or else to Sadr's (2003) 'hunters-with-sheep' (which, given a relatively early date on cattle (Orton et al. in press), are perhaps better termed 'hunters-with-stock'). Whatever the situation, it is nevertheless quite apparent that no Namaqualand assemblages unequivocally reflect the kind of pastoralist signature proposed by A. Smith et al. (1991) from their Vredenburg Peninsula data.

\subsection{Shellfish}

Shellfish are not cultural artefacts in and of themselves. Acquisition of terrestrial food parcels, besides plants, generally follows opportunistic strategies with antelope needing to be chased and caught and ground game collected when chanced upon. Shellfish, 
however, are easily harvested; their collection can be planned and several species are present. Shellfish choice may, therefore, be an artefact of culture. For this reason and considering Binneman's (2001) observed variability between sites with and without sheep and pottery, shellfish species frequency is explored here.

When the relative frequencies of shellfish species are examined through time there are no abrupt changes but a distinctive trend towards the use of larger food parcels is evident. In particular, the limpet $C$. granatina increases markedly through time to become approximately half of all collected shellfish, while the other common limpet, S. granularis, decreases in tandem (Figure 6.26). It would be tempting to conclude that people were becoming more accustomed to wading deeper, but this is only poorly supported by the slight increases in S. argenvillei and S. barbara, both of which (but particularly the latter) are generally subtidal (Figure 6.27). Black mussels (C. meridionalis) and whelks (Burnupena sp.) live in similar areas and both decrease (Figure 6.28); they form a small but consistent presence until about AD 400, after which they were seldom collected. With one exception, shellfish frequencies do not relate to groups at all, since there is plenty of variability within each. The exception is the lack of black mussels and whelks in Group 2 assemblages (highlighted in Table 6.7), which, together with their stone and pottery features, continue to stand out from the remaining groups.

Table 6.7: Minimum and maximum shellfish frequencies by assigned lithic group with the scarcity of mussels and whelks in Group 2 highlighted.

\begin{tabular}{lcc:cc|cc|cc}
\hline & \multicolumn{2}{c}{ Group 1 } & \multicolumn{2}{c|}{ Group 2 } & \multicolumn{2}{c|}{ Group 3 } & \multicolumn{2}{c}{ Mixed groups } \\
& Min & Max & Min & Max & Min & Max & Min & Max \\
\hline C. granatina & 7.4 & 62.9 & 17.3 & 74.9 & 7.2 & 63.7 & 26.9 & 70.5 \\
S. granularis & 6.8 & 79.8 & 21.2 & 81.5 & 25.1 & 80.3 & 18.6 & 51.5 \\
S. argenvillei & 0 & 24.0 & 0 & 28.7 & 0.6 & 27.3 & 0.8 & 18.6 \\
S. barbara & 0 & 3.4 & 0 & 1.1 & 0 & 2.1 & 0 & 5.9 \\
C. meridionalis & 0 & 24.7 & 0 & 0 & 0 & 16.9 & 0 & 0.4 \\
Burnupena sp. & 0 & 15.9 & 0 & 0.1 & 0 & 1.4 & 0 & 10.0 \\
\hline
\end{tabular}


When the trends within each assigned lithic group are examined, a different picture emerges. In Group 1 there is consistency in $S$. granularis frequencies but $C$. granatina rises markedly at the expense of the minor species (Figure 6.29). Much variety exists in both primary species, but this is emphasized more in the earlier assemblages when people chose to focus on one of them; later both were harvested more equally.

Group 2 assemblages show a decline in $S$. granularis in the face of increasing $S$. granatina frequencies (Figure 6.30). Group 3 assemblages, interestingly, show a similar trend to Group 2, but with the increase in C. granatina more marked. There is also more variation among the minor species with a notable inclusion of black mussels at times (Figure 6.31). It seems evident that there was a conscious shift in focus from $S$. granularis to C. granatina, which is far more evident in these groups than in Group 1.

Unsurprisingly, no clear pattern emerges from the combination groups. Assemblage 49 is known to be historical and, besides not being strongly dominated by any one species (Figure 6.32), it has an unusually high number of $C$. compressa shells which grow on the stalks of kelp plants (Orton 2009a). This species was extremely rare in all other assemblages, perhaps because the animals usually detach when the plants are torn free of their roots, although small numbers do still cling to washed-up kelp (R. Anderson, pers. comm. 2012). With Hondeklipbaai being a protected, kelp-rich embayment, people may have waded into the water to collect the shells from the kelp stalks. 


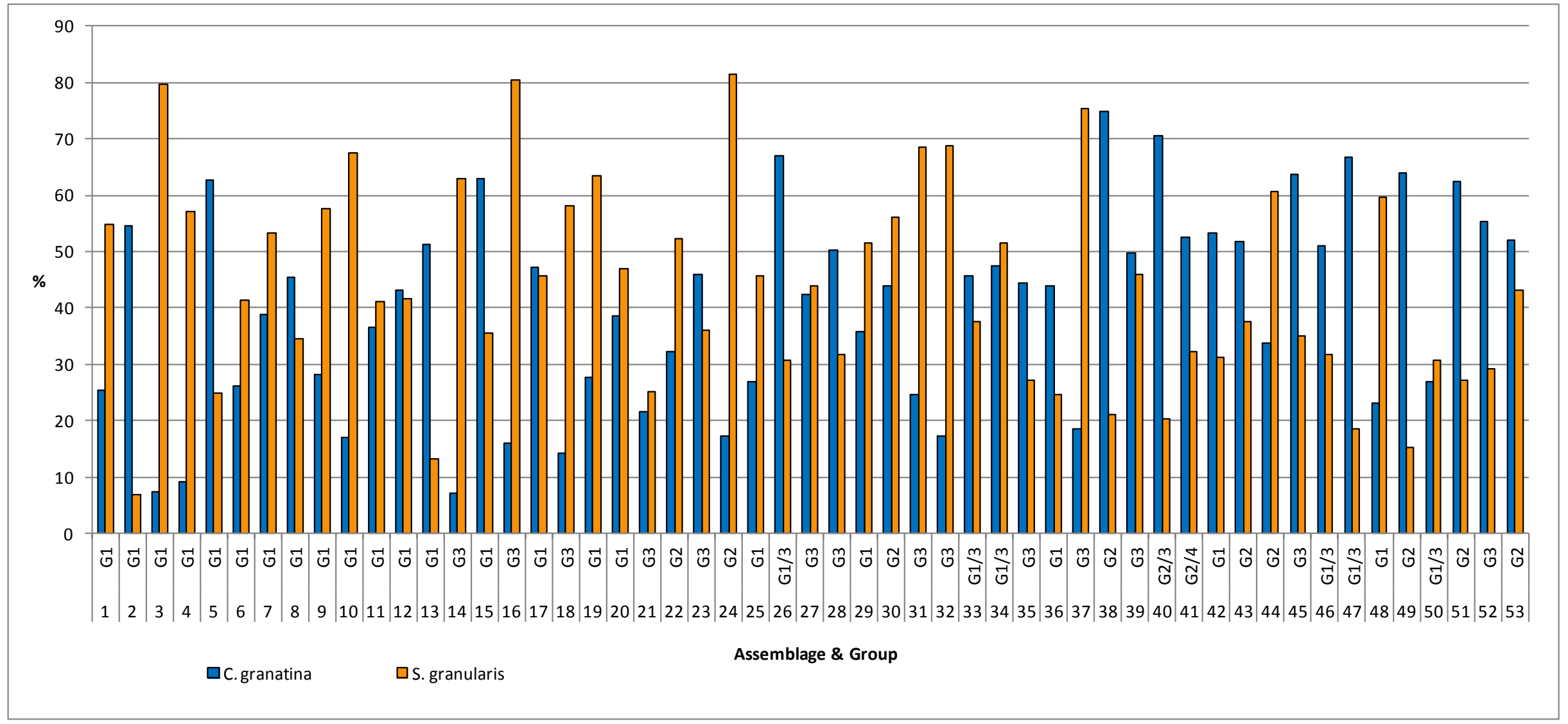

Figure 6.26: $C$. granatina and $S$. granularis frequencies in temporal order. 


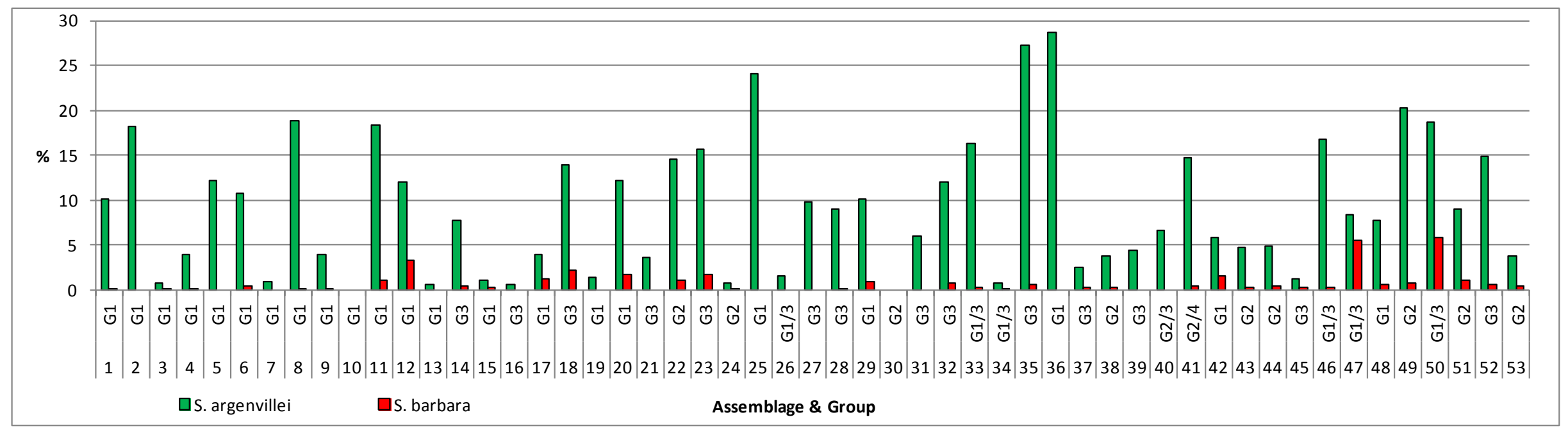

Figure 6.27: S. argenvillei and S. barbara frequencies in temporal order.

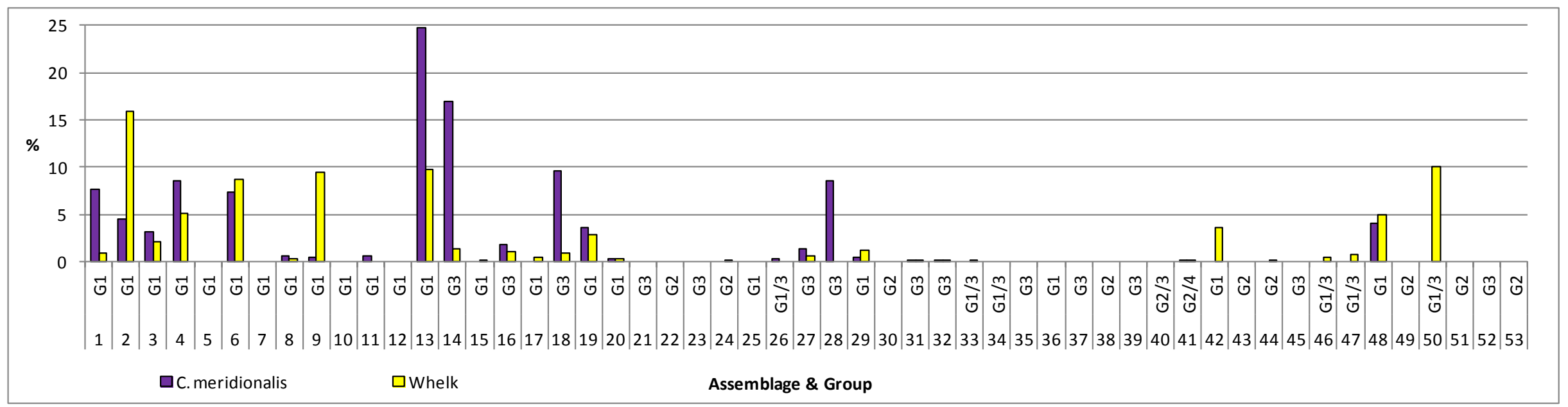

Figure 6.28: $C$. meridionalis and Burnupena sp. (whelk) frequencies in temporal order. 


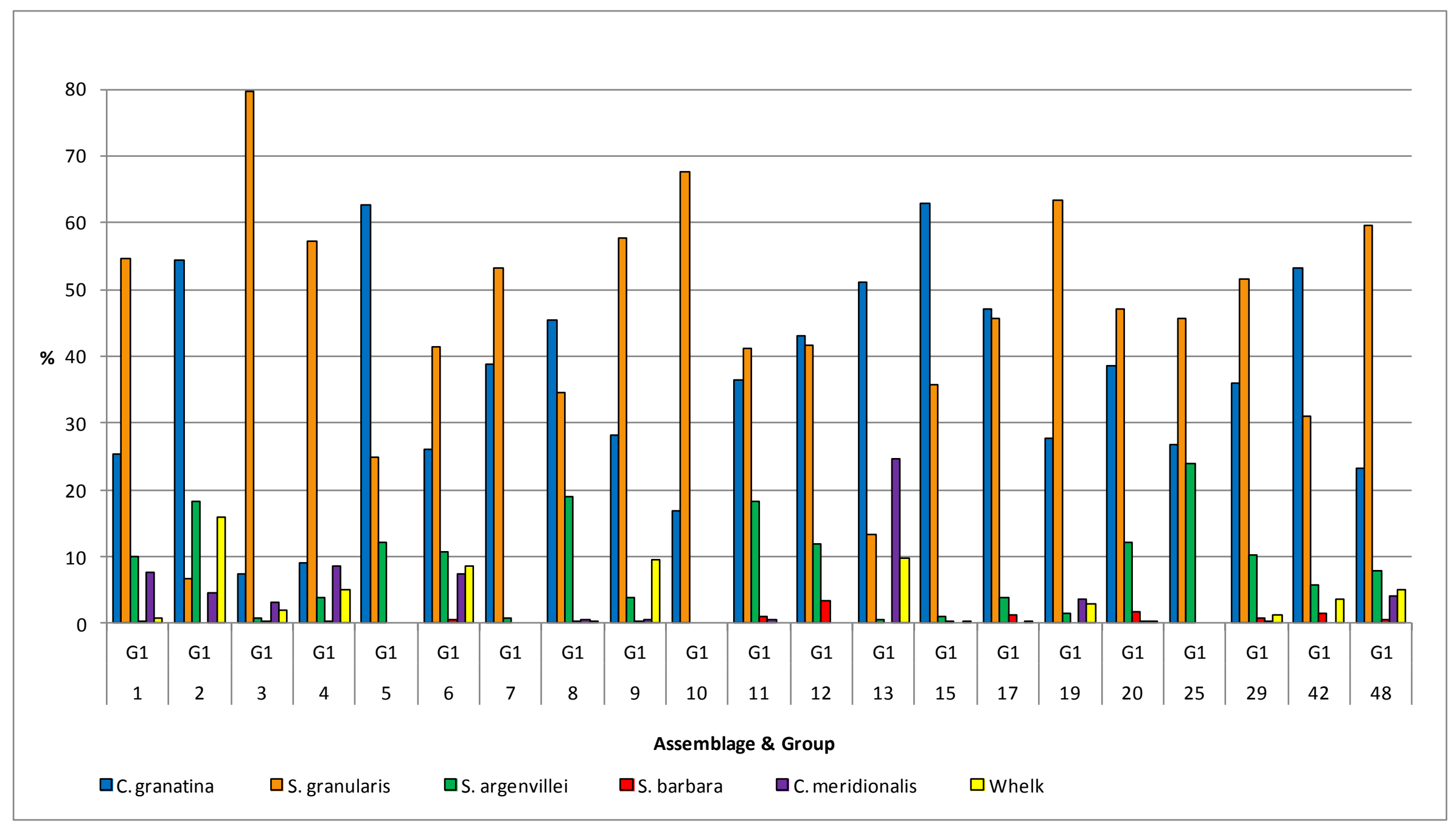

Figure 6.29: Group 1 shellfish species frequencies. 
In Groups 1, 2 and 3 the increase in $C$. granatina appears to be a function of the more consistent selection of that species in later assemblages, although substantial variation continues throughout. What is clear is that there are no distinct 'shellfish signatures' associated with the lithic groups. Whether the observed shifts could be related to environmental change is unknown, but this seems unlikely given the strong dependence on C. meridionalis in recent sites further to the south (Jerardino 2007a; Jerardino et al. 2009a) and their prevalence on the Namaqualand coastline today.

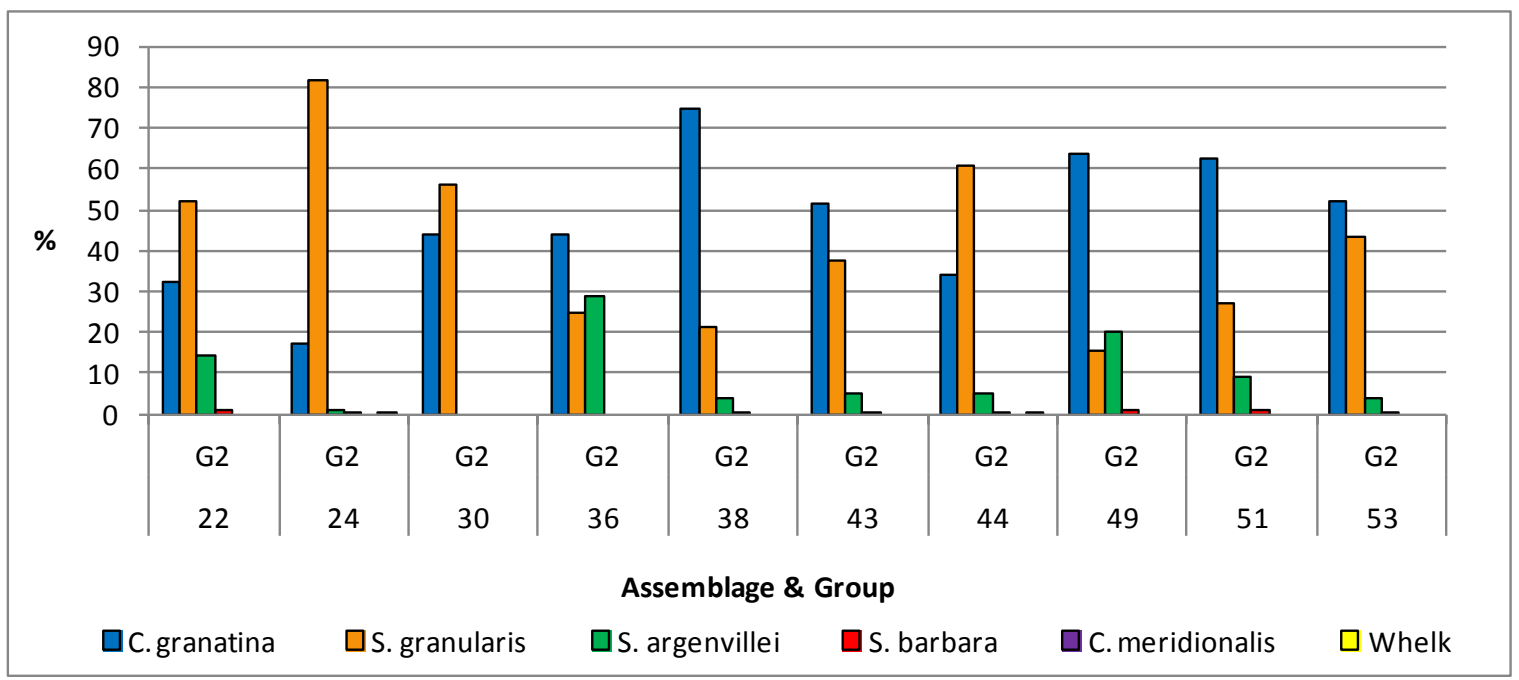

Figure 6.30: Group 2 shellfish species frequencies.

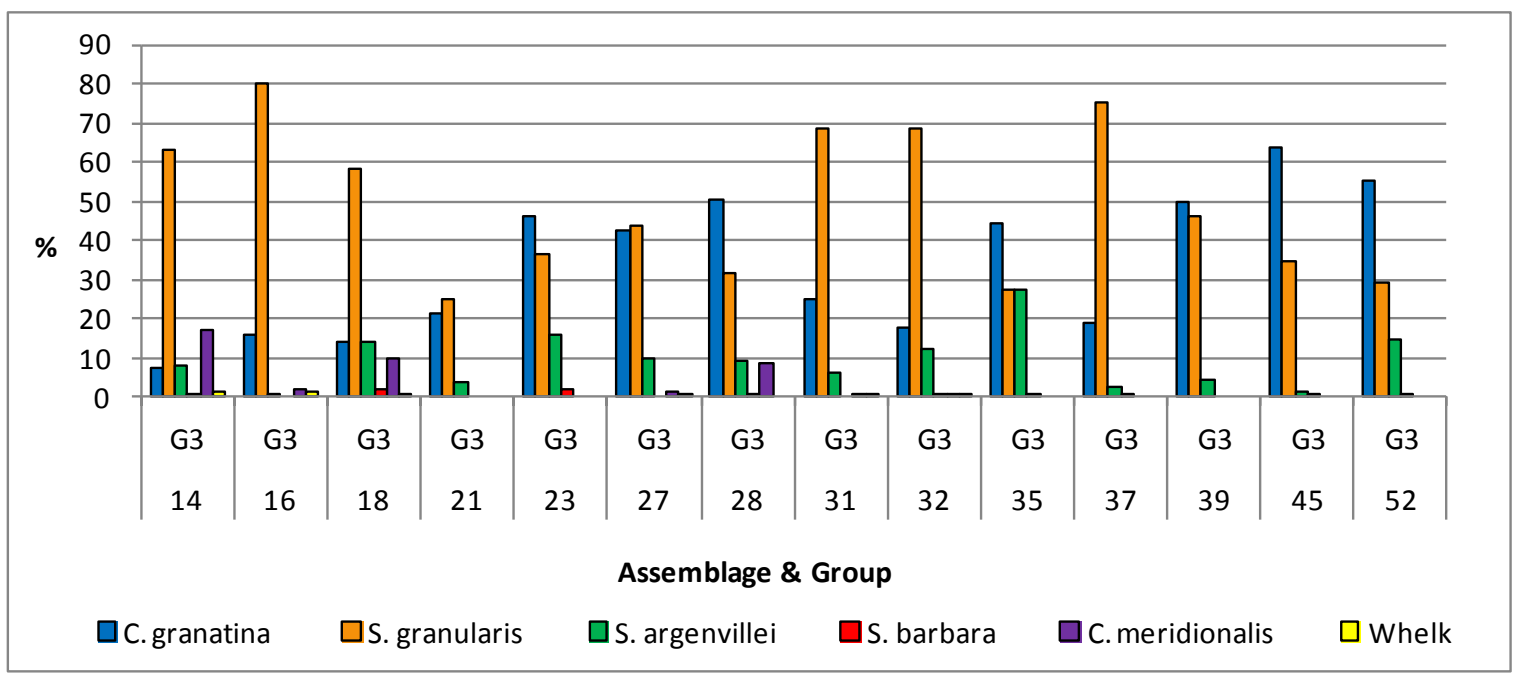

Figure 6.31: Group 3 shellfish species frequencies. 


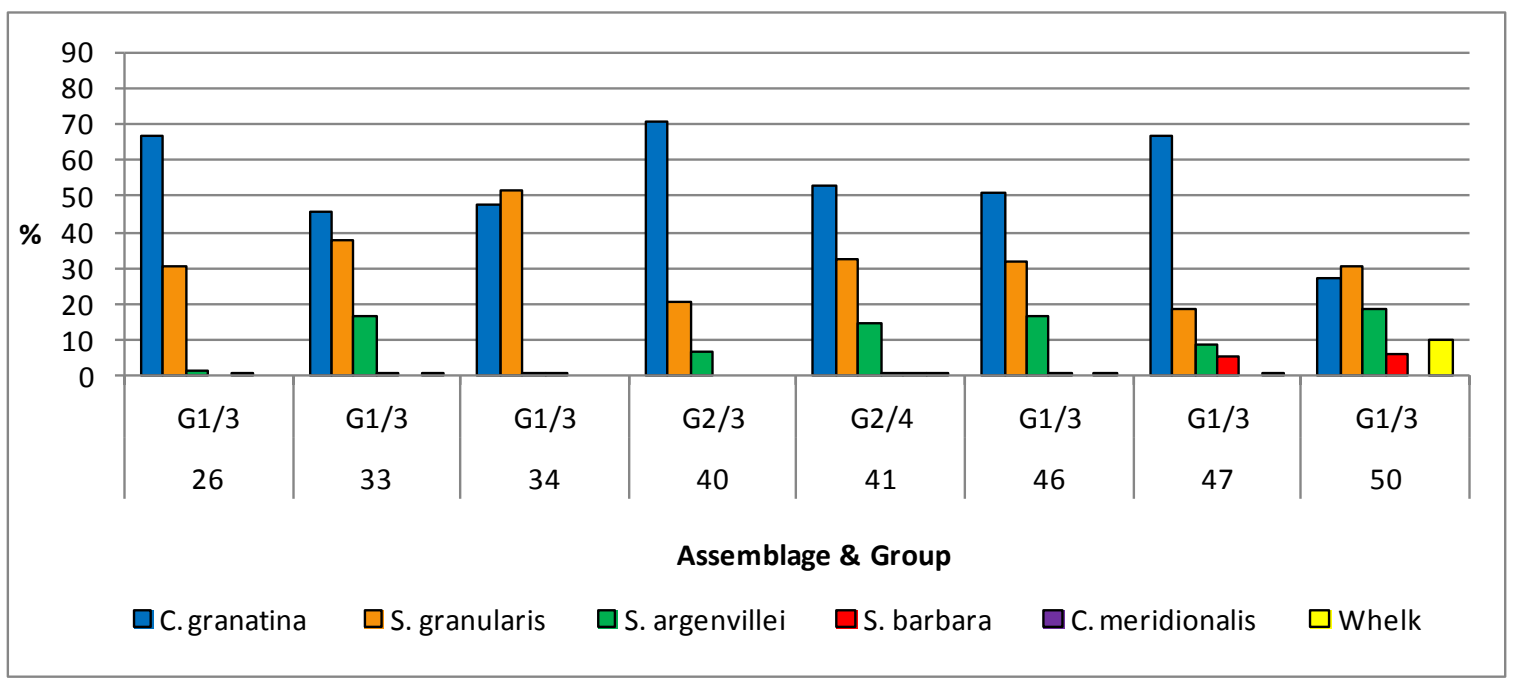

Figure 6.32: Combination groups shellfish species frequencies.

\subsection{Summary and discussion}

From the preceding discussion it is apparent that the Namaqualand Holocene lithic sequence exhibits considerable variability amongst most characteristics. Two reasons may be advanced for this: (1) the assemblages come largely from single occupation open sites where specific tool kits may have been manufactured for specific and differing purposes and (2) the lithic assemblages separate easily into three groups with strongly variable defining characteristics. Other cultural artefacts exibit less variability and sometimes clearer temporal patterning. Overall, enough patterning is evident to create a partial chronology (the first aim of this chapter) and future research should be able to fill some of the remaining gaps. The identification of socio-economic groupings (the second aim) has been less successful; some clues have arisen and these will be examined from a more theoretical perspective in Chapter 7. This section presents a chronological overview of the analyses above, essentially summarising the sequence and highlighting dominant features. The review is broken into time periods that are created largely through the changes evident in the stone artefact assemblages and the northern and central Sandveld assemblage numbers are provided in the headers for convenience. 


\subsubsection{Last Glacial Maximum to 4000 BC}

Little is known of the pre-mid-Holocene LSA along the Namaqualand coastline with just two assemblages on record. People were present during the late Pleistocene when a bladelet-rich assemblage was left at AK2006/001G (Orton 2008a) and the early Holocene when typically large scrapers were made at Spoeg River Cave (Webley 2002). These isolated occurrences merit no further discussion here except to say that, broadly, they are consistent with observations elsewhere in southern Africa.

\subsubsection{BC to $1000 \mathrm{BC}$ (Assemblages 1-8)}

This period contains only Group 1 assemblages. CCS is used more frequently than later on, often comprising some $25-30 \%$ of the total, and its use for retouch is overwhelmingly dominant. The exception is the oldest site (MB2005/005B), but whether it represents an earlier phase remains unknown. Retouch types are variable but backed tools, most often made on CCS, usually comprise about half of the total. The number of retouched tool classes is generally higher at this time than later. At Spoeg River Cave scrapers appear to be slightly more numerous than backed tools and quartz maintains a consistently high presence. Despite some variation, assemblages from the far north and far south of the study area generally replicate the expected patterns.

During this period, throughout Namaqualand, ostrich eggshell beads are small, although occasional medium sized beads do occur. Engraved ostrich eggshell includes both parallel lines and more complex geometric patterns. This period pre-dates the introduction of domesticates and all assemblages are assumed to be those of huntergatherers. 


\subsubsection{BC to AD 100 (Assemblages 9-19)}

Although high incidences of CCS use occur during this period, its overall use drops and towards the end of this period we see the introduction of Group 3 assemblages with their very strong clear quartz dominance. Scrapers dominate now, but in the later centuries of this millennium their frequencies decline below 50\%. Interestingly, while later Group 3 assemblages are very strongly focused on the production of backed tools, the two earliest ones still show scrapers at $75 \%$ and $33 \%$ respectively. Backed scrapers are particularly pertinent since they do not occur in assemblages dating later than about $A D$ 100 and are thus a fossile directeur for pre-pottery assemblages. The variability in the number of retouched classes increases with very high and very low values noted. Spoeg River Cave maintains its scraper dominance at this time. Assemblages from this period are absent from the Richtersveld and southern Namaqualand with one exception: at Reception Shelter we find an assemblage little different from those that post-date AD 100.

During this period the ostrich eggshell beads throughout Namaqualand remain in the small-medium range, but one coastal assemblage late in this period includes large beads. Engraved ostrich eggshell continues to have either parallel lines or geometric patterns. Although the earliest dated sheep bone from Spoeg River Cave may predate AD 100, this period generally pre-dates the introduction of domesticates and all assemblages are again assumed to be those of hunter-gatherers.

\subsubsection{AD 100 to $A D 1700$ (Assemblages 20-52)}

During the final two millennia we see the greatest variety among stone artefact assemblages. Group 1 assemblages continue to occur, albeit infrequently. Group 2 appears (c. AD 500) and Group 3 assemblages proliferate. Overall, and primarily on 
account of Groups 2 and 3, CCS is far less frequently used with quartz usually comprising more than $85 \%$ of the total. The main exceptions occur either as a result of higher quartzite use (c. AD 1300-1400) or when CCS undergoes a late resurgence (c. AD 1500-1600). Backed tools either dominate strongly or are present in similar numbers to scrapers. In Spoeg River Cave scrapers are rare in the surviving deposits from the early part of this period. Although Group 3 assemblages have the majority of their retouched artefacts made on clear quartz, the Group 1 assemblages continue to have CCS tools present. In general, fewer classes of retouched tools are made during this period with all the larger numbers attributable to Group 3. Sites in the Richtersveld are all Group 2, but the rock shelter assemblages in the south show mixed signatures with Groups 1 and 3 both clearly evident in the Knersvlakte. Group 3 appears to be absent from coastal sites in the south (Halkett et al. 1993), but is strongly evident just inland at KK002.

Like the stone artefacts, ostrich eggshell bead size is strongly variable throughout the last 1900 years, but with an overall tendency to increase in size with time. Although one coastal assemblage contains many very large beads at about 1000 years ago, we find a steady increase in the occurrence of this size of bead from about AD 1400 onwards. However, small and medium beads continue to occur, sometimes in large numbers. In the far north we find similar variability, but again with an increase through time. The rock shelters in the south display a somewhat different pattern where, although increasing in mean size with time, beads remain generally small throughout and very large beads fail to appear at all. That very large beads do occur in the area is evidenced by their presence at VR048. Engraved ostrich eggshell seems to occur more rarely during this period, but from the available evidence it seems that geometric patterns disappear between about AD 1000 and 1300 leaving only parallel lines. 
Pottery first appears at the start of this period, at or just after 2000 years ago, and is more consistently present after AD 500. Pottery Index remains low until AD 1300 whereafter it generally stays above 5 on sites with pottery. At Spoeg River Cave, however, the index is above 5 from the mid-first millennium AD. Incised decoration occurs with some impressions during the first millennium $A D$ but unfortunately the sample lacks decorated pots between AD 800 and 1300. Impressed decoration clearly proliferates after this time in the absence of incised lines. Lugs are rare, but all those from dated contexts occur after about $A D 700$ and a few others can be inferred to be relatively late.

The presence of domestic stock, sadly, adds little to the discussion. Although occurring in very few sites overall, sheep and cattle are present throughout the last 2000 years thanks to their early occurrence in Spoeg River Cave (Sealy \& Yates 1996) with cattle following a few centuries later at KN2005/041 (Orton et al. in press).

Figure 6.33 charts the patterns revealed above, as well as the occurrence of tortoise burials as discussed in Orton (2012). Overall, with the exception of the switch from backed tool- to scraper-dominance, it appears that a fairly fixed pattern was present before AD 1. This pattern can no doubt be ascribed to hunter-gatherers, since it is widely known that no other economy was practised before that date. In the first two centuries $A D$, however, we see the beginning of a period of change (Figure 6.33). Various aspects of material culture continue to change until about AD 1300 after which stability once more prevails. At some point within this broad period we know that the Khoekhoen arrived on the landscape. What these changes mean relative to their arrival cannot be said at this stage without deeper consideration of the social dynamics at play during the last two millennia. Focusing on this interesting period, I explore these factors below. 
O

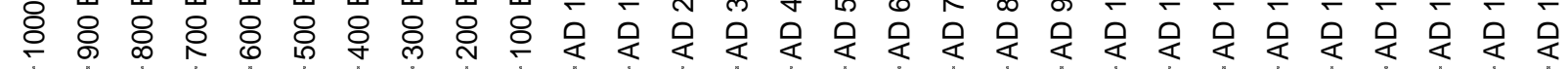

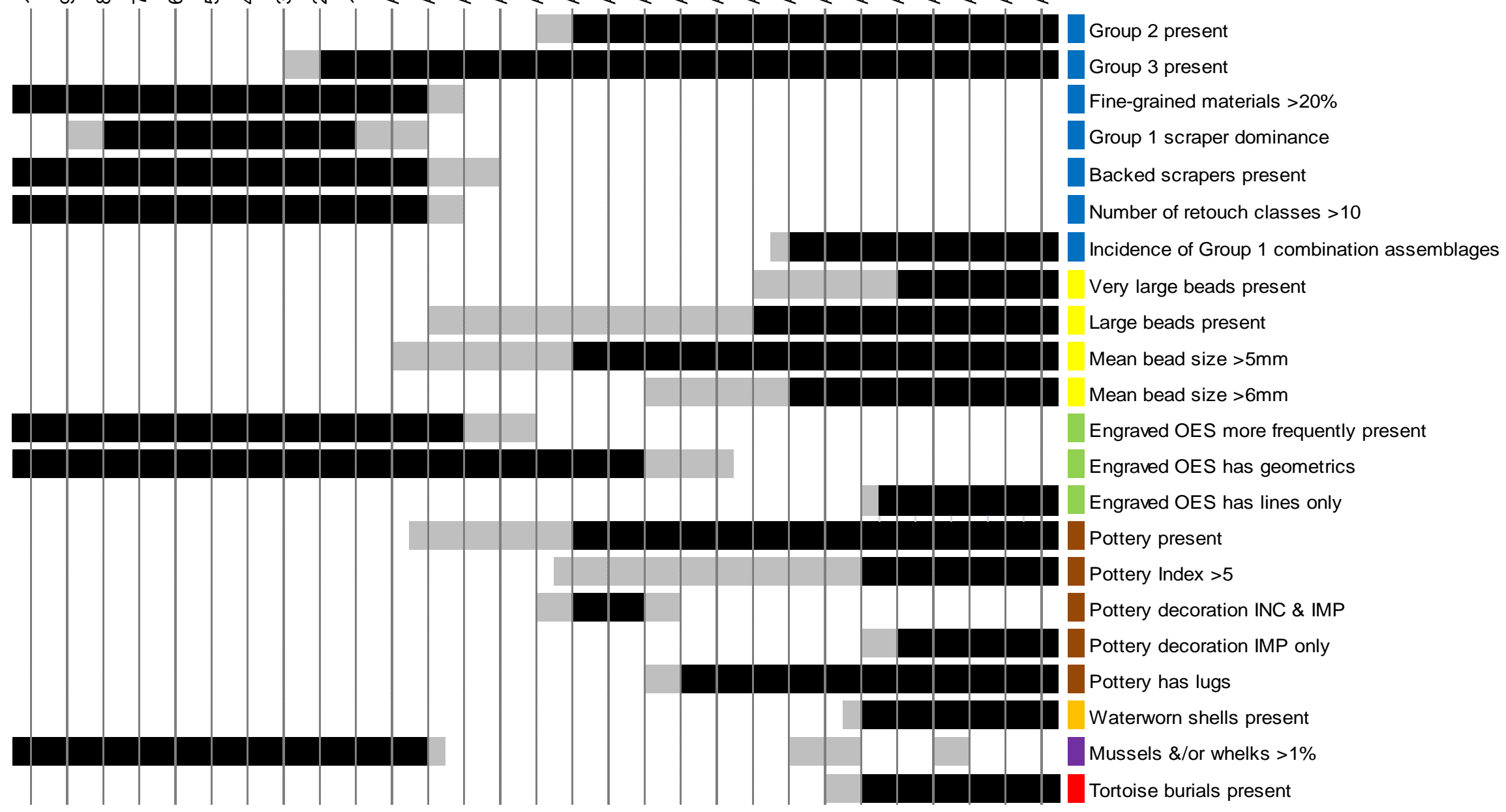

Figure 6.33: Summary chart showing the cultural change evident in Namaqualand. The black bars represent clear patterns, while the grey bars indicate periods of uncertainty, due either to limited observations, lack of clarity of the observations or lack of dating precision. 


\section{Chapter 7. Pottery-period hunter-gatherers and herders}

While the first aim of this research was met by Chapters 5 and 6, the present chapter explores various themes that include the next three aims: distinguishing hunter-gatherers and herders, examining interactions between them and understanding the clear quartz assemblages with backed artefacts. After several millennia of relative stability in material culture in Namaqualand a period of sustained change began c. AD 100, co-incident with or immediately after the first appearance of domestic stock. This period lasted for about 1200 years and included some key changes and introductions. Group 1 assemblages are clearly hunter-gatherer pre-AD 1, and presumably so after that, but it is unclear who made Group 2 and 3 assemblages. The indigenous Bushmen and immigrant Khoekhoen are both possibilities and interaction between ethnic groups may have caused some of the observed overlaps. The lithic groups are clearly differentiated: technological and material differences indicate that Group 2 cannot merely represent sites at which no retouched tools were discarded. These and other issues are explored here through various topics, although ultimately this chapter is about the impact of the introduction of pottery, domesticates and the Khoekhoen on the material culture of Namaqualand, an impact that was variable across southern Africa and is still poorly understood despite the volume of research directed at it. Given the importance of Namaqualand in the various models of pastoralist expansion, the chapter concludes by re-examining this topic, but for the first time with a good base of archaeological data from the region itself.

\subsection{Late Holocene occupation history}

In coastal Namaqualand, Dewar (2008) postulated a pulsing of Holocene occupation during more favourable climatic periods. Within the last two thousand years her data suggested a gap in occupation during the Medieval Warm Phase (AD 800-1300). 
However, with the additional dates now available, we see greater continuity (Figure 7.1). Although 105 dates for the northern and central Sandveld is still a relatively small number, there do not appear to be any particular gaps through the last 5000 years and certainly not within the last 2000 years. However, if one plots the approximate date range for each occupation at open coastal sites alone then a different picture emerges (Figure 7.2). Two significant points arise: firstly, a gap in occupation does appear c. AD 6001000 (slightly earlier than Dewar's (2008) hiatus) and, secondly, three occupations fall squarely within the Medieval Warm Phase. Of the four Sandveld dates on Figure 7.1 falling between AD 600 and 1000, three are from Spoeg River Cave and the fourth has an approximate mid-point only fractionally before AD 1000. This may raise questions of environmental suitability at that time, but with the presumably always relatively dry Richtersveld seemingly well-occupied this gap may yet relate to sampling. There are too few dates from other areas to be able to make similar statements about them, but it is noticeable that lengthy, but not concurrent, gaps in occupation clearly exist in both the deep sequences from the Knersvlakte. Whether these may be filled by occupations at proximate open sites is, and likely will remain, unknown.

The reason for the considerable number of dates between AD 1300 and 1600 may be, as Dewar (2008) suggested, that an ameliorating climate brought more people to the coast. Perhaps a more likely reason, however, is simply that with the vastly superior preservation and visibility of recent sites more of them have been selected for excavation and dating. The dearth of dates after AD 1600 remains puzzling, although we know from a 1907 British military map that indigenous people continued to occupy this coastline into at least the early $20^{\text {th }}$ century (Figure 7.3; Source: Pietermaritzburg Archives) - the glass beads from KKO02 in the far south also bear this out. 


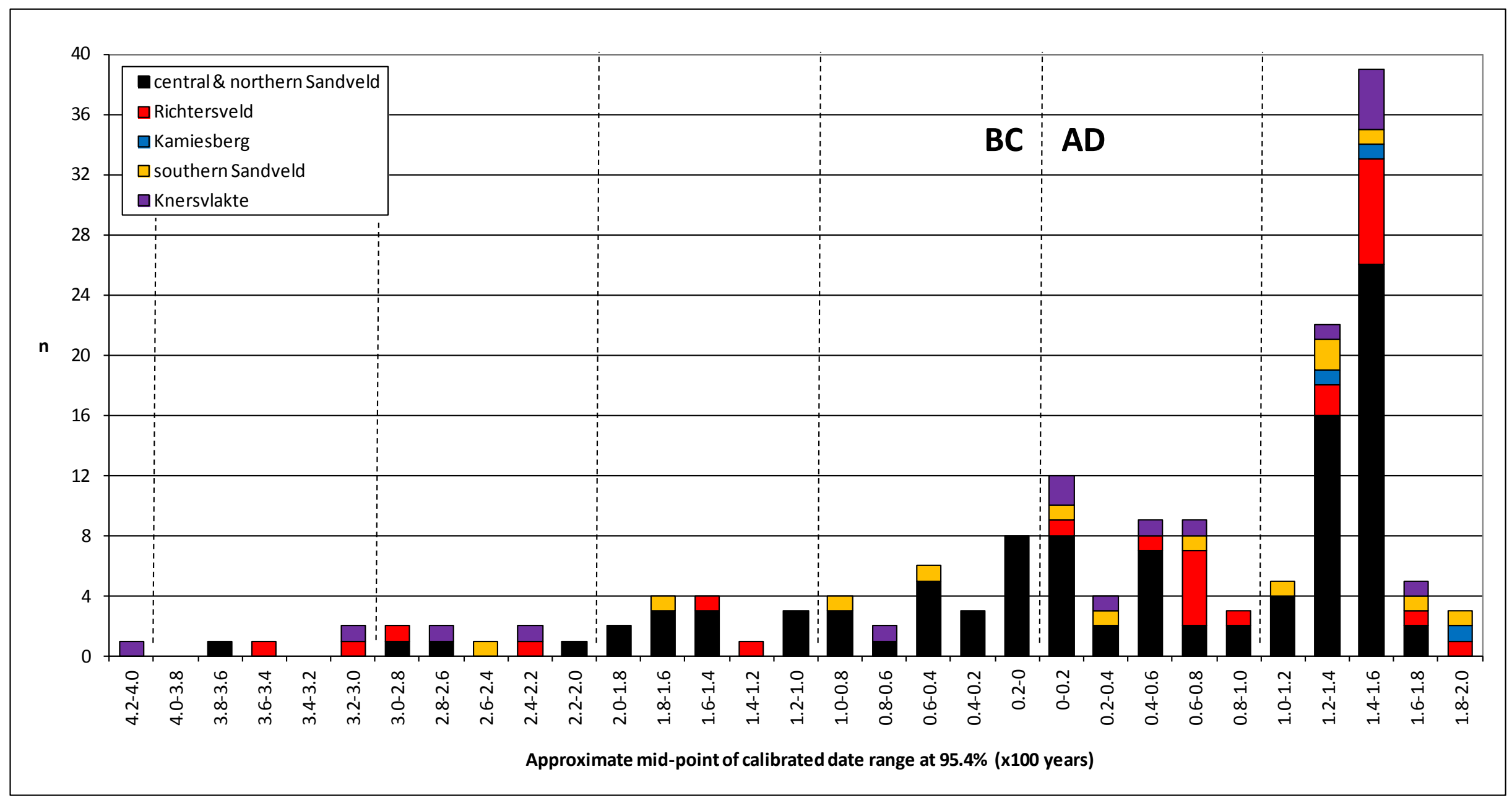

Figure 7.1: Temporal distribution of radiocarbon dates from Namaqualand in 200 year intervals. 


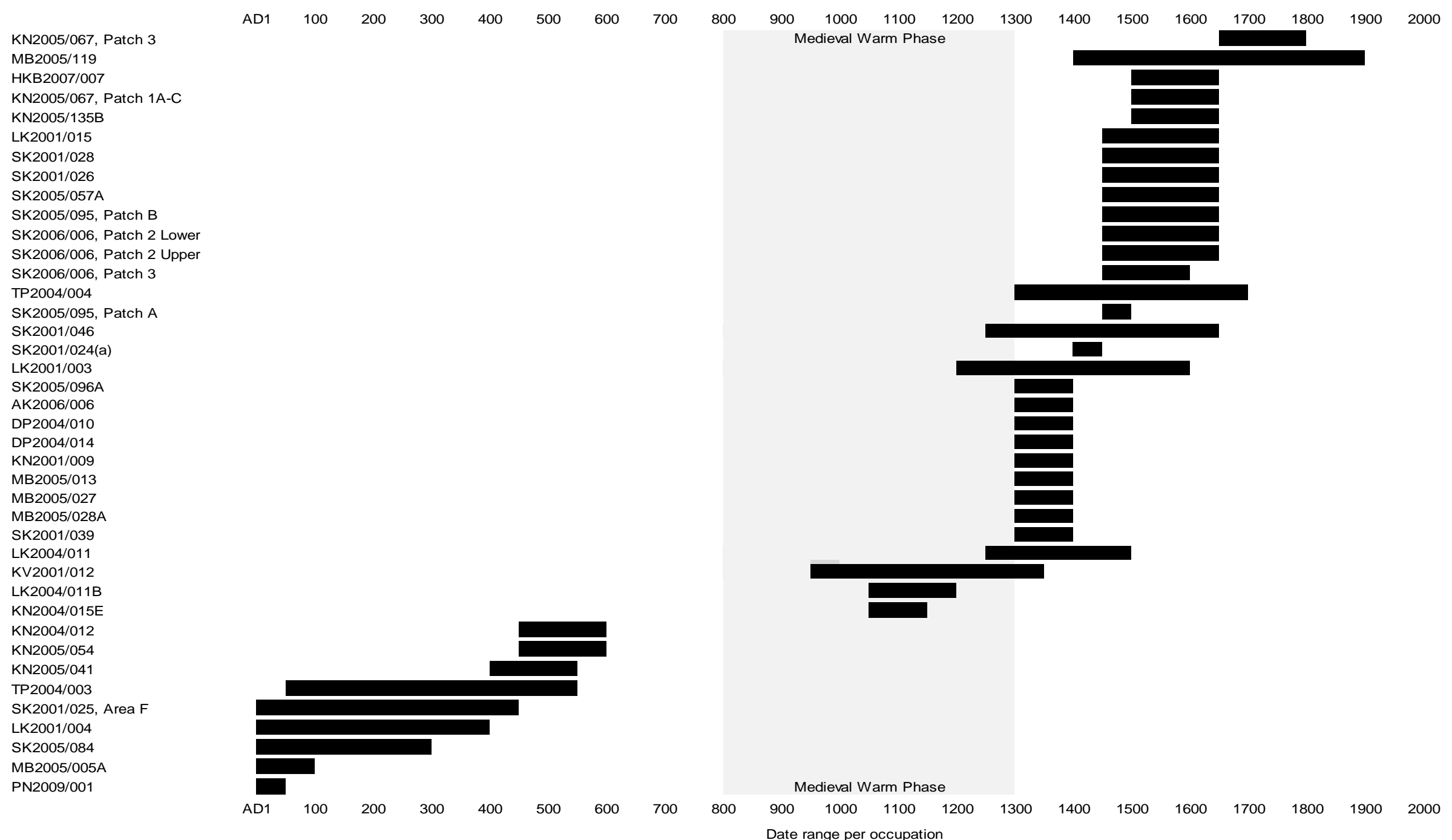

Figure 7.2: Temporal distribution of occupation date ranges from the northern and central Sandveld (rounded off to the nearest 50 years and excluding Spoeg River Cave). 


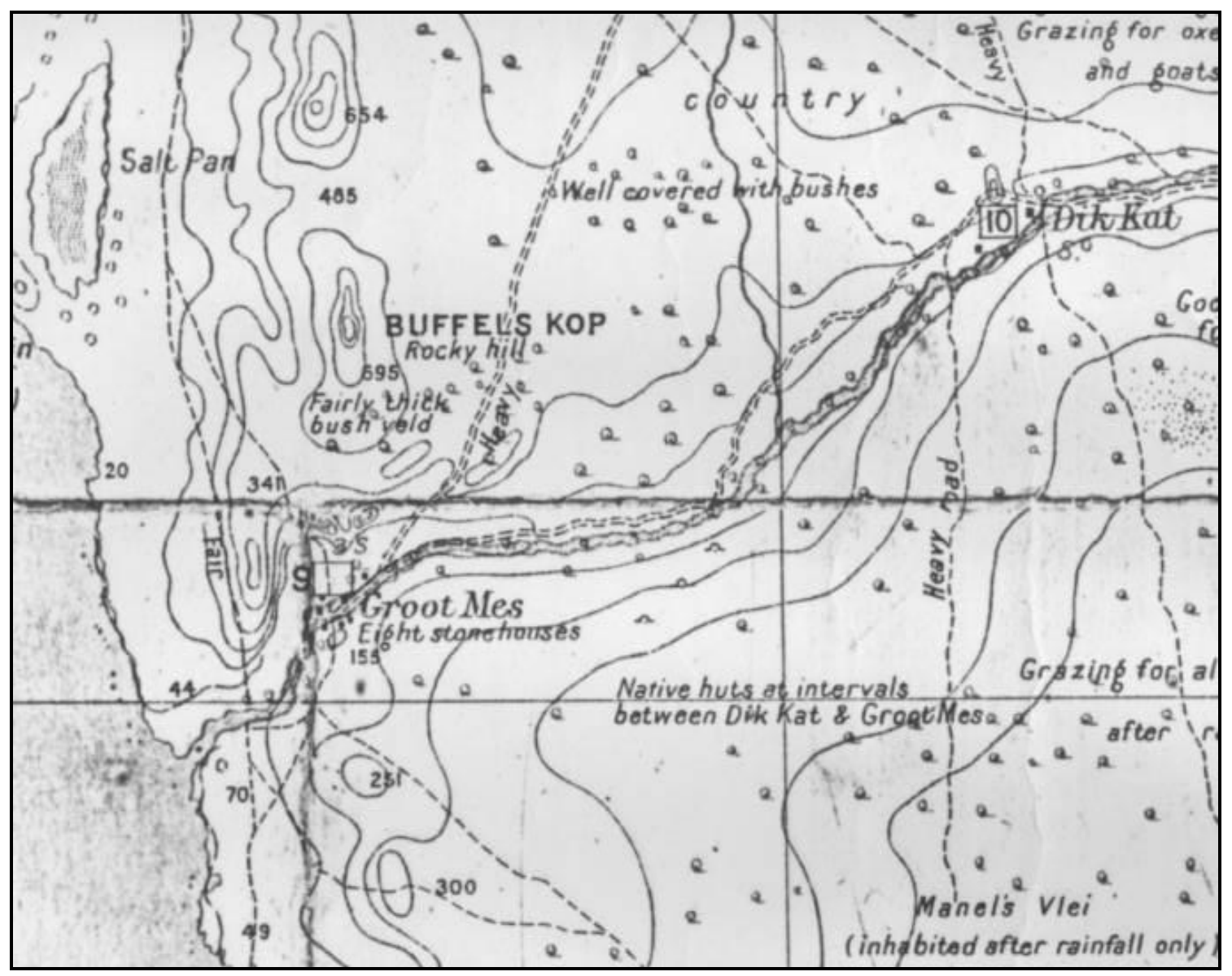

Figure 7.3: Extract from a 1907 British map of northern Namaqualand showing 'Native huts at intervals' inland of the Buffels River Mouth (Source: Pietermaritzburg Archives).

\subsection{Group 1: Continuity in retouch}

Group 1 assemblages were manufactured by hunter-gatherers and occur throughout the study area - and indeed the subcontinent - before 2000 years ago (Figure 7.3). These stone artefact assemblages are typical of the 'Holocene microlithic'22 and have been extensively documented (J. Deacon 1984a; Orton 2006). Within the last two millennia other assemblage types were added to the Namaqualand landscape and Group 1 assemblages became generally rare, although this may be an artefact of selective dating. An alternative could see hunter-gatherers retreating to refugia as proposed in the

22 Such assemblages occur within the technocomplex known as 'Wilton' (Lombard et al. 2012). I have argued elsewhere that 'Wilton' should not be applied to stone artefact assemblages alone but rather for the general time period in which such assemblages occur (Orton 2006). 
south-western Cape by Parkington et al. (1986), but this does not seem defensible on the current, and still limited, body of evidence from Namaqualand, particularly its interior. Given the general continuity in retouched types and other defining characteristics of these late Group 1 assemblages, it seems logical that they too were produced by huntergatherers (Table 7.1). Kusimba (2003) noted that both curated and expedient technologies can occur simultaneously. Group 1 displays characteristics of both: locally available milky quartz formed the bulk of the assemblages and was used expediently, while varying quantities of fine-grained materials were used in a manner indicative of curation. The sources of CCS and fine-grained silcrete, and whether they might be termed exotic/non-local, are largely unknown.

Table 7.1: Hunter-gatherer assemblage criteria (A. Smith et al. 1991) and their applicability to post-AD1 Namaqualand assemblages. A '?' indicates lack of clarity.

\begin{tabular}{lccc}
\hline Criteria & Group 1 & Group 2 & Group 3 \\
\hline High frequency of retouch & $\sqrt{ }$ & $X$ & $\sqrt{ }$ \\
High frequency of fine-grained materials & $\sqrt[X]{ }$ & $X$ \\
Low density of potsherds & $\sqrt{ }$ & $\sqrt{ }$ \\
Presence of shell scrapers & (absent from Namaqualand) \\
Mean OES bead diameters $<5.5 \mathrm{~mm}$ & $?$ & $?$ & $?$ \\
\hline
\end{tabular}

The only real change evident in Group 1 is the disappearance of backed scrapers and CCS segments from the sequence about 2000 years ago. Perhaps the next most striking shift is in the frequency of thumbnail scrapers which comprise some $8.6 \%$ of all scrapers before c. AD 100 and $23.3 \%$ after this date but were nevertheless manufactured throughout. This contrasts with observations at Elands Bay where thumbnail scrapers disappear completely about 2500 years ago (Orton 2006). Thumbnail scrapers are thus unlikely to offer any insights into the introduction of herding.

It is interesting to note that, despite the existence of Group 3 from the last centuries BC, assemblages combining Groups 1 and 3 only occur during the second millennium AD. 
Could this be an indication of ethnic interaction and mixing of material culture? Unfortunately, ostrich eggshell beads - often cited as ethnic indicators - do not help, since Group 1 accompanies all mean sizes during the last 2000 years. Likewise, pottery occurs with all assemblage types, and the impressed decoration common in Group 2 and 3 assemblages appears with Group $1 / 3$ as well. The two Group 1 assemblages with pottery (one very early and one late) have only plain sherds but this may be a function of sampling. Interestingly, Group 1 never appears in combination with Group $2^{23}$.

\subsection{Group 2: Informal and expedient assemblages}

Group 2 assemblages appear in the northern and central Sandveld during the mid-first millennium AD. All but one post-date $A D$ 1300, although this temporal distribution may yet be due to sampling. The assemblages are almost exclusively of local materials, predominantly milky quartz, and were aimed at the expedient production of flakes as and when needed. The lack of prepared single platform cores supports this. Although no metric study of flake size was undertaken, it is evident from the general impressions one gets just looking at the material that Group 2 artefacts are generally larger and chunkier than those of Group 3. That clear quartz was not employed in the manufacture of Group 2 artefacts is no doubt due to the fracture planes usually included within the material. Why silcrete was almost never flaked remains a mystery: although the quality is at times very poor, it is abundant in the landscape and would have served an expedient industry well. Group 2 undoubtedly falls within Orton's (2006) 'late Holocene assemblages' and, from the description in Beaumont et al. (1995), may correlate with the Doornfontein sites of the Northern Cape interior.

\footnotetext{
${ }^{23}$ LK2001/015 (Assemblage 41) may reflect all groups but its assemblage is far too small to be conclusive and is best ignored.
} 
The informal nature of the stone artefacts and absence of fine-grained materials makes Group 2 assemblages a prime candidate for equation with A. Smith et al.'s (1991) herder assemblages (Table 7.1), although this cannot be satisfactorily confirmed as the bead data do not support a herder designation for Group 2 sensu A. Smith et al. (1991). Furthermore, they expected many seal and sheep bones to occur on herder sites. This does not occur in coastal Namaqualand, although this may be due to the general scarcity of domesticates as a whole and the likelihood that, in reality, many herder sites did not contain sheep or seal bones in any number, if at all (Table 7.2; Figure 7.4). The scarcity of domesticates might be explained by Penn's (1995) observation that the Namaqua were a small tribe who generally preferred the hills ${ }^{24}$. Perhaps the vast majority of coastal dwellers were hunter-gatherers?

Table 7.2: Relative frequencies of seal, domesticate and small bovid bones from post-AD1 coastal Namaqualand assemblages. Assemblages listed are: all Group 2 assemblages with meaningful faunal collections, all assemblages with domesticates, and all other assemblages with more than 5 seal bones.

\begin{tabular}{lccccl}
\hline Assemblage (number) & Group & Seal & Domesticate & Small bovid & Reference \\
\hline MB2005/005A (16) & 3 & 489 & - & 130 & Dewar 2008 \\
LK2001/004 (18) & 3 & 297 & - & 49 & Orton et al. 2005 \\
KN2005/041 (22) & $2 / 3$ & 3 & 1 & 10 & \\
KN2004/012 (24) & 2 & 0 & - & 11 & \\
LK2004/011B (27) & 3 & 1 & 1 & 6 & \\
LK2004/011 (28) & 3 & 4 & - & 265 & Dewar 2008 \\
MB2005/027 (32) & 3 & 9 & - & 3 & \\
SK2005/096A (33) & $1 / 3$ & 10 & - & 2 & \\
SK2001/039 (34) & $1 / 3$ & 5 & - & 2 & \\
TP2004/004 (36) & 2 & 1 & - & - & Dewar 2008 \\
SK2001/024 (38) & 2 & 4 & - & 67 & \\
SK2005/095 (39 \& 45) & $2 / 3$ & - & 1 & - & \\
LK2001/015 (41) & $1 / 2 / 3 / 4$ & 8 & - & 7 & \\
SK2001/026 (43) & 2 & - & - & - & Dewar 2008 \\
\hline
\end{tabular}

${ }^{24}$ Penn (1995) does, however, note a Khoekhoen kraal described near Vanrhynsdorp in AD 1661 with about 700 people, 3000 sheep and 4000 cattle. 


\begin{tabular}{lccccc}
\hline Assemblage (number) & Group & Seal & Domesticate & Small bovid & Reference \\
\hline SK2005/057A (44) & 2 & - & 1 & 52 & \\
KN2005/067, Patch 1C (49) & 2 & - & 1 & 7 & \\
HKB2007/007 (50) & $1 / 3$ & - & 22 & 7 & \\
KN2005/067, Patch 1A (51) & 2 & - & - & 126 \\
KN2005/067, Patch 1B (52) & 3 & - & 1 & 183 & \\
\hline
\end{tabular}

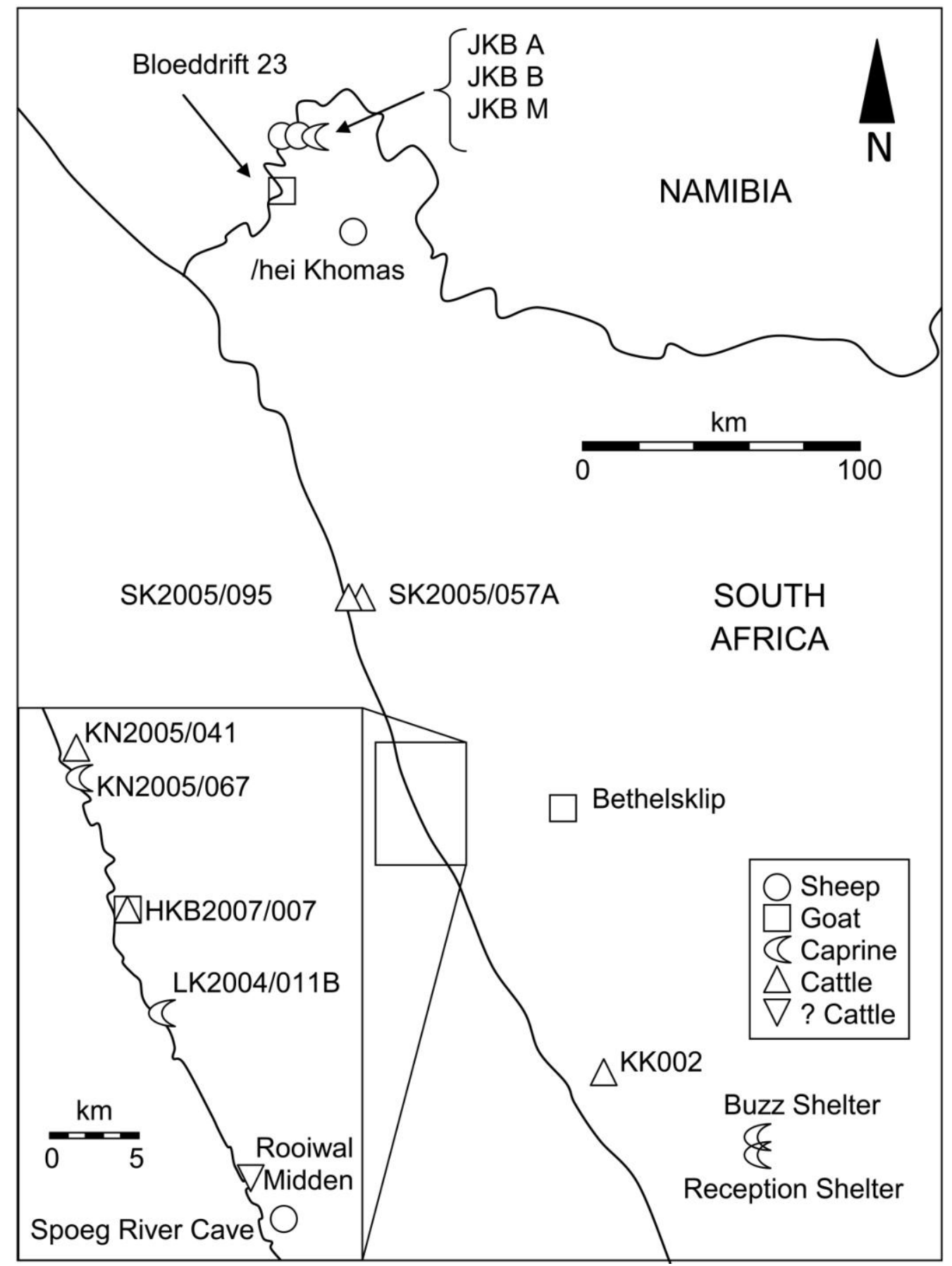

Figure 7.4: Map showing all sites in Namaqualand at which domesticates have been found. Note that most, if not all, sheep are likely to be caprines but I have retained the identifications published. 
Supporting Penn's (1995) observation, it is only away from the coast that greater numbers of domestic bones are found. At the Jakkalsberg sites we find domestic stock occurring in conjunction with Group 2 assemblages and pottery, but the beads are again unhelpful. However, a herder assignation seems most likely (see also Webley 1997a). Cave deposits are harder to interpret due to their generally mixed deposits from repeated longer term occupations and at Reception Shelter and Buzz Shelter early caprines accompany mixed assemblages - probably reflecting mainly Groups 2 and 3 - and small beads. Interestingly, the earliest cattle in the Sandveld (KN2005/041), and indeed South Africa, appear with a Group 2/3 combination assemblage and small beads. Group 3 will be further discussed below, but this does raise the possibility that Groups 2 and 3 both reflect herders in one form or another, as does the lack of Group 1 and 2 combination assemblages. That Groups 1 and 3 occur in combination, however, confounds the interpretation.

At various times throughout North America the shift from formalised to expedient core technology was associated with a change to village occupation (Parry \& Kelly 1987). Although fully sedentary villages only began in the 1800s in Namaqualand under the influence of European missionaries, the Khoekhoen did have mobile settlements composed of matjieshuise at least since the earliest European observers arrived. Unfortunately, there is no way to tell whether some of the sites we find today resulted from such camps or not, although SK2001/024 and LK2001/015 in particular are persuasive. Andrefsky (1994) argues that abundance and quality of stone material are primary determinants of technology with poor materials used expediently and high-quality materials in formal technology. The implication for settled people is that they did not travel in search of high quality material. In Namaqualand, all assemblage types occur in all areas suggesting that material distribution played no role and that people deliberately chose the materials they did - the immediately proximate Group 1 and Group 2 sites at 
Jakkalsberg best exemplify this with fine- and course-grained materials abundantly available within a few hundred metres of all the sites.

It is interesting to note that in north-western Namibia Vogelsang et al. (2002:120) recorded two contemporaneous stone artefact assemblage types which they referred to as (1) "a continuation of the LSA tradition with a few, extraordinary (sic) small microliths" and (2) "an indifferent, unstandardised stone artefact industry with nearly no retouched tools". These certainly recall Groups 1 and 2 and the authors tentatively link the latter to pastoralists or at least herders.

\subsection{Group 3: Quartz-rich assemblages dominated by backed artefacts}

Although first noted at Dunefield Midden 1, near Elands Bay (Orton 2002; Parkington et al. 1992), Group 3 assemblages were not recognised as a distinct 'industry' until reported from the Namaqualand coast (Orton et al. 2005), and they remain poorly understood. The earliest examples in Namaqualand just pre-date 2000 years ago - possibly slightly before the earliest dates associated with pottery and domesticates in South Africa. (The clear quartz assemblage from JKB L (Orton \& Halkett 2010) is distinguished from Group 3 assemblages on the basis of its significant CCS component and the fact that the many crystal facets indicate that quartz crystals were used as a material rather than typical clear quartz sourced from veins - the crystals would constitute a better quality material.) Five arguments for the origin of Group 3 assemblages are discussed, but, given their earliest dating, this must surely be a primary consideration in any interpretation of these assemblages.

1. Group 3 assemblages could indicate a local hunter-gatherer choice to assert their identity in the face of a herder migration through the implementation of new 
technology (c.f. the suggestion by Parkington et al. (1986:313) that "the intrusion of pastoralists increased stress on residual hunter-gatherers and stimulated both ecological and social responses, two of the latter being an intensification of ritual and an increase in painting."); or

2. They could be the result of hunters being "forced to modify their lifestyle after the introduction of domestic animals into southern Africa ca. 2000 years ago" (A. Smith 1998b:208).

These related arguments imply a strong herder presence on the landscape but, despite the likelihood that herding was introduced via the west coast and the certainty that herders did live there, few sites clearly support their presence and at that early stage (c. 2000 years ago) their presence would have been ephemeral. Unfortunately, the geographical extent of Group 3 (and other) assemblages beyond the west coast is unknown so comment on whether stone material sources became restricted with the arrival of a new population cannot be evaluated. The switch to a focus on clear quartz for retouch and the abandonment of milky quartz would, of course, have been conscious choices, but why scrapers, which were so common in the preceding Group 1 assemblages, should be almost entirely dropped from the formal tool inventory cannot be readily explained. Surely, also, if hunter-gatherers wanted to reinforce their identity this would more likely have been through continuity, not change? Whether a shift to clear quartz could have been forced is as yet inexplicable, since material sources are still too poorly understood. Key here is the occurrence of CCS, since it is this material that drops out of general use. In order for herders to cut off stone sources from other groups they would probably have to have had a great deal of power and control within the landscape, but this seems unlikely in the absence of a large population. Group 3 is well represented along the coast and it is probable that herders would have also placed some emphasis on coastal occupation for the marine foods and water sources available to them there. 
Social interaction between ethnic groups on the coastal landscape is thus likely (see Section 7.5 below) and the above counter-arguments may therefore be supported.

3. Given the timing of their introduction, Group 3 assemblages could actually represent the incoming herders themselves, reflecting new activities for which tools were required.

Despite the strong evidence of the dating, this argument seems less plausible. If these assemblages belonged to incoming herders, then the backed bladelets would have to reflect activities not carried out by hunter-gatherers. That backed bladelets were previously well established in the local sequence (despite reducing in frequency post1000 BC) militates against this. Furthermore, A. Smith et al. (1991; A. Smith 2006a) are quite adamant that herder assemblages should lack retouched artefacts and, similarly, Parkington et al. (1992) ascribed Dunefield Midden 1 to hunter-gatherers.

4. Group 3 assemblages could be a regional (west coast) hunter-gatherer development that evolved spontaneously out of Group 1, which, in turn, persisted.

This argument is more plausible and has been tentatively proposed by Parsons (2006) in Bushmanland. Should such evolution have occurred in Namaqualand then two expectations should be met: Group 1 elements should persist for some time and Group $1 / 3$ combination assemblages should date close to 2000 years ago. While the former expectation is met by the two earliest Group 3 assemblages, relevant combination assemblages all date within the second millennium $A D$ suggesting that other factors possibly social interaction - were their source. It is acknowledged, however, that sampling could easily account for this lack of earlier combination sites. Should assemblage evolution have occurred, then the almost complete (and rapid) loss of both CCS and scrapers from the assemblages seems difficult to explain. 
5. Group 3 assemblages may signify hunter-gatherer groups - possibly ProtoKhoekhoe speaking (Güldemann 2008) - who adopted herding and moved into the area from the north.

Though related to the previous two arguments, this seems the most parsimonious explanation for the introduction of Group 3 assemblages. Their language, of course, cannot be proved, but Güldemann (2008) sees Proto-Khoekhoe as being the result of the southward expansion of early Khoe populations. Table 7.2 shows that domesticates are only associated with Groups 2 and 3 and suggests, in turn, a degree of shared economy between these Groups. What level of herding may have been practised by the makers of either Group remains unknown, but Sadr's (2003) 'hunters-with-sheep' may be the best fit model, at least for Group 3. It may be that full-scale herding (and perhaps cattle) only arrived with the Khoekhoen when Group 2 was introduced. I have already argued against the 'adoption' of backed bladelets within this new technology (point 3 above), but, if the technology was brought into the area from the north by a different population group (i.e. it was not new), then the extensive use of backed bladelets is quite plausible. Similarly, the adoption of clear quartz can be explained by the artefact producers being new to the landscape (i.e. CCS was not summarily discarded from use) and selecting the best local material available to them. It is acknowledged, however, that CCS should still have been available through exchange, although its higher value may have resulted in the makers of Group 1 restricting its dissemination. That the makers of Group 2 did not employ clear quartz is likely due to its unsuitability for larger artefacts. Since the working of skins would not have diminished, the technological adaptation must have included an alternative to the retouched stone scrapers dropped from the toolkit. While backed tools continue to occur, Webley (2002) relates the lack of scrapers in the pottery period at Spoeg River Cave directly to the use of $/ / \mathrm{khom}$ stones, which, in turn, she relates to herders (Webley 2005). The only other archaeologically documented //khom stone in Namaqualand comes from Buzz Shelter where retouched scrapers are extremely rare 
and just one overlies the //khom stone. Overall, the tremendous rarity of //khom stones might argue against Webley's interpretation but her caution that such stones may have been discarded in the past without due examination may be relevant, particularly on open sites where organic residues seldom preserve. If //khom stones do represent skin scrapers, then we would probably expect to find them associated with both Groups 2 and 3. With just two known, further discussion is pointless.

Tortoise burials, which represent archaeological traces of ritual activity (Orton 2012), contribute to several of the above arguments. Significantly, they appear in both Group 2 and Group 3 contexts, suggesting that the makers of both Groups adhered to the same ideology, or, at least, had begun doing so by about AD 800 . Unfortunately, whether this means that hunter-gatherers with stock effectively became herders, adopting their ideology, or that both Groups were manufactured by herders (one of whom may have originated as Proto-Khoekhoe speakers) cannot yet be stated. If we accept that full-time herders (Group 2) were Khoe-speakers (and the likely ancestors of the historically observed Khoekhoen), then if the makers of Group 3 spoke Proto-Khoekhoe we could be dealing with an early and limited influx of hunter-gatherers who kept limited domestic stock as a 'cash resource' - these could be the first herders who initially acquired domestic stock in the northern Botswana area. This loosely matches the model proposed by Güldemann (2008:123; and see also Barnard 1992) in which the "Pre-Khoekhoe, while maintaining basic subsistence and language, blended even more into the local population profile by relying more on a foraging subsistence component, by adding to their language a strong Tuu substrate, and last but not least by undergoing a greatly increased genetic admixture from local Khoisan."

Another aspect of material culture shared by Groups 2 and 3, is the water worn shells collected from the beaches, presumably as decorative items. That such shells are 
common in Group 2 and Group 3 assemblages but so rare in Group 1 (Table 6.5) supports a relationship between the former two.

Group 3 assemblages were largely curated: the backed artefacts were almost certainly part of complex, multi-purpose tools and may well have been manufactured as arrow inserts in anticipation of future need. Keeley (1982) suggested that unhafted tools would be more likely disposed of at or near the place where they were used, but the Group 3 backed bladelets described here were probably being replaced on the sites where they were found. Although bipolar cores usually indicate expedience, in the Group 3 (and Group 1) context they more likely relate to recycling of worked out cores to maximise the available material.

While Group 3 assemblages are plentiful along the coast (Orton \& Halkett 2005, 2006; Orton et al. 2005), possible, very ephemeral examples occur on low dune tops further inland where stone artefacts are generally rare but always in clear quartz (Orton \& Webley 2012a). I would argue that these sites could represent the one night camps of highly mobile Group 3 people with domestic stock.

Group 3 technology was certainly persistent. That it continued until recent times is demonstrated archaeologically at Reception Shelter and particularly at KK002. In all cases the clear quartz is assumed to be local. Rudner (1979) reviewed several eighteenth and nineteenth century accounts of the use of stone tipped arrows in Namaqualand by both the Bushmen and Khoekhoen, noting in particular the use of clear quartz. Whether these accounts actually reflect Group 3 technology is unknown, although if they did the fact that both ethnicities are referred to does not help in the identification of the Group 3 makers. 


\subsection{Social interaction}

I have often mentioned the possibility of social interaction, but evidence for its occurrence remains limited. Based on historical accounts, A. Smith (1998) describes the domination and marginalisation of indigenous hunter-gatherers by the intruding Khoekhoen herders in the south-western Cape as seen by the first European observers from the late $15^{\text {th }}$ century $A D$ onwards. The nature of the relationship between the two groups varied greatly from hostility, where captured individuals of the other group might even be killed, to clientship, where the hunter-gatherers were employed by the herders to perform various functions within their society. A. Smith (1998) suggests that these 'jobs' might have included being lookouts, hunting wild animals, collecting honey or perhaps even herding. The last is puzzling given the time and energy Smith has devoted to arguing for the inability of hunter-gatherers to herd stock! In any case, archaeological evidence is lacking and he relies only on historical records which might, of course, reflect a society very different from that which pertained during the first millennium $A D$ when the first interactions must have occurred.

What archaeological possibilities for social interaction occur in Namaqualand? The combination lithic groups are one. However, if herders are represented by Group 2 and indigenous hunter-gatherers by Group 1, then surely we should be finding Group 1/2 combination assemblages? This potential interaction does not occur. Group 3 might then represent the indigenous hunter-gatherers but I have already discounted this possibility above. Seeing Group 3 as made by immigrant hunter-gatherers with stock would, however, potentially allow this interaction to occur as these two groups would be more likely to associate in a way that might leave two signatures on the same sites. Either way, whether interaction could even have manifested itself as combination assemblages is open to debate. Although the excavations are generally fairly small, it is frequently the case that both artefact signatures occur within the same middens arguing for close 
physical and social contact between their makers. The type of relationships described by Smith would probably have resulted in the development of a 'we/they' dichotomy aimed at "keeping people on the periphery" (A. Smith 1998:201).

The sharing of ritual in the form of tortoise burials argues for a stronger relationship than clientship and suggests that the makers of Group 2 had far more in common with the makers of Group 3 than with those of Group 1. If Group 3 represents the kind of hunterswith-sheep I have suggested them to represent (i.e. a Proto-Khoekhoe-speaking population), then Group 2/3 combination sites may reflect the idea that Namaqualand herders employed only those groups that were ideologically closer to them rather than the Bushmen who were substantially different. It is possible that, through inter-marriage and frequent interaction, the historical records failed to distinguish between the makers of Groups 2 and 3 but could more easily isolate the Bushman hunter-gatherers.

A third aspect of social interaction in Namaqualand may be demonstrated by the sharing of material culture. Although this clearly did not apply to stone artefact assemblages, which maintained very distinctive signatures throughout the last two thousand years, ostrich eggshell beads and pottery are different. Ostrich eggshell beads of all sizes occur in association with all three lithic groups, and pottery is similarly shared. It might be that these elements of culture were important as exchange items and therefore permeated all social barriers.

\subsection{Mobility, settlement and exchange}

The study of mobility in Namaqualand is hampered by our inability to determine the number of people living at any particular site, whether sites were reoccupied during subsequent visits to the area, and whether they may have functioned as aggregation or dispersal sites. In general, though, most if not all groups living in the Sandveld would 
have been highly mobile; even the largest discrete shell middens probably do not reflect occupations spanning more than a few weeks and very small, often ephemeral shell scatters are abundant, particularly slightly further away from the coast (Orton 2007d; Orton \& Webley 2012a, 2012c). Binford (1980) described 'residential mobility' by foragers, where settlement location is determined by resource location, and 'logistical mobility' by collectors, where resources are collected by small task groups and brought back to residential camps. In coastal Namaqualand a combination of these strategies was likely at play with marine resources driving the first strategy and other resources (including grazing) the second. Dewar (2008) considers most sites to be short term processing camps focused on subsistence activities, with ready access to water not critical in the choice of campsite location; this describes residential mobility, perhaps focused on ensuring that coastal resources were never over-utilised. Logistical forays are apparent from the lack of domestic debris at the many quarried quartz outcrops in the coastal Sandveld. This pattern would have applied to both hunter-gatherers and herders, since, with the exception of meat and milk from domestic stock, both groups would have been subjected to similar environmental constraints through their reliance on the same set of wild resources. Although more activities would likely have occurred at longer term camps, preservation in coastal Namaqualand is poor and the commercial excavations have very seldom, if ever, covered areas large enough to determine the various uses of space that might have occurred on site.

Exotic items can be seen as evidence of either mobility or exchange. What constitutes exotic? Higgs and Vita-Finzi (1972:30) considered a 'site territory' in mobile economies to be "the area habitually exploited from a single site" and proposed a radius of about 10 km, while a 'site catchment' was larger, including all land occasionally exploited by Binford's (1980) task groups. While local materials should be available within the site territory, exotic materials are perhaps best considered as originating outside the site catchment. Whether people acquired exotic items directly or through exchange cannot 
be proved (Hodder 1984) and common items traditionally thought to have been used in hxaro (gift exchange) like beads and bone points may not have actually moved anywhere at all (Mitchell 2002a) and cannot be sourced; they are unhelpful here. However, as intimated above, that pottery and different sized beads appear to have been used by everyone in the Sandveld does suggest that these items may have been locally exchanged.

Two clearer indicators of mobility and/or exchange are exotic stone materials and marine shells. Presumably greater distance from source would suggest a greater likelihood of exchange. Just how mobile the Namaqua were in pre-colonial times is unknown. Stow (1905) notes that in the late seventeenth century the Namaqua frequently travelled to within about $100 \mathrm{~km}$ of Cape Town but later states that "it was rarely that a Namaqua left his own country even on a temporary visit to another" (Stow 1905:254). Group 1 assemblages in the northern and central Sandveld include CCS in reasonable quantities. Although some may have been sourced from nearby or at least within the site catchment, the majority probably came from much further afield. That so few CCS artefacts have either pebble or calcrete cortex on them suggests long distance transport; any original cortex would, in such cases, have been removed as cortical flakes closer to the material source, leaving well developed and perhaps steadily reducing cores to travel on into the Sandveld. A regional study of cortical flake frequency may be revealing in this regard, since the two obvious sources of cobble CCS in Namaqualand are the present Orange River gravels and the palaeo-Orange terraces on the Knersvlakte. Andrefsky (1994) has argued that when local materials are poor in quality the majority of formal tools will be made on non-local materials; I previously illustrated this for the Elands Bay area via the 
raw material retouch index ${ }^{25}$ (RMRI; Orton 2008b). Figure 7.5 graphs the indices for the northern and central Sandveld sites reported here and shows that quartz, being a local material, is always low, while CCS and sometimes silcrete command far higher values. Figure 7.6 shows the material abundance and quality relationship (Andrefsky 1994). The makers of Group 1 treated their materials differently with high quality but rare materials being the focus for retouch. For Group 3 it can be argued that the clear quartz is less abundant than milky quartz and of somewhat lesser quality than CCS - the intermediate RMRI values in Figure 7.5 illustrate this. Group 2 obviously focused on the use of the most easily available material, regardless of quality. Since clear quartz was obviously available to Group 2 makers, they must have consciously avoided it for some reason.

${ }^{25} \mathrm{RMRI}=$ frequency of stone material among all retouched artefacts divided by frequency of same stone material among all stone artefacts. 


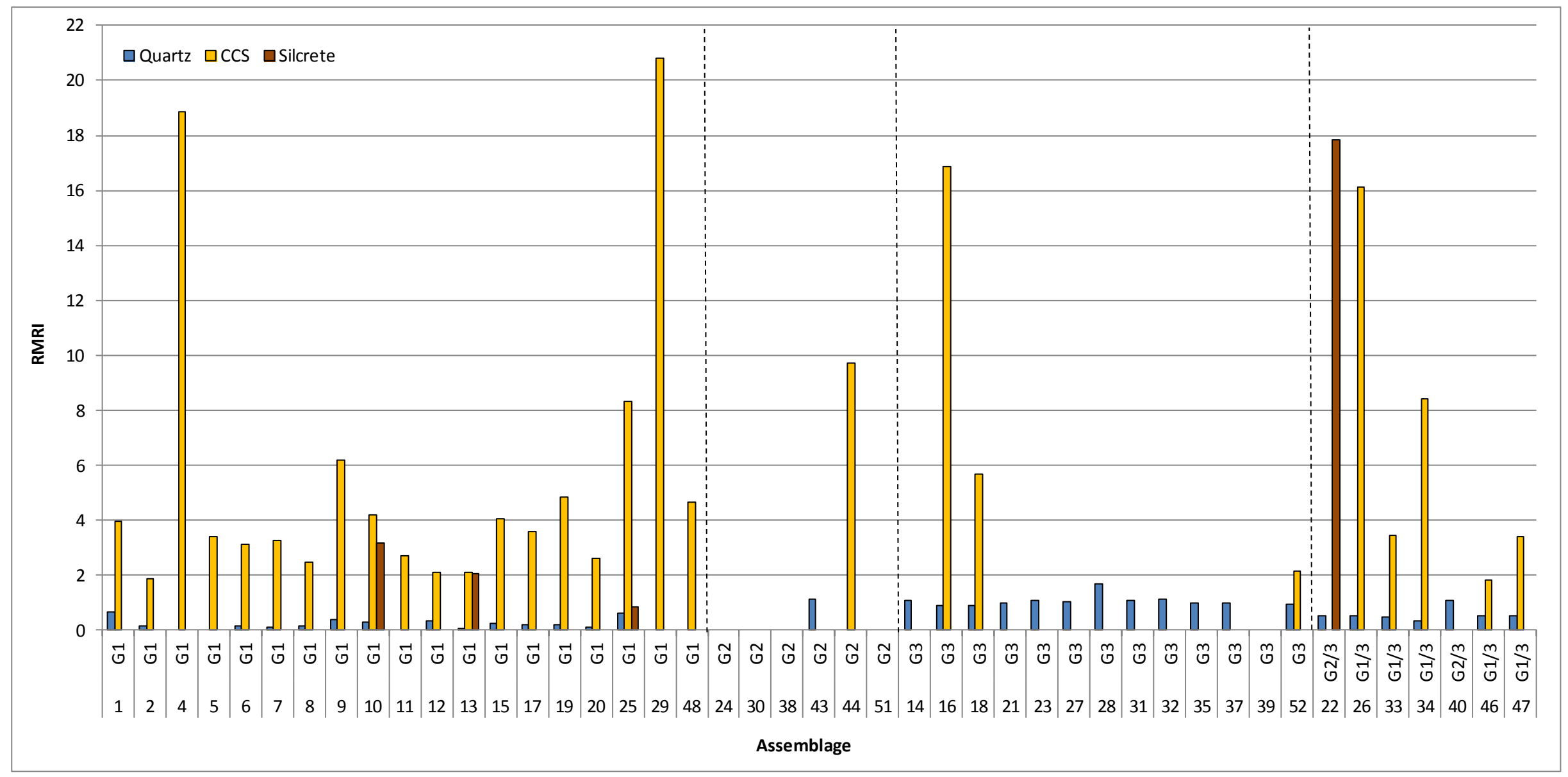

Figure 7.5: RMRI for primary stone materials by assigned group. 


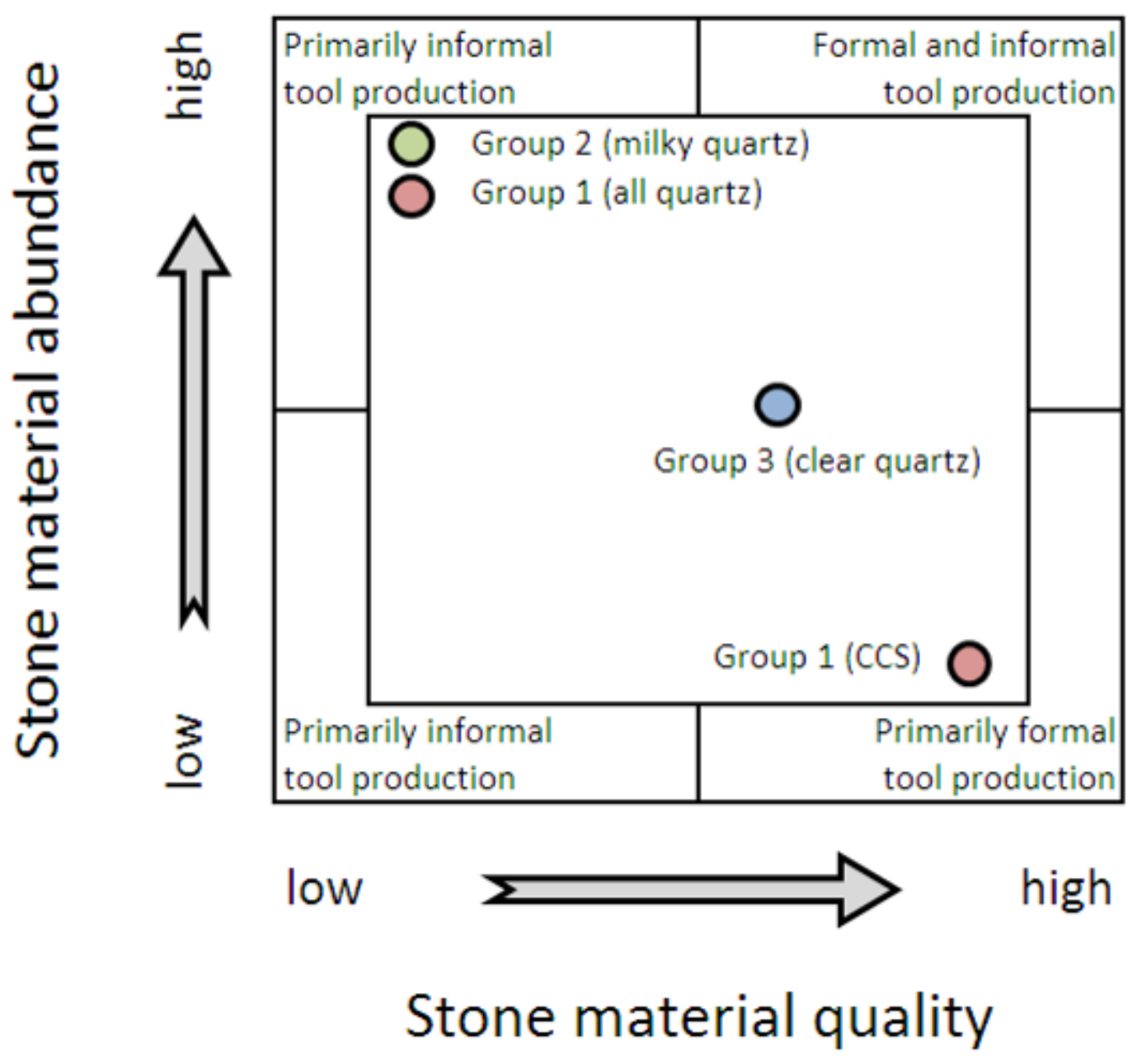

Figure 7.6: Relationship of stone material abundance and quality and its effect on northern and central Sandveld assemblages (modified from Andrefsky 1994: fig. 2).

Marine shells were frequently used as decorative items and shells collected for this purpose are often found far from their ultimate origins (Hudson 2006; Mitchell 1996). Namaqualand examples occur in the Richtersveld, more than $60 \mathrm{~km}$ inland (Orton \& Halkett 2010; Webley et al. 1993) and particularly at Bethelsklip (Webley 1984) and Buzz Shelter (Orton et al. 2011) where pendants were found made from shells sourced at least $280 \mathrm{~km}$ and $200 \mathrm{~km}$ from their natural habitats respectively. Although the Namaqua may well have sourced the shells themselves, exchange seems a more likely means of acquisition. 


\subsection{Rock art in the arid west}

Although not studied in any detail in this thesis, a discussion of rock art and its implications for the spread of herding is warranted owing to (1) the description of what is assumed to be 'Khoekhoen art' from the Central Limpopo Basin (CLB) in northern South Africa (Eastwood 2003; Eastwood \& Smith 2005; Smith \& Ouzman 2004), (2) its occurrence in Namaqualand, and (3) the presence of domesticated animals in fine-line hunter-gatherer art.

Three types of art are distinguished in the CLB: brush-painted San art in various colours, daubed art in white made by the ancestors of the present North Sotho, and red and white geometric finger-painted art (Eastwood and Smith 2005; S. Hall \& Smith 2000). Through a process of elimination, the latter is confidently ascribed by B. Smith and Ouzman (2004) to the Khoekhoen and, despite the reservations of some researchers (Parkington et al. 2008; and see comments following B. Smith \& Ouzman 2004), I refer to it as 'herder art' for the sake of simplicity. Various features distinguish this art from that of hunter-gatherers (Table 7.3). (Note that other 'geometric' art in the Western Cape may represent entoptics (images 'seen'/experienced while in trance; Lewis-Williams \& Dowson 1988, 1999) or other abstract forms (Maggs \& Sealy 1983) and is not part of the herder tradition.) The typical 'herder art' features are very strongly evident in the Komkans (KK003) example described in Chapter 5 and it is undoubtedly part of the same tradition.

Can we be sure that this art is indeed 'herder art'? Ultimately, no. Space precludes a full investigation and the reader is directed to B. Smith and Ouzman (2004) for further exploration over and above the discussion below. In the arid west of South Africa, the Bushmen and Khoekhoen are the only potential authors. This reinforces the likelihood that the CLB interpretation, where more potential authors existed, is correct. That no 
subsurface archaeology can be ascribed to the Khoekhoen in the CLB is concerning, but the presence of sheep in the hunter-gatherer art (S. Hall \& Smith 2000) and the residual traces of Khoekhoen in local languages (Ehret 1982; Westphal 1963; Eastwood et al. 2010) may confirm a herder presence on the landscape. Mitchell (2004a) also notes the similarities between motifs known from Khoekhoe ethnography (Webley 1997b) and those in the art as further support for Khoekhoe authorship. If it is the work of herders, this art may be the only currently identifiable and unambiguously Khoekhoe material culture in Namaqualand - and perhaps in all of southern Africa. Whether it should be associated with early or late groups remains unknown.

Table 7.3: Comparison between the characteristics of typical 'herder' and hunter-gatherer rock art. Sources: Eastwood 2003; Eastwood \& Smith 2005; S. Hall \& Smith 2000; B. Smith \& Ouzman 2004).

\begin{tabular}{|c|c|c|}
\hline Characteristic & Herder & Hunter-gatherer \\
\hline Sites & $\begin{array}{l}\text { Enclosed, uninhabitable, elevated } \\
\text { shelters with low inner recesses, } \\
\text { often along water courses. However, } \\
\text { many occur in the same shelters as } \\
\text { hunter-gatherer art, sometimes } \\
\text { deliberately on open walls. }\end{array}$ & $\begin{array}{l}\text { Easily habitable shelters or open } \\
\text { walls in various locations. }\end{array}$ \\
\hline Canvas & Smooth and rough surfaces. & Smooth surfaces strongly favoured. \\
\hline Application & $\begin{array}{l}\text { Broad, often thickly applied finger- } \\
\text { painted lines. }\end{array}$ & $\begin{array}{l}\text { Fine, thinly applied brush-painted } \\
\text { lines. }\end{array}$ \\
\hline Colours & $\begin{array}{l}\text { Mostly red, but also white, red, } \\
\text { orange \& black. }\end{array}$ & $\begin{array}{l}\text { Mostly red of varying shades but } \\
\text { also yellow, black \& white. }\end{array}$ \\
\hline Subjects & $\begin{array}{l}\text { Geometric shapes: circles, divided } \\
\text { circles, concentric circles, rayed } \\
\text { shapes, grids, lines, crosses, finger } \\
\text { dots, finger strokes \& handprints } \\
\text { (see Eastwood \& Smith 2005: fig. 2). }\end{array}$ & $\begin{array}{l}\text { Naturalistic images, humans, } \\
\text { animals, therianthropes, trance } \\
\text { scenes \& entoptic phenomena. }\end{array}$ \\
\hline
\end{tabular}

Two issues need highlighting. Although B. Smith and Ouzman (2004) addressed the overlaps between entoptic imagery and geometric art, specifically noting their different application styles and that the latter are not integrated with representational imagery, 
Parkington et al. (2008:76) still found the fuzzy boundary between the two to be problematic and commented that many of the images were "rather basic shapes, common in many demonstrably different contexts". The problem, they surmised, stems from a lack of good terminology to describe non-animal and non-human imagery. The other, perhaps partly related, issue is that of hand prints. In the CLB they are confidently ascribed to the 'herder art' tradition (Eastwood \& Smith 2005; B. Smith \& Ouzman 2004), but noted to be "oddly absent" from the central interior of South Africa (B. Smith \& Ouzman 2004:509). In the Western Cape hand prints are common - unlike 'herder art' and sometimes include the nested-U shapes (Manhire 1998; Parkington et al. 2008) admitted to be entoptic by B. Smith and Ouzman (2004). Lewis-Williams and Dowson (1989) associate hand prints with San shamans, but Manhire (1998), through length measurements, considers them far more likely to have been made by young people, perhaps during initiation rites. Although Manhire (1998) considers all Western Cape hand prints to post-date the introduction of domestic stock, he considers plain prints to be more likely those of hunter-gatherers and decorated prints, which are absent from the mountains, to be those of herders. He notes the world-wide distribution of hand prints which shows that they could easily have been made independently by both herders and hunter-gatherers in South Africa. Two factors support differing interpretations of hand prints in the two regions: (1) most CLB examples are in white or yellow (Eastwood \& Smith 2005), while the vast majority of Western Cape examples are in red, and (2) decorated prints are entirely absent from the CLB (B. Smith, pers. comm. 2012).

'Herder art' occurs along water courses in the interior of South Africa and B. Smith and Ouzman (2004) see it continuing seamlessly westwards in the many pecked geometric engravings at sites like Driekopseiland. Engraved geometrics, too, are strongly focused on river valleys and $\mathrm{D}$. Morris (1988) recognises differences in the content of fine line and pecked engravings: fine lines lack 'sun-bursts', have far fewer curvilinear motifs, and are generally much smaller. Although he did not understand the geometrics in the same 
way they are understood today, Willcox (1963) did note the significance of rayed circular motifs ('sun-bursts') which, he said, occurred at all pecked geometric engraving sites. Although this distinction may offer support for the 'herder art' theory, that pecked engravings have diverse subject matter - including domestic animals - may also be problematic (D. Morris 1988; Wallis 2004). That very typical 'herder art' occurs well away from water courses in western Bushmanland (Orton \& Webley 2012b; Rudner \& Rudner 1968; Webley 1991) shows that the artists also camped alongside pans far away from rivers.

Pecked engravings in southern Namibia (Rudner \& Rudner 1959) and at Twyfelfontein in the north (Viereck \& Rudner 1957) contain motifs clearly reminiscent of the CLB 'herder art', while Willcox (1963; see also Teixeira 1952) juxtaposes rayed circular engravings from south-western Angola with examples from Driekopseiland showing the unquestionably 'herder' character of both. However, another style of art from northern Namibia is tentatively linked to herders by Lenssen-Erz \& Vogelsang (2005: fig. 4 \& 5) but seems, from the illustrated examples, quite different. Nevertheless, B. Smith (2006) sees the maximum northwards extent of 'herder art' as being southern Angola/western Zambia. The distribution is thus widespread, but from Cooke et al.'s (1959) illustrations of geometric art from Zimbabwe and Zambia it is clear that, although the style seems similar, there are differences in subject matter.

Moving south, rock art is rare in Namaqualand (Figure 7.7) but includes both representational and geometric motifs in a variety of styles, some of which clearly resemble 'herder art'. Aside from KK003 reported above, known painted sites are as follows: 


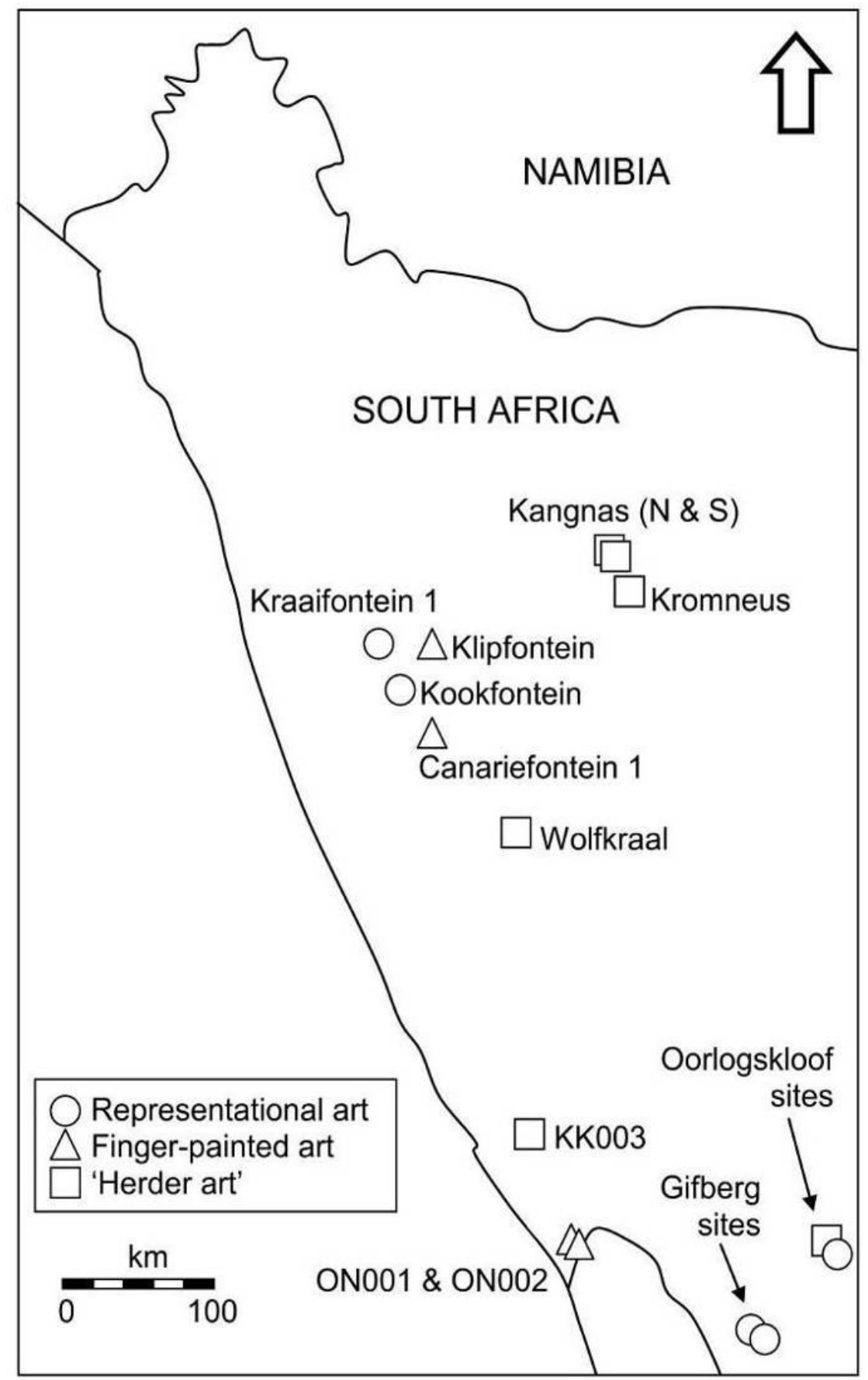

Figure 7.7: Map showing the distribution of known rock art sites in Namaqualand. Typical huntergatherer art, 'herder art' and other finger-painted geometrics are distinguished. Sites known to the author in the sandstone mountains fringing Namaqualand to the southeast are also indicated.

- Kraaifontein 1 has four red elephants painted on a granite boulder (D. Morris \& Webley 2004);

- Kookfontein 6 has poorly preserved red paintings likely including human figures in a large granite cave (D. Morris \& Webley 2004); 
- Wolfkraal ${ }^{26}$ contains seven dark red geometric motifs in a granite rock shelter (Figure 7.8; personal observation);

- Canariesfontein 1 contains white crosses painted in an obscure corner of a granite cave with a sloping floor and located in a river valley (D. Morris \& Webley 2004);

- Klipfontein contains crude white finger-painted crosses and animals in a granite rock shelter (Rudner \& Rudner 1968);

- ON001, on the banks of the Olifants River, is a large sandstone cave with its deposit destroyed. Its ceiling contains a myriad of finger dots and smears along with a few circular images (Figures 7.9 to 7.11 ; personal observation); and

- ON002, just $200 \mathrm{~m}$ north of ON001, is a small sandstone overhang containing a few finger dots (personal observation).

Much rock art occurs in the Western Cape but few sites can be ascribed to the herder tradition. In the Sandveld, near Elands Bay, Manhire (1981) found boldly finger-painted geometric images that included some of the motifs described by Eastwood and Smith (2005) but excluded rayed motifs. Certain others were very rare. These might be 'herder' paintings. They are by far in the minority and, although certainly not typical of CLB 'herder art', Van Rijssen $(1984,1994)$ did consider this body of art to have been produced by herders. B. Smith (2006:93) explains the Western and Northern Cape finger-painted art as a fusion of San and Khoekhoen art that resulted from "a twothousand year history of interaction", but he fails to reveal why this fusion should not have occurred elsewhere and the reasoning thus seems weak.

${ }^{26}$ Rudner and Rudner (1968) called the site Twee Rivieren after the nearby village but Webley (1984) found it referred to as Wolfkraal by local herders. 
The distribution of domestic species in rock art has been addressed in some detail by Manhire et al. (1986), who found them to be widespread but generally rare in comparison to other subjects. Comparison of their distribution maps reveals interesting inconsistencies, particularly in the Western Cape. There, sheep paintings are frequently encountered in the Cederberg but, with one exception (Steenbokfontein Cave; Jerardino \& Yates 1996), are absent from the coastal Sandveld, while cattle fail to appear anywhere in either area. Fine-line painting disappeared from the Western Cape within the last 2000 years but whether this occurred during the first few centuries AD between the introductions of sheep and cattle is unknown. Both species occur in the Drakensberg art which may have meant that cattle were accorded greater significance there.

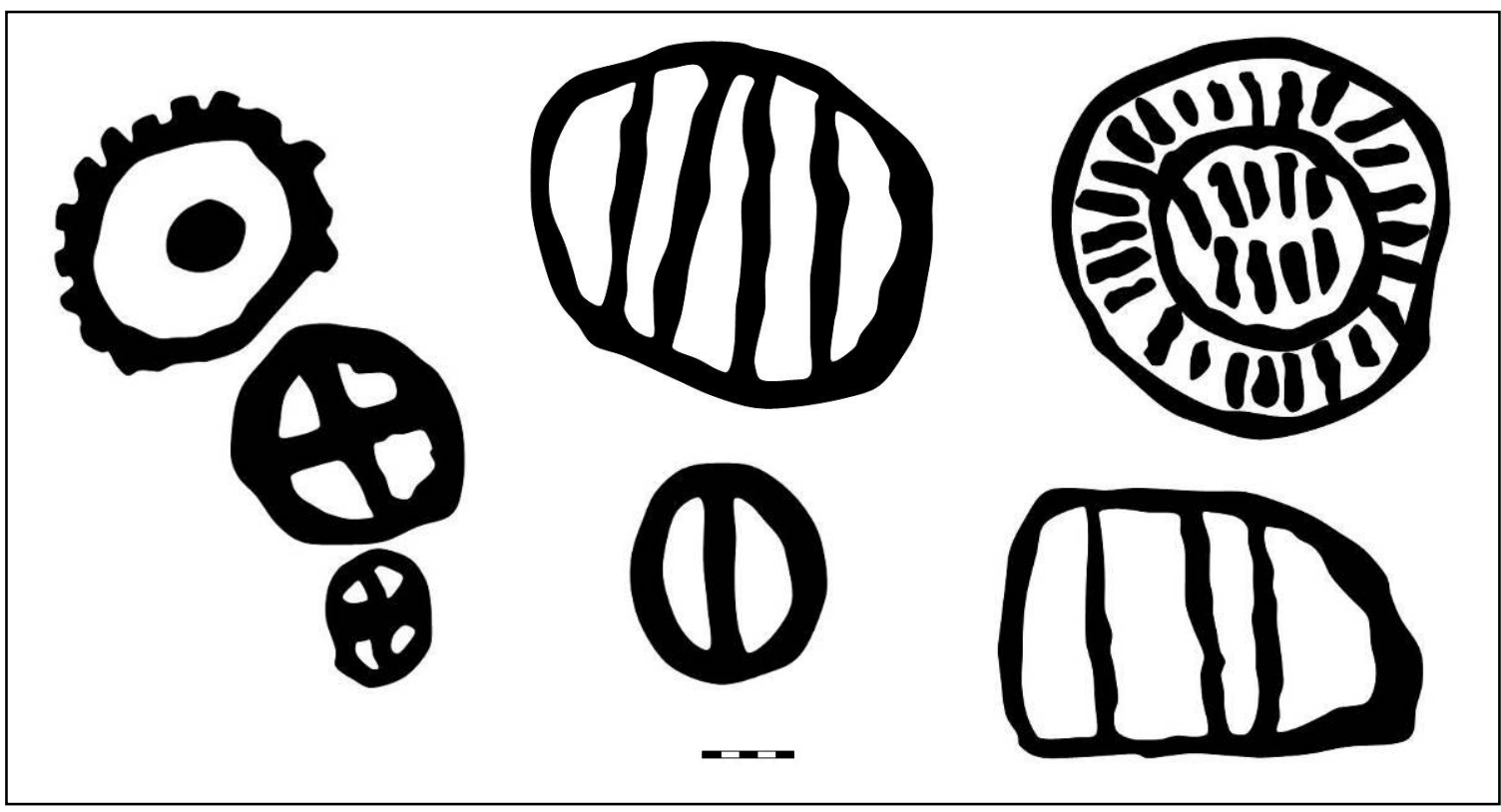

Figure 7.8: Dark red geometric motifs from Wolfkraal. The left three are shown in true association. Scale bar in $10 \mathrm{~mm}$ intervals. Note that the rock surface is exfoliating and the original images may have differed slightly.

That clear occurrences of 'herder art' occur in the arid west shows that the tradition does extend to this area. Its apparent rarity, however, may be ascribed to the immensity of Namaqualand, the sparsity of research therein, and the generally concealed nature of 
the paintings. It is absolutely impossible, given present knowledge, to associate "herder art' with the makers of either Group 2 or Group 3.

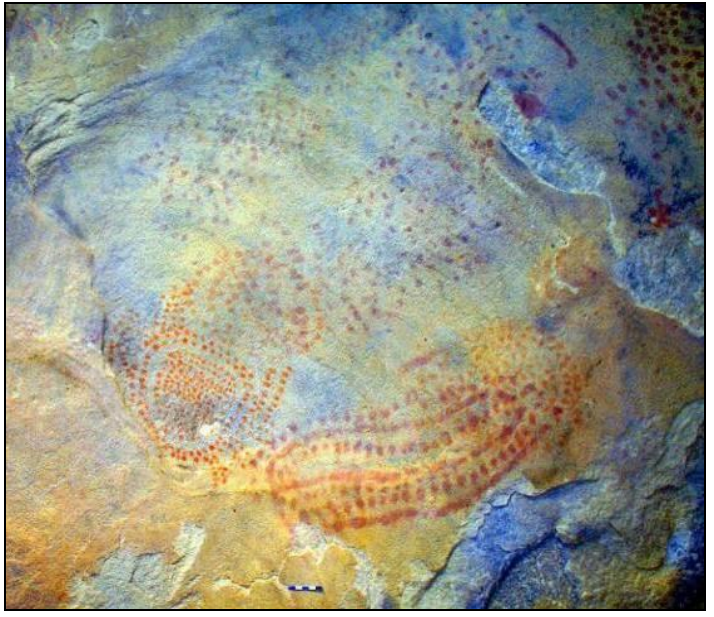

Figure 7.9: Finger-painted rock art at ON001. Colour saturation and contrast adjusted to emphasize the art. Scale in $10 \mathrm{~mm}$ intervals.

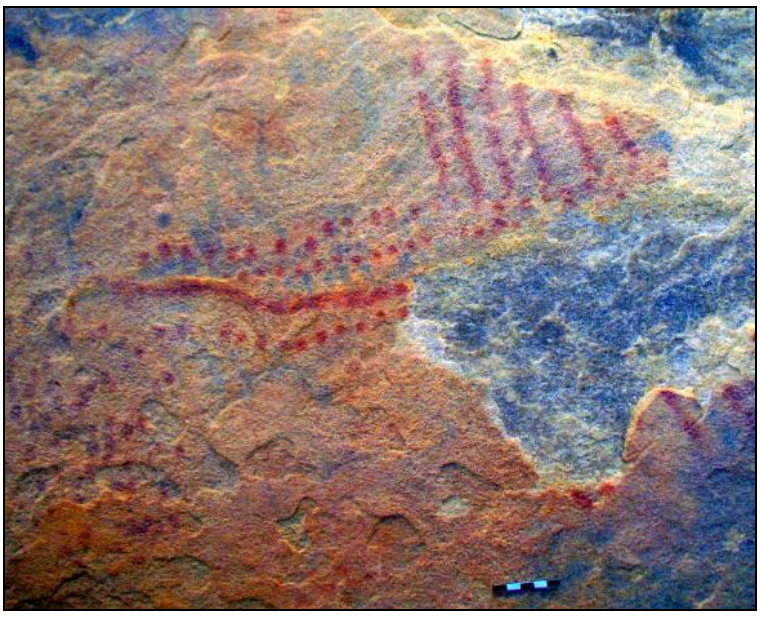

Figure 7.10: Finger-painted rock art at ON001. Colour saturation and contrast adjusted to emphasize the art. Scale in $10 \mathrm{~mm}$ intervals.

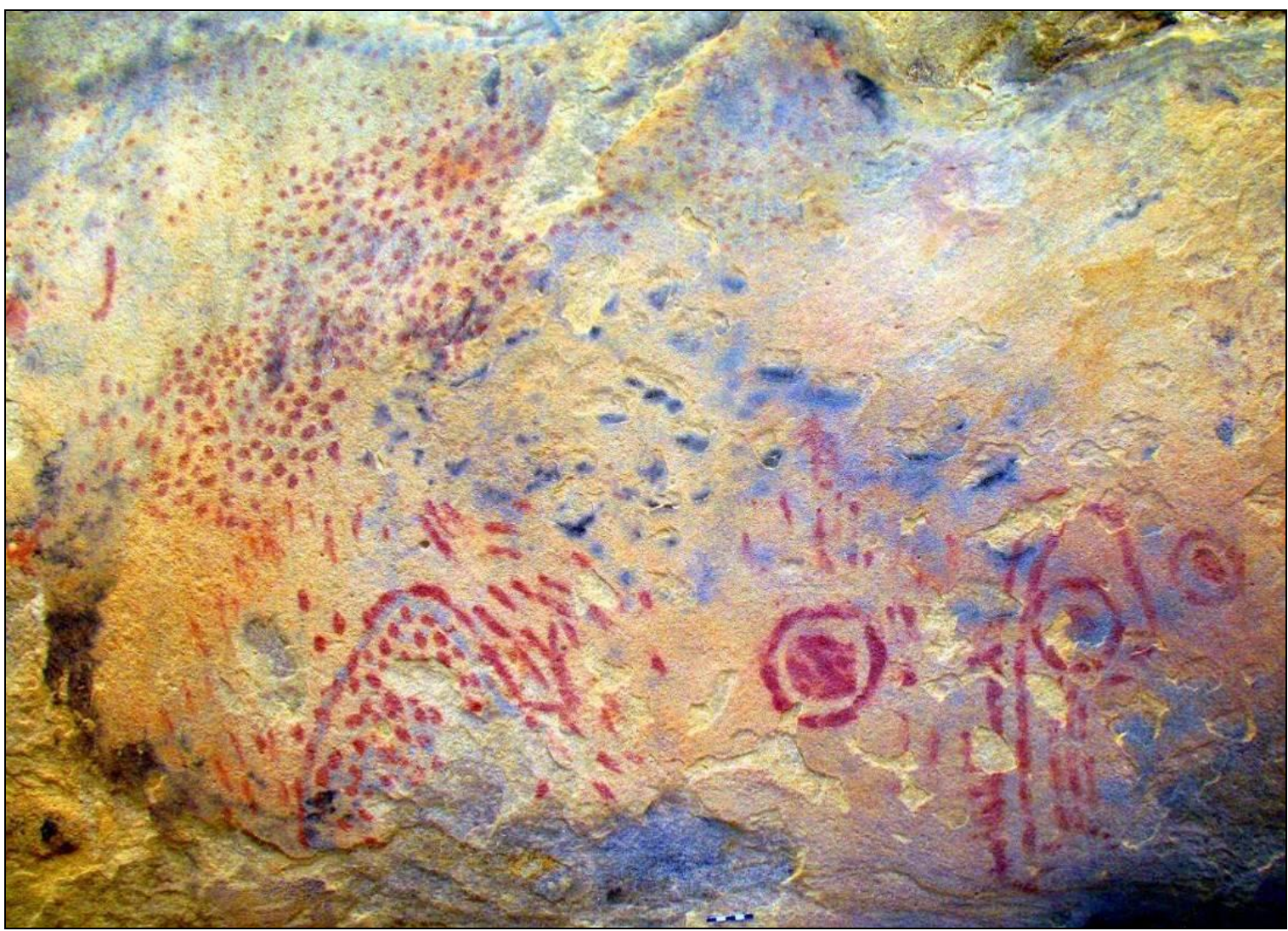

Figure 7.11: Finger-painted rock art at ON001. Colour saturation and contrast adjusted to emphasize the art. Scale in $10 \mathrm{~mm}$ intervals. 


\subsection{The southward spread of pastoralism: what, where, when and how?}

This topic has been explored extensively over the years but, as Chapter 2 shows, few significant questions have been answered. Here I review and discuss the key debates in light of the Namaqualand data presented above.

\subsubsection{Archaeological signatures}

The identification by A. Smith et al. (1991) of distinct archaeological signatures that they ascribed to hunter-gatherers and herders marked a watershed moment in southern African archaeological research. However, the validity of their ascriptions was soon questioned (Schrire 1992). In a later study, Sadr et al. (2003) considered the two archaeological signatures to represent mobile herder-foragers focused on inland resources and more sedentary herder-foragers focused on coastal resources. Like Schrire, they too questioned the degree of overlap between the two signatures. Table 2.2 listed Western Cape sites falling into the two groups but most sites are hard to classify, seemingly reinforcing the difficulty of keeping these signatures clearly separate.

For various reasons, as contemplated in Tables 7.1 and 7.2, these signatures are poorly reflected in Namaqualand and several factors argue for a local reinterpretation:

- The presence of three, rather than two, distinct lithic industries;

- The sudden appearance of Group 3 assemblages, which are linked to Group 2 and thus herding - through tortoise burials (and perhaps collected ornamental shells) and by virtue of their date of first appearance;

- The fact that ostrich eggshell bead size does not behave as predicted in the A. Smith et al. (1991) model; and 
- The fact that the Namaqualand pottery sequence does not follow that recorded further south and/or in the Karoo.

The most obvious indicator of the presence of herding on any archaeological landscape is surely the bones of domesticates. Sadr (2003) noted a disjunction whereby sites either have less than $10 \%$ or more than $30 \%$ domesticates among their mammal bones. He suggested that the former reflect 'hunters-with-sheep' (or -stock), and the latter herders. Following Sadr then, are there no herder sites in coastal Namaqualand? (HKB2007/007 has the most domesticates $-24.4 \%$ - among its identifiable bones.) A. Smith (2008b, 2009) would argue that they have to be there as a source of domestic animals for the hunters. I do not believe that herders were absent from the Namaqualand Sandveld and have suggested above, based primarily on lithics and pottery, that they are represented archaeologically by the Group 2 assemblages. From the Richtersveld, JKB A and JKB B offer support with their high frequencies of domestic bones $(41.8 \%$ and $57.7 \%$ respectively; Brink \& Webley 1996: tables 1 \& 2). Marshall and Hildebrand (2002:119) commented that "the earliest [southern African] pastoralists may have been so mobile and patchily distributed as to be archaeologically invisible in some places". In coastal Namaqualand herders may well be represented by some of the small shell scatters with minimal stone that are so commonly encountered (Orton 2007d) but which, sadly, remain undated. Only a large-scale radiocarbon dating program would be able to reveal when such sites were deposited. While herding may be invisible, the herders certainly are not they may just at times be unrecognisable (Arthur 2008). Sufficient evidence exists to ascribe Group 1 to hunter-gatherers, but what of Group 3?

This peculiar industry occurs throughout the Namaqualand Sandveld and appears to extend along the Western Cape coast as well. I suggested above that Group 3 assemblages might represent Proto-Khoekhoe-speaking 'hunters-with-sheep. This, of course, cannot be proved. That Group 3 appears around 2000 years ago does, however, 
argue strongly that it is linked to the introduction of sheep and pottery to southern Africa at that time. Either way, we potentially see three 'artefact-producing populations' on the landscape which is clearly different to the situation on the Vredenburg Peninsula to the south (A. Smith et al. 1991) and in Bushmanland to the east (Beaumont et al. 1995). Parsons (2006) tentatively noted the possibility that overlapping characteristics between the two Bushmanland signatures might relate to the one (Doornfontein) arising from the other (Swartkop) as hunter-gatherers who had adopted stock through diffusion modified their toolkits accordingly. That Group 2 in Namaqualand is so different to Groups 1 and 3 precludes a similar interpretation for its origin, but the presence of scrapers in the earlier Group 3 assemblages could support its development from Group 1. As noted before (point 4, Section 7.4), however, the abandonment of CCS would be hard to explain. More likely is that Group 3 was made by newcomers who had existing technology but had to find new sources of stone for its manufacture and settled on clear quartz. They chose clear quartz for its fine flaking properties and the fact that it was far more suited to their technology than milky quartz. One assumes CCS would have been even better, but, for whatever reason, they were content to use the best of what was readily available locally.

Ostrich eggshell beads were seen by A. Smith (2006a; A. Smith et al. 1991) as a major cultural marker distinguishing hunter-gatherers (small beads) from herders (large beads). As elsewhere (Yates et al. 1994), that the mean size of beads from all Namaqualand sites predating AD 1 is consistently small does suggest a common cultural affinity. That these people were hunter-gatherers is beyond doubt, so the implication is that the large beads were those of herders. Yates et al. (1994) saw an increase in mean bead size in the early centuries AD, a situation likely reflected in Namaqualand by Assemblage 19 (c. 196 BC-AD 325; UGAMS-6608), the only one with beads $>6 \mathrm{~mm}$ until the end of the first millennium AD. Yates et al. (1994) also saw a further size increase in coastal sites compared to inland sites between c. AD 650 and AD 1000. This latter shift may well be manifested in the present Namaqualand sample c. AD 1000-1200, whereafter beads 
$>6 \mathrm{~mm}$ are consistently present. The lack of clarity during the first millennium AD in Namaqualand is likely a direct result of the limited number of assemblages dating to that period but the overall pattern is broadly consistent with that seen further south. Certain details, however, differ.

A. Smith et al. (1991) postulated a one-way exchange of material culture, exemplified by beads, from herders to hunter-gatherers and that this exchange became more prevalent from about AD 1500. The evidence from Namaqualand is contradictory: herder (Group 2) lithics are sometimes accompanied by small-medium beads, and large beads already occurred with a hunter-gatherer (Group 1) lithic assemblage c. AD 960-1282 (Assemblage 25; UGAMS-9707 \& OxA-22934). Insufficient evidence exists to merit much discussion of the possibility of material culture being shared both ways, but this surely must have been very likely. The identification of one-way exchange or acceptance of material culture may be spurious, since, with the earliest herders having been huntergatherers anyway (Boonzaier et al. 1996:25), they would have already possessed hunter-gatherer material culture and had little or nothing new to acquire. Although enigmatic, A. Smith and Pheiffer's (1993:32) translation of a seventeenth century Dutch text implies that the Khoekhoen wore both small and large beads. This suggests either that they made and used both sizes themselves or that material culture was indeed exchanged both ways

Changing aperture size was also seen as a cultural trait by Yates et al. (1994), since they saw the apertures of both small and large beads increasing from about AD 650-1000. This does not appear to occur in Namaqualand where large beads consistently have larger apertures and small beads smaller apertures. The Namaqualand sample more likely reflects natural wear and tear with the heavier (larger and stronger) beads wearing more and breaking later in life. That aperture sizes of finished beads are consistently larger than those of unfinished beads supports this (Orton 2008d: tables 3 \& 4). 
The degree to which ethnicity drove ostrich eggshell bead size change is unclear, but bead size does generally increase with time. Correspondingly, large beads in Namaqualand do not appear to denote a herder occupation - some Group 2 sites have a clear small-to-medium bead focus. Overall, the increasing size of beads could be seen as an indication of general diversification of material culture within the last 2000 years, perhaps through ethnic interaction. A. Smith et al.'s (1991) addition of large (herder) beads to the small hunter-gatherer beads is not apparent in Namaqualand, since bead assemblages there are inevitably dominated by either small-medium beads or large-very large ones, irrespective of lithic group.

Pottery is unfortunately rather uninformative due to the fact that the collections are small and generally well fragmented. Pottery was widely available and certainly used by both herders and hunter-gatherers. Decoration is not present in Group 1 assemblages but, with such a small sample, one cannot consider that a defining feature of regional huntergatherer pottery, or, rather, pottery used (but not necessarily made) by them. The only clear pattern is a temporal one: first millennium $A D$ assemblages contain both incised and impressed decoration, while only the latter occur during the following millennium.

\subsubsection{Routes and timing of introduction}

The route(s) of entry of sheep and pottery into southernmost Africa has long been debated and, while evidence for a central route remains poor, the western route finds increasing support. Until recently, the lack of early domesticates in the Karoo and the presence of early sheep and pottery at Spoeg River Cave were the main pointers towards the west coast route (Sadr 1998). The dating of both has been well established at around 2000 years ago and is reinforced by a further early pottery date from Namaqualand (196 BC-AD 325 at SK2005/084; UGAMS-6608) and the 388-180 BC (Beta-270164) sheep at Leopard Cave, Namibia (Pleurdeau et al. 2012). Note, however, 
that very early pottery is present in the interior of South Africa (Sadr \& Sampson 2006). A new early cattle date may now rule out their introduction from the east via Iron Age farmers (Orton et al. in press). Cattle too, then, must have moved south via Namaqualand. Overall, pottery and sheep seem to have been introduced to the southwestern Cape via the west coast within the first two centuries $A D$ with cattle following a few hundred years later, but the limits of radiocarbon dating do not allow a tighter chronology. How they reached northern Namaqualand remains unclear, but a route along the Orange River is perhaps most likely with Namibian evidence possibly relating to west- and southwards diffusion via the Caprivi Strip.

When the Khoekhoen arrived in Namaqualand is still debateable, but domesticates and pottery, at least, were certainly present c. 2000 years ago. A. Smith (2006a) vigorously supports a herder arrival some 2000 years ago, but if, following Jacobson (1987), the Khoekhoen were represented by ostrich eggshell beads $>7.5 \mathrm{~mm}$ in diameter, then they would have only arrived in Namaqualand c. AD 1000. This date coincides with Sadr's (2003) suggestion of an approximately AD 900-1200 arrival but the event may actually have been earlier in Namaqualand. I have ascribed Group 2 technology to Khoekhoen herders and thus implied that they first appeared in Namaqualand around AD 500. Sadly Namaqualand pottery contributes little here, since the only temporal change one sees in decoration - lacks resolution; it occurs sometime between AD 800 and AD 1300. Although lugs post-date $A D 700$, we cannot be certain that earlier lugs will not still be found.

Occasional rock paintings attributable to herders occur in Bushmanland and Namaqualand, well removed from the only other area - in north-eastern South Africa where stylistically similar art has been documented (B. Smith \& Ouzman 2004). Other sites conforming less well may nevertheless be similarly ascribable. Should more such paintings be located in Namaqualand they would no doubt add additional weight to the 
west coast route, especially given Parkington et al.'s (2008:76) doubt over whether the "superficially similar images across the subcontinent are really the concrete trace of a swathe of herding people moving inexorably from northeast to southwest". The paintings in the Limpopo region would then more likely have been produced by an independent branch of migrating herders. Dating of rock art is debilitatingly difficult, but B. Smith and Ouzman (2004) have assigned the Limpopo herder art an early first millennium AD age, since Iron Age farmer occupation was minimal then and there would not have been strong competition for grazing resources. This seems logical, but does not necessarily imply that the migration continued all the way to the south-western Cape at that time. Furthermore, the Limpopo area may have been an end-point of migration rather than being part of an onward route.

\subsubsection{The nature of introduction: migration or diffusion?}

This is the most debated aspect of early pastoralism in South Africa and it is likely to remain difficult to clarify, especially since it is hampered by the lack of any independent measure of the speed with which innovations can spread through either mechanism (Mitchell 2002b). Parsons (2006) reviewed the introduction of agriculture and stockkeeping to various parts of the world reaching the following conclusions:

Migration and indigenous adoption (diffusion) are the two principal mechanisms cited for the introductions;

Most researchers agree that "the main evidence in support of migration is change (and homogeneity) in material culture, whilst continuity (and diversity) is often taken to indicate indigenous adoption"; and

$>$ "The adoption of selected features of a farming economy without making an immediate and complete transition to the lifestyle as a whole is often ascribed to the effectiveness of existing subsistence strategies" (Parsons 2006:24-25). 
A. Smith (2006a:68) notes that the migration hypothesis is based on two assumptions: "that only a long-term relationship with food producers can pass on the skills of animal husbandry, and that the Khoe-speakers living between the Zambesi (sic) and the Caprivi Strip had just such a relationship." Here, "assumption is built on assumption" (Hodder 1984:27) and, although Smith brings in other observations, largely from recent ethnography, it would appear that a great leap of faith has been made (Hodder 1984:28). A. Smith (2006a) argues passionately that local hunter-gatherers could not have taken up herding due to the ideological difficulties of doing so. However, that he assumes that this in fact did happen in northern Botswana surely allows for it to happen again? He suggests the need for several generations of contact but this cannot be proved, particularly given that modern radiocarbon dates c. 2000 BP with an error of just 25 years have two sigma calibrated ranges of about 160 years, or as many as eight generations. Also, with the landscape learning required by new groups (Meltzer 2003; Rockman 2003), interaction would have been a key factor. As a result, diffusion among a pre-existing knowledgeable population or migration of a Proto-Khoekhoe-speaking hunter-gatherer people with stock (as I suggest) may have more easily occurred around 2000 years ago than a full Khoekhoe migration. A. Smith (2008b:57) admits that the "archaeological evidence for the passage of early herders from the Kalahari to the Cape is weak" but yet he assumes the presence of sheep and pottery to imply the presence of herders. In the light of similar economic changes being ascribed to a combination of migration and diffusion in both East Africa (Marshall 1986, 2000) and Europe (Bogucki 2000; Price 2000), his 'evidence' is surely similarly weak. In East Africa the diffusion of herding through indigenous groups was seen as a way of increasing the predictability of food supply in marginal environments, rather than the yield (Marshall \& Hildebrand 2002), and this was likely forced by a combination of social, cultural, economic and environmental pressures (Marshall 1986). An uptake in such circumstances seems likely 
in northern Botswana and theoretically possible among the Bushmen in Namaqualand but, again, neither can be proved.

Given the importance of exchange in hunter-gatherer culture (Mitchell 2002a), the adoption of stock and pottery may have been beneficial to hunter-gatherer groups (both originally in northern Botswana and later in other areas) by providing readily exchangeable animals. Such exchange could also have facilitated a rapid spread of stock as people were only too pleased to pass on items/ideas that would benefit their new and/or existing trading partners as well. Also, without knowing just how big any one group's site catchment area is, we cannot tell how quickly items and ideas were passed on, but the potential for rapid movement via a combination of migration and diffusion surely exists when groups may travel some distance within a calendar year.

With the inherent unreliability of ethnographic projection (see Section 2.4), the assumptions required when arguing from theory (Sadr 1998), and the limited resolution of radiocarbon dating, we are left with little option but to return to hard archaeological data. In arguing for diffusion, that is exactly what Sadr (1998) did. He showed that the earliest pottery from the northern and southern parts of the subcontinent shared functional and technological features but yet differed stylistically. He ascribed this regional diversity in pottery style to an independent adoption of pot-making in different areas. This implies diffusion of the knowledge of pottery, because if the Khoekhoen had migrated through the subcontinent - particularly as fast as A. Smith (2006a, 2008b) suggested - then they would have left a trail of pots decorated in their favoured style. The Namaqualand data contribute a further stylistic province in that the sequence there appears different to those recorded elsewhere (see Sadr 1998; Sadr \& Sampson 1999; Sadr \& Smith 1991). In common with other areas however, the earliest pottery is also the thinnest. The limited Namaqualand data unfortunately do not allow further comment on the functional features of pottery - such as lugs, spouts and changing pot shapes - that 
Sadr (1998) also considered meaningful. While A. Smith (2006a:69) considers problematic the existence of "simple designs of similar nature" at all three sites discussed by Sadr (1998), I contend that such designs would, by their very nature, be very likely to occur throughout the region and that only more complex designs would be regionally specific. Indeed, in Namaqualand most designs appear simple, yet the timing of their appearance is very different to elsewhere.

Ostrich eggshell beads are unfortunately enigmatic, seemingly relating more to time than ethnicity. The stone artefact assemblages, however, are more helpful, and Parsons' (2006) second point above is strongly relevant. Although assemblage continuity has been widely documented in southern Africa (see Table 2.4), the introduction of Group 3 and particularly the later Group 2 assemblages to Namaqualand and their subsequent homogeneity seem to argue for migration of the makers of both. Diffusion of pottery and stock probably occurred in tandem as a result of social contact during and after both migration phases. Two factors would have facilitated diffusion: (1) the first herders to enter Namaqualand were also hunter-gatherers and would have been able to interact relatively easily with other hunter-gatherers who likely had a similar ideology to themselves, and (2) the newcomers would have desired positive interaction as they sought to learn the new landscape (Rockman \& Steele 2003) from those already familiar with it.

The evidence of rock art is probably not yet comprehensive enough to be informative here. Too much doubt exists (Parkington et al. 2008) and too little is known of Namaqualand's rock art.

Owing to broad similarities with the introduction of herding to East Africa, some comparison is merited. Bower (1991) noted that, as in Namaqualand, cultural connections to the north were lacking in both lithic and pottery assemblages of the early 
Pastoral Neolithic. Cultural change was archaeologically invisible; although it must have been introduced, along with livestock. He suggests a model, with which Marshall (2000) agrees, whereby "the first food-producing societies of East Africa may have been indigenous foragers who acquired domestic livestock from small groups of herders escaping dessication in areas to the north" (Bower 1991:74). Later, new economic practices were introduced and discontinuities in lithic and pottery assemblages appear; these, he argued, were more consistent with the entry of more substantial herding groups. This 'trickle-and-splash' model as proposed by Bower (1991) fits the Namaqualand data in many respects with the trickle being represented by the makers of Group 3 assemblages and the splash by those of Group 2.

Robbins et al. (1998) showed that Lake Ngami in western Botswana dried significantly during the first millennium $\mathrm{BC}$, and it is towards the end of that millennium that herders must have begun leaving the area for the earliest sheep bones to have been deposited at Spoeg River Cave c. 350 BC-AD 115 (OxA-3862; Sealy \& Yates 1994). This and the very early sheep at Leopard Cave in central Namibia (Pleardeau et al. 2012) argue for an even earlier introduction to Botswana than that shown by Robbins et al. (2005). While Lake Ngami appears to have subsequently refilled, a further dessication phase occurred in the second half of the first millennium AD (Robbins et al. 2008). Depending on the exact timing of the start of this phase, it could have provided the impetus for the main migration of full-time herders out of the area. As a result, these herders would have appeared on the South African landscape from the mid-first millennium AD, perhaps represented by the Group 2 assemblages. Unfortunately too little is known of the earliest herding in the northern parts of the subcontinent, but the association between Bambata pottery and domesticates at Bambata Cave and a possible date of 368 BC-AD 80 (SR75; Walker 1983) for Bambata ware at Tshangula Cave are very suggestive of an early herding phase there. In the substantial body of literature on the colonisation of unfamiliar landscapes (e.g. Gamble 1994; M. Smith 2005; Rockman \& Steele 2003) the need for a 
pioneer/dispersal phase prior to colonisation is commonly noted. A 'trickle' of ProtoKhoekhoe-speaking hunter-gatherers with stock could well have fulfilled this role prior to the arrival of the fully fledged Khoekhoe herder society that must have developed during the early first millennium $A D$, perhaps in Botswana.

\subsubsection{The 'pastoralist package': fact or fiction?}

Whether sheep and pottery arrived in South Africa together has been much debated, but Mitchell (2002b) points out that their variable first occurrence in sites across the subcontinent argues against this, while Sadr and Sampson (2006) propose an independent invention of pottery by hunter-gatherers in the central interior. Nevertheless, within the practical limits of radiocarbon dating, the Namaqualand data overwhelmingly support an approximately simultaneous arrival there about 2000 years ago, but there too we do not see them in the same sites at the same times. This is no doubt due to the very light imprint that the earliest herders would have had on the landscape. Cattle probably did arrive a little later but at least by AD 421-559, as testified by the KN2005/041 evidence (OxA-22933; Orton et al. in press). The dated cow from Toteng 1 in Botswana, however, remains the oldest southern African example at 162 BC-75 AD (Beta-190488; Robbins et al. 2005). Goats and dogs are seldom found in archaeological sites and the oldest securely dated examples of each are many centuries younger than pottery, sheep and cattle - they may have arrived far later.

Whether something akin to the historically observed Khoekhoen 'pastoralist package' appeared in southernmost Africa 2000 years ago now seems highly unlikely, with the earliest herding probably not carried out by 'pastoralists' in the strict sense of the word, but by hunter-gatherers with stock. The possibility that the Khoekhoen arrived at a later date, perhaps around AD 500, with all four animals (and perhaps some new features to their pottery) certainly exists, although it is impossible to make any further 
pronouncements on this from the currently available information. We have no way of proving exactly when they did first arrive and it could be that we have simply not yet found the sites we need to link the mid-first millennium AD signatures of Namaqualand with the late first millennium $A D$ signatures at Kasteelberg. A time lapse of a few hundred years between the appearance of the Khoekhoen in Namaqualand and on the Vredenburg Peninsula is almost certainly untenable.

\subsubsection{Ecological considerations}

Water, grazing and predators are factors that may have limited pre-colonial herding in Namaqualand. Although disease would have been a constraint to the southward spread of domesticates from East Africa, this factor does not come into play when considering their dissemination within South Africa as the relevant diseases do not occur in the majority of the country (Gifford-Gonzalez 2000).

Although Namaqualand has few natural springs and the rivers seldom flow, water is inevitably available from coastal springs and seeps (Orton et al. in press). Mists are almost daily occurrences along the coastline and sometimes extend all the way to the foot of the Kamiesberg Mountains. These mists and the accompanying dewfalls leave moisture on the plants which is available to both them and grazing animals. That small stock can go without water for up to six months, given reasonable grazing on succulent vegetation (Cornell 1920; Webley 1982), would have allowed significant movement through the Sandveld, so long as the people could carry water for themselves which, we know from their flasks, they did. Cattle cannot obtain sufficient water by grazing, but Cornell (1920) noted that local pack oxen could go for three to four days without drinking. The climatic data summarised above (Section 3.4.3) indicate that just prior to 2000 years ago south-western Africa may have been wetter. Such a wet spell could well have been part of the impetus behind the spread of herding through that area. In the south-western 
Cape, Sadr (2002) has argued that there were two periods of more intense pastoralism; these he correlates with cooler, wetter climatic periods. This kind of detail is not yet possible in Namaqualand, although JKB A and JKB B do coincide with Sadr's earlier period.

The Sandveld was also good for grazing, particularly so before the pressure of fenced commercial stock farms. One Sandveld farmer shared how the plants there are slow growing because of the low rainfall, but due to the deep soil they grow larger and provide good grazing. This contrasts with the Hardeveld where higher rainfall means faster growth but the shallower soils result in smaller plants that support stock for shorter periods. Furthermore, the numerous heuweltjies (ancient termitaria) that occur in some parts of Namaqualand below c. $400 \mathrm{~m}$ elevation have better quality soils and are favoured for grazing by small to medium mammals (Desmet 2007; Palmer et al. 1999). Micromammal evidence from Spoeg River Cave shows that the area was even more favourable around 2000 years ago with greater grass cover (D. Avery 1992).

Modern-day stock farmers generally have access to land in both the summer and winter rainfall zones, Bushmanland and the Sandveld respectively, trucking their stock from one to the other as required. Such seasonal transhumance also occurred during pre-colonial times as testified by historical literature. Webley (2007) describes how the winter months, during which the mountains were too cold, were spent in the warmer Sandveld where streams would occasionally flow. This allowed the vegetation around the mountain water holes to recover for the following summer's occupation. Occasional forays into Bushmanland to take advantage of good grazing resulting from summer thunder showers were also documented and must therefore have been feasible in earlier times.

Focusing on the availability of fodder and water, Skead (1980) summarised historical descriptions of the environment from travel diaries dating from the 1680 s to early 1800 s. 
His description emphasises the fickle nature of the environment. Although mid-summer grazing occurred south of the Olifants River, the Knersvlakte was very arid and had salty rivers. Other rivers, although usually dry, revealed water through digging in their beds; some contained pools at times. The Buffels River seemed most reliable with pasture and either surface or subsurface water reported; some parts were tree-lined. Inland, water was harder to find but a good spring was found near present-day Springbok. Along the Orange River abundant trees and grass occurred, while southern Namibia had wide grassy plains.

Predators would naturally have been an issue with lions, leopards, hyaenas and jackals the main culprits. The indigenous animal population in pre-colonial times may have been quite small (Hoffman \& Rhode 2007), which in turn would have precluded significant numbers of predators. Small stock are naturally more vulnerable to predation, but it would have likely been easier to guard against this in the flat and more open Sandveld than in the mountains. (Of course dogs would aid in this, but how early they were present in Khoekhoe society remains unknown.) Together, all these factors suggest that the Sandveld, and particularly the immediate coastal strip, would have acted as a good conduit for domesticates, with marine resources providing ready food for their keepers.

\subsection{The introduction of herding: a summary from Namaqualand}

For many years a Khoekhoen migration into southern Africa was accepted as the mechanism by which pottery and sheep were introduced to south-western Cape archaeological sites about 2000 years ago. Sadr $(1998,2003)$ countered that a Khoekhoen migration only occurred around the start of the second millennium AD based on changes in the archaeology, with diffusion of pottery and stock into the region during 
the preceding millennium. Interestingly, Sealy (2010) concluded that cattle-based pastoralism only began around the same time.

In a study of pastoralism in Namaqualand completed shortly before the commencement of the present research, Webley (2007:637) concluded that "the archaeology does not support a migration of a separate pastoralist group into the area and we must assume that livestock and pottery were introduced to the resident hunter-gatherer populations, perhaps by Khoe-speaking hunter-gatherers with stock." The expanded Namaqualand sequence as presented in the foregoing chapters supports this. The new arrivals were familiar with retouched artefacts, obtained the vast majority of their food by hunting and gathering, and kept limited numbers of domestic stock as a 'cash resource' for food in times of need or for fulfilling $h x a r o$ requirements, both with their existing trading partners and with new ones who they met. They probably spoke Proto-Khoekhoe (cf. Güldemann 2008) and made Group 3 assemblages. The assemblages were focused on locally available clear quartz which was well suited to the manufacture of tiny backed artefacts. The function of these tools remains unknown for the time being and why these people would have focused so heavily on them is puzzling given that 1000 years earlier similar artefacts, usually made in CCS, had been dropped from the local stone artefact assemblages.

Owing to small sample size, early pottery style in the Sandveld remains unknown but the pots may have been undecorated. The ostrich eggshell bead signature is also unfortunately compromised by small sample size. Between the five Group 3 assemblages that fall before the mid-first millennium AD, when Group 2 was introduced, there are a total of fifteen beads. Five are medium in size and all the rest small supporting the idea that these earliest hunter-gatherers with stock shared bead size with those already living in Namaqualand. Although other aspects of material culture were shared between Groups 2 and 3, this only occurred later with tortoise burials and 
collected ornamental shells only known to occur from c. AD 800 and AD 1300 respectively.

The spread of herding was likely boosted at this time through exchange and diffusion amongst locals who knew the environment well and recognised the advantage of 'storing' live meat. The incoming hunter-gatherers with stock would have relied on local knowledge to learn the landscape and this, in turn, would have facilitated their relatively rapid spread through western South Africa. Given this, it seems odd that CCS would have been shunned, since it should have continued to be available to the locals through existing exchange networks. However, they may have deliberately chosen to focus on the clear quartz as a means of maintaining social identity.

The set of changes evident in Namaqualand through the middle and later centuries of the first millennium $A D$, and specifically including the advent of Group 2 technology around AD 500, is more likely to reflect the migration and subsequent establishment of fullyfledged herders in the area - these are presumably the ancestors of the Khoekhoe herders encountered at the Cape during historical times. The similar pattern of introduction proposed for East Africa by Bower (1991) fits the Namaqualand data well. The migration is, of course, earlier than the timing proposed by Sadr (1998), but further research may yet fill some temporal gaps, either within Namaqualand or to the south. While Sealy's (2010) isotopic data support the emergence of a cattle-based economy around 1000 years ago, Sadr (1998: footnote 5) believes specialised pastoralism as observed in historical times may have only developed once the possibilities of trade with European explorers became known. With the Namaqualand data suggesting a full Khoekhoe incursion around AD 500, it would be interesting to see Sealy's (2010) first millennium $A D$ isotopic data presented in finer time slices - they may yet reveal subtler changes than those presently realised. 
The above model seems a best-fit for the Namaqualand data. The traditional view of the pre-colonial landscape being shared only by Bushman hunter-gatherers and Khoekhoe herders cannot easily be entertained when we find three so strongly distinctive assemblage types. The model was inspired partly by the linguistic work of Tom Güldemann (2008) who proposed a southward expansion of an early Khoe (ProtoKhoekhoe-speaking) population and finds the linguistic homogeneity of the Khoekhoe language to be irreconcilable with a 2000 year antiquity in South Africa.

Every model has its challenges and those identified here include:

- Why should such specifically focused assemblages as Group 3 be needed by part-time herders when full-time hunter-gatherers and full-time herders have such different stone artefacts?

- Why did the Group 3 signature persist so purely and until so recently alongside hunter-gatherers and full-time herders without being obliterated by the others through nearly two millennia of contact? The likelihood of a third population group (in the loosest possible socio-economic terms) surviving intact alongside the others for so long surely seems slim (cf Schrire 1992:63); and

- How do the combination assemblages fit in? While ethnic interaction must have occurred, it seems unlikely that it would have manifested itself within individual sites in this way.

These short-comings will need further investigation along with a number of other points as discussed in Section 8.2 below. In addition, it will be important to see if a similar model could be found to fit archaeological data from other regions. 


\section{Chapter 8. Conclusions}

\subsection{Discussion: Namaqualand and the Neolithic}

Prior to commencement of this research, the cultural sequence in Namaqualand was unclear. The value of a regional study incorporating a large number of assemblages has been highlighted here through the improved archaeological sequence obtained for the Sandveld (cf Dewar 2008; Webley 2007). Although gaps, both temporal and in knowledge, still remain, the mid- to late Holocene sequence is now far better understood. Sites dating before this time remain rare. They may well lie deeply buried as a result of repeated cycles of dune formation and deflation, but the early Holocene material from Spoeg River Cave certainly betrays at least some presence of people along this coast at that time.

From the fourth millennium BC until about 2000 years ago Bushman hunter-gatherers were the sole occupants of coastal Namaqualand. They produced a diverse array of flaked stone artefacts ascribable to a single cultural entity. They also made small ostrich eggshell beads. With the exception of a shift of emphasis from backed tools to scrapers about 3000 years ago, little else changed; it was a period of general cultural stability. The first millennium $A D$, by contrast, was a time of great cultural and social transformation, due no doubt to the revolution - some might argue Neolithic revolution (Sadr 2003) - that took hold of the region. I return to this topic shortly.

Meanwhile, the present research has made significant contributions to our understanding of the late Holocene archaeological sequence in Namaqualand. The four main points are discussed in turn below. 
Firstly, with numerous additional analysed assemblages, the flaked stone artefact sequence from the Sandveld is now described in far greater detail than before. A key finding is that broadly co-incidental with the introduction of domesticates and pottery to Namaqualand 2000 years ago we see the beginning of a completely new stone artefactmaking tradition. This contrasts strongly with the continuity documented in many other areas at this time. Shortly afterwards, yet another tradition appears on the landscape such that three distinctive flaked stone artefact signatures co-occur during the last 1500 years.

Secondly, a large suite of observations on bead size change that incorporates Dewar's (2008) samples is now available to compliment Webley's (2002) work at Spoeg River Cave. The gradual increase evident in the cave is mirrored on open sites, but the finer details show that the way this increase was effected differs from that suggested to the south. Specifically, evidence for larger beads strongly dominating herder sites and forming an increasingly larger component on hunter-gatherer sites is lacking. Rather, we see a mix of all sizes in different assemblages at different times but with a general mean size increase through time. This suggests widespread sharing of material culture across ethnic boundaries.

The third contribution relates to pottery. Although many pots from coastal Namaqualand were described in isolation by Rudner (1968), we now have some sense of sequence, admittedly, and due to the fragmented nature of the assemblages, based only on decoration. First millennium AD pots had incised lines, sometimes in combination with small impressions, while the second millennium saw only impressions applied to pots. One large and unfortunate temporal gap prevents us knowing when the first style switched to the second, but what we have is sufficient to demonstrate a different sequence to those documented in other regions (e.g. Sadr \& Smith 1991; Sampson et al. 1989). 
Finally, with several new identifications of domesticates we now have a far improved understanding of their spatial distribution across the Sandveld. Though there are still massive spatial gaps on the map, we can postulate that domesticates were widely distributed throughout the region, particularly along its coastline. It should be noted that the spread of dates from the Sandveld is not ideal with most of the early dates coming from rock shelters (Figure 8.1); whether anything should be read into this is moot. No doubt the imprint of early herding on pre-colonial society was very light and it is partly for this reason that, throughout southern Africa, so few early dates for domesticates are on record. In Namaqualand, the majority of open sites with domesticates are dated within the last 600 years and this likely relates simply to the increasing number of animals on the landscape. Whether the end of the Medieval Warm Phase played a significant role in this increase is uncertain, but this does seem very likely given the limited evidence for occupation of the region during that time. The quality of the grazing in Namaqualand may also have slightly improved with the milder climate.

Chapter 2 discussed the major themes commonly explored by any work on the origins and identification of herding in South Africa. Many questions remain unanswered and may always remain so. Debates will no doubt rage on. Nevertheless, that the keeping of livestock - however defined - occurred in Namaqualand from some 2000 years ago is beyond doubt. That Namaqualand is critical to the study of the beginnings of herding in South Africa is equally certain; it has yielded the earliest South African direct dates on both sheep (Sealy \& Yates 1994) and cattle (Orton et al. in press). Taken with the even earlier caprines from Namibia (Pleurdeau et al. 2012), these dates have increased the likelihood that the Namaqualand coastline was the primary route by which herding was introduced to southernmost Africa. Whether it proceeded southwards through Namibia or westwards along the Orange River to reach the mouth of the latter is beyond the geographical remit of the present work. 


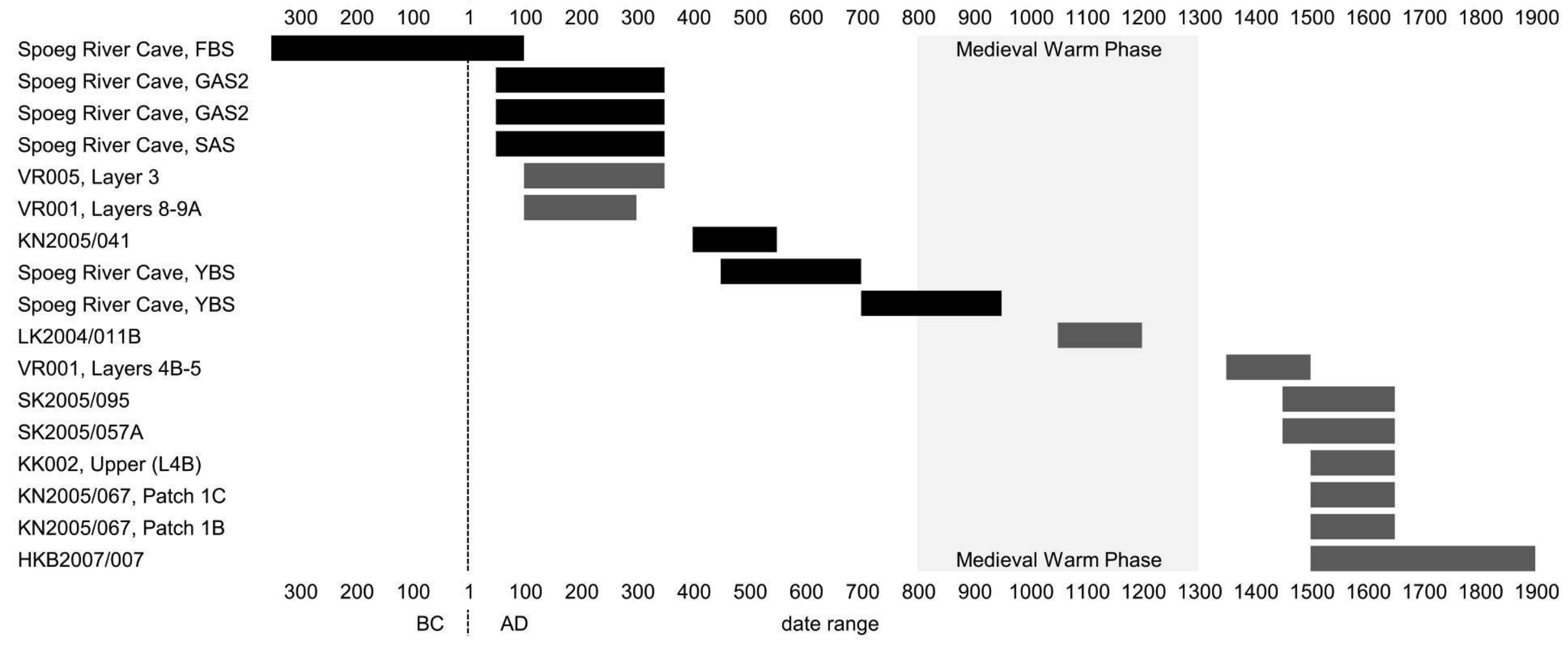

Figure 8.1: Ages of domestic animal bones from the Sandveld. Black bars indicate directly dated bones and grey bars are those dates associated with domestic bones. The '?' indicates an estimate from an undated layer. 
As reviewed in Section 2.4, most recent discussion on the manner of introduction of domesticates and pottery has been focused on proving either cultural or demic diffusion as the relevant mechanism. The former is suggested to have involved the exchange of domesticates and pottery among indigenous hunter-gatherer groups, while the latter is argued to be represented by a migration of Khoekhoe herders into southernmost Africa. Without trying to find an easy way out, I have proposed that both mechanisms had a role to play, and that not one, but two population migrations took place. An initial migration by Proto-Khoekhoe-speaking hunter-gatherers with domestic animals and pottery likely occurred around 2000 years ago. These people would have had much in common with the local hunter-gatherer population, and would have been the descendents of those hunter-gatherers that originally adopted the herding way of life in the region of northern Botswana. These shared features would no doubt have helped the newcomers learn the landscape and become established in it, thus facilitating their southwards spread. Meanwhile, to the north, the Khoekhoen 'package' (language, economy, social customs, etc.) was forming as herding intensified, perhaps even to the point that we might refer to it as pastoralism. Subsequently, these people followed the 'trail' blazed by their predecessors as they too began expanding throughout the region to eventually become the historically documented herders living in the south-western Cape and elsewhere. We might even tentatively postulate that Proto-Khoekhoe-speaking groups moved into the eastern part of South Africa and left the early LSA pottery found by Mazel (1992). By the time the Khoekhoen began their expansion several hundred years later, the eastern parts of southern Africa were already well settled by Bantu-speaking Iron Age people and it may well be that the Khoekhoen never moved into those parts at all. Whether the 'herder art' of the Limpopo area (or anywhere else) might be shown to be that of earlyKhoe people rather than the Khoekhoen is another question worth considering.

The primary role of cultural diffusion in the process would have been the dissemination of domestic stock and particularly pottery among the general population. To what degree 
the indigenous hunter-gatherers actively herded stock remains unknown for lack of evidence, and, although no Group 1 assemblages were found to contain domestic stock bones, this could be due to sampling and the possibility should be kept open for debate.

Practical issues around herding have also been explored in this thesis. For many years questions were asked as to whether herders could even be identified in the archaeological landscape and the signatures proposed by A. Smith et al. (1991) remained hard to find. While some aspects of material culture were no doubt shared, others seem to have differed. It seems likely that fully-fledged Khoekhoe herders employed simple, expedient stone artefact assemblages (Group 2), while both their predecessors (Group 3) and the indigenous inhabitants of the region (Group 1) made strikingly different tools. Interestingly, these lithic differences were maintained, but the pottery and large ostrich eggshell beads brought into southernmost Africa were soon diffused among the local population such that the changes we see in their patterning in the archaeological record are only time-related and do not appear to reflect ethnicity or socio-economy. From beads and pottery in $A D$ contexts it is thus not possible to differentiate between hunter-gatherers and herders.

So, given all the change documented in Namaqualand, particularly during the first millennium AD, do we have a Neolithic revolution? Sadr (2003) has argued for a reintroduction of the term 'Neolithic' to southern African archaeology so as to better encompass the great variety and flexibility of economies that seem to have been present during the last 2000 years. He does not refer to the set of changes that took place as a revolution as has been done in other parts of the world, but, given the far reaching effects these changes had on pre-colonial society, revolution may not be the wrong word. The changes and introductions comprising this revolution in pottery-period Namaqualand would have had far-reaching consequences and certainly encompassed most aspects of daily life. They include the following: 
- Two new stone artefact making traditions were introduced;

- The introduction of pottery allowed storage and cooking of liquids;

- The introduction of domestic stock allowed 'storage' of live meat, thereby increasing the predictability of food supply;

- The arrival of new ethnic groups would have increased the complexity of the social landscape, perhaps adding political tension;

- As a result, landscape use would likely have been reorganised with access to certain areas perhaps becoming curtailed for some groups; and

- The range of decorative material culture increased and that which was already there (small ostrich eggshell beads) changed.

Sadr (1998:197) reviewed the various definitions of the term 'Neolithic' that have been applied through the years and settled on using it for "a period in a region's history when food production was known but metals were not widely used: simply put, Stone Age with food production". He stressed that cultivation and herding, at any intensity and in any proportion with hunting and gathering should all be included. Although evidence for precolonial agriculture is lacking in western South Africa, and cultivation of tropical African cereals such as sorghum (Sorghum bicolor) and pearl millet (Pennisetum glaucum) is impossible there for climatic reasons, there is no doubt that stock-raising has occurred for two millennia. I, for one, would support the application of the term Neolithic in southern Africa and would argue that referring to this period of prehistory as a revolution is probably not unjustified.

Interpretation of the cultural data outlined above relating to the introduction of herding to Namaqualand has been challenging and the outcome was not always expected. It appears as though the situation, at least in Namaqualand (but probably also elsewhere), may be far more complicated than has hitherto been suggested for other regions. Stone 
artefacts seem strongly related to ethnicity but beads and pottery are clearly temporally patterned. Yet, at the same time, the differences between pottery decoration in Namaqualand and areas to its north, east and south could suggest that the variety is more cultural and regional than temporal in nature. Indeed, Sadr and Sampson (2006:245) noted that "half a dozen regional styles may be distinguished". Perhaps the different ways in which bead size changed in the south-western Cape and Namaqualand is also due to regionality? The stone artefact sequence along the south-western Cape coast seems different in many ways to that documented in Namaqualand with less evidence for a clear separation of Groups 1 and 2 - Group 3 seems reasonably clearly represented in a few sites near Elands Bay, particularly Dunefield Midden 1 (Jerardino 2007b; Orton 2002). The observed differences between the two areas may well be largely the result of the different shorelines - the south-western Cape is dominated by sandy beaches and rocky points, while Namaqualand has a continuously rocky coast. This means that most sites to the south are focused around rocky shores and were occupied repeatedly; their assemblages are therefore perhaps largely mixed, as occurs in rock shelters. This again underscores the value of studying single occupation open sites.

Looking east into Bushmanland, Beaumont et al. (1995; see also Parsons 2007) found typical hunter-gatherer assemblages which they called Springbokoog. Those dating less than 2000 years old and with pottery added to them they named Swartkop. These, presumably, would correlate with Group 1. A second type of pottery-period assemblage, with markedly less retouched items and a preponderance of 'coarse irregular flakes', was termed Doornfontein. Significantly, the pottery from Swartkop sites - and from many central Karoo sites (Sampson 1988; Sampson et al. 1989) - was grass-tempered, while that from Doornfontein sites was mostly mineral-tempered. Grass-tempered pottery is almost unheard of in westernmost South Africa and, here again, we see a regional pattern that failed to spread more widely than the central and western interior. 
The south coast is well beyond the geographical scope of this research but it is worth noting that there, too, the cultural sequence is very different. Although an assemblage type dominated by large quartzite flakes and that might be expected to correlate with Group 2 exists, it begins more than 1500 years too early (e.g. H. Deacon 1976; Inskeep 1987; Robertshaw 1984) and obviously has a different origin. Decorative items, in particular those deliberately shaped from marine shell, are substantially more common than on the west coast. Looking inland, Boomplaas, with its good evidence for stockkeeping, shows 'herder' assemblages more similar to Group 1 than to Group 2, although retouch is considerably less frequent than in 'pre-herder' levels (H. Deacon et al. 1978).

This brief review of other regions shows that in order to truly understand the mechanisms behind the introduction of herding to southern Africa we will need to first study the process in many areas. Only once we have a grasp of each, both from the point of view of archaeology and other related disciplines, can we begin to pull together a truly regional picture of the last 2000 years of prehistory.

\subsection{Where to now? Problems and opportunities}

Namaqualand has yet to reveal anything remotely approaching the 'pastoralist' sites at Kasteelberg and, with the limited information to hand, I, like others before me, have had to build upon assumptions and make leaps of faith. Nevertheless, the above seems the best working hypothesis with which to move forward. I have already noted some of the problems associated with the model developed in this thesis but these can also be seen as opportunities for further research. Such research needs to target proving or disproving the various arguments of my hypothesis, as well as examining several key topics that emerged during its construction as follows: 
- There is a great need for more first millennium AD open sites to be studied in order to better understand the earlier part of the pottery-period sequence. Sites suspected to fall within that period should be targeted for dating and excavation;

- Linked to the above point is the need to better understand the introduction of Group 2 technology, both in Namaqualand and elsewhere should it prove to be found in other areas. Vogelsang et al.'s (2002) examples from northern Namibia may well be a case in point;

- Group 3 assemblages would very strongly benefit from use-wear and residue analyses of the kind already undertaken elsewhere in southern African LSA and MSA contexts by Binneman (1982, 1984), Lombard $(2008,2011)$ and Williamson (1997) to help elucidate their function and thus better understand some of the unanswered questions concerning these assemblages;

- The combination Groups are unsatisfactorily explained and certainly require further detailed examination;

- As has been done with sheep and cattle bones, the direct dating of potsherds needs to be explored more consistently in LSA sites. Potsherds can be dated by optically stimulated luminescence dating (OSL) as has been done recently in Lesotho (Collis 2010; Hobart 2004) or, in the central interior with its grasstempered sherds, radiocarbon (Sadr \& Sampson 2006). Small potsherds can easily migrate within deposits or be mis-associated, as has been shown to have occurred with sheep bones (Sealy \& Yates 1994, 1996), and direct dating will help better resolve the timing of the introduction of pottery to southern Africa. Sealy and Yates (1996) considered pottery and domestic animals to have been introduced at different times but the evidence to me seems inconclusive;

- Many potsherds from Namaqualand have relatively thick residues caked onto one surface. These would likely lend themselves to residue analysis to determine the uses to which pots were put in Namaqualand; 
- The present study has yielded a good number of domestic animal bones but, owing to the dating being largely completed prior to commencement of the faunal analyses, many could not be dated. This needs to be rectified, particularly for the sheep remains from Buzz Shelter which are potentially close to 2000 years old. This would build on the success of the early cattle date processed during the course of the present research (Orton et al. in press);

- Now that a regional sequence has been built from excavations that aimed primarily to capture representative samples of site contents, there is a need to conduct spatially extensive excavations in order to explore the use of space on individual sites. Two such excavations have come close but both these sites (AK2006/006 and KN2005/067) could benefit from further work to be truly useful in this regard;

- There is a need for further rock art research in the relatively unknown Kamiesberg Mountains and surrounding granite hills, since too few sites are on record to be able to identify regional patterns; and

- Further palaeoenvironmental studies targeting Namaqualand may isolate environmental changes that helped shape the region's prehistoric settlement patterns. An archaeozoological example would be to study fish bone assemblages from Namaqualand sites in order to gain further insights into sea level change as was successfully done at Elands Bay (Poggenpoel 1987). Although most assemblages are small, a fair number are present, notably from sites close to the Buffels River estuary.

\subsection{Last words}

This research has been based largely on grey literature produced for commercial clients. The lack of publication of such literature is a perennial problem among academic 
researchers and it can hide important information (Ford 2010). Until a few years ago, much of the prehistory of Namaqualand was safely stored in a few computers and filing cabinets (and a large store room) but the present work and that of Dewar (2008) have demonstrated the great value in revisiting both the excavated evidence and the commercial reports. Too few contract archaeologists publish their commercial research, usually for lack of time. However, if we all assume responsibility for the discipline we love and engage in publication, even if only as brief field reports or broad-brush summaries, we will greatly enrich the state of knowledge of archaeology as a whole. We might reduce the need for assumption and, just possibly, also the size of our leaps of faith. 


\section{References}

Abell, P.I. \& Plug, I. 2000. The Pleistocene/Holocene transition in South Africa: evidence for the Younger Dryas event. Global and Planetary Change 26: 173-179.

Albrecht, M., Berke, H., Eichhorn, B., Frank, T., Kuper, R., Prill, S., Vogelsang, R. \& Wenzel, S. 2001. Oruwanje 95/1: a late Holocene stratigraphy in northwestern Namibia. Cimbebasia 17: 1-22.

Alexander, J.E. 1838. An expedition of discovery into the interior of Africa, through the hitherto undescribed countries of the Great Namaquas, Boschmans, and Hill Damaras. Vol. 1. London: Henry Colburn.

Andersson, C.J. 1857. Lake Ngami; or, explorations and discoveries during four years' wanderings in the wilds of south western Africa. New York: Dix, Edwards and Co.

Andrefsky, W. Jr. 1994. Raw-material availability and the organization of technology. American Antiquity 59: 21-34.

Andrefsky, W. Jr. 2005. Lithics: macroscopic approaches to analysis. Cambridge: Cambridge University Press.

Appleton, C.C. 2002. Mollusca. In: De Moor, I.J. \& Day, J.A. (eds) Guides to the freshwater invertebrates of southern Africa. Volume 6: Arachnida \& Mollusca. Araneae, water mites and mollusca: 42-125. Water Research Commission Report No. TT 182/02.

Argyle, J. 1994/95. Khoisan-Southern Bantu livestock exchanges: reinterpreting the linguistic evidence. Azania 29-30: 199.

Arthur, C. 2008. The archaeology of indigenous herders in the Western Cape of South Africa. Southern African Humanities 20: 205-220.

Avery, D.M. 1992. Micromammals and the environment of early pastoralists at Spoeg River Cave, western Cape Province, South Africa. South African Archaeological Bulletin 47: 116-121. 
Avery, D.M. 1995. Physical environment and site choice in South Africa. Journal of Archaeological Science 22: 343-353.

Avery, G. 1975. Discussion on the age and use of tidal fish-traps (visvywers). South African Archaeological Bulletin 30: 105-113.

Badenhorst, S. 2002. The ethnography, archaeology, rock art and history of goats (Capra hircus) in southern Africa: an overview. Anthropology Southern Africa 25: 96-103.

Badenhorst, S. 2006. Goats (Capra hircus), the Khoekhoen and pastoralism: current evidence from southern Africa. African Archaeological Review 23: 45-53.

Bamforth, D.B. 1986. Technological efficiency and tool curation. American Antiquity 51: 38-50.

Bamforth, D.B. 1987. Settlement, raw material and lithic procurement in the Central Mojave Desert. Journal of Anthropological Archaeology 9: 70-104.

Barnard, A. 1992. Hunters and herders of southern Africa: comparative ethnography of the Khoisan peoples. Cambridge: Cambridge University Press.

Barrow, J. 1801. An account of travels into the interior of southern Africa, in the years 1797 and 1978: including cursory observations on the geology and geography of the southern part of that continent; the natural history of such objects as occurred in the animal, vegetable and mineral kingdoms; and sketches of the physical and moral character of the various tribes of inhabitants surrounding the settlement of the Cape of Good Hope. London: T. Cadell Jun. and W. Davies.

Barth, F. 1969. Introduction. In: Barth, F. (ed.) Ethnic groups and boundaries: the social organization of culture difference: 9-38. Prospect Heights: Waveland Press.

Baxter A.J. 1989. Pollen analysis of Table Mountain cave deposit. Unpublished BSc (Hons) Project, University of Cape Town.

Baxter, A.J. 1997. Late Quaternary palaeoenvironments of the Sandveld, Western Cape Province, South Africa. Unpublished PhD thesis, University of Cape Town. 
Baxter, A.J. \& Meadows, M.E. 1999. Evidence for Holocene sea level changes at Verlorenvlei, Western cape, South Africa. Quaternary International 56: 65-79.

Beaumont, P.B. \& Vogel, J.C. 1984. Spatial patterning of the ceramic Later Stone Age in the northern Cape Province, South Africa. In: Hall, M., Avery, G., Avery, D.M., Wilson, M.L. \& Humphreys, A.J.B. (eds) Frontiers: southern African archaeology today: 80-95. Oxford: British Archaeological Reports International Series 207.

Beaumont, P.B., Smith, A.B. \& Vogel, J.C. 1995. Before the Einiqua: the archaeology of the frontier zone. In: Smith, A.B. (ed.) Einiqualand: studies of the Orange River frontier: 236-264. Cape Town: University of Cape Town Press.

Binford, L.R. 1979. Organization and formation processes: looking at curated technologies. Journal of Anthropological Research 35: 255-273.

Binford, L.R. 1980. Willow smoke and dogs' tails: hunter-gatherer settlement systems and archaeological site formation. American Antiquity 45: 4-20.

Binneman, J.N.F. 1982. Mikroegebruikstekens op steenwerktuie: eksperimentele waarnemings en 'n studie van steenwerktuie afkomstig van Boomplaasgrot. Unpublished MA dissertation, University of Stellenbosch.

Binneman, J. 1984. Mapping and interpreting wear traces on stone implements: a case study from Boomplaas Cave. In: Hall, M.J., Avery, G., Avery, D.M., Wilson, M.L. \& Humphreys, A.J.B. (eds) Frontiers: Southern African Archaeology Today: 143151. Oxford: British Archaeological Reports Series 207.

Binneman, J.N.F. 1995. Symbolic construction of communities during the Holocene Later Stone Age in the south-eastern Cape. Unpublished PhD thesis, University of the Witwatersrand.

Binneman, J. 2001. An introduction to the Later Stone Age research project along the south-eastern Cape coast. Southern African Field Archaeology 10: 75-87.

Bleek, W.H.I. 1864. Reynard the fox in South Africa; or, Hottentot fables and tales. London: Trübner \& Co. 
Blench, R. 2006. Archaeology, language, and the African past. Oxford: AltaMira Press.

Bogucki, P. 2000. How agriculture came to north-central Europe. In: Price, T.D. (ed.) Europe's first farmers: 197-218. Cambridge: Cambridge University Press.

Bollong, C.A. \& Sampson, C.G. 1996. Later Stone Age ceramic stratigraphy and direct dates on pottery: a comparison. Southern African Field Archaeology 5: 3-16.

Bollong, C.A., Sampson, C.G. \& Smith, A.B. 1997. Khoikhoi and Bushman pottery in the Cape Colony: ethnohistory and Later Stone Age ceramics of the South African interior. Journal of Anthropological Archaeology 16: 269-299.

Bollong, C.A., Vogel, J.C., Jacobson, L., Van der Westhuizen, W. \& Sampson, C.G. 1993. Direct dating and identity of fibre temper in pre-Contact Bushman (Basarwa) pottery. Journal of Archaeological Science 19: 41-55.

Boonzaier, E., Malherbe, C., Smith, A. \& Berens, P. 1996. The Cape herders: a history of the Khoikhoi of southern Africa. Claremont: David Phillip Publishers.

Botha, G.A. 2000. Paleosols and duricrusts. In: Partridge, T.C. \& Maud, R.R. (eds) The Cenozoic of Southern Africa: 131-44. New York: Oxford University Press.

Bousman, C.B. 1991. Holocene paleoecology and Later Stone Age hunter-gatherer adaptations in the South African interior plateau. Unpublished PhD thesis, Southern Methodist University, Dallas.

Bousman, C.B. 1998. The chronological evidence for the introduction of domestic stock into southern Africa. African Archaeological Review 15: 133-150.

Bower, J. 1991. The Pastoral Neolithic of East Africa. Journal of World Prehistory 5: 4982.

Brink, J. \& Webley, L. 1996. Faunal evidence for pastoralist settlement at Jakkalsberg, Richtersveld, northern Cape Province. Southern African Field Archaeology 5: 7078. 
Brink, J. \& Webley, L. 2007. Ethnographic observations on the butchering of domestic stock amongst the descendants of Nama-speaking pastoralists in Namaqualand, Northern Cape. Southern African Field Archaeology 15\&16: 12-25.

Bronk Ramsey C. 1995. Radiocarbon calibration and analysis of stratigraphy: the OxCal program. Radiocarbon 37: 425-430.

Bronk Ramsey, C. 2009. Bayesian analysis of radiocarbon dates. Radiocarbon 5: 337360.

Brown, L.H. 1971. The biology of pastoral man as a factor in conservation. Biological Conservation 3: 93-100.

Brown, P.C., Painting, S.J. \& Cochrane, K.L. 1991. Estimates of phytoplankton and bacterial biomass and production in the northern and southern Benguela ecosystems. South African Journal of Marine Science 11: 537-564.

Budack, K.F.R. 1977. The $\neq$ Aonin or Topnaar of the Lower !Khuiseb Valley, and the sea. In: Traill, A. (ed.) Khoisan Linguistic Studies 3: 1-42. Johannesburg: University of the Witwatersrand African Studies Institute.

Burchell, W.J. 1822. Travels in the interior of Southern Africa. Volume I. London: Longman, Hurst, Rees, Orme, Brown \& Green.

Burchell, W.J. 1824. Travels in the interior of Southern Africa. Volume II. London: Longman, Hurst, Rees, Orme, Brown \& Green.

Burke, P. 1995. The siege of Okiep. Bloemfontein: War Museum of the Boer Republics.

Carstens, P.W. 1969. Some aspects of Khoikhoi (Hottentot) settlement patterns in historico-ecological perspective. In: Damas, D. (ed.) Contributions to anthropology: ecological essays. Proceedings of the Conference on Cultural Ecology, Ottawa, 3-6 August 1966. National Museums of Canada Bulletin 230: 95-101. 
Cartwright, C. \& Parkington, J. 1997. The wood charcoal assemblages from Elands bay Cave: principles, procedures and preliminary interpretation. South African Archaeological Bulletin 52: 59-72.

Gatto, M.C. 2002. Ceramic traditions and cultural territories: the "Nubian Group" in prehistory. Sudan and Nubia 6: 8-19.

Chappel, C.A. 1968. A Strandloper skeleton found at Cape St Francis. Diastema 2(3): 37-39.

Chase, B.M. 2005. Late Quaternary palaeoenvironments of the west coast of South Africa: the Aeolian record. Unpublished DPhil thesis, University of Oxford.

Chase, B.M. \& Meadows, M.E. 2007. Late Quaternary dynamics of southern Africa's winter rainfall zone. Earth-Science Reviews 84: 103-138.

Chase, B.M. \& Thomas, D.S.G. 2006. Late Quaternary dune accumulation along the western margin of South Africa: distinguishing forcing mechanisms through the analysis of migratory dune forms. Earth and Planetary Science Letters 251: 318333.

Cockcroft, M.J., Wilkinson, M.J. \& Tyson, P.D. 1987. The application of a present-day climatic model to the late Quaternary in Southern Africa. Climatic Change 10: $161-181$

Coetzee, J.A. 1967. Pollen analytical studies in East and Central Africa. Palaeoecology of Africa 3: 1-146.

Cohen, A.L., Parkington, J.E., Brundritt, G.B. \& Van der Merwe, N.J. 1992. A Holocene marine climate record in mollusc shells from the southwest African coast. Quaternary Research 38: 379-385.

Collis, B. 2010. Dating the introduction of pottery to the Maloti-Drakensberg region of southern Africa, using Optically Stimulated Luminescence. Unpublished BA (Hons) thesis, University of Oxford.

Colson, R. 1905. The Port Nolloth Kitchen Middens. Man 93: 166-168. 
Compton, J.S. 2001. Holocene sea-level fluctuations inferred from the evolution of depositional environments of the southern Langebaan Lagoon salt marsh, South Africa. The Holocene 11: 395-405.

Compton, J.S. 2006. The mid-Holocene sea-level highstand at Bogenfels Pan on the southwest coast of Namibia. Quaternary Research 66: 303-310.

Compton, J.S. \& Franceschini, G. 2006. Holocene geoarchaeology of the Sixteen Mile Beach barrier dunes in the Western Cape, South Africa. Quaternary Research 63: 99-107.

Cooke, C.K. 1965. Evidence of human migrations from the rock art of Southern Rhodesia. Africa 35: 263-285.

Copley, M.S., Hansel, F.A., Sadr, K. \& Evershed, P. 2004. Organic residue evidence for the processing of marine animal products in pottery vessels from the pre-colonial archaeological site of Kasteelberg D east, South Africa. South African Journal of Science 100: 279-283.

Cornell, F.C. 1920. The glamour of prospecting: the wanderings of a South African prospector in search of copper, gold, emeralds and diamonds. London: T. Fisher Unwin.

Cornell, D.H., Thomas, R.J., Moen, H.F.G., Reid, D.L., Moore, J.M. \& Gibson, R.L. 2006. The Namaqua-Natal Province. In: Johnson, M.R., Anhaeusser, C.R. \& Thomas, R.J. (eds) The geology of South Africa: 325-379. Johannesburg: Geological Society of South Africa / Pretoria: Council for Geoscience.

Cowling, R.M., Esler, K.J., Rundel, P.W. 1999. Namaqualand, South Africa - an overview of a unique winter rainfall desert ecosystem. Plant Ecology 142: 3-21.

Cowling, R. \& Pierce, S. 1999. Namaqualand: a succulent desert. Cape Town: Fernwood Press.

Cribb, R. 1991. Nomads in archaeology. Cambridge: Cambridge University Press. 
Cruz-Uribe, K. \& Klein, R.G. 1994. Chew marks and cut marks on animal bones from the Kasteelberg-B and Dunefield Midden Later Stone Age sites, Western Cape Province, South Africa. Journal of Archaeological Science 27: 949-952.

Dahl, G. \& Hjört, A. 1976. Having herds: pastoral herd growth and household economy. Stockholm Studies in Social Anthropology 2. Stockholm: Department of Social Anthropology, University of Stockholm.

Deacon, H.J. 1976. Where hunters gathered: a study of Holocene Stone Age people in the Eastern Cape. South African Archaeological Society Monograph Series No. 1.

Deacon, H.J. 1979. Excavations at Boomplaas Cave - a sequence through the upper Pleistocene and Holocene in South Africa. World Archaeology 10: 241-257.

Deacon, H.J., Deacon, J., Brooker, M. \& Wilson, M. 1978. The evidence for herding at Boomplaas Cave in the Southern Cape. South African Archaeological Bulletin 33: 39-65.

Deacon, H.J., Deacon, J., Scholtz, A., Thackeray, J.F. \& Brink, J.S. 1984. Correlation of palaeoenvironmental data from the late Pleistocene and Holocene deposits at Boomplaas cave, southern Cape. In: Vogel, J.C. (ed.) Late Cainozoic palaeoclimates of the southern hemisphere: 339-351. Rotterdam: Balkema.

Deacon, J. 1972. Wilton: an assessment after fifty years. South African Archaeological Bulletin 27: 10-48.

Deacon, J. 1984a. Later Stone Age people and their descendants in Southern Africa. In: Klein, R.G. (ed.) Southern African prehistory and palaeoenvironments: 221-328. Rotterdam: A.A. Balkema.

Deacon, J. 1984b. The Later Stone Age of southernmost Africa. Oxford: British Archaeological Reports International Series 213.

Desmet, P.G. 2007. Namaqualand - a brief overview of the physical and floristic environment. Journal of Arid Environments 70: 570-587. 
Desmet, P., Cowling, R., 1999. The climate of the Karoo - a functional approach. In: Dean, W.R.T. \& Milton, S.J. (eds) The Karoo: ecological patterns and processes: 3-16. Cambridge: Cambridge University Press.

Dewar, G. 2007. The archaeology of the coastal desert of Namaqualand, South Africa: a regional synthesis. Unpublished PhD thesis, University of Cape Town.

Dewar, G. 2008. The archaeology of the coastal desert of Namaqualand, South Africa: a regional synthesis. Oxford: British Archaeological Reports International Series 1761.

Dewar, G., Halkett, D., Hart, T., Orton, J. and Sealy, J. 2006. Implications of a mass kill site of springbok (Antidorcas marsupialis) in South Africa: hunting practices, gender relations and sharing in the Later Stone Age. Journal of Archaeological Science 33: 1266-1275.

Dewar, G. \& Jerardino, A. 2007. Micromammals: when humans are the hunters. Journal of Taphonomy 5: 1-14.

Dewar, G., Reimer, P.J., Sealy, J. \& Woodborne, S. 2012. Holocene marine radiocarbon reservoir correction $(\Delta \mathrm{R})$ for the west coast of South Africa. The Holocene. Online version DOI: 10.1177/0959683612449755.

Dewar, G. \& Stewart, B. 2012. Preliminary results of excavations at Spitzkloof Rockshelter, Richtersveld, South Africa. Quaternary International. Online version doi:10.1016/j.quaint.2011.04.046.

De Wit, M.C.J. 1999. Post-Gondwana drainage and the development of diamond placers in western South Africa. Economic Geology 94: 721-740.

Downey, J.T. 2010. Working with expedient lithic technologies in the Northern Highlands of Peru. Explorations in Anthropology 10: 77-95.

Dreyer, T.F. \& Meiring, A.J.D. 1937. A preliminary report on an expedition to collect Hottentot skulls. Soologiese Navorsing van die Nasionale Museum, Bloemfontein $1(7): 81-88$. 
Du Toit, A.L. 1954. The geology of South Africa. Edinburgh: Oliver \& Boyd.

Eastwood, E.B. 2003. A cross-cultural motif in San, Khoekhoe and Northern Sotho rock paintings of the Central Limpopo Basin. South African Archaeological Bulletin 58: 14-26.

Eastwood, E.B. \& Smith, B.W. 2005. Fingerprints of the Khoekhoen: geometric and handprinted rock art in the Central Limpopo Basin, Southern Africa. South African Archaeological Society Goodwin Series 9: 63-76.

Eastwood, E.B., Blundell, G. \& Smith, B.W. 2010. Art and authorship in southern African rock art: examining the Limpopo-Shashe Confluence Area. In: Blundell, G. Smith, B. \& Chippendale, C. (eds) Seeing and knowing: understanding rock art with and without ethnography: 75-97. Johannesburg: Wits University Press.

Ehret, C. 1982. The first spread of food production to southern Africa. In: Ehret, C. \& Posnansky, M. (eds) The archaeological and linguistic reconstruction of African history: 151-181. Berkeley: University of California Press.

Ehret, C. 1998. An African classical age: eastern and southern Africa in world history, $1000 B C$ to $A D$ 400. Oxford: James Curry.

Elphick, R. 1985. Khoikhoi and the founding of white South Africa. Johannesburg: Ravan Press.

Fauvelle-Aymar, F.-X. 2004. Between the first herders and the last herders: are the Khoekhoe descendents of the Neolithic 'hunters-with-sheep'? Before Farming [Online Version] 2004/4: article 5.

Fauvelle-Aymar, F.-X. \& Sadr, K. 2008. Trends and traps in the reconstruction of early herding societies in southern Africa. Southern African Humanities 20: 1-6.

Fauvelle-Aymar, F.-X., Sadr, K. Bon, F. \& Gronenborn, D. 2006. The visibility and invisibility of herders' kraals in southern Africa, with reference to a possible early contact period Khoekhoe kraal at KFS5, Western Cape. Journal of African Archaeology 4: 253-271. 
Flemming, B.W. 1977. Depositional processes in Saldanha Bay and Langebaan Lagoon. Unpublished PhD thesis, University of Cape Town.

Ford, M. 2010. Hidden treasure. Nature 464: 826-827.

Galaty, J.G. 1979. Pollution and pastoral antipraxis: the issue of Maasai inequality. American Ethnologist 6: 803-816.

Gamble, C. 1994. Timewalkers: the prehistory of global colonization. Cambridge (Massachusetts): Harvard University Press.

Gifford-Gonzalez, D.P., Damrosch, D.B., Damrosch, D.R., Pryor, J. \& Thunen, R.L. 1985. The third dimension in site structure: an experiment in trampling and vertical dispersal. American Antiquity 50: 803-818.

Gifford-Gonzalez, D. 2000. Animal disease challenges to the emergence of pastoralism in sub-Saharan Africa. African Archaeological Review 17: 95-139.

Gingele, F.X. 1996. Holocene climatic optimum in South West Africa: evidence from the marine clay Mineral record. Palaeogeography, Palaeoclimatology, Palaeoecology 122: 77-87.

Ginther, J.K. 2008. A bioarchaeological study of mid-Holocene communities in the Eastern Cape, South Africa: the interface between foraging and pastoralism. Unpublished DPhil thesis, University of Toronto.

Godee Molsbergen, E.C. 1916. Reizen in Zuid-Afrika in de Hollandse tijd, Vol. 1. Tochten naar het Noorden 1652-1686. The Hague: S-Gravenhage Martinus Nijhoff.

Goodwin, A.J.H. 1946. Prehistoric fishing methods in South Africa. Antiquity 20: 134141.

Goodwin, A.J.H. 1952. Jan van Riebeeck and the Hottentots 1652-1662. South African Archaeological Bulletin 7: 7-53. 
Goosen, R. \& Burger, E. 1995. Phase One archaeological investigation Steenkampskraal, Vanrhynsdorp region. Unpublished report prepared for Setplan. Department of Archaeology: University of Stellenbosch.

Gowlett, J.A.J., Hedges, R.E.M., Law, I.A., \& Perry, C. 1987. Radiocarbon dates from the Oxford AMS system: Archaeometry datelist 5. Archaeometry 29: 125-155.

Grace, R. 1997. The 'chaîne opératoire' approach to lithic analysis. Internet Archaeology 1997, Issue 2. http://ezproxy.ouls.ox.ac.uk:3996/journal/issue2/grace/toc.html. Accessed 21 February 2011.

Gray, C.E.D. 2009. Characterising the Namaqualand mudbelt: chronology, palynology and palaeoenvironments. Unpublished DPhil thesis, University of Cape Town.

Heydorn, A.E.F. \& Grindley, J.R. 1981. Estuaries of the Cape, Part II: synopses of available information on individual systems. Stellenbosch: Council for Scientific and Industrial Research.

Güldemann, T. 2008. A linguist's view: Khoe-Kwadi speakers as the earliest foodproducers of southern Africa. Southern African Humanities 20(1): 93-132.

Halkett, D. 1999a. A phase 1 archaeological assessment of heritage resources in the Transhex Diamond Concession Richtersveld. Unpublished report prepared for Transhex Mining Ltd. Archaeology Contracts Office: University of Cape Town.

Halkett, D. 1999b. A phase 1 archaeological assessment of the proposed site of a Vodacom base station and powerline at Baken Mine, Richtersveld. Unpublished report prepared for SRK Consulting. University of Cape Town: Archaeology Contracts Office.

Halkett, D. 2000. An initial assessment of heritage resources within the Transhex west coast diamond concessions. Unpublished report prepared for Trans Hex Mining Ltd. University of Cape Town: Archaeology Contracts Office.

Halkett, D. 2001a. An inspection of and assessment of a Middle Stone Age site at the Groen River mouth: Namaqualand. Unpublished report prepared for De Beers Namaqualand Mines. University of Cape Town: Archaeology Contracts Office. 
Halkett, D. 2001b. A report on archaeological excavations on the Orange River floodplain between Jakkalsberg and Sendelingsdrift: Richtersveld. Unpublished report prepared for Transhex Mining Ltd. University of Cape Town: Archaeology Contracts Office.

Halkett, D. 2002. An analysis of a randomly collected Early Stone Age artefact assemblage from the Sandkop mining area, Kleinzee, Namaqualand. Unpublished report prepared for De Beers Namaqualand Mines. University of Cape Town: Archaeology Contracts Office.

Halkett, D. 2003. A report on the archaeological mitigation program at De Beers Namaqualand Mines March 2002 to June 2003. Unpublished report prepared for De Beers Namaqualand Mines. University of Cape Town: Archaeology Contracts Office.

Halkett, D. and Dewar, G. 2007. Mitigation of archaeological sites in the Buffels Marine and Koingnaas complexes, Namaqualand, July to October 2006. Unpublished report prepared for De Beers Consolidated Mines NM. University of Cape Town: Archaeology Contracts Office.

Halkett, D. J. \& Hart, T. J. G. 1997. An archaeological assessment of the coastal strip, and a proposed heritage management plan for: De Beers Namaqualand Mines. Unpublished report prepared for De Beers Consolidated Mines NM. University of Cape Town: Archaeology Contracts Office.

Halkett, D., Hart, T.J.G. \& Parkington J.E. 1993. Excavations at six archaeological sites in the near shore diamond mining area, Brand se Baai, Namaqualand. Unpublished report prepared for De Beers Namaqualand Mines Division. University of Cape Town: Archaeology Contracts Office.

Halkett, D. \& Orton, J. 2009. Final report on archaeological excavations on Portion 91 of Farm 394, Noetzie, Knysna, Western Cape. Unpublished report prepared for Pezula Private Estate Pty (Ltd). University of Cape Town: Archaeology Contracts Office.

Hall, M. 1987. The changing past: farmers, kings \& traders in southern Africa 200-1860. Claremont: David Philip. 
Hall, S.L. 1990. Hunter-gatherer-fishers of the Fish River Basin: a contribution to the Holocene prehistory of the eastern Cape. Unpublished DPhil thesis, University of Stellenbosch.

Hall, S. \& Smith, B. 2000. Empowering places: rock shelters and ritual control in farmerforager interactions on the Northern Province. South African Archaeological Society Goodwin Series 8: 30-46.

Harmse, J.T. 1988. The mobility of aeolian deposits of the South African west coast. In: Dardis, G.F. \& Moon, BP (eds) Geomorphological studies in southern Africa: 137-144. Rotterdam: A.A. Bakema.

Hart, T.J.G. 1989. Haaskraal and Volstruisfontein: Later Stone Age events at two rockshelters in the Zeekoe Valley, Great Karoo, South Africa. Unpublished MA dissertation, University of Cape Town.

Hart, T. 1999. A phase 1 archaeological assessment of the proposed Liebenbergs Bay Mine, Vredendal. Unpublished report prepared for Rency (Pty) Ltd. University of Cape Town: Archaeology Contracts Office.

Hart, T. 2003. Phase 1 archaeological assessment of proposed diamond mining areas situated at the farms Geelwal Karoo, Klipvley Karoo Kop and Graauduinen, Vredendal District, Western Cape Unpublished report Prepared for SRK Consulting. University of Cape Town: Archaeology Contracts Office.

Hart, T. 2005. Heritage impact assessment of a proposed Sutherland golf estate, Sutherland, Northern Cape Province. Unpublished report prepared for DJ Environmental. University of Cape Town: Archaeology Contracts Office.

Hart, T. 2007. Heritage impact assessment (prepared as part of an EIA) of a proposed wind energy facility to be situated at Olifants River Settlement 617, 620 and Grave Water Kop 158/5 situated on the Namaqualand coast in the Vredendal District, south western Cape. Unpublished report prepared for Savannah Environmental (Pty) Ltd. University of Cape Town: Archaeology Contracts Office.

Hart, T.J.G. \& Halkett, D. 1994. Report on Phase 2 archaeological excavations at the Namakwasands project (first phase) Vredendal District Namaqualand. 
Unpublished report prepared for Namakwa Sands Ltd. University of Cape Town: Archaeology Contracts Office.

Hart, T.J.G. \& Halkett, D. 1999. An assessment of recent archaeological baseline surveys in the Sperregebiet. Unpublished report prepared for Namdeb Diamond Corporation (Pty) Ltd. University of Cape Town: Archaeology Contracts Office.

Hart, T. \& Lanham, J. 1997. Phase 2 archaeological excavations at two Late Stone Age sites in the Phase II (WOB) mining area, Namakwa Sands, Vredendal District, Western Cape. Unpublished report prepared for Namakwa Sands Ltd. University of Cape Town: Archaeology Contracts Office.

Hart, T. \& Orton, J. 2005. Namakwa Sands EMPR amendment specialist study report on heritage. Unpublished report prepared for Golder Associates Africa (Pty) Ltd. University of Cape Town: Archaeology Contracts Office.

Hausman, A.J. 1980. Holocene human evolution in southern Africa: the biocultural development of the Khoisan. Unpublished PhD thesis, State University of New York at Binghampton.

Hausman, A.J. 1982. The biocultural evolution of Khoisan populations of southern Africa. American Journal of Physical Anthropology 58: 315-330.

Heaton, T.H.E., Talma, A.S. \& Vogel, J.C. 1986. Dissolved paleotemperatures and O18 variations derived from groundwater near Uitenhage, South Africa. Quaternary Research 25: 79-88.

Henderson, Z. 2002. A dated cache of ostrich eggshells from Thomas' Farm, Northern Cape Province, South Africa. South African Archaeological Bulletin 57: 38-40.

Hendricks, H., Bond, W., Midgley, J. \& Novellie, P.A. 2005. Herd size does not matter in the Richtersveld communal livestock production system. In: Allsopp, N. \& Hoffman, M.T. (eds) Towards sustainable land use in Namaqualand: proceedings of the Namaqualand colloquium 24-26 May 2005: 46-47. Cape Town: Namaqualand Colloquium Organising Committee, University of the Western Cape. 
Henn, B.M., Gignoux, C., Lin, A.A., Oefner, P.J., Shen, P., Scozzari, R., Cruciani, F., Tishkoff, S.A., Mountain, J.L. \& Underhill, P.A. 2008. Y-chromosomal evidence of a pastoralist migration though Tanzania to southern Africa. Proceedings of the National Academy of Sciences (USA) 105: 10 693-10 698.

Henshilwood, C. 1996. A revised chronology for pastoralism in southernmost Africa: new evidence of sheep at c. 2000 b.p. from Blombos Cave, South Africa. Antiquity 70: 945-949.

Henshilwood, C. S. 2008. Holocene prehistory of the southern Cape, South Africa: excavations at Blombos Cave and the Blombosfontein Nature Reserve. BAR S1860. Cambridge: Cambridge Monographs in African Archaeology 75.

Henshilwood, C., Nilssen, P. \& Parkington, J. 1994. Mussel drying and food storage in the late Holocene, SW Cape, South Africa. Journal of Field Archaeology 21: 1039.

Higgs, E.S. \& Vita-Finzi, C. 1972. Prehistoric economies: a territorial approach. In: Higgs, E.S. (ed.) Papers in Economic Prehistory: 27-36. Cambridge: Cambridge University Press.

Hine, P.J. 2008. Stone-walled tidal fish traps: and archaeological and archival investigation. Unpublished MPhil dissertation, University of Cape Town.

Hine, P.J. \& Sealy, J. Halkett, D. \& Hart, T. 2010. Antiquity of stone-walled tidal fish traps on the Cape coast, South Africa. South African Archaeological Bulletin 65: 35-44.

Hiscock, P. 2006. Blunt and to the point. In: Lilley, I. (ed.) Archaeology of Oceania: Australia and the Pacific Islands: 69-95. Oxford: Blackwell Publishing.

Hitchcock, R.K. \& Ebert, J.I. 1984. Foraging and food production among Kalahari hunter/gatherers. In: Clark, J.D. \& Brandt, S.A. (eds) From hunters to farmers: the causes and consequences of food production in Africa: 328-348. Berkeley: University of California Press.

Hobart, J.H. 2003. Forager-farmer relations in south-eastern Africa: a critical reassessment. Unpublished DPhil thesis, University of Oxford. 
Hobart, J. 2004. Pitsaneng: evidence for a Neolithic Lesotho? Before Farming [Online Version] 2004/4, article 4.

Hodder, I. 1984. Archaeology in 1984. Antiquity 58: 25-32.

Hodder, I. (1982) Symbols in action: ethnoarchaeological studies of material culture. New York: Cambridge University Press.

Hoffman, M.T. \& Cowling, R.M. 1987. Plant physiognomy, phenology and demography. In: Cowling, R.M. \& Roux, P.W. (eds) The Karoo biome: a preliminary synthesis. Part 2 - vegetation and history: 1-34. Pretoria: South African National Scientific Programme Report 142.

Hoffman, M.T. \& Rohde, R.F. 2007. From pastoralism to tourism: the historical impact of changing land use practices in Namaqualand. Journal of Arid Environments 70: 641-658.

Holmgren, K., Tyson, P.D., Moberg, A. \& Svanered, O. 2001. A preliminary 3000-year regional temperature reconstruction for South Africa. South African Journal of Science 97: 49-51.

Holmgren, K., Lee-Thorp, J.A., Cooper, G.R.J., Lundblad, K., Partridge, T.C., Scott, L., Sithaldeen, R., Talma, A.S. \& Tyson, P.D. 2003. Persistent millennial-scale climatic variability over the past 25,000 years in southern Africa. Quaternary Science Reviews 22: 2311-2326.

Homewood, K. 2008. Ecology of African pastoralist societies. Oxford: James Currey Ltd.

Horsburgh, K.A. 2008. The origins of southwest African pastoralism: addressing classical debates using ancient DNA. Unpublished PhD thesis, Stanford University.

Hudson, A. 2006. Exchange in Holocene Southern Africa: indications from marine shell at inland sites. Unpublished Mst dissertation, School of Archaeology, University of Oxford.

Huffman, T. 2005. The stylistic origin of Bambata and the spread of mixed farming in southern Africa. Southern African Humanities 17: 57-79. 
Humphreys, A.J.B. 1988. A prehistoric frontier in the northern Cape and western Orange Free State: archaeological evidence of interaction and ideological change. Kronos 13: 3-13.

Humphreys, A.J.B. \& Thackeray, A.I. 1983. Ghaap and Gariep: Later Stone Age studies in the northern Cape. Cape Town: South African Archaeological Society Monograph Series No. 2.

Hutton, J.T., Twidale, C.R. \& Milnes, A.R. 1978. Characteristics and origin of some Australian silcretes. In: Langford-Smith, T. (ed.) Silcrete in Australia. Armidale: Department of Geography, University of New England.

Ikeya, K. 1993. Goat raising among the San in the central Kalahari. African Study Monographs 14: 39-52.

Ingold, T. 1975. Reply to Robert Paine. Man (New Series) 10: 619-620.

Ingold, T. 1980. Hunters, pastoralists and ranchers: reindeer economies and their transformations. Cambridge: Cambridge University Press.

Inskeep, R. 1987. Nelson Bay Cave, Cape Province, South Africa: the Holocene levels. Oxford: British Archaeological Reports International Series 357(i \& ii).

Inskeep, R.R. \& Vogel, J.C. 1985. Radiocarbon dates from the Holocene levels at Nelson Bay Cave, and an interim report on their associations. South African Archaeological Bulletin 40: 103-105.

Jacobson, L. 1977. A pottery cache from the Bethanie District, South West Africa. Cimbebasia (B) 2: 227-234.

Jacobson, L. 1987. The size variability of ostrich eggshell beads from central Namibia and its relevance as a stylistic and temporal marker. South African Archaeological Bulletin 42: 55-58.

Jacobson, L. \& Noli, D. 2008. New finds of decorated whole ostrich eggshells from southern Namibia and the Northern Cape Province, South Africa. Poster 
presented at the 2008 Association of Southern African Professional Archaeologists Conference, University of Cape Town.

Jerardino, A. 1993. Mid- to late Holocene sea-level fluctuations: the archaeological evidence at Tortoise Cave, south-western Cape, South Africa. South African Journal of Science 89: 481-488.

Jerardino, A.M.S. 1995. Late Holocene Neoglacial episodes in southern South America and southern Africa: a comparison. The Holocene 5: 361-368.

Jerardino, A.M.S. 1996. Changing social landscapes of the Western Cape coast of southern Africa over the last 4500 Years. Unpublished PhD thesis, University of Cape Town.

Jerardino, A. 2007a. Changes in Shellfish Species Composition and Mean Shell Size from a Late-Holocene Record of the West Coast of Southern Africa. Journal of Archaeological Science 24: 1031-1044.

Jerardino, A. 2007b. Excavations at a hunter-gatherer site known as 'Grootrif G' shell midden, Lamberts Bay, Western Cape province. South African Archaeological Bulletin 62: 162-170.

Jerardino, A., Dewar, G. \& Navarro, R. 2009a. Opportunistic subsistence strategies among Late Holocene coastal hunter-gatherers, Elands Bay, South Africa. Journal of Island and Coastal Archaeology 4: 37-60.

Jerardino, A., Horwitz, L., Mazel, A. \& Navarro, R., 2009b. Just before Van Riebeeck: glimpses into terminal LSA lifestyle at Connies Limpet Bar, West Coast of South Africa. South African Archaeological Bulletin 64: 75-86.

Jerardino, A. \& Maggs, T. 2007. Simon se Klip at Steenbokfontein: the settlement pattern of a built pastoralist encampment on the west coast of South Africa. South African Archaeological Bulletin 62: 104-114.

Jerardino, A. \& Yates, R. 1996. Preliminary results from excavations at Steenbokfontein Cave: implications for past and future research. South African Archaeological Bulletin 51: 7-16. 
Jerardino, A. \& Yates, R. 1997. Excavations at Mike Taylor's Midden: a summary report and implications for a re-characterisation of megamiddens. South African Archaeological Bulletin 52: 43-51.

Jerardino, A.M., Yates, R., Morris, A.G. \& Sealy, J.C. 1992. A dated human burial from the Namaqualand coast: observations on culture, biology and diet. South African Archaeological Bulletin 47: 75-81.

Kaplan, J. 1987. Settlement and subsistence at Renbaan Cave. In: Parkington, J.E. \& Hall, M. (eds) Papers in the Prehistory of the western Cape, South Africa: 350372. Oxford: British Archaeological Reports International Series 332(ii).

Kaplan, M.R., Schaefer, J.M., Denton, G.H., Barrel, D.J.A., Chinn, T.J.H., Putnam, A.E., Anderson, B.G., Finkel, R.C., Schwartz, R. \& Doughty, A.M. 2010. Glacier retreat in New Zealand during the Younger Dryas Stadial. Nature 467: 194-197.

Keeley, L.A. 1982. Hafting and retooling: effects on the archaeological record. American Antiquity 47: 798-809.

Kelly, R.L. 1992. Mobility/sedentism: concepts, archaeological measures and effects. Annual Review of Anthropology 21: 43-66.

Kelso, C. \& Vogel, C. 2007. The climate of Namaqualand in the nineteenth century. Climatic Change 83:357-380.

Kent, S. 1992. The current forager controversy: real versus ideal views of huntergatherers. Man (New Series) 27: 45-70.

Kent, S. 1993. Sharing in an egalitarian Kalahari community. Man (New Series) 28: 479514.

Kinahan, J. 1981. An early pottery date from southern Kaokoland. Journal of the South West African Scientific Society 34/35: 43-46.

Kinahan, J. 1984. The stratigraphy and lithic assemblages of Falls Rock Shelter, Western Damaraland, Namibia. Cimbebasia (B) 4: 13-27. 
Kinahan, J. 1994/1995. A new archaeological perspective on nomadic pastoralist expansion in south-western Africa. Azania 29-30: 211-226.

Kinahan, J. 2001. Pastoral nomads of the Namib Desert: the people history forgot. Windhoek: Namibia Archaeological Trust.

Kinahan, J. \& Kinahan, J.H.A. 1984. Holocene settlement and subsistence on the Namib coast: the example of the Ugab River mouth. Cimbebasia (B) 4: 59-72.

Kinahan, J. \& Kinahan, J.H.A. 2003. Excavation of a late Holocene cave deposit in the southern Namib Desert, Namibia. Cimbebasia 18: 1-10.

Kinahan, J.H.A. 2000. Cattle for beads: the archaeology of historical contact and trade on the Namib Coast. Studies in African Archaeology 17. Uppsala: Department of Archaeology and Ancient History, University of Uppsala \& Windhoek: Namibia Archaeological Trust.

Klein, R.G. 1978. A preliminary report on the larger mammals from the Boomplaas Stone Age cave site, Cango Valley, Oudtshoorn District. South African Archaeological Bulletin 33: 66-75.

Klein, R.G. 1979. Palaeoenvironmental and cultural implications of late Holocene archaeological faunas from the Orange Free State and north-central Cape Province, South Africa. South African Archaeological Bulletin 34: 34-49.

Klein, R.G. 1984. The prehistory of Stone Age herders in South Africa. In: Clark, J.D. \& Brandt, S.A. (eds) From hunters to farmers: the causes and consequences of food production in Africa: 281-289. Berkeley: University of California Press.

Klein, R. G. 1986. The prehistory of Stone Age herders in the Cape Province of South Africa. South African Archaeological Society Goodwin Series 5: 5-12.

Klein, R.G. \& Cruz-Uribe, K. 1987. Large mammal and tortoise bones from Elands Bay Cave and nearby sites, western Cape Province, South Africa. In: Parkington, J.E. \& Hall, M. (eds) Papers in the prehistory of the western Cape, South Africa: 132163. Oxford: British Archaeological Reports International Series 332(ii). 
Klein, R.G. \& Cruz-Uribe, K. 1989. Faunal evidence for prehistoric herder-forager activities at Kasteelberg, western Cape Province, South Africa. South African Archaeological Bulletin 44:82-97.

Klein, R.G., Cruz-Uribe, K., Halkett, D., Hart, T. \& Parkington, J. 1999. Paleoenvironmental and human behavioral implications of the Boegoeberg 1 Late Pleistocene hyena den, Northern Cape Province, South Africa. Quaternary Research 52: 393-403.

Klopatek, J.M. \& Stock, W.D. 1994. Partitioning of nutrients in Acanthosicyos horridus, a keystone endemic species in the Namib Desert. Journal of Arid Environments 26: 233-240.

Kusimba, S.B. 2003. African foragers. Walnut Creek: AltaMira Press.

Kusimba, S.B. 2005. What is a hunter-gatherer? Variation in the archaeological record of eastern and southern Africa. Journal of Archaeological Research 13: 337-366.

Laidler, F.W. 1929a. Burials and burial methods of the Namaqualand Hottentots. Man 110: 151-153.

Laidler, P.W. 1929b. Hottentot and Bushman pottery of South Africa. South African Journal of Science 26: 758-786.

Laidler, P.W. 1935. Shell mound cultures. South African Journal of Science 32: 560-571.

Laidler, P.W. 1936. A Late Stone Age cave deposit in the Transkei. South African Journal of Science 33: 888-892.

Lenssen-Erz, T. \& Vogelsang, R. 2005. Populating no-man's-land - rock art in northern Namibia. South African Archaeological Society Goodwin Series 9: 54-62.

Le Roux, A. \& Schelpe, T. 1988. Namaqualand. South African Wildflower Guide 1. Claremont: Botanical Society of South Africa.

Lewis-Williams, J.D. \& Dowson, T.A. 1988. The signs of all times: entoptic phenomena in Upper Palaeolithic art. Current Anthropology 29: 201-245. 
Lewis-Williams, J.D. \& Dowson, T.A. 1999. Images of power: understanding Bushman rock art. Johannesburg: Southern Books.

Lichtenstein, H. 1812. Travels in southern Africa in the years 1803, 1804, 1805 and 1806. Cape Town: Van Riebeeck Society.

Liltved, W. 2000. Cowries and their relatives of southern Africa : a study of the southern African Cypraeacean and Velutinacean gastropod fauna. Cape Town: Seacomber Publications.

Lombard, M. 2008. Finding resolution for the Howiesons Poort through the microscope: micro-residue analysis of segments from Sibudu Cave, South Africa. Journal of Archaeological Science 35: 26-41.

Lombard, M. 2011. Quartz-tipped arrows older than $60 \mathrm{ka}$ : further use-trace evidence from Sibudu, KwaZulu-Natal, South Africa. Journal of Archaeological Science 38: 1918-1930.

Lombard, M., Wadley, L., Deacon, J., Wurz, S., Parsons, I., Mohapi, M., Swart, J. \& Mitchell, P. 2012. South African and Lesotho Stone Age sequence updated (1). South African Archaeological Bulletin 67: 123-144.

Louw, J.T. 1960. Matjes River Rock Shelter. Researches of the National Museum, Bloemfontein, Memoir 1: 1-124.

Mackay, A., Orton, J., Schwortz, S. \& Steele, T. 2010. Soutfontein (SFT)-001: preliminary report on an open-air site rich in bifacial points, southern Namaqualand, South Africa. South African Archaeological Bulletin 65: 84-95.

Maggs, T.M.O'C. \& Sealy, J. 1983. Elephants in boxes. South African Archaeological Society Goodwin Series 4: 44-48.

Maggs, T.M.O'C. \& Sealy, J. 2008. Africanis: the pre-colonial dog of Africa. In: Van Sittert, L. \& Swart, S. (eds) Canis Africanis: a dog history of Southern Africa: 3551. Leiden: Brill. 
Manhire, A.H. 1981. Rock art of the Sandveld. Unpublished Honours project, University of Cape Town.

Manhire, A. 1993. A report on the excavations at Faraoskop Rock Shelter in the Graafwater district of the south-western Cape. Southern African Field Archaeology 2: 3-23.

Manhire, A. 1998. The role of hand prints in the rock art of the south-western Cape. South African Archaeological Bulletin 53: 98-108.

Manhire, A.H., J.E. Parkington, A.D. Mazel, and T.M.0'C. Maggs. 1986. Cattle, sheep, and horses: A review of domestic animals in the rock art of southern Africa. South African Archaeological Society Goodwin Series 5: 2-30.

Marshall, F.B. 1986. Aspects of the advent of pastoral economies in East Africa. Unpublished PhD thesis, University of California, Berkeley.

Marshall, F. 1994. Archaeological perspectives on East African pastoralism. In: Fratkin, E., Galvin, K.A. \& Roth, E.A. (eds) African pastoralist systems: an integrated approach: 17-43. Boulder: Lynne Rienner Publishers.

Marshall, F. 2000. The origins and spread of domestic animals in East Africa. In: Blench, R.M. \& McDonald, K.C. (eds) The origins and development of African livestock: archaeology, genetics, linguistics and ethnography: 191-221. London: UCL Press.

Marshall, F. \& Hildebrand, E. 2002. Cattle before crops: the beginnings of food production in Africa. Journal of World Prehistory 16: 99-143.

Martin, H. 1965. The Precambrian geology of South West Africa and Namaqualand. Cape Town: Precambrian Research Unit, University of Cape Town.

Matimati, I., Musil, C., Raitt, L. \& February, E. 2010. Fog and dew in the Succulent Karoo. Veld \& Flora 96: 140-141. 
Mazel, A. 1978. Stories in stones: aspects of artefact distribution in the Clanwilliam district, south-western Cape. Unpublished BA Honours project, University of Cape Town.

Mazel, A.D. 1992. Early pottery from the eastern part of southern Africa. South African Archaeological Bulletin 47: 3-7.

Mazel, A.D. 1999. iNkolimahasi Shelter: the excavation of Later Stone Age rock shelter deposits in the central Thukela Basin, KwaZulu-Natal, South Africa. Natal Museum Journal of Humanities 11: 1-21.

McCormac, F. G., Hogg, A. G., Blackwell, P. G., Buck, C. E., Higham, T. F. G., and Reimer, P. J. 2004. SHCal04 Southern Hemisphere Calibration 0-11.0 cal kyr BP. Radiocarbon 46:1087-1092.

Meadows, M.E. \& Baxter, A.J. 1999. Late Quaternary palaeoenvironments of the southwestern Cape, South Africa: a regional synthesis. Quaternary International 57/58: 183-206.

Meadows, M.E. \& Baxter, A.J. 2001. Holocene vegetation history and palaeoenvironments at Klaarfontein Springs, Western Cape, South Africa. The Holocene 11: 699-706.

Meadows, M.E., Baxter, A.J. \& Parkington, J. 1996. Late Holocene environments at Verlorenvlei, Western Cape Province, South Africa. Quaternary International 33: $81-95$.

Mellars, P. 1996. The Neanderthal legacy: an archaeological perspective from western Europe. Princeton: Princeton University Press.

Meltzer, D.J. 2003. Lessons in landscape learning. In: Rockman, M. \& Steele, J. (eds) Colonization of unfamiliar landscapes: the archaeology of adaptation: 222-241. London: Routledge.

Midgley, G., Rutherford, M. \& Musil, C. 2005. Climate change and biodiversity in Namaqualand, from the late Pleistocene to the coming Anthropocene. In: Allsopp, N. \& Hoffman, M.T. (eds) Towards sustainable land use in Namaqualand: 
proceedings of the Namaqualand colloquium 24-26 May 2005: 30-33. Cape Town: Namaqualand Colloquium Organising Committee, University of the Western Cape.

Miller, D.E. 1990. A southern African late Quaternary sea-level curve. South African Journal of Science 86: 456-458.

Miller, D., Manhire, T., Yates, R., Jerardino, A. And Parkington, J. 1998. Metalwork found in Late Stone Age contexts in the western and southern Cape. Southern African Field Archaeology 7: 106-110.

Miller, D. \& Markell, A. 1993. Dutch brass buttons from the Cape to the Marico. Southern African Field Archaeology 2: 107-108.

Miller, D. \& Webley, L. 1994. The metallurgical analysis of artefacts from Jakkalsberg, Richtersveld, Northern Cape. Southern African Field Archaeology 3: 82-93.

Miller, D.E., Yates, R.J., Parkington, J.E. \& Vogel, J.C. 1993. Radiocarbon-dated evidence relating to a mid-Holocene high sea-level on the south-western Cape coast, South Africa. South African Journal of Science 89: 35-44.

Mitchell, P.J. 1993a. Archaeological investigations at two Lesotho rock-shelters: terminal Pleistocene/early Holocene assemblages from $\mathrm{Ha}$ Makotoko and Ntloana Tsoana. Proceedings of the Prehistoric Society 59: 39-60.

Mitchell, P.J. 1993b. The archaeology of Tloutle rock-shelter, Maseru District, Lesotho. Navorsinge van die Nasionale Museum Bloemfontein 9: 77-132.

Mitchell, P.J. 1995. Revisiting the Robberg: new results and a revision of old ideas at Sehonghong Rock Shelter, Lesotho. South African Archaeological Bulletin 50: 28-38.

Mitchell, P.J. 1996. Prehistoric exchange and interaction in southeastern Southern Africa: Marine Shells and Ostrich Eggshell. African Archaeological Review 13: 3576. 
Mitchell, P.J. 2000. The Quaternary Archaeological Record in Southern Africa. In: Partridge, T.C. \& Maud, R.R. (eds) The Cenozoic of Southern Africa: 357-70. New York: Oxford University Press.

Mitchell, P. 2002a. Anyone for hxaro? Thoughts on the theory and practice of exchange in Southern African Later Stone Age Archaeology. In: Mitchell, P., Haour, A. And Hobart, J. (eds) Researching Africa's past: new contributions from British archaeologists. Oxford: Oxford University School of Archaeology Monograph No. 57.

Mitchell, P.J. 2002b. The archaeology of Southern Africa. Cambridge: Cambridge University Press.

Mitchell, P.J. 2004a. Comments on 'Taking stock: identifying Khoekhoen herder rock art in southern Africa'. Current Anthropology 45: 517-518.

Mitchell, P.J. 2004b. Some reflections on the spread of food production in southernmost Africa. Before Farming [Online Version] 2004/4: article 2.

Mitchell, P.J. 2006/2007. Remembering the Mountain Bushmen: observations of nineteenth century hunter-gatherers in Lesotho as recorded by Victor Ellenberger. Southern African Field Archaeology 15 \& 16: 3-10.

Mitchell, P.J. 2008. The canine connection: dogs and southern African hunter-gatherers. In: Badenhorst, S., Mitchell, P.J. \& Driver, J. C. (eds) Animals and People: Archaeozoological Papers in Honour of Ina Plug. British Archaeological Reports International Series 1849: 104-116.

Mitchell, P.J. 2009. Hunter-gatherers and farmers: some implications of 1,800 years of interaction in the Maloti-Drakensberg region of southern Africa. In: Ikeya, K., Ogawa, H. \& Mitchell, P. (eds) Interactions between hunter-gatherers and farmers: from prehistory to present: 15-46. Osaka: National Museum of Ethnology.

Mitchell, P.J. 2010. Genetics and southern African prehistory: an archaeological view. Journal of Anthropological Sciences 88: 73-92. 
Mitchell, P.J., Plug, I., Bailey, G. \& Woodborne, S. 2008. Bringing the Kalahari debate to the mountains: late first millennium $A D$ hunter-gatherer/farmer interaction in highland Lesotho. Before Farming [Online Version] 2008/2: article 4.

Morris, A.G. 1992. A master catalogue: Holocene human skeletons from South Africa. Johannesburg: Witwatersrand University Press.

Morris, A. 1995. The Einiqua: an analysis of the Kakamas skeletons. In: Smith A.B. (ed.) Einiqualand: studies of the Orange River frontier: 110-164. Cape Town: University of Cape Town Press.

Morris, D. 1988. Engraved in place and time: a review of variability in the rock art of the northern Cape and Karoo. South African Archaeological Bulletin 43: 109-120.

Morris, D. 1994. An ostrich eggshell cache from the Vaalbos National Park, Northern Cape, South Africa. Southern African Field Archaeology 3: 55-58.

Morris, D. \& Beaumont, P. 1991. !Nwabdanas: archaeological sites at Renosterkop Kakamas District, northern Cape. South African Archaeological Bulletin 46: 115124 ,

Morris, D. \& Von Bezing, I. 1996. The salvage of a cache of ostrich eggshell flasks near Kenhardt, Northern Cape. McGregor Miscellany 6(2): 3-4.

Morris, D. \& Webley, L. 2004. Cultural history in and adjacent the Namaqua National Park. Unpublished report prepared for SANParks. Kimberley \& Grahamstown, McGregor and Albany Museums.

Mossop, E.E. 1935. The journal of Hendrik Jacob Wikar (1779). Cape Town: The Van Riebeeck Society.

Movius, H.L., David, N.C., Bricker, H.M. \& Clay, R.B. 1968. The analysis of certain classes of Upper Palaeolithic tools. Bulletin of the American School of Prehistoric Research, Peabody Museum, Harvard. 26: 1-58.

Mucina, L., Adams, J.B., Knevel, I.C., Rutherford, M.C., Powrie, L.W., Bolton, J.J., Van der Merwe, J.H., Anderson, R.J., Bornman, T.G., Le Roux, A. \& Janssen, A.M. 
2006a. Coastal vegetation of South Africa. In: Mucina, L. \& Rutherford, M.C. (eds) The vegetation of South Africa, Lesotho and Swaziland. Strelitzia 19. Pretoria: South African National Biodiversity Institute.

Mucina, L., Jürgens, N., Le Roux, A., Rutherford, M.C., Schmeidel, U. Esler, K.J., Powrie, L.W., Desmet, P.G. \& Milton, S.J. 2006b. Succulent Karoo biome. In: Mucina, L. \& Rutherford, M.C. (eds) The vegetation of South Africa, Lesotho and Swaziland. Strelitzia 19. Pretoria: South African National Biodiversity Institute.

Nesse, W.D. 2000. Introduction to mineralogy. New York: Oxford University Press.

Nienaber, G.S. \& Raper, P.E. 1977. Toponymica Hottentotica. Pretoria: Human Sciences Research Council.

Noli, D. \& Avery, G. 1987. Stone circles in the Cape Fria area, northern Namibia. South African Archaeological Bulletin 42: 59-63.

Norman, N. \& Whitfield, G. 2006. Geological journeys: a traveller's guide to South Arica's rocks and landforms. Cape Town: Struik Publishers.

Olivier, J. 1995. Spatial distribution of fog in the Namib. Journal of Arid Environments 29: 129-138.

Orton, J. 2002. Patterns in stone: the lithic assemblage from Dunefield Midden, Western Cape, South Africa. South African Archaeological Bulletin 57: 31-37.

Orton, J.D.J. 2004. The quartz conundrum: understanding the role of quartz in the composition of late Pleistocene and Holocene lithic assemblages from the Verlorenvlei area, Western Cape. Unpublished MA dissertation, University of Cape Town.

Orton, J. 2005a. A report on the second excavation season at DP2004/014 in the BMC mining area, Namaqualand. Unpublished report prepared for De Beers Consolidated Mines Ltd. University of Cape Town: Archaeology Contracts Office.

Orton, J. 2005b. Phase 1 archaeological survey of a small area at Annex Kleinzee, Buffels Marine Complex, Namaqualand. Unpublished report prepared for De 
Beers Consolidated Mines NM. University of Cape Town: Archaeology Contracts Office.

Orton, J. 2006. The Later Stone Age lithic sequence at Elands Bay, Western Cape, South Africa. Southern African Humanities 18(2): 1-28.

Orton, J. 2007a. Archaeological impact assessment of erven 13, 14 \& 392, Hondeklipbaai, Namakwa Magisterial District, Northern Cape Province. Unpublished report prepared for C.D. Venter Land Surveyors. University of Cape Town: Archaeology Contracts Office.

Orton, J. 2007b. Excavations at four sites near Jakkalsberg in the Richtersveld. The Digging Stick 24(1): 9-13.

Orton, J. 2007c. Mitigation of archaeological sites within the Buffels Marine, Buffels Inland and Koingnaas Complexes, Namaqualand, August to September 2007. Unpublished report prepared for De Beers Consolidated Mines NM. University of Cape Town: Archaeology Contracts Office.

Orton, J. 2007d. The sampling of ephemeral shell scatters in Namaqualand, South Africa. South African Archaeological Bulletin 62: 74-78.

Orton, J. 2008a. A late Pleistocene microlithic Later Stone Age assemblage from coastal Namaqualand, South Africa. Before Farming [Online Version] 2008/1: article 3.

Orton, J. 2008b. A useful measure of the desirability of different raw materials for retouch within and between assemblages: the raw material retouch index (RMRI). Journal of Archaeological Science 35: 1090-1094.

Orton, J. 2008c. Heritage statement for five proposed camps at Sanbona Wildlife Reserve, Montagu and Swellendam magisterial districts. Unpublished report prepared for Sanbona Game Reserve (Pty) Ltd. University of Cape Town: Archaeology Contracts Office.

Orton, J. 2008d. Later Stone Age ostrich eggshell bead manufacture in the Northern Cape, South Africa. Journal of Archaeological Science 35: 1765-1775. 
Orton, J. 2009a. Archaeological mitigation on erven 13 and 14, Hondeklipbaai, Namakwa Magisterial District, Northern Cape. Unpublished report prepared for HKB Eiendomme BK. University of Cape Town: Archaeology Contracts Office.

Orton, J. 2009b. Hunters or herders? Evidence from the cultural assemblages at Bakoond, Western Cape, South Africa. Before Farming [Online Version] 2009/4: article 1.

Orton, J. 2009c. Rescue excavation at Diaz Street Midden, Saldanha Bay, South Africa. Azania: Archaeological Research in Africa 44: 107-120.

Orton, J. 2010. Environmental Impact Assessment: identification of regional landfill site and permit application for the Northern West Coast District Municipality. Unpublished report prepared for Anél Blignaut Environmental Consultants. University of Cape Town, Archaeology Contracts Office.

Orton, J. 2011a. Heritage assessment of prospecting borehole locations near Klawer, Vanrhynsdorp Magisterial District, Western Cape. Unpublished report prepared for SitePlan. University of Cape Town, Archaeology Contracts Office.

Orton, J. 2011b. Heritage impact assessment for the proposed Vredendal Inca Solar Energy Facility, Vredendal Magisterial District, Western Cape. Unpublished report prepared for Savannah Environmental (Pty) Ltd. Diep River: ACO Associates cc.

Orton, J. 2012. Tortoise burials in Namaqualand: uncovering ritual behaviour on South Africa's west coast. Azania: Archaeological Research in Africa 47: 99-114.

Orton, J. and Compton, J.S. 2006. A reworked mid-Holocene lithic assemblage at Dunefield Midden 1, Elands Bay, South Africa. South African Archaeological Bulletin 61: 90-95.

Orton, J.D.J. \& Halkett, D.J. 2001. Mid-Holocene denticulates in the Richtersveld. Southern African Field Archaeology 10:19-22.

Orton, J. \& Halkett, D. 2005. A report on the archaeological mitigation program at De Beers Namaqualand Mines, August to September 2004. Unpublished report 
prepared for De Beers Consolidated Mines NM. University of Cape Town: Archaeology Contracts Office.

Orton, J. \& Halkett, D. 2006. Mitigation of archaeological sites within the Buffels Marine and Koingnaas Complexes, Namaqualand, September 2005 to May 2006. Unpublished report prepared for De Beers Consolidated Mines NM. University of Cape Town: Archaeology Contracts Office.

Orton, J. \& Halkett, D. 2007a. Archaeological impact assessment of new mining areas along the Buffels River, Namaqualand, Namakwaland Magisterial District, Northern Cape. Unpublished report prepared for ERM SA (Pty) Ltd. University of Cape Town: Archaeology Contracts Office.

Orton, J. \& Halkett, D. 2007b. Excavations at Noetzie Midden: an open site on the Cape south coast. The Digging Stick 24 (3): 5-7.

Orton, J. \& Halkett, D. 2010. Stone tools, beads and a river: two Holocene microlithic sites at Jakkalsberg in the northwestern Richtersveld, Northern Cape. South African Archaeological Bulletin 65: 13-25.

Orton, J. \& Hart, T. 2005. Heritage impact assessment for the proposed raising of the Clanwilliam Dam wall, Olifants River valley, Clanwilliam district. Unpublished report prepared for Ninham Shand Environmental Consulting (Pty) Ltd. University of Cape Town: Archaeology Contracts Office.

Orton, J., Hart, T. \& Halkett, D. 2005. Shell middens in Namaqualand: two huntergatherer sites at Rooiwalbaai, Northern Cape Province, South Africa. South African Archaeological Bulletin 60: 24-32.

Orton, J., Klein, R.G., Mackay, A. Schwortz, S. \& Steele, T.E. 2011. Two Holocene rock shelter deposits from the Knersvlakte, southern Namaqualand, South Africa. Southern African Humanities 23: 109-150.

Orton, J. \& Mackay, A. 2008. New excavations at Klein Kliphuis rock shelter, Cederberg Mountains, Western Cape, South Africa: the late Holocene deposits. South African Archaeological Bulletin 63: 69-76. 
Orton, J., Mitchell, P., Klein, R. \& Steele, T. In press. Early dates for cattle from Namaqualand, South Africa: implications for the origins of herding in southern Africa. Antiquity.

Orton, J. \& Webley, L. 2009. Phase 1 archaeological impact assessment of mining areas in the Oena Mine, Richtersveld, Namakwaland Magisterial District, Northern Cape. Unpublished report prepared for Surf Zone Diamonds Pty (Ltd). University of Cape Town: Archaeology Contracts Office.

Orton, J. \& Webley, L. 2012a. Heritage impact assessment for the proposed ESKOM Kleinsee Wind Energy Facility, Namakwaland Magisterial District, Northern Cape. Unpublished report prepared for Savannah Environmental (Pty) Ltd. Diep River: ACO Associates cc.

Orton, J. \& Webley, L. 2012b. Heritage impact assessment for the proposed Kangnas Wind and Solar Energy Facilities, Namakwa Magisterial District, Northern Cape. Unpublished report prepared for Aurecon South Africa (Pty) Ltd. Diep River: ACO Associates cc.

Orton, J. \& Webley, L. 2012c. Heritage impact assessment for the proposed Project Blue Wind Energy Facility, Kleinzee, Namakwa Magisterial District, Northern Cape. Unpublished report prepared for Savannah Environmental (Pty) Ltd. Diep River: ACO Associates cc.

O'Toole, M.J., Shannon, L.V., De Barros Neto, V. \& Malan, D.E. 2001. Integrated management of the Benguela Current region: a framework for future development. In: Von Bodungen, B. \& Turner, R.K. (eds) Science and integrated coastal management: 229-251. Berlin: Dahlem University Press.

Paine, R. 1971. Animals as capital: comparisons among northern nomadic herders and hunters. Anthropological Quarterly 44: 157-172.

Palmer, A.R., Novellie, P.A. \& Lloyd, J.W., 1999. Community patterns and dynamics. In: Dean, W.R.J., Milton, S.J. (eds.) The Karoo: ecological patterns and processes: 208-223. Cambridge: Cambridge University Press. 
Parkington, J. 1980. Time and place: some observations on spatial and temporal patterning in the Later Stone Age sequence in Southern Africa. South African Archaeological Bulletin 35: 73-83.

Parkington, J. 1984. Changing views of the Later Stone Age of South Africa. Advances in World Archaeology 3: 89-142.

Parkington, J. 1993. ALEXKOR Environmental Management Program Report (EMPR). Specialist report on: Archaeological importance of the ALEXKOR mining area. Unpublished report, Department of Archaeology, University of Cape Town.

Parkington, J. 2012. Megamiddens and megamyths. The Digging Stick 28(3): $10 \& 14$.

Parkington, J., Cartwright, C., Cowling, R.M., Baxter, A., Meadows, M., 2000. Palaeovegetation at the Last Glacial Maximum in the Western Cape, South Africa: wood charcoal and pollen evidence from Elands Bay Cave. South African Journal of Science 96: 543-546.

Parkington, J. Morris, D. \& Rusch, N. 2008. Karoo rock engravings. Cape Town: Creda Communications.

Parkington, J., Nilssen, P., Reeler, C. \& Henshilwood, C. 1992. Making sense of space at Dunefield Midden Campsite, Western Cape, South Africa. Southern African Field Archaeology 1: 63-70.

Parkington, J.E. \& Poggenpoel, C.A. 1971. Excavations at De Hangen 1968. South African Archaeological Bulletin 26: 3-36.

Parkington, J.E. \& Poggenpoel, C. 1990. West coast heavy mineral sands project: archaeological report. Unpublished report. Archaeology Contracts Office, University of Cape Town.

Parkington, J.E., Poggenpoel, C., Buchanan, B., Robey, T., Manhire, T. \& Sealy, J. 1988. Holocene coastal settlement patterns in the western Cape. In: Bailey, G. \& Parkington, J. (eds) The archaeology of prehistoric coastlines: 22-41. Cambridge: Cambridge University Press. 
Parkington, J., Yates, R., Manhire, A. \& Halkett, D. 1986. The social impact of pastoralism in the southwestern Cape. Journal of Anthropological Archaeology 5: 313-329.

Parry, W., Kelly, R. L. 1987. Expedient core technology and sedentism. In: Johnson, J.K. \& Morrow, C.A. (eds) The organization of core technology: 285-304. Boulder: Westview Press.

Parsons, I. 2006. Later Stone Age socio-economic variability during the last 2000 years in the Northern Cape, South Africa. Unpublished PhD thesis, University of Cambridge.

Parsons, I. 2007. Hunter-gatherers or herders? Reconsidering the Swartkop and Doornfontein Industries, Northern Cape Province, South Africa. Before Farming [Online Version] 2007/4: Article 3.

Partridge, T.C. 1997. Cainozoic environmental change in southern Africa, with special reference on the last 200000 years. Progress in Physical Geography 21: 3-22.

Partridge, T.C., Scott, L. \& Hamilton, J.E. 1999. Synthetic reconstructions of southern African environments during the Last Glacial Maximum (21-18 kyr) and the Holocene Altithermal (8-6 kyr). Quaternary International 57-8: 207-214.

Paterson, W. 1789. A narrative of four journeys into the country of the Hottentots, and Caffraria. In the years one thousand seven hundred and seventy-seven, eight and nine. London: J. Johnson.

Patrick, M., de Koning A.J. \& Smith, A.B. 1985. Gas liquid chromatographic analysis of fatty acids in food residues from ceramics found in the southwestern Cape, South Africa. Archaeometry 27: 231-236.

Peacock, P. 1978. Discovering old buttons. Haverfordwest: C.I. Thomas \& Sons.

Peel, M.C., Finlayson, B.L. \& McMahon, T.A. 2007. Updated world map of the KöppenGeiger climate classification system. Hydrology and Earth System Sciences 11: 1633-1644. 
Penn, N.G. 1995. The Northern Cape Frontier Zone, 1700-c.1815. Unpublished PhD thesis, University of Cape Town.

Pettijohn, F.J. 1975. Sedimentary rocks. New York: Harper \& Row.

Pikirayi, I. 2007. Ceramics and group identities: towards a social archaeology in southern African Iron Age ceramic studies. Journal of Social Archaeology 7: 286-301.

Pleurdeau D., Imalwa E, Détroit F., Lesur J., Veldman A., Bahain, J.-J. \& Marais, E. 2012. "Of Sheep and Men": Earliest Direct Evidence of Caprine Domestication in Southern Africa at Leopard Cave (Erongo, Namibia). PLoS ONE 7(7): e40340. doi:10.1371/journal.pone.0040340

Plug, I. 1996. Domestic animals during the Early Iron Age in southern Africa. In: Pwiti, G. \& Soper, R. (eds) Aspects of African archaeology: 515-520. Harare: University of Zimbabwe Press.

Plug, I. 2003. Appendix D: Report on Pitsaneng fauna. In: Hobart, J.H. Forager-farmer relations in south-eastern southern Africa: a critical reassessment: 425-428. Unpublished DPhil thesis, University of Oxford.

Plug, I., Bollong, C.A., Hart, T.J.G., \& Sampson, C.G. 1994. Context and direct dating of pre-European livestock in the upper Seacow River valley. Annals of the South African Museum 104: 31-48.

Plug, I. \& Mitchell, P.J. 2008. Sehonghong: hunter-gatherer utilization of animal resources in the highlands of Lesotho. Annals of the Transvaal Museum 45: 123.

Poggenpoel, C. 1987. The implications of fish bone assemblages from Eland's Bay Cave, Tortoise Cave and Diepkloof for changes in the history of Verlorenvlei. In: Parkington, J. \& Hall, M. (eds) Papers in the prehistory of the western Cape, South Africa: 212-236. Oxford: British Archaeological Reports International Series 332 (ii).

Poggenpoel, C.A. \& Robertshaw, P.T. 1981. The excavation of Smitswinkelbaai Cave, Cape Peninsula. South African Archaeological Bulletin 36: 29-35. 
Popov, A.A. 1966. The Nganasan: the material culture of the Tavgi Samoyeds. Indiana University Uralic and Altaic Series 56. Bloomington: Indiana University.

Price, T.D. 2000. Europe's first farmers: an introduction. In: Price, T.D. (ed.) Europe's first farmers: 1-18. Cambridge: Cambridge University Press.

Raven-Hart, R. 1967. Before Van Riebeeck. Callers at South Africa from 1488 to 1652. Cape Town: Struik

Rebelo, A.G., Boucher, C., Helme, N., Mucina, L. \& Rutherford, M.C. 2006. Fynbos biome. In: Mucina, L. \& Rutherford, M.C. (eds) The vegetation of South Africa, Lesotho and Swaziland. Strelitzia 19. Pretoria: South African National Biodiversity Institute.

Reid, A., Sadr, K. \& Hansom-James, N. 1998. Herding traditions. In: Lane, P., Reid, A. \& Segobye, A. (eds) Ditswa mmung: the archaeology of Botswana :81-100. Gaborone: The Botswana Society \& Pula Press.

Reimer, P.J., Baillie, M.G.L., Bard, E., Bayliss, A., Beck, J.W., Blackwell, P.G., Bronk Ramsey, C., Buck, C.E., Burr, G.S., Edwards, R.L., Friedrich, M., Grootes, P.M., Guilderson, T.P., Hajdas, I., Heaton, T.J., Hogg, A.G., Hughen, K.A., Kaiser, K. F., Kromer, B., McCormac, F.G., Manning, S.W., Reimer, R.W., Richards, D.A., Southon, J.R., Talamo, S., Turney, C.S.M., van der Plicht, J., \& Weyhenmeyer, C.E. 2009. IntCal09 and Marine09 radiocarbon age calibration curves, 0-50,000 years cal BP. Radiocarbon 51: 1111-1150.

Richardson, N. 1992. Conjoin sets and stratigraphic integrity in a sandstone shelter: Kenniff Cave (Queensland, Australia). Antiquity 66: 408-418.

Robbins, L.H., A.C. Campbell, M.L. Murphy, G.A. Brook, F. Liang, S.A. Skaggs, P. Srivastava, A.A. Mabuse \& S. Badenhorst. 2008. Recent archaeological research at Toteng, Botswana: early domesticated livestock in the Kalahari. Journal of African Archaeology 6: 131-149.

Robbins, L.H., Campbell, A.C., Murphy, M.L., Brook, G.A., Srivastava, P. \& Badenhorst, S. 2005. The advent of herding in southern Africa: early AMS dates on domestic livestock from the Kalahari Desert. Current Anthropology 46: 671-677. 
Robbins, L.H., Murphy, M.L., Campbell, A.C., Brook, G.A., Reid, D.M., Haberyan, K.A. \& Downey, W.S. 1998. Test excavations and reconnaissance palaeoenvironmental work at Toteng, Botswana. South African Archaeological Bulletin 53: 125-132.

Roberts, D.L. 2003. Age, genesis and significance of South Africa coastal belt silcretes. Council for Geoscience Memoir 95: 1-61.

Roberts, D.L., Botha, G.A., Maud, R.R. \& Pether, J. 2006. Coastal Cenozoic deposits. In: Johnson, M.R., Anhaeusser, C.R. \& Thomas, R.J. (eds) The geology of South Africa: 605-628. Johannesburg: Geological Society of South Africa / Pretoria: Council for Geoscience.

Robertshaw, P.T. 1978a. The archaeology of an abandoned pastoralist camp. South African Journal of Science 74: 29-31.

Robertshaw, P.T. 1978b. The origins of pastoralism at the Cape. South African Historical Journal 10: 117-133.

Robertshaw, P.T. 1979. Coastal settlement, freshwater fishing and pastoralism in the later prehistory of the western Cape, South Africa. Unpublished $\mathrm{PhD}$ thesis, University of Cambridge.

Robertshaw, P.T. 1984. Excavations at Fairview Rockshelter - a contribution to the prehistory of the eastern Cape Province of South Africa. Annals of the Cape Provincial Museums (Human Sciences) 1: 55-92.

Robertshaw, P., Wood, M., Melchiorre, E., Popelka-Filcoff, R.S. \& Glascock, M.D. 2010. Southern African glass beads: chemistry, glass sources and patterns of trade. Journal of Archaeological Science 30: 1898-1912.

Robertson, G., Attenbrow, V. \& Hiscock, P. 2009. Multiple uses for Australian backed artefacts. Antiquity 83: 296-308.

Robey, T. 1984. Burrows and Bedding: site taphonomy and spatial archaeology at Tortoise Cave. Unpublished MA dissertation, University of Cape Town. 
Robey, T. 1987. The stratigraphic and cultural sequence at Tortoise Cave, Verlorenvlei. In: Parkington, J.E. \& Hall, M. (eds) Papers in the prehistory of the western Cape, South Africa: 294-325. Oxford: British Archaeological Reports International Series 332(ii).

Rockman, M. 2003. Knowledge and learning in the archaeology of colonization. In: Rockman, M. \& Steele, J. (eds) Colonization of unfamiliar landscapes: the archaeology of adaptation: 3-24. London: Routledge.

Rockman, M. \& Steele, J. (eds). 2003. Colonization of unfamiliar landscapes: the archaeology of adaptation. London: Routledge.

Rosen, S.A. 1998. The development of pastoral nomadic systems in the southern Levantine periphery: an economic model based on archaeological evidence. In: Pearce, M. \& Tosi, M. (eds) Papers from the EAA third annual meeting: pre- and proto-history: 92-97. British Archaeological Reports International Series 717. Oxford: Archaeopress.

Rudner, J. 1968. Strandloper pottery from South and South West Africa. Annals of the South African Museum 49: 441-663.

Rudner, J. 1979. The use of stone artefacts and pottery among the Khoisan peoples in historic and proto-historic times. South African Archaeological Bulletin 34: 3-17.

Rudner, J. \& Grattan-Bellew, P. 1964. Archaeological sites along the southern coast of South West Africa. South African Journal of Science 60: 67-79.

Rudner, I. \& Rudner, J. 1959. Who were the artists? Archaeological notes from South West Africa. South African Archaeological Bulletin 14:106-108.

Rudner, J. \& Rudner, I. 1968. Rock-art in the thirstland areas. South African Archaeological Bulletin 23: 75-89

Russell, T.M. 2004. The spatial analysis of radiocarbon databases: the spread of the first farmers in Europe and of the fat-tailed sheep in Southern Africa. Oxford: British Archaeological Reports International Series 1294. 
Sadr, K. 1997. Kalahari Archaeology and the Bushman Debate. Current Anthropology 38: 104-112

Sadr, K. 1998. The first herders at the Cape of Good Hope. African Archaeological Review 15: 101-132.

Sadr, K. 2002. Ancient pastoralists in the Sudan and in South Africa. In: Jennerstrasse 8 (ed.) Tides of the desert: contributions to the archaeology and environmental history of Africa in honour of Rudolph Kuper: 471-484. Koln: Heinrich-BarthInstitut.

Sadr, K. 2003. The Neolithic of southern Africa. Journal of African History 44: 195-209.

Sadr, K. 2004. Feasting on Kasteelberg? Early herders on the west coast of South Africa. Before Farming [Online Version] 2004 (3): article 2.

Sadr, K. 2005a. From foraging to herding: the west coast of South Africa in the first millennium AD. Human Evolution 20: 217-230.

Sadr, K. 2005b. Hunter-gatherers and herders of the Kalahari during the late Holocene. In: Veth, P., Smith, M. \& Hiscock, P. (eds) Desert peoples: archaeological perspectives: 206-221. Oxford: Blackwell Publishing Ltd.

Sadr, K. 2008a. An ageless view of first millennium AD southern African ceramics. Journal of African Archaeology 6: 103-129.

Sadr, K. 2008b. Invisible herders? The archaeology of Khoekhoe pastoralists. Southern African Humanities 20: 179-203.

Sadr, K. 2009. Marine shell dates and surface lithic assemblages on the west coast of South Africa. Journal of Archaeological Science 36: 2713-29.

Sadr, K. \& Gribble, J. 2010. The stone artefacts from the Vredenburg Peninsula, archaeological survey west coast of South Africa. Southern African Humanities 22: 19-88. 
Sadr, K. \& Plug, I. 2001. Faunal remains in the transition from hunting to herding in southeastern Botswana. South African Archaeological Bulletin 56: 76-82.

Sadr, K. \& Sampson, C.G. 1999. Khoekhoe ceramics of the upper Seacow River valley. South African Archaeological Bulletin 54: 3-15.

Sadr, K. \& Sampson, C.G. 2006. Through thick and thin: early pottery in southern Africa. Journal of African Archaeology 4: 235-252.

Sadr, K. \& Smith, A.B. 1991. On ceramic variation in the south-western Cape, South Africa. South African Archaeological Bulletin 46: 107-114.

Sadr, K., Smith, A., Plug, I,. Orton, J. \& Mütti, B. 2003. Herders and foragers on Kasteelberg: interim report on excavations 1999-2002. South African Archaeological Bulletin 58: 27-32.

Sampson C.G. 1974. The Stone Age archaeology of southern Africa. New York: Academic Press.

Sampson, C.G. 1985. Atlas of Stone Age settlement in the central and upper Seacow Valley. Memoirs of the National Museum (Bloemfontein) 20: 1-116.

Sampson, C.G. 1988. Stylistic boundaries among mobile hunter-foragers. Washington: Smithsonian Institution Press.

Sampson, C.G. 2010. Chronology and dynamics of Later Stone Age herders in the Seacow River valley, South Africa. Journal of Arid Environments 74: 848-848.

Sampson, C.G., Hart, T.J.G., Wallsmith, D.L. \& Blagg, J.D. 1989. The ceramic sequence in the upper Seacow Valley: problems and implications. South African Archaeological Bulletin 44: 3-16.

Sampson, C.G. \& Sadr, K. 1999. On the size and shape of Later Stone Age fibretempered vessels from the Upper Seacow River valley. Southern African Field Archaeology 8: 3-16. 
Sampson, C.G. \& Vogel J.C. 1995. Radiocarbon chronology of Later Stone Age pottery decorations in the upper Seacow Valley. Southern African Field Archaeology 4: 84-94.

Samuels, M.I., Allsopp, N. \& Hoffman, T. 2008. Mobility patterns of livestock keepers in semi-arid communal rangelands of Namaqualand, South Africa. Nomadic Peoples 12: 123-148.

Sandelowsky, B.H. 1983. Archaeology in Namibia: Fossils, stone tools, and abundant rock art testify to the continuous hominid and human occupation of this corner of southwestern Africa for the last two million years. American Scientist 71: 606615.

Sandelowsky, B.H., Van Rooyen, J.H. \& Vogel, J.C. 1979. Early evidence for herders in the Namib. South African Archaeological Bulletin 34: 50-51.

Shapera, I. 1930. The Khoisan peoples of South Africa: Bushmen and Hottentots. London: Routledge \& Kegan Paul Ltd.

Schapera, I. \& Farrington, E. 1933. The early Cape Hottentots described in the writings of Olfert Dapper (1668) Willem ten Rhyne (1686) and Johannes Gulielmus de Grevenbroek (1695). Cape Town: The Van Riebeeck Society.

Schrire, C. 1980. An inquiry into the evolutionary status and apparent identity of San hunter-gatherers. Human Ecology 8: 9-32.

Schrire, C. 1992. The archaeological identity of hunters and herders at the Cape over the last 2000 years: a critique. Cape. South African Archaeological Bulletin 47: 6264.

Schrire, C. \& Deacon, J. 1989. The indigenous artefacts from Oudepost 1, a colonial outpost of the VOC at Saldanha Bay, Cape. South African Archaeological Bulletin 44: 105-113.

Schrire, C., Deetz, J., Lubinsky, D. \& Poggenpoel, C. 1990. The chronology of Oudepost I, Cape, as Inferred from an analysis of clay pipes. Journal of Archaeological Science 17: 269-300. 
Schulze R.E. \& McGee O.S. 1978. Climatic indices and classifications in relation to the biogeography of southern Africa. In Werger M.J.A. (ed.) Biogeography and ecology of Southern Africa Vol. 1: 19-52. The Hague: Junk.

Schweitzer, F.R. 1974. Archaeological Evidence for Sheep at the Cape. South African Archaeological Bulletin 29: 75-82.

Schweitzer, F.R. 1979. Excavations at Die Kelders, Cape Province, South Africa. Annals of the South African Museum 78: 101-232.

Scott, L. 1993. Palynological evidence for late Quaternary warming episodes in southern Africa. Palaeogeography, Palaeoclimatology, Palaeoecology 101: 229-236.

Scott, L. 1996. Palynology of hyrax middens: 2000 years of palaeoenvironmental history in Namibia. Quaternary International 33: 73-96.

Sealy, J. 2010. Isotopic evidence for the antiquity of cattle-based pastoralism in southernmost Africa. Journal of African Archaeology 8: 65-81.

Sealy, J., Maggs, T., Jerardino, A. \& Kaplan, J. 2002. Excavations at Melkbosstrand: variability among herder sites on Table Bay, South Africa. South African Archaeological Bulletin 59: 17-28.

Sealy, J. \& Yates, R. 1994. The chronology of the introduction of pastoralism to the Cape, South Africa. Antiquity 68: 58-67.

Sealy, J. \& Yates, R. 1996. Direct radiocarbon dating of early sheep bones: two further results. South African Archaeological Bulletin 51: 109-110.

Seddon, J.D. \& Vinnicombe, P. 1967. Domestic animals, rock art and dating. South African Archaeological Bulletin 22: 112-113.

Shackley, M. 1985. Palaeolithic archaeology of the central Namib Desert.: a preliminary survey of chronology, typology and site location. Cimbebasia Memoir No. 6. Windhoek: State Museum. 
Shahack-Gross, R., Marshal, F. \& Weiner, S. 2003. Geo-ethnoarchaeology of pastoral sites: the identification of livestock enclosures in abandoned Maasai settlements. Journal of Archaeological Science 30: 439-459.

Shaw, B. 1840. Memorials of South Africa. London: Adams \& Co.

Shi, N., Dupont, L.M., Beug, H-J. \& Schneider, R. 1998. Vegetation and climate changes during the last 21000 years in SW Africa based on a marine pollen record. Vegetation History and Archaeobotany 7: 127-140.

Shikama, T. 1974. On two new allied cowry and cowry shells from South African Sea. Science Reports of the Yokohoma National University (Sect. 2) 21: 23-26.

Shott, M. 1986. Technological organization and settlement mobility: an ethnographic examination. Journal of Anthropological Research 42: 15-51.

Sievers, C. 1984. Test excavations at Rosh Pinah Shelter southern Namibia. Cimbebasia (B) 4: 29-40.

Skead, C.J. 1980. Historical mammal incidence in the Cape Province. Volume 1: the western and northern Cape. Cape Town: Department of Nature and Environmental Conservation of the Provincial Administration of the Cape of Good Hope.

Smith, A.B. 1983. Prehistoric pastoralism in the southwestern Cape, South Africa. World Archaeology 15: 79-89.

Smith, A.B. 1987. Seasonal exploitation of resources on the Vredenburg Peninsula after 2000 B.P. In: Parkington, J.E. \& Hall, M. (eds) Papers in the prehistory of the western Cape, South Africa: 393-402. Oxford: British Archaeological Reports International Series 332(ii).

Smith, A.B. 1990. On becoming herders: Khoikhoi and San ethnicity in southern Africa. African Studies 49(2): 51-73.

Smith, A.B. 1992. Pastoralism in Africa: origins and development ecology. London: Hurst. 
Smith, A.B. 1998a. Early domestic stock in southern Africa: a commentary. African Archaeological Review 15: 151-156.

Smith, A.B. 1998b. Keeping people on the periphery: the ideology of social hierarchies between hunters and herders. Journal of Anthropological Archaeology 17: 201215.

Smith, A.B. 2000. The origins of the domesticated animals of southern Africa. In: Blench, R.M. \& MacDonald, K.C. (eds) The origins and development of African livestock: archaeology, genetics, linguistics and ethnography: 222-238. London: UCL Press.

Smith, A.B. 2005a. African herders: emergence of pastoral traditions. Walnut Creek: AltaMira Press.

Smith, A.B. 2005b. The concepts of 'Neolithic' and 'Neolithisation' for Africa? Before Farming [Online Version] 2005/1: article 2.

Smith, A.B. 2006a. Excavations at Kasteelberg and the origins of the Khoekhoen in the Western Cape, South Africa. Oxford: British Archaeological Reports International Series 1537.

Smith, A.B. 2006b. Kasteelberg: a pastoralist sealing camp in Western Cape Province, South Africa. Journal of Island and Coastal Archaeology 1: 109-122.

Smith, A.B. 2008a. Is absence of evidence, evidence of absence? In: Barnard, H. \& Wendrich, W. (eds) The archaeology of mobility: Old World and New World nomadism: 264-279. Los Angeles: Cotsen Institute of Archaeology, UCLA.

Smith, A.B. 2008b. Pastoral origins at the Cape, South Africa: influences and arguments. Southern African Humanities 20: 49-60.

Smith, A.B. 2009. The hegemony of the Neolithic: or what we have lost by becoming food producers. South African Archaeological Bulletin 64: 100-103.

Smith, A.B., Halkett, D., Hart, T. \& Mütti, B. 2001. Spatial patterning, cultural identity and spatial integrity on open sites: evidence from Bloeddrift 23, a pre-colonial herder 
camp in the Richtersveld, Northern Cape province, South Africa. South African Archaeological Bulletin 56: 23-33.

Smith, A.B. \& Jacobson, L. 1995. Excavations at Geduld and the appearance of early domestic stock in Namibia. South African Archaeological Bulletin 50: 3-14.

Smith, A.B. \& Kinahan, J. 1984. The invisible whale. World Archaeology 16: 89-97.

Smith, A.B. \& Pheiffer, R.H. 1992. Col. Robert Jacob Gordon's notes on the Khoikhoi 1779-80. Annals of the South African Cultural History Museum 5(1): 1-56.

Smith, A.B. \& Pheiffer, R.H. 1993. The Khoikhoi at the Cape of Good Hope: seventeenth century drawings in the South African Library. Cape Town: South African Library.

Smith, A.B., Sadr, K., Gribble, J. \& Yates, R. 1991. Excavations in the south-western Cape, South Africa, and the archaeological identity of prehistoric hunter-gatherers within the last 2000 years. South African Archaeological Bulletin 46: 71-91.

Smith, A. \& Webley, L. 2000. Women \& men of the Khoekhoen of southern Africa. In: Hodgson, D.L. (ed.) Rethinking pastoralism in Africa: gender, culture and the myth of the patriarchal pastoralist: 72-96. Oxford: James Currey Ltd.

Smith, B. 2006. Reading rock art and writing genetic history: regionalism, ethnicity and the rock art of southern Africa. In: Soodyall, H. (ed.) The prehistory of Africa: tracing the lineage of modern man: 76-96. Johannesburg: Jonathan Ball Publishers.

Smith, B.W. \& Ouzman, S. 2004. Taking stock: identifying Khoekhoen herder rock art in Southern Africa. Current Anthropology 45: 499-526.

Smith, M. 2005. Moving into the southern deserts: an archaeology of dispersal and colonisation. In: In: Smith, M. \& Hesse, P. (eds) $23^{\circ} \mathrm{S}$ : archaeology and environmental history of the southern deserts: 92-107. Canberra: National Museum of Australia. 
Southon, J., Kashgarian, M., Fontugne, M., Metivier, B. \& Yim, W.W-S. 2002. Marine reservoir corrections for the Indian Ocean and southeast Asia. Radiocarbon 44: $167-180$.

Sparrman, A. 1785. A voyage to the Cape of Good Hope towards the Polar Circle and round the world but chiefly into the country of the Hottentots and Caffres from the year 1772, to 1776 . Volume 1. London: G.G.J. \& J. Robinson.

Steele, T.E., Mackay, A., Orton, J. \& Schwortz, S. 2010. Varsche River 3, a new Middle Stone Age site in southern Namaqualand, South Africa. Poster presented at the $75^{\text {th }}$ anniversary meeting of the Society for American Archaeology. St. Louis, Missouri.

Steele, T.E., Mackay, A., Orton, J. \& Schwortz, S. 2012. Varsche Rivier 003, a new Middle Stone Age site in southern Namaqualand, South Africa. South African Archaeological Bulletin 67: 108-119.

Stenning, D.J. 1964. Savannah nomads: a study of the Wodaabe pastoral Fulani of western Bornu Province, Northern Region, Nigeria. London: Oxford University Press.

Stewart, B.A. 2005. The Dunefield Midden ceramics: technical analysis and placement in the Western Cape Sequence. South African Archaeological Bulletin 60: 103111.

Stewart, B.A., Parkington, J. \& Fisher, J.W. 2011. The tortoise and the ostrich egg: projecting the home base hypothesis into the 21 st century. In: Sept, J. \& Pilbeam, D. (eds) Casting the net wide: papers in honor of Glynn Isaac and his approach to human origins research: 255-278. Oxford: Oxbow Books.

Stow, G.W. 1905. The native races of South Africa: a history of the intrusion of the Hottentots and the Bantu into the hunting grounds of the Bushmen, the aborigines of the country. London: Swan Sonnenschein \& Co.

Stuiver, M., Reimer, P.J. \& Reimer, R. 2012. Calib 6.0. http://calib.qub.ac.uk/calib/ calib.html. Accessed 20 December 2012. 
Stynder, D.D. 2009. Craniometric evidence for South African Late Stone Age herders and hunter-gatherers being a single biological population. Journal of Archaeological Science 36: 798-806.

Stynder, D.D., Ackerman, R.R. \& Sealy, J.C. 2007. Craniofacial variation and population continuity during the South African Holocene. American Journal of Physical Anthropology 134: 489-500.

Summerfield, M.A. 1982. Distribution, nature and probable genesis of silcrete in arid and semi-arid Southern Africa. Catena Supplement 1: 37-65.

Summerfield, M.A. 1983. Silcrete In: Goudie, A.S. \& Pye, K. (eds) Chemical sediments and geomorphology: precipitates and residua in the near-surface environment. 59-91. London: Academic Press.

Swidler, W.W. 1972. Some demographic factors regulating the formation of flocks and camps among the Brahui of Baluchistan. Journal of Asian and African Studies 7: 69-75.

Talma, A.S. \& Vogel, J.C. 1992. Late Quaternary palaeotemperatures derived from a speleothem from Cango Caves, Cape Province, South Africa. Quaternary Research 37: 203-213.

Tankard, A.J. 1976. The Late Pleistocene history and coastal morphology of the Ysterfontein-Elands Bay area, Cape Province. Annals of the South African Museum 69: 73-119.

Teixeriea, M.A. de Pimental. 1952. Rock-peckings from Angola. South African Archaeological Bulletin 7: 130.

Testart, A. 1982. The significance of food storage among hunter-gatherers: residence patterns, population densities, and social inequalities. Current Anthropology 23: 523-537.

Theron, J.N. 1984. The geology of Cape Town and environs: explanation of Sheets $3318 C D$ and $D C$, and $3418 A B, A D$ and $B A$. Pretoria: Department of Mineral and Energy Affairs. 
Thorp, C.R. 1996. A preliminary report on evidence of interaction between huntergatherers and farmers along a hypothesised frontier in the eastern Free State. South African Archaeological Bulletin 51: 57-63.

Torrence, R. 1983. Time budgeting and hunter-gatherer technology. In: Bailey, G. (ed.) Hunter-gatherer economy in prehistory: a European perspective: 11-22. Cambridge: Cambridge University Press.

Truswell, J.F. 1970. An introduction to the historical geology of southern Africa. Cape Town: Purnell.

Tyson, P.D. 1999. Late Quaternary and Holocene palaeoclimates of southern Africa: a synthesis. South African Journal of Geology 102: 335-349.

Tyson, P.D., Karlén, W. Holmgren, K. \& Heiss, G.A. 2000. The little Ice Age and Medieval warming in South Africa. South African Journal of Science 96: 121-126.

Tyson, P.D. \& Lindesay, J.A. 1992. The climate of the last 2000 years in southern Africa. The Holocene 2: 271-276.

Tyson, P.D. \& Partridge, T.C. 2000. Evolution of Cenozoic climates. In: Partridge, T.C. \& Maud, R.R. (eds) The Cenozoic of Southern Africa: 371-87. New York: Oxford University Press.

Tyson, P.D. \& Preston-Whyte, R.A. 2000. The weather and climate of southern Africa. Cape Town: Oxford University Press.

Van Doornum, B. 2008. Sheltered from change: hunter-gatherer occupation of Balerno Main Shelter, Shashe-Limpopo Confluence area, South Africa. Southern African Humanities 20(2): 249-284.

Van Riebeeck, J. 1952. Journal of Jan van Riebeeck 1651-1662. Volume I. Cape Town: Balkema.

Van Riebeeck, J. 1954. Journal of Jan van Riebeeck 1651-1662. Volume II. Cape Town: Balkema. 
Van Rijssen, W.J. 1984. South-western Cape rock art - who painted what? South African Archaeological Bulletin 39: 125-129.

Van Rijssen, W.J. 1992. The late Holocene deposits at Klein Kliphuis Shelter, Cederberg, western Cape Province. South African Archaeological Bulletin 47: 34-39.

Van Rijssen, W.J. 1994. Rock art: the question of authorship. In: Dowson, T.A. \& LewisWilliams, D. (eds) Contested images: diversity in southern African rock art research: 159-175. Johannesburg: Witwatersrand University Press.

Veth, P. 2005. Cycles of aridity and human mobility: risk minimization among late Pleistocene foragers of the Western Desert, Australia. In: Veth, P., Smith, M. \& Hiscock, P. (eds) Desert peoples: archaeological perspectives: 100-115. Oxford: Blackwell Publishing Ltd.

Viereck, A. \& Rudner, J. 1957. Twyfelfontein - a centre of prehistoric art in South West Africa. South African Archaeological Bulletin 12: 15-26.

Villa, P. \& Courtin, J. 1983. The interpretation of stratified sites: a view from underground. Journal of Archaeological Science 10: 267-281.

Visser, D.J.L. \& Van Riet Lowe, C. 1955. The geology and archaeology of the Little Caledon River Valley. South African Geological Survey Memoir 47: 1-64

Vogel, J.C. 1970. Groningen Laboratory dates IX. Radiocarbon 12: 444-471.

Vogel, J.C. 1989. Evidence of past climatic change in the Namib Desert. Palaeogeography, Palaeoclimatology, Palaeoecology 70: 355-366.

Vogel, J.C. 2003. The age of dead trees at Sossusvlei and Tsondabvlei, Namib Desert, Namibia. Cimbebasia 18: 247-251.

Vogel, J.C. Fuls, A., \& Visser, E. 1986. Pretoria radiocarbon dates III. Radiocarbon 28: 1133-1172. 
Vogel, J., Plug, I. \& Webley, L. 1997. New evidence for the introduction of sheep into South Africa: the evidence from Spoegrivier Cave in Namaqualand. South African Journal of Science 93: 246-248.

Vogel, J.C. \& Visser, E. 1981. Pretoria radiocarbon dates II. Radiocarbon 23: 43-80.

Vogel, J.C., Visser, E. \& Fuls, A 2001. Suitability of ostrich eggshell for radiocarbon dating. Radiocarbon 43: 133-137.

Vogelsang, R., Eichhorn, B. \& Richter, J. 2002. Holocene human occupation and vegetation history in northern Namibia. Die Erde 133: 113-132.

Voigt, E. A. 1983. Mapungubwe: an archaeozoological interpretation of an Iron Age community. Pretoria: Transvaal Museum Monographs 1: 1-203.

Von den Driesch, A. \& Deacon, H.J. 1985. Sheep remains from Boomplaas Cave, South Africa. South African Archaeological Bulletin 40: 39-44.

Wadley, L. 1979. Big Elephant Shelter and its role in the Holocene prehistory of central South West Africa. Cimbebasia Series B 3: 1-76.

Wadley, L. 1987. Later Stone Age hunters and gatherers of the southern Transvaal: social and ecological interpretation. Oxford: British Archaeological Reports International Series 380.

Wadley, L. 1993. The Pleistocene Later Stone Age south of the Limpopo River. Journal of World Prehistory 7: 243-296.

Wadley, L., Hodgskiss, T. \& Grant, M. 2009. Implications for complex cognition from the hafting of tools with compound adhesives in the Middle Stone Age, South Africa. Proceedings of the National Academy of Sciences (USA) 106: 9590-9594.

Wagner, P.A. \& Merensky, H. 1928. The diamond deposits on the coast of Little Namaqualand. Transactions of the Geological Society of South Africa 31: 1-41.

Walker, N.J. 1983. The significance of an early date for pottery and sheep in Zimbabwe. South African Archaeological Bulletin 38: 88-92. 
Wallis, R.J. 2004. Comments on "Taking stock: identifying Khoekhoen herder rock art in southern Africa" by B.W. Smith \& S. Ouzman. Current Anthropology 45: 519-520.

Wandsnider, L. \& Camilli E.I. 1992. The character of surface archaeological deposits and its influence on survey accuracy. Journal of Field Archaeology 19: 169-188.

Wasson, R.J., Hunt, P.A. \& Clarke, M.F. 1979. A re-evaluation of the "silcretes" of the Cobar area, Australia. Geoderma 22: 137-159.

Waterhouse, G. 1932. Simon van der Stel's journal of his expedition to Namaqualand 1685-6. London: Longmans, Green and Company.

Webley, L.E. 1982. Settlement studies among descendents of Nama herders: an ethnoarchaeological approach. Khoisis 3: 1-26.

Webley, L.E. 1984. Archaeology and ethnoarchaeology in the Leliefontein Reserve and surrounds, Namaqualand. Unpublished MA Dissertation, University of Stellenbosch.

Webley, L. 1986. Pastoralist ethnoarchaeology in Namaqualand. In: Hall, M. \& Smith, A.B. (eds) Prehistoric pastoralism in southern Africa. South African Archaeological Society Goodwin Series 5: 57-61.

Webley, L.E. 1990. The use of stone 'scrapers' by semi-sedentary pastoralist groups in Namaqualand, South Africa. South African Archaeological Bulletin 45: 28-32.

Webley, L.E. 1992a. Early evidence for sheep from Spoeg River Cave, Namaqualand. Southern African Field Archaeology 1: 3-13.

Webley, L.E. 1992b. The history and archaeology of pastoralism and hunter-gatherer settlement in the north-western Cape, South Africa. Unpublished PhD thesis, University of Cape Town.

Webley, L. 1997a. Jakkalsberg A and B: the cultural material from two pastoralist sites in the Richtersveld, Northern Cape. Southern African Field Archaeology 6: 3-19. 
Webley, L. 1997b. Wives and sisters: changing gender relations among Khoe pastoralists in Namaqualand. In: Wadley, L. (ed.) Our gendered past: archaeological studies of gender in South Africa: 167-208. Johannesburg: Witwatersrand University Press.

Webley, L., 2001. Excavations at /hei-/khomas (Vaalhoek) in the Richtersveld, Northern Cape. Southern African Field Archaeology 10: 46-74.

Webley, L. 2002. The re-excavation of Spoegrivier Cave on the West Coast of South Africa. Annals of the Eastern Cape Museums 2: 19-49.

Webley, L. 2005. Hide-working among descendants of Khoekhoen pastoralists in the Northern Cape, South Africa. In Frink, L. \& Weedman, K. (eds) Gender and hide production: 153-174. New York: Altamira Press.

Webley, L. 2007. Archaeological evidence for pastoralist land-use and settlement in Namaqualand over the last 2000 years. Journal of Arid Environments 70: 629640.

Webley, L. 2009. Archaeological impact assessment: Port Nolloth Borrow Pits, Richtersveld Municipality, Northern Cape. Unpublished report prepared for Richtersveld Municipality. Archaeology Contracts Office, University of Cape Town.

Webley, L., Archer, F. \& Brink, J. 1993. Die Toon: a late Holocene site in the Richtersveld National Park, northern Cape. Koedoe 36 (2): 1-9.

Webley, L. \& Orton, J. 2010. Port Nolloth. Phase 2 archaeological impact assessment: Port Nolloth Borrow Site 1 (PN001), Richtersveld Municipality, Northern Cape. Unpublished report prepared for Richtersveld Municipality. Archaeology Contracts Office, University of Cape Town.

Wendt, W.E. 1972. Preliminary report on an archaeological research programme in South West Africa. Cimbebasia (B) 2: 1-61.

Werz, B. 1994. Dutch brass buttons from the shipwreck of the "Oosterland" (1697): a response to Miller and Markell. Southern African Field Archaeology 3: 48-50. 
Westphal, E.O.J. 1963. The linguistic prehistory of southern Africa: Bush, Kwadi, Hottentot and Bantu linguistic relationships. Africa 33: 237-265.

Whitten, D.G.A. \& Brooks, J.R.V. 1972. The Penguin dictionary of geology. London: Penguin Books.

Willcox, A.R. 1963. The rock art of South Africa. Johannesburg: Nelson.

Willcox, A.R. 1965. Archaeological notes from the northern Cape. South African Archaeological Bulletin 20: 139-140.

Williamson, B.S. 1997. Down the microscope and beyond: microscopy and molecular studies of stone tool residues and bone samples from Rose Cottage Cave. South African Journal of Science 93: 458-464.

Wilson, M. 1969. The hunters and herders. In: Wilson, M. \& Thompson, L. (eds) The Oxford history of South Africa: 40-74. London: Oxford University Press.

Wilson, M.L. 1986. Notes on the nomenclature of the Khoisan. Annals of the South African Museum 97: 251-266.

Wilson, M.L. 1996. The late Holocene occupants of Die Kelders: hunter-gatherers or herders? Southern African Field Archaeology 5: 79-83.

Wilson, M.L., Van Rijssen, W.J.J., Jacobson, L. \& Noli, H.D. 1990. Comments on the indigenous artefacts from Oudepost 1. South African Archaeological Bulletin 45: $122-124$

Wilson, M.L. \& Halkett, D. 1981. The use of marine shell for decorating coastal (Khoisan) pottery. South African Archaeological Bulletin 34: 43.

Wood, J.G. 1870. The uncivilised races of men in all countries of the world; being a comprehensive account of their manners and customs, and of their physical, social, mental, moral and religious characteristics. Vol. I. Hartford: J.B. Burr and Company. 
Wood, M. 2011a. A glass bead sequence for southern Africa from the 8th to the 16th century AD. Journal of African Archaeology 9: 67-84.

Wood, M. 2011b. Interconnections: glass beads and trade in southern and eastern Africa and the Indian Ocean - 7th to 16th centuries AD. Department of Archaeology and Ancient History. Studies in Global Archaeology 17. 62 pp. Uppsala.

Woodburn, J. 1980. Hunters and gatherers today and reconstruction of the past. In: Gellner, E. (ed.) Soviet and western anthropology: 95-117. London: Duckworth.

Wuras, C.F. 1929. An account of the Korana. Bantu Studies 3: 287-296

Yates, R. 1995. Report on the analysis of ostrich eggshell beads from Geduld. South African Archaeological Bulletin 50: 17-20.

Yates, R.J., Miller, D.E., Halkett, D.J., Manhire, A.H. \& Parkington, J.E. 1986. A Late Mid-Holocene high sea level: a preliminary report on geoarchaeology at Elands Bay, western Cape Province, South Africa. South African Journal of Science 82: $164-165$.

Yates, R., Manhire, A. \& Parkington, J. 1994. Rock painting and history in the southwestern Cape. In: Dowson, T.A. \& Lewis Williams, D. (eds) Contested images: diversity in southern African rock art: 29-60. Johannesburg: Witwatersrand University Press.

Yates, R. \& Smith, A.B. 1993. Ideology and hunter/herder archaeology in the south western Cape. Southern African Field Archaeology 2: 96-104.

Yellen, J. 1984. The integration of herding into prehistoric hunting and gathering economies. In: Hall, M., Avery, G., Avery, D.M., Wilson, M.L. \& Humphreys, A.J.B. (eds) Frontiers: southern African archaeology today: 53-64. Oxford: British Archaeological Reports International Series 207.

Zeder, M.A. \& Pilaar, E. 2010. Assessing the reliability of criteria used to identify mandibles and mandibular teeth in sheep, Ovis, and goats, Capra. Journal of Archaeological Science 37: 225-242. 


\section{Appendix 1: Pottery data.}

Here some basic attributes of the pottery collections are tabulated. Only sites with pottery present in them are listed. Temper is not listed, since all have quartz and the various additional minerals were not always identifiable.

Note:

- The following abbreviations are used: PLAIN: no decoration (for rims only), IMP: impressed, INC: incised, RED: red slip present. ? indicates uncertainty.

- Mean thickness is calculated by averaging the mean thicknesses of all individual measureable sherds.

- Decoration style: impression/incisions are recorded on body and/or rim sherds, plain only recorded for rims.

- Rim orientation and lip form explained in Chapter 4.

\begin{tabular}{|l|l|c|c|c|c|c|c|l|}
\hline Site & $\begin{array}{l}\text { Layer } / \\
\text { Patch }\end{array}$ & $\mathbf{n}$ & $\begin{array}{c}\text { Weight } \\
\mathbf{( g )}\end{array}$ & $\begin{array}{c}\text { Mean } \\
\text { thickness }\end{array}$ & $\begin{array}{c}\text { Decoration } \\
\text { style (n) }\end{array}$ & $\begin{array}{c}\text { Rim } \\
\text { orientations }\end{array}$ & Lip forms & $\begin{array}{l}\text { Other features present in the assemblage } \\
\text { (i.e. not necessarily on same pot) \& notes }\end{array}$ \\
\hline \multirow{2}{*}{ DP2004/010 } & A & 4 & 25.1 & $5.51 \pm 0.34$ & RED & & & Possible spout, coil manufacture \\
\cline { 2 - 9 } & B & 11 & 36.8 & $5.09 \pm 0.18$ & & & & \\
\hline KN2004/012 & & 2 & 2.2 & $4.79 \pm 0.82$ & $\begin{array}{c}\text { IMP \& } \\
\text { IMP/Broad-INC }\end{array}$ & Vertical & Simple round & $\begin{array}{l}\text { Two patterns present, one with IMP \& INC on } \\
\text { same sherd }\end{array}$ \\
\hline KN2004/015E & & 9 & 29.4 & $5.76 \pm 0.46$ & PLAIN & Vertical & $\begin{array}{c}\text { Tapered, } \\
\text { simple round }\end{array}$ & \\
\hline KN2005/054 & & 2 & 17.1 & $7.08 \pm 0.45$ & Fine-INC & ?Vertical & Simple round & \\
\hline
\end{tabular}




\begin{tabular}{|c|c|c|c|c|c|c|c|c|}
\hline Site & $\begin{array}{l}\text { Layer / } \\
\text { Patch }\end{array}$ & $\mathbf{n}$ & $\begin{array}{l}\text { Weight } \\
\text { (g) }\end{array}$ & $\begin{array}{c}\text { Mean } \\
\text { thickness }\end{array}$ & $\begin{array}{l}\text { Decoration } \\
\text { style }(\mathbf{n})\end{array}$ & $\begin{array}{c}\text { Rim } \\
\text { orientations }\end{array}$ & Lip forms & $\begin{array}{l}\text { Other features present in the assemblage } \\
\text { (i.e. not necessarily on same pot) \& notes }\end{array}$ \\
\hline \multirow{4}{*}{ KN2005/067 } & $1 \mathrm{~A}$ & 37 & 273.9 & $6.72 \pm 0.96$ & & & & Thickly caked residue inside \\
\hline & $1 \mathrm{~B}$ & 35 & 154.0 & $5.58 \pm 1.04$ & IMP (4) & Vertical & $\begin{array}{l}\text { Flat, } \\
\text { Simple round }\end{array}$ & $\begin{array}{l}\text { Mouths } c .100,120 \& 140 \mathrm{~mm} \text {, smoothed } \\
\text { breaks }\end{array}$ \\
\hline & $1 \mathrm{C}$ & 2 & 3.1 & $4.43 \pm 0.39$ & & & & \\
\hline & 3 & 2 & 15.9 & $7.35 \pm 0.09$ & & & & \\
\hline LK2001/015 & $\mathrm{F}$ & 2 & 8.1 & $4.07 \pm 0.25$ & & & & Reused sherd with smoothed break \\
\hline MB2005/013 & & 10 & 38.5 & $5.36 \pm 1.02$ & PLAIN (1) & - & Simple round & \\
\hline MB2005/059 & & 32 & 196.5 & $5.69 \pm 0.61$ & RED (25) & & & Maximum diameter ?280 mm, neck ?140 mm \\
\hline MV2007/005 & & 1 & 3.6 & 5.94 & IMP (1) & Vertical & Simple round & \\
\hline MV2007/009 & $1 \mathrm{~A}$ & 43 & 428.5 & $\mathrm{n} / \mathrm{a}$ & & & & $\begin{array}{l}\text { Lug; large vessel with nippled base; not all } \\
\text { sherd thicknesses measured }\end{array}$ \\
\hline SK2001/024 & $\mathrm{M}$ & 3 & 73.5 & $5.90 \pm 0.22$ & PLAIN (2) & Vertical & ?Everted & Lip form may be convergent \\
\hline SK2001/039 & & 29 & 174 & $5.71 \pm 0.61$ & IMP (4) & Flared & $\begin{array}{l}\text { Tapered, } \\
\text { simple round }\end{array}$ & 'Scratched' surface, coil manufacture \\
\hline SK2005/057A & & 86 & 317.1 & $6.32 \pm 1.12$ & $\begin{array}{c}\text { IMP (1) } \\
\text { PLAIN (1) }\end{array}$ & $\begin{array}{l}\text { Vertical, } \\
\text { flared }\end{array}$ & Simple round & Includes slump, mouth c. $100 \mathrm{~mm}$ \\
\hline SK2005/074A & & 1 & 3.30 & 4.20 & & & & \\
\hline SK2005/084 & & 6 & 6.0 & $3.56 \pm 0.45$ & PLAIN (3) & $\begin{array}{l}\text { Vertical, } \\
\text { flared }\end{array}$ & Tapered & \\
\hline SK2005/095 & & 3 & 18.7 & $5.95 \pm 0.37$ & & & & \\
\hline SK2005/096A & & 10 & 73.6 & $5.92 \pm 0.47$ & & & & \\
\hline
\end{tabular}




\begin{tabular}{|c|c|c|c|c|c|c|c|c|}
\hline Site & $\begin{array}{l}\text { Layer / } \\
\text { Patch }\end{array}$ & $\mathbf{n}$ & $\begin{array}{l}\text { Weight } \\
\text { (g) }\end{array}$ & $\begin{array}{c}\text { Mean } \\
\text { thickness }\end{array}$ & $\begin{array}{l}\text { Decoration } \\
\text { style }(\mathbf{n})\end{array}$ & $\begin{array}{c}\text { Rim } \\
\text { orientations }\end{array}$ & Lip forms & $\begin{array}{l}\text { Other features present in the assemblage } \\
\text { (i.e. not necessarily on same pot) \& notes }\end{array}$ \\
\hline \multirow{4}{*}{ SK2006/006 } & Patch 1 & 1 & 1.5 & 5.61 & & & & \\
\hline & $\begin{array}{l}\text { Patch } 2 \\
\text { Upper }\end{array}$ & 12 & 68.9 & $6.12 \pm 0.37$ & & & & Horizontally pierced lug \\
\hline & $\begin{array}{l}\text { Patch } 2 \\
\text { Lower }\end{array}$ & - & & & & & & \\
\hline & Patch 3 & 8 & 26.4 & $5.34 \pm 0.31$ & & & & \\
\hline \multirow{2}{*}{ KK002 } & Upper & 15 & 52.0 & $5.59 \pm 0.71$ & & - & Flat top & \\
\hline & Lower & 1 & 1.6 & 5.96 & & & & \\
\hline KK003 & & 1 & - & 5.85 & & & & \\
\hline \multirow{6}{*}{ VR001 } & $\begin{array}{l}\text { Layers } \\
1-4 \mathrm{~A}\end{array}$ & 2 & 16.3 & $8.24 \pm 2.64$ & & & & \\
\hline & $\begin{array}{l}\text { Layers } \\
\text { 4B-5 }\end{array}$ & 13 & 133.6 & $7.59 \pm 1.45$ & & - & Simple round & Mouth c. $140 \mathrm{~mm}$, coil manufacture \\
\hline & Layer 6 & 11 & 50.3 & $6.01 \pm 1.63$ & RED & - & Everted & $\begin{array}{l}\text { Quartz temper includes smashed quartz, } \\
\text { internal reinforcing suggests lug or spout, coil } \\
\text { manufacture }\end{array}$ \\
\hline & Layer 7 & - & & & & & & \\
\hline & $\begin{array}{l}\text { Layers } \\
8-9 \mathrm{~A}\end{array}$ & 38 & 99.5 & $5.21 \pm 0.71$ & & Vertical & Thickened flat & Coil manufacture \\
\hline & $\begin{array}{l}\text { Layer } \\
9 \mathrm{~B}\end{array}$ & 4 & 10.6 & 4.720 .59 & & & & Possible grog temper \\
\hline
\end{tabular}




\begin{tabular}{|c|c|c|c|c|c|c|c|c|}
\hline Site & $\begin{array}{l}\text { Layer / } \\
\text { Patch }\end{array}$ & $\mathbf{n}$ & $\begin{array}{l}\text { Weight } \\
\text { (g) }\end{array}$ & $\begin{array}{c}\text { Mean } \\
\text { thickness }\end{array}$ & $\begin{array}{l}\text { Decoration } \\
\text { style (n) }\end{array}$ & $\begin{array}{c}\text { Rim } \\
\text { orientations }\end{array}$ & Lip forms & $\begin{array}{l}\text { Other features present in the assemblage } \\
\text { (i.e. not necessarily on same pot) \& notes }\end{array}$ \\
\hline \multirow{2}{*}{ VR005 } & Layer 2 & 1 & 20.1 & 4.69 & & & & Residue inside \\
\hline & Layer 3 & 1 & 3.4 & 5.6 & & & & \\
\hline VR048 & & 264 & 760.3 & $5.97 \pm 1.37$ & $\begin{array}{c}\text { INC } \\
\operatorname{RED}(114)\end{array}$ & Vertical & Simple round & $\begin{array}{l}\text { Lugs (horizontally-pierced), red slip } \\
\text { occasionally inside, occasional sherds have } \\
\text { quartz chips and limestone temper with sand }\end{array}$ \\
\hline JKB K & & 412 & 982.6 & $5.22 \pm 0.94$ & RED (x1) & $\begin{array}{c}\text { Flared } \\
\text { Flared } \\
- \\
- \\
\text { Flared }\end{array}$ & $\begin{array}{l}\text { Half round } \\
\text { Tapered } \\
\text { Thickened flat } \\
\text { Simple round } \\
\text { Simple round }\end{array}$ & $\begin{array}{l}\text { In situ sherds only, probable spout, mouth } c \text {. } \\
80-100 \mathrm{~mm} \text {, mouth } c .140 \mathrm{~mm}(\times 3) \text {, mouth } \\
140-160 \mathrm{~mm} \text {, mouth } c .200 \mathrm{~mm} \text {, mending } \\
\text { holes, horizontally pierced lugs, some } \\
\text { mineral/fibre temper }\end{array}$ \\
\hline JKB M & & 201 & 393.4 & $5.38 \pm 1.04$ & $\begin{array}{c}\text { INC \& } \\
\operatorname{RED}(115)\end{array}$ & $\begin{array}{l}\text { ?Flared } \\
\text { Thickened }\end{array}$ & $\begin{array}{l}\text { Everted } \\
\text { Round }\end{array}$ & $\begin{array}{l}\text { Lugs, coil manufacture, some mineral/fibre } \\
\text { temper (likely incidental), rounded edges } \\
\text { (reused pots/sherds) }\end{array}$ \\
\hline
\end{tabular}




\section{Appendix 2: Subsistence data.}

Data on ostrich eggshell, shellfish, rock lobster and fauna are presented here. Unless otherwise referenced, subsistence data are from my own analyses.

Table A2.1: Ostrich eggshell frequencies and weights. Note that some of these data predate this research and are variable and/or incomplete. Since OES is not germane to the research, the analyses were not repeated. Missing/non-calculable data are indicated by ' - '. Density is provided for single occupation open sites only.

\begin{tabular}{|c|c|c|c|c|c|c|c|c|c|c|c|c|}
\hline Site & Layer / Patch & 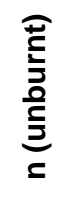 & 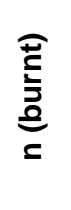 & 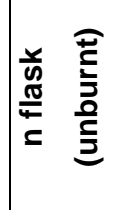 & 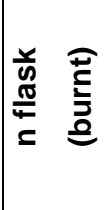 & 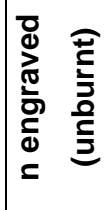 & 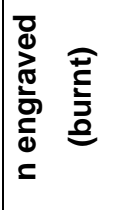 & 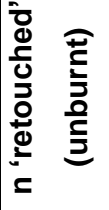 & 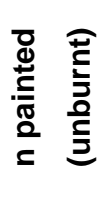 & 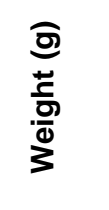 & $\frac{\sqrt[N]{E}}{\sigma}$ & Comment \\
\hline \multirow{2}{*}{ DP2004/010 } & Patch A & 206 & 2 & 5 & & & & & & 182.9 & 12.19 & \\
\hline & Patch B & 3 & & & & & & & & 0.4 & 0.08 & \\
\hline HKB2007/007 & & 1 & & & & & & & & - & - & \\
\hline KN2001/009 & & 529 & 14 & 4 & & & & & & 602.0 & 17.20 & \\
\hline KN2004/012 & & 1 & & & & & & & & 1.6 & 0.13 & \\
\hline KN2004/015E & & 143 & & 3 & & & & & & 118.9 & 11.89 & \\
\hline KN2005/040 & & 50 & & & & & & & & - & - & \\
\hline KN2005/041 & & 8 & & & & & & & & - & - & \\
\hline KN2005/050 & & 146 & & 1 & & & & & & - & - & \\
\hline KN2005/054 & & 3 & & & & & & & & - & - & \\
\hline
\end{tabular}




\begin{tabular}{|c|c|c|c|c|c|c|c|c|c|c|c|c|}
\hline Site & Layer / Patch & 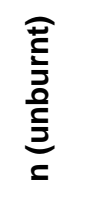 & 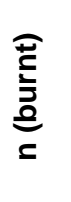 & 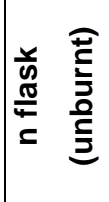 & 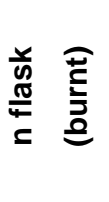 & 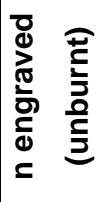 & 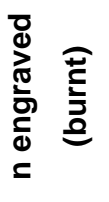 & 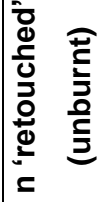 & 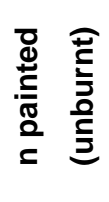 & 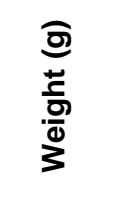 & $\frac{{ }^{N} E}{\sigma]}$ & Comment \\
\hline \multirow{7}{*}{ KN2005/067 } & Patch $1 \mathrm{~A}$ & 1323 & 6 & 14 & & & & & & 642.2 & 16.06 & \\
\hline & Patch 1B & 452 & 5 & 8 & & 2 & & & & 275.6 & 10.21 & \\
\hline & Patch 1C & 11 & 3 & & & & & & & 27.3 & 1.95 & \\
\hline & Patch 2 & & & & & & & & & & 0 & \\
\hline & Patch 3 & 2 & & & & & & & & 5.4 & 0.90 & \\
\hline & Patch 4 & 2 & & & & & & & & 1.6 & 0.40 & \\
\hline & Patch 5 & 14 & & & & & & & & 4.2 & 1.05 & \\
\hline KN2005/135A & & 4 & & & & & & & & - & - & \\
\hline KN2005/135B & & 65 & & & & & & & & - & - & \\
\hline \multirow{3}{*}{ KV2001/012 } & Area A & 1444 & 305 & 9 & & & & & & $1212.3^{*}$ & 27.56 & * flasks unweighed \\
\hline & Area B & 455 & 64 & 2 & & & & & & $509^{*}$ & 9.25 & * flasks unweighed \\
\hline & Area C & 18 & & & & & & & & 12.6 & 0.74 & \\
\hline \multirow{10}{*}{ LK2001/015 } & Patch A & 1 & & & & & & & & 0.3 & 0.15 & \\
\hline & Patch B & & & & & & & & & & 0 & \\
\hline & Patch Ci & & & & & & & & & & 0 & \\
\hline & Patch Cii & 57 & 1 & & & & & & & 39.0 & 3.25 & \\
\hline & Patch D & 5 & & & & & & & & 3.5 & 0.50 & \\
\hline & Patch E & 1 & & & & & & & & 0.2 & 0.05 & \\
\hline & Patch F & 21 & 2 & & & & & & & 25 & 12.50 & \\
\hline & Patch G & 3 & & & & & & & & 3.3 & 1.65 & \\
\hline & Patch H & 3 & & & & & & & & 2.5 & 2.50 & \\
\hline & Patch I & 36 & & & & & & & & 29.5 & 2.95 & \\
\hline
\end{tabular}




\begin{tabular}{|c|c|c|c|c|c|c|c|c|c|c|c|c|}
\hline Site & Layer / Patch & 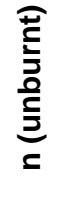 & 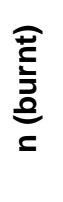 & 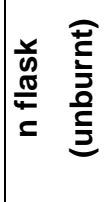 & 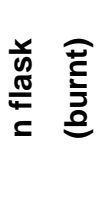 & 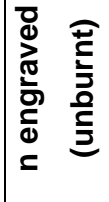 & 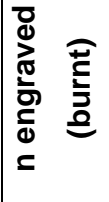 & 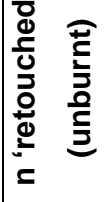 & 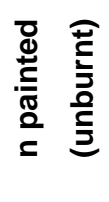 & 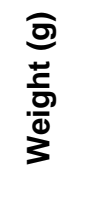 & $\frac{n}{\sigma}$ & Comment \\
\hline \multirow{2}{*}{ LK2004/011B } & In situ & 12 & & & & & & & & - & - & \\
\hline & Slump & - & & 2 & & & & & & - & - & \\
\hline \multirow{4}{*}{$\begin{array}{l}\text { MB2005/001E } \\
\text { (north) }\end{array}$} & Layer 1 & 20 & & 1 & & & & & & 25.0 & - & \\
\hline & Layer 2 & 6 & & & & & & & & 9.9 & - & \\
\hline & Layer 3 & 18 & 4 & 4 & & & & & & - & - & \\
\hline & Layer 4 & 9 & 1 & & & & & & & - & - & \\
\hline MB2005/013 & & 335 & 4 & 5 & & & & & & 406.6 & 20.33 & \\
\hline MB2005/027 & & 217 & 4 & & & & & & & 206.4 & 18.76 & \\
\hline MB2005/028A & & 118 & 2 & & & & & & & 106.2 & 26.55 & \\
\hline \multirow{2}{*}{ MB2005/059 } & Patch A & 36 & & 2 & & & & & & 49.8 & 3.32 & \\
\hline & Patch B & & & & & & & & & & 0 & \\
\hline MV2007/005 & & 6 & & & & & & & & 6.8 & - & Surface collection \\
\hline \multirow{4}{*}{ MV2007/009 } & Area 1 & 24 & & & & & & & & 18.7 & - & Surface collection \\
\hline & Area 2 & 2 & & & & & & & & 1.2 & - & Surface collection \\
\hline & Area 3 & & & & & & & & & & - & Surface collection \\
\hline & Area 4 & 24 & & & & & & & & 15.7 & - & Surface collection \\
\hline PN2009/001 & & 460 & 10 & 3 & & 17 & & & & 471.6 & 4.29 & \\
\hline SK2001/024 & Patch A & 32 & & 1 & & & & & & 54.7 & 18.23 & \\
\hline
\end{tabular}




\begin{tabular}{|c|c|c|c|c|c|c|c|c|c|c|c|c|}
\hline Site & Layer / Patch & 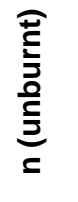 & 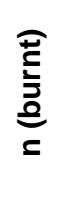 & 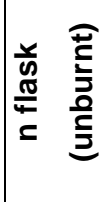 & 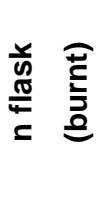 & 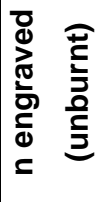 & 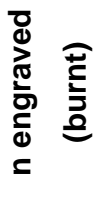 & 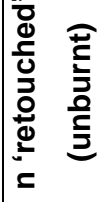 & 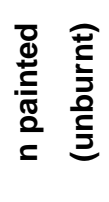 & 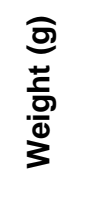 & $\stackrel{n}{\sigma}$ & Comment \\
\hline \multirow{6}{*}{ SK2001/025 } & Area A & 5 & & & & & & & & - & - & \\
\hline & Area B & 19 & 1 & & & & & & & - & - & \\
\hline & Area C & 30 & 1 & & & 1 & & & & - & - & \\
\hline & Area D & 8 & & & & & & & & - & - & \\
\hline & Area E & 5 & & & & & & & & - & - & \\
\hline & Area F & 98 & & 1 & & & & & & - & - & \\
\hline SK2001/039 & & 287 & 6 & 2 & & & & & & 361.6 & 45.20 & \\
\hline SK2005/057A & & 183 & 9 & 2 & & & & & & $76.5^{\star}$ & 1.42 & * flasks unweighed \\
\hline \multirow{4}{*}{ SK2005/074A } & Layer 1 & 75 & 4 & & & & & & & 55.1 & 3.24 & \\
\hline & Layer 2 & 70 & 12 & 2 & & & & & & 103.7 & 10.37 & \\
\hline & Layer 3 & & & & & & & & & & 0 & \\
\hline & Layer 4 & & & & & & & & & & 0 & \\
\hline SK2005/084 & & 18 & & & & 1 & & & & - & - & \\
\hline \multirow{6}{*}{ SK2005/095 } & Patch A & 130 & & & & & & & & 22.9 & 3.27 & \\
\hline & Patch B, M25 & & & & & & & & & & 0 & \\
\hline & Patch B, U23 & & & & & & & & & & 0 & \\
\hline & $\begin{array}{l}\text { Patch B, } \\
\text { S19/20 }\end{array}$ & 59 & 1 & 1 & & & & & & 67.0 & 33.50 & \\
\hline & Patch B, S16 & & & & & & & & & & 0 & \\
\hline & Patch B, N16 & 58 & & 1 & & & & & & 8.4 & 8.40 & \\
\hline SK2005/096A & & 21 & & 1 & & & & & & - & - & \\
\hline SK2005/096B & & 24 & & & & & & & & - & - & \\
\hline
\end{tabular}




\begin{tabular}{|c|c|c|c|c|c|c|c|c|c|c|c|c|}
\hline Site & Layer / Patch & 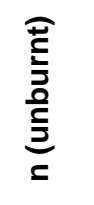 & 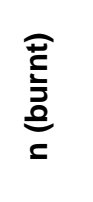 & 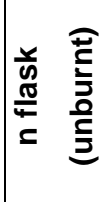 & 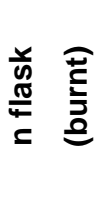 & 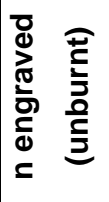 & 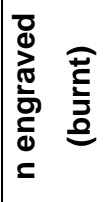 & 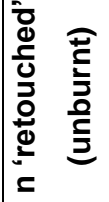 & 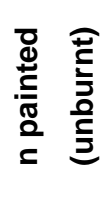 & 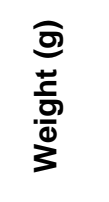 & $\frac{n}{\sigma}$ & Comment \\
\hline \multirow{4}{*}{ SK2006/006 } & Patch 1 & 24 & & & & & & & & 12.8 & 1.28 & \multirow{4}{*}{$\begin{array}{l}\text { Includes fresh and } \\
\text { weathered fragments }\end{array}$} \\
\hline & Patch 2 Upper & 39 & & & & 1 & & & & 31.6 & 2.43 & \\
\hline & Patch 2 Lower & 86 & & & & & & & & 85.1 & 17.02 & \\
\hline & Patch 3 & 30 & & 1 & & & & & & 30.3 & 3.79 & \\
\hline TP2004/003 & & 3 & & & & 2 & & & & 4.9 & 0.54 & \\
\hline TP2004/014 & & 11 & & & & & & & & 4.9 & 0.82 & \\
\hline \multirow{2}{*}{ KK002 } & Upper & 2495 & 471 & & & & & 2 & & 1295.6 & $n / a$ & \\
\hline & Lower & 125 & 99 & & & & & & & 79.2 & $\mathrm{n} / \mathrm{a}$ & \\
\hline \multicolumn{13}{|l|}{ KK003 } \\
\hline \multirow{6}{*}{ VR001 } & Layers $1-4 \mathrm{~A}$ & 1116 & 55 & & & 1 & & & 1 & 565.8 & - & \\
\hline & Layers 4B-5 & 1563 & 1109 & 1 & & & & 1 & 2 & 1836.2 & - & \\
\hline & Layer 6 & 1180 & 397 & 2 & & & & 3 & 12 & 1512.7 & & \\
\hline & Layer 7 & 337 & 31 & & & & & 1 & & 448.2 & - & \\
\hline & Layers 8-9A & 1725 & 1792 & 15 & & & & & & 3201.4 & - & \\
\hline & Layer 9B & 281 & 137 & 1 & & & & & & 415.3 & - & \\
\hline
\end{tabular}




\begin{tabular}{|c|c|c|c|c|c|c|c|c|c|c|c|c|}
\hline Site & Layer / Patch & 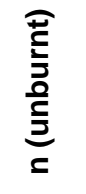 & 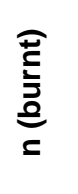 & 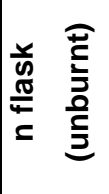 & 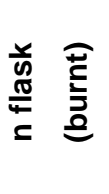 & 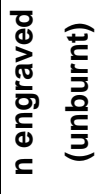 & 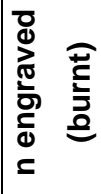 & 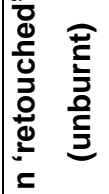 & 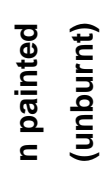 & 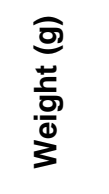 & $\frac{\pi}{\pi}$ & Comment \\
\hline \multirow{7}{*}{ VR005 } & Layer 1 & 257 & 22 & & & & & & & 216.2 & - & \\
\hline & Layer 2 & 282 & 38 & & & & & & 2 & 507.6 & - & \\
\hline & Layer 3 & 903 & 526 & 1 & 2 & 2 & 1 & 4 & 17 & 1294.1 & - & \\
\hline & Layer 4 & 1017 & $868^{*}$ & 3 & 1 & & 3 & 2 & 2 & 1311.5 & - & $\begin{array}{l}{ }^{*} \text { Includes a disc } \\
\text { (possible pendant blank) }\end{array}$ \\
\hline & Layer 5 & 318 & 164 & & & & & & & 251.7 & - & \\
\hline & Layer 6 & 643 & 848 & & & 3 & & & & 994.9 & - & \\
\hline & Layer 7 & 58 & 72 & & & & & & & 94.0 & - & \\
\hline VR048 & & 4677 & 111 & 2 & & $? 3$ & & & & 1935.6 & 3.00 & \\
\hline JKB K & & 173 & 303 & 2 & & & & & & 217.7 & 3.25 & In situ material only \\
\hline JKB M & & 212 & & & & & & & & 78.5 & 3.78 & \\
\hline
\end{tabular}


Table A2.2: Marine shellfish. Frequencies of occasional unidentifiable limpets and minor species probably introduced incidentally are not provided, but their numbers are included in the overall MNI. Figures are percent of overall MNI of the counted samples. Rare shells assumed to be deliberately collected for decorative purposes are excluded. All own data except PN2009/001: Webley \& Orton (2010).

\begin{tabular}{|c|c|c|c|c|c|c|c|c|}
\hline Site & Layer / Patch & 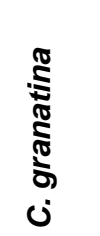 & 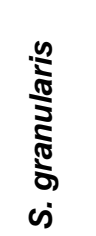 & 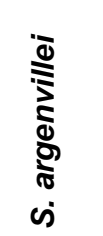 & 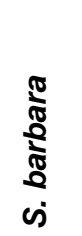 & 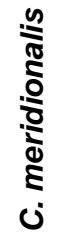 & $\begin{array}{l}\frac{x}{d} \\
\frac{\sum}{\zeta}\end{array}$ & 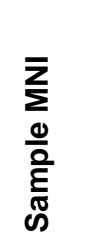 \\
\hline \multirow{2}{*}{ DP2004/010 } & Patch A & 43.24 & 56.68 & & & & & 1161 \\
\hline & Patch B & 46.30 & 53.70 & & & & & 324 \\
\hline HKB2007/007 & & 26.90 & 30.70 & 18.62 & 5.86 & & 10.00 & 290 \\
\hline KN2001/009 & & 44.49 & 27.27 & 27.27 & 0.64 & & & 627 \\
\hline KN2004/012 & & 17.33 & 81.54 & 0.72 & 0.09 & & 0.02 & 4594 \\
\hline KN2004/015E & & 67.04 & 30.74 & 1.48 & & 0.37 & & 270 \\
\hline KN2005/040 & & 28.27 & 57.71 & 3.97 & 0.12 & 0.47 & 9.46 & 856 \\
\hline KN2005/041 & & 32.26 & 52.20 & 14.53 & 1.01 & & & 592 \\
\hline KN2005/050 & & 45.35 & 34.49 & 18.90 & 0.16 & 0.63 & 0.31 & 635 \\
\hline KN2005/054 & & 45.87 & 36.13 & 15.70 & 1.76 & & & 739 \\
\hline \multirow{11}{*}{ KN2005/067 } & Patch 1A (N) & 61.81 & 30.31 & 7.34 & 0.32 & & & 927 \\
\hline & Patch 1A (SE) & 69.66 & 9.14 & 18.62 & 1.98 & 0.17 & & 1160 \\
\hline & Patch 1A (S) & 70.18 & 24.15 & 3.24 & 1.94 & & & 617 \\
\hline & Patch 1A (SW) & 57.31 & 35.22 & 6.57 & 0.90 & & & 335 \\
\hline & Patch 1B (N) & 46.50 & 43.75 & 9.25 & 0.5 & & & 400 \\
\hline & Patch 1B (S) & 48.92 & 48.41 & 2.54 & & 0.13 & & 787 \\
\hline & Patch 1C & 63.81 & 15.16 & 20.29 & 0.73 & & & 409 \\
\hline & Patch 2 & 49.61 & 42.68 & 7.48 & 0.23 & & & 1284 \\
\hline & Patch 3 & 52.01 & 43.23 & 3.83 & 0.47 & & & 1071 \\
\hline & Patch 4 & 33.19 & 50.33 & 14.10 & 1.95 & & & 461 \\
\hline & Patch 5 & 54.76 & 16.48 & 28.39 & & & & 546 \\
\hline KN2005/135A & & 36.55 & 41.19 & 18.33 & 1.07 & 0.60 & & 840 \\
\hline KN2005/135B & & 23.11 & 59.56 & 7.78 & 0.52 & 4.07 & 4.96 & 1350 \\
\hline \multirow{3}{*}{ KV2001/012 } & Area $\mathrm{A}$ & 62.61 & 24.77 & 12.16 & & & & 231 \\
\hline & Area B & 26.80 & 45.70 & 24.00 & & & & 1000 \\
\hline & Area C & 40.43 & 54.64 & 0.29 & & & & 699 \\
\hline
\end{tabular}




\begin{tabular}{|c|c|c|c|c|c|c|c|c|}
\hline Site & Layer / Patch & 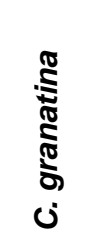 & 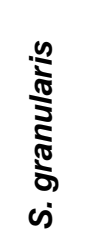 & 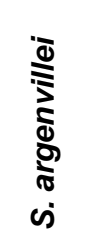 & $\begin{array}{l}\frac{\pi}{\pi} \\
\frac{0}{\pi} \\
\frac{8}{8} \\
\text { c) }\end{array}$ & 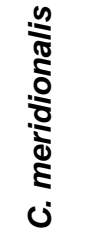 & 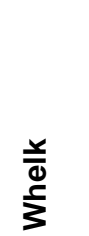 & 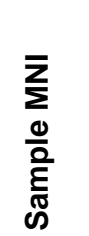 \\
\hline \multirow{10}{*}{ LK2001/015 } & Patch A & 64.29 & 12.66 & 21.10 & 1.94 & & & 308 \\
\hline & Patch B & 60.17 & 29.56 & 10.06 & 0.21 & & & 477 \\
\hline & Patch $\mathrm{Ci}$ & 50.95 & 11.84 & 37.20 & & & & 422 \\
\hline & Patch Cii & 44.26 & 40.10 & 14.98 & 0.61 & & 0.06 & 6270 \\
\hline & Patch D & 71.95 & 15.03 & 12.64 & 0.05 & 0.05 & 0.26 & 1929 \\
\hline & Patch E & 68.82 & 18.31 & 12.44 & & & 0.43 & 1174 \\
\hline & Patch F & 39.69 & 52.63 & 7.25 & & & 0.44 & 1600 \\
\hline & Patch G & 58.83 & 14.57 & 25.87 & 0.55 & 0.18 & & 549 \\
\hline & Patch $\mathrm{H}$ & 42.68 & 50.00 & 3.66 & 3.66 & & & 82 \\
\hline & Patch I & 56.07 & 27.58 & 15.90 & 0.27 & & 0.18 & 2183 \\
\hline \multirow{2}{*}{ LK2004/011B } & In situ & 42.48 & 43.79 & 9.80 & & 1.31 & 0.65 & 459 \\
\hline & Slump & & & & & & & - \\
\hline \multirow{6}{*}{$\begin{array}{l}\text { MB2005/001E } \\
\text { (north) }\end{array}$} & Layer 1 & 10.17 & 58.51 & 8.59 & & 12.08 & 5.88 & 629 \\
\hline & Layer 2 & 10.21 & 65.25 & 2.41 & 0.14 & 15.18 & 5.25 & 705 \\
\hline & Layer 3 & 10.84 & 72.51 & 3.46 & 0.11 & 6.15 & 6.48 & 895 \\
\hline & Layer 4 & 7.60 & 82.65 & 0.72 & 0.10 & 5.54 & 2.98 & 974 \\
\hline & Layer 5 & 7.39 & 87.39 & 1.08 & & 3.24 & 0.90 & 555 \\
\hline & Layer 6 & 10.56 & 82.61 & 0.62 & & 3.73 & 1.86 & 161 \\
\hline \multirow{8}{*}{$\begin{array}{l}\text { MB2005/001E } \\
\text { (south) }\end{array}$} & Surface & 4.57 & 66.40 & 1.70 & 0.30 & 20.88 & 2.09 & 1006 \\
\hline & $2^{\text {nd }}$ Layer & 10.46 & 69.61 & 4.25 & 0.33 & 11.77 & 0.98 & 306 \\
\hline & $3^{\text {rd }}$ Layer & 9.82 & 52.68 & 26.49 & 1.19 & 8.33 & & 336 \\
\hline & $4^{\text {th }}$ Layer & 15.53 & 56.71 & 17.48 & & 8.74 & 0.97 & 103 \\
\hline & $5^{\text {th }}$ Layer & 6.67 & 73.33 & 13.33 & & 6.67 & & 15 \\
\hline & $6^{\text {th }}$ Layer & & & & & & & - \\
\hline & $7^{\text {th }}$ Layer & 7.75 & 86.05 & 0.78 & & 3.88 & 0.78 & 129 \\
\hline & $8^{\text {th }}$ Layer & 6.24 & 92.81 & 0.53 & & 0.42 & & 946 \\
\hline MB2005/013 & & 35.90 & 51.52 & 10.14 & 0.84 & 0.41 & 1.18 & 1184 \\
\hline MB2005/027 & & 17.38 & 68.67 & 11.98 & 0.68 & 0.06 & 0.12 & 1628 \\
\hline MB2005/028A & & 24.74 & 68.5 & 5.95 & & 0.24 & 0.08 & 2542 \\
\hline \multirow{2}{*}{ MB2005/059 } & Patch A & 5.72 & 88.31 & 3.41 & 0.49 & 1.83 & 0.24 & 821 \\
\hline & Patch B & 8.82 & 80.51 & 1.47 & & 9.01 & 0.18 & 544 \\
\hline MV2007/005 & & & & & & & & 0 \\
\hline MV2007/009 & & & & & & & & 0 \\
\hline
\end{tabular}




\begin{tabular}{|c|c|c|c|c|c|c|c|c|}
\hline Site & Layer / Patch & 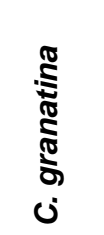 & 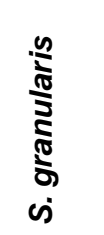 & 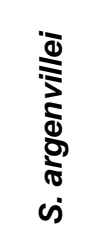 & 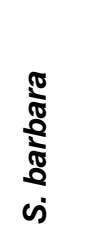 & 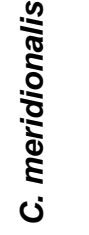 & 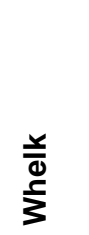 & 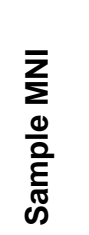 \\
\hline \multirow{7}{*}{ PN2009/001 } & North (J70) & 66.0 & 19.6 & 1.8 & & 1.8 & 10.7 & 112 \\
\hline & North (W87) & 62.8 & 11.4 & 2.8 & & 11.4 & 11.4 & 35 \\
\hline & Centre (I64) & 21.7 & 8.6 & 1.8 & & 45.9 & 21.7 & 161 \\
\hline & Centre (F64) & 21.3 & 6.3 & 0.4 & & 60.2 & 11.8 & 560 \\
\hline & $\begin{array}{l}\text { South (ZY36 \& } \\
\text { ZY37) }\end{array}$ & 45.4 & 18.4 & & & 0.7 & 34.8 & 141 \\
\hline & South (F48 L1) & 84.5 & 15.0 & 0.2 & & 0.2 & & 538 \\
\hline & South (F48 L2) & 68.6 & 31.3 & & & & & 134 \\
\hline SK2001/024 & Patch A, G10 & 74.90 & 21.19 & 3.70 & 0.21 & & & 486 \\
\hline \multirow{6}{*}{ SK2001/025 } & Area A & 55.11 & 37.19 & 6.31 & 0.68 & $x$ & 0.65 & 3377 \\
\hline & Area B & 44.86 & 43.01 & 9.70 & 2.37 & $x$ & 0.07 & 1351 \\
\hline & Area C & 62.91 & 35.63 & 1.08 & 0.25 & $x$ & 0.07 & 6837 \\
\hline & Area D & 46.00 & 33.73 & 18.00 & 2.09 & $x$ & $x$ & 1100 \\
\hline & Area E & 37.66 & 48.05 & 11.04 & 3.25 & & $x$ & 154 \\
\hline & Area F & 38.49 & 47.04 & 12.17 & 1.64 & 0.33 & 0.33 & 304 \\
\hline SK2001/039 & & 47.55 & 51.53 & 0.78 & 0.14 & $x$ & & 1039 \\
\hline SK2005/057A & & 33.79 & 60.74 & 4.86 & 0.46 & $x$ & 0.09 & 4564 \\
\hline \multirow{4}{*}{ SK2005/074A } & Layer 1 & 39.64 & 48.99 & 6.06 & 1.77 & & 0.51 & 396 \\
\hline & Layer 2 & 51.15 & 43.98 & 2.84 & 0.95 & $x$ & 0.41 & 739 \\
\hline & Layer 3 & & & & & & & - \\
\hline & Layer 4 & 56.21 & 41.34 & 1.23 & 1.09 & 0.14 & & 733 \\
\hline SK2005/084 & & 27.70 & 63.31 & 1.44 & & 3.60 & 2.88 & 278 \\
\hline \multirow{6}{*}{ SK2005/095 } & Patch A & 49.61 & 46.01 & 4.38 & & & & 776 \\
\hline & Patch B, M25 & 61.72 & 36.90 & 0.34 & 1.03 & & & 290 \\
\hline & Patch B, U23 & 45.07 & 53.52 & 1.41 & & & & 142 \\
\hline & Patch B, S20 & 71.74 & 28.26 & & & & & 1472 \\
\hline & Patch B, S16 & 67.46 & 24.60 & 7.94 & & & & 126 \\
\hline & Patch B, N16 & 35.83 & 58.63 & 5.21 & 0.33 & & & 307 \\
\hline SK2005/096A & & 45.57 & 37.52 & 16.30 & 0.34 & & 0.20 & 1466 \\
\hline SK2005/096B & & 43.06 & 41.63 & 11.96 & 3.35 & & & 209 \\
\hline \multirow{4}{*}{ SK2006/006 } & Patch 1 & 48.13 & 43.45 & 3.93 & 0.92 & & 2.05 & 3029 \\
\hline & Patch 2 Upper & 66.67 & 18.62 & 8.33 & 5.50 & & 0.71 & 564 \\
\hline & Patch 2 Lower & 50.89 & 31.81 & 16.70 & 0.20 & & 0.40 & 558 \\
\hline & Patch 3 & 53.30 & 31.10 & 5.81 & 1.50 & & 3.61 & 1135 \\
\hline TP2004/003* & & 21.52 & 25.06 & 3.54 & & & & 395 \\
\hline TP2004/014 & & 38.80 & 53.22 & 0.89 & $x$ & & & 902 \\
\hline
\end{tabular}




\begin{tabular}{|c|c|c|c|c|c|c|c|c|}
\hline Site & Layer / Patch & 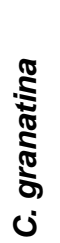 & 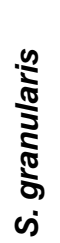 & 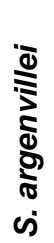 & 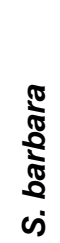 & 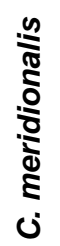 & 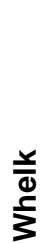 & $\begin{array}{l}\sum \\
\sum \\
\frac{\Sigma}{0} \\
\frac{0}{E} \\
\text { 心 }\end{array}$ \\
\hline \multirow{2}{*}{ KK002 } & Upper & 16 & 13 & 1 & & $x$ & 2 & 41 \\
\hline & Lower & $x$ & $x$ & $\mathrm{x}$ & & $x$ & $x$ & - \\
\hline KK003** & & $x$ & $x$ & $x$ & & $x$ & $x$ & - \\
\hline \multirow[t]{6}{*}{ VR001** } & Layers 1-4A & $x$ & & & & & & - \\
\hline & Layers 4B-5 & $x$ & & & & & & - \\
\hline & Layer 6 & & & & & $x$ & & - \\
\hline & Layer 7 & & & & & $x$ & & - \\
\hline & Layers 8-9A & & & & & $x$ & & - \\
\hline & Layer 9B & & & & & & & - \\
\hline \multirow[t]{7}{*}{ VR005** } & Layer 1 & & & & & $x$ & & - \\
\hline & Layer 2 & & & & & $x$ & & - \\
\hline & Layer 3 & & & & & $x$ & & - \\
\hline & Layer 4 & & & & & $x$ & & - \\
\hline & Layer 5 & & & & & & & - \\
\hline & Layer 6 & & $x$ & & & & & - \\
\hline & Layer 7 & & & & & & & - \\
\hline VR048** & & $x$ & & $x$ & & $x$ & & - \\
\hline JKB K & & & & & & & & - \\
\hline JKB M & & & & & & & & - \\
\hline
\end{tabular}

* Frequencies unreliable due to poor preservation; remainder all indeterminate limpets

** Very few countable shells, only species recorded 
Table A2.3: Rock lobster. Mean lengths in $\mathrm{mm}$.

\begin{tabular}{|c|c|c|c|c|c|c|c|c|c|}
\hline Site & Layer/Area & Broken left & Broken right & Fragments & Left (n) & Left (mean) & Right (n) & Right (mean) & MNI \\
\hline \multirow{2}{*}{ DP2004/010 } & Patch A & 28 & 24 & 24 & 50 & $11.57 \pm 2.50$ & 65 & $12.21 \pm 2.91$ & 79 \\
\hline & Patch B & 2 & & & 1 & 9.02 & 1 & 9.03 & 3 \\
\hline HKB2007/007 & & 6 & 4 & 1 & 5 & not meas. & 0 & - & 11 \\
\hline KN2001/009 & & 33 & 43 & 9 & 44 & $12.15 \pm 2.50$ & 46 & $12.84 \pm 2.78$ & 89 \\
\hline KN2004/012 & & 64 & 53 & 15 & 66 & $12.26 \pm 3.05$ & 75 & $12.82 \pm 3.23$ & 128 \\
\hline KN2004/015E & & 17 & 20 & 3 & 23 & $11.28 \pm 1.16$ & 13 & $12.08 \pm 2.83$ & 33 \\
\hline KN2005/040 & & 33 & 29 & 15 & 40 & $12.69 \pm 2.88$ & 42 & $13.62 \pm 3.02$ & 73 \\
\hline KN2005/041 & & 81 & 86 & 113 & 145 & $13.43 \pm 3.14$ & 152 & $13.63 \pm 3.03$ & 238 \\
\hline KN2005/050 & & 36 & 47 & 56 & 84 & $15.63 \pm 3.99$ & 82 & $16.98 \pm 4.18$ & 129 \\
\hline KN2005/054 & & 6 & 9 & 3 & 154 & $13.11 \pm 3.12$ & 129 & $14.09 \pm 3.34$ & 160 \\
\hline \multirow{7}{*}{ KN2005/067 } & Patch 1A & 77 & 101 & 162 & 154 & $15.04 \pm 3.48$ & 152 & $15.81 \pm 3.75$ & 253 \\
\hline & Patch 1B & 35 & 41 & 24 & 36 & $11.81 \pm 3.41$ & 35 & $12.78 \pm 3.24$ & 76 \\
\hline & Patch 1C & 14 & 26 & 29 & 16 & $12.93 \pm 4.53$ & 20 & $13.79 \pm 4.39$ & 46 \\
\hline & Patch 2 & 3 & 3 & 4 & 5 & $14.09 \pm 3.87$ & 4 & $12.74 \pm 3.25$ & 8 \\
\hline & Patch 3 & 2 & 5 & 19 & 18 & $14.30 \pm 4.41$ & 10 & $14.05 \pm 4.39$ & 20 \\
\hline & Patch 4 & 3 & 6 & 4 & 4 & $11.00 \pm 1.53$ & 6 & $13.24 \pm 4.32$ & 12 \\
\hline & Patch 5 & 3 & 2 & 5 & 2 & $16.22 \pm 2.56$ & 5 & $14.31 \pm 2.98$ & 7 \\
\hline KN2005/135A & & 70 & 59 & 74 & 80 & $12.47 \pm 2.39$ & 96 & $12.75 \pm 2.77$ & 155 \\
\hline KN2005/135B & & 61 & 67 & 59 & 47 & $12.20 \pm 2.22$ & 47 & $12.22 \pm 2.18$ & 108 \\
\hline \multirow{3}{*}{ KV2001/012 } & Area A & 3 & 1 & & & - & & - & 3 \\
\hline & Area B & 55 & 51 & 9 & 10 & $13.92 \pm 2.69$ & 15 & $14.14 \pm 2.65$ & 66 \\
\hline & Area C & 23 & 17 & 13 & 3 & $13.00 \pm 2.67$ & 5 & $12.93 \pm 4.08$ & 26 \\
\hline
\end{tabular}




\begin{tabular}{|c|c|c|c|c|c|c|c|c|c|}
\hline Site & Layer/Area & Broken left & Broken right & Fragments & Left (n) & Left (mean) & Right (n) & Right (mean) & MNI \\
\hline \multirow{10}{*}{ LK2001/015 } & Patch A & 7 & 5 & 16 & & - & & - & 7 \\
\hline & Patch B & & 3 & 2 & & - & & - & 3 \\
\hline & Patch Ci & 3 & 4 & & & - & & - & 4 \\
\hline & Patch Cii & 70 & 91 & 61 & 97 & $11.86 \pm 3.00$ & 92 & $12.26 \pm 2.54$ & 183 \\
\hline & Patch D & 5 & 2 & 4 & 9 & $15.83 \pm 3.83$ & 7 & $15.88 \pm 3.51$ & 14 \\
\hline & Patch E & 1 & & 1 & & - & 1 & 8.61 & 1 \\
\hline & Patch F & 7 & 11 & 9 & 1 & 11.52 & 1 & 14.66 & 12 \\
\hline & Patch G & 1 & 1 & & 1 & 12.91 & & & 2 \\
\hline & Patch $\mathrm{H}$ & 3 & 2 & 4 & & - & & - & 3 \\
\hline & Patch I & 8 & 28 & 17 & 9 & $11.05 \pm 1.80$ & 5 & $14.11 \pm 4.14$ & 33 \\
\hline \multirow{2}{*}{ LK2004/011B } & In situ & 2 & 6 & 6 & 9 & $14.70 \pm 3.00$ & 9 & $13.77 \pm 4.09$ & 15 \\
\hline & Slump & 22 & 29 & 16 & 15 & $14.50 \pm 3.09$ & 19 & $15.80 \pm 2.75$ & 48 \\
\hline \multirow{4}{*}{$\begin{array}{l}\text { MB2005/001E } \\
\text { (North) }\end{array}$} & Layer 1 & 52 & 94 & 46 & 132 & $10.91 \pm 2.63$ & 133 & $11.30 \pm 2.57$ & 227 \\
\hline & Layer 2 & 1 & 1 & 1 & 11 & $13.90 \pm 4.18$ & 13 & $15.84 \pm 4.36$ & 14 \\
\hline & Layer 3 & 11 & 15 & 7 & 41 & $12.24 \pm 2.54$ & 53 & $11.58 \pm 3.35$ & 68 \\
\hline & Layer 4 & 2 & 1 & & 13 & $10.40 \pm 1.27$ & 4 & $12.64 \pm 0.95$ & 15 \\
\hline MB2005/013 & & 45 & 40 & 33 & 20 & $12.43 \pm 2.43$ & 13 & $13.16 \pm 2.15$ & 65 \\
\hline MB2005/027 & & 36 & 52 & 28 & 19 & $12.08 \pm 3.02$ & 24 & $12.53 \pm 2.26$ & 76 \\
\hline MB2005/028A & & 28 & 30 & 52 & 42 & $12.34 \pm 2.67$ & 33 & $13.73 \pm 3.41$ & 70 \\
\hline \multirow{2}{*}{ MB2005/059 } & Patch A & 3 & 4 & 7 & 8 & $11.73 \pm 2.62$ & 2 & $12.19 \pm 1.01$ & 11 \\
\hline & Patch B & & 1 & 2 & 1 & 11.42 & & - & 1 \\
\hline MV2007/005 & & & & & & - & & - & 0 \\
\hline MV2007/009 & & & & & & - & & - & 0 \\
\hline PN2009/001 & & 663 & 1059 & 605 & 1109 & $11.19 \pm 1.84$ & 824 & $11.82 \pm 1.98$ & 1883 \\
\hline
\end{tabular}




\begin{tabular}{|c|c|c|c|c|c|c|c|c|c|}
\hline Site & Layer/Area & Broken left & Broken right & Fragments & Left (n) & Left (mean) & Right (n) & Right (mean) & MNI \\
\hline \multirow{4}{*}{ SK2001/024 } & Patch A & 2 & 10 & 3 & 5 & $11.83 \pm 3.21$ & 6 & $13.11 \pm 2.25$ & 16 \\
\hline & Patch B & & & & & - & & - & 0 \\
\hline & Patch C & 1 & 1 & & 2 & $12.21 \pm 0.73$ & 1 & 11.18 & 2 \\
\hline & Patch M & & 4 & 2 & 3 & $18.25 \pm 4.14$ & & - & 4 \\
\hline \multirow{6}{*}{ SK2001/025 } & Area A & 95 & 112 & 64 & 103 & $11.98 \pm 2.16$ & 67 & $12.76 \pm 2.40$ & 198 \\
\hline & Area B & 97 & 127 & 33 & 71 & $10.90 \pm 2.05$ & 58 & $11.65 \pm 1.44$ & 185 \\
\hline & Area C & 89 & 121 & 36 & 164 & $11.77 \pm 1.78$ & 150 & $12.38 \pm 1.95$ & 271 \\
\hline & Area D & 88 & 118 & 36 & 68 & $10.79 \pm 1.36$ & 49 & $12.09 \pm 2.08$ & 167 \\
\hline & Area E & 4 & 5 & 1 & 6 & $11.21 \pm 2.12$ & 7 & $11.4 \pm 2.38$ & 12 \\
\hline & Area F & 117 & 176 & 21 & 73 & $11.69 \pm 1.76$ & 45 & $12.48 \pm 2.50$ & 221 \\
\hline SK2001/039 & & 52 & 83 & 30 & 48 & $11.10 \pm 1.89$ & 51 & $12.68 \pm 2.26$ & 134 \\
\hline SK2005/057A & & 293 & 300 & 423 & 251 & $13.92 \pm 3.80$ & 227 & $15.20 \pm 3.59$ & 544 \\
\hline \multirow{4}{*}{ SK2005/074A } & Surf & 88 & 113 & 95 & 50 & $11.11 \pm 1.87$ & 35 & $11.86 \pm 2.21$ & 139 \\
\hline & M1/ L1 & 80 & 102 & 96 & 114 & $11.37 \pm 2.07$ & 97 & $12.42 \pm 2.59$ & 199 \\
\hline & L2 & 3 & 1 & 8 & 11 & $10.53 \pm 1.03$ & 5 & $11.24 \pm 2.10$ & 14 \\
\hline & M2 & & & & & - & & - & 0 \\
\hline SK2005/084 & & 12 & 33 & 14 & 16 & $11.69 \pm 2.46$ & 16 & $11.79 \pm 2.08$ & 51 \\
\hline \multirow{2}{*}{ SK2005/095 } & Patch A & 11 & 20 & 28 & 21 & $14.24 \pm 2.48$ & 18 & $15.89 \pm 2.54$ & 38 \\
\hline & Patch B & 16 & 14 & 16 & 13 & $13.45 \pm 3.42$ & 14 & $15.50 \pm 3.00$ & 29 \\
\hline SK2005/096A & & 90 & 187 & 79 & 203 & $11.73 \pm 2.30$ & 189 & $12.53 \pm 2.29$ & 376 \\
\hline SK2005/096B & & 13 & 9 & 3 & 33 & $11.41 \pm 2.09$ & 15 & $13.58 \pm 3.72$ & 46 \\
\hline
\end{tabular}




\begin{tabular}{|c|c|c|c|c|c|c|c|c|c|}
\hline Site & Layer/Area & Broken left & Broken right & Fragments & Left (n) & Left (mean) & Right (n) & Right (mean) & MNI \\
\hline \multirow{4}{*}{ SK2006/006 } & Patch 1 & 10 & 19 & 6 & 17 & $12.53 \pm 2.69$ & 17 & $14.72 \pm 3.25$ & 36 \\
\hline & $\begin{array}{l}\text { Patch } 2 \\
\text { Upper }\end{array}$ & 68 & 95 & 71 & 105 & $12.33 \pm 2.78$ & 90 & $13.02 \pm 3.06$ & 185 \\
\hline & $\begin{array}{l}\text { Patch } 2 \\
\text { Lower }\end{array}$ & 51 & 74 & 57 & 104 & $12.44 \pm 3.15$ & 93 & $13.53 \pm 3.56$ & 167 \\
\hline & Patch 3 & 18 & 24 & 22 & 25 & $11.51 \pm 2.79$ & 13 & $12.09 \pm 3.03$ & 43 \\
\hline TP2004/003 & & 25 & 23 & 14 & 8 & $13.84 \pm 1.91$ & 5 & $14.29 \pm 3.44$ & 33 \\
\hline TP2004/014 & & 54 & 51 & 67 & 58 & $11.73 \pm 2.26$ & 64 & $12.40 \pm 2.61$ & 115 \\
\hline \multirow{2}{*}{ KK002 } & Upper & 24 & 25 & 28 & 35 & $12.36 \pm 2.40$ & 42 & $13.47 \pm 3.06$ & 67 \\
\hline & Lower & 1 & 2 & 1 & 1 & 13.75 & 0 & - & 2 \\
\hline KK003 & & & & & & - & & - & \\
\hline VR001 & & & & & & - & & - & \\
\hline VR005 & & & & & & - & & - & \\
\hline VR048 & & & & & & - & & - & \\
\hline JKB K & & & & & & - & & - & \\
\hline JKB M & & & & & & - & & - & \\
\hline
\end{tabular}


Table A2.4.1: Fauna (part 1). NISP/MNI listed where available, otherwise presence is marked by an ' $x$ '. Please see A2.4.3 for references and notes.

\begin{tabular}{|c|c|c|c|c|c|c|c|c|c|c|c|c|c|c|c|c|c|c|c|c|c|c|c|c|}
\hline Site & $\begin{array}{l}\text { Layer / } \\
\text { Area }\end{array}$ & 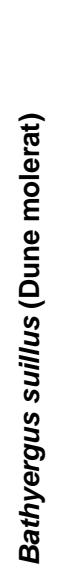 & 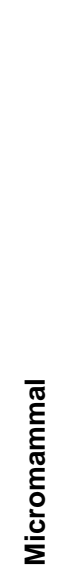 & 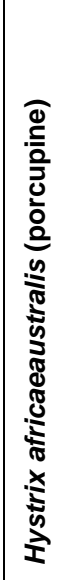 & 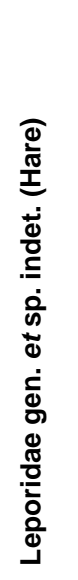 & 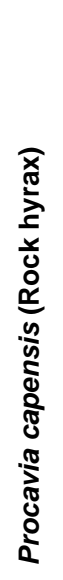 & 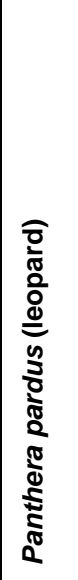 & 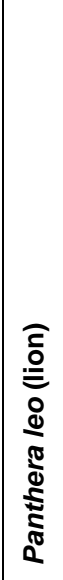 & 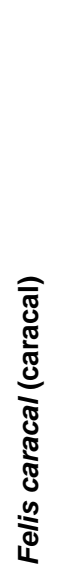 & 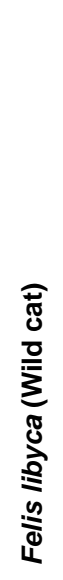 & 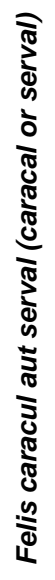 & 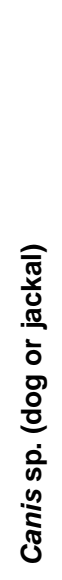 & 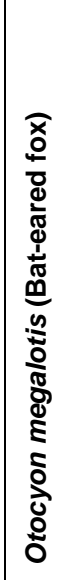 & 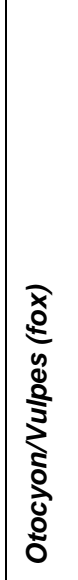 & 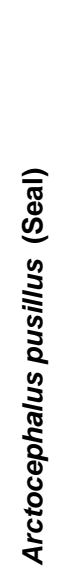 & 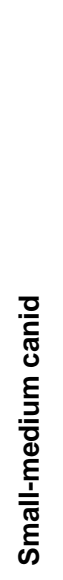 & 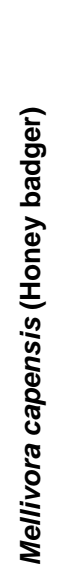 & 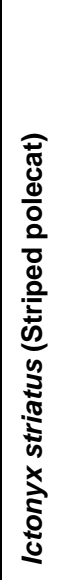 & 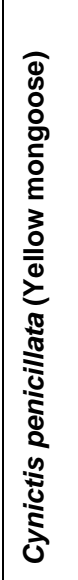 & 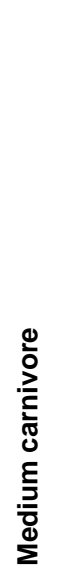 & 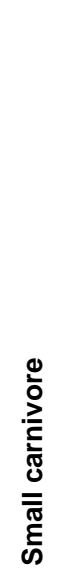 & 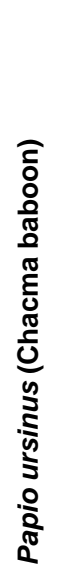 & 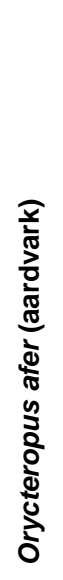 & 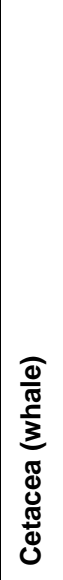 \\
\hline \multirow{2}{*}{ DP2004/010 } & Patch A & & & & & & & & & & & & & & $x$ & & & & & & & & & $x$ \\
\hline & Patch B & & & & & & & & & & & & & & & & & & & & & & & \\
\hline HKB2007/007 & & & & & & & & & & & & $1 / 1$ & & & & & & & & & & & & \\
\hline KN2001/009 & & & $x$ & & $1 / 1$ & & & & & & & $3 / 1$ & & & & & & & $2 / 1$ & & & & & \\
\hline KN2004/012 & & & $x$ & & $2 / 1$ & & & & & & & & & & & & & & & & & & & \\
\hline KN2004/015E & & & $x$ & & & & & & & & & & & & & & & & & & & & & \\
\hline KN2005/040 & & & $x$ & & & & & & & & & & & & & & & & & & & & & \\
\hline KN2005/041 & & & & & & $3 / 1$ & & & & & & & & & $3 / 1$ & & & & & $1 / 1$ & $3 / 1$ & & & \\
\hline KN2005/041 & & & & & $10 / 2$ & & & & & $1 / 1$ & & & & & $3 / 1$ & & $1 / 1$ & & & & & & & \\
\hline KN2005/50 & & & $2 / 1$ & & & & & & & & & & & & & & & & & & $21 / 2$ & & & \\
\hline KN2005/054 & & & $x$ & & & & & & & & & & & & & & & & & & & & & \\
\hline \multirow{3}{*}{ KN2005/067 } & Patch $1 \mathrm{~A}$ & & $x$ & & $3 / 1$ & & & & & $1 / 1$ & & & & & & & & & & & & & & \\
\hline & Patch 1B & & & & $2 / 1$ & & $3 / 1$ & & & $4 / 1$ & & & & & & & & & & & & & & \\
\hline & Patch 1C & & & & & & $2 / 1$ & & & & & & & & & & & & & & & & & \\
\hline
\end{tabular}




\begin{tabular}{|c|c|c|c|c|c|c|c|c|c|c|c|c|c|c|c|c|c|c|c|c|c|c|c|c|}
\hline Site & $\begin{array}{l}\text { Layer / } \\
\text { Area }\end{array}$ & 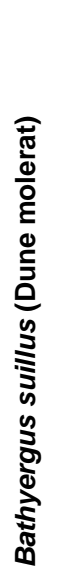 & 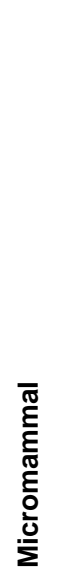 & 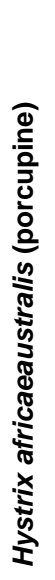 & 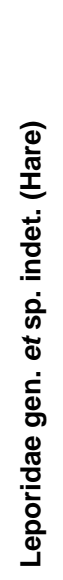 & 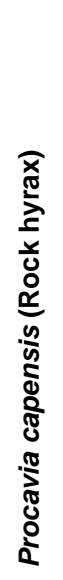 & 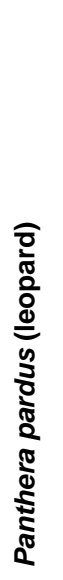 & 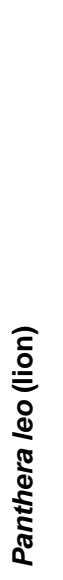 & 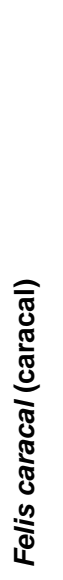 & 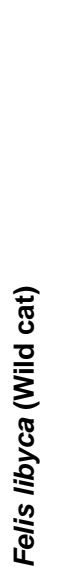 & 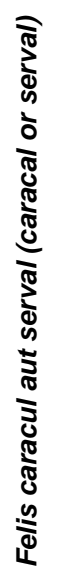 & 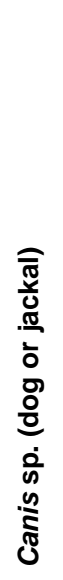 & 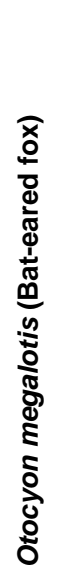 & 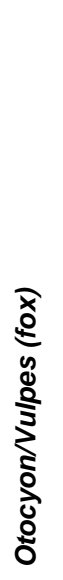 & 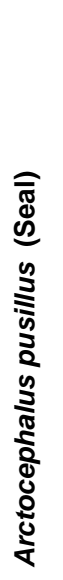 & 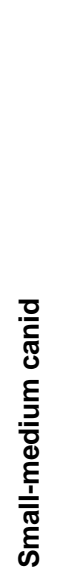 & 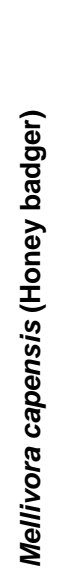 & 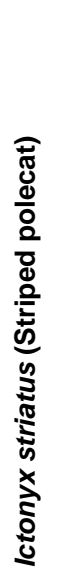 & 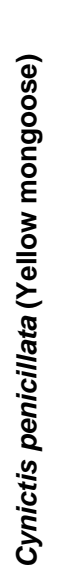 & 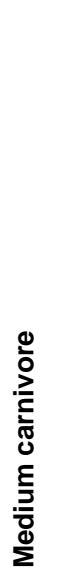 & 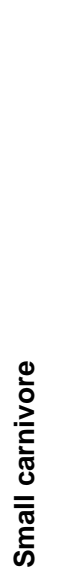 & 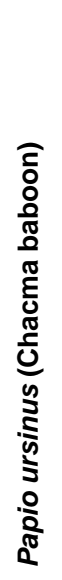 & 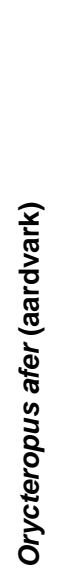 & 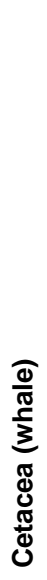 \\
\hline \multirow{4}{*}{ KN2005/067 } & Patch 1 & & & & $5 / 1$ & & $5 / 1$ & & & $5 / 1$ & & & & & & & & & & & & & & \\
\hline & Patch 2 & & & & & & & & & & & & & & & & & & & & & & & \\
\hline & Patch 3 & & & & & & & & & & & & & & & & & & & & & & & \\
\hline & Patch 4 & & & & & & & & & & & & & & & & & & & & & & & \\
\hline KN2005/135A & & & $x$ & & & & & & & & & & & & & & & & & & & & & \\
\hline \multicolumn{25}{|l|}{ KN2005/135B } \\
\hline \multirow{3}{*}{ KV2001/012 } & Area A & & $\mathrm{x}$ & & & & & & & & & & & & & & & & & & & & & \\
\hline & Area B & & & & & & & & & & & & & & & & & & & & & & & \\
\hline & Area C & & & & & & & & & & & & & & & & & & & & & & & \\
\hline \multirow{8}{*}{ LK2001/015 } & Patch A & & & & & & & & & & & & & & & & & & & & & & & \\
\hline & Patch B & & & & & & & & & & & & & & & & & & & & & & & \\
\hline & Patch $\mathrm{Ci}$ & & & & & & & & & & & & & & $1 / 1$ & & & & & & $1 / 1$ & & & \\
\hline & Patch Cii & & & & & & & & & & & & & & & & & & & & $1 / 1$ & & & \\
\hline & Patch D & & & & & & & & & & & & & & $8 / 1$ & & & & & & & & & \\
\hline & Patch E & & & & & & & & & & & & & & & & & & & & & & & \\
\hline & Patch F & & & & & & & & & & & & & & $2 / 1$ & & & & & & & & & \\
\hline & Patch G & & & & & & & & & & & & & & & & & & & & & & & \\
\hline
\end{tabular}




\begin{tabular}{|c|c|c|c|c|c|c|c|c|c|c|c|c|c|c|c|c|c|c|c|c|c|c|c|c|}
\hline Site & $\begin{array}{l}\text { Layer / } \\
\text { Area }\end{array}$ & 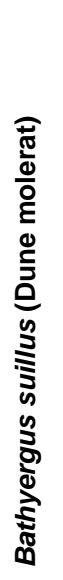 & 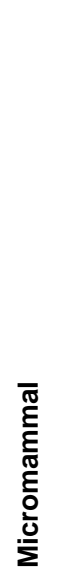 & 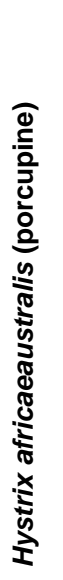 & 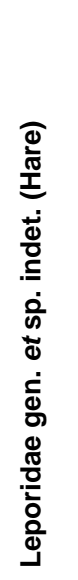 & 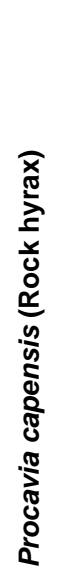 & 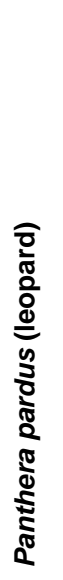 & 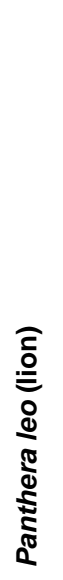 & 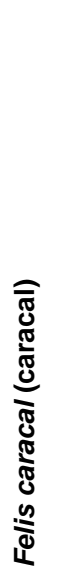 & 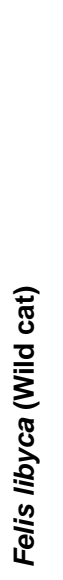 & 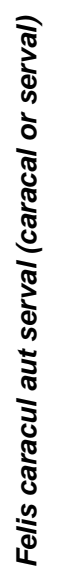 & 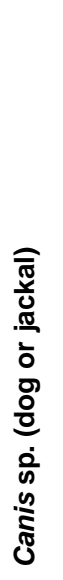 & 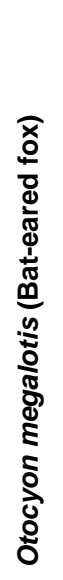 & 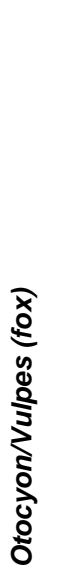 & 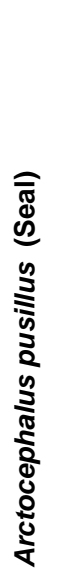 & 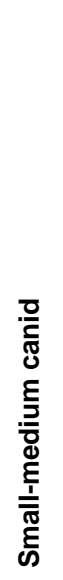 & 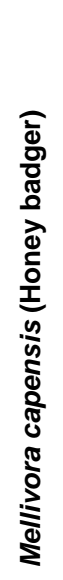 & 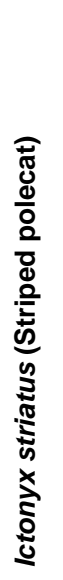 & 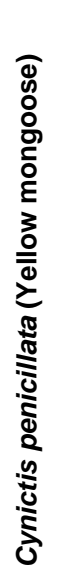 & 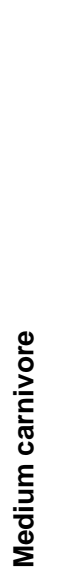 & 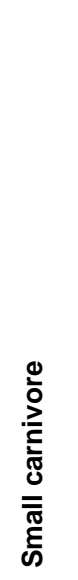 & 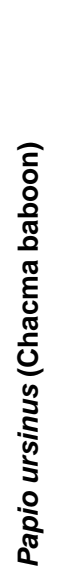 & 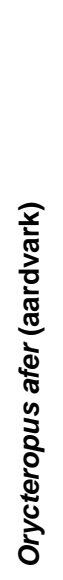 & 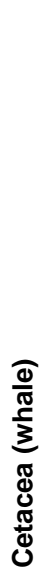 \\
\hline \multirow{2}{*}{ LK2001/015 } & Patch $\mathrm{H}$ & & & & & & & & & & & & & & & & & & & & & & & \\
\hline & Patch I & & & & & & & & & & & & & & & & & & & & & & & \\
\hline \multirow{2}{*}{ LK2004/011B } & Slump & & $3 / 2$ & & & & & & & & & & & & $2 / 1$ & & & & & & & & & \\
\hline & In situ & & $8 / 2$ & & & & & & & & & & & & & & & & & & $1 / 1$ & & & \\
\hline \multirow{2}{*}{ LK2004/011B } & Slump & & $x$ & & & & & & & & & & & & $1 / 1$ & & & & & & & & & \\
\hline & In situ & & $x$ & & & & & & & & & $3 / 1$ & & & & & & & & & & & & \\
\hline MB2005/001E & Layer 1 & & $\mathrm{x}$ & & & & & & & & & & & & $x$ & & & & & & & & & \\
\hline MB2005/001E & Layer 2 & & $\mathrm{x}$ & & & & & & & & & & & & & & & & & & & & & \\
\hline MB2005/001E & Layer 3 & & $x$ & & & & & & & & & & & & $x$ & & & & & & & & & \\
\hline MB2005/001E & Layer 4 & & $x$ & & & & & & & & & & & & & & & & & & & & & \\
\hline MB2005/013 & & $x$ & $x$ & & & & & & & & & & & & & & & & & & $x$ & & & \\
\hline MB2005/027 & & & $8 / 2$ & & & & & & & & & & & & $9 / 2$ & & & & & & $2 / 1$ & & & \\
\hline \multicolumn{25}{|l|}{ MB205/028A } \\
\hline MB2005/059 & & & $x$ & & & & & & & & & & & & & & & & & & & & & \\
\hline \multicolumn{25}{|l|}{ MV2007/005 } \\
\hline \multicolumn{25}{|l|}{ MV2007/009 } \\
\hline PN2009/001 & & & $x$ & & $12 / 1$ & & & & & $1 / 1$ & & & & & & & & & & & & & & \\
\hline
\end{tabular}




\begin{tabular}{|c|c|c|c|c|c|c|c|c|c|c|c|c|c|c|c|c|c|c|c|c|c|c|c|c|}
\hline Site & $\begin{array}{l}\text { Layer / } \\
\text { Area }\end{array}$ & 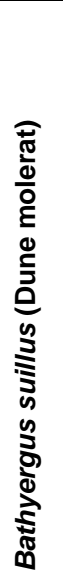 & 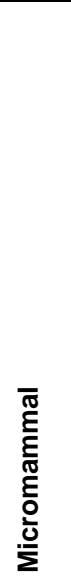 & 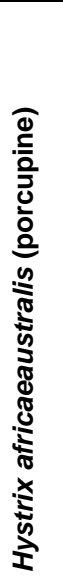 & 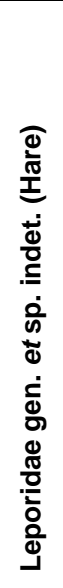 & 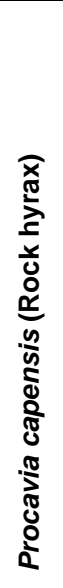 & 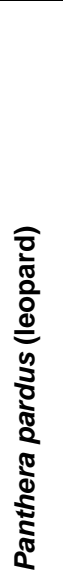 & 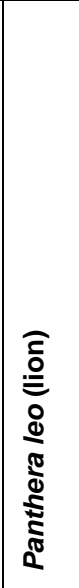 & 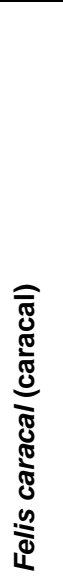 & 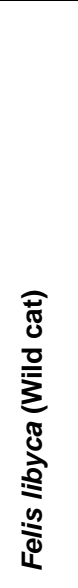 & 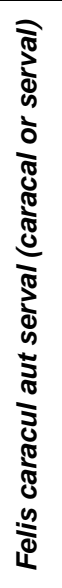 & 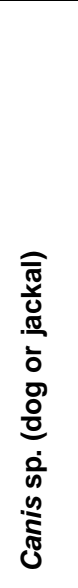 & 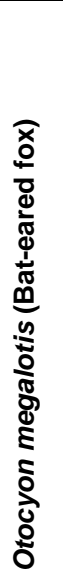 & 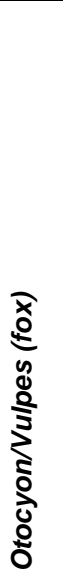 & 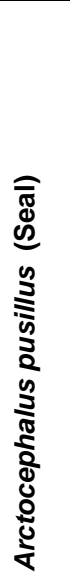 & 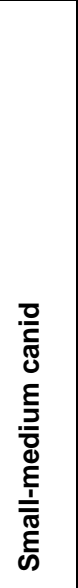 & 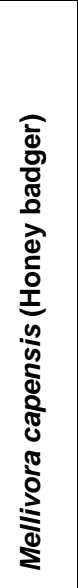 & 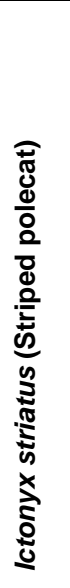 & 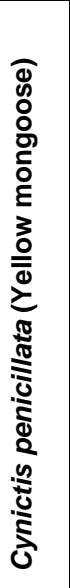 & 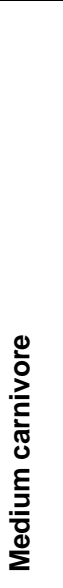 & 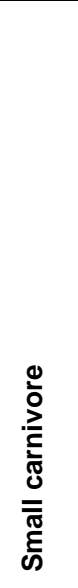 & 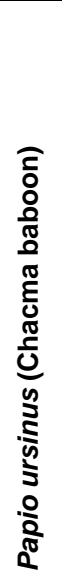 & 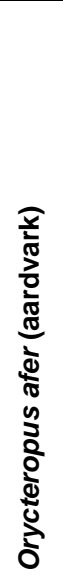 & 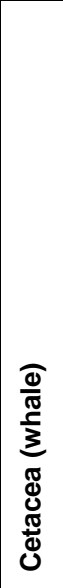 \\
\hline \multirow{4}{*}{ SK2001/024 } & Patch A & & & & & & & & & $1 / 1$ & & & & & $4 / 1$ & & & & $1 / 1$ & & $x$ & & & \\
\hline & Patch B & & & & & & & & & & & & & & & & & & & & & & & \\
\hline & Patch C & & & & & & & & & & & & & & & & & & & & & & & \\
\hline & Patch M & & & & & & & & & & & & & & $?$ & & & & & & & & & \\
\hline \multirow{5}{*}{ SK2001/025 } & Area A & & & & & & & & & & & & & & & & & & & & & & & \\
\hline & Area B & & & & & & & & & & & & & & & & & & & & & & & \\
\hline & Area C & & $2 / 1$ & & & & & & & & & & & & $1 / 1$ & & & & & & & & & \\
\hline & Area D & & & & & & & & & & & & & & & & & & & & & & & \\
\hline & Area F & & $38 /-$ & & & & & & & & & & & & & & & & & & & & & \\
\hline SK2001/039 & & & $x$ & & & & & & & & & & & & $5 / 1$ & & & & & & & & & \\
\hline SK2005/057A & & & $\mathrm{x}$ & & & & & & & $2 / 1$ & & $12 / 2$ & & & & & & $4 / 1$ & $8 / 3$ & & & & & \\
\hline \multirow{4}{*}{ SK2005/074A } & Surf & & & & & & & & & & & & & & & & & & & & & & & \\
\hline & $\mathrm{M} 1 / \mathrm{L1}$ & & $x$ & & & & & & & & & & & & & & & & & & & & & \\
\hline & $\mathrm{L} 2$ & & $x$ & & & & & & & & & & & & & & & & & & & & & \\
\hline & M2 & & & & & & & & & & & & & & & & & & & & & & & \\
\hline \multicolumn{25}{|l|}{ SK2005/084 } \\
\hline SK2005/095 & & & & & & & & & & & & $1 / 1$ & & & & & & & & & & & & \\
\hline
\end{tabular}




\begin{tabular}{|c|c|c|c|c|c|c|c|c|c|c|c|c|c|c|c|c|c|c|c|c|c|c|c|c|}
\hline Site & $\begin{array}{l}\text { Layer / } \\
\text { Area }\end{array}$ & 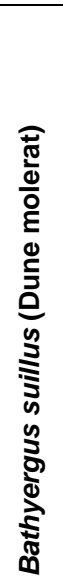 & 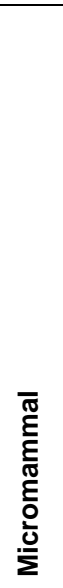 & 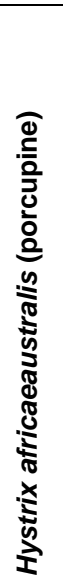 & 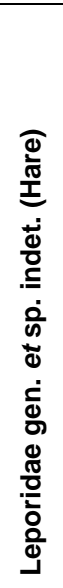 & 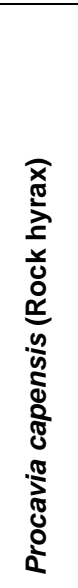 & 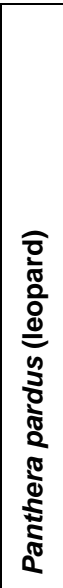 & 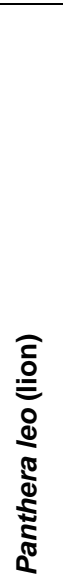 & 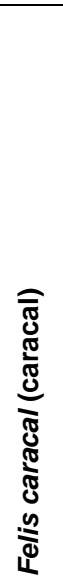 & 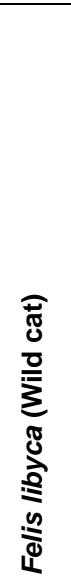 & 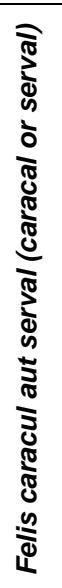 & 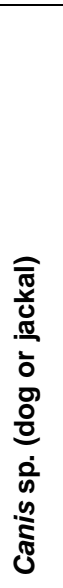 & 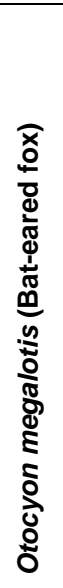 & 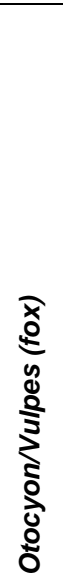 & 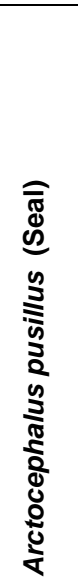 & 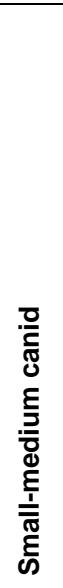 & 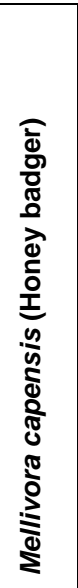 & 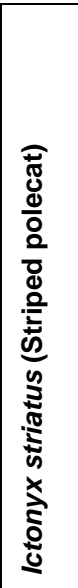 & 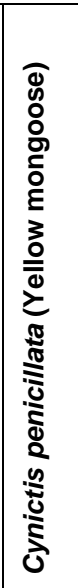 & 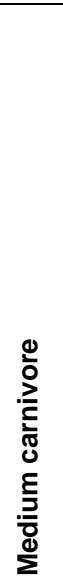 & 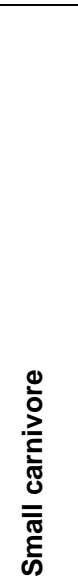 & 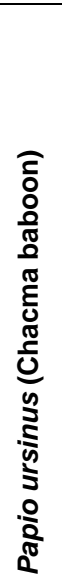 & 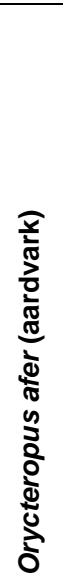 & 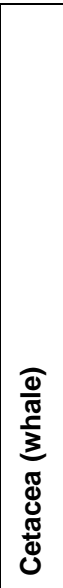 \\
\hline SK2005/096A & & & $5 / 1$ & & & & & & & & & & & & $10 / 1$ & & & & & & $1 / 1$ & & & \\
\hline SK2005/096B & & & $x$ & & & & & & & & & & & & & & & & & & & & & \\
\hline \multirow{4}{*}{ SK2006/006 } & Patch 1 & & & & & & & & & & & & & & & & & & & & & & & \\
\hline & $\begin{array}{l}\text { Patch } 2 \\
\text { Upper }\end{array}$ & & $x$ & & & & & & & & & & & & & & & & & & & & & \\
\hline & $\begin{array}{l}\text { Patch 2 } \\
\text { Lower }\end{array}$ & & $x$ & & & & & & & & & & & & & & & & & & & & & \\
\hline & Patch 3 & & & & & & & & & & & & & & $x$ & & & & & & & & & \\
\hline \multicolumn{25}{|l|}{ TP2004/003 } \\
\hline TP2004/014 & & & $x$ & & & & & & & & & & & & & & & & & & & & & \\
\hline \multirow{2}{*}{ KK002 } & Upper & $1 / 1$ & & $1 / 1$ & $5 / 1$ & $37 / 4$ & & & $1 / 1$ & $17 / 2$ & & $5 / 1$ & & & & & $2 / 1$ & & & & & $1 / 1$ & $1 / 1$ & \\
\hline & Lower & & & & $5 / 1$ & $8 / 2$ & & & & $3 / 1$ & & & & & & & & \begin{tabular}{|l|}
$1 / 1$ \\
\end{tabular} & & & & & & \\
\hline KK003 & & & & & & $x$ & & & & & & & & & & & & & & & & & & \\
\hline
\end{tabular}




\begin{tabular}{|c|c|c|c|c|c|c|c|c|c|c|c|c|c|c|c|c|c|c|c|c|c|c|c|c|}
\hline Site & $\begin{array}{l}\text { Layer / } \\
\text { Area }\end{array}$ & 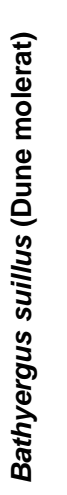 & 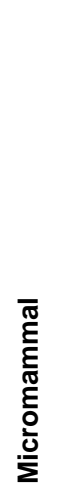 & 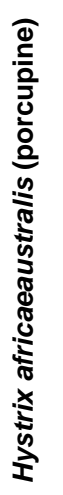 & 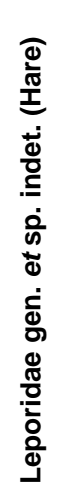 & 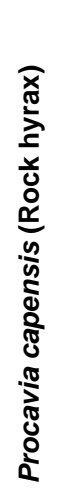 & 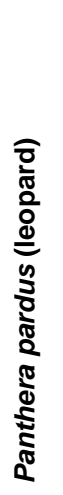 & 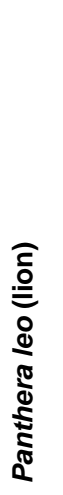 & 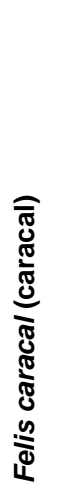 & 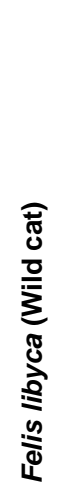 & 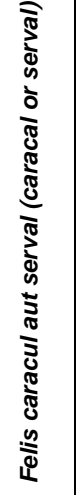 & 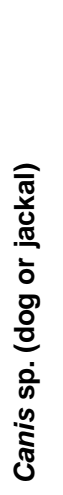 & 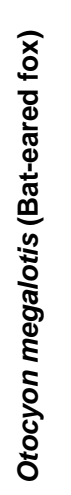 & 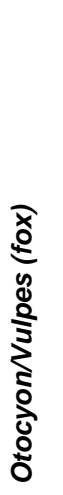 & 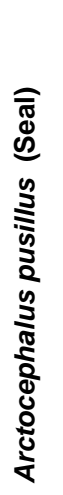 & 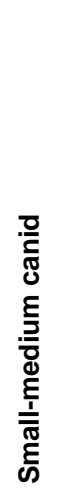 & 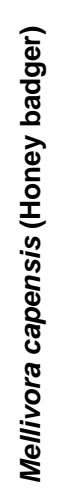 & 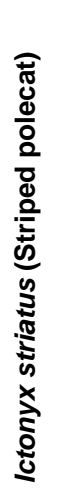 & 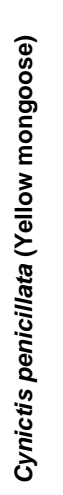 & 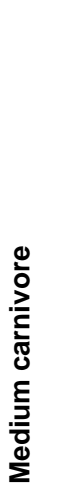 & 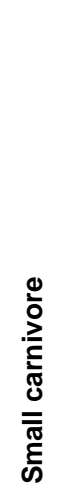 & 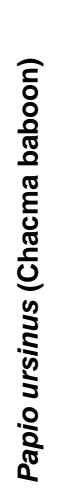 & 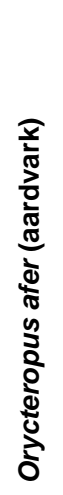 & 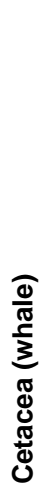 \\
\hline \multirow{6}{*}{ VR001 } & $\begin{array}{l}\text { Layers } \\
1-4 \mathrm{~A}\end{array}$ & $3 / 1$ & & & $4 / 1$ & $5 / 2$ & & & & $3 / 1$ & & $4 / 1$ & & & & & & & & & & & & \\
\hline & $\begin{array}{l}\text { Layers } \\
4 \mathrm{~B}-5\end{array}$ & $2 / 1$ & & & $5 / 1$ & $8 / 1$ & $1 / 1$ & $1 / 1$ & $1 / 1$ & $9 / 1$ & & & & & & & & & & & & & & \\
\hline & Layer 6 & & & & $1 / 1$ & & & & & & & $1 / 1$ & & & & & & & & & & $1 / 1$ & & \\
\hline & Layer 7 & & & & $1 / 1$ & $2 / 1$ & & & & & & $1 / 1$ & & & & & & & & & & & & \\
\hline & $\begin{array}{l}\text { Layers } \\
8-9 A\end{array}$ & & & & $7 / 1$ & $3 / 1$ & & & & $7 / 2$ & & $1 / 1$ & & & & & & & & & & & & \\
\hline & $\begin{array}{l}\text { Layer } \\
\text { 9B }\end{array}$ & & & & $5 / 1$ & & & & & $2 / 1$ & & $1 / 1$ & & & & & & & & & & & & \\
\hline \multirow{7}{*}{ VR005 } & Layer 1 & $4 / 1$ & & $2 / 1$ & $21 / 1$ & $6 / 1$ & & & & $13 / 2$ & $1 / 1$ & $4 / 1$ & & $1 / 1$ & & & & & & & & & & \\
\hline & Layer 2 & $6 / 2$ & & $5 / 1$ & $6 / 1$ & $15 / 3$ & & & & $21 / 3$ & $1 / 1$ & $2 / 1$ & $1 / 1$ & $2 / 1$ & & & & $1 / 1$ & & & $2 / 1$ & & & \\
\hline & Layer 3 & $6 / 1$ & & $1 / 1$ & $6 / 2$ & $6 / 1$ & & & & $16 / 2$ & $1 / 1$ & $7 / 2$ & & & & & & & & & & & & \\
\hline & Layer 4 & $5 / 2$ & & & $16 / 2$ & $6 / 1$ & & & & & & $2 / 1$ & & & & & & & & & & & & \\
\hline & Layer 5 & & & & $7 / 1$ & & & & & & & & & & & & & & & & & & & \\
\hline & Layer 6 & & & & & $2 / 1$ & & & & $1 / 1$ & & & & & & & & & & & & & & \\
\hline & Layer 7 & & & & & & & & & & & & & & & & & & & & & & & \\
\hline VR048 & & & $x$ & & & & & & & & & & & & & & & & & & & & & \\
\hline JKB K & & & & & & $x$ & & & & & & & & & & & & & & & & & & \\
\hline JKB M & & & & & $x$ & & & & & & & & & & & & & & & & & & & \\
\hline
\end{tabular}


Table A2.4.2: Fauna (part 2). NISP/MNI listed where available, otherwise presence is marked by an ' $x$ '. Please see A2.4.3 for references and notes.

\begin{tabular}{|c|c|c|c|c|c|c|c|c|c|c|c|c|c|c|c|c|c|c|}
\hline Site & $\begin{array}{l}\text { Layer / } \\
\text { Area }\end{array}$ & 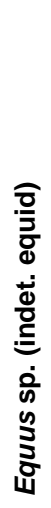 & 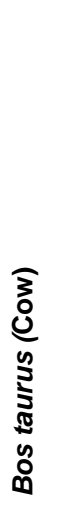 & 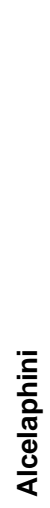 & 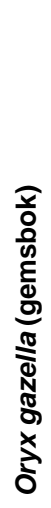 & 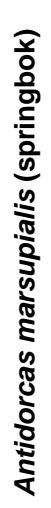 & 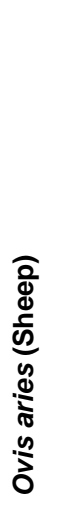 & 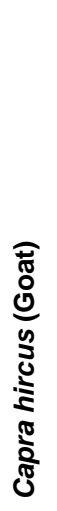 & $\begin{array}{l}\bar{\pi} \\
\text { o } \\
\frac{0}{0} \\
\frac{d}{\omega} \\
\frac{5}{\omega}\end{array}$ & 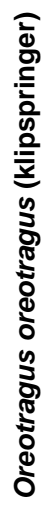 & 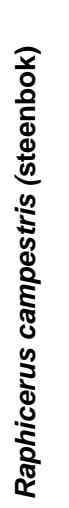 & 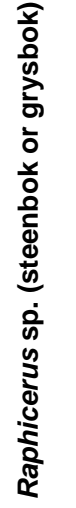 & 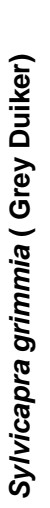 & 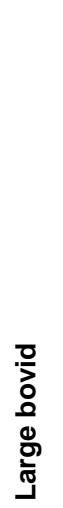 & 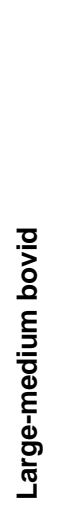 & 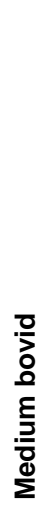 & 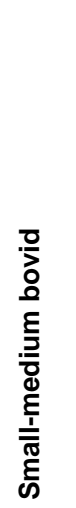 & 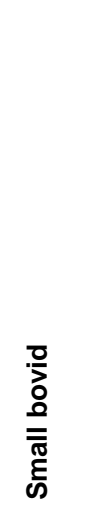 \\
\hline \multirow{2}{*}{ DP2004/010 } & Patch A & & & & & & & & & & & & & & & & & $x$ \\
\hline & Patch B & & & & & & & & & & & & & & & & & \\
\hline HKB2007/007 & & & $1 / 1$ & & & & & $1 / 1$ & $20 / 3$ & & & & & $3 / 1$ & & & $52 / 2$ & $7 / 1$ \\
\hline KN2001/009 & & & & & & & & & & & & $2 / 1$ & & & & & & $13 / 1$ \\
\hline KN2004/012 & & & & & & & & & & & & & & & & & & $11 / 2$ \\
\hline KN2004/015E & & & & & & & & & & & & & & & & & & $?$ \\
\hline KN2005/040 & & & & & & & & & & & & & & & & & & $x$ \\
\hline KN2005/041 & & & & & & & & & & & $2 / 1$ & & & $1 / 1$ & & & & \\
\hline KN2005/041 & & & $1 / 1$ & & & & & & & & $1 / 1$ & & & $3 / 1$ & $1 / 1$ & & & $9 / 1$ \\
\hline KN2005/50 & & & & & & & & & & & $77 / 2$ & & & $1 / 1$ & & & & $5 / 1$ \\
\hline KN2005/054 & & & & & & & & & & & & & & & & & & $x$ \\
\hline \multirow{3}{*}{ KN2005/067 } & Patch 1A & & & & & & & & & & $6 / 3$ & $15 / 4$ & & $5 / 1$ & $5 / 1$ & & $2 / 1$ & $105 / 4$ \\
\hline & Patch 1B & & & & & & $1 / 1$ & & & & $7 / 3$ & $34 / 7$ & & $2 / 1$ & & & $1 / 1$ & $142 / 6$ \\
\hline & Patch 1C & & & & & & $1 / 1$ & & & & & & & & & & $1 / 1$ & $7 / 2$ \\
\hline
\end{tabular}




\begin{tabular}{|c|c|c|c|c|c|c|c|c|c|c|c|c|c|c|c|c|c|c|}
\hline Site & $\begin{array}{l}\text { Layer / } \\
\text { Area }\end{array}$ & 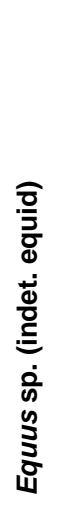 & 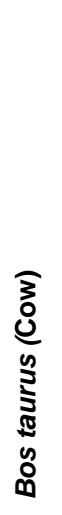 & 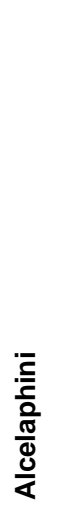 & 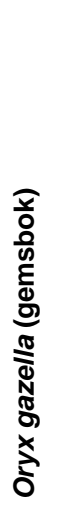 & 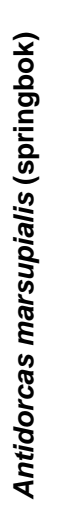 & 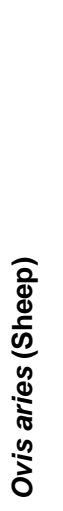 & 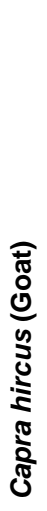 & 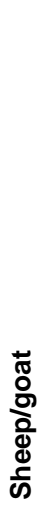 & 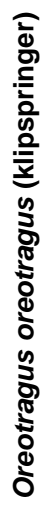 & 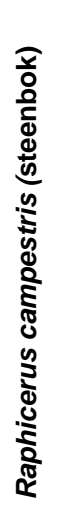 & 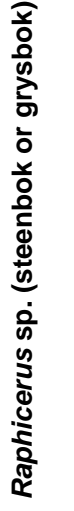 & 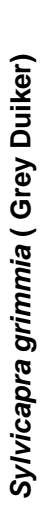 & 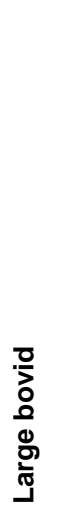 & 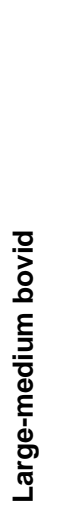 & 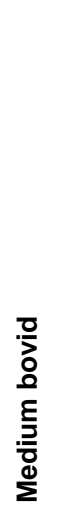 & 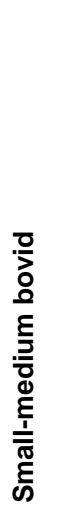 & $\begin{array}{l}\text { o } \\
\text { o } \\
\overline{\bar{\sigma}} \\
\tilde{E} \\
\text { 心 }\end{array}$ \\
\hline \multirow{4}{*}{ KN2005/067 } & Patch 1 & & & & & & $2 / 1$ & & & & $13 / 5$ & $49 / 8$ & & $7 / 1$ & $5 / 1$ & & $4 / 1$ & $256 / 8$ \\
\hline & Patch 2 & & & & & & & & & & & & & & & & & \\
\hline & Patch 3 & & & & & & & & & & & & & & & & & \\
\hline & Patch 4 & & & & & & & & & & & & & & & & & $7 / 1$ \\
\hline KN2005/135A & & & & & & & & & & & & & & & & & & $x$ \\
\hline KN2005/135B & & & & & & & & & & & & & & & & & & $x$ \\
\hline \multirow{3}{*}{ KV2001/012 } & Area A & & & & & & & & & & & & & & & & & \\
\hline & Area B & & & & & & & & & & & & & & & & $?$ & $x$ \\
\hline & Area C & & & & & & & & & & & & & & & & & $x$ \\
\hline \multirow{8}{*}{ LK2001/015 } & Patch A & & & & & & & & & & & & & & & & & \\
\hline & Patch B & & & & & & & & & & & & & & & & & \\
\hline & Patch Ci & & & & & & & & & & & & & & & & $7 / 1$ & \\
\hline & Patch Cii & & & & & & & & & & & & & & & & $1 / 1$ & $8 / 1$ \\
\hline & Patch D & & & & & & & & & & & & & $1 / 1$ & & & & $7 / 1$ \\
\hline & Patch E & & & & & & & & & & & & & & & & & \\
\hline & Patch F & & & & & & & & & & & & & & & & & \\
\hline & Patch G & & & & & & & & & & & & & & & & & \\
\hline
\end{tabular}




\begin{tabular}{|c|c|c|c|c|c|c|c|c|c|c|c|c|c|c|c|c|c|c|}
\hline Site & $\begin{array}{l}\text { Layer / } \\
\text { Area }\end{array}$ & 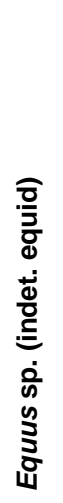 & 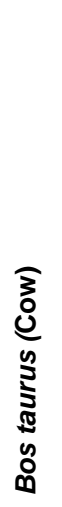 & $\begin{array}{l}\overline{\bar{z}} \\
\overline{\frac{\pi}{2}} \\
\frac{\bar{\sigma}}{0} \\
\frac{0}{4}\end{array}$ & 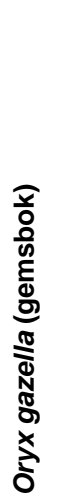 & 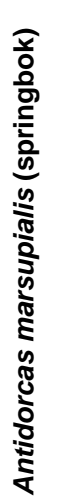 & 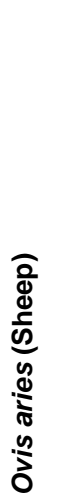 & 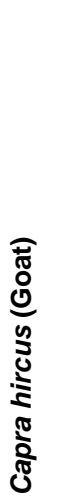 & 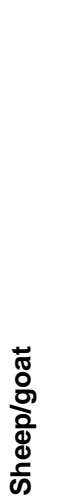 & 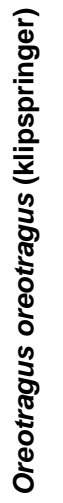 & 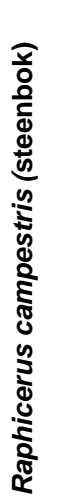 & 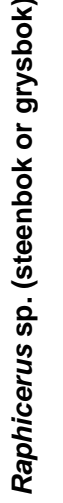 & 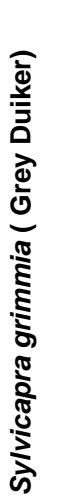 & 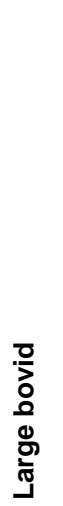 & 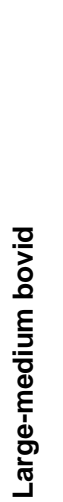 & 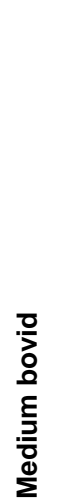 & 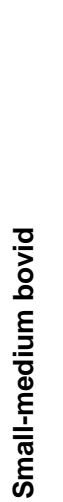 & 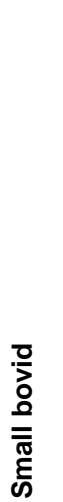 \\
\hline \multirow{2}{*}{ LK2001/015 } & Patch $\mathrm{H}$ & & & & & & & & & & & & & & & & & \\
\hline & Patch I & & & & & & & & & & & & & & & & & $2 / 1$ \\
\hline \multirow{2}{*}{ LK2004/011B } & Slump & & & & & & & & & & $2 / 1$ & & $1 / 1$ & $1 / 1$ & & & & $1 /-$ \\
\hline & In situ & & & & & & & & & & $4 / 2$ & & & & & & & \\
\hline \multirow{2}{*}{ LK2004/011B } & Slump & & & & & & & & & & & & & $6 / 1$ & & & & \\
\hline & In situ & & & & & & $1 / 1$ & & & & $1 / 2$ & $1 / 1$ & $1 / 1$ & & & & $2 / 1$ & $4 / 2$ \\
\hline \multirow{4}{*}{ MB2005/001E } & Layer 1 & & & & & & & & & & & & & & & & & $?$ \\
\hline & Layer 2 & & & & & & & & & & & & & & & & & \\
\hline & Layer 3 & & & & & & & & & & & & & & & & & \\
\hline & Layer 4 & & & & & & & & & & & & & & & & & \\
\hline MB2005/013 & & & & & & & & & & & & & & & & & & $\mathrm{x}$ \\
\hline MB2005/027 & & & & & & & & & & & $3 / 1$ & & & $1 / 1$ & & & & \\
\hline MB205/028A & & & & & & & & & & & & & & & & & & $\mathrm{x}$ \\
\hline \multicolumn{19}{|l|}{ MB2005/059 } \\
\hline \multicolumn{19}{|l|}{ MV2007/005 } \\
\hline MV2007/009 & & & & & & & & & & & & & & & & & & $1 / 1$ \\
\hline$\overline{P N 2009 / 001}$ & & & & & & & & & & & & & & $1 / 1$ & $1 / 1$ & & $4 / 1$ & $1 / 1$ \\
\hline
\end{tabular}




\begin{tabular}{|c|c|c|c|c|c|c|c|c|c|c|c|c|c|c|c|c|c|c|}
\hline Site & $\begin{array}{l}\text { Layer / } \\
\text { Area }\end{array}$ & 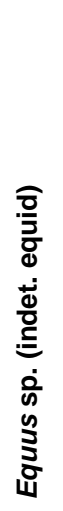 & 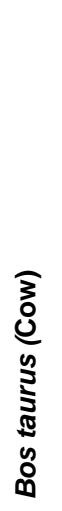 & 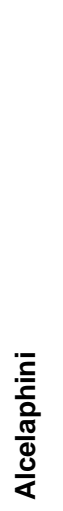 & 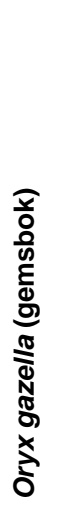 & 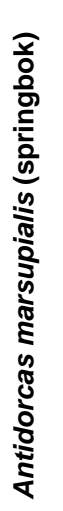 & 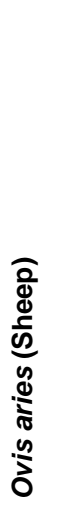 & 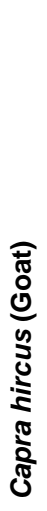 & 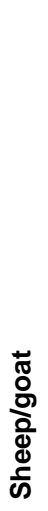 & 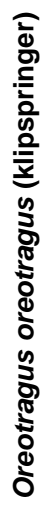 & 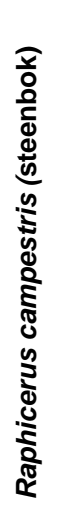 & 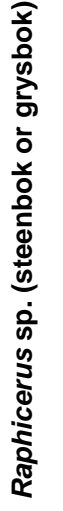 & 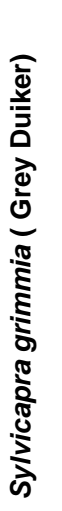 & 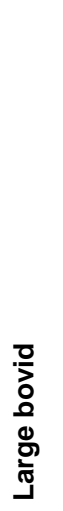 & 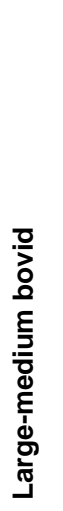 & 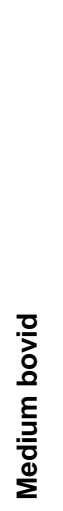 & 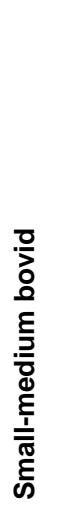 & 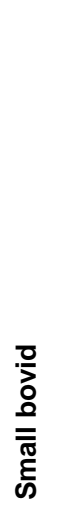 \\
\hline \multirow{4}{*}{ SK2001/024 } & Patch A & & & & & & & & & & $1 / 1$ & $6 / 4$ & & & & & $1 / 1$ & $60 / 4$ \\
\hline & Patch B & & & & & & & & & & & & & & & & & \\
\hline & Patch C & & & & & & & & & & & & & & & & & \\
\hline & Patch M & & & & & & & & & & & & & & & & & \\
\hline \multirow{5}{*}{ SK2001/025 } & Area A & & & & & & & & & & & & & & & & & \\
\hline & Area B & & & & & & & & & & & & & & & & & \\
\hline & Area C & & & & & & & & & & $15 / 2$ & & & & & & & $1 / 1$ \\
\hline & Area D & & & & & & & & & & & & & & & & & \\
\hline & Area F & & & & & & & & & & & & & & & & & \\
\hline SK2001/039 & & & & & & & & & & & & $1 / 1$ & & & & & $2 / 1$ & $1 / 1$ \\
\hline SK2005/057A & & & $1 / 1$ & & & & & & & & $1 / 1$ & $9 / 2$ & & $1 / 1$ & & & $1 / 1$ & $42 / 2$ \\
\hline \multirow{4}{*}{ SK2005/074A } & Surf & & & & & & & & & & & & & & & $x$ & & \\
\hline & M1/L1 & & & & & & & & & & & & & & & & & $x$ \\
\hline & L2 & & & & & & & & & & & & & & & & & \\
\hline & M2 & & & & & & & & & & & & & & & & & \\
\hline \multicolumn{19}{|l|}{ SK2005/084 } \\
\hline SK2005/095 & & & $1 / 1$ & & & & & & & & & & & $1 / 1$ & $1 / 1$ & & & \\
\hline
\end{tabular}




\begin{tabular}{|c|c|c|c|c|c|c|c|c|c|c|c|c|c|c|c|c|c|c|}
\hline Site & $\begin{array}{l}\text { Layer / } \\
\text { Area }\end{array}$ & 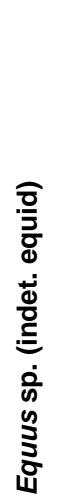 & 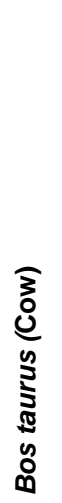 & 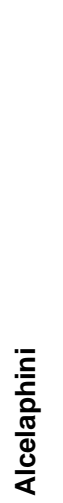 & 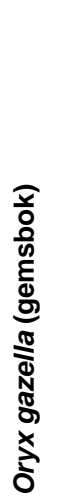 & 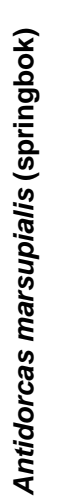 & 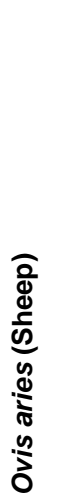 & 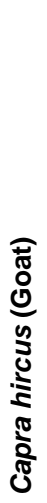 & 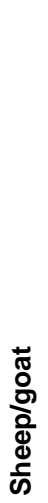 & 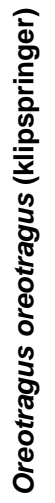 & 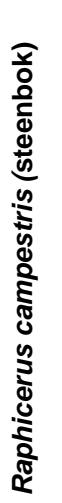 & 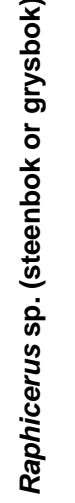 & 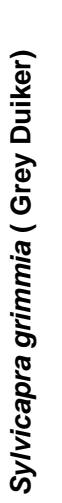 & 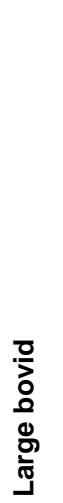 & 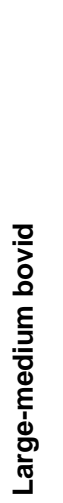 & 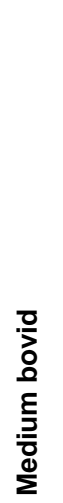 & 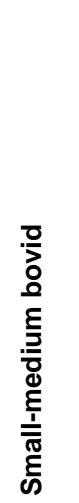 & 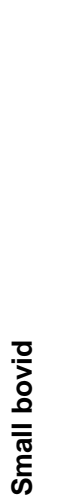 \\
\hline SK2005/096A & & & & & & & & & & & $2 / 1$ & & & & & & & \\
\hline SK2005/096B & & & & & & & & & & & & & & & & & & \\
\hline \multirow{4}{*}{ SK2006/006 } & Patch 1 & & & & & & & & & & & & & & & & & \\
\hline & $\begin{array}{l}\text { Patch 2 } \\
\text { Upper }\end{array}$ & & & & & & & & & & & & & & & & & $?$ \\
\hline & $\begin{array}{l}\text { Patch } 2 \\
\text { Lower }\end{array}$ & & & & & & & & & & & & & & & & & \\
\hline & Patch 3 & & & & & & & & & & & & & & & & $?$ & $\mathrm{x}$ \\
\hline \multicolumn{19}{|l|}{ TP2004/003 } \\
\hline \multicolumn{19}{|l|}{ TP2004/014 } \\
\hline \multirow{2}{*}{ KK002 } & Upper & & $1 / 1$ & & & & & & & & $1 / 1$ & $17 / 2$ & $1 / 1$ & $3 / 1$ & $7 / 1$ & & $12 / 1$ & $78 / 3$ \\
\hline & Lower & $1 / 1$ & & & & & & & & & $7 / 2$ & $9 / 3$ & & $1 / 1$ & & & & $27 / 3$ \\
\hline KK003 & & & & & & & & & & & & & & & & & & \\
\hline
\end{tabular}




\begin{tabular}{|c|c|c|c|c|c|c|c|c|c|c|c|c|c|c|c|c|c|c|}
\hline Site & $\begin{array}{l}\text { Layer / } \\
\text { Area }\end{array}$ & 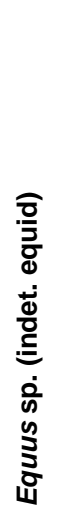 & 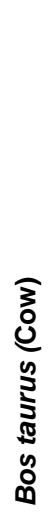 & 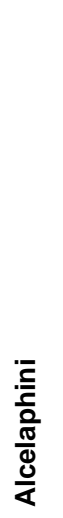 & 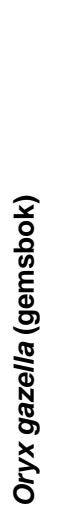 & 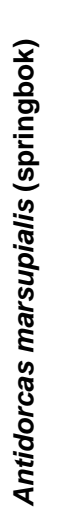 & 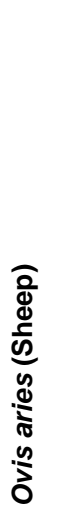 & 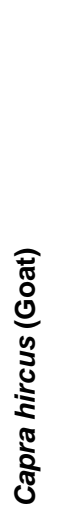 & $\begin{array}{l}\text { बू } \\
\text { बे } \\
\frac{0}{\Phi} \\
\frac{\delta}{\omega}\end{array}$ & 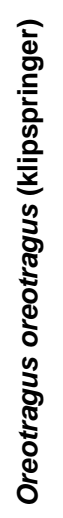 & 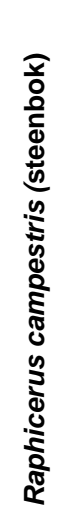 & 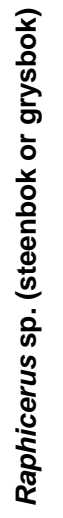 & 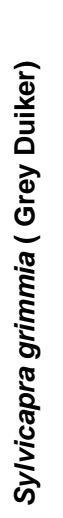 & 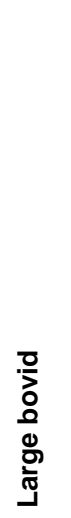 & 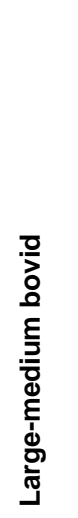 & 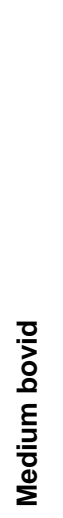 & 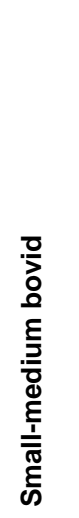 & 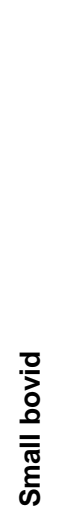 \\
\hline \multirow{6}{*}{ VR001 } & $\begin{array}{l}\text { Layers } \\
1-4 \mathrm{~A}\end{array}$ & & & $1 / 1$ & & & & & & & $2 / 1$ & $2 / 1$ & & $2 / 1$ & $3 / 1$ & & $3 / 1$ & $12 / 2$ \\
\hline & $\begin{array}{l}\text { Layers } \\
4 \mathrm{~B}-5\end{array}$ & & & & & & & & $1 / 1$ & & $12 / 3$ & $6 / 2$ & $1 / 1$ & $4 / 1$ & & & $10 / 1$ & $70 / 3$ \\
\hline & Layer 6 & & & & & & & & & & $1 / 1$ & $1 / 1$ & & & $1 / 1$ & & $1 / 1$ & $19 / 2$ \\
\hline & Layer 7 & $1 / 1$ & & & $2 / 1$ & & & & & & & & & & $2 / 1$ & & $1 / 1$ & $8 / 1$ \\
\hline & $\begin{array}{l}\text { Layers } \\
8-9 \mathrm{~A}\end{array}$ & $2 / 1$ & & & $3 / 1$ & & & & $1 / 1$ & $1 / 1$ & $3 / 2$ & $3 / 2$ & $1 / 1$ & $17 / 1$ & $30 / 2$ & & $15 / 1$ & $35 / 2$ \\
\hline & $\begin{array}{l}\text { Layer } \\
9 \mathrm{~B}\end{array}$ & $1 / 1$ & & & & & & & & & $1 / 1$ & & & $2 / 1$ & $1 / 1$ & & & $15 / 2$ \\
\hline \multirow{7}{*}{ VR005 } & Layer 1 & & & & & & & & & & & $1 / 1$ & & $5 / 1$ & $2 / 1$ & & $12 / 1$ & $21 / 2$ \\
\hline & Layer 2 & & & & & & & & & & $2 / 1$ & $8 / 2$ & & $7 / 1$ & $9 / 1$ & & $23 / 1$ & $90 / 3$ \\
\hline & Layer 3 & $2 / 1$ & & & & $1 / 1$ & $2 / 1$ & & & & $1 / 1$ & $2 / 1$ & & $3 / 1$ & $4 / 1$ & & $20 / 2$ & $36 / 2$ \\
\hline & Layer 4 & & & & & & & & & & & $4 / 1$ & & $3 / 1$ & $2 / 1$ & & $8 / 1$ & $26 / 1$ \\
\hline & Layer 5 & & & & & & & & & & & $2 / 1$ & & & & & & $4 / 1$ \\
\hline & Layer 6 & & & & & & & & & & & & & & & & $1 / 1$ & $8 / 1$ \\
\hline & Layer 7 & & & & & & & & & & & & & & & & & \\
\hline VR048 & & & & & & & & & & & & & & & & & & $\mathrm{x}$ \\
\hline JKB K & & $x$ & & & & & & & & & & & & & & & $x$ & $\mathrm{x}$ \\
\hline JKB M & & & & & & & $x$ & & & & & & & & & & $x$ & $x$ \\
\hline
\end{tabular}


Table A2.4.3: Fauna (part 3). NISP/MNI listed where available, otherwise presence is marked by an ' $x$ '. Where tortoise has an ' $h$ ' this refers to the number of distal humeri present. References denote formal analyses done by specialists.

\begin{tabular}{|c|c|c|c|c|c|c|c|c|c|c|c|c|c|c|}
\hline Site & $\begin{array}{l}\text { Layer / } \\
\text { Area }\end{array}$ & 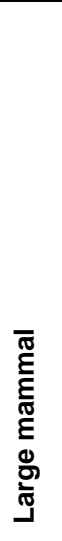 & 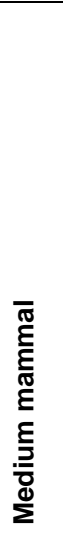 & 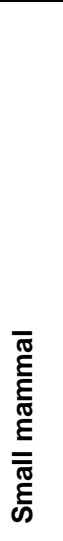 & 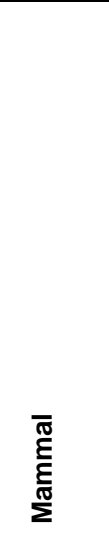 & 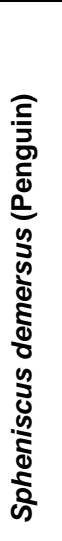 & 름 & 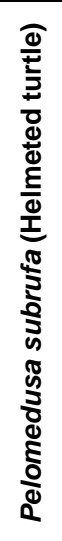 & $\begin{array}{l}\frac{\mathscr{D}}{.0} \\
\stackrel{0}{0} \\
\stackrel{0}{0}\end{array}$ & 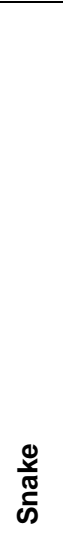 & 을 & $\frac{\frac{5}{\infty}}{i \frac{1}{4}}$ & 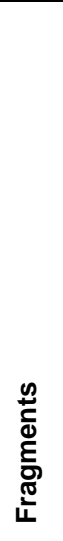 & References \& Notes \\
\hline \multirow{2}{*}{ DP2004/010 } & Patch A & & & & & & & & & & & $\mathrm{x}$ & & \\
\hline & Patch B & & & & & & & & & & & & $\mathrm{x}$ & \\
\hline HKB2007/007 & & & & & & & & & & $1 / 1$ & & & & R. Klein \& T. Steele, pers. comm. 2009 \\
\hline KN2001/009 & & & & & & & & & $x$ & $x$ & & & & R. Klein \& T. Steele, pers. comm. 2011 \\
\hline KN2004/012 & & & & & $x$ & & & & $\mathrm{x} / 4$ & & & $\mathrm{x}$ & & R. Klein, pers. comm. 2012 \\
\hline KN2004/015E & & & & & & & & & $\mathrm{x}$ & & & $\mathrm{x}$ & & \\
\hline KN2005/040 & & & & & & & & & $x$ & $x$ & & & & \\
\hline KN2005/041 & & $2 / 1$ & $1 / 1$ & & $1698 /-$ & $1 / 1$ & $1 /-$ & & $15 / 1$ & & $1 / 1$ & $4 / 1$ & & G. Dewar, pers. comm. 2010 \\
\hline KN2005/041 & & & & & & $\mathrm{x}$ & $x$ & & $\mathrm{x}$ & & $\mathrm{x}$ & $x$ & & R. Klein \& T. Steele, pers. comm. 2011 \\
\hline KN2005/50 & & & & $8 /-$ & $2036 /-$ & & $6 / 1$ & & $61 / 2$ & $1 / 1$ & & & & G. Dewar, pers. comm. 2010 \\
\hline KN2005/054 & & & & & & & & & $x$ & & & $x$ & & \\
\hline \multirow{3}{*}{ KN2005/067 } & Patch 1A & & & & & & & & & $x$ & & & & \multirow{3}{*}{ R. Klein \& T. Steele, pers. comm. 2011} \\
\hline & Patch 1B & & & & & & & & & $x$ & & & & \\
\hline & Patch 1C & & & & & & & & & $\mathrm{x}$ & & & & \\
\hline
\end{tabular}




\begin{tabular}{|c|c|c|c|c|c|c|c|c|c|c|c|c|c|c|}
\hline Site & $\begin{array}{l}\text { Layer / } \\
\text { Area }\end{array}$ & 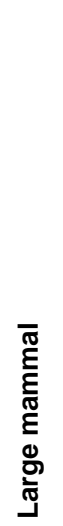 & 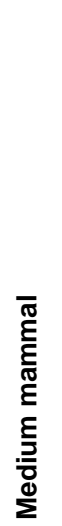 & 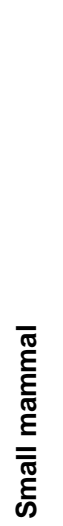 & 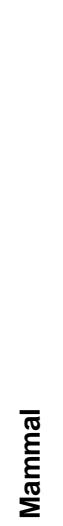 & 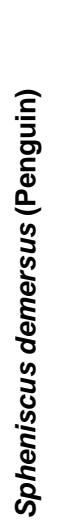 & 홈 & 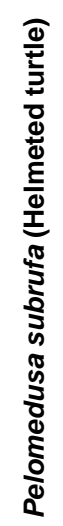 & 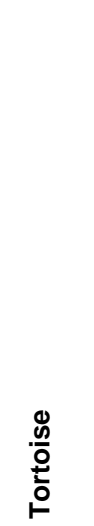 & 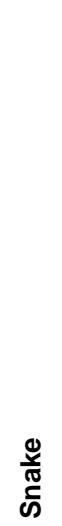 & $\begin{array}{l}\text { Do } \\
\stackrel{N}{N} \\
\stackrel{J}{J}\end{array}$ & $\frac{\frac{c}{\omega}}{\frac{\omega}{4}}$ & 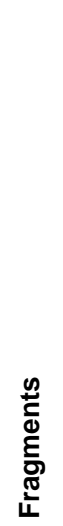 & References \& Notes \\
\hline \multirow{4}{*}{ KN2005/067 } & Patch 1 & & & & & & & & & $\mathrm{x}$ & & & & \multirow{4}{*}{ R. Klein \& T. Steele, pers. comm. 2011} \\
\hline & Patch 2 & & & & & & & & & & & & & \\
\hline & Patch 3 & & & & & & & & & $\mathrm{x}$ & & & & \\
\hline & Patch 4 & & & & & & & & & & & & & \\
\hline KN2005/135A & & & & & & & & & $\mathrm{x}$ & & & & & \\
\hline KN2005/135B & & & & & $\mathrm{x}$ & & & & $\mathrm{x}$ & & & & & \\
\hline \multirow{3}{*}{ KV2001/012 } & Area $\mathrm{A}$ & & & & & & & & & & & & & \\
\hline & Area $B$ & & & & & & & & $\mathrm{x}$ & & & & & \\
\hline & Area C & & & & & & & & $\mathrm{x}$ & & & & & \\
\hline \multirow{8}{*}{ LK2001/015 } & Patch A & & & & & & & & & & & & $\mathrm{x}$ & \multirow{8}{*}{ G. Dewar, pers. comm. 2010} \\
\hline & Patch B & & & & $6 / 1$ & & & & $7 / 1$ & & & & & \\
\hline & Patch $\mathrm{Ci}$ & & & & $7 /-$ & & & & $4 / 1$ & & & & & \\
\hline & Patch Cii & & & & $10 /-$ & & & & $117 / 4$ & $5 / 1$ & & & & \\
\hline & Patch D & $2 /-$ & & $2 / 1$ & $71 /-$ & & & & $4 / 1$ & & & & & \\
\hline & Patch E & & & & $4 / 1$ & & & & & & & & & \\
\hline & Patch F & & & $1 / 1$ & $3 /-$ & & & & $1 / 1$ & & & & & \\
\hline & Patch $\mathrm{G}$ & & & & $1 / 1$ & & & & & & & & & \\
\hline
\end{tabular}




\begin{tabular}{|c|c|c|c|c|c|c|c|c|c|c|c|c|c|c|}
\hline Site & $\begin{array}{l}\text { Layer / } \\
\text { Area }\end{array}$ & 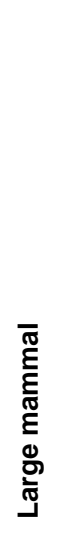 & 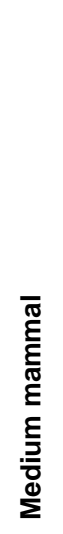 & 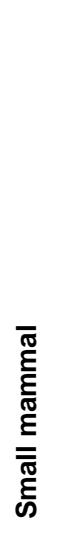 & 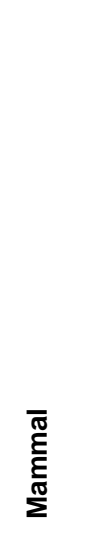 & 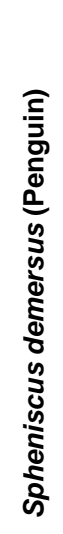 & 홀 & 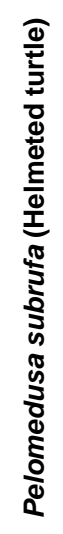 & 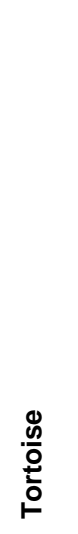 & 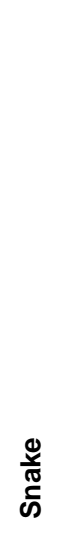 & 苞 & $\frac{\frac{\sigma}{\omega}}{i \frac{p}{L}}$ & 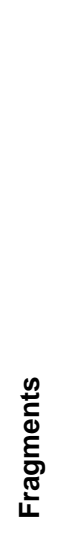 & References \& Notes \\
\hline \multirow{2}{*}{ LK2001/015 } & Patch $\mathrm{H}$ & & & & & & & & & & & & $\mathrm{x}$ & \multirow{2}{*}{ G. Dewar, pers. comm. 2010} \\
\hline & Patch I & & & & $55 /-$ & & & & $7 / 1$ & & & & & \\
\hline \multirow{2}{*}{ LK2004/011B } & Slump & & & & $203 /-$ & & $1 / 1$ & & $1 / 1$ & & & & & \multirow{2}{*}{ G. Dewar, pers. comm. 2010} \\
\hline & In situ & & & $2 / 1$ & $187 /-$ & & & & & & $1 / 1$ & & & \\
\hline \multirow{2}{*}{ LK2004/011B } & Slump & & & & & & & & & & & & & \multirow{2}{*}{ R. Klein \& T. Steele, pers. comm. 2011} \\
\hline & In situ & & & & & & & & & & & & & \\
\hline \multirow{4}{*}{ MB2005/001E } & Layer 1 & & & & $\mathrm{x}$ & & $\mathrm{x}$ & & $x$ & $x$ & & $x$ & $x$ & \\
\hline & Layer 2 & & & & $\mathrm{x}$ & & & & $\mathrm{x}$ & & & & $\mathrm{x}$ & \\
\hline & Layer 3 & & & & $\mathrm{x}$ & & $x$ & & $x$ & & & $x$ & $x$ & \\
\hline & Layer 4 & & & & $x$ & & & & & & & $x$ & $\mathrm{x}$ & \\
\hline MB2005/013 & & & & & & & & & $x$ & & & & & \\
\hline MB2005/027 & & & & $3 / 1$ & $487 /-$ & & & & $11 / 1$ & $2 /-$ & & & & G. Dewar, pers. comm. 2010 \\
\hline MB205/028A & & & & & & & & & $x$ & $\mathrm{x}$ & & & & \\
\hline MB2005/059 & & & & & & & & & $x$ & & & & $x$ & \\
\hline \multicolumn{15}{|l|}{ MV2007/005 } \\
\hline MV2007/009 & & & & & & & & & & & & & & ?recent \\
\hline PN2009/001 & & & & & & $x$ & & & $\mathrm{x}$ & & & $\mathrm{x}$ & & R. Klein, pers. comm. 2011 \\
\hline
\end{tabular}




\begin{tabular}{|c|c|c|c|c|c|c|c|c|c|c|c|c|c|c|}
\hline Site & $\begin{array}{l}\text { Layer / } \\
\text { Area }\end{array}$ & 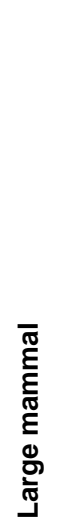 & 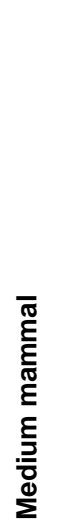 & 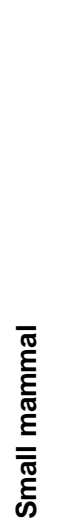 & 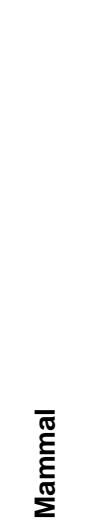 & 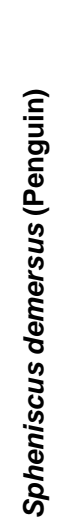 & 홈 & 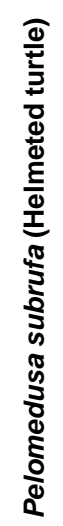 & $\begin{array}{l}\frac{0}{.0} \\
\frac{.0}{0} \\
\stackrel{0}{0} \\
\end{array}$ & 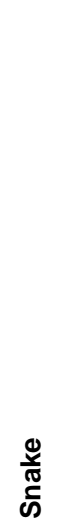 & 亭 & $\frac{\frac{5}{5}}{\frac{0}{4}}$ & 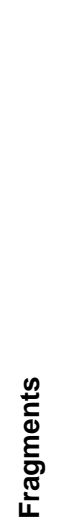 & References \& Notes \\
\hline \multirow{4}{*}{ SK2001/024 } & Patch A & & & & & & & & $\mathrm{x}$ & $\mathrm{x}$ & & & & \multirow{4}{*}{ R. Klein \& T. Steele, pers. comm. 2011} \\
\hline & Patch B & & & & & & & & & & & & $\mathrm{x}$ & \\
\hline & Patch C & & & & & & & & & & & & $x$ & \\
\hline & Patch M & & & & & & & & & & & & & \\
\hline \multirow{5}{*}{ SK2001/025 } & Area A & & & $1 / 1$ & $10 /-$ & & & & & & $1 / 1$ & & & \multirow{5}{*}{ G. Dewar, pers. comm. 2010} \\
\hline & Area B & & & $1 / 1$ & $19 / 1$ & & & & $1 / 1$ & & $1 / 1$ & & & \\
\hline & Area C & & & $1 / 1$ & $252 / 1$ & & & & $2 / 1$ & $12 / 1$ & & & & \\
\hline & Area D & & & & $5 /-$ & & & & $1 / 1$ & & & & & \\
\hline & Area F & & & & & & & & & & $1 / 1$ & & & \\
\hline SK2001/039 & & & & & & & & & $x$ & $x$ & & $x$ & & R. Klein \& T. Steele, pers. comm. 2011 \\
\hline SK2005/057A & & & & & & & & & $\mathrm{x}$ & $\mathrm{x}$ & & $\mathrm{x}$ & & R. Klein \& T. Steele, pers. comm. 2011 \\
\hline \multirow{4}{*}{ SK2005/074A } & Surf & & & & & & & & $x$ & & & $x$ & & \\
\hline & $\mathrm{M} 1 / \mathrm{L} 1$ & & & & & & & & $x$ & $x$ & & $x$ & & \\
\hline & L2 & & & & & & & & $x$ & & & $x$ & & \\
\hline & M2 & & & & & & & & & & & & & \\
\hline SK2005/084 & & & & & & & & & $x$ & & & & $x$ & \\
\hline SK2005/095 & & & & & & & & & $x$ & & & $\mathrm{x}$ & & R. Klein \& T. Steele, pers. comm. 2011 \\
\hline
\end{tabular}




\begin{tabular}{|c|c|c|c|c|c|c|c|c|c|c|c|c|c|c|}
\hline Site & $\begin{array}{l}\text { Layer / } \\
\text { Area }\end{array}$ & 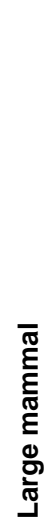 & 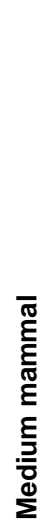 & 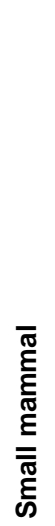 & 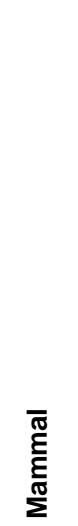 & 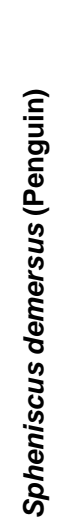 & 홈 & 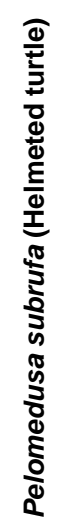 & $\begin{array}{l}\stackrel{0}{.0} \\
\stackrel{.0}{0} \\
\stackrel{0}{\circ}\end{array}$ & 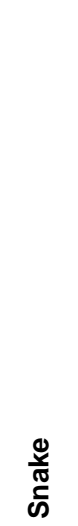 & $\begin{array}{l}\text { Do } \\
\stackrel{N}{N} \\
\stackrel{N}{J}\end{array}$ & 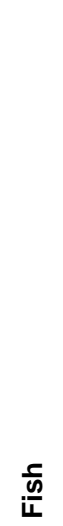 & 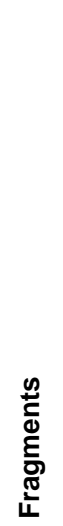 & References \& Notes \\
\hline SK2005/096A & & & & $2 / 1$ & $395 /-$ & & & & $1 / 1$ & & & & & G. Dewar, pers. comm. 2010 \\
\hline SK2005/096B & & & & & & & & & $x$ & & & $x$ & & \\
\hline \multirow{4}{*}{ SK2006/006 } & Patch 1 & & & & & & & & & & & & $x$ & \\
\hline & $\begin{array}{l}\text { Patch } 2 \\
\text { Upper }\end{array}$ & & & & & & $\mathrm{x}$ & & $x$ & & & $x$ & & \\
\hline & $\begin{array}{l}\text { Patch } 2 \\
\text { Lower }\end{array}$ & & & & & & $\bar{x}$ & & $x$ & & & $x$ & & \\
\hline & Patch 3 & & & & & & & & & & & $\mathrm{x}$ & & \\
\hline \multicolumn{15}{|l|}{ TP2004/003 } \\
\hline TP2004/014 & & & & & & & & & & $\mathrm{x}$ & & & & \\
\hline \multirow{2}{*}{ KK002 } & Upper & & & & & & & & $63 \mathrm{~h}$ & 123/- & & 4/- & & \multirow{2}{*}{$\begin{array}{l}\text { R. Klein \& T. Steele, pers. comm. } 2011 \\
\text { Geometric tortoise carapace noted in Upper (NISP=5) } \\
\text { and Lower (NISP=1). }\end{array}$} \\
\hline & Lower & & & & & & & & $22 \mathrm{~h}$ & $58 /-$ & & 1/- & & \\
\hline KK003 & & & & & $\mathrm{x}$ & & & & $\mathrm{x}$ & & & & $\mathrm{x}$ & \\
\hline
\end{tabular}




\begin{tabular}{|c|c|c|c|c|c|c|c|c|c|c|c|c|c|c|}
\hline Site & $\begin{array}{l}\text { Layer / } \\
\text { Area }\end{array}$ & 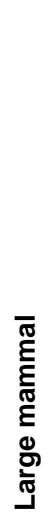 & 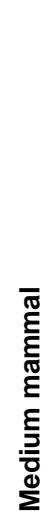 & 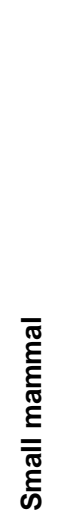 & 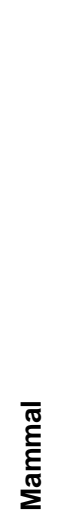 & 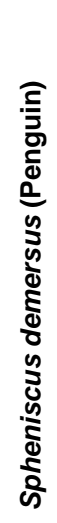 & $\stackrel{0}{\frac{0}{n}}$ & 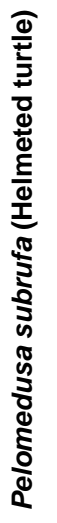 & $\begin{array}{l}\stackrel{\oplus}{0} \\
\stackrel{.0}{0} \\
\stackrel{0}{0}\end{array}$ & $\begin{array}{l}\frac{\mathscr{v}}{\pi} \\
\text { ஸे }\end{array}$ & 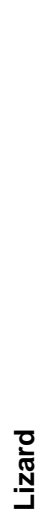 & $\frac{\frac{c}{\omega}}{\frac{\omega}{L}}$ & 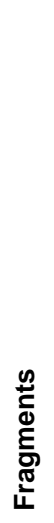 & References \& Notes \\
\hline \multirow{6}{*}{ VR001 } & $\begin{array}{l}\text { Layers } \\
1-4 A\end{array}$ & & & & & & $1 /-$ & & $15 \mathrm{~h}$ & $171 /-$ & & & & \multirow{6}{*}{$\begin{array}{l}\text { Updated from Orton et al. (in press) by R. Klein \& T. } \\
\text { Steele, pers. comm. } 2012 \text { and data reorganised into } \\
\text { present layers by T. Steele (pers. comm. 2012). }\end{array}$} \\
\hline & $\begin{array}{l}\text { Layers } \\
4 \mathrm{~B}-5\end{array}$ & & & & & & $2 /-$ & $1 /-$ & $39 \mathrm{~h}$ & $1135 /-$ & & $2 /-$ & & \\
\hline & Layer 6 & & & & & & & $1 /-$ & $8 \mathrm{~h}$ & $94 /-$ & & $1 /-$ & & \\
\hline & Layer 7 & & & & & & & & $3 \mathrm{~h}$ & $10 /-$ & & & & \\
\hline & $\begin{array}{l}\text { Layers } \\
8-9 \mathrm{~A}\end{array}$ & & & & & & $8 /-$ & & $39 \mathrm{~h}$ & 140/- & & $17 /-$ & & \\
\hline & $\begin{array}{l}\text { Layer } \\
9 \mathrm{~B}\end{array}$ & & & & & & & & $2 \mathrm{~h}$ & $60 /-$ & & $2 /-$ & & \\
\hline \multirow{7}{*}{ VR005 } & Layer 1 & & & & & & & $1 /-$ & $26 \mathrm{~h}$ & $245 /-$ & & $1 /-$ & & \multirow{7}{*}{$\begin{array}{l}\text { Tented tortoise carapace noted in Layer } 1(\mathrm{NISP}=1) \\
\text { and Layer } 2(\mathrm{NISP}=2) \text {. } \\
\text { Helmeted turtle identified from humeri. }\end{array}$} \\
\hline & Layer 2 & & & & & & & & $26 \mathrm{~h}$ & $384 /-$ & & $3 /-$ & & \\
\hline & Layer 3 & & & & & & $2 /-$ & & $24 \mathrm{~h}$ & $328 /-$ & & $5 /-$ & & \\
\hline & Layer 4 & & & & & & & & $15 \mathrm{~h}$ & $52 /-$ & & $28 /-$ & & \\
\hline & Layer 5 & & & & & & & & $2 \mathrm{~h}$ & $1 /-$ & & $1 /-$ & & \\
\hline & Layer 6 & & & & & & & & $5 \mathrm{~h}$ & $13 /-$ & & $1 /-$ & & \\
\hline & Layer 7 & & & & & & & & & $2 /-$ & & & & \\
\hline VR048 & & & & & $\mathrm{x}$ & & & & $\mathrm{x}$ & $\mathrm{x}$ & & & $x$ & \\
\hline JKB K & & & & & & & & & & & & & & R. Klein \& T. Steele, pers. comm. 2006 \\
\hline JKB M & & & & & & & & & & & & & & R. Klein \& T. Steele, pers. comm. 2006 \\
\hline
\end{tabular}




\section{Appendix 3: Radiocarbon dates.}

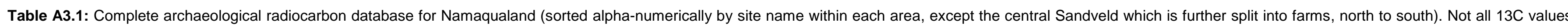

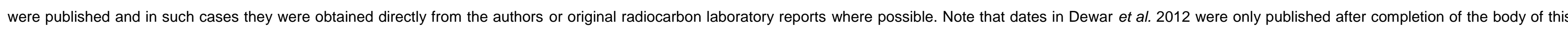
thesis.

\begin{tabular}{|c|c|c|c|c|c|c|c|}
\hline Site & $\begin{array}{l}\text { Laboratory } \\
\text { Number }\end{array}$ & ${ }^{14} \mathrm{C}$ age & $\delta^{13} \mathrm{C}$ & Material & \begin{tabular}{|l|} 
Calibrated at 2 \\
sigma (95.4\%)
\end{tabular} & Provenience & References \\
\hline \multicolumn{8}{|c|}{ Richtersveld } \\
\hline Bloeddrift 23 & Pta-7942 & $355 \pm 15$ & Unknown & Charcoal & AD 1501-1636 & Hearth 3B & A. Smith et al. 2001 \\
\hline Bloeddrift 32 & Pta-8498 & $370 \pm 35$ & -24.8 & Charcoal & AD 1464-1636 & lens $1(72 \mathrm{~cm})$ & Gray 2009 \\
\hline Bloeddrift 32 & Pta-8497 & $350 \pm 30$ & -24.4 & Charcoal & AD 1490-1645 & lens in column $1(102 \mathrm{~cm})$ & Gray 2009 \\
\hline Die Toon & Pta-5963 & $3110 \pm 60$ & -12.5 & Charcoal & $1451-1121 \mathrm{BC}$ & Unit 3, 16-18 cm, A5, ThF & Webley et al. 1993 \\
\hline Die Toon & Pta-5960 & $3840 \pm 60$ & -23.6 & Charcoal & 2457-2034 BC & Unit 2, hearth, square B6, PDA & Webley et al. 1993 \\
\hline /hei-/khomas & Pta-5458 & $420 \pm 50$ & -22.3 & Charcoal & AD 1443-1629 & Area 1, N33, Layer BL, $5 \mathrm{~cm}$ depth & Webley $1992 b$ \\
\hline /hei-/khomas & Pta-5452 & $330 \pm 45$ & -19.7 & Charcoal & AD 1464-1667 & Area 2, P32, Layer SLS2, $16 \mathrm{~cm}$ depth & Webley 1992b \\
\hline /hei-/khomas & Pta-5444 & $106.1 \pm 0.6$ & -23.2 & Charcoal & AD 1816-1916 & Area 3, Y21, Layer Unit 2, $7 \mathrm{~cm}$ depth & Webley $1992 b$ \\
\hline /hei-/khomas & Pta-5530 & $1980 \pm 80$ & -19.7 & Charred bone & 159 BC-AD 317 & Area 3, Y21, Layer LBS3, $18 \mathrm{~cm}$ depth & Webley 1992b \\
\hline Jakkalsberg A & Pta-5958 & $1330 \pm 60$ & -23.2 & Charcoal & AD 653-886 & Hearth 1 & Webley 1997 \\
\hline Jakkalsberg A & Pta-6100 & $1300 \pm 25$ & -23.5 & Charcoal & AD 684-869 & Hearth 2 & Webley 1997 \\
\hline Jakkalsberg A & Pta-8494 & $1250 \pm 50$ & -23.5 & Charcoal & AD 688-970 & Lens $\mathrm{A}(20 \mathrm{~cm})$ & Gray 2009 \\
\hline Jakkalsberg B & Pta-6122 & $1420 \pm 25$ & -23.8 & Charcoal & AD 612-762 & K11 Hearth 1 & Webley 1997 \\
\hline Jakkalsberg B & Pta-6101 & $1380 \pm 50$ & -23.3 & Charcoal & AD 610-855 & J13-J14 Hearth 2 & Webley 1997 \\
\hline Jakkalsberg L & GX-32065 & $3330 \pm 70$ & -24.6 & Charcoal & $1737-1415 \mathrm{BC}$ & F16 & Orton \& Halkett 2010 \\
\hline Jakkalsberg $\mathrm{N}$ & Pta-8496 & $4500 \pm 50$ & -6.8 & Ostrich eggshell & $3490-2458$ BC & random collection & Orton \& Halkett 2010 \\
\hline Jakkalsberg N & GX-32754 (AMS) & $4960 \pm 40$ & 0 & Marine shell & $3437-2880 \mathrm{BC}$ & J259 & Orton \& Halkett 2010 \\
\hline Jakkalsberg $\mathrm{N}$ & GX-32755 (AMS) & $4860 \pm 40$ & -5.3 & Engraved ostrich eggshell & 3962-3105 BC & $\mathrm{X} 256$ & Orton \& Halkett 2010 \\
\hline Jakkalsberg M & GX-32760 & $1740 \pm 75$ & -6.1 & Ostrich eggshell & AD 83-943 & L32, L33, M33 & Orton \& Halkett 2010 \\
\hline Jakkalsberg K & GX-32761 & $660 \pm 100$ & -24.4 & Charcoal & AD 1212-1459 & Alongside Hearth A1 & Orton \& Halkett 2010 \\
\hline Jakkalsberg K & OxA-24528 & $358 \pm 26$ & -13.72 & Bone (R. campestris) & AD 1488-1640 & K60 & Present thesis \\
\hline Jakkalsberg $\mathrm{O}$ & Pta-8492 & $310 \pm 15$ & -21.4 & Organic soil (dung-rich) & AD 1510-1655 & La $2(70 \mathrm{~cm})$ & Gray 2009 \\
\hline Jakkalsberg $\mathrm{O}$ & Pta-8500 & $720 \pm 50$ & -25.3 & Organic soil (dung-rich) & AD 1235-1398 & La $4(120 \mathrm{~cm})$ & Gray 2009 \\
\hline Jakkalsberg $\mathrm{O}$ & Pta-8493 & $303 \pm 50$ & -26.1 & Organic soil & AD 1483-1800 & Ash Lens 2 & Gray 2009 \\
\hline Jakkalsberg O & Pta-8495 & $1340 \pm 50$ & -25.5 & Organic soil & AD 654-869 & Ash Lens 3 & Gray 2009 \\
\hline Boegoeberg 1 & GX-21191 & $\begin{array}{l}37,220+5010 / \\
-3060\end{array}$ & -7.9 & Ostrich eggshell & (out of range) & Hyena den - GBS, sq H15/8 & Klein et al. 1999 \\
\hline Boegoeberg 1 & GX-21189 & $\begin{array}{l}33,230+2,630 / \\
-1,980\end{array}$ & -6.9 & Ostrich eggshell & (out of range) & Hyena den - Schist Chips, sq H16/7 & Klein et al. 1999 \\
\hline
\end{tabular}




\begin{tabular}{|c|c|c|c|c|c|c|c|}
\hline Site & $\begin{array}{l}\text { Laboratory } \\
\text { Number }\end{array}$ & ${ }^{14} \mathrm{C}$ age & $\delta^{13} \mathrm{C}$ & Material & $\begin{array}{l}\text { Calibrated at } 2 \\
\text { sigma (95.4\%) }\end{array}$ & Context & References \\
\hline Boegoeberg 1 & GX-21190 & $\begin{array}{l}34,990+3,110 / \\
-2,240\end{array}$ & -6.7 & Ostrich eggshell & (out of range) & Hyena den - Brown Powdery, sq G15/8 & Klein et al. 1999 \\
\hline Boegoeberg 2 & Pta-6956 & $\begin{array}{l}44,200 \pm \\
1200\end{array}$ & -7.2 & Ostrich eggshell & (out of range) & Unknown & Klein et al. 1999 \\
\hline \multicolumn{8}{|c|}{ Northern Sandveld: Port Nolloth } \\
\hline PN2009/001 & UGAMS-6607 & $2670 \pm 30$ & -0.3 & Marine shell & 504 BC-AD 28 & 164 & Webley \& Orton 2010 \\
\hline \multicolumn{8}{|c|}{ Northern Sandveld: Tweepad } \\
\hline TP2004/003 & UGAMS-8424 & $2230 \pm 25$ & -2.1 & Marine shell & AD 52-539 & S20 & Present thesis \\
\hline TP2004/004 & GX-32058 & $990 \pm 60$ & 1.2 & Marine shell & AD 1300-1680 & Unknown & Dewar 2008 \\
\hline TP2004/014 & UGAMS-8425 & $3430 \pm 25$ & 0.1 & Marine shell & $1417-908 \mathrm{BC}$ & H44 Lower & Present thesis \\
\hline \multicolumn{8}{|c|}{ Northern Sandveld: Kareedoringvlei } \\
\hline KV2001/011 & Pta-9306 & $2940 \pm 45$ & 1.04 & Marine shell & 826-339 BC & Unknown & Dewar 2008 \\
\hline KV2001/012 & UGAMS-8870 & $3760 \pm 25$ & -2.5 & Marine shell & $1857-1360 \mathrm{BC}$ & F14 Surface, Area A & Present thesis \\
\hline KV2001/012 & OxA-22934 & $1219 \pm 23$ & -7.25 & Ostrich eggshell bead & AD 717-1282 & G24 Surface, Area B & Present thesis \\
\hline KV2001/012 & UGAMS-9707 & $1380 \pm 20$ & 1.5 & Marine shell & AD 960-1331 & N26 \& M27, Area B & Present thesis \\
\hline \multicolumn{8}{|c|}{ Northern Sandveld: Dreyer's Pan } \\
\hline DP2004/010 & OxA-24078 & $712 \pm 24$ & -25.59 & Charcoal & AD 1282-1388 & $\mathrm{H} 16$ & Present thesis \\
\hline DP2004/014 & GX-32060 & $1020 \pm 60$ & 1.6 & Marine shell & AD 1287-1666 & Unknown & Dewar 2008 \\
\hline DP2004/014 & UBA-9943 & $665 \pm 21$ & -17.4 & Bone (terrestrial mammal) & AD 1300-1396 & M16 Top & Dewar et al. 2012 \\
\hline \multicolumn{8}{|c|}{ Northern Sandveld: Annex Kleinzee } \\
\hline AK2006/006 & UBA-9946 & $1189 \pm 24$ & 3.5 & Marine shell & AD 1140-1480 & J21 Midden & Dewar et al. 2012 \\
\hline AK2006/006 & UBA-9945 & $649 \pm 20$ & -17.3 & Charcoal & AD 1309-1401 & J21 Midden & Dewar et al. 2012 \\
\hline \multicolumn{8}{|c|}{ Northern Sandveld: Sandkop } \\
\hline SK2001/024(a) & OxA-24523 & $570 \pm 25$ & -19.54 & Bone (C. angulata) & AD 1393-1440 & F10 & Present thesis \\
\hline SK2001/025 & Pta-9310 & $2640 \pm 60$ & 1.29 & Marine shell & 497 BC-AD 84 & Area $\mathrm{C}$ & G. Dewar (pers. com. 2006) \\
\hline SK2001/025 & OxA-22976 & $2172 \pm 25$ & -16.81 & Bone (R. campestris) & $346 \mathrm{BC}-47 \mathrm{BC}$ & P197 Midden, Area C & Present thesis \\
\hline SK2001/025 & UGAMS-9708 & $2320 \pm 25$ & 0.8 & Marine shell & 65 BC-AD 428 & YC/YD 119/120, Area F & Present thesis \\
\hline SK2001/028 & Pta-9124 & $370 \pm 45$ & -16.6 & Bone (A. marsupialis) & AD 1460-1640 & Square unknown, Surface & Dewar et al. 2006 (but site reported wrongly) \\
\hline SK2001/026 & Pta-9099 & $430 \pm 45$ & -15.8 & Bone (A. marsupialis) & AD 1438-1627 & Square unknown, Surface & Dewar et al. 2006 \\
\hline SK2001/026 & Pta-9105 & $420 \pm 45$ & -16.3 & Bone (A. marsupialis) & AD 1445-1627 & Square unknown, Lower & Dewar et al. 2006 \\
\hline SK2001/039 & OxA-24524 & $606 \pm 25$ & -18.98 & Bone (C. angulata) & AD 1319-1425 & J33 & Present thesis \\
\hline SK2001/039 & OxA-24525 & $609 \pm 25$ & -19.03 & Bone (C. angulata) & AD 1319-1422 & J33 & Present thesis \\
\hline SK2001/046 & Beta-201929 & $1050 \pm 60$ & -1.5 & Marine shell & AD 1266-1652 & N25, Surface & R.G. Klein (pers. comm. 2005) \\
\hline SK2005/057A & OxA-22981 & $400 \pm 22$ & -21.34 & Charcoal & AD 1455-1625 & Y22, Hearth & Present thesis \\
\hline
\end{tabular}




\begin{tabular}{|c|c|c|c|c|c|c|c|}
\hline Site & $\begin{array}{l}\text { Laboratory } \\
\text { Number }\end{array}$ & ${ }^{14} \mathrm{C}$ age & $\delta^{13} \mathrm{C}$ & Material & $\begin{array}{l}\text { Calibrated at } 2 \\
\text { sigma (95.4\%) }\end{array}$ & Context & References \\
\hline SK2005/074 & OxA-24526 & $2132 \pm 27$ & -14.86 & Bone (R. campestris) & 185 BC-AD 1 & N24, Surface & Present thesis \\
\hline SK2005/074 & OxA-24527 & $2052 \pm 34$ & -18.57 & Bone (C. angulata) & $107 \mathrm{BC}-\mathrm{AD} 85$ & M24, Layer 1 & Present thesis \\
\hline SK2005/084 & UGAMS-6608 & $2420 \pm 30$ & -1.0 & Marine shell & 196 BC-AD 325 & S3 & Present thesis \\
\hline SK2005/095 & OxA-24550 & $389 \pm 24$ & -15.52 & Bone (bovid) & AD 1459-1626 & S20 L2, Patch B & Present thesis \\
\hline SK2005/095 & OxA-24551 & $468 \pm 25$ & -18.38 & Bone (C. angulata) & AD 1429-1497 & F29 Midden, Patch A & Orton 2012 \\
\hline SK2005/096A & OxA-22974 & $611 \pm 23$ & -18.22 & Bone (C. angulata) & AD 1319-1420 & G28, Surface & Present thesis \\
\hline SK2005/096A & OxA-22975 & $654 \pm 23$ & -18.23 & Bone (C. angulata) & AD 1301-1401 & G28, Surface & Present thesis \\
\hline SK2005/096B & UGAMS-8871 & $2740 \pm 25$ & 0.6 & Marine shell & $648-60 \mathrm{BC}$ & F15 & Present thesis \\
\hline SK2006/006 & OxA-24077 & $377 \pm 24$ & -18.53 & Charcoal & AD 1465-1630 & Patch 2, S39 Lower 2 & Present thesis \\
\hline SK2006/006 & OxA-25329 & $401 \pm 25$ & -23.44 & Charcoal & AD1455-1625 & Patch 2, S39 Lower 2A & Present thesis \\
\hline SK2006/006 & OxA-24076 & $425 \pm 24$ & -22.29 & Charcoal & AD 1446-1621 & Patch 3, B53 & Present thesis \\
\hline \multicolumn{8}{|c|}{ Northern Sandveld: Elands Klip } \\
\hline ELK 4 & GX-32061 & $4820 \pm 60$ & 1.9 & Marine shell & $3318-2675$ BC & Collected from surface & ACO, unpublished \\
\hline ELK 14 & GX-32056 & $3410 \pm 70$ & 1.7 & Marine shell & $1428-846 \mathrm{BC}$ & Collected from surface & ACO, unpublished \\
\hline \multicolumn{8}{|c|}{ Central Sandveld: Koingnaas } \\
\hline KN2001/008C & Pta-9335 & $3720 \pm 45$ & -0.42 & Marine shell & 1813-1272 BC & M18, SMU & Dewar 2007 (but location reported wrongly) \\
\hline KN2001/008C & Pta-9325 & $3740 \pm 60$ & -0.43 & Marine shell & 1862-1293 BC & M18, Surf 1 & Dewar 2007 \\
\hline KN2001/008C & Pta-9316 & $4630 \pm 70$ & 1.74 & Marine shell & $3036-2401 \mathrm{BC}$ & M18, Surf 3 & Dewar 2007 \\
\hline KN2001/008C & OxA-22970 & $3355 \pm 28$ & -17.65 & Bone (C. angulata) & 1681-1498 BC & G16, Surface & Present thesis \\
\hline KN2001/009 & OxA-24516 & $607 \pm 24$ & -15.01 & Bone (R. campestris.) & AD 1320-1423 & E11, Surface & Present thesis \\
\hline KN2004/012 & OxA-22977 & $1579 \pm 24$ & -7.25 & Charcoal & AD 432-606 & H16, Midden & Present thesis \\
\hline KN2004/015E & OxA-22930 & $973 \pm 24$ & -18.41 & Bone (C. angulata) & AD1035-1174 & WW73, Surface & Present thesis \\
\hline KN2005/040 & OxA-22971 & $2695 \pm 26$ & -18.05 & Bone (C. angulata) & 895-772 BC & K12, Surface & Present thesis \\
\hline KN2005/041 & OxA-22933 & $1625 \pm 25$ & -15.75 & Bone (Bos taurus) & AD 421-559 & E6, Midden, directly dated cow & Orton et al. in press \\
\hline KN2005/041 & OxA-22979 & $1631 \pm 23$ & -14.15 & Charcoal & AD 418-552 & H6, Midden & Orton et al. in press \\
\hline KN2005/050 & OxA-22972 & $2993 \pm 27$ & -17.36 & Bone (C. angulata) & 1263-1065 BC & L26 & Present thesis \\
\hline KN2005/054 & OxA-22932 & $1598 \pm 25$ & -16.56 & Bone (C. angulata) & AD 429-584 & D13, MS1 & Present thesis \\
\hline KN2005/067 & OxA-24517 & $262 \pm 23$ & -17.96 & Bone (C. angulata) & AD 1637-1799 & $\mathrm{X}-11, \mathrm{P3}$ & Present thesis \\
\hline KN2005/067 & OxA-24518 & $321 \pm 23$ & -18.89 & Bone (C. angulata) & AD 1505-1652 & H-5, Midden, Patch 1B & Orton 2012 \\
\hline KN2005/067 & OxA-24522 & $355 \pm 24$ & -19.9 & Bone (C. angulata) & AD 1496-1640 & R-10, Patch 1C & Orton 2012 \\
\hline KN2005/067 & OxA-24519 & $891 \pm 23$ & -18.34 & Bone (C. angulata) & AD 1155-1261 & L1, Tort. 3, Patch 1A & Orton 2012 \\
\hline KN2005/067 & OxA-24521 & $354 \pm 23$ & -19.25 & Bone (C. angulata) & AD 1497-1640 & O5, Midden/SAM, Patch 1A & Orton 2012 \\
\hline KN2005/067 & OxA-24520 & $339 \pm 24$ & -17.89 & Bone (C. angulata) & AD 1501-1646 & O5, Tortoise Burial, Patch $1 \mathrm{~A}$ & Orton 2012 \\
\hline KN2005/135A & OxA-22973 & $2523 \pm 27$ & -17.12 & Bone (C. angulata) & $761-414 \mathrm{BC}$ & K23, Top & Present thesis \\
\hline KN2005/135B & OxA-22931 & $368 \pm 23$ & -17.52 & Bone (C. angulata) & AD 1482-1634 & D30, Surface & Present thesis \\
\hline
\end{tabular}




\begin{tabular}{|c|c|c|c|c|c|c|c|}
\hline Site & $\begin{array}{l}\text { Laboratory } \\
\text { Number }\end{array}$ & ${ }^{14} \mathrm{C}$ age & $\delta^{13} \mathrm{C}$ & Material & $\begin{array}{l}\text { Calibrated at } 2 \\
\text { sigma (95.4\%) }\end{array}$ & Context & References \\
\hline \multicolumn{8}{|c|}{ Central Sandveld: Hondeklipbaai } \\
\hline HKB2007/007 & UGAMS-5252 & $340 \pm 30$ & -16.2 & Charcoal & AD 1497-1648 & Q7 \& Q8, L2 & Orton 2009a \\
\hline HKB2007/035 & UGAMS-5153 & $3590 \pm 30$ & -13.4 & Charcoal & $1962-1748$ BC & G15, L4 & Orton 2009a \\
\hline \multicolumn{8}{|c|}{ Central Sandveld: Langklip } \\
\hline LK2001/003 & Pta-8910 & $1110 \pm 50$ & -0.1 & Marine shell & AD 1196-1581 & G7a & Orton et al. 2005 \\
\hline LK2001/004 & Pta-8909 & $2360 \pm 60$ & 0.5 & Marine shell & 156 BC-AD 410 & Area D, R35 & Orton et al. 2005 \\
\hline LK2001/004 & Pta-8915 & $2505 \pm 20$ & -0.3 & Marine shell & $331 \mathrm{BC}-\mathrm{AD} 180$ & Area A, $\mathrm{H} 14$ & Orton et al. 2005 \\
\hline LK2001/013 & Pta-9326 & $2180 \pm 50$ & 1.5 & Marine shell & AD 85-595 & Square unknown, Top & Dewar 2008 \\
\hline LK2001/013 & UBA-9941 & $1524 \pm 22$ & -20.4 & Bone (C. angulata) & AD 550-645 & Square unknown, Top & Dewar et al. 2012 \\
\hline LK2001/013 & Pta-9312 & $2870 \pm 60$ & 0.87 & Marine shell & $777-218 \mathrm{BC}$ & Square unknown, Top & Dewar 2008 \\
\hline LK2001/013 & UBA-9942 & $932 \pm 45$ & -16.5 & Bone (Raphicerus sp.) & AD 1034-1225 & Square unknown, Top & G. Dewar, pers. comm. 2011 \\
\hline LK2001/015 & OxA-24557 & $394 \pm 24$ & -18.07 & Bone (Raphicerus sp.) & AD 1457-1626 & Patch Ci, J29 Lower & Present thesis \\
\hline LK2001/015 & OxA-24558 & $420 \pm 24$ & -18.81 & Bone (C. angulata) & AD 1448-1622 & Patch Cii, N32 Hearth/Ash & Present thesis \\
\hline LK2001/015 & OxA-24560 & $401 \pm 22$ & -19.7 & Bone (C. angulata) & AD 1455-1625 & Patch D, ZA35 & Present thesis \\
\hline LK2001/015 & OxA-24561 & $442 \pm 24$ & -19.79 & Bone (C. angulata) & AD 1442-1615 & Patch D, ZA35 & Present thesis \\
\hline LK2001/015 & OxA-24562 & $398 \pm 25$ & -18.92 & Bone (?Raphicerus sp.) & AD 1456-1626 & Patch F, ZE32 & Present thesis \\
\hline LK2001/015 & OxA-24559 & $403 \pm 24$ & -14.31 & Bone (Raphicerus sp.) & AD 1454-1625 & Patch I, J6 Lower & Present thesis \\
\hline LK2004/011 & GX-32057 & $1200 \pm 60$ & -0.8 & Marine shell & AD 1084-1481 & Square unknown, Midden 1 & Dewar 2008 \\
\hline LK2004/011 & UBA-9940 & $707 \pm 37$ & -16.8 & Bone (Oryx gazella) & AD 1280-1392 & P46, Midden 2 & Dewar et al. 2012 \\
\hline LK2004/011 & GX-32059 & $1080 \pm 50$ & 0 & Marine shell & AD 1241-1624 & Square unknown, Midden 3 & Dewar 2008 \\
\hline LK2004/011B & GX-32064 & $1250 \pm 60$ & -1 & Marine shell & AD 1055-1447 & Q28d & ACO, unpublished \\
\hline LK2004/011B & OxA-22980 & $924 \pm 22$ & -15.45 & Charcoal & AD 1050-1218 & R27b & Present thesis \\
\hline \multicolumn{8}{|c|}{ Central Sandveld: Mitchell's Bay } \\
\hline MB2005/001E & OxA-24552 & $2190 \pm 27$ & -19.6 & Bone (C. angulata) & $353-52 \mathrm{BC}$ & Layer 1 (A39, $2^{\text {nd }}$ Layer) & Present thesis \\
\hline MB2005/001E & OxA-24553 & $2176 \pm 27$ & -18.86 & Bone (C. angulata) & $349-46$ BC & Layer 1 (A39, $4^{\text {th }}$ Layer $)$ & Present thesis \\
\hline MB2005/001E & OxA-24554 & $2796 \pm 27$ & -17.45 & Bone (C. angulata) & $975-812 \mathrm{BC}$ & Layer 2 (A39, $8^{\text {th }}$ Layer) & Present thesis \\
\hline MB2005/001E & GX-32756 & $3810 \pm 145$ & 0.7 & Marine shell & $2121-1226 \mathrm{BC}$ & Layer $3(\mathrm{H} 43, \mathrm{TOP})$ & Orton 2007c \\
\hline MB2005/001E & GX-32757 & $4180 \pm 90$ & 1.8 & Marine shell & $2470-1751 \mathrm{BC}$ & Layer 4 (H43, Layer 6) & Orton 2007c \\
\hline MB2005/005A & GX-32524 & $2560 \pm 60$ & 0.9 & Marine shell & 383 BC-AD 154 & Square unknown, L2a & Dewar 2007 \\
\hline MB2005/005A & UBA-9939 & $2202 \pm 32$ & -13.4 & Bovid/tortoise & $357-54 \mathrm{BC}$ & L12, L2b & Dewar et al. 2012 \\
\hline MB2005/005A & GX-32525 & $2620 \pm 70$ & 1.2 & Marine shell & 482 BC-AD 118 & Square unknown, L2c & Dewar 2007 \\
\hline MB2005/005B & GX-32526 & $5390 \pm 70$ & -0.9 & Marine shell & $3932-3383 \mathrm{BC}$ & G14, BSM & Dewar 2007 \\
\hline MB2005/013 & OxA-24555 & $717 \pm 25$ & -19.05 & Bone (C. angulata) & AD 1281-1387 & I24, Lower & Present thesis \\
\hline MB2005/016 & GX-32534 & $2860 \pm 60$ & 0.1 & Marine shell & $770-205$ BC & J17, Layer 2 & Orton 2007c \\
\hline MB2005/016 & GX-32535 & $3140 \pm 60$ & 1.1 & Marine shell & $1132-499 \mathrm{BC}$ & J18, Layer 12 & Orton 2007c \\
\hline
\end{tabular}




\begin{tabular}{|c|c|c|c|c|c|c|c|}
\hline Site & $\begin{array}{l}\text { Laboratory } \\
\text { Number }\end{array}$ & ${ }^{14} \mathrm{C}$ age & $\delta^{13} \mathrm{C}$ & Material & $\begin{array}{l}\text { Calibrated at } 2 \\
\text { sigma }(95.4 \%)\end{array}$ & Context & References \\
\hline MB2005/027 & OxA-22978 & $650 \pm 22$ & -15.77 & Charcoal & AD 1304-1402 & G13, Hearth 1 & Present thesis \\
\hline MB2005/028A & OxA-24626 & $680 \pm 25$ & -18.5 & Bone (C. angulata) & AD 1296-1392 & C11, Lower & Present thesis \\
\hline MB2005/059 & OxA-24556 & $2641 \pm 29$ & -18.5 & Bone (C. angulata) & $821-557 \mathrm{BC}$ & Patch A, L45 & Present thesis \\
\hline MB2005/119 & GX-32521 & $850 \pm 60$ & -2.2 & Marine shell & AD 1416-1879 & I17, Lower Midden & Dewar 2008 \\
\hline Spoeg River Cave & Pta-4753 & $1390 \pm 50$ & -23.2 & Charcoal & AD 603-806 & C9, Hearth 3 in Twiggy, $20 \mathrm{~cm}$ & Vogel et al. 1997; Webley 1992b \\
\hline Spoeg River Cave & Pta-4745 & $1920 \pm 40$ & -21.0 & Charcoal & AD 54-248 & Hearth 12, above FBS \& Shelly Patch, $91 \mathrm{~cm}$ & Vogel et al. 1997; Webley 1992b \\
\hline Spoeg River Cave & OxA-3862 & $2105 \pm 65$ & -14.1 & Bone (Ovis aries) & 350 BC-AD 115 & FBS (? Layers 7-12 of 1994 excavation) & Sealy \& Yates 1994 \\
\hline Spoeg River Cave & Pta-6334 & $2020 \pm 60$ & -17.5 & Crayfish carapace (J. Ialandii) & AD 430-752 & C9, Patella, $45 \mathrm{~cm}$ & Vogel et al. 1997; Webley 2002 \\
\hline Spoeg River Cave & Pta-6750 & $1450 \pm 50$ & -17.0 & Charcoal & AD 554-766 & Layer 4, CST, Sq C6, $12-15 \mathrm{~cm}$ & Vogel et al. 1997; Webley 2002 \\
\hline Spoeg River Cave & Pta-6749 & $1930 \pm 50$ & -17.9 & Charcoal & AD 6-313 & Layer 6b, Twiggy 6, Sq C6, 40-50 cm & Vogel et al. 1997; Webley 2002 \\
\hline Spoeg River Cave & GrA-9027 & $1260 \pm 50$ & Unknown & Bone (Ovis aries) & AD 685-961 & Layer 7, YBS, Sq C5 & Webley 2002 \\
\hline Spoeg River Cave & GrA-9030 & $1490 \pm 50$ & Unknown & Bone (Ovis aries) & AD 469-680 & Layer 7, YBS, Sq D6 & Webley 2002 \\
\hline Spoeg River Cave & GrA-9029 & $1890 \pm 50$ & Unknown & Bone (Ovis aries) & AD 62-333 & Layer 9, GAS 2, Sq C4 & Webley 2002 \\
\hline Spoeg River Cave & GrA-9032 & $1900 \pm 50$ & Unknown & Bone (Ovis aries) & AD 55-325 & Layer 9, GAS 2, Sq C6 & Webley 2002 \\
\hline Spoeg River Cave & Pta-7200 & $2400 \pm 25$ & -16.9 & Charcoal & $518-366 \mathrm{BC}$ & Layer 10, SAS, Sq C6, 60-67 cm & Vogel et al. 1997; Webley 2002 \\
\hline Spoeg River Cave & GrA-9028 & $1900 \pm 50$ & Unknown & Bone (Ovis aries) & AD 55-325 & Layer 10, SAS, Sq C6 & Webley 2002 \\
\hline Spoeg River Cave & Pta-6987 & $3580 \pm 60$ & -15.4 & Charcoal & $2026-1691$ BC & Layer 12, BSB2, Sq D5, $50 \mathrm{~cm}$ & $\begin{array}{l}\text { Webley } 2002 \text { (date reported incorrectly in Vogel } \\
\text { et al. } 1997 .\end{array}$ \\
\hline Spoeg River Cave & Pta-6754 & $3520 \pm 50$ & -16.0 & Charcoal & $1921-1636 \mathrm{BC}$ & Layer 13, Hearth 34, Sq D5, $50 \mathrm{~cm} / 60-100 \mathrm{~cm}$ & Vogel et al. 1997; Webley 2002 \\
\hline \multicolumn{8}{|c|}{ Central Hardeveld } \\
\hline Bethelsklip & Pta-3512 & $800 \pm 50$ & -21.7 & Charcoal & AD 1182-1381 & K14, BLL2, stone hearth, $59 \mathrm{~cm}$ depth & Webley 1984 \\
\hline Bethelsklip & Pta-4741 & $360 \pm 40$ & -22.9 & Charcoal & AD 1464-1643 & K14, BL, Hearth AF4, $10 \mathrm{~cm}$ depth & Webley $1992 b$ \\
\hline \multicolumn{8}{|c|}{ Southern Sandveld } \\
\hline BSB2 & Pta-6050 & $860 \pm 50$ & -0.8 & Marine shell & AD 1503-1863 & Layer 2 (LBS) & Halkett et al. 1993 \\
\hline BSB2 & Pta-6053 & $4510 \pm 30$ & -0.6 & Marine shell & $2622-2272 \mathrm{BC}$ & Layer 5 (BBRL) & Halkett et al. 1993 \\
\hline BSB3 & Pta-6051 & $2930 \pm 50$ & -0.1 & Marine shell & $828-323 \mathrm{BC}$ & Layer 9 (THL) & Halkett et al. 1993 \\
\hline BSB4 & Pta-6049 & $2430 \pm 40$ & 0.2 & Marine shell & $221 B C-326 A D$ & Layer 3 (BDO) & Halkett et al. 1993 \\
\hline BSB6 & Pta-6052 & $2170 \pm 50$ & 0 & Marine shell & AD 96-601 & PSS1 & Halkett et al. 1993 \\
\hline MS1 & GX-32063 & $3870 \pm 70$ & -0.1 & Marine shell & $1842-1407 \mathrm{BC}$ & Unknown & ACO, unpublished \\
\hline MS3 & GX-32062 & $3160 \pm 70$ & 1.6 & Marine shell & 966-492 BC & Unknown & ACO, unpublished \\
\hline
\end{tabular}




\begin{tabular}{|c|c|c|c|c|c|c|c|}
\hline Site & $\begin{array}{l}\text { Laboratory } \\
\text { Number }\end{array}$ & ${ }^{14} \mathrm{C}$ age & $\delta^{13} \mathrm{C}$ & Material & $\begin{array}{l}\text { Calibrated at } 2 \\
\text { sigma (95.4\%) }\end{array}$ & Context & References \\
\hline \multicolumn{8}{|c|}{ Southern Hardeveld } \\
\hline Komkans 2 & OxA-25346 & $701 \pm 23$ & -18.69 & Bone (C. angulata) & AD 1285-1390 & I11 NW L2/4 interface & Present thesis \\
\hline Komkans 2 & OxA-25347 & $334 \pm 23$ & -20.05 & Bone (C. angulata) & AD 1503-1647 & I11 NW L4B & Present thesis \\
\hline Komkans 2 & OxA-25348 & $175 \pm 23$ & -18.99 & Bone (C. angulata) & AD 1671-1954 & G10 NE L6 & Present thesis \\
\hline Komkans 2 & OxA-25349 & $1462 \pm 24$ & -18.65 & Bone (C. angulata) & AD 597-666 & I12 SE L5B & Present thesis \\
\hline Komkans 2 & OxA-25350 & $932 \pm 24$ & -18.3 & Bone (C. angulata) & AD 1046-1218 & $18 \mathrm{NE} \mathrm{L3}$ & Present thesis \\
\hline Komkans 2 & OxA-25351 & $644 \pm 23$ & -18.71 & Bone (C. angulata) & AD 1305-1404 & I8 NE L3C & Present thesis \\
\hline \multicolumn{8}{|c|}{ Knersvlakte } \\
\hline Reception Shelter (VR001) & AA-89907 & $679 \pm 44$ & -10.1 & Ostrich eggshell & AD 1220-1951 & P43 NW L1 (5 cm bel surf) & Orton et al. 2011 \\
\hline Reception Shelter (VR001) & AA-89908 & $21900 \pm 120$ & -8.7 & Ostrich eggshell & (out of range) & Q43 SW L6 (105 cm bel surf) & Orton et al. 2011 \\
\hline Reception Shelter (VR001) & OxA-24513 & $589 \pm 23$ & -22.16 & Bone (C. angulata) & AD 1326-1422 & X40 SW L6 & Present thesis \\
\hline Reception Shelter (VR001) & OxA-22876 & $622 \pm 21$ & -19.86 & Small sticks from bedding & AD 1318-1411 & Y40 L7 & Orton 2012 (but material reported wrongly) \\
\hline Reception Shelter (VR001) & OxA-22982 & $474 \pm 22$ & -22.91 & Charcoal (?A. karoo) & AD 1429-1483 & Y40 L11 & Orton 2012 (but material reported wrongly) \\
\hline Reception Shelter (VR001) & AA-89909 & $828 \pm 44$ & -22.2 & Bone (C. angulata) & AD 1177-1293 & X40 NW L15a & Orton et al. 2011 \\
\hline Reception Shelter (VR001) & OxA-22983 & $2578 \pm 25$ & -22.93 & Charcoal (?A. karoo) & 794-539 BC & Y40 L18 & Present thesis \\
\hline Reception Shelter (VR001) & OxA-25353 & $1897 \pm 25$ & -19.38 & Bone (C. angulata) & AD 85-292 & X40 SW L22 & Orton et al. 2012 \\
\hline Reception Shelter (VR001) & OxA-25354 & $1840 \pm 26$ & -16.08 & Bone (Oryx gazella) & AD 133-336 & X40 SE L24B & Orton et al. 2012 \\
\hline Reception Shelter (VR001) & AA-89910 & $2560 \pm 49$ & -19.2 & Bone (C. angulata) & $793-416$ BC & Y40 SW L25 & Orton et al. 2011 \\
\hline Reception Shelter (VR001) & OxA-24514 & $394 \pm 23$ & -20.9 & Bone (C. angulata) & AD 1457-1626 & U47 SW Spit 2 & Present thesis \\
\hline VR003 & UGAMS-11684 & $220 \pm 20$ & -22 & Small stick & AD 1653-1804 & Hole III, Layer 1 & T. Steele, pers. comm. 2012 \\
\hline VR003 & UGAMS-11685 & $1410 \pm 20$ & -21.4 & Bone (C. angulata) & AD 639-763 & Hole III, Layer 8 & T. Steele, pers. comm. 2012 \\
\hline Buzz Shelter (VR005) & OxA-22984 & $3327 \pm 26$ & -20.45 & Charcoal (?A. karoo) & $1627-1455 \mathrm{BC}$ & M11 NE L3 & Present thesis \\
\hline Buzz Shelter (VR005) & OxA-25352 & $1646 \pm 25$ & -20.91 & Bone (C. angulata) & AD 410-543 & O11 SW L3a & Present thesis \\
\hline Buzz Shelter (VR005) & OxA-24515 & $1921 \pm 25$ & -20.71 & Bone (C. angulata) & AD 76-232 & O11 SW L4a & Present thesis \\
\hline Buzz Shelter (VR005) & OxA-22985 & $12770 \pm 50$ & -23.11 & Charcoal (?A. karoo) & (out of range) & N11 NW L5 & Present thesis \\
\hline Buzz Shelter (VR005) & OxA-24722 & $12955 \pm 60$ & -23.34 & Charcoal (?A. karoo) & (out of range) & N11 NW L5 & Present thesis \\
\hline Buzz Shelter (VR005) & OxA-22877 & $324 \pm 22$ & -27.84 & Grass & AD 1505-1650 & N11NW L7 & Present thesis \\
\hline Buzz Shelter (VR005) & AA-89911 & $4551 \pm 54$ & -17.6 & Bone (terrestrial mammal) & $3366-2945$ BC & M11 NE/NW L9a & Orton et al. 2011 \\
\hline Buzz Shelter (VR005) & UGAMS-11683 & $3890 \pm 20$ & -22 & Grass & $2458-2155$ BC & N11 SE L10 & Present thesis \\
\hline Buzz Shelter (VR005) & OxA-22986 & $4185 \pm 31$ & -24.57 & Charcoal (?A. karoo) & $2872-2580 \mathrm{BC}$ & M11 NE L12 & Present thesis \\
\hline Buzz Shelter (VR005) & AA-89912 & $5452 \pm 54$ & -19.3 & Bone (terrestrial mammal) & $4347-4053 \mathrm{BC}$ & M11 SE/SW L15c & Orton et al. 2011 \\
\hline
\end{tabular}




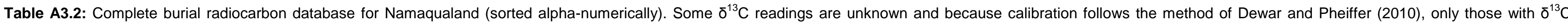

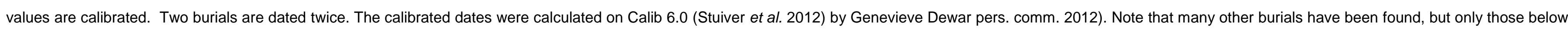
are dated.

\begin{tabular}{|c|c|c|c|c|c|c|c|c|}
\hline Burial & \begin{tabular}{|l|} 
Accession \\
number \\
(where exists)
\end{tabular} & $\begin{array}{l}\text { Dating } \\
\text { Laboratory } \\
\text { Number }\end{array}$ & ${ }^{14} \mathrm{C}$ age & Material & $\begin{array}{l}\text { Archaeometry } \\
\text { Laboratory } \\
\text { Number }\end{array}$ & $\delta^{13} \mathrm{C}$ & Calibrated at 2 sigma (95.4\%) & References \\
\hline Port Nolloth & SAM-AP-1446 & Pta-9085 & $740 \pm 30$ & Collagen & - & unknown & - & Stynder et al. 2007 \\
\hline AK2006/006 & & UBA-9944 & $750 \pm 20$ & Collagen & UBA-9944 & -14.03 & AD 1404-1561 & Dewar \& Orton, in prep. \\
\hline Near LK2004/011B & & GX-32523 & $800 \pm 70$ & Collagen & UCT12775 & -16.4 & AD 1267-1444 & Dewar 2008 \\
\hline Noup & & GX-32522 & $850 \pm 70$ & Collagen & UCT 10982 & -13.1 & AD 1306-1570 & Dewar 2008 \\
\hline Lutzville & UCT227 & Pta-4405 & $1000 \pm 50$ & Collagen & - & unknown & - & Hausman 1980; Morris 1992; Stynder et al. 2007 \\
\hline Somnaas & UCT579 & GX-32527 & $1250 \pm 70$ & Collagen & UCT 12756 & -12.8 & AD 982-1293 & Dewar 2008 \\
\hline Kleinsee & UCT172 & GX-32537 & $2100 \pm 50$ & Collagen & UCT 620 & -12.3 & AD 90-475 & Dewar 2008 \\
\hline \multirow{2}{*}{ Kleinsee } & UCT164 & GX-32542 & $2240 \pm 50$ & Collagen & UCT 624 & -12.6 & 64 BC-AD327 & Dewar 2008 \\
\hline & \begin{tabular}{|l|l|l} 
UCT 164 \\
\end{tabular} & Pta-8750 & $2360 \pm 30$ & Collagen & - & unknown & & Stynder et al. 2007 \\
\hline SK rehab adult skull & & GX-32539 & $2500 \pm 50$ & Collagen & UCT 12758 & -12.4 & 375 BC-AD 1 & Dewar 2008 \\
\hline Kleinsee & SAM-AP-4932 & GX-32541 & $2660 \pm 60$ & Collagen & UCT 425 & -14.8 & $755-383 \mathrm{BC}$ & Dewar 2008; \\
\hline GRM5 & UCT445 & Pta-5617 & $2720 \pm 60$ & Collagen & UCT 4447 & -14.8 & $772-407 \mathrm{BC}$ & Dewar 2008; Jerardino et al. 1992; Morris 1992; Stynder et al. 2007 \\
\hline SK300 burial & & GX-32538 & $2750 \pm 50$ & Collagen & UCT 12776 & -13.6 & 759-399 BC & Dewar 2008 \\
\hline SK rehab humerus & & GX-32536 & $2750 \pm 50$ & Collagen & UCT 12755 & -14.0 & $765-407 \mathrm{BC}$ & Dewar 2008 \\
\hline Somnaas & & GX-32528 & $3490 \pm 70$ & Collagen & UCT 12757 & -18.4 & $1914-1508$ BC & Dewar 2008 \\
\hline \multirow{3}{*}{ Kleinsee } & SAM 4931 & Pta-2267 & $3750 \pm 60$ & Collagen & - & Unknown & - & Morris 1992 \\
\hline & SAM-AP 4931 & Pta-4827 & $3750 \pm 60$ & Collagen & - & Unknown & & Stynder et al. 2007 (Lab number assumed to be an error) \\
\hline & SAM-AP-4931 & GX-32540 & $3820 \pm 50$ & Collagen & UCT 591 & -13.0 & 2042-1608 BC & Dewar 2008 \\
\hline
\end{tabular}




\begin{tabular}{|ll|l|}
\hline $\begin{array}{l}\text { Assemblage Number } \& \\
\text { Name }\end{array}$ & Age (95.4\%) \\
\hline 1 & MB2005/005B & $3932-3383$ BC \\
\hline 2 & KN2001/008C, Lower & $3036-2401$ BC \\
\hline 3 & MB2005/001E, Layer 4 & $2470-1751$ BC \\
\hline 4 & MB2005/001E, Layer 3 & $2121-1226$ BC \\
\hline 5 & KV2001/012, Area A & $1857-1360$ BC \\
\hline 6 & KN2001/008C, Upper & $1862-1272$ BC \\
\hline 7 & TP2004/014 & $1417-908$ BC \\
\hline 8 & KN2005/050 & $1263-1065$ BC \\
\hline 9 & KN2005/040 & $895-772$ BC \\
\hline 10 & KV2001/011 & $826-339$ BC \\
\hline 11 & KN2005/135A & $761-414$ BC \\
\hline 12 & SK2005/096, Patch B & $648-60$ BC \\
\hline 13 & PN2009/001, all areas & 504 BC-AD 28 \\
\hline 14 & MB2005/001E, Layer 1 & $349-46$ BC \\
\hline 15 & SK2001/025, Area C & 346 BC-47 BC \\
\hline 16 & MB2005/005A & 383 BC-AD 118 \\
\hline 17 & SK2005/074A, Layers & 107 BC-AD 1 \\
\hline 18 & LK2001/004 & 331 BC-AD410 \\
\hline 19 & SK2005/084 & 196 BC-AD 325 \\
\hline 20 & SK2001/025, Area F & 65 BC-AD 428 \\
\hline 21 & TP2004/003 & AD 52-539 \\
\hline 22 & KN2005/041 & AD 421-552 \\
\hline 23 & KN2005/054 & AD 429-584 \\
\hline 24 & KN2004/012 & AD 432-606 \\
\hline 25 & KV2001/012, Area B & AD 960-1282 \\
\hline 26 & KN2004/015E & AD 1035-1174 \\
\hline
\end{tabular}

\section{GREY = Group 1}

RED = Group 2

BLUE = Group 3

WHITE $=$ Mixed Groups

\begin{tabular}{|c|c|}
\hline \begin{tabular}{|l} 
Assemblage Number \& \\
Name
\end{tabular} & Age (95.4\%) \\
\hline 27 LK2004/011B & AD 1010-1218 \\
\hline 28 LK2004/011 & AD 1241-1481 \\
\hline 29 MB2005/013 & $A D$ 1281-1387 \\
\hline $\begin{array}{l}30 \text { DP2004/010, Patch } \\
\text { A \& B }\end{array}$ & AD 1282-1388 \\
\hline $31 \mathrm{MB} 2005 / 028 \mathrm{~A}$ & AD 1296-1392 \\
\hline 32 MB2005/027 & AD 1304-1402 \\
\hline 33 SK2005/096, Patch A & AD 1319-1401 \\
\hline 34 SK2001/039 & AD 1319-1422 \\
\hline 35 KN2001/009 & AD 1320-1423 \\
\hline 36 TP2004/004 & AD 1300-1680 \\
\hline 37 LK2001/003 & AD 1196-1581 \\
\hline \begin{tabular}{|l|}
$38 \begin{array}{l}\text { SK2001/024, All } \\
\text { Patches }\end{array}$ \\
\end{tabular} & AD 1393-1440 \\
\hline 39 SK2005/095, Patch A & AD 1429-1497 \\
\hline 40 DP2004/014 & AD 1287-1666 \\
\hline $\begin{array}{l}41 \begin{array}{l}\text { LK2001/015, all } \\
\text { patches }\end{array} \\
\end{array}$ & AD 1442-1626 \\
\hline 42 SK2006/006, Patch 3 & AD 1446-1621 \\
\hline 43 SK2001/026 & AD 1438-1627 \\
\hline 44 SK2005/057A & AD 1455-1625 \\
\hline 45 SK2005/095, Patch B & AD 1459-1626 \\
\hline $\begin{array}{l}46 \text { SK2006/006, Patch } 2 \\
\text { Lower }\end{array}$ & AD 1455-1625 \\
\hline \begin{tabular}{|c|}
47 SK2006/006, Patch 2 \\
Upper
\end{tabular} & AD 1465-1630 \\
\hline 48 KN2005/135B & AD 1482-1634 \\
\hline 49 KN2005/067, Patch 1C & AD 1496-1640 \\
\hline 50 HKB2007/007 & AD 1497-1648 \\
\hline 51 KN2005/067, Patch 1A & AD 1501-1640 \\
\hline 52 KN2005/067, Patch 1B & AD 1505-1652 \\
\hline 53 KN2005/067, Patch 3 & AD 1637-1799 \\
\hline
\end{tabular}

